


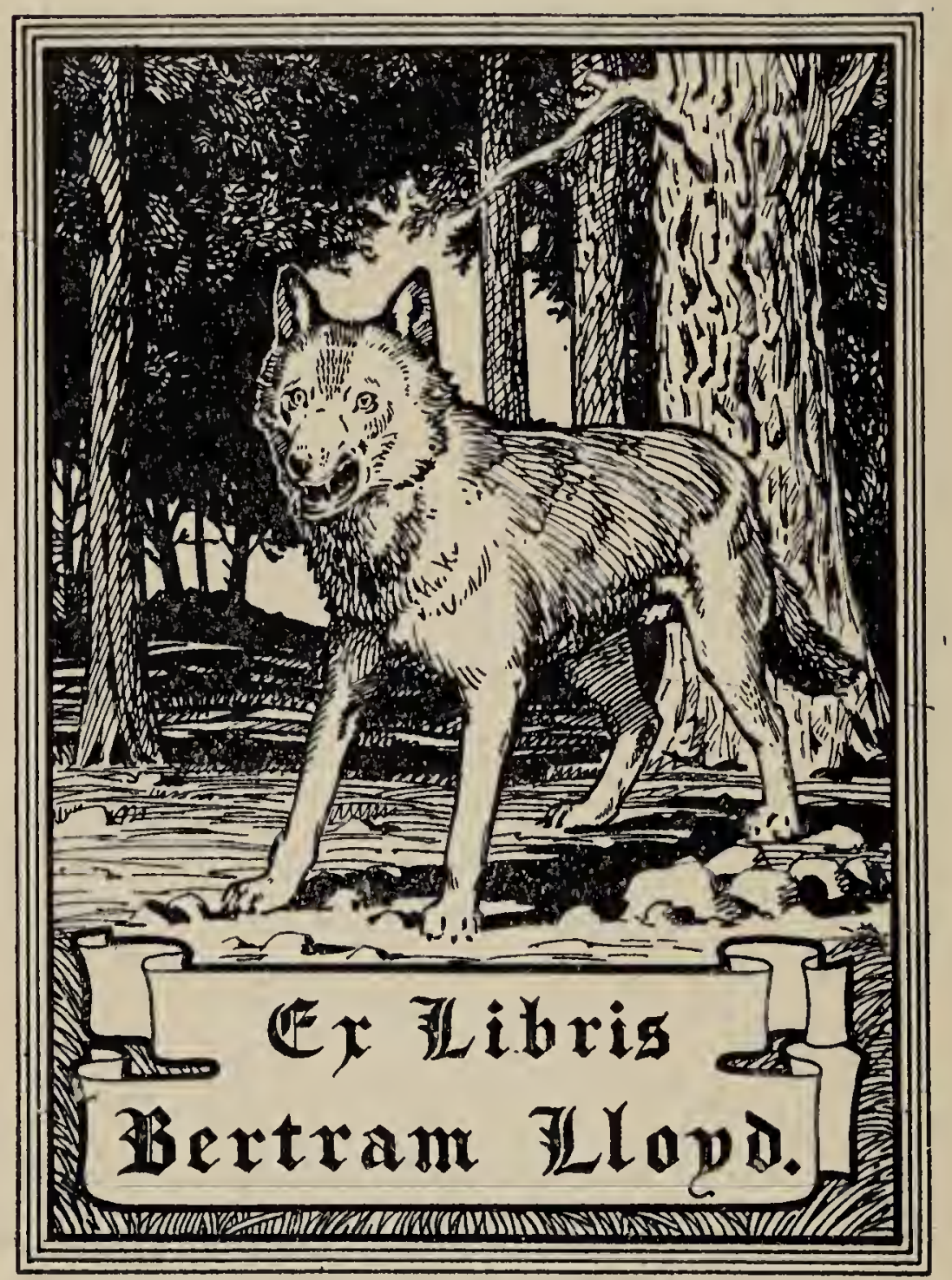





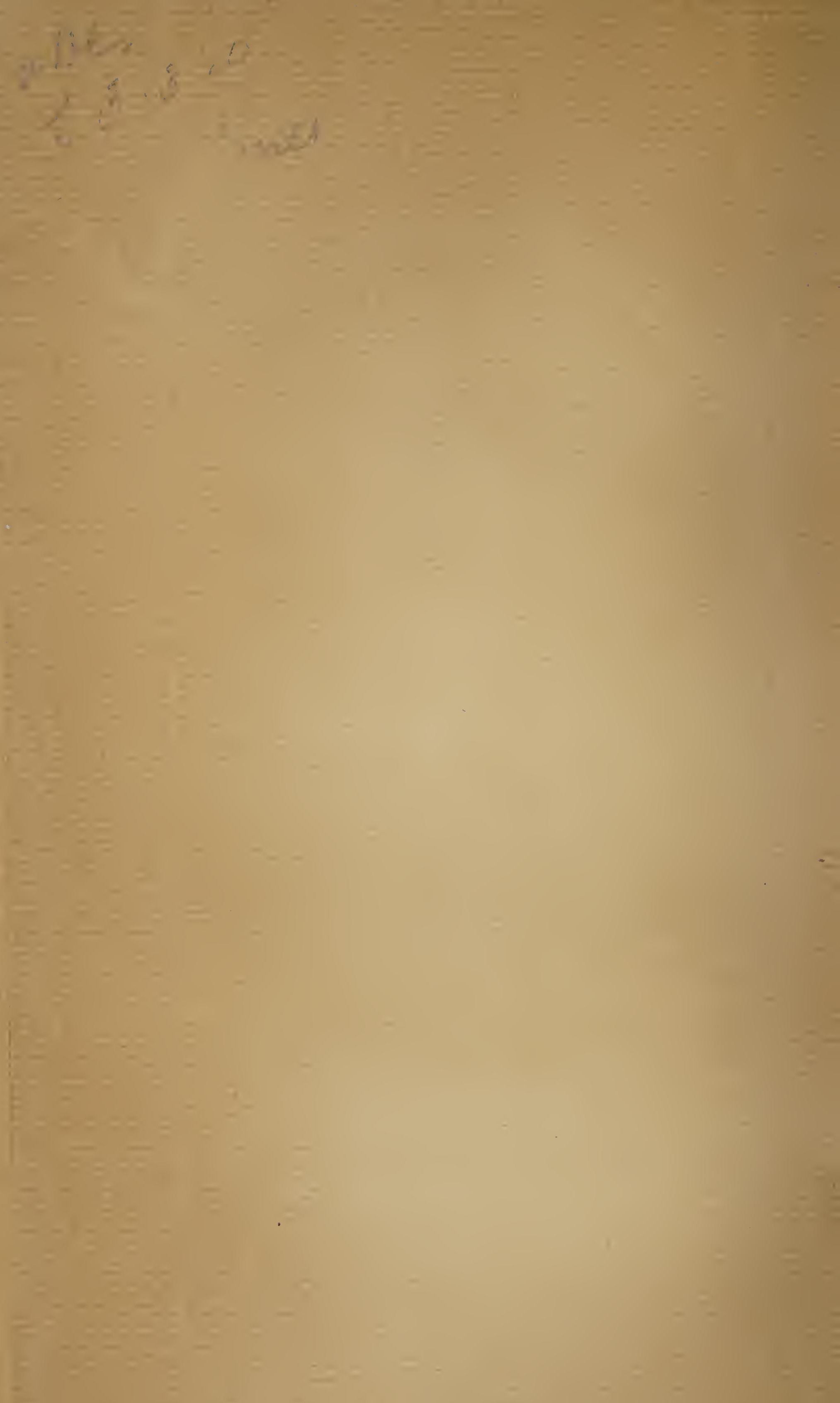




\section{B R IT IS H F I S H E.}

VOL. I. 
LONDON :

PRINTLD BY WOODFALL AND KINDER, ANGEL COURT, SKINNER STREFT. 
Digitized by the Internet Archive in 2018 with funding from University of Toronto

https://archive.org/details/historyofbritish01 yarr_3 


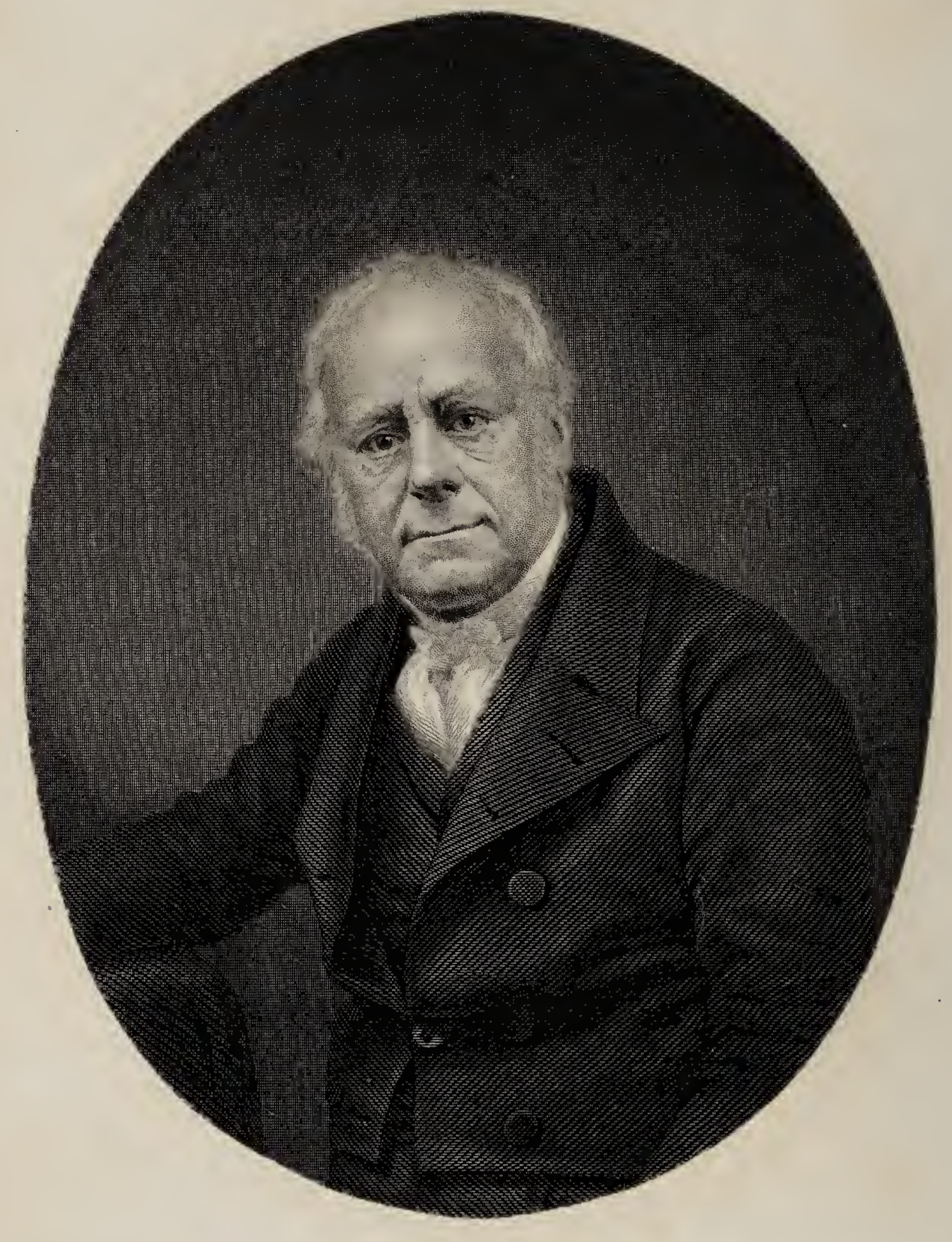

$$
\begin{aligned}
& \text { Zours sincencly, } \\
& \text { Stmorrell. }
\end{aligned}
$$




\section{H I S T O R Y}

\section{$O F$ \\ B R I T I S H F I S H E S. \\ $\mathrm{BY}$ \\ WILLIAM YARRELL, F.L.S., V.P.Z.S.}

THIRD EDITION,

EDITED BY

S I R J OHN RICHARDSON, C.B., F.R.S. LOND.; HON. F.R.S. ED.; ETC.

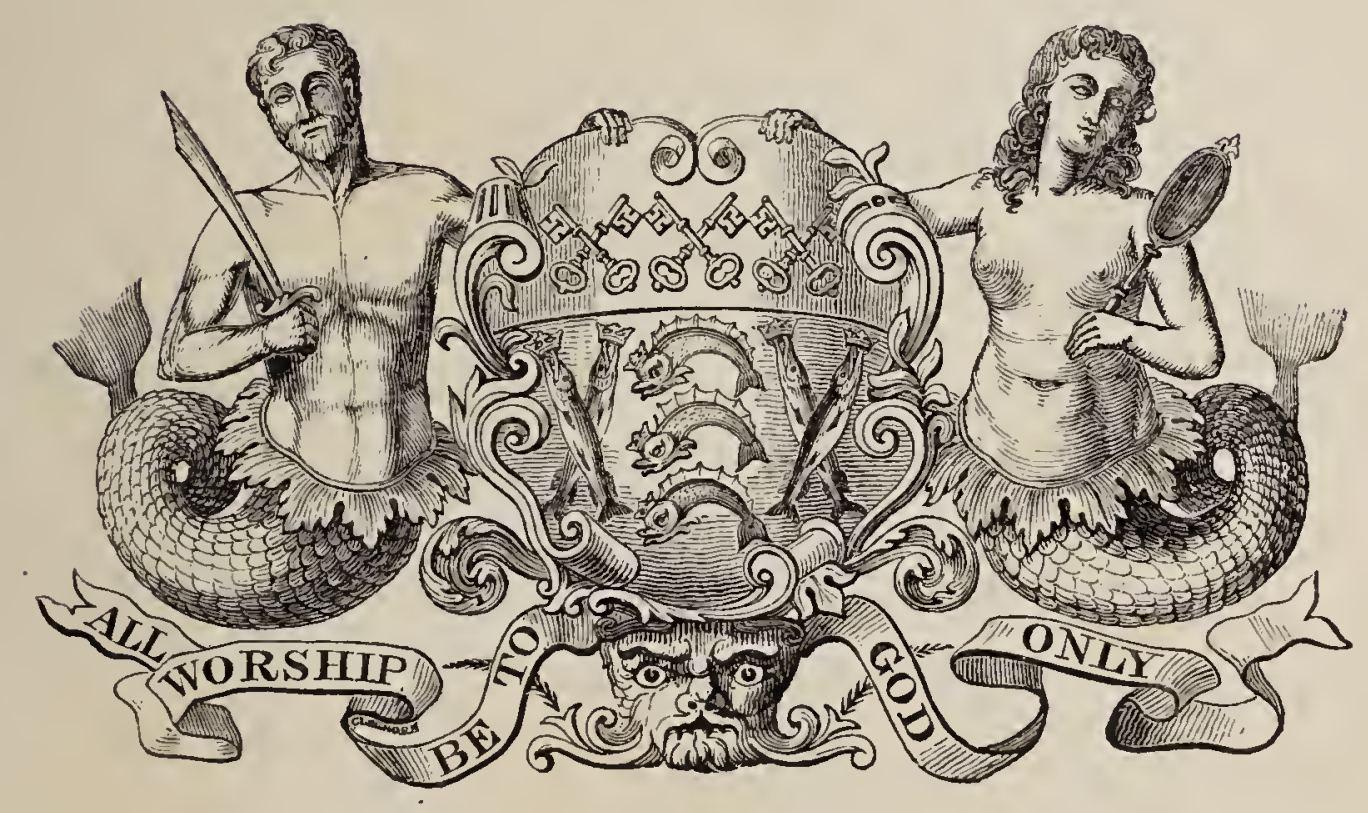

ILLUSTRATED BY 522 WOOD-ENGRAVINGS.

IN TWO VOLUMES.-VOL. I.

L O N D O N :

JOHN VAN VOORST, PATERNOSTER ROW. M.DCCC.Lix. 



\section{MEMOIR OF WILLIAM YARRELL。}

William Yarrell was a man rather below the middle height, having a robust, well-knit frame, a sagacious and pleasing countenance, and frank and agreeable manners. His aspect was that of a stout yeoman, such as in times past have contributed with head and hand to elevate their native England to its present rank among the nations, or rather his demeanour may be said to have indicated exactly what he was in fact-a citizen who had thriven in the greatest of commercial cities, but who, strong in native honesty and self-respect, had passed unscathed through the perils of money-making, his cheerful countenance bearing no lines traced by the thirst of gain or the debasing passion for hoarding: on the contrary, his mild but fearless eye, and his open forehead, showed, even to a stranger, a man at peace with himself and with his fellow mell.

He was born on the 3rd of June, 1784, in the parish of St. James's, where his home continued to be for the seventy-two years of his life. In Duke Street his father and uncle carried on in partnership the business of newspaper agents. On the death of his father, his mother removed to a private residence in Great Ryder 
Street, and there the son lived with her, and during that time was joined in trade with his cousin, then carrying on the business of their late fathers at, and living in, the north-east corner of Little Ryder Street; and whither, on Edward Jones ceasing to reside, William Yarrell went, and continued to dwell, till death.* A domicile so permanent offers no field for stirring incident, but it is salutary to contemplate the career of a man, who, possessing the ability, judgment and industry that lead to success, and placed by the accidents of birth and connection among the busy throng of the metropolitan worshippers of wealth, deliberately chose the safer middle path of competency,in an age when money has power to raise its possessor to a seat among the law-givers of the land, and the art of acquiring it is considered in the social estimate of the day as equivalent to high breeding, education and virtue, -when, in short, the cry "get money, per fas aut nefas," has gone far towards sapping the national character for honesty, and the vaunted good faith of the British merchant is in danger of becoming a myth.

The following brief narrative is compiled from obituary notices published immediately after Mr. Yarrell's death by several of his intimate and attached friendsProfessor Bell, President of the Linnean Society, Dr. R. G. Latham, Edward Newman and Lovell Reeve, Esqs. These gentlemen have referred mainly to $\mathrm{Mr}$. Yarrell's scientific pursuits, and have mentioned few or no particulars of his private life, nor is the compiler of this memoir able to supply the deficiency. But he, who attained the length of days usually allotted to man, and survived all his brothers and sisters as well as father and

* A year before that event, he had ceased to have any connection with the business, having retired in favour of Messrs. Joseph and Charles Clifford. 
mother, though he never married, must have had the depths of his sensitive nature often stirred by the breaches made by death in the circle of his relatives and friends, even should no tenderer tie have been untimely snapt asunder. That such was the case may be inferred from the feeling which only two years before his death prompted him to transfer to the album of his relatives, the Misses Pallett of Dover, the subjoined lines from Wordsworth :-

\section{"first and last,}

The earliest summoned and the longest spared, Are here deposited."

The following is the marriage certificate of his parents :-

"At Bermondsey Parish Church, Surrey, Francis Yerrall, of this Parish, Bachelor, to Sarah Blane, of this Parish, Spinster. By Banns, 26 June, $17 \% 2$.

\section{Present, William Hawkins,} John Beszant."

Subsequently his father transposed the $\mathrm{e}$ and a in writing his surname, as appears by this register of birth :-

"St. James's, Westminster, June 27, 1784. William Yarrell, son of Francis and Sarah, born June 3rd."

Of his father's origin, except that he was born the 10th of February, 1749, married the 26th of June, 1772, died the 25th of March, 1794, was the eldest of seven brothers and sisters, the children of Francis Yerrall, born in 1797, died the 5th of January, 1786, and of Sarah his wife, born in 1719, died the 12th of December, 1800,-nothing can now be ascertained; and it is believed that the son never knew his father's native place exactly, though he used to think that he came from Bedfordshire, where the surname is a common 
one, but is spelt in various ways. The second Francis Yerrall is reported to have been a proud man. Sarah Blane is said by a relative to have been born of parents who were small farmers at Bayford in Herts, and to have been remarkable for nothing but her temper, which was wholly unlike to that of her distinguished son. If the dispositions of the mind are, as has been supposed, like the constitution of the body and the lineaments of the countenance, in some degree hereditary, and that consequently pride and quickness of temper descended to the offspring of Francis and Saralı Yarrell, William, the ninth-born child, was fortunately endowed at the same time with so much firmness and good sense as to be able to keep his passions under control and to become remarkable in after-life for modesty and urbanity.

In his boyhood William Yarrell occasionally visited his maternal relatives at Claypits Farm, Bayford, and there, doubtless, his love of rural scenery originated; but his earliest tastes for Natural History seem to have been fostered by his mother, who took him with her in the frequent excursions she made to Margate, then a favourite resort of Londoners. Their conveyance was the usual one of the time, the Margate Hoy, and young Yarrell found amusement on the sands in picking up sea-weeds, which he and his sister afterwards laid out on paper. He also collected shells and other marine productions.

His school days were passed at the large scholastic establishment kept by Dr. Nicholas at Ealing, where he acquired the character of a quiet, studious boy. The late General Sale, G. S. Heales, Esq., of Doctors' Commons, who survived him but a few months, and Mr. Edward Jones, were his fellow pupils, the last-mentioned 
being his cousin, the son of his father's partner, and his own future associate in the business carried on in Ryder Street. He had also for playmates his relatives, $\mathrm{Mr}$. Bird and Mr. Goldsmith.

In 1802, being then in the eighteenth year of his age, he entered the banking-house of Herries, Farquhar and Co., as a clerk, but shortly afterwards left that employ, and returned to his father's business. Previous to this event his love of angling had made him acquainted with the streams in the vicinity of London, and the perusal of Izaac Walton's fascinating colloquies had taught him to combine practical philosophy with that pastime. In the course of this pursuit he afterwards often associated with a Londoner of maturer years, an old sportsman named Adams, with whom he was wont to angle under Putney bridge and in other parts of the Thames when the calls of business did not press. Under the guidance of this early friend he acquired the art of shooting, and as it was his custom throughout life to pursue zealously whatever he undertook, he became a proficient in the management of the gun. This led to an intimacy with George Manton, the well-known gun-maker of Bond Street, and with Shoobridge, the hatter of Bond Street, known among sporting men as an unerring shot. Yarrell, who was thought by some to be the better shot of the two, became a member of the Old Hats Club, and was a successful competitor at shooting matches near London. He was constantly in friendly consultation with George Manton when any new form of breech or lock in a fowling-piece was to be tried. At a later time he shot game in Hertfordshire and Cambridgeshire over differerent manors which he rented in conjunction with his friend Wortham. His exploits with the gun are still remembered in the neighbourhood of Royston, and the 
same healthful exercise led him also frequently into other localities. His tastes, says one of his friends, were those of a Londoner, whom the rus in urbe suited better, perhaps, than the unmixed country. They were those of Izaac Walton, citizen and angler, rather than those of the full and perfect yeoman.

These amusements of his earlier life led to his acquiring an intimate knowledge of the habits of our native birds and fishes, their food and migrations, his observation of the objects that engaged his attention being as accurate as it was keen. They were not, however, the only occupations in which he sought relief from the monotony of business, for in 1817 he studied Chemistry at the Royal Institution. Before he attained middle life he engaged in the systematic study of Zoology, and pursuing it in the intervals of business with his accustomed application, he gradually gave up field sports, and it is believed that for thirty years before his death he handled neither rod nor gun.

In 1823 he commenced noting the appearance of strange and rare birds, and in $\mathbf{1 8 2 5}$ he lent his aid to Bewick by sending him scarce British birds to figure. He also presented a collection of the trachex of waterbirds to the Royal College of Surgeons. His own museum at this time contained a series of British Birds and their eggs, and he now cultivated the society of scientific men, among whom he had made the acquaintance of Sir William Jardine, Bart., and P. J. Selby, Esq., of Twizel House, who were then engaged in publishing their respective works on British Ornithology. In November of the same year he was admitted a Fellow of the Linnean Society, and in 1826 he became one of the original members or founders of the Zoological Society. Next year he was chosen to be one of the 
Council of the Medico-Botanical Society, and henceforward his readiness to oblige, the clearness of his understanding, and his business habits, coming to be known, his services in the management of the societies to which he belonged were in constant requisition. "It was only with reluctance, and in compliance with established rules," says Professor Bell, "that his name was omitted from the council lists of either the Linnean or Zoological Societies." Of the latter he was occasionally Auditor, for a time Secretary, and frequently one of its VicePresidents. He was also a warm supporter, and for a long time treasurer, of the Entomological Society. On the deatl of Mr. Forster, in 1849, he was elected Treasurer of the Limnean Society, and continued to fill that office and to be one of its Vice-Presidents until his death. With respect to the Royal Society, the following is the statement of Professor Bell, who was fully cognizant of the circumstances: "Many years since, long. before the present plan of selecting a certain number of candidates by the Council was adopted, $\mathrm{Mr}$. Yarrell was proposed as a Fellow, and his certificate signed and suspended. At that time the Council had notling whatever to do with the election nor with the recommendation of the candidates. Mr. Yarrell's scientific character was not so well kllown and appreciated as it has since become. A gentleman, long since deceased, who would afterwards have gladly recalled the act, expressed some objection to his being elected, and his certificate was, from a feeling of delicacy on Mr. Yarrell's part, withdrawn; but subsequently, since the present system has been in action, the writer of this notice, with the full concurrence of many members of the Council, who were most desirous of his election, drew up a certificate in his favour, and obtained some signatures before he men- 
tioned the subject to Mr. Yarrell, hoping that when he knew such a step had been taken he would consent to be put in nomination. On being informed, however, of this movement, which there is no doubt would have met with the unanimous approval of the Council, he declined the honour solely on the ground of advancing age, and his increasing inability to avail himself of the advantages of the position."

The subjoined list of Mr. Yarrell's publications affords evidence of his industry and the variety of his zoological studies. He became an author evidently from the love of his subjects, and being in no haste to publish until he had duly investigated the matter in hand and brought his clear judgment to bear on the evidence before him, his writings on Natural History soon acquired that value among scientific men which simple and truthful narrative always commands. His great works on the Birds and Fishes of Britain are quoted as authorities in all the scientific circles of Europe and America, and are models of local Faunæ, both on account of the strictness with which doubtful species are noted or rejected, as well as for the completeness of the lists gained by unwearied diligence and inquiry in every direction. The synonymy is elaborated with care and skill, and the illustrations, liberally provided by his friend and publisher, are worthy of the work, which is no mean praise. Mr. Yarrell and Mr. Van Voorst were first brought together by their mutual friend, the late Mr. Martin, the librarian of the Duke of Bedford, and the conjunction was a most fortunate one for the progress of British Zoology, a series of unrivalled illustrated monographs having originated therefrom. Mr. Yarrell's inquiries into the changes of plumage of hen' Pheasants and of birds generally, his dissertations on the horny tip of the bill of young chickens, 
on the production and migration of Eels, on the gestation of eggs by the male Pipe-fish, his investigations into the route pursued by American birds in their casual visits to England, and numerous other passages of his works, show much originality of thought and a careful examination of facts.

One of his friends* says, "There was one trait in the character of Mr. Yarrell which must not be passed over in silence, a trait which no one was better acquainted with than myself, and that was his extreme readiness to afford information. Often have I had occasion to appeal to him in difficulties about specific character or points of economy, and from the very moment of mentioning the doubt or the object of inquiry, his whole attention was absorbed by it; books, specimens, memory, every auxiliary was at his fingerends; and no sacrifice of time or trouble was too great for him to make; neither was the subject ever left undecided while diligence or a disposition to teach could throw on it a single ray of light. No other subject seemed to occur to him during the investigation; he had no other occupation; that one inquiry was, for the time, the object of his life. His power of concentrating his attention on a single subject was most extraordinary, and more extraordinary still was the facility with which that concentrated attention was turned to any subject; he used it after the fashion of a burning glass, casting the focus wherever he pleased. This faculty was at the service of all; and the attention of which I speak thus gratefully from personal experience was given to every truth-seeking inquirer."-Zoologist, 5258.

Another friend $\uparrow$ writes as follows: "Mr. Yarrell's

* Edward Newman, Esq., Editor of the Zoologist.

+ Dr. R. G. Latham. 
purely intellectual character is seen in his works. The part which the author himself always took most credit for, was the geographical distribution of birds. He considered that in treating it as he had done, he smuggled in a certain amount of geography under the garb of ornithology. For the high qualities of accuracy, terseness of description, and felicity of illustration, they speak for themselves."-Edinburgh New Philosophical Journal, 1856.

So much for the excellence of his works on Zoology, of which the best tests are the continually-increasing demand for them at home after twenty-two years' circulation, and the frequency and confidence with which they are quoted by naturalists abroad. With regard to $\mathrm{Mr}$. Yarrell's character as a man, the following extracts from the obituary notices referred to, will show the estimation in which he was held by those who were most intimately acquainted with his conduct in private and public life. "Strong social instincts," says a keen observer of men and manners, "geniality of temper, warmth of heart (exhibited in an extreme fondness for children), made him loved, even as his simple and straightforward independence of character made him respected. His advice, too, was always valued, freely asked and freely given, for his mind was observant, active, practical, and wholly unclouded by fancies or prejudices; his knowledge varied and accurate. Indeed he was essentially a reliable man, knowing what he knew well, and caring to undertake nothing that he was likely to fail in. For this a strong will and perseverance is needed. It was strong enough to keep a warm temper in thorough control; for Mr. Yarrell, knowing what was due to himself, knew also what was due to others. He helped many, not only with his advice but by his purse, ever valuing money for 
its uses only, never for its own sake; moderate (as a man of business) in his aims, though attentive to what he undertook; hating waste, yet never ambitious of accumulation." . . . . "For many years his house was familiar to all naturalists, and to visitors of every rank from the country, not to mention foreigners, to whom the reputation of one of the soundest of living zoologists was well known, and who never visited it without being struck by the kind and communicative manners of its hospitable inmate." . . . . "His habits, angler and ornithologist as he was, were eminently those of a Londoner. He loved glees, and sung them well, and at one time of his life was a frequent attendant at the theatres."-Dr. R. G. Latham.

The testimony of Professor Bell, who knew him well, is as follows:- "In speaking of Mr. Yarrell's intellectual and social qualities, it is difficult to do them justice without danger of appearing hyperbolical. His judgment was clear and sound, his appreciation of the value of facts and of evidence most accurate, his advice always practical and thoughtful. His truthfulness and simple. heartedness were even child-like, his temper gentle, his heart loving and affectionate, and he was liberal and charitable almost to the verge of imprudence. A kindlier spirit never lived. His friendships were sincere and lasting, and only changeable on discovery of the worthlessness of the subject, and then how hard was he to believe the painful truth! If ever man realized the beautiful apostolical definitions of Charity, it was William Yarrell. There were, indeed, in Mr. Yarrell's character many points of resemblance to that of Izaac Walton and of Gilbert White. The same charming' bonhomie and truthfulness and simplicity and elegant taste as in the former; and the close and accurate obser- 
vation and clear and graphic description which characterize the writings of the latter."

A third friend (Mr. Lovell Reeve) mentions the following traits of character:- "Notwithstanding his retired manners, Mr. Yarrell was a frequent diner-out, and a jovial companion at table. He sang a capital song, and was a constant attendant at the theatre, generally selecting, with the gusto of a dilettante, the front row of the pit. In the days of the elder Mathews, he would manage to get the songs of the great mimic, in spite of the rapidity of their utterance, by taking down the alternate lines one night, and filling in the others on the next. A song of Dibdin's we heard him sing only recently, with admirable spirit and pathos. He seldom missed the Linnean Club dinners and country excursions, and was at all times the liveliest of the party."

By the methodical distribution of his time $\mathrm{Mr}$. Yarrell was enabled, without neglecting his business concerns, to assist in the management of the scientific societies of which he was a member, and to carry on his zoological inquiries and publications. His enjoyment. of social life was combined with temperance; and being blessed with a sound constitution he possessed continuous good health up to the year 1853, when some premonitory symptoms of indisposition began to appear, without, however, affecting the activity of his intellect or the cheerfulness of his manners. On the 3rd of August, 1856, as he was returning from St. James's Church, which for some years he had constantly attended, a slight giddiness seized him, his steps became uncertain, and he felt for a moment unable to proceed. After a short rest he reached home without assistance. This attack proved to be a slight paralysis, from which 
he so far recovered as to able to give his uninterrupted attention to matters of business. On Monday, the 25th of August, he attended a Council of the Linnean Society, and was as cheerful, and apparently nearly as well as usual. In answer to a wish expressed by his intimate and attached friend the President of the Society, that he would soon be able to pay him a quiet visit, he said that though pretty well he felt a "wooliness" in the brain, and that he was restricted in his diet. On the following Saturday, however, he felt himself well enough to take charge of an invalid friend in a voyage by sea to Yarmouth, and thus the very last act of his life was one of kindness. He enjoyed the voyage, took a moderate dinner at the Royal Hotel with appetite, and retired to bed anticipating a good night's rest. But scarcely had he lain down before he felt a difficulty of breathing, and fearing, as he said, that "he might die and no one know it," he got up, unlocked the door, and rang the bell. The attentive landlady was speedily at his bedside, medical assistance was procured without delay, but nothing availed, and he expired calmly at half-past twelve on Monday morning the 1st of September, in the seventy-third year of his age. He experienced no pain, and remained perfectly conscious until within a few minutes of his entering the unseen world. The immediate cause of his death was judged to be disease of the heart, with which the previous symptoms of apoplexy were but indirectly connected. No autopsy was made. On the following Monday he was buried at Bayford in Hertfordshire (where a great many of his maternal kinsfolk and ancestors lie), in a spot selected by himself, his body being attended to the grave by the President and other office-bearers of the Linnean Society, as well as by his executors and surviving relatives. 
A tombstone erected to his memory bears the following inscription :-

HERE LIE THE REMAINS

OF

WILLIAM YARRELL, V.P.I.S., F.Z.S., of St. James's, Westminster,

Anthor of a History of British Birds, and of a History of British Fishes.

Born, June 3rd, MdCclXxxiv.

Died, SEPt. 1st, MDCCCLVT.

He was the survivor of twelve Brothers and Sisters, who, with their Father and Mother, are placed close to this spot.

"first and last,

The earliest summoned and the longest spared-

Are here deposited."-WordsworTH.

His executors were his relative Mr. Bird, and his friend and publisher Mr. Van Voorst, and the property administered to amounted to about 17,000l. After his death his extensive library of Natural History books and his valuable collections of British Birds and Fishes were sold by auction, at which the Fishes were purchased for the British Museum.

A portrait of him, painted in 1839 by Mrs. Carpenter, is suspended in the hall of Burlington House, the expense having been defrayed by forty Fellows of the Linnean Society; and a Medallion Tablet executed by $\mathrm{Mr}$. Neville Burnard, has been affixed in St. James's Church, at the west end of the south aisle.

The portrait facing the title-page of Vol. I., engraved by Mr. Frederick A. Heath, is from a photograph by Messrs. Maull and Polyblank, taken in 1855. 


\section{LIST OF MR. YARRELL'S WRITINGS.}

1. Notices of the occurrence of some rare British Birds observed during the years 1823, 1824, and 1825.-Zool. Journ., ii. p. 24, March, 1825.

2. Ditto, second communication.-Zool. Journ., iii. p. 85, October, 1826.

3. Ditto, third communication.-Zool. Journ., iii. p. 497.

4. Some observations on the anatomy of the British Birds of Prey.-Zool. Journ., iii. p. 181, October, 1826.

5 . On the small horny appendage to the upper mandible in very young chickens.-Zool. Journ., ii. p. 443, written 17th October, 1825, published 1826.

6. Notice of the occurrence of a species of duck (Anas rufina) new to the British Fauna.-Zool. Journ., ii. p. 492, 1826.

7. Observations on the tracher of Birds, with descriptions and representations of several not hitherto figured.-Linn. Trans., xv. p. 378, 1827. Read February 6th, 1827.

8. On the change of plumage of some Hen Pheasants.-Phit. Trans., written February, 1827. Read in May, 1827.

9. On the osteology of the Fennec (Canis cerdo).-Zool. Journ., iii. p. $401,1827$.

10. On the osteology of the Chlamyphorus truncatus of Dr. Harlan, March, 1828.-Zool. Journ., iii. p. 544.

11. Some remarks on the habits of the Kingfisher, March, 1828. -Loudon's Mag. of Nat. Hist. and Journ. of Zool., de., i. p. 23, 1828.

12. Description of a species of Tringa (T. rufescens) killed in Cambridgeshire, new to England and Europe-Linn. Trans., xvi. p. 109. Read June 17th, 1828.

13. On the supposed identity of Whitebait and Shad, August, 1828.-Zool. Journ., iv. p. 137.

VOL. I. 
14. Observations on the Tapir of America. - Zool. Journ., iv. p. 210 .

15. On the use of the Xiphoid bone and its muscles in the Cormorant (Pelecanus carbo, L.), August, 1828.-Zool. Journ., iv. p. 234.

16. Notes on the internal appearance of several animals examined after death, in the collection of the Zoological Society (Otter, Paradoxure, Ocelot, Chinchilla, Agouti, Porpoise, Touraco, Javanese Peacock, Silver Pheasant, Hybrid Pheasant, White Stork, Common Bittern, Crested Grebe, Red-throated Diver, Tame Swan, Wild Swan, Black Swan, Canada Goose, White-fronted Goose, Indian Tortoise, Active Gibbon, Diana Monkey, Weeper Monkey, Mexican Dog, Jerboa, Bobac, Malabar Squirrel, Crested Porcupine, Alpine Hare).-Zool. Journ., iv. pp. 314-322.

17. On the structure of the beak and its muscles in the Cross-bill (Loxia curvirostra).-Zool. Journ., iv. p. 459.

18. Remarks on some English Fishes, with notices of three species new to the British Fauna (Solea pegusa, Cottus bubalis, Anguilla). -Zool. Journ., iv. p. 465.

19. Descriptive and Historical Notice of British Snipes.-Loudon's Mag. of Nat. Hist., de., ii. p. 143, 1829.

20. Supplement to ditto.-Loudon's Mag. of Nat. Hist., iii. p. 27, 1830 .

21. On the organs of voice in Birds.-Linn. Trans., xvi. p. 305. Read June, 1829.

22. On a new species of Wild Swan (Cygnus Bewickii) taken in England, and hitherto confounded with the Hooper.-Linn. Trans., xvi. p. 445. Read January, 1830.

23. Reply to the statement respecting the Discovery of Cygmus. Bewickii, published in the Philosophical Magazine and Annals for August.-Richard Taylor's Philos. Mag. and Annals.

24. On the occurrence of the Sylvia Tithys of Scopoli in England.-Proceed. of Com. of Science of Zool. Soc., i. p. 18, 1830.

25. On the assumption of the male plumage by the female of the common Game Forvl.-Ibid., i. p. 22, 1830.

26. On the anatomy of the Cereopsis Norce Hollandice, Lath., and on the relations between the Natatores and Grallatores.-Ibid., i. p. 25,1830 .

27. On the sexual organs of the hybrid Pheasant.-Ibid., i. p. 27.

28. On the specific identity of the Gardenian and Night Herons (Ardea Gardenii and nycticorax).-Ibid., i. p. 27.

29. On the Anatomy of the Chinchilla lanigera.-Ibid., i. p. 32.

29*. On the trachea of the Red-knobbed Curassow (Cra: Yarrellii, Benn.).-Ilicl., i. p. 33. 
30. Characters of a new species of Herring (Clupea, L.).-Ibid., i. p. 34 .

31. On the occurrence of several North American Birds in England.-Ibid., i. p. 35 .

32. On the anatomy of the Lesser American Flying Squirrel (Pteromys volucella).-Ibid., i. p. 38.

33. On the anatomy of the Ctenodactylus Massonii, Gray.-Ibicl., i. p. 48 .

34. On the sterno-tracheal muscles of the Razor-billed curassow (Ourax mitu, Cuv.).-Ibid., i. p. 59.

35. On the distinctive characters of the Tetrao medius, Temm.Ibid., i. p. 73.

36. On two species of Entozoa in the Eel.-Ibid., i. p. 132.

37. On the generation of Eels and Lampreys.-Ibid., i. p. 132.

38. On the Brown-headed Gull (Larus capistratus, Temm.).-Ibid., i. p. 151.

39. On the anatomy of the Conger Eel (Conger vulgaris), and on the differences between the Conger and the Fresh-water Eels.Ibid., i. p. 159.

40. Additions to the British Fauna, Class Fishes, September, 1830. -Loudon's Mag. of Nat. Hist., iii. p. 521.

41. Specific characters of Cygmus Bewickii and $C$. ferus.-Taylor's Phil. Mag. and Annals, vii. p. 194.

42. Additions to the catalogue of British Birds, with notices of the occurrence of several rare species, January, 1831.-Loudon's Mag. of Nat. Hist., iv. p. 116.

43. On a hybrid between a Muscovy Duck (Anas moschata) and a Common Duck (Anas boschas).-Proc. Com. of Sc. of Zool. Soc., ii. p. $100,1832$.

44. On two species of Mammalia new to Britain, one of them (Sorex remifer) new to science.-Ibid., ii. p. 429, 1832.

45. Description of the organs of voice in a new species of Wild Swan (Cygmus buccinator of Richardson).-Linn. Trans., xvii. p. 1. Read 20th March, 1832.

46. Description of three British species of Fresh-water Fishes belonging to the genus Leuciscus of Klein.-Ibid., xvii. p. 5. Read June, 1832.

47. Additions to the British Fauna, Class Mammalia (Arvicola riparia, Sorex remifer), August, 1832.-Loudon's Mag. of Nat. Hist., v. p. 598.

48. Notice of a new species of Herring.-Zool. Journ., v. p. 277.

49. Observations on the laws which appear to influence the assumption and changes of plumage in Birds.-Proceed. Zool. Soc., 
i. pp. 9,56 ; Trans. Zool. Soc., i. p. 13. Read February and April, 1833.

50. Description, with some additional particulars, of Apteryx australis of Shaw.-Proc. Zool. Soc., i. p. 24; Trans. Zool. Soc., i. p. 71. Read June, 1833.

51. On the trachex of the Penelope gouan, Temm., and the Anas magellanica, Auct.-Proceed. Zool. Soc., i. p. 3.

52. On the Woolly and Hairy Penguins (Aptenodytes).-Proceed. Zool. Soc., i. pp. 24, 80; Trans. Zool. Soc., i. p. 13, 1833.

53. On the identity of the Woolly Penguin of Latham with the Aptenodytes patachonica of Gmelin.-Proceed. Zool. Soc., i. p. 33, 1833.

54. Characters of the Irish Hare, a new species of Lepus.-Ibid., i. p. 88 .

55. On the deficiency of teeth in the hairless Egyptian variety of the dog.-Ibid., i. p. 113.

56. Notice of the occurrence of Squilla Desmarestii on the British shores.-Loudon's Mag. of Nat. Hist., \&c., vi. p. 230.

57. On the reproduction of the Eel.-Report of Brit. Assoc., 1833, p. 446.

58. On the anal pouch of the male fishes in certain species of Syngnathus.-Proceed. Zool. Soc., ii. p. 118.

59. Observations on the economy of an insect destructive to turnips (Athalia centifolia).-Trans. Zool. Soc., ii. p. 67. Read November, 1835.

60. On the mode of union after fracture of the processes of the vertebræ of a Sole (Solea vulgaris, Cuv.).-Proceed. Zool. Soc., iii. p. $57,1835$.

61. On the trachea of the Stanley Crane (Anthropoides paradiseus, Besch.).-Itid., iii. p. 183.

62. On the fotal pouch of the male Needle Pipe-fish (Syngrathus acus, L.).-Ibid., iii. p. 183, 1835.

63. A History of British Fishes. Van Voorst, London, 1836, 2 vols., 8vo., (published in parts, finished in 1836, containing vol. i. pp. 408, vol. ii. pp. 472).

64. Supplement to ditto, March, 1839 (vol. i. pp. 48, vol. ii. pp. 78, containing 27 new species).

64*. On an interwoven mass of filaments of Conferva fluviatilis of extraordinary size.-Proceed. Linn. Soc., i. p. 65, 1838.

65. A History of British Fishes. Van Voorst, London, 1841, 2 vols., 8vo., Second Edition (vol. i. pp. 464; vol. ii. pp. 628, containing 263 species, and 500 figures).

66. A History of British Birds. Van Voorst, London, 1843, 3 
vols., 8vo. (published in parts at intervals of two months, the first one in July, 1837, and the last one in May, 1843. Vol. i. pp. 525; vol. ii. pp. 669 ; vol. iii. pp. 528).

67. Supplement to ditto, October, 1845 (number of species in the first edition and supplement 354).

68. A History of British Birds. Van Voorst, London, 1845, 3 vols., 8vo., Second Edition.

69. On a new species of Swan (Cygnus immutabilis),-Proceed. Zool. Soc., ix. p. 70, 1841.

70. On the trachea of a male Spur-winged Goose (Anser gambensis).-Ilid., ix. p. 70, 1841.

71. On a new species of Smelt from the isle of Bute (Osmerus hebridicus).-Report of Brit. Assoc. for 1838, p. 108.

72. On the preservation of Crustacea.-Entom. May., vi. p. 421.

73. Remarks on some species of Syngnathus.-Annals of Nat. Hist. and Mag. of Zool., Jardine, \&., iii. p. 81.

74. Growth of Salmon in fresh water.-Ibid., iv. p. 334.

75. On Motacilla alba, L.-Ibid., vii. p. 350.

76. Description of the eggs of some of the birds of Chile.-Zool. Proceed., 1847.

77. Occurrence of a Petrel new to Britain on the coast of Ireland, June, 1853.-Zoologist, 3947.

78. On birds lately ascertained to be British, p. 79; and on rare English fishes, p. 85.-Ibid., 79. 1843.

79. On the influence of the sexual organ in modifying external character.-Journ. Linn. Soc., June, 1856, i. p. 76.

80. On Mucor observed by Colonel Montagu in the air-cells of a bird.-Annals and Mag. of Nat. Hist., de., ix. p. 131.

81. Chapter VIII. in the Third Edition of Harvey's Sea-side Bools "On Marine Fishes," pp. 237-269. 



\section{PREFACES}

TO THE FIRST AND SECOND EDIIIONS, ABRIDGED

AND COMBINED.

'lo every inhabitant of Great Britain who is desirous of promoting the national welfare, a knowledge of the numerous species of Fish which frequent our coasts must be an object of importance. These creatures, reared without cost in our seas and fresh waters, furnish a large and constant supply of wholesome food, obtained by remunerative labour; and the fisheries are excellent nurseries of seamen and able pilots, for the successful exercise of the fisherman's vocation depends no less on an intimate acquaintance with the nature of the seabottom, the situation of banks and channels, and the direction of tides and currents, than on an insight into the habits and migrations of fish. The encouragement of the fisheries, therefore, not only for the food they supply to a growing population, but also as a means of raising many thousands of hardy fishermen, from whom our war marine and mercantile navy can be recruited, is indeed an object of national interest.

It has long, however, been matter of general regret that the subjects of this particular branch of natural history, so valuable as articles of food and commerce, and so interesting from their organization, and the pecu- 
liarities and beauty of their varied forms and colours, shouid, with the exception of those inhabiting the fresh waters, and the marine species most in request for the table, be almost wholly unknown.

Bewick's work, illustrated with engravings on wood of unrivalled excellence, may justly claim the distinguished merit of having done more towards rendering Ornithology popular in this country than any other book that could be named; and it was hoped that this eminent artist would have devoted his great talents to the delineation of the subjects of other classes in natural history, as well as to the Quadrupeds and Birds. It is certain that he had once contemplated producing a work on British Fishes: but he had abandoned the design before his lamented death in 1828. Some few engravings of British Fishes were executed by him with his usual success, impressions of which were occasionally to be seen in the possession of his most intimate friends.

The time that has now elapsed since his death leaves but little room to hope that this branch was ever so far prosecuted by him as to be made available in the present day, or that an object so desirable as a work on Britrsh Fismes executed to any extent by him can now be expected. Could it have been ascertained that any such intention still existed at Newcastle, the present work would never have been attempted.

An extensive collection of British Fishes in the possession of the author, containing upwards of one hundred and sixty species, to increase which no opportunity has been neglected during several past years, and the cordial assistance of some of the best naturalists from Scotland to the Land's End, are among the advantages the author of this work has enjoyed to assist him in his undertaking. 
So great has been the success in obtaining species either entirely new, or new to our coast, and so extensive the resources available in the present instance, that this work contains a number of species greater by one-fourth than has yet appeared in any British catalogue, with an extensive list of well-authenticated localities and local names. Two hundred and twenty-six species are described and figured, several of them in different stages of growth. The number of representations of fishes amounts to two hundred and forty. The drawings in almost every instance have been made under the author's superintendence from the specimens. The best artists, both as draughtsmen and engravers on wood, have been employed, and the representations will be found characteristic of the species, and highly creditable as works of art. Besides the figures of the fishes, there are upwards of one hundred and forty illustrative vignettes subservient to the general subject, representing teeth, scales, gillcovers, swimming-bladders, and occasionally other viscera, when interesting in structure, form, or function. The different boats, nets, and apparatus in use at our various fishing stations on the coast, are also figured, and the modes of employing them described.-Ryder Street, June 1836.

The additions to the British Catalogue of Fishes in the Second Edition are so many gratifying testimonials of the increasing number of observers, whose attention is directed towards the inhabitants of our seas; and I feel a sincere pleasure in the prospect of the many new subjects, and more correct illustrations, which our Ichthyology is likely to derive from the great interest now taken in this branch of Natural History.

Since the completion of the First Edition of the Fishes 
in the summer of 1836, thirty-seven new species have been added to our list, twenty-seven of which appeared in the Supplement to the British Fishes, published in 1839, and ten have been ascertained since; all of which are incorporated in their respective places, and we know now two hundred and sixty-three species. Twenty-seven fishes have been newly engraved for this second edition, either from specimens, or from better representations than were previously available; thirty-four new vignettes, illustrative or ornamental, have also been added, and the whole work contains impressions from four hundred and eighty-five blocks, producing more than five hundred figures.-W. Y. Ryder Street, October 1841.

The following acknowledgments are made in the two Prefaces :-

To Mr. Couch of Polperro, the indefatigable ichthyologist of Cornwall, the author is indebted for several examples of the most rare species found on the Cornish coast, for the use of a large and valuable collection of characteristic coloured drawings, and the whole of his manuscript notes.

W. J. Broderip, Esq., Vice-President of the Zoological and Geological Societies, having in his possession an interleaved copy of Mr. Donovan's Natural History of British Fishes, which formerly belonged to the late Colonel Montagu, the author of the Ornithological Dictionary and Testacea Britannica, containing voluminous notes of observations on fishes and fishing, made by Colonel Montagu during his long residence near the coast of Devonshire, has with the greatest kindness most liberally allowed the whole of these notes to be transcribed.

The author is also indebted to W. Walcott, Esq., of Bristol, for the use of a valuable manuscript, with a collection of more than one hundred drawings of British 
Fishes, executed by his father, the author of the Synopsis of British Birds, and other works on natural history, during his residence at Teignmouth.

To Sir William Jardine, Bart., the author is under obligations for many examples, and various communications on the species of the genus Salmo, from which materials were drawn for the elucidation of this difficult but important genus.

Dr. George Johnston of Berwick-upon-Tweed, whose name will be found to occur very frequently in this work, has very kindly transmitted rare specimens from that locality, with various notices of the natural history of some of the most remarkable species of the eastern coast.

The author is also desirous of recording his thanks to Dr. Edward Moore of Plymouth, for frequent communications on the fishes taken in that neighbourhood, and for an extensive catalogue of local names.

To W. Thompson, Esq., of Belfast, Vice-President of the Natural History Society of that town, the author's thanks are due for many valuable notes of the fishes of the Irish lakes, and communications of the occurrence of many marine species at various localities on the Irish coast.

The author's acknowledgments are especially due to his friend E. T. Bennett, Esq., Secretary to the Zoological Society, for his valuable advice and assistance throughout the progress of the work.

To the Rev. Robert Holdsworth of Brixham he is indebted for a long series of notes upon British Fishes, many of which will be found incorporated in these volumes; and from this gentleman he learned that a very rare fish, the Silvery Hairtail, Trichiurus lepturus, was taken at Brixham in the spring of the year 1841. (The species is figured and described, vol. ii.; pp. 275-279.) 
Mr. Couch of Polperro has continued to supply the author with notices of new or rare occurrences on the Cornish coast, and has lately obtained a large-sized specimen of the Blenny (figured at p. 371 of volume ii.) which, with his characteristic liberality, he has presented to the British Museum.

To Dr. Richard Parnell, whose Essay on the Fishes of the Forth gained him the prize of the Wernerian Society of Edinburgh, the author is also indebted for the loan of many useful specimens from his extensive and valuable collection.

He begs finally to acknowledge and record his obligations to the zoological officers of the British Museum for their uniform kindness and assistance upon all occasions.

W. Y.

Note by the Editor of the Third Edition.

THE prospect of a demand for a Third Edition of British Fishes had led the Author to make preparation for such a contingency, and he had drawn up a list of references to notices and descriptions of newly-discovered species, or supposed species, published from time to time in the periodicals devoted to Natural History, and more especially in the Zoologist conducted by Edward Newman, Esq. Beyond this, however, he had not gone, there being neither descriptions of additional species, nor critiques upon the notices found among his papers, he having evidently relied on the information he could command when it was needed. On the eve of his death he suggested to his executor and publisher, Mr. Van Voorst, that the present Editor should be 
asked to undertake the task left in this incipient stage, and the request when made was complied with out of respect to the memory and wishes of the departed,- the remembrance of his many kind offices during a long acquaintance having overcome the natural reluctance to intermeddle with a work of such established reputation.

A genəral revision of the species would have required a previous close study of our native fishes, and a full collection of specimens in various stages of growth, neither of which preliminaries existed, therefore no such revision has been attempted; and with the exceptions of a few additions to the histories of species made by recent observers, whose names are noted in the text, of a very few corrections left in manuscript by the Author, and of the insertion of a few species recently discovered, the work is substantially the same as it was left by its Author. The most material alteration is a change in the arrangement made in conformity with the views of Dr. Johannes Müller and Professor Owen, and in connection with it the characters of families and genera have been re-written; the Introduction, altered for more convenient binding to an Appendix, has also been re-cast, to bring it into harmony with the new arrangement. In the histories of the species, Mr. Yarrell's diction in the first person is preserved wherever his personal authority could give weight to the opinions or facts therein stated, and the present Editor's interferences have been with the following species chiefly, the Pride (i. p. 22); the Pearly-side; the Sail-Fluke, new ; Fabricius' Sea Bullhead, new ; the Bogue, new; the Dotted Mackerel, new ; the Germon, new; the Derbio, new; Banks's Oar-fish; the Sturgeon; the Gray Notidanus, new; and the White Shark. Some additions have also been made to the accounts of the habits or distribution of species 
$\mathrm{x} \times \mathrm{xii}$

NOTE ON THE THIRD EDITION.

from British and foreign authorities which are quoted in their respective places.

The present edition, in which some supposed species are suppressed and new ones added, contains in all two hundred and sixty species, with cuts of the new ones, and many additional ornamental vignettes, the Publisher having spared neither pains nor expense to render the work worthy of the continued patronage of the public. The Editor has pleasure in acknowledging his many obligations to Dr. John Edward Gray of the British Museum for aid liberally received from him. His thanks are also due to Mr. Charles Barron, Curator of the Museum of the Royal Naval Hospital at Haslar, for his obliging services. The assistance he received from other correspondents is acknowledged in the text.-J.R.

Lancrigg, Grasmere, 1859.

VIEW OF LANCRIGG.

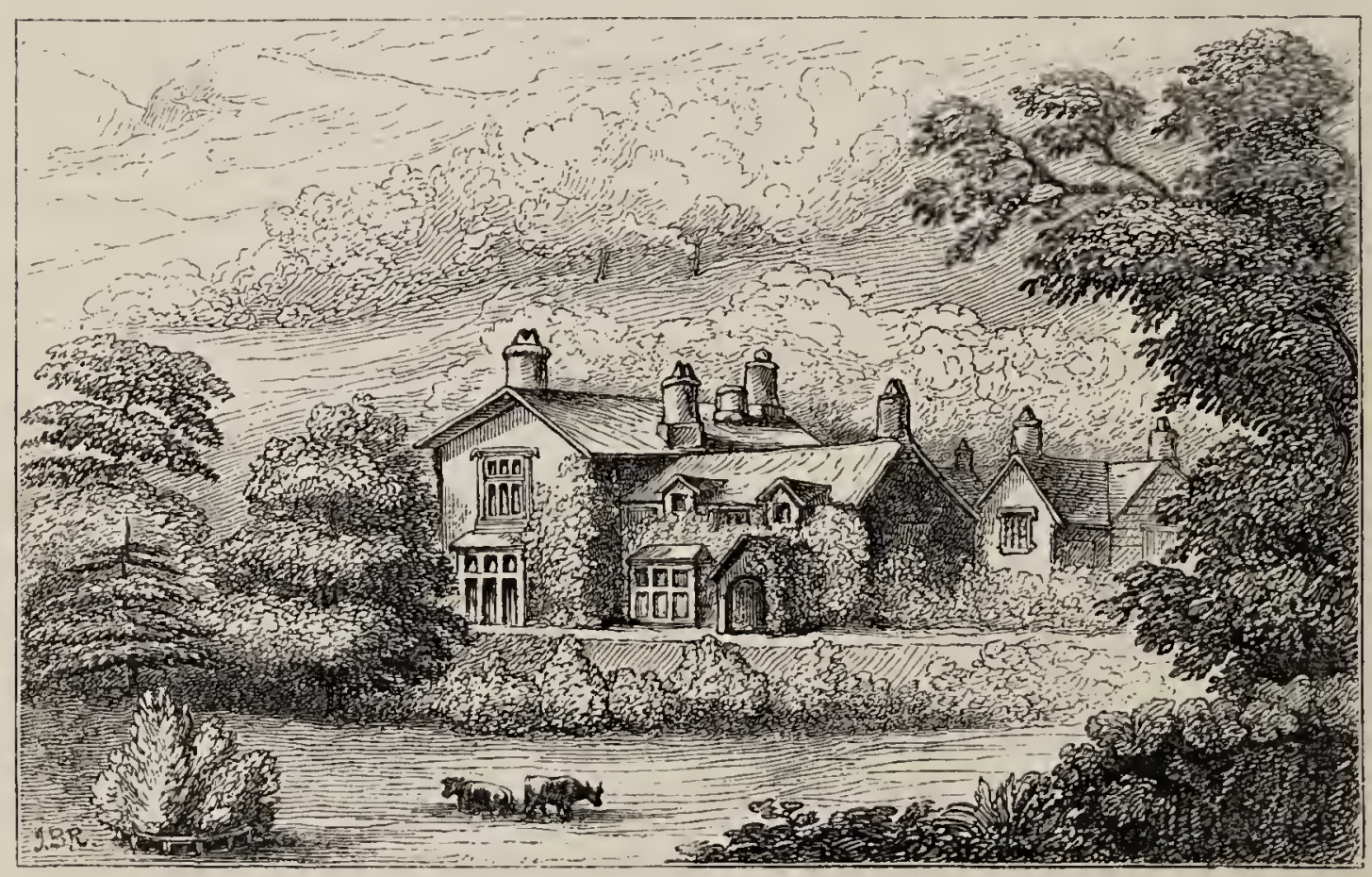




\section{T A B L E}

OF THE

\section{ARRANGEMENT OF FISHES IN THIS WORK.}

\section{Class of Frshes.}

Order I. Denmopteri.-Vermiform, scaleless, abrachial and apodal fishes, with a non-ossified internal skeleton, and vertical fins: no pancreatic cæca and no air-bladder.

Agassiz names this group Myzontes, and considers it to be of equal rank in classification with the Fishes proper, composed of Cycloids and Ctenoids. Some Dermopteri have lately been ascertained to undergo a kind of metamorphosis, which farther research may perhaps extend to all. (See Vol. i. p. 22.) The Dermopteri want the mandible, their bodies are cylindrical, more or less compressed towards the tail, and their vertical fins, for the most part mere folds of slin, are continued into one another. The nervous axis, protected by a tendinous tubular envelope, passes through cartilaginous rings, which are more or less coalescent, and correspond to the vertebre of bony fishes. No ribs are developed, and the gills are inclosed in a cartilaginous cage, instead of fringing the branchial arches, as in the osseous fishes.

Sub-Order i.-Pharyngobranchii or Cirrhostomi. Gills free, pharyngeal, inoperculate; no heart.

The Lancelet, which is the only British example of this suborder, is considered by Agassiz to be probably the Ammocote or young of a Cyclostome.

Sub-Order ii.-Marsipobranchii or Cyclostomi. Gills fixed, purseshaped, receiving the respiratory streams usually by numerous lateral apertures, distinct from the mouth; a heart. (See i. p. 34.)

The British families are the Myxinida and Petromyzontida. 
Order II.-Malacopteri or Physostomi. Internal skeleton ossified; dermal skeleton, for the most part, in form of cycloid scales (in a few in form of ganoid scales) ; fin-rays all (save sometimes the first of the dorsal and pectoral), soft and jointed; gills free, operculate; a swim-bladder with an air-duct.

The fin-rays consist of segments joined by sychondrosis; when the pieces are short and thick, the ray is stiff, as in some of the rays of a Carp whose joints in age become wholly or partially obsolete.

Sub-Order i.-Helmichthyi (lemniscati), Kölliker. For the characters of the Leptocephatide, the only representatives of the order, see i. p. 40.

Most of these fishes have a caudal continuous with the other two vertical fins, but distinguished from them by the size or form of the rays. The genus Esunculus, moreover, possesses small ventrals, so that the Leptocephalide cannot as a family be ranked with the Apodals, though with the exception of that genus all of them are destitute of ventrals. Ichthyologists have compared these small fishes to earth-worms or tape-worms. Their vertebral column is cartilaginous, and in that respect they are inferior to the Anguilliform fishes, but their jaws are indurated, and well provided with raptorial teeth.

Sub-Order ii.-Apodes. The Anguilliform Apodals are destitute of ventrals, have an elongated, serpent-like form, and are clothed in a thick, slimy skin, which is naked in most of the genera, but in some contains deeply-imbedded, tender scales, disposed in groups, lattice-wise. The skeleton has either no ribs or merely rudimentary ones, the pyloric cæca are wanting, and the swimbladder in many instances has an uncommon form.

The British Apodal families are the Anguitlod a, whose characters are identical with those of Anguilla, the only genus of the family; the Congerile; and the Muranala. Our seas nourish no examples of the curious Ophisurida. The Ophidide are codlike Apodals, with sword-shaped bodies, whose dorsal and anal fins coalesce at the point of the tail, but occasionally with such an abrupt change in the size of the rays as warrants the appellation of a caudal, the membrane of the three vertical fins being even and continuous. The Ophitida, Ammodytida, and the foreign Gymnotila have ribs, and in that respect, as well as in some others, differ in structure from the Anguilliform Apodals.

Sub-Order iii.-Abdominales. Malacopterous fishes with ventrals behind the pectorals. The British families are the Clupecelce (i. 98); the Satmonita (i. 1555); the Scopetide (i. 330); the Eso- 
cidce (i. p. 342); the Cyprinita (i. p. 354); and the Acanthopsida (i. p. 446). To these the Siluridce have been appended because of the reported capture of the Sheat-fish in Scotland and Ireland. The Siluridle are ranked by Agassiz, with some doubt, among the Ganoids, and, in fact, in the skeleton and other parts of structure, they differ considerably from the ordinary osseous fishes. (i. p. 454.)

Order III.-Pharyngognathi (Müller). Internal skeleton ossified; external skeleton in form of cycloid or ctenoid scales; inferior pharyngeals coalesced; swim-bladder destitute of a duct (i. p. 459 ).

Sub-Order i.-Malacopterygii represented in our seas by the Scomberesocidae (i. p. 459).

Sub-Order ii.-Acanthopterygii. The Cyclo-labrila are the only British family of this sub-order. (i. p. 482.)

Order IV.-Anacanthini (Müller). Internal skeleton ossified; dermal skeleton consisting of cycloid or ctenoid scales; fins supported by flexible, jointed rays; ventrals situated beneath the pectorals.

Of this order are the Gadide (i. p. 524); the Pleuronectide (i. p. 605); and the Echeneida or Anacanthini colacides (i. p. 6r0).

Order V.-Acanthopteri (Müller). Internal skeleton ossified; delmal skeleton appearing in form of ctenoid scales, or, thongh much more rarely, in form of cycloid scales; most of the fins with one or more of their proximal rays in form of jointless, pungent spines: ventrals most generally situated beneath the pectorals or in advance of them, and connected through the pubic bones with the scapulo-coracoid arch; swim-bladder closed.

This order embraces the bull of the Acanthopterygian fishes of Linnæus, and includes the British families of Uranoscopida (ii. p. 1); Sclerogenida (ii. p. 10); Mullide (ii. p. 97); Scianade (ii. p. 104); Percada (ii. p. 112); Sparida (ii. p. 135); Chatodontida (ii.p. 165); Atherinade (ii. p. 170); Mugilida (ii. p. 175); Aulostomida (ii. p. 190); and Scombrida (ii. p. 193), this last being a group which differs in many respects from the other Acanthopterous fishes, its members having a feebler scaly covering, except on the lateral line, much more red blood, a more complicated pancreas, and a more fragile and less-compact but still fibrous skeleton, which in the Tunnies contains osseous corpuscles. The first six families which follow are more or less allied to the Scombride by the delicacy of their dermal and internal skeletons, and the vigour of their muscles. Xiphicde (ii. p. 240); VOL. I. 
Coryphancede (ii. p. 247); Zeida (ii. p. 251) ; Gempylida (ii. p. 269); Taniada (ii. p. 282); Cepolada (ii. p. 305); Callionymide (ii. p. 310); Gobiida (ii. p. 318); Gobiesocide (ii. p. 335); Blenniide (ii. p. 355); Lophiida (ii. p. 388).

Order VI.-Lophobranchit. Endo-skeleton partially ossified ; exoskeleton ganoid ; gills tufted ; gill-opening small; swim-bladder closed. Body almost fleshy, cased in rings of scaly armour ; face tubular. In most species the males carry the eggs while hatching. (See ii. p. 395.)

British fishes of this order enter the families of Syngnathide (ii. p. 395).

Order VII.-Plectognathi. Endo-skeleton partially ossified; exoskeleton has ganoid scales, or spines. Maxillaries and premaxillaries joined immovably to each other; swim-bladder shut; no pancreatic crea; merely vestiges of ribs, and no distinctlydeveloped ventrals. (See ii. p. 423.) British families, Balistida (ii. p. 422); Diodontida (ii. p. 426).

Order VIII.--Ganoider (Müller). Endo-skeleton osseous, or cartilaginous, or partly the one, partly the other; usually a strong spine in front of the fins; swim-bladder with a pneumatic tube; numerous valves in the arterial stem; no decussation of the optic nerves; opercula, with free gills, and a single external opening on each side; ventrals situated on the abdomen.

The only British family is that of the Acipenseride (ii. p. 442).

Order IX.-Holocephali. Endo-skeleton cartilaginous; exo-skeleton in form of placoid granules. Most of the fins commence with a strong spinous ray; ventrals abdominal; laminated gills, fixed at their margins; a single external gill-opening on each side; no swim-bladder; intestine furnished with a spiral valve; two rows of valves in the long, muscular, arterial stem. The Chimarade (ii. p. 464) are the only family.

Order X.-Plagiostoni (Selachii, Cuv.). Endo-skeleton cartilaginous or partially ossified; exo-skeleton placoid. Gills lining five or more sacs, each having an external opening, and no operculum ; no swim-bladder; coraco-scapular arch not attached to the cranium; ventrals abdominal; intestine furnished with a spiral valve. (See ii. p. 4i1.) There are two sub-orders.

Sub-Order i.-Squali. Plagiostomi with lateral gill-openings; free supplementary eyelids ; an incomplete coraco-scapular arch, and no naso-pectoral cartilage. The families represented in the 
British seas are the following:-Scylliide (ii. p. 470); Carchariade (ii. p. 482); Sphyrnctle (ii. p. 486); Galeida (ii. p. 491); Mustelide (ii. p. 495); Lamnada (ii. p. 498); Alopeciada (ii. p. 512); Notidanida (ii. p. 515); Spinacida (ii. p. 518); Scymnida (ii. p. 522); Squatincele (ii. p. 536).

Sub-Order ii.-Raice. Plagiostomi with flatly-depressed bodies; five slit-like gill-openings on the ventral aspect, under the expanded pectorals. Eyes and spout-holes on the dorsal aspect; coraco-scapular arch complete and attached to the spine. Naso-pectoral cartilages. No eyelid, or merely an adnate upper one.

The British families are, the Torpedinide (ii. p. 539); Raiade (ii. p. 548); Trygonida (ii. p. 591); Myliobatida (ii. p. 595); and Cephaloptercede (ii. p. 600).

Recently, Professor A. Kölliker, of Würzburg has made some most interesting microscopical researches into the structure of fishbones, from which he has deduced the following generalizations :-

Fishes with bone corpuscles.

I. All the higher organized Phyostomi, viz. the--

Siluroids.

Cyprinoids.

Characinoids.

Mormyroids.

Clupeoids.

Murænoids.

Gymnotids.

II. All the Ganoids.

III. All the Sirenoids.

IV. Of all the Acanthopteres, only the Tumnies.
Fishes whose skeletons contain no bone corpuscles.

I. All the Acanthopteres except the Tunnies.

II. All the Anacanths.

III. The Pharyngognaths.

IV. Some small, more lowly organized groups of Physostomes, as the

Cyprinodonts. Esocids.

Galaxids. Scopelids.

Chauliodonts.

Heteropygians.

Symbranchs.

V. The Plectognaths.

VI. The Lophobranchs.

He recognises three types of structure in the skeletons, viz:-

1. Type of the Selachians, whose endo-skeletons are of cartilage or ossified cartilage. As to the exo-skeletons, the spines of the Selachians and scales of the Plectognaths are composed of dentine.

2. Type of the Acanthopteres, with skeletons of homogeneous or tubular osteoid substance, often of true dentine, but containing no bone-corpuscles. Scales of homogeneous and fibrous osteoid substance. 


\section{XXXViii ARRANGEMENT OF THE GROUPS OF FISHES.}

3. Type of the Ganoills, whose skeletons show real osseous tissue, associated partly with homogeneous osteoid substance (ganoin), and dentinal tubes. Includes the Physostomes, Ganoids, and Sirenoids. The scales of the Ganoids, Sirenoids, some Siluroids, some Clupeoids, and of the Tunnies, are also more or less of real bone.

(Proc. Roy. Soc. ix. 656.)

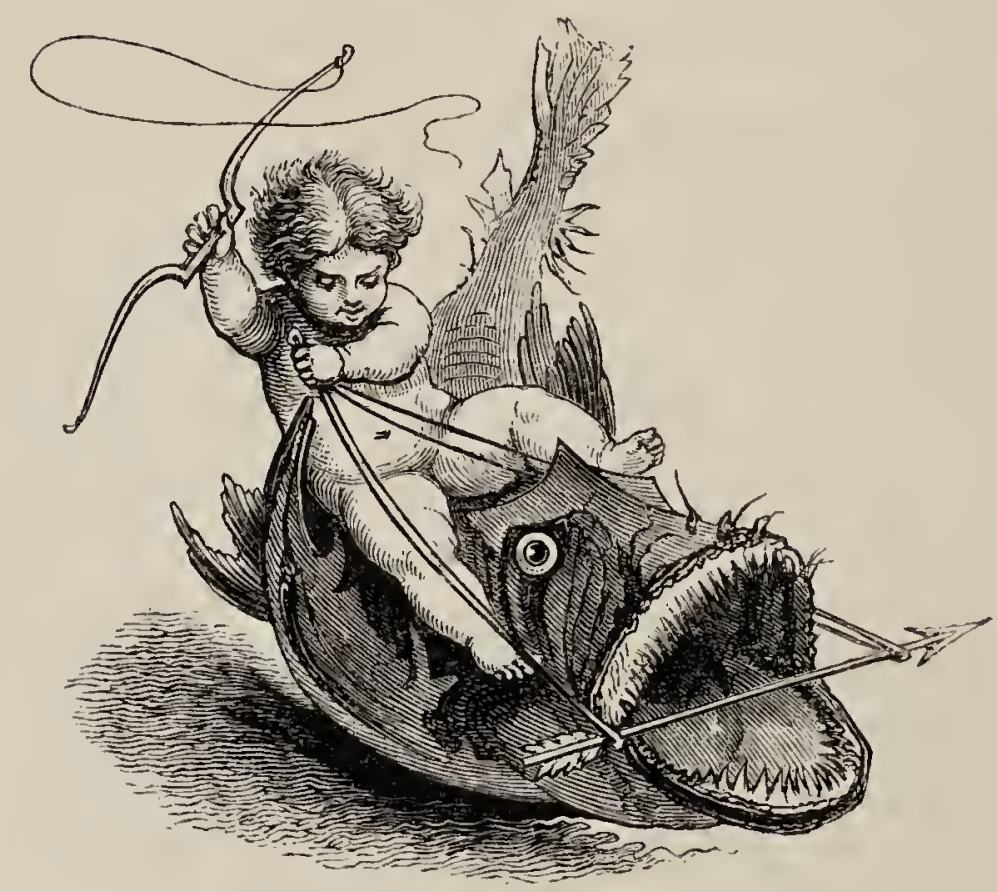

OMNIA VINCIT AMOR. 


\section{B R I T ISH F ISHES.}
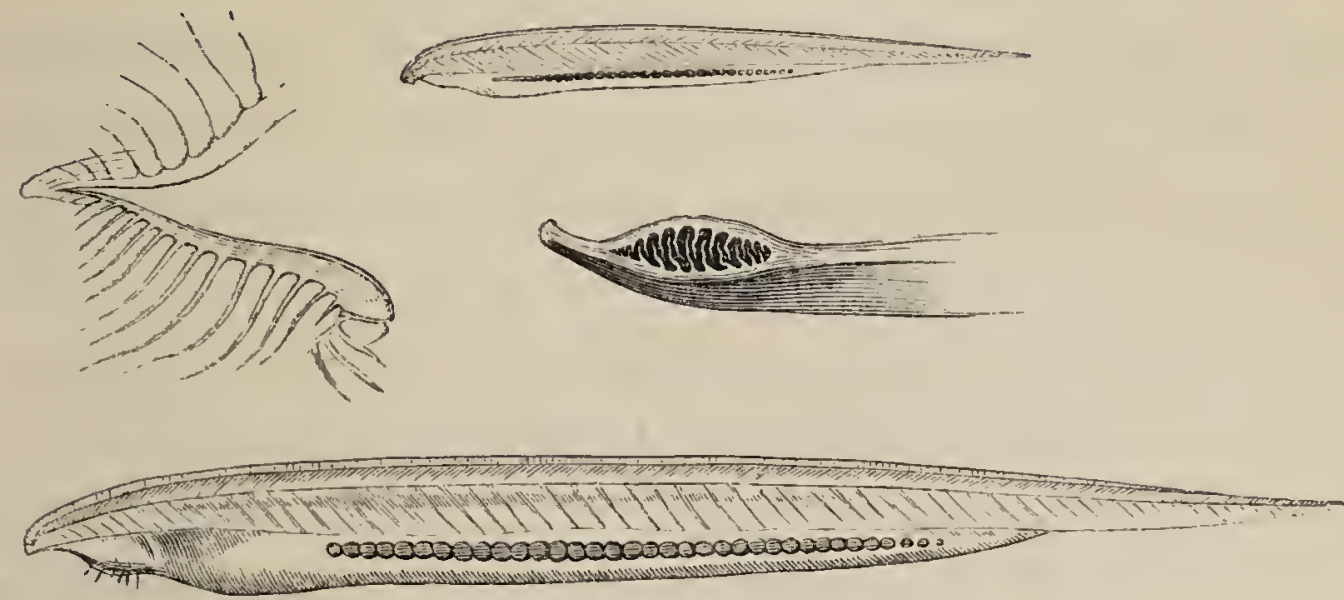

\section{THE LANCELET.}

Amphyoxus lanceolatus, Yarreli, 1836.

$\begin{array}{ll}, & , \\ , & , \\ , & , \\ , & , \\ & ,\end{array}$

Coucil, Mag. Nat. Hist., 1838, Corn. Fauna, 54. Goonsir, Trans. Roy. Soc. Edin., 1841, xv. 254. Gray, Cat. of Cart. Fishes, Br. Mus. 150. Winte, Cat. Br. Fishes, Br. Mus. 146.

Rathкe, Bemerkungen über den Bau des $\Lambda \mathrm{m}$ phyoxus lanceolatus, p. 17, Koningsberg, 1841.

Owen, Lect. Comp. An. of Vert. An. p. 171, et passim, London, 1846.

Branchiostoma lubricum, Costs, Cenni Zoologici, p. 49. Napoli, 1834, e Fauna Nap. t. 30.

$\begin{array}{ll}, & , \\ , & , \\ , & ,\end{array}$

Müller, Ueber den Bau und die Lebenserscheinungen des Branchiostoma lubrieum, Berlin, 1841.

Quatrefages, Mém. sur le Branchiostome, ou Amphyoxus, Ann. des Scien. Nat. 1845.

Del Martino, Giormale dell J. R. Istituto Lombardo, tom. vii. Milano, 1846, 17 and 94.

Auphroxus. Generic Characters. - Identical with those of the Family and of the sub-order Pinaryagobrancini, of which this genus is the only representative hitherto detected (see General Table in Introduction).

This delicate little animal, though one of the smallest of British Fishes, is of very great interest to naturalists VOL. I. 
as presenting the lowest type of vertebrated animals, and possessing characters of importance in common with the class of mollusks. At the date of the first edition of the History of British Fishes, the only known existing specimen was the one sent to me by Mr. Couch, who found it on the shore near Polperro, and I here insert with pleasure Mr. Couch's own statement, as now published in his Fauna of Cornwall, p. 54:- "When alive, this fish had a very evident, though diaphanous fin, extending from near the snout, round the extremity of the tail, which it encircled in the manner of the same organ in the Eel, and terminating at the vent; and the appearance in the engraving is probably owing to the influence of the preserving liquor which has caused the membrane to contract. The rays of this fin are arched transversely, in a very singular manner. The specimen was not found in a pool, but lay buried in a small quantity of sand, at about fifty feet from the receding tide; and on turning over a small flat stone that was on the sand, the tail of the fish appeared exposed. When moved it exhibited signs of great activity, so that the head could not readily be distinguished from the tail; and as there can be no doubt that the fish had sought the shelter of the sand in which it was found, there is little question that such is its usual habitation : a circumstance rendered still more probable by its want of eyes. It was discovered on the 21 st of December, 1831, after a heavy storm that had torn it from its native situation, which, from its rarity, we may suppose to be in deep water. In February, 1838, I obtained two other specimens, which had been thrown up by a tempest. The largest measured two inches and three-tenths in length, which enabled me to discern still more of the internal structure of this fish."

It had, however, been previously detected on the same 
coast and sent to Pallas, who noticed it in his Spicilegia Zoologica, as Dr. John Edward Gray pointed out to me. Pallas considered it to be a slug, and states that he had never seen it alive, but kept it preserved in spirits. His Latin description, * inserted at the foot of the page, contains all that had been published respecting this exceedingly curious little animal previous to the time of its re-discovery by $\mathrm{Mr}$. Couch. The situation claimed for it as a vertebrated animal, and the publicity given to it in the first edition of the British Fishes, have led to many satisfactory results. Being diligently searched for, specimens were found in various localities, and the most able and expert zoologists employed themselves in exploring its anatomical structure. My lamented friend, the late Mr. Edward Forbes, dredged up two specimens from a sandbank in deep water on the east coast of the Isle of Man; they were extremely active, and on superficial examination resembled small Sand-eels. With his characteristic liberality, he placed these two specimens in the hands of Mr. John Goodsir, Conservator of the Museums of the Royal College of Surgeons in Edinburgh, with a request that he would employ them for the purpose of drawing up a detailed account of the animal. This account, forming an elaborate anatomical paper, is published in the fifteenth volume of the Transactions of the Royal Society of Edinburgh.

The Zoological Society have since received two speci mens of the Lancelet, which were forwarded in a small bottle, with several examples of Leptocephalus Morrissii,

* "Limax lanceolatus. Corpus anceps, planum, lineari lanceolatum, utrinque acutissimum. Margo undique limbo membranaceo auctus; subtus vero ad duas tertias longitudinis margo bilabiatus est, sulcatusque, ut sit quasi pes limacinus angustissimus. Tentacula plane nulla. Latera striis obsoletis, antrorsum obliquatis prope dorsum angulo recurvatis, ut quasi latus pisciculi desquamatum referant." 
from the Mediterranean, by the late Dr. Leach, but no particular locality was named with them.

In 1837, I had the pleasure of receiving a visit from Professor Johann Müller when he was in London, and placed before him for his examination the opened specimen of the Lancelet from which I had taken my description. Professor Müller has since received two examples, and the result of his dissections, embodying also observations by Professors Retzius and Sundevall of Sweden, will be found in the Proceedings of the Academy of Berlin for 1839, page 19\%. The Lancelet has now been taken on the coasts of Norway and Sweden, and it has been procured in many parts of the British seas. Mr. Adam White states it to be an inhabitant of the Firth of Clyde; Messrs. M'Andrew and William Thompson obtained it off Cork; and in the Zoologist, Falmouth, Redcar, and the Moray Firth are named among its haunts, the last having yielded a specimen seven inches long. A considerable number of specimens were exhibited alive at the Southampton meeting of the British Association in 1846, and in 1851 it was taken at Guernsey.

The form of the fish is compressed; the head pointed; the eye is a minute depression of the skin covered by dark pigment, as simple an eye-speck as that of the Leech;* the nose rather produced: the mouth on the under edge, in shape an elongated fissure, the sides of which are flexible; from the inner margin extend various slender filaments, regularly disposed, which cross and intermingle with those of the opposite side. Along the sides of the body the muscles are arranged in regular order, diverging from a central line, one series passing. obliquely upward and backward, the other series as obliquely downward and backward: the anal aperture is 
situated one-fourth of the whole length of the fish, in advance of the pointed end of the tail: from the nose to the end of the tail a delicate membranous dorsal fin extends the whole length of the back, supported by very numerous and minute soft rays: the anal fin, according to Goodsir, is a fold of integument commencing before the anus, by which opening it is interrupted, but reappearing immediately, it is continued to the point of the tail, where it joins the dorsal fin. The abdominal pore for the exit of the water of respiration, and corresponding to the gill openings of more highly organized fishes, is situated on the ventral edge of the fish, and very nearly in the middle of its entire length. The surface of the body is smooth, and destitute of scales. A series of membranous folds on the belly are thus described by Mr. Goodsir :- "The folds commence, minute, on each side of the hyoid apparatus, pass back on the sides of the abdomen, increasing in breadth till they are as broad as one-fifth of the depth of the animal; they then diminish and terminate at the point where the muscles approach on each side of the intestine,- that is, at the junction of the middle and posterior thirds of the animal."

The figure at the top of the illustration represents this fish of the natural size. The right-hand figure in the middle is an enlarged representation of the mouth as seen from below; the outline on the left shows the oral filaments, one lip being cut short; and the lowest figure is an enlarged view of the whole fish.

Of the habits of this curious little fish little is known; it is extremely active when in water, and its food is probably some of the most minute among the thin-skinned crustacea, or decomposing animal matter. 
Extract from a Narrative of a Voyage to Madeira, Teneriffe, and along the Shores of the Mediterranean, by W. R. Wilde, M.R.I.A.

"As I obtained several of the Lancelets during our stay at Algiers, I may be permitted to offer some observations on them. They were of two descriptions; the first, and most common, about an inch and a half long, the Amphyoxus lanceolatus of Yarrell and the Limax of Pallas, who first noticed it. The body is diaphanous, and enclosed in a thin flexible envelope, not circular, but preserving a five, and, in some instances, a seven-sided figure. This in every respect resembles the calamus or pen of some of the Mollusca, especially that in the common cuttle-fish. These little animals had a power of attaching themselves to each other in a remarkable manner, sometimes clustering together, and at others forming a string six or eight inches long; the whole mass seemed to swim in unison, and with great rapidity, going round the vessel in a snake-like form and motion. They adhered to one another by their flat sides; when in line, the head of one coming up about one-third on the body of the one before it; no doubt those sides are of use in forming this attachment. The other variety was thinner, and from two and a half to three inches long, having a large dorsal fin, which moved continually in an extraordinary manner, describing a circle by rotating upon its narrow base. The mouth was a circular disk, surrounded by ciliæ that continued in constant motion. When put into a tumbler of water it moved round the glass, and although no eyes were perceptible, it carefully avoided the finger, or any substance put in its way, stopping suddenly, or turning aside from it. Both these animals when taken out of the water kept up a strong pulsatory motion for some time. The small one, the Amphyoxus lanceolatus, by this means 
pumped out of its interior a quantity of air and water ; and they could be seen coming to the surface to inhale, when a globule of air was observed floating through the internal cavity. In the larger species the internal tube was perfectly distinct, and of a blue colour. When put into spirits and water it died almost immediately, and turned opaque. A number of circular bands also appeared on it. Mr. Yarrell, in his beautiful work on British Fishes, has placed this singular little animal among the finny tribe. With all due deference to him, I would suggest the following reasons for ranging it with the Mollusca: the absence of vertebral column, the transparency, and the thin flexible skeleton of the animal being external."

At the time of writing this Mr. Wilde was not aware of the dissections and consequent conclusions of others.

A third species of the genus discovered in the China seas, has been named by Dr. Gray.

The minute anatomical details of Müller, Goodsir, Filippo de Filippi, Rathke, Del Martino, Owen, and other eminent physiologists, are unsuited to popular pages, yet a small space may be profitably occupied by a few notices of the structure of a creature which is the very lowest in the ascending chain of vertebrated animals, and in this slight sketch we shall make as small a use as possible of technical terms. The highest division of the animal kingdom takes its name from the essential peculiarity of the existence of a spine which traverses the body longitudinally, and to which the limbs and the muscles are directly or mediately attached. The exterior parts of the spine are named vertebra, whence the words "vertebral" and "vertebrated," but the indispensable part of the structure is the nervous centre named spinal marrow or myelon, which the vertebræ enclose and protect 
from injury during such flexion as the jointed structure of the spinal column admits of. In some fishes the bony element of the vertebræ not being developed, the original membranous envelope of the spine persists, the separation into vertebræ is more or less completely arrested, and the requisite motions are dependent on the elasticity of a cartilaginous chord, corresponding to the bodies, or centra of bony vertebræ, and of which portions remain as intervertebral cartilages when the species have distinctly articulated vertebræ. The anterior end of the spinal marrow swells out, and gives origin to the nerves of smell, sight, taste, hearing, and other important nervous organs, the whole enlargement being named in common language the brain, or technically the encephalon, the vertebræ enclosing it being segments of the skull, while these with the soft parts and integuments form by their aggregation the head. Vertebrated animals possess, moreover, a muscular organ named a heart for keeping up the circulation of the blood, kidneys for the secretion of urine from the circulating fluid, and an intestinal canal for the digestion of the aliment, of which the only part which it is necessary at present to mention is the cesophagus, a membranous tube that leads from the gullet or pharynx at the back part of the mouth to the dilated part of the alimentary canal called the stomach. The liver and pancreas are organs accessory to the digestive apparatus. The well-being of the animal requires not only that the circulating fluid should receive nutritive matter from the alimentary canal, and get rid of parts noxious, or at least no longer useful, by means of excretory organs, but that it should also receive constant supplies of oxygen by respiration, a process bearing no small analogy to combustion. In many animals lower in the scale than vertebrals, and in tadpoles in the first hours after they issue from the 
egg, * the oxygenation of the blood takes place through the medium of the skin, but this mode of respiration is not only very rare, but also merely temporary in the vertebral class. In these the respiration is performed by means of gills, if the animal obtains its oxygen from the air contained in the water in which it lives, or lungs when it breatlies the atmospheric air. All the higher classes of vertebrals breathing air have lungs : fishes being specially organized to live in water require gills. These very general observations seemed necessary to enable one who has not studied the animal structure to understand the peculiarities of the Amphyoxus, why it takes its place at the bottom' of the vertebral scale, and why it is a subject of such interest to physiologists, as being a link or transitional form between the fishes and mollusks. It is, in fact, more like a larva than an adult fish, and as the Lampreys are known to pass the first period of their existence in a larval (or tadpole) condition, it is possible that we may not yet have obtained adult examples of this fish. $\nmid$ Having made these preliminary observations then, we proceed to mention the most important deviations exhibited by the Amphyoxus from the general structure of fishes and other vertebrals. In the first place it wants that enlargement of the nervous axis which constitutes the brain, and which exists in all other fishes; and as a consequence of this it has no distinct head, both its ends being acute, as expressed by the Greek words, of which its name is compounded. The anterior end of the spinal marrow, however, shows some homology with a brain, by giving off the optic and trigeminal nerves, and by making a slight approach to fibrous structure. The rest of the

* Milne Edwards, Leçons sur Physiologie, vol. ii. p. 200. 1858.

+ The ventral seam-like fin before the anus is often a characteristic of young fishes, which becomes obliterated with age. 
spinal column is a simple, continuous, sub-transparent, cellular chord enclosed in a membranous sheath. This is the most simple form of the neural axis known in vertebral animals, and the absence of a brain is denoted technically by the term anencephalous, used in the general table in the Introduction. The Amphyoxus is, moreover, without a heart, the only indication of that organ being a small dilatation in the middle of the large blood-vessel which runs along the belly to the tail. It is likewise destitute of gills, the mechanism by which its blood is oxygenated being similar to that of some mollusks, but peculiar to itself among fishes, its respiratory surface consisting of the ciliated lining of the fore part of the alimentary canal, termed occasionally from its situation or use the pharyngeal or branchial chamber in fishes, and tunicated ascidean mollusks. The pharyngeal cavity of the Lancelet, commencing in the posterior part of the mouth, is so large as to occupy more than a third of the length of the animal, and it encloses a sort of barrel-shaped cartilaginous cage, perforated by very numerous vertical slits, like button-holes, whose borders are clothed with minute vibratory ciliæ. Before this cage, and forming a boundary ledge between the mouth and pharynx superiorly, there is a fold of membrane with finger-like processes, which are also lined by ciliated mucous membrane. The water is propelled into the mouth by the action of the external fringed labial processes which border its orifice, and thence into the pharyngeal cage, which is also lined with ciliated membrane. From the cage it finds an exit through the vertical slits into the cavity of the abdomen, which is not ciliated, and whence it is expelled through the abdominal pore mentioned above in the description of the fish. In its passage through the pharynx the water furnishes oxygen to the fluid circulating in the large 
blood-vessels disposed vertically on the pharyngeal cage, and communicating with the main dorsal and ventral vascular trunks. The current of the water is accelerated and guided by the rotatory movement of the cilire on the lining membrane of the mouth and cage, and these minute organs serve also to direct particles of food to the alimentary canal, their functions being thus, as in the mollusks referred to, subservient both to respiration and alimentation; but though the respiratory function is here assigned to the mucous lining of the parts in question, Professor Owen is inclined to think that the finger-like processes in the back part of the cavity of the mouth are the true homologues of the gills. The abdominal pore gives exit to the spawn as well as to the water that has served for respiration, and this double office is another sign of the low place the Lancelet occupies in the vertebral scale, the higher animals being endowed with special organs for each of the functions of life. The Lancelet has no proper stomach, the intestinal canal proceeding from the pharynx to the anus without visible change in the capacity of its bore. Like the other Dermopteri the Lancelet wants the pancreatic cæca, but it has a small sac-like organ, generally tinged with bile, which Del Martino considers to be a liver of the simplest form, and it has also kidneys and reproductive organs. Like the larvæ or Ammocoetes of the Lampreys, the Lancelet has no teeth. 


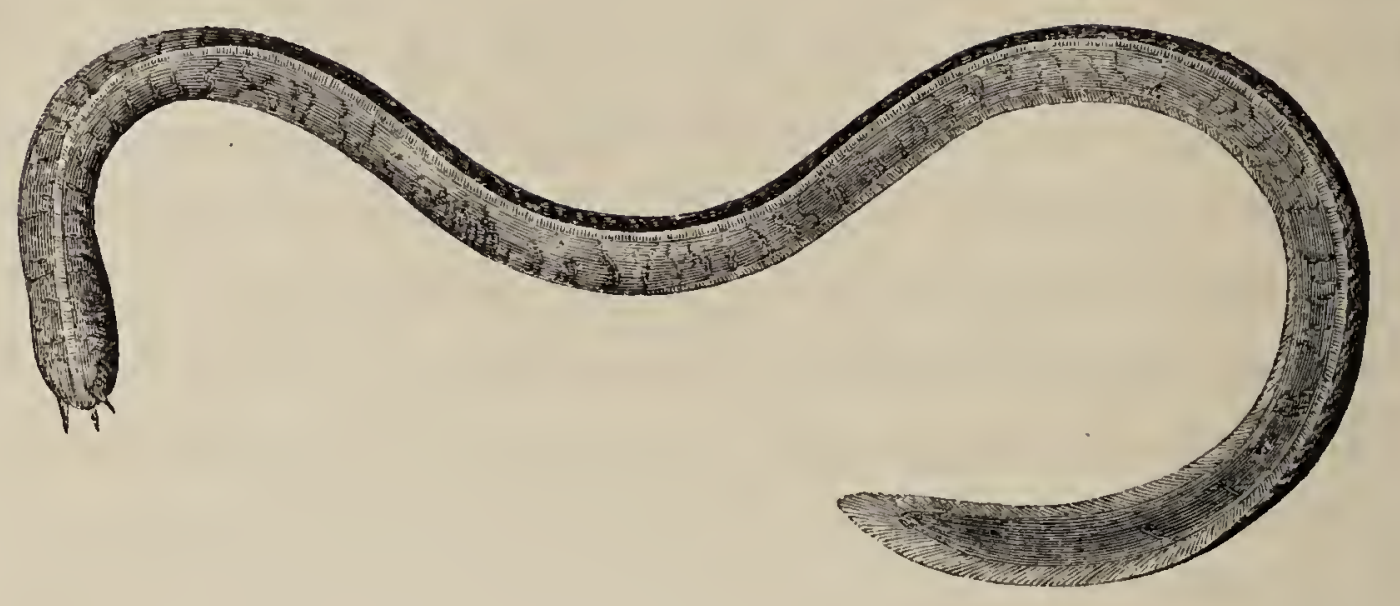

THE MYXINE.

GLUTINOUS HAG, AND BORER.

Myxine glutinosa, Linnwus, Grax, Cart. Fish, B. Mus. 147.

" " $\quad$ Glutinous Hag, Flem, Brit. An. p. 164, sp. 4.

", ", , JENyns, Man. Brit. Vert. p. 523.

Gastrobranchus caecus, Blindfish, BLoch, pt. xii. pl. 413.

" ", Cuvier, Règne An. t. ii. p. 406.

, " , Glutinous Hag, Penn, Brit. Zool. vol. iii. p. 109.

Myxinide. Family Characters. - Vascular branchial sacs six or seven of a side, sub-orbicular or discoid, each receiving water from the pharynx by a short tube, and emitting it again by a tube appropriated to itself into an expiratory canal common to all that side of the branchial region, and having its external exit on the ventral surface of the fish, on one side of the solitary inspiratory orifice, by which the water enters the pharynx or commencement of the alimentary tube. Naso-palatine tube or solitary nostril having a valvular opening in the roof of the mouth. Eye very lowly organized. Mouth cirrated.

Mrxine. Generic Characters.-A solitary median tooth on the palate. Lingual teeth biserial.

THE worm-like form of the fish figured above induced several systematic authors, including Linnæus, to class it with the Worms; and it was not till after dissections and published descriptions that its true relations with the 
Lampreys were acknowledged. Of these memoirs, that furnished to the French Institute in 179\%, by Bloch, the ichthyologist of Berlin, will be read with interest; and the substance of it will be found in the twelfth part of his valuable work on Fishes, in which the internal structure is rendered obvious by various coloured illustrations.

In the family of fishes now under consideration, the spinal column is in a rudimentary condition. In the Lampreys it is but indistinctly divided into rounded portions. In the Myxine, in place of a series of vertebral bones, there is merely a flexible cartilaginous envelope to the soft spinal marrow, while in the Lancelet we have seen that this support is reduced to a small and slender semitransparent column, extending throughout and connecting the whole length of the body like the flexible pen in some species of Cephalopods, to which class that fish has other relations of structure.

As a British fish, the Myxine occurs most frequently on the eastern coast. "It enters," says Pennant, "the mouths of other fish when on the hooks attached to the lines which remain a tide under water, and totally devours the whole except the skin and bones. The Scarborough fishermen often take it in the robbed fish on drawing up their lines." On this part of our coast it is called Hag, and also Borer, because, as others say, it first pierces a small aperture in the skin, and afterwards buries its head in the abdomen or body. It is most usually found in the body of the Cod, or some other equally rapacious fish.

For the only specimens of the Myxine I ever possessed, I am indebted to the unremitting kindness of Dr. George Johnston of Berwick, who has assisted me most materially by sending me examples of many interesting species which have been referred to throughout this work. The Myxine is not uncommon at Berwick; but it is only to be ob- 
tained at a particular season of the year in one or two localities, when during fine weather, at the end of spring or the beginning of summer, the fishermen lay their long lines on a bank with a soft mud bottom near that coast in fishing for Cod and Haddock. It is considered by some that the Myxine, which has very rudimentary eyes, obtains access to the interior of the body of the fish by passing in at the anal aperture; others endeavour to account for its being found in the belly of a voracious fish by supposing it had been swallowed; while many experienced fishermen still repeat their belief that the Myxine enters the mouth of the Codfish while it is hanging on the line. It is conjectured that the Myxine does not fasten upon any fish unless it be either dead or entangled on a hook: but how a fish that is nearly or wholly blind is able to find its way to a particular aperture, is a matter not easily explained. The eight barbules or cirri about the mouth of the Myxine are, there is no doubt, delicate organs of touch, by which it obtains cognizance of the nature and quality of the substances with which they are in contact; and its single hooked tooth upon the palate enables it to retain its hold till the double rows of lingual teeth are brought into action to gratify the appetite for food.

The high northern geographical range of this singular fish is shown by Pr. Nilsson including it among the fishes of the shores of Scandinavia, where, he adds, four and even six examples have been found within the body of one Haddock, the flesh of which was entirely consumed. Gunner includes it, with a figure, in the Natural History Memoirs of Drontheim, as an inhabitant of the west coast of Norway. Mr. Thompson records it as found at Belfast ; and Mr. Couch names it as occurring, though rarely, on the coast of Cornwall. The Myxine is oviparous, and 
the ova are of the same colour, size, and form as those of the Lampern, - that is, small, round, and yellow.

Along the whole length of the under surface of the body, from head to tail, there are two rows of mucous pores, from which a large quantity of a gelatinous secretion is poured out occasionally at the will of the animal, and by which, either in reference to its quality or quantity, or both, this fish is said to escape its enemies. So copious and so thick in its consistence is this jelly-like secretion, that some of the older naturalists believed this fish had the power of converting water into glue, and it obtained in consequence the name of the Glutinous Hag. The name of Gasterobranch given to it by Bloch, is intended to signify the position of the external gill-apertures on the belly of the fish, as described in the family character at the commencement of the account of this fish.

The body is elongated, eel-like in form, cylindrical throughout the greater part of its length, tapering and compressed towards the tail; the whole length from twelve to fifteen inches; the skin perfectly smooth and unctuous; the head obtusely pointed, with a single spiracle or nostril connected with the interior of the mouth; eyes rudimentary ; eight barbels, cirri, or feelers, as they are called, are placed about the lips, four near the front, and two on each side; lips soft, extensible, inclining to a circle in their figure; one single hooked tooth on the palate; the tongue furnished with two transverse rows of small pointed teeth. The anal aperture is an elongated fissure situated about two inches before the end of the tail ; along the whole under surface of the body are ranged two rows of pores, which afford exit to the secretion of the numerous glands within; the dorsal fin is low and rudimentary, except towards the tail, where the membrane is dilated, and being continued round the end 
of the tail, and thence forwards to the anal aperture, forms in addition a caudal and an anal fin, which no doubt materially assist this fish in swimming. In colour the Myxine is dark brown along the back, lighter chestnutbrown on the sides, and yellowish white underneath.

The vignette here added is from a drawing by $\mathrm{Mr}$. Clift, engraved for the Philosophical Transactions for the year 1815, where it illustrates a paper by Sir E. Home on the organs of respiration in the Lamprey and Myxine.

The anterior angle of the figure exhibits the single spiracle, or valvular orifice of the nostril; about it the eight tentacula, and on the centre of the palate the single hooked tooth; posteriorly are the double rows of lingual teeth : farther back, on each side are the six discoid branchial cells, ${ }^{*}$ and their internal tubular communications with the pharynx; on the outside each cell communicates with a tube that is common to the six cells on that side, which, passing downward, ends at the external aperture below. Between this expiratory orifice and its fellow, not exactly in the median line, the solitary inspiratory orifice which admits water to the pharynx is situated. Behind this is the intestinal canal, which is straight and simple, and, as in the other Dermopteri, without a stomachal dilatation; the rounded marks along the margin of the figure on both sides from end to end show the numerous mucous glands that have already been referred to. It is impossible to dissect a Myxine, and attend to the structure and substance of its investing skin, without being forcibly reminded of its great resemblance to the investing mantle of the Cephalopods.

Among other anatomical characteristics of the Myxin-

* M. Lereboullet found seven in an individual which he dissected.-Milne Edwards, Legons, vol. ii. p. 248. 
ida is the existence of a pulsating venous sac, named a portal heart for propelling the blood collected by the veins from the viscera of the abdomen; and the heart of these fishes consisting of an auricle and ventricle, without the bulbus arteriosus which exists in Osseous fishes, is situated, like the pulsating sinus of the Lancelet, far back from the head.*

The relations of structure in the Myxine to the Lampreys on the one hand, and through the Lancelet to the first class of mollusca, the Cephalopods, on the other, appear to prove that the situation claimed for this fish by Bloch, and systematic authors since his time, is the natural one. The relation to the Lampreys is shown in the elongated, cylindrical form of the body; the single nostril on the head; the general similarity in the parts of the mouth; the character of the vascular branchial cells; and the structure of the viscera.

The relation to the Cephalopods is apparent in the eight tentacula or feelers about the head, the horny but flexible nature of the columnar support of the body, the character of its external covering, and by the power of ejecting a copious secretion whenever it considers itself in danger.

The second sub-order of the Dermopteri was named by Cuvier Cyclostomes, or Suckers, and more lately by the Prince of Canino and Johann Müller Marsipobranchs; in the former instance because of their habit of adhering to other fishes, or to stones by the mouth used as an exhausting sucker, and in the latter because of their purselike gill-chambers. The existence of vascular gills in this sub-order denotes a considerable advance in the scale of structure by the evolution of a special organ for respiration, instead of the ciliated lining of the pharynx, whose function is double in the Lancelets. In the Marsi-

\footnotetext{
* Owen's Hunterian Lectures, part 1, p. 254.
}

VOL. I. 
pobranchs the bony or cartilaginous frame work which supports the branchial arches of Osseous fishes is almost entirely wanting, the hyoid bones being represented chiefly by a lingual cartilage, and in the Lampreys when young, or in the condition of Ammocetes, there are small ligamentous bands at the internal orifices of the branchial sacs, which can no longer be traced in the adult fish. In these, however, there is a kind of cage developed between the skin and the intervals of the external branchial openings, and composed of cartilage, which serves by its elasticity an important purpose in the mechanism of respiration. The Suckers, or Cylostomes, all want the lower jaw.

The subjoined figure is copied from Plate XII. of the Philosophical Transactions for 1815, and is explained two pages back.

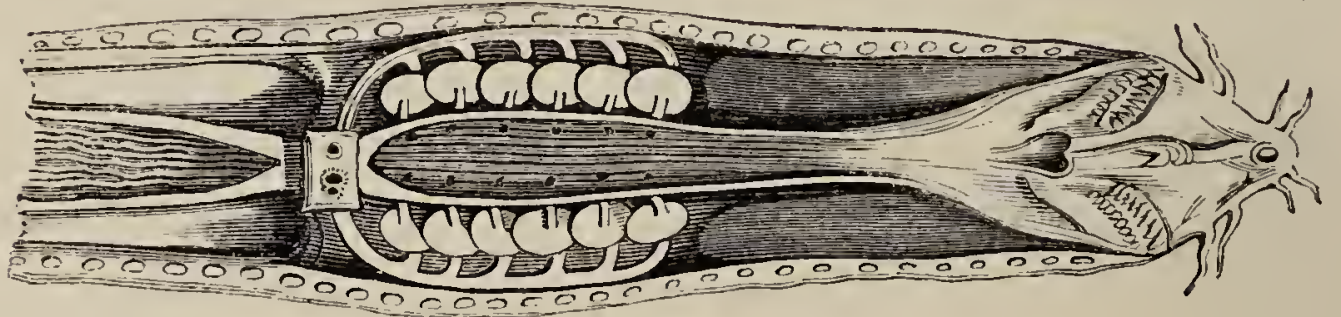




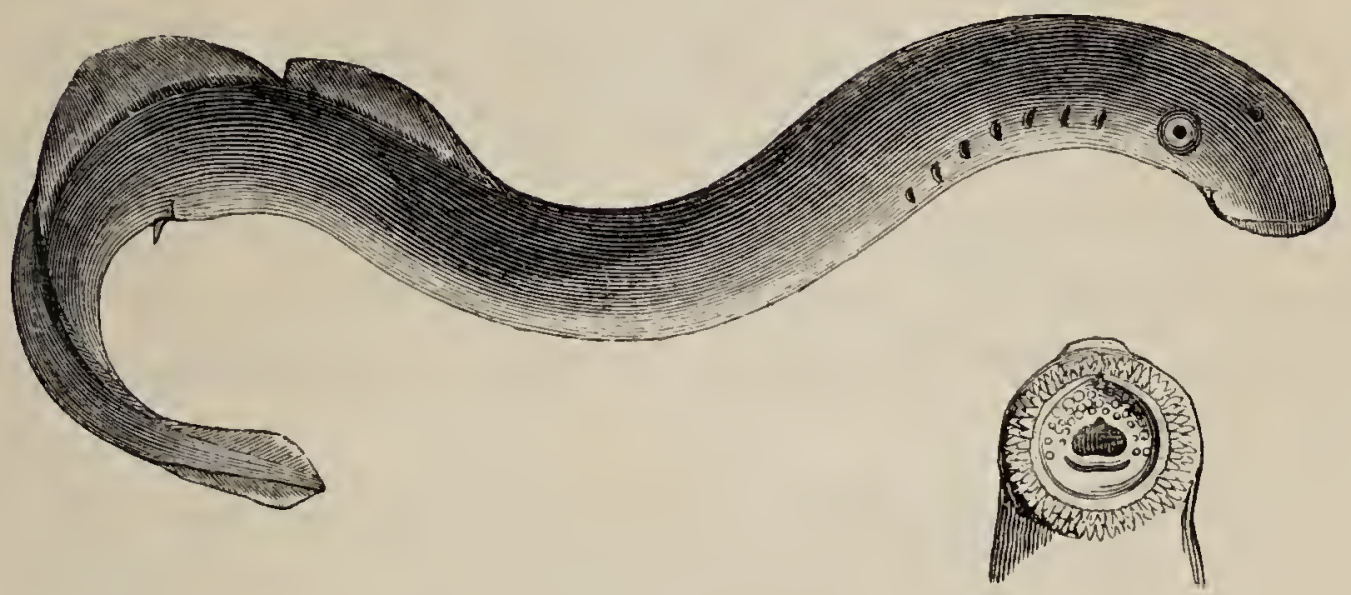

\section{THE FRINGE-LIPPED LAMPERN.}

\section{PLANER'S LAMPREY.}

Lampetra Planeri, Gray, Cat. Cart. Fish of Br. Mus. 1857.

Petromyzon Planeri, Planer's Lamprey, BLoch, pt. iii. pl. 78, fig. 3.

\begin{tabular}{|c|c|c|c|c|}
\hline &, & La Petit & e Lamproye, & Cuvier, Règne An. t. ii. p. 404. \\
\hline &, & Planer's & Lamprey, & Jenyns, Man. Br. Vert. p. 522. \\
\hline , &, &, & , & $\begin{array}{l}\text { JoH. MüLler, Mém. de l'Ac. Ber- } \\
\text { lin, 78. } 1834 .\end{array}$ \\
\hline & ", & ," & , & $\begin{array}{l}\text { AUG. MüLler, Ann. des Sciences, } \\
\text { Nat. tom. v. } 375.1856-7 \text {. }\end{array}$ \\
\hline
\end{tabular}

Petromyzonide. Family Characters. - Seven transversely-elongated branchial sacs on each side, that open exteriorly on the neck by as many roundish holes, lined within by the gills, and receive the water by a single median inspiratory tube, that enters the bottom of the oval cavity. Nostril single, median, tubular, on the top of the head, leading to a flask-shaped nasal sac, which descends to the base of the skull, and is closed by the imperforate mucous membrane of the palate-the olfactory organ being single, as in the other Dermopteri. Teeth various, furnishing characters for the genera.

LAmpetra. Generic Characters.-Upper inner tooth single, transverse, crescentic, entire, with a conical cusp at each end. Lower inner tooth single transverse, crescentic, multi-cuspidate, outer lobe largest. Labial teetl very numerous, of various sizes. Lingual teeth, consisting of a crescentic crenated tooth lying transversely, two compressed pectinated teeth, and a conical pro. jection in the centre. ${ }^{*}-\mathrm{GR \Lambda Y}$.

* The teeth of the Petromyzonidae are composed of indurated albumen, and are acted upon by alcohol, so that they flake off in layers when touched. Specimens preserved in spirits do not, therefore, in general exhibit the proper size of the teeth, though the cuticular papillæ on which they are moulded retain their form. 
THIs species, when adult, is easily distinguished from the River Lampern to be next described, by its being much shorter in length, and yet equally thick in substance : it may also be recognised at all ages, when they are compared, by its having the whole broad edge of the circular lip furnished with numerous papillæ forming a thicklyset fringe, and by the depth and close connection of the two dorsal fins.

Dr. Parnell says, this species is found in the Forth, the Teith, the Allan, and several other rivers in Scotland. I am indebted to the kindness of Sir William Jardine for two specimens of the young of this species, which were sent from the Tweed. Dr. Jolnnston has been told that it is not uncommon at Melrose. I have received some from Surrey, and Mr. Linwood mentions having found some in Sussex. Mr. Couch has obtained specimens from a branch of the Looe, in Cornwall; and I have received some specimens from Lancashire, the males of which measured eight inches in length, and the females nine inches. Mr. William Thompson mentions it, in his Fauna, as having been taken in the north, east, and south of Ireland.

The species was named by Bloch after his friend Planer, a professor at Erfurt, who sent him specimens; but if Bloch's species be the same as our British fish, his figure is exceptionable. This Lampern appears to be well known to M. Nilsson, who includes it in his Prodromus of the Fishes of Scandinavia, and says that it is an inhabitant of almost all the brooks and rivers of Sweden, and that it spawns in April or May. M. Nilsson gives to it the length of six inches only: it appears therefore that, like $P$. marinus and $P$. fluviatilis, this fish does not acquire so great a size in high northern regions as in this country. It is common in the fresh waters near Berlin, and has been there studied with great advantage 
to science by August Müller, whose observations we shall have occasion to quote below.

When compared with $\boldsymbol{P}$. fuviatilis, Planer's Lampern is found to have the orifice on the forehead, the eye, and the first of the branchial apertures, much nearer the anterior edge of the lip; the lip broad and fringed, and the disposition of the teeth as shown in the separate figure of the mouth : the first dorsal fin begins about the middle of the whole length of the fish, and is in close contact with the second dorsal fin, which in its base is as long again as the first: the tail is furnished with an extension of membrane above and below, forming a caudal fin; and a narrow slip passing forwards towards the anal sheath, forms a rudimentary anal fin.

In its colour this species agrees with the common Lampern, being dusky blue on the back and sides, passing into silvery white on the belly, the fins having a brown tint.

In its habits, Planer's Lampern so closely resembles the common Lampern, as frequently, no doubt, to have been mistaken for it. Both may go to the salt or brackish water from that part of a river within the influence of the tide.

The adult Petromyzonida have suctorial mouths, but when young the lower edge of the orifice is not sufficiently developed for the performance of that function, the teeth are not formed, and there are other remarkable differences of structure, so that the assumption of the adult form amounts to a metamorphosis, and the young and the old are so unlike that, until lately, they have been placed by ichthyologists in distinct genera and even in separate families. This curious fact was discovered by August. Müller in the course of his investigations into the reproduction and growth of the Fringe-lipped Lampern, and we have, therefore, found it convenient to 
commence our account of the family with a description of that species. In its larval state it was figured in the former editions of the British Fishes, as a perfect fish under the name of the "Pride," or "Ammocœetes branchialis, and we shall here reprint that article, with some additions from Müller at the end.

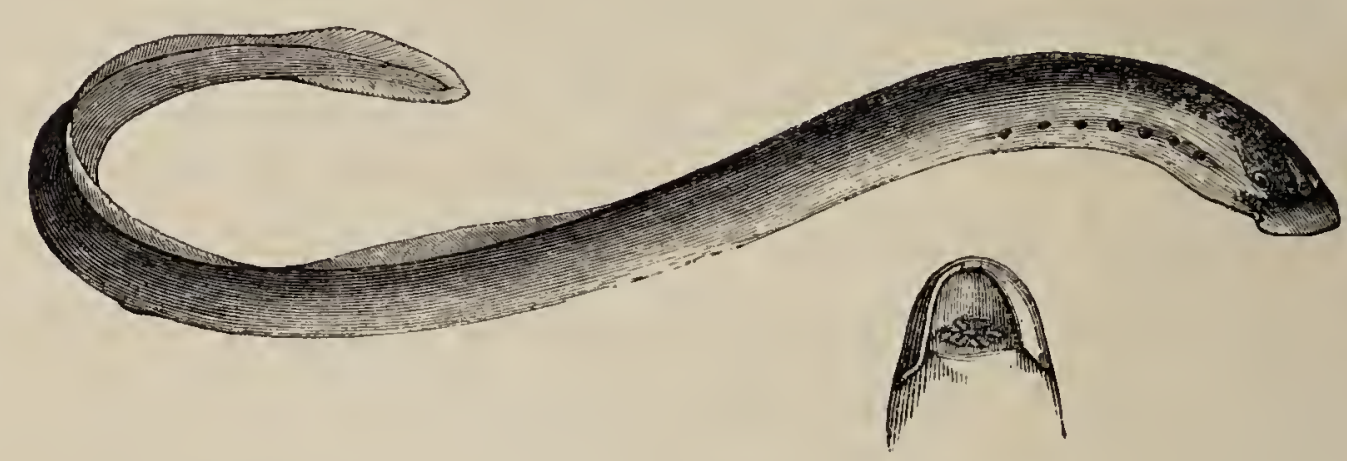

Ammocate of the Fringed Lampern.

PRIDE，SANDPRIDE，SANDPREY，SANDLURKER，STONEGRIG, AND MUD LAMPREY.

Ammocotes branchicalis, Lamprillon, Cuvier, Règne An. t. ii. p. 406.

\begin{tabular}{|c|c|c|c|}
\hline$"$ & "' & Pride, & FlEM, Brit. An. p. 164, sp. 3 . \\
\hline & " & & Jenyns, Man. Brit. Vert. p. 522, sp. 212. \\
\hline Petromyzon & $"$ & LINNEUS. & BLOCH, pt. iii. pl. 78 , fig. 2 . \\
\hline ", & $\begin{array}{c}\prime \prime \\
\text { ceccus, }\end{array}$ & $\begin{array}{l}\text { Pride, } \\
\text { Mud La }\end{array}$ & $\begin{array}{l}\text { Penn. Brit. Zool. vol. iii. p. } 107 \text {, pl. } 10 . \\
\text { ey, Couch, Loudon's Mag. Nat. Hist. vol. v. } \\
\text { p. } 23 \text {, figs. } 9 \& 10 \text {. }\end{array}$ \\
\hline
\end{tabular}

Thrs small fish is very similar in its general appearance to the young of the Lampreys found in fresh water; but its prominent lip is in the form of a horse-shoe, and the circle not being complete, it has not the power of adhering to stones and other substances like the true Lampreys, but generally hides itself in the mud or loose sandy bottoms of rivers and brooks in this country, in most of which it will be found, though close search is needful to detect it. It is of little value, seldom exceeding six 
or seven inches in length, and is about as thick as a large quill.

It was formerly considered to be a Lamprey, and was called Petromyzon cacus by Ray, on account of its very small eyes: it afterwards had the trivial name of branchialis bestowed upon it by Linnæus, from a notion that it attached itself to the gills of fishes. It is said to be common about Oxford, and was called by Dr. Plot, in his History of Oxfordshire, the Pride of the Isis ; Prid being an ancient diminutive for Lamprey. It is very common in the Thames about Hampton, where it is called Sandpride. Mr. Jesse says the Eel is one of its greatest enemies, and feeds greedily upon it. I have received it from Hertfordshire, and some other inland counties. It spawns towards the end of April or early in May, and feeds upon worms, insects, and dead or even putrid animal matter. Dr. Parnell and Dr. George Johnston have noticed it as an inhabitant of the Forth and Tweed.

Mr. Couch says, "I find this species frequenting our smaller streams in Cornwall, living in the muddy bottom, from which it rarely, if ever, willingly emerges. I have kept it for months in stagnant water, with mud at the bottom, without injury to its health or activity. The only apparent use of its fins is to enable it to regain its station, when forced from it by violent torrents. When kept in clear water it seems to sleep much. I have never found this species to attach itself to any object by the mouth; but the lips are capable of extensive and complicated motions. Our fishermen collect them to use as bait for their hooks when whiffing for Pollacks." It inhabits the Devonshire rivers also. All the British Lampreys are found in the waters of Ireland, and this diminutive species has been taken in the north, the east, and the south of that island. 
The upper lip and the mouth in this species, as shown in the enlarged representation of the lower surface of the head under the figure of the whole fish, is in the form of a horse-shoe; the inner part furnished with numerous short and slender membranous cirri; "the lingual and palatine plates somewhat harder than the other portion, but no true teeth :" on the top of the forehead is a small orifice and canal, which leads to the internal tube between and connected with each lateral set of branchial cells, as in the Lampreys; the eye is very small, so much so as to have been occasionally overlooked, and it is situated at the bottom of a small and deep depression: the branchial apertures are seven on each side, arranged along a kind of lateral groove: the body of the fish at this part is rather tumid; behind this the form of the body is nearly round, the portion beyond the anal opening compressed: there are two dorsal fins, the first short and low, the second longer and higher, with a distinct diminution between it and the first dorsal fin, and also with the dilated membrane forming the caudal fin, which is somewhat rounded, the fleshy portion of the tail being pointed; a narrow slip of membrane forms an anal fin.

Some variations occur in specimens of this fish from different localities, and there is even reason to suppose that two species may exist. The most frequent colour is yellowish brown, approaching to blackish brown on the top of the head and upper part of the back, much lighter underneath and on the fins.

The preceding pages represent very fairly our knowledge of the Pride, previous to the researches into its history by August Müller, and it contains indications of other Ammocœtes in the British waters, doubtless the larvæ of the other Lamperns or Lampreys which will hereafter be eagerly investigated by British ichthyologists. 
Müller watched the Lamperns in the act of spawning, secured the roe, and kept the eggs under examination during the growth of the fœetal fishes until they were hatched, which took place at the end of eighteen days. The newborn fish was white and opaque, the brain and spinal marrow resembled a thread, swollen at the anterior end, and constricted at intervals. The eyes were seen as faint points on the sides of the brain, and there were eight slits on each side of the neck, the anterior one becoming effaced in a short time. Before the heart an organ became visible in the median line, resembling a narrow oval vesicle, which, at a future period in the life of the animal, becomes the suctorial muscle that distinguishes the Lampern from its Ammocœte. Soon a muscular fold or velum was developed in the mouth, which allowed the water to enter, but prevented its return, and papillæ sprouted in the upper walls of the mouth, increasing in number and size, and pushing out fringes, so as to act as a lattice to keep out useless or noxious particles. At this period these young fish, sprung from the eggs of Lamperns, could not be distinguished either by general appearance or structure, from the Ammocœete or Sand-lurker. In this immature fish, the alimentary canal and the respiratory tube are not separate in their passage through the mouth as in the Lampern, but the gullet or entrance to the cesophagus forms a vertical fissure at the back of the mouth. The transformation from this larval condition to the adult form takes place in the fourth year, and requires only about ten days for its completion. There is no increase in the size of the animal in these ten days, but the respiratory tube is formed, teeth are evolved, the velum in the mouth disappears, and the roe, which was previously transparent, becomes opaque, while at the same time the intestinal canal is sensibly abbreviated. 'The feeble eyes of the Ammo- 
cote shunned the light, and the animal sought the most shady places, or buried itself in the mud or sand, and lived on what flowed to its mouth strained through its oral trellis, and propelled onwards by the vibratory cilix lining its gullet. Its chief food in its larval state seems to be microscopic infusory animalculæ, Müller having found the shells of bacillaria in the stomachs of all that he examined. The Ammocœete is not unfrequently larger than the young Lampern, the shortening of the intestine allowing of a shrinking of the body.

The young Lampern assumes a brilliant silvery hue, which the Ammocœte wants, swims in the purest water, seeks the light with its larger eyes, and has acquired the power of remaining stationary in a strong current, by adhering to a stone with its circular suctorial mouth. The transformation which has taken place is not so great as that in the change from a tadpole to a frog, but hitherto nothing of the kind has been observed in any other fishes than those of the Lamprey family. The Lampreys also resemble the frogs and other naked amplibians in the structure of the brain, and differ from other fishes in that respect.* August Müller assigns reasons for thinking that the adult Fringe-lipped Lampern lives but a short time after spawning. He found many dead ones after that epoch, and their empty egg-sacs contained no germs of future ova, as in other animals.

Milne Edwards first used the name of Ammocœete to designate the larval state of the Lamperns. Heckel (Susswasser Fish. der Oesterreichen Monarchie, 1858) disputes the conclusion drawn by Müller from his observations on two grounds-1. That the Ammocotes of other Lamperns have not been discovered, but in our account of the River

* They have a third ventricle separate from the quadrigemina, and a rudimentary cerebellum.-Aug. Müller, Ann. des Sc. Nat. 4e Serie, Zool. v. 287. 
Lampern, it will be seen that this objection is not wellfounded. 2. Because distinct sexes exist in the Ammocoetes, which is not the case with the larvæ of other animals. This remark cannot weigh against direct observation, and Herr Van Beneden, Member of the Royal Belgian Academy, after studying the Ammocœetes and Lamperns, which are very abundant in a river at Lovenjoul, near Berlin, confirms, without hesitation, all that Müller has recorded on the subject.

The vignette represents the New Hall and the Barge of the Company of Fishmongers of London.

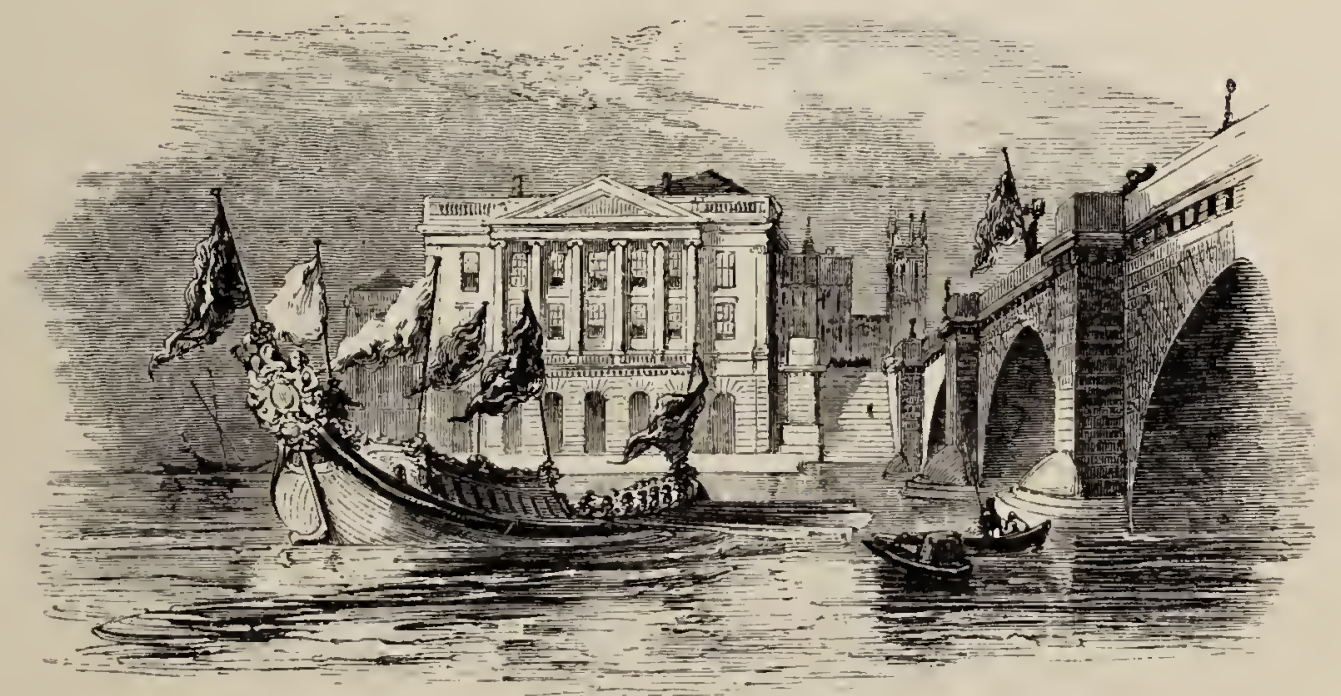




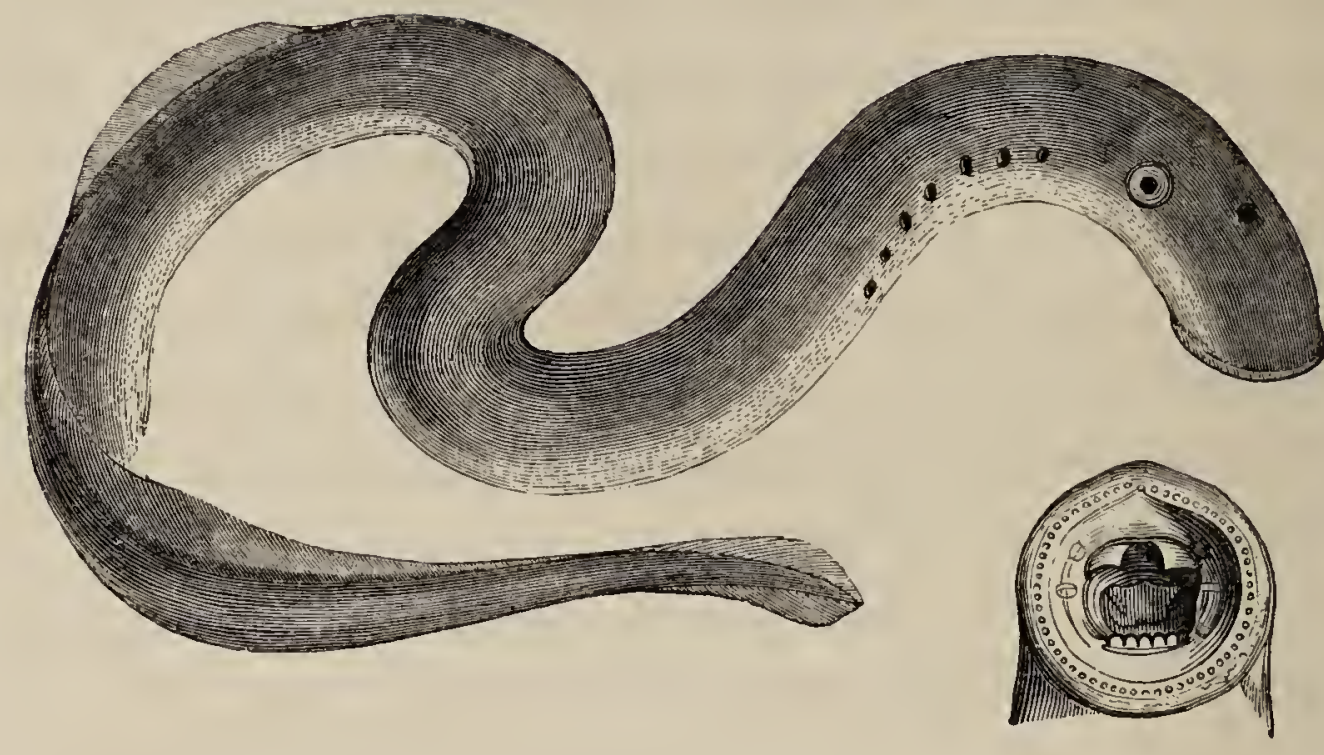

\section{THE LAMPERN, OR RIVER LAMPREY.}

Lampetra fluviatilis, Gray, Cat. Cart. Fish. Br. Mus. 140, t. 1, f. 2.

Petromyzon ,, Linnasus, Bloch, pt. iii. pl. 78, fig. 1.

, $\quad, \quad$ Cuvier, Règne An. t. ii. p. 404.

" , "Lesser Lamprey, Penn. Brit. Zool. vol. iii. p. 106, pl. 10.

", $\quad$ Lampern, Don. Brit. Fish. pl. 80.

", " River Lamprey, Fuem. Brit. An. p. 163, sp. 2.

," $\quad, \quad, \quad$ Jenyns, Man. Brit. Vert. p. 521, sp. 210. Lampetra, medium genus, WruL. Hist. Pisc. 106, t. G. 3, f. 2.

Petromyzon, Negen-oog, prick, Gron. Mus. 1, 64.

The River Lamprey, or Lampern, as it is called by fishermen for distinction, is a well-known species which abounds in many rivers of England, particularly the Thames, the Severn, and the Dee: it is also said to be abundant in the Tweed, in several rivers of Scotland, and in the north, the east, and the south of Ireland.

Some authors state that this species, like that last described, visits our rivers in spring, and returns to the sea after spawning; but the recorded opinions of others, and my own observations, induce me to believe that it generally remains all the year in the fresh water. In the Thames I am certain it is to be obtained every month in 
the year; but is considered to be in the best condition for the table from October to March, during which time it is permitted to be caught, according to the rules adopted for the conservation of the fishery.

Formerly the Lampern was a fish of considerable importance. It was taken in great quantities in the Thames from Battersea Reach to Taplow Mills, and was sold to the Dutch as bait for the Turbot, Cod, and other fisheries. Four hundred thousand have been sold in one season for this purpose, at the rate of forty shillings per thousand. From five pounds to eight pounds the thousand have been given; but a comparative scarcity of late years, and consequent increase in price, has obliged the line fishermen to adopt other substances for bait. Formerly the Thames alone supplied from one million to twelve hundred thousand Lamperns annually. They are very tenacious of life, and the Dutch fishermen managed to keep them alive at sea for many weeks.

If this species, which is very easily obtained, be examined in the months of March or April, the distinction of the sexes will be immediately evident on opening them. The female may generally be known externally by the larger size of the abdomen, and the male by his lips being more tumid and the mouth larger than that of the female. The season of spawning is May, and the process has been described by several observers. This sometimes takes place in pairs only, and at others by many of both sexes occupying one general spawning bed.

The food of this species, according to Bloch, is insects, worms, small fish, and the flesh of dead fish.

The adult fish is usually from twelve to fifteen inches in length; the body rather slender, cylindrical for twothirds of its length, then compressed to the end of the tail; the head rounded, with a solitary nostril on the 
crown: the eye rather large; the seven lateral openings ranged in a line behind, but a little obliquely and below it, on each side: the lip surrounding the mouth has a continuous row of small points on its margin; the mouth and teeth as represented near the figure of the fish: the back furnished with two rather elongated dorsal fins, with a separation between them and the tail, edged by an extension of the membrane above and below.

The skin is quite smooth, of a blue colour on the back and sides, passing into silvery white underneath.

In The Treatyse of Fysshynge wyth an Angle, attributed to Dame Juliana Berners, and first printed by Wynkyn de Worde, in his edition of the Book of St. Albans, in 1496, the learned lady, after recommending a minnow and a worm as proper baits for the Trout in the month of March, adds, "In Aprill take the same baytes: and also Juneba, other wyse named VII. eyes." Seven eyes and nine eyes, in reference to the apertures about the head, are common names for the Lamprey in this and some other countries; but a derivation for the term Juneba is a desideratum.

Linnæus, in his Tour in Lapland, particularly notices this species, vol. ii. p. 196, as found in West Bothnia, and describes the modes by which it is caught,-namely, hollow cylinders of wood, and elongated wicker-baskets, like those in use in this country for catching Eels. These, he says, "are laid at the depth of two ells in the river, and kept down with stones, the opening being turned to meet the current."

This species is also said to be found at Moscow, and in the Black and the Caspian Seas.

August Müller discovered the Ammocœte of the River Lampern in the larger rivers of Prussia in the year 1854, and found that, like the Ammocœte of the fringe- 
lipped species, it possessed a gall-bladder which disappears in the adult River Lampern, though it continues in the other. The same remark applies to the otolites, or auditory bones of these fishes.

\section{Teeth of Petromyzon Omalii.}

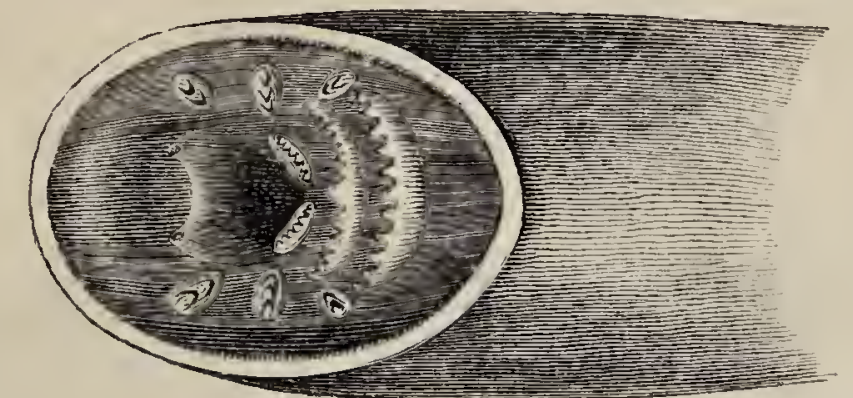

M. P. I. Van Beneden has discovered a Lampern that he names Petromyzon Omalii, but which, from its dentition, evidently belongs to Dr. Gray's genus Lampetra. It is an inhabitant of the British Channel, but has hitherto been taken only on the Belgian coast, and by its discoverer alone. As it will doubtless sooner or later be captured in British waters, we think it right to direct the attention of our ichthyologists to its characters by giving a view of its dentition, and adding the essential parts of the description from the paper referred to below.* Its length was under six inches; its thickness a sixteenth of its length. The colour a silvery white, and the fins and external branchial orifices, or stigmata as some call them, like those of the Fringe-lipped Lampern. Its teeth differ from those of all the other species known. The mouth is circular and symmetrical. Van Beneden took three female specimens at different times in the months of April and May, all of the same size, and full of mature roe. He considered them to be adult fish, and their skins had the bright metallic lustre of spawning time.

* Bulletin de l'Acad. Roy. de Belgique, 2me Serie 11, No. 7, 1857. 


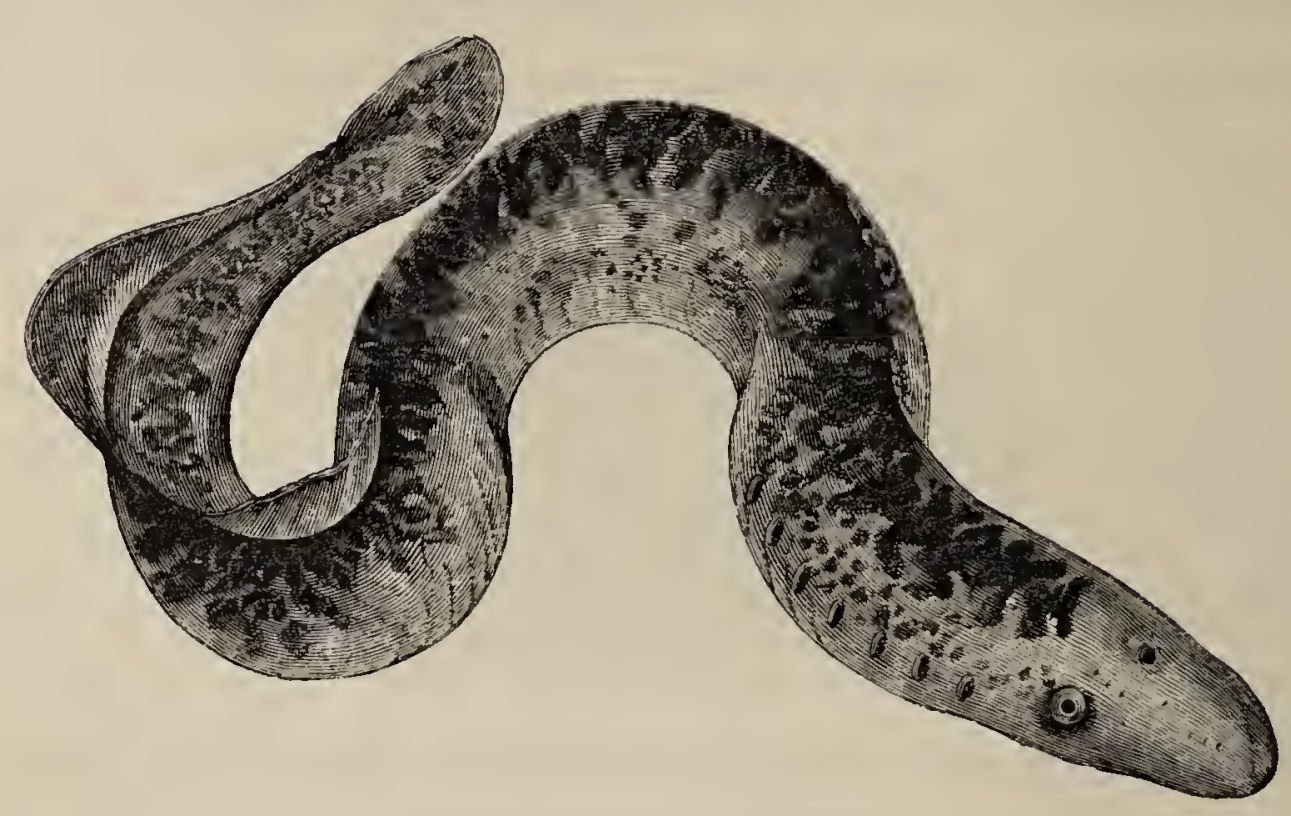

\section{THE LAMPREY.}

Petromyzon marinus, Gray, Cat. Cart. Fish. Br. Mus. 138.

, $\quad, \quad$ Linneus. Bloch, pt. iii. pl. 77.

, $\quad$, La Grande Lamproye, Cuvier, Règne An. t. ii. p. 404. Lampetra Rondeletii, Willugirby, p. 105, G. 2, f. 2.

Petromyzon marinus, Sea Lamprey, Penv. Brit. Zool. vol. iii. p. 102, pl. 10. ", Spotted Lamprey, Don. Brit. Fish. pl. 81.

," $\quad$, Lamprey, Flem. Brit. An. p. 163, sp. 1.

,, , Sea Lamprey, Jenrws, Man. Brit. Vert. p. 520, sp. 209.

Petromyzon. Generic Characters.--Upper inner teeth two, triangular, close together. Lower inner tooth solitary, large, crescentic, many-cusped. Labial teeth numerous, acutely conical in concentric arches. Tongue armed with two compressed pectinated teeth, and a broad serrated tooth, bent sharply in the middle, between the other two.-Gray.

The form of the mouth in this genus and the distribution of its teeth will be understood by a reference to the vignette a few pages further on; the figure on the left hand of which shows the flexible lip concealing the mouth; the figure on the right hand represents the rounded mouth, the small and numerous conical teeth of indurated albumen, and the central aperture leading by the throat to the stomach. 
The Lampreys, like the Sharks and Rays, have no swimming-bladder; and being also without pectoral fins are usually seen near the bottom. To save themselves from the constant muscular exertion which would be necessary to prevent them being carried along by the current of the water, they attach themselves by the mouth to stones or rocks, and whence the name of Petromyzon, or Stone-sucker.

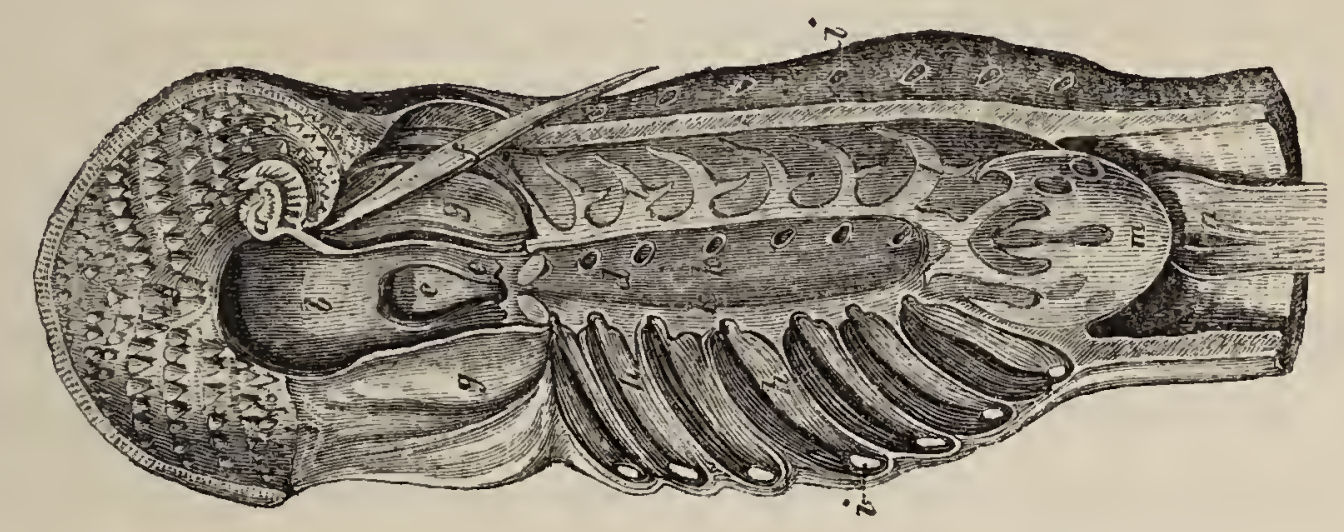

We give here a representation of the parts concerned in the respiration of the Lamprey, reduced from Plate XI. of the Philosophical Transactions for 1815.

The tongue $(a)$, which is armed with teeth, is turned to one side, and the inspiratory tube $(d)$ is laid open. The loose edge of the latter $(c)$ is shown at the orifice of the œsophagus. 'The linear branchial sacs $(h, h)$ are laid open on the under side, and may be compared with the discoid sacs of the Myxine represented on a preceding page (18).

In the Myxine the whole interior of each sac is supplied with blood for oxygenation by one artery belonging to it alone; in the Lamprey the artery running in the partition between two gill sacs supplies the contiguous sides of two cavities, and each sac therefore receives branches from two arteries, as in the biserial gills of the osseous fishes. The external orifices of the branchial sacs, or stigmata $(i$ i $)$ are seen from within on the under side of the figure, and 
on their dermal aspect on the upper side. Parts of the cartilaginous basket of the branchiæ are marked ( $l l$ and $m$ ), the letter $m$ designating the perforated cartilaginous case of the heart, which is considered by Professor Owen to be a modification of the last pair of branchial arches. The entire apparatus, though exercising the function of the branchial skeleton of osseous fishes, is regarded by this able physiologist as a homological representative of the thorax of air-breathing vertebrals. The numerous buccal teeth are shown within the margin of the mouth on the left hand, and the continuation of the alimentary canal at the other end of the figure, where $n$ marks the termination of the osophagus. $b$ is placed in the cavity of the mouth, $c$ on a tooth on its roof, $f$ is on the cartilaginous support of the lingual retractor muscles, and $g g$ point out salivary glands.'

In reference to the respiratory apparatus in the species of this genus, Mr. Owen has remarked, * that "when the Lamprey is firmly attached to foreign bodies by means of its suctorial mouth, it is obvious that no water can pass by that aperture from the pharynx to the gills; it is therefore alternately received and expelled by the external apertures. If a Lamprey, while so attached to the side of a vessel, be held with one series of apertures out of the water, the respiratory currents are seen to enter by the submerged orifices, and, after traversing the corresponding sacs and the pharynx, to pass through the opposite branchiæ, and to be forcibly ejected therefrom by the exposed orifices. The same mode of respiration must take place in the Myxine" (already

* Descriptive and Illustrated Catalogue of the Physiological Series of Comparative Anatomy contained in the Museum of the Royal College of Surgeons in London, vol. ii. page 80 . 
described), "while its head is buried in the flesh of its prey. The cyclostomous fishes thus present an obvious affinity to the Cephalopoda, inasmuch as the branchial currents are independent of the actions of the parts concerned in deglutition."

The intestinal canal, as in the other Dermopteri, is small, and extends in a straight line along the abdomen to the anal aperture without any convolution or dilatation resembling a stomach. The Lampreys are oviparous, spawning late in the spring; the roe escaping, in both sexes, by a small membranous sheath, which has internally at its base five apertures, one leading upward to the intestine, one to each kidney, and one to each lateral cavity of the abdomen.

The Marine Lamprey, which from its mottled appearance was called $P$. maculosus by Artedi, has a very extensive geographical range. It is found in the Mediterranean, and from thence northwards in most of the rivers of Europe as far as Scandinavia, during the spring. Professor Reinhardt includes it among the fishes of Iceland, and our countryman Pennant gives it a place in his Arctic Zoology. From a description and figure in the Natural History of the Fishes of Massachusetts, by Dr. Smith of Boston, this fish appears to be common in the rivers of North America, attaining a large size in those of the more southern States, but not exceeding seventeen or twenty inches in length in a high northern latitude. Dr. Mitchell includes this species among his fishes of New York. Dr. Storer of Boston, however, considers Mitchell's fish to be distinct from the European Iamprey, and calls it the $P$. Americanus of Le Sueur. Our fish is rather common during spring and summer in some of the rivers on the southern coast of England, particularly the Severn, and 
is found in smaller numbers in several of the rivers of Scotland and Ireland about the same period of the year.

I have received specimens of large size from the Severn in April and May, during which months it ascends that river to a great distance from the sea for the purpose of depositing its spawn. At this time it is considered to be in perfection, and considerable quantities are prepared in various ways for the table: the potted Lampreys and Lamperns of Worcester are in high estimation. A few are caught in the Thames almost every year, up which river it travels notwithstanding all the numerous and various obstacles which the port of London presents. I am indebted to my friend Mr. Broderip for a note of one taken in June, 1834, and of another in the same month of $\mathbf{1 8 3 5}$, as high up the Thames as Sunbury Weir. A fisherman saw the Lamprey, and struck at it with his punt pole, and supposed he hit it, as the fish rose to the surface, and was taken as it was swimming along. The haunt of this Marine Lamprey at Sunbury is a little above the church, and nearly opposite the vicarage, in a place called the Church Deep.

In Scotland, the appearance of the Lamprey in the fresh water is rather later in the year than in the rivers of the south. Sir William Jardine says, "They ascend our rivers to breed about the end of June, and remain until the beginning of August. They are not furnished with the elongation of the jaw, afforded to most of our fresh-water fish, to form the receiving furrows at this important season: but the want is supplied by the suckerlike mouth, by which they individually remove each stone. Their power is immense. Stones of a very large size are transported, and a large furrow is soon formed. The $P$. marinus remain, in a pair, on each spawning place; and 
while there employed, retain themselves affixed by the mouth to a large stone."

After the spawning season is over, the flesh of the Lamprey, like that of other fish, loses for a time its firmness and other good qualities, and the weakened fish makes its way back to the sea, to recruit its wasted condition.

The food of the Lamprey consists generally of any soft animal matter ; and in the sea it is known to attack other fishes even of large size, by fastening upon them, and with its numerous small rasp-like teeth eating away the soft parts down to the bone. It is not very often caught while it remains at sea.

This species usually measures from twenty to twentyeight inches in length; the head is rounded; the form of the body long and cylindrical, slightly compressed towards the tail; on the top of the head, rather before and between the eyes, is the external aperture of the nostril, which if examined with a blunt probe is found to lead to a tube that passes downward and backward, to the skull: along each outside of the neck are seven rounded apertures, leading to as many branchial cells lined with a membrane constructed like that of the gills in fishes; each of these cells has an internal opening into a tube which is closed by a cartilaginous pericardium at the bottom ( $m$, fig. p. 33), but communicates upwards with the mouth: the lips surrounding the mouth, and the numerous small teeth within, are represented in the woodcuts at pages 33 and 38 : on the lower third portion of the body are two distinct membranous dorsal fins, the second of which is the most elevated, the edges of both convex : a continuation of this membrane round the extreme fleshy portion of the tail forms a caudal fin, and 
a narrow slip passing upwards on the under side forms an anal fin.

The skin is perfectly smooth; the colour of the body olive brown, mottled and spotted on the back and sides with darker green and dark brown; the margins of the fins inclining to reddish-brown; the irides golden yellow.
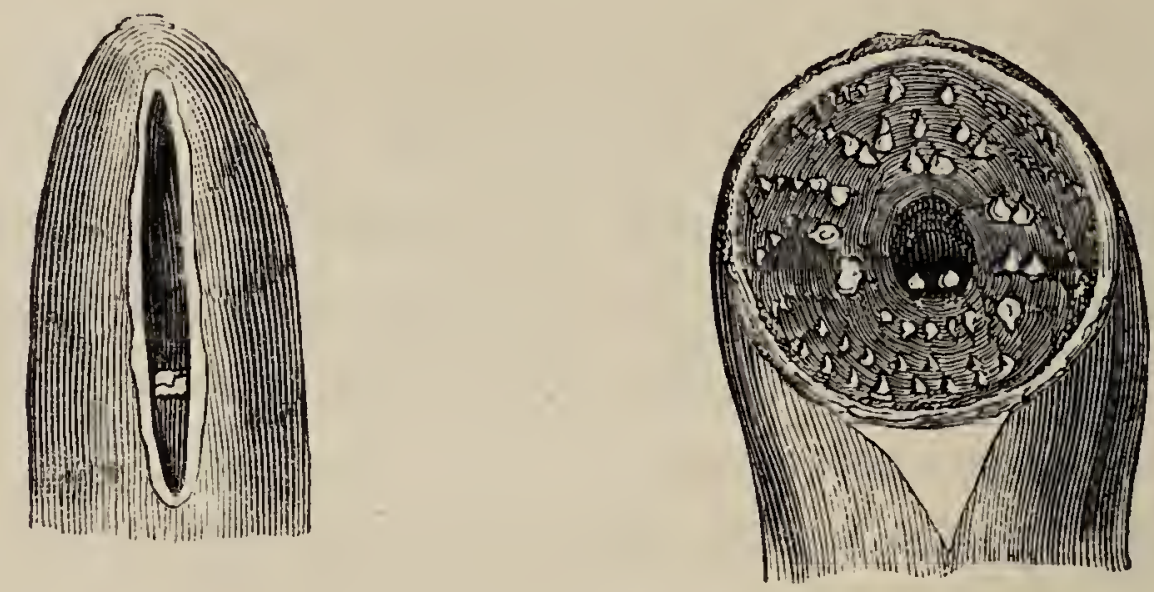

In slowly-running water the Lamprey swims with a lateral motion of the body; where the current is rapid, it makes successive plunges forward, attaching itself quickly to any fixed substance that offers to secure the advance gained.

Dr. Parnell says that in the Forth above Alloa, when the fishermen take the Lamprey in their nets, they invariably return them again to the water, having a prejudice against them. They are consequently never seen in the Edinburgh markets. Pennant states that it is an ancient custom in the City of Gloucester, annually to present the Sovereign of the realm with a Lamprey-pie, covered with a large raised crust. Mr. Couch says in his Cornish Fauna that it is a common fish in that county, but is rarely used for food. 
Teeth of Petromyzon Jure.

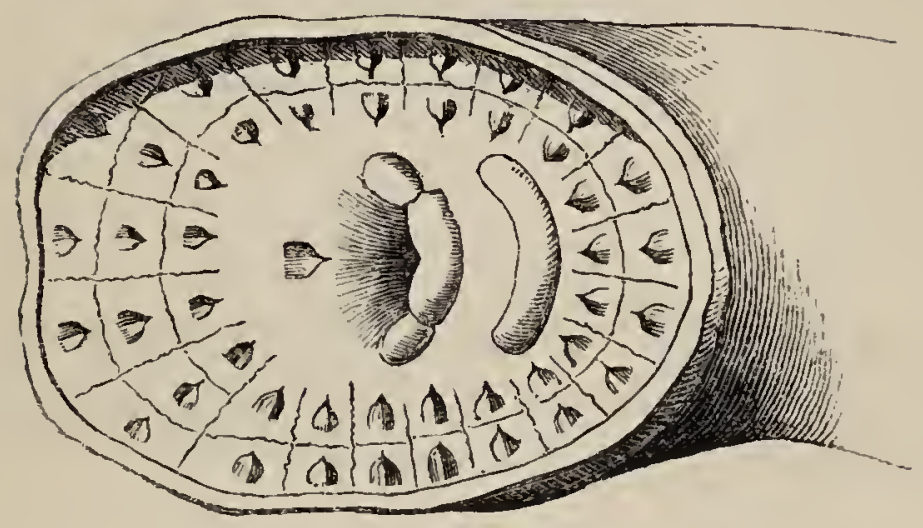

The Petromyzon Jura, figured in Mac Culloch's Western Isles (vol. ii. pp. 186-7, t. 29, f. 1) is probably of this genus. If the teeth are correctly represented, the fish has no relation to Lampetra fluvialis (vide GRAY, Cat. Fish, B. Mus. p. 139). It was found adhering to a Gurnard on the coast of the island of Jura, one of the Hebrides. 
HELMICHTHYI.

LEPTOCEPHALID 2.

LEMNISCATI.

\section{THE ANGLESEY MORRIS.}

Leptocephalus Morrisii, Anglesey Morris, Penn, Brit. Zool. vol. iii. pl. 28.

, " " , Montagu, Wern. Mem. vol. ii.

p. 436, pl. 22, f. 1.

" $\quad, \quad \quad, \quad$ FLEM. Brit. An. p. 200, sp. 111.

" " " " , Jenyns, Brit. Vert. p. 480.

", ", Le Leptocephiale, Cuvier, Règne An. t. ii. p. 358.

, candidissimus,

, vitreus,

Costa, Fauna Nap. t. 20.

Kölliker, Zeitsch. für Wiss. Zool. iv. 360 .

Ophidium pellucidum,

Couch, Lond. Mag. Nat. Hist. v. 313 and 742 .

LEPTOCEPHALID , Bon. (Helmicthyide, Köll.) Family Character`s.-Small, greatly compressed, blade-shaped, diaphanous fishes, totally destitute of scales; with or without teeth ; ventrals present in one genus, wanting in the others; anus on the ventral edge of the fish; blood colourless; no spleen ; no air-bladder; gills free, sub-operculate; skeleton very incomplete, the skull and spine being cartilaginous, though the jaws are ossified; spinal marrow prolonged into the base of the skull; fins cutaneous searns, as in the Dermopteri, but generally with visible rays in the caudal.

Leprocepinauus. Generic Characters.-Muscular fasciculi meeting chevronwise on the sides, forming a lateral line ; caudal not prolonged into a filament, by which it is distinguished from Tilurus; teeth, in some species long and pointed, in others absent; pectorals small, or altogether wanting; anal opening generally very minute.

THrs species was discovered in the sea near Holyhead by Mr. William Morris, who sent the specimen to Pennant, by whom it was named after his friend. Pennant subsequently sent the same specimen to Gronovius, who 
described it under the generic name of Leptocephalus, in reference to the small size of the head.

Any doubts which might formerly have been raised as to the real existence of such a species, to which Colonel Montagu has alluded, must have ceased to exist, as this fish has now been taken and recognised in various localities. Pennant, in his first description, perhaps from the state of his specimen, was not aware of all the characters this delicate fish possesses; but Colonel Montagu has well described and given a figure of it in the Wernerian Memoirs, as quoted. More than twenty specimens have within a few years been taken at different parts of the coast of England, Wales, and Ireland. By the kindness of $\mathrm{Mr}$. Couch, I possess three samples that were taken in Cornwall; and from Mr. William Thompson, of Belfast, we learn that five or six specimens have been obtained by him and his collecting friends. In the Zoologist for 1854 Mr. Harris mentions that four samples of this fish were thrown on the beach in a gale at Pennan in Aberdeenshire; Mr. Norman in the same work states that in 1857 he dredged up this fish in fifteen fathoms of water off Falmouth, and another correspondent says that he captured a specimen at Redcar.

There is also an interesting account of this fish, with a good figure, in the sixth volume of Mr. Loudon's Magazine of Natural History, page 330, by H. V. Deere, Esq., who states that his specimen, to all appearance dead, was brought to him by a Devonshire fisherman, who had carried it in his pocket, wrapped in brown paper, for three hours. After this gentleman had held the fish in his hand for about a minute, examining it, symptoms of life appeared, and then the little animal was placed in a tumbler of salt and water, where it survived its incarceration in brown paper for several hours. Its appearance is 
described as most pleasing, from its semitransparent and silvery hue, its prominent eye, and graceful motions. It is usually found among seaweed.

I carefully dissected off the whole of one side from one of the three specimens sent me by Mr. Couch, laying bare the vertebral column and the intestinal canal. The bones forming the vertebræ have no spinous processes whatever, either superior or inferior; the angular junctions of the ascending and descending oblique indented striæ, visible on the external surface of the skin, mark the points of union of the different vertebræ; the oblique muscles between the striæ are attached to the bodies of the bones forming the column; the margin all round each vertebral bone is opaque, but the centre or body of each is transparent.

The intestine is a single straight canal of small calibre, reaching from the head to the vent; after passing from the posterior part of the head, it descends to the abdominal line, which it traverses without convolution to the vent. This canal may be distinctly seen in the perfect fish when placed flat on a slip of glass, and looked at against a good light, particularly the descending portion from the head to the level of the abdominal line.

The head is small, short, and rather blunt: the eyes large; irides silvery, the pupil dark: the lower jaw slender; teeth in both jaws, numerous and minute; gillopenings and pectoral fins very small; the body behind the head becomes deeper, very much compressed, as thin as tape, and when rendered opaque by the effect of a mixture of spirit of wine and water, which is the best mode of preserving them, this fish very much resembles a piece of a tape-worm.

The dorsal fin commences rather before the middle of the whole length of the fish; the anal fin rather behind 
it; and both extend to the tail, where they are united, and end in a point. These fin-like appendages have the appearance of an extension of the skin, and are so delicate that it is not always easy to decide where they do begin, or may be called fin; the dorsal and abdominal margins, as well as the lateral line, exhibit a series of small black specks; the obliquely-striated appearance of the sides has been already referred to. The general colour is most like that of opal.

In the Catalogue of the Apodal Fish in the British Museum, Dr. Kaup has introduced eighteen species of Leptocephalus, and three other genera of the same family, comprising four species more. The list will be hereafter considerably extended, for Dr. Kaup confined himself to the species that he had an opportunity of examining, neglecting the indications of others by voyagers, who have noticed these curious fishes in all the Oceans. Esunculus, one of Kaup's new genera, has ventrals, and that ichthyologist therefore considers this family to be the lowest or least-organized group of the Abdominal Malacopterous fishes. Many reasons, founded on their structure, incline us to place them next to the Dermopteri, and provisionally in a distinct order, whose appellation of Helmicthyi we have borrowed from Kolliker, adding the epithet lemniscati to denote their ribbon-like form.

Dr. Kaup says that he can detect no difference between Yarrell's figure of L. Morrisii and that of candidissimus of Costa, and we have seen a specimen thrown up during the eruption of Graham's volcanic island in the Mediterranean, which resembled the British fish in all points. 


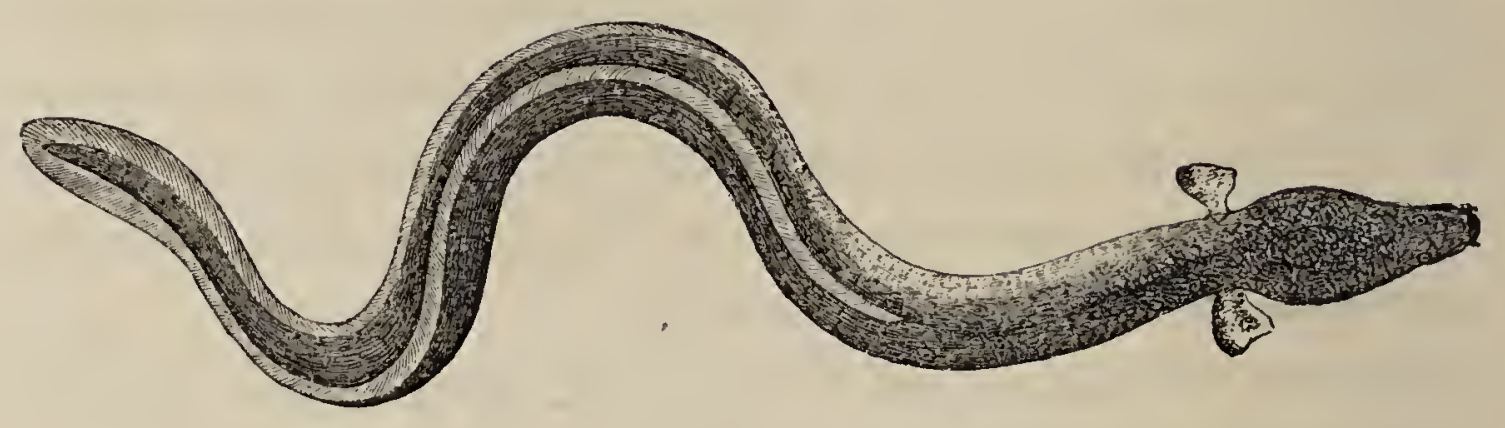

\section{SHARP-NOSED EEL.}

Anguilla acutirostris, Sharp-nosed Eel, YARReLu, Proceed. Zool. Soc. 1831, pp. 133 and 159. Zool. Journ. vol. iv. p. 469.

„, omnium auctorum, WILLUGHBY, p. 109, G. 5.

,, acutirostris, Sharp-nosed Eel, Jenses, Man. Brit. Vert. p. 474. Murcena anguilla, L'Anguille, Linnaus. Blocir, pt. iii. pl. 73.

, Common Eel,

Anguilla vulgaris,

$, \quad, \quad$

",,

Campagnola o Storla,

,, ,,
Long-bec, Common Eel,

Anguilua. Generic Characters. - Teeth, more or less card-like, in bands; gill-openings lateral; pectorals conspicuous; dorsal and anal fins coalescing round the point of the tail ; scales in groups, which lie in different directions. Gills, four biserial ones, with an uniserial one on the interior of the operculum ; four very small internal openings between the branchial arches, which are bent upon themselves at an unusually acute angle. - The family characters are the same, there being but one genus.

The Apodal order of fishes, which have no spinous rays in their fins, or being as they are termed Malacopterous, has been most fully investigated by Dr. Kaup, who, in his Catalogue of Apodal Fish, drawn up for the British Museum in 1856, characterizes these fishes as having serpentiform bodies, destitute of ventrals, and generally covered by a slippery skin, with, in some of the 
genera, small scales imbedded therein. No ribs are developed in the skeleton; the pyloric cæca are absent; the greater number have a swimming bladder, which is in some of an uncommon form. The species are numerous, and form many generic and family groups, some of which are remarkable for the fewness of their branchial arches, or for the positions of their external gill-openings. The representatives of the order in the British waters are comparatively few. Kaup separates the families into two sections: in one, which he names Cryptomycteres, the hinder nostrils are situated in a fold on the border of the lip or on the inner side thereof. In the other section, called Phaneromycteres, the hinder nostril is plainly visible, and is situated either before or over the eye. The Latin name Anguilla, signifying a little serpent, is still the vernacular appellation in Italy. Eustathius tells us that its Greek designation Enchelys had reference to its habit of burrowing in the mud.

The general appearance of the Eel is so well known, and so unlike that of most other fishes, as to require but a slight description; yet it was not till a period of very modern date that naturalists became acquainted with the fact that the fresh waters of several countries produce three or four distinct species, which had previously been confounded together. Thus the first edition of the Règne Animal, published in 1817, included but one species of common fresh-water Eel as well known: the second edition, published in 1829, contains a short notice of four different species; three of which, if not all four, are found in this country.

The form of the Eel, resembling that of the serpent, has long excited a prejudice against it, which exists in some countries even to the present time; and its similarity to a snake has even been repeated by those, who, from the 
advantages of education, and their acquirements in natural history, might have been supposed capable of drawing more accurate conclusions. There is but little similarity in the snake and the Eel except in the external form of the body: the important internal organs of the two animals, and the character of the skeletons, are most decidedly different.

Eels are in reality a valuable description of fish : their. flesh is excellent as food; they are very numerous, very prolific, and are found in almost every part of the world. The various species are hardy, tenacious of life, and very easily preserved. In this country they inhabit almost all our rivers, lakes, and ponds; they are in great esteem for the table, and the consumption in our large cities is very considerable. The London market is principally supplied from Holland by Dutch fishermen. There are two companies in Holland, having five vessels each : their vessels are built with a capacious well, in which large quantities of Eels are preserved alive till wanted. One or more of these vessels may be constantly seen lying off Billingsgate; the others go to Holland for fresh supplies, each bringing a cargo of 15,000 to 20,000 pounds' weight of live Eels, for which the Dutch merchant pays a duty of 13l. per cargo for his permission to sell. Eels and Salmon are the only fish sold by the pound weight in the London market.

Eels are not only numerous, but they are also in great request, in many other countries. Ellis, in his Polynesian Researches, vol. ii. page 286, says, "In Otaheite, Eels are great favourites, and are tamed and fed until they attain an enormous size. These pets are kept in large holes, two or three feet deep, partially filled with water; on the sides of which they generally remained, excepting when called by the person who fed them. I have been several times with 
the young chief, when he has sat down by the side of the hole, and, by giving a shrill sort of whistle, has brought out an enormous Eel, which has moved about the surface of the water, and eaten with confidence out of its master's hand."

At a meeting of the Wernerian Natural History Society of Edinburgh, Professor Jameson, in the chair, Mr. Walter C. Trevelyan read an account of the habits of some tame "Eels. "In a small pond in a walled garden at Craigo, the seat of David Carnegie, Esq., near Montrose, Eels have been kept for nine or ten years. They lie torpid during the whole winter, except the sun is shining brightly, when they will occasionally come out from their hiding-place under some loose stones, and sprawl about the bottom of the pond, but refuse to take any food. The 26th of April was the first day in 1840 that they rose for worms; but they eat sparingly until the warm weather begins, when they become quite insatiable: one of them will then swallow twenty-seven large worms one after the other. When they were first put into the pond, and had no food given to them, they devoured one another. They generally lie quietly at the bottom of the pond, except when any of the family go and look into it, when they invariably rise to the surface, sometimes for food, and at others merely to play with the hand, or take the fingers into their mouths. About the month of August they become very restless, and take every opportunity of the pond overflowing from rain to get out; when sought for in the garden, on these occasions, they are invariably found travelling eastwards (the direction of the sea, which is about four miles from Craigo). Towards the end of August, or beginning of September, they retire to their winter retreat under the stones. Whether they breed in this pond or not is uncertain; but on clear- 
ing it out last summer a few very small Eels were discovered, and how else they could have found their way there is not easy to conjecture, as there is a fine rose on the mouth of the pipe by which the water enters. From their rapacity, shown in devouring their companions,some Goldfish,-it is possible they may eat the greater part of their own small fry."-Edin. New Phil. Journ. for - April, 1841, p. 439.

Most of the writers on the habits of the Eel have described them as making two migrations in each year: one in the autumn to the sea; the other in spring, or at the beginning of summer, from the sea. The autumn migration is performed by adult Eels, and is believed to be for the purpose of depositing their spawn; it is also said that these parent fish never return up the rivers. The spring migration is commonly supposed to be confined to very small Eels, not more than three inches in length, and in reference to the fry alone, it is too well known, and too often recorded, to be matter of doubt. The passage of countless hundreds of young Eels has been seen and described as occurring in the Thames, * the Severn, the Dee, and the Ban. I am, however, of opinion, that the passage of adult Eels to the sea, or rather to the brackish water of the estuary, is an exercise of choice, and not a matter of necessity; and that the parent Eels return up the river as well as the fry.

All authors agree that Eels are extremely averse to cold. There are no Eels in the arctic regions,-none in the rivers of Siberia, the Wolga, nor even in some of the

* See an excellent account by Dr. William Roots, of Kingston, published in the second series of Gleanings in Natural History, by Edward Jesse, Esq., p. 50. The Rev. J. C. Atkinson, who has paid much attention to the habits of Eels, furnished the Zoologist for 1844 (p. 527) with an interesting paper on the subject. He states the eels are seldom to be caught with hooks in moon-light nights, and that the eel-fare of the Whitadder is in May. 
tributaries of the Danube; yet the rivers of the southern parts of Europe produce four species. There is no doubt that fishes in general, and Eels in particular, are able to appreciate even minute alterations in the temperature of the water they inhabit. The mixed water they seek to remain in during the colder months of the year is of a higher temperature than the pure fresh water of the river, or that of the sea. It is a well-known law in chemistry, that when two fluids of different densities come in contact, the temperature of the mixture is elevated for a time in proportion to the difference in the density of the two fluids, from the mutual penetration and condensation. Such a mixture is constantly taking place at the mouths of rivers that run into the sea, and the mixed water maintains a temperature two degrees warmer than that of the river or the sea. This elevation in the temperature of the water of estuaries and the mouths of rivers is, I have no doubt, one reason why they in general abound in young fish.

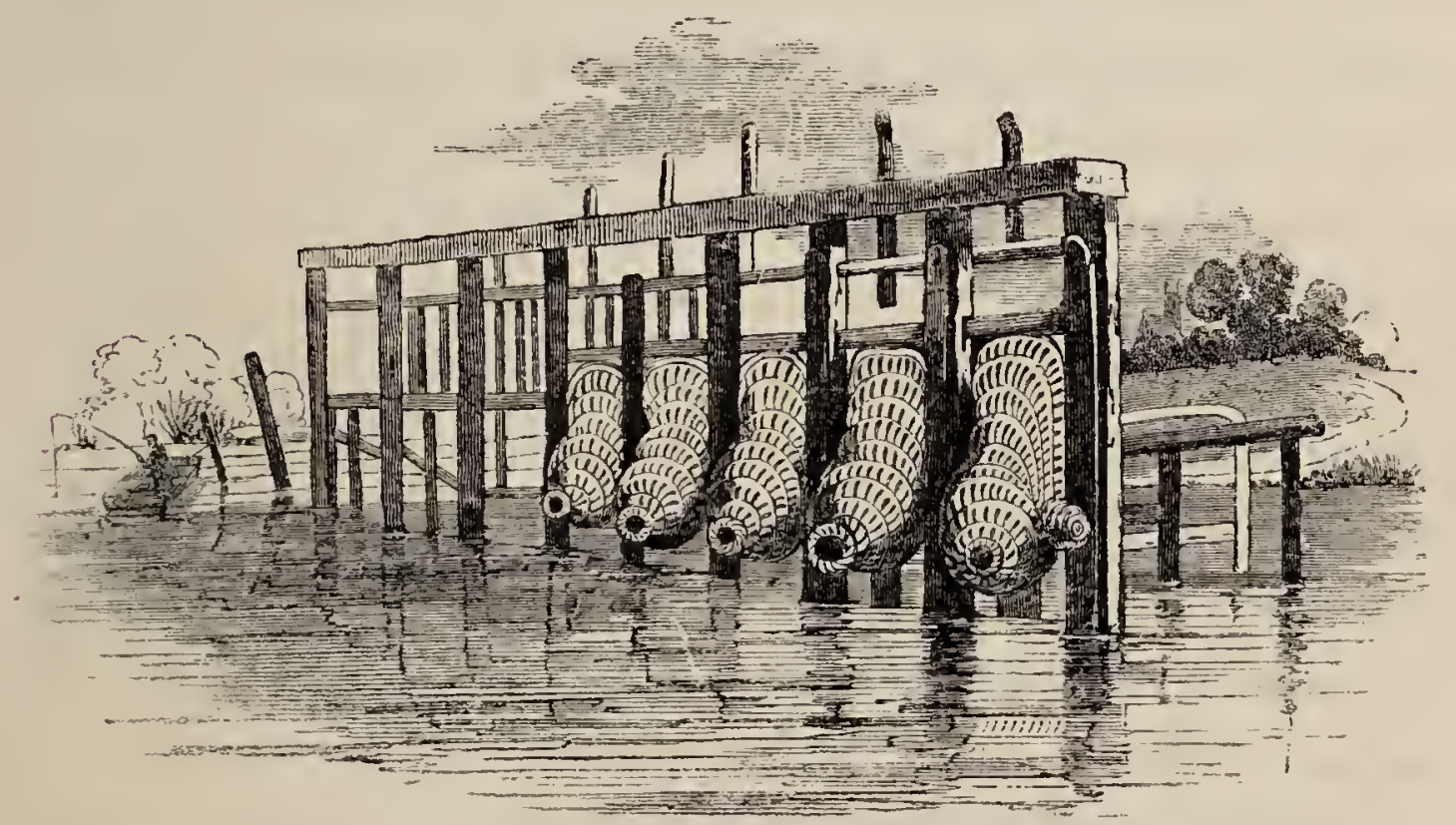

In a tideway river the descent of the Eels towards the brackish water takes place during the autumn, and various devices are employed in different streams to intercept them in their progress. The above figure represents VOL. I. 
the form of an apparatus used in various parts of the Thames, called an Eelbuck, consisting of a framework of wood supporting various wicker-baskets of a particular form. The large open end of each basket is opposed to the stream, and by the peculiar structure of the inside, any fish once within the body of the basket cannot escape.

During the cold months of the year Eels remain embedded in mud; and large quantities are frequently taken by Eel-spears in the soft soils of harbours and banks of rivers, from which the tide recedes, and leaves the surface exposed for several hours every day. The Eels bury themselves twelve or sixteen inches deep, near the edge of the navigable channel, and generally near some of the many land-drains, the water of which continues to run in its course over the mud into the channel during the whole time the tide is out. In Somersetshire the people know how to find the holes in the banks of rivers in which Eels are laid up, by the hoar-frost not lying over them as it does elsewhere, and dig them out in heaps. The practice of searching for Eels in mud in cold weather is not confined to this country. Dr. Mitchell, in his paper on the Fishes of New York, published in the Transactions of the Literary and Philosophical Society of that city, says, "In the winter Eels lie concealed in the mud, and are taken in great numbers by spears."

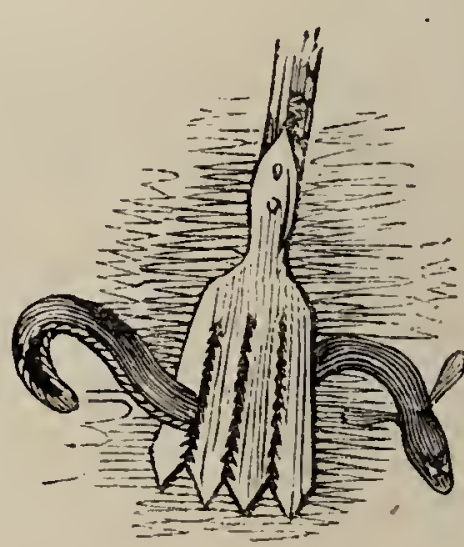
Thus embedded in mud, in a state of torpidity, the Eel indicates a low degree of respiration. Dr. Marshall Hall has shown that the quantity of respiration is inversely as the degree of irritability. With a high degree of irritability and a low respiration, co-exist 
-1st. The power of sustaining the privation of air and of food; 2nd. A low animal temperature; 3rd. Little activity; 4th. Great tenacity of life. All these peculiarities Eels are well known to possess. The high degree of irritability of the muscular fibre explains the restless motions of Eels during thunder-storms, and helps to account for the enormous captures made in some rivers by the use of gratings, boxes, and eel-pots or baskets, which imprison all that enter. The power of enduring the effects of a low temperature is shown by the fact, that Eels exposed on the ground till frozen, then buried in snow, and at the end of four days put into water, and so thawed slowly, discovered gradually signs of life, and soon perfectly recovered.

The mode by which young Eels are produced appears to have long been a subject of inquiry, and the notions of the ancients as well as of some of the moderns were numerous and fanciful. Aristotle believed that they sprang from the mud; Pliny, from fragments which were separated from their bodies by rubbing against rocks; others supposed that they proceeded from the carcasses of animals; Helmont believed that they came from May-dew, and might be obtained by the following process :- "Cut up two turfs covered with May-dew, and lay one upon the other, the grassy sides inwards, and thus expose them to the heat of the sun; in a few hours there will spring from them an infinite quantity of Eels." Horse-hair from the tail of a stallion, when deposited in water, was formerly believed to be a never-failing source of a supply of young Eels. It was long considered certain that they were viviparous: this belief had its origin probably in the numerous worms that are frequently to be found in various parts of the bodies of Eels, sometimes in the serous cavities, at others in the intestinal canal. Ru- 
dolphi has enumerated eight different species of entozoa common to fresh-water Eels. The enormous number of young known to be produced by Eels is a good negative proof that they are oviparous: viviparous fishes producing, on the contrary, but few young at a time, and these, too, of considerable size when first excluded. Having devoted time and attention to the close examination of numbers of Eels for many months in succession, the further details of which will be found in $\mathrm{Mr}$. Jesse's second series of Gleanings in Natural History, I need only here repeat my belief that Eels are oviparous, producing their young like other true bony fishes.

The sexual organ consists of two long narrow sacs extending one on each side of the air-bladder throughout the whole length of the abdominal cavity, and continued for two inches posterior to the vent. The membranes forming this tubular sac, secreting on the inner surface the milt of the male, and affording attachment for the ova in the female, are puckered or gathered along the line of junction to the peritoneal covering of the spine, and the free or loose floating edge is therefore thrown into creases or plaits like a frill. It is probably from this folded or convoluted appearance that the sexual organs of the Eel have frequently been called fringes. By the kindness of my friends, Mr. Clift and Mr. Owen, of the Royal College of Surgeons, I have had the pleasure of seeing some drawings belonging to the collection of John Hunter, in which these peculiarities of the sexual organs in the Eel are beautifully exhibited in various magnified representations. These representations are now published. Dr. Hornschuch, in an inaugural thesis dated 1842, has given good figures and descriptions of this part of the structure of the Eel, and shown the situation of the aperture by which the mature roe escapes after drop- 
ping from the surface of the ovaria into the cavity of the abdomen.

Eels that have lain in brackish water all the winter under the constant influence of the higher temperature of that locality, probably deposit their spawn earlier in the spring than those which have passed the winter in places from which there existed for them no possible egress. In the Mole, the Wey, the Longford River, and in some large ponds, the Eels in the spring of 1833 did not deposit their spawn till near the end of April; but in two Eels from Sheerness received and examined on the 18th of May, the internal appearances induced me to believe that the roes had been passed some time. How long the ova remain deposited before the young Eel is produced, is, I believe, unknown. The duration of this interval is very variable in different fishes. The roe of the Herring, deposited at the end of October, or the beginning of November, is said to become living fry within three weeks: the ova of Eels, the produce of which is very small, do not probably require a longer period. Both the parent Eels and the fry occupying the brackish water appear to have the power of going either to the salt water or to the fresh without inconvenience, from the previous preparation which the respiratory organs have undergone, and many of both are found in pure sea water: the great bulk of the young, however, certainly ascend the stream of the river, and their annual appearance in certain places is looked for with some interest. The passage of young Eels up the Thames at Kingston in the year 1832 commenced on the 30th of April, and lasted till the 4th of May; but I believe I am correct in stating that few young Eels were observed to pass up the Thames either in the year 1834 or $1835 . \quad$ Mr. J. Reeve informed me, that in 1843 the Elvers, or young eels, did 
not go up till the end of August, and were then of the thickness of a man's finger. Some notion may be formed of the quantity of young Eels, each about three inches long, that pass up the Thames in the spring, and in other rivers at the beginning of summer, from the circumstance that two observers of the progress of the young Eels at Kingston in 1832, calculated that from sixteen to eighteen hundred passed a given point in the space of one minute of time. This passage of young Eels is called Eel-fare on the banks of the Thames,-the Saxon word signifying to go, to pass, to travel; * and I have very little doubt that the term Elver, in common use on the banks of the Severn for a young Eel, is a modification or corruption of Eel-fare. When the Elvers appear in the Severn, they are taken in great quantities with sieves of hair cloth, or even with a common basket, and, after being scoured and boiled, are offered for sale. They are either fried in cakes or stewed, and are accounted very delicious.

There is no doubt that Eels occasionally quit the water, and when grass meadows are wet from dew, or other. causes, travel during the night over the moist surface in search of frogs and other suitable food, or to change their situation. Some ponds continually produce Eels, though the owners of these ponds are most desirous of keeping the water free from Eels, from a knowledge of their destructive habits towards the spawn and fry of other fishes. Other ponds into which Eels have been constantly introduced are obnoxious to them from some quality in the water; and they are known to leave such places during the night, and have been found on their passage to other

* A pedestrian on the road is called "a way-faring man ;" and hence, also, the price for travelling by a conveyance is called "the fare." We have also "thoroughfare," \&c. 
retreats. Dr. Hastings, in his Illustrations of the Natural History of Worcestershire, says, at page 134, "I will here mention a curious confirmation of the opinion in favour of the overland migration of Eels. A relative of the late Mr. Perrott was out in his park with his keeper near a large piece of water, on a very beautiful evening, when the keeper drew his attention to a fine Eel quietly ascending the bank of the pool, and with an undulating motion making its way through the long grass: on further observation he perceived a considerable number of Eels quietly proceeding to a range of stews, nearly the distance of a quarter of a mile from the large piece of water from whence they started. The stews were supplied by a rapid brook, and in all probability the instinct of the fish led them in that direction as a means of finding their way to some large river from whence their ultimate destination, the sea, might be obtained. This circumstance took place at Sandford Park, near Enstone."

That Eels breed also in the fresl water of inland rivers and lakes from which they are unable to visit the sea is, I believe, certain. A constant supply for the table is obtained throughout the winter in these localities, as well as at other seasons, by gamekeepers and fishermen, who have charge of waters thus situated; and no doubt exists in their minds that these Eels are bred in the places from which they are obtained, and of which the great variation that occurs in the size is an additional proof.

The following letter from Mr. Young, extracted from the Literary Gazette for June 15, 1844, confirms the accuracy of the opinion just stated, which was published in the first edition of this work in 1836.

"You are aware that the broad and sharp-nosed Eels are inhabitants of all our northern rivers, and were supposed, 
even said, to descend to brackish water to spawn, and return in spring to the rivers. On the 28th of April, 1842, we had what we call the Eel-fair, or Eel-fry, ascending the rivers. I then took a few of them from the river, measuring from an inch to an inch and a half in length, and placed them in a pond closely grated. They grew very fast in course of the following summer; and became so tame, that as soon as I threw in meat of any kind, they ate with the greatest familiarity; on the approach of winter they entirely disappeared, and through the course of winter I thought they were dead; but last spring, as soon as the weather and water turned warm, they again appeared, and very soon got into their familiar habit. I often fed them last summer; and on 21st October, 1843, I caught one of them in the pond, measuring twenty-five inches, which I have preserved in spirits; the remainder in the pond have disappeared as last year on the approach of winter, and will not appear until April or May month. The rivers were very low in July month, and I watched the motion of the Eels in swarms on the sand and gravel banks in the river Shin as I thought spawning, and would have mentioned the circumstance to you while here, had I not wished to be more certain; but in October last I got a few men, and made them wheel out one of the gravel banks, where I observed the Eels altogether, and found it swarming with young Eels, at the depth of from six to fifteen inches, and some of them scarcely alive. This entirely changes the former history of the Eels; and the habits of our river Eels are as follow:-The adults spawn in the summer months in sand and gravel banks in the rivers, and do not descend to brackish water to deposit their spawn. The spawn becomes vivid in the following September and October, but remains under the gravel in the spawning-beds until the 
following April or May, depending entirely upon the heat and cold of the weather. We never have the Eel-swarm or fry at the exact same time, although we have it some time in April or May. And the adult Eels, in place of emigrating, get into holes in the banks of the rivers and underneath large stones as soon as the water turns cold, and remain stationary until the warmth of summer again heats the water of the rivers."

The Eel is a voracious feeder during certain months of the year. In winter the stomachs of those which I examined were empty; by the middle of March I found the stomachs of others distended with the larva of various insects, and the bones of small fishes. They are known to consume a large quantity of spawn, and will attack large Carp, seizing them by the fins, though without the power of doing them further injury. Occasionally they eat vegetable substances, and have been seen swimming about the surface of water, cropping the leaves of small aquatic plants. By aid of a long and capacious airbladder, Eels rise to various elevations in the water with great ease, and sometimes swim very high even in deep water. When Whitebait-fishing in the Thames, I once caught an Eel in the net in twenty-six feet depth of water, though the Whitebait-net does not dip more than about three feet below the surface.

Eels appear to be slow of growth, not attaining greater length than twelve inches during the first year, and do not mature roe till the second or third year. 'The sharpnosed species, however, acquires a large size. I saw at Cambridge the preserved skins of two which weighed together fifty pounds; the heaviest twenty-seven pounds, the second twenty-three pounds. They were taken on draining a fen-dyke at Wisbeach. No other fish of any sort was found in that dyke. 
Ely is said to have been so named from rents being formerly paid in Eels : the lords of manors in the isle were annually entitled to more than 100,000 Eels. A stitch or stick of Eels was twenty-five; and the practice of stringing Eels on tough slender willow-twigs, put in at the gill-aperture and out at the mouth, still prevails in Dorsetshire among those who carry Eels about for sale from house to house; one, two, or three pounds' weight being thus strung on a stick, to suit different customers. Elmore on the Severn obtained its name from the immense number of Eels which are taken there.

In a Sharp-nosed Eel of twenty-two inches in lengtl, three distances taken from the point of the lower jaw are

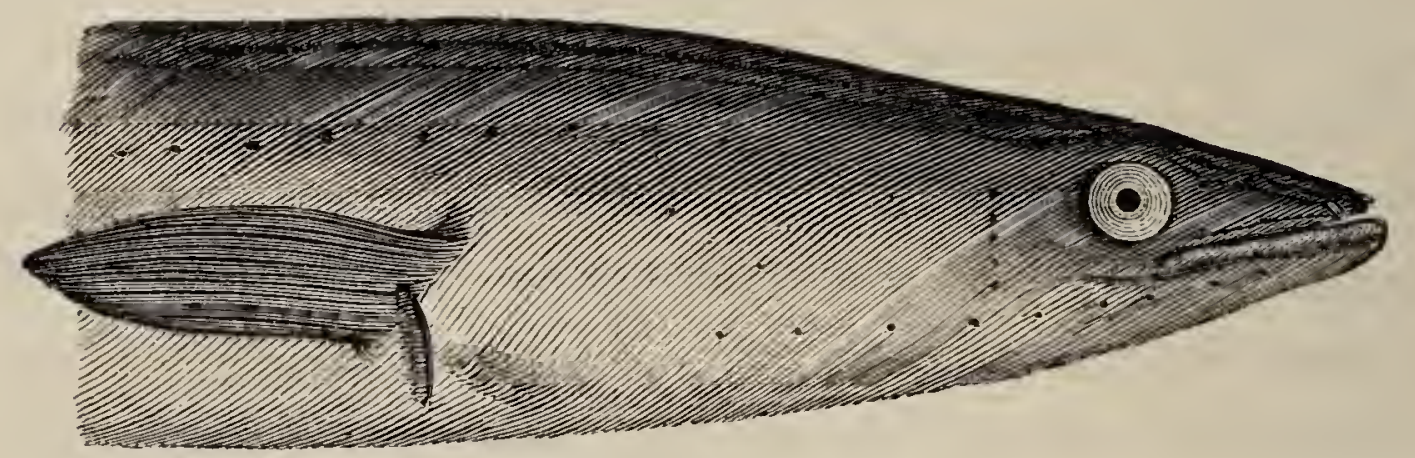

to the whole length of the Eel as follows;-to the upper part of the base of the pectoral fin, as two to seventeen ; to the commencement of the dorsal fin, as two to seven; and to the commencement of the anal fin, as nine to twentytwo. In a Sharp-nosed Eel of twenty inches in length, the pectoral fin will be almost one inch, and the vent more than an inch, nearer the head than the same parts in a Broad-nosed Eel of the same length.

The head is compressed, the top convex, depressed as it slopes forward: the eye small, placed with its fore part over the angle of the mouth, and having rather a lateral aspect; irides reddish yellow: the jaws very narrow, slightly rounded at the end; the lower jaw the longest; 
nostrils with two openings on each side, the anterior one tubular, the other a simple orifice; both jaws furnished with a narrow, crowded, brush-like band of small teeth; pharyngeal teeth setaceous; gape small; various mucous pores about the mouth and other parts of the head, among which there is an auditory aperture on each side; gillopening a small aperture immediately before and rather below the origin of the pectoral fin ; the scales on the body rather small and delicate, oblong and lying in close groups lattice-ways: dorsal fin extending over more than twothirds of the whole length of the fish; anal fin occupying more than half of the whole length; both united at the end, forming a tail-fin; the number of rays in the fins not easily ascertained, from the thickness of the skin; the lateral line exhibits a long series of mucous orifices; vertebræ 113. The vent includes four distinct openings, the foremost of which leads upwards to the intestine, the posterior one backwards to the urinary bladder, and an elongated lateral opening on each side communicates with the cavity of the abdomen, for the exit of the roe. Air bladder fusiform, with two short processes at the anterior end, enveloped in the common integument; the inferior or ventral process is closely bound to the osophagus, and is cellular, as is also the posterior point of the viscus. There are, moreover, several membranous diaphragms in the air-bladder and a vascular ganglion.

The cranium on the right hand of the three, figured at page 67 , is that of the Sharp-nosed Eel.

The prevailing colour of all the upper surface is a dark olivaceous green; the sides lighter; the belly white. When the fish are obtained from pure streams, the colours are clear and bright, and it is called a Silver Eel ; when taken from water over a muddy bottom, the colours are brown and dusky. 
Dr. Marshall Hall, in 1831, while pursuing some physiological investigations on the circulation of the blood in various reptiles and fishes, observed a pulsating sac near the tail of the Eel. The form, action, and connections of this sac are best seen under the microscope. A young Eel of six or seven inches in length, if rolled up in a strip of linen cloth, leaving out a small portion only of the tail, will remain quiet when placed on a long slip of glass, or may be tied to it with thread. The pulsation observed in this sac is entirely independent of the action or influence of the heart, and the number of beats more than double in the same period of time; they also continue after the heart has been removed. Some Continental physiologists have ascertained that these pulsating sacs, which are found in the frog, the toad, the salamander, and the green lizard, * contain lymph, and direct its motion, and they have accordingly called them lymphatic hearts. They are only observed in connection with veins. "Such is," says Dr. Müller, "the pulsating organ discovered by Dr. Marshall Hall in the Eel, where that organ receives the vessels of the extremity of the tail, and conducts its blood into the vena caudalis. But organs of pulsation in the lymphatic system have hitherto been altogether unknown; it is not probable that they should exist only in amphibia, and important discoveries of a similar nature in the higher animals, such as birds and mammalia, may be expected; my researches, as regards these, have, however, been hitherto unsuccessful." In another part of his paper, Dr. Müller observes, "I have never discovered a trace of motion in the cysterna chyli and ductus thoracicus of mammalia."

In a conversation with Mr. Owen on this subject, he

* See a paper in the Philosophical Transactions for 1833, by Dr. John Müller, Professor of Physiology in the University of Bonn. 
suggested, that as the valves of the lymphatic vessels are very few and imperfect in reptiles and fishes, especially in the latter, these pulsating sacs would seem to be superadded as a compensating power in the absence of that mechanism which impresses a definite direction and an unintermitting flow upon the currents of the lymph in the higher vertebrata, especially mammalia.

I am indebted to the kindness of Dr. Marshall Hall for permission to copy the excellent illustration of this structure in the tail of the Eel, from his very interesting critical and experimental Essay on the Circulation of the Blood. In the vignette the arrow-heads indicate the direction of the currents.

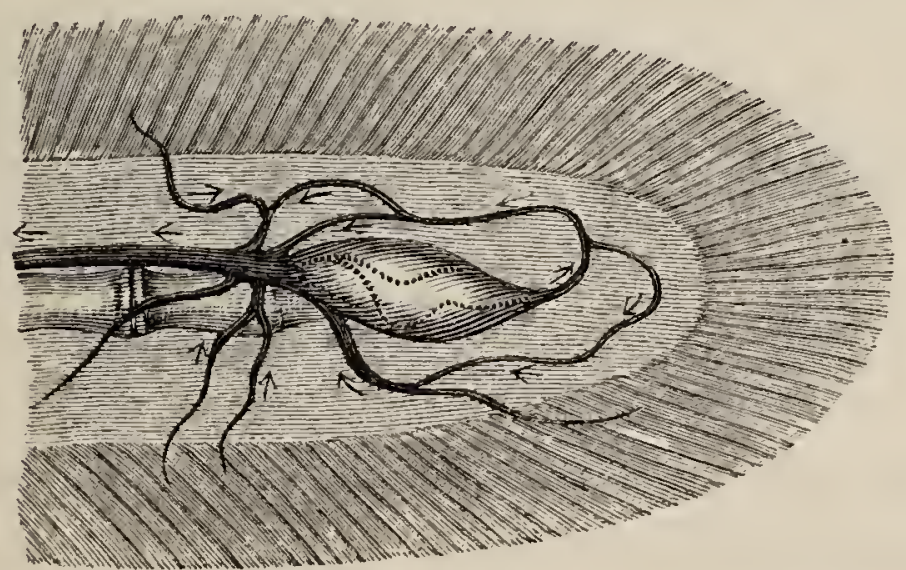


MALACOPTERI. APODES.

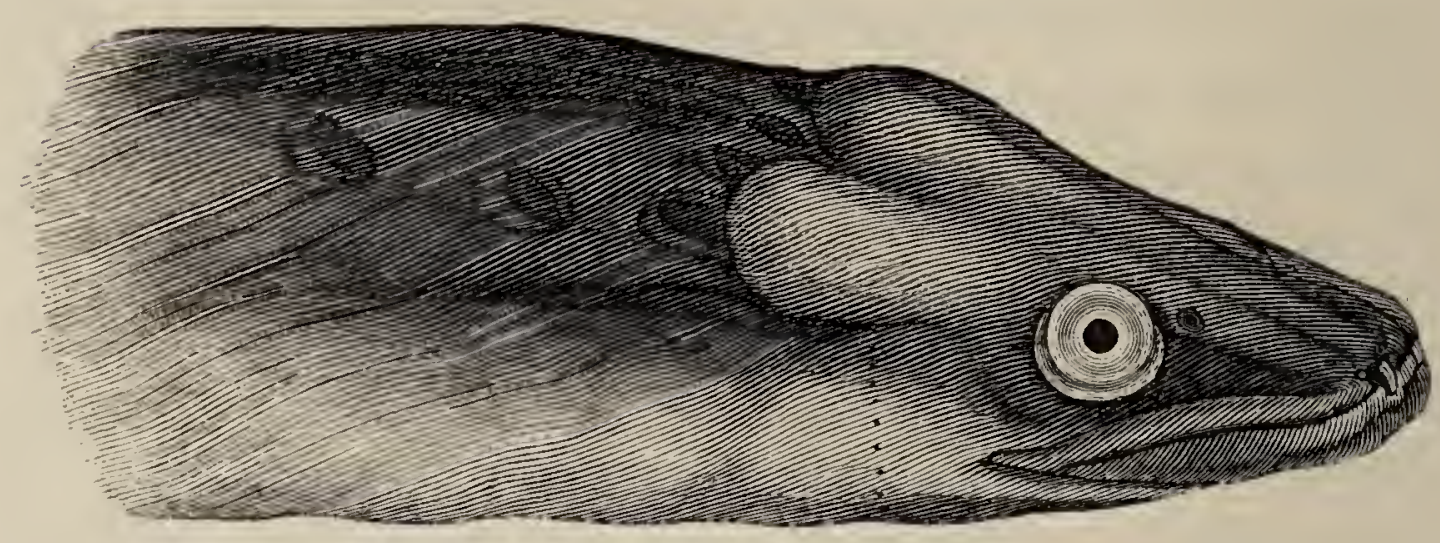

THE BROAD-NOSED EEL.

Anguilla latirostris, Broad-nosed Eel, Yarreli, Proceed. Zool. Soc. 1831. pp. 133 and 159. Zool. Journ. vol. iv. p. 469 .

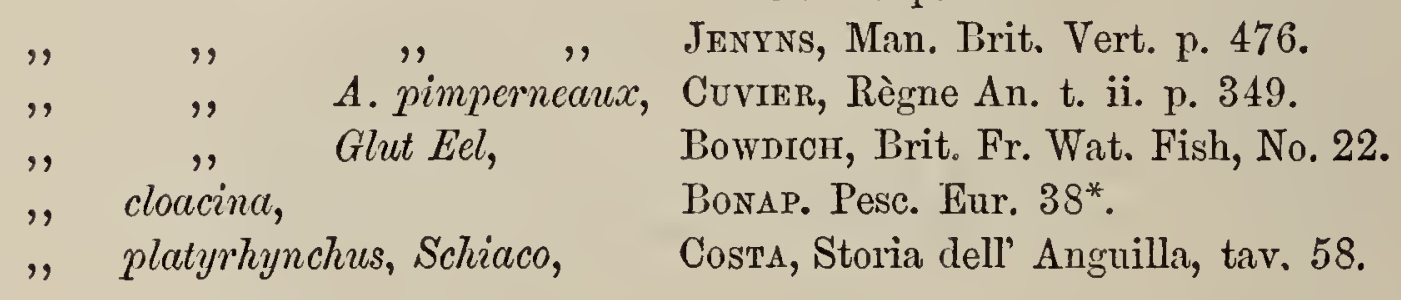

The Broad-Nosed Eel is almost as common a species as the Sharp-nosed Eel, but is immediately distinguished from it by the much greater comparative breadth of the head; the representation at the top of the page is therefore confined to that part of the fish which exhibits the best distinctions; and the vignette to the Snig Eel, page 67 , represents in the left-hand figure of the three heads the cranium of the Broad-nosed Eel, to show this character as it exists in the bone. This Eel is the Grig or Glut Eel of Pennant, who says, "They have a larger head, blunter nose, and thicker skin than the common sort." It is, probably, also the Frog-mouthed Eel of the Severn, referred to by Dr. Hastings, in his Natural History of 
Worcestershire, page 135, and so called by the fishermen from the extraordinary width of the mouth.

In its habits the Broad-nosed Eel is not distinguished by any peculiarity that I am aware of from the other common $\mathrm{Eel}$; but it does not appear to attain so large a size, the largest I have seen not exceeding five pounds in weight. It exists in many of the waters which produce the sharp-nosed Eel, is much thicker in the body in proportion to its length, and fishermen can distinguish this species readily when fishing in the dark by its more soft and unctuous feel in the hand.

The term Grig is, however, in and about London, applied to a particular Eel of small size, of which the figure here introduced represents the head. This Eel is

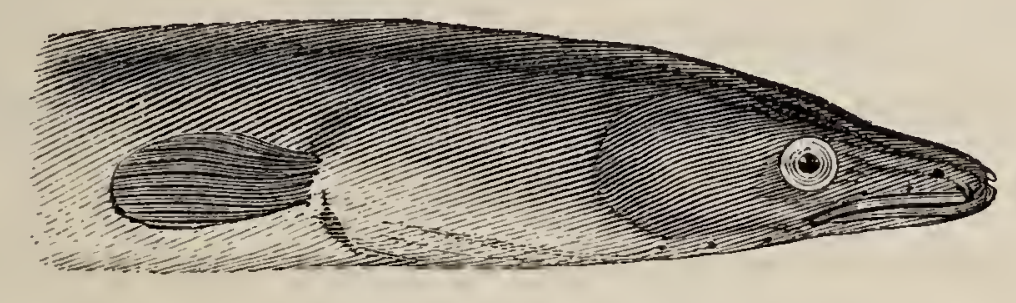

the Anguille plat-bec of Cuvier, Règne Animal, tom. ii. p. 349, who considers it a distinct species. It is the Grig Eel also of Mrs. Bowdich's British Fresh Water Fishes, No. 28, in which work the three Eels already spoken of here are well figured; and the species were considered by Cuvier as identical with those of the Règne Animal. 'The name Grig is also applied by Thames fishermen to any small-sized Eel of any species when not longer than eight or nine inches, and of which eight or ten are required to make up a pound weight.

In a Broad-nosed Eel of twenty-two inches in length, three distances taken from the point of the lower jaw are to the whole length as follows:- to the upper part of the base of the pectoral fin, as two to thirteen ; to the com- 
mencement of the dorsal fin, as one to three; and to the commencement of the anal fin, as ten to twenty-two.

The Broad-nosed Eel has the head rounded at the back part, and flattened from the eyes forward; both jaws broad and blunt; the lower jaw the widest, and longer than the upper: nostrils double, one tubular, the other a plain orifice; the gape large; the lips fleshy: teeth more numerous than in either of the other British fresh-water species, larger, stronger, and forming a much broader brush-like band on each jaw : the eyes large, placed before the line of the gape, and having a more vertical aspect than those of the sharp-nosed species; irides golden yellow: the gill-openings, pectoral fins, the commencement of the dorsal fin, and the vent, placed farther back than in the Sharp-nosed Eel; dorsal and anal fins also much deeper and thicker; the tail broad and rounded; the body of the fish thicker for the same length than in other Eels : the number of vertebræ 115.

The colour of the upper surface of the body is a darkgreenish brown, subject to some variation, depending on locality, soil, and the quality of the water.

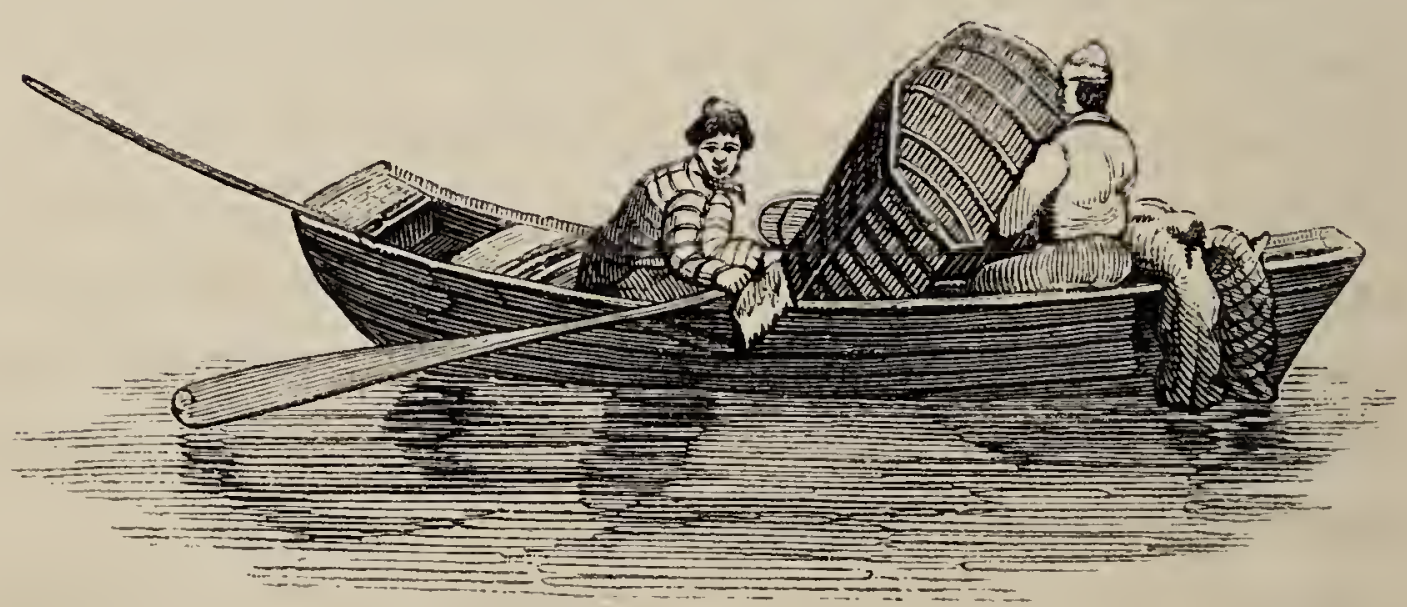




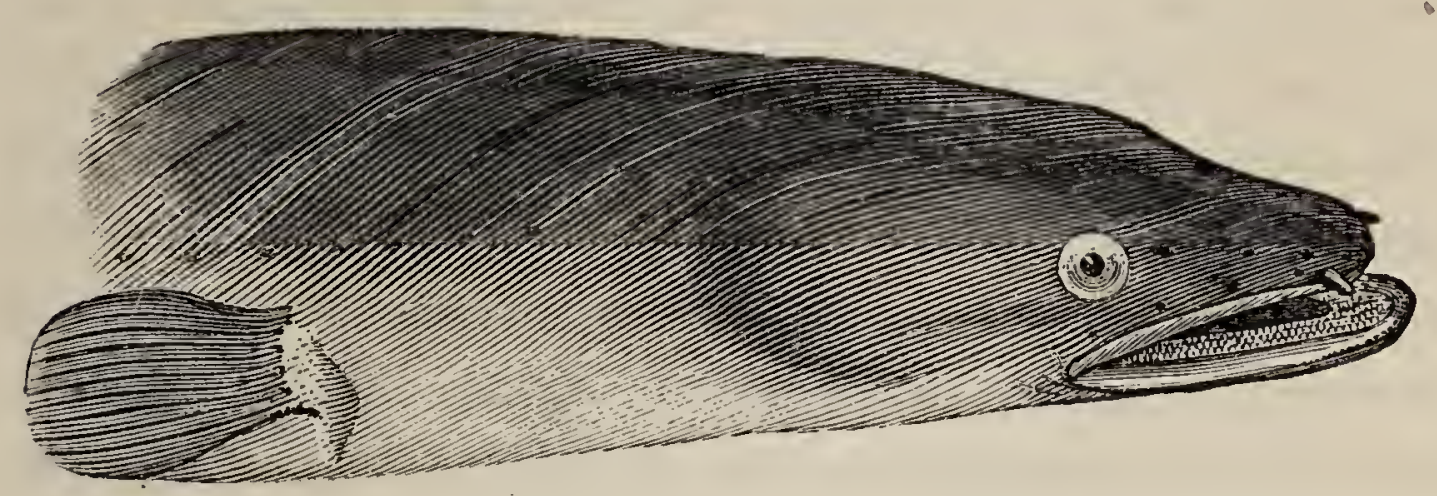

THE SNIG.

Anguilla mediorostris, Snig Eel, Yarreul. Jesse, Glean. Nat. Hist. 2nd Series, pp. 75 and 76 .

I A $\mathrm{M}$ indebted to the kindness of Mr. Jesse, and his friend, Francis Mills, Esq., for the first specimens of this Eel I have seen; and from some differences in its external characters, in its habits, and also in the comparative size of the head, as well as some peculiarity in the five cervical vertebræ that are nearest the head, I believe it to be a different species from either of those previously described in this work.

The specimens I have had were from the Avon in Hampshire, where this Eel, rather remarkable for its yellow colour, is called the Snig, and is considered distinct from the other well-known and more common Eels.

Dr. Hastings, in the Appendix to his Illustrations of the Natural History of Worcestershire, page 135, says, that besides an Eel called the Frog-mouthed Eel by the fishermen, from the extraordinary width of the mouth,identical, probably, with the Broad-nosed Eel of this work,- " there are two distinct kinds of Eels in the Worcestershire Avon, the Silver and Yellow Eel," which last may be similar to the Snig of the Avon of Hamp- 
shire. The term Snig, it should, however, be stated, is in some counties a general name for any sort of Eel; and a particular mode of fishing for Eels, which is described in most of the works on Angling, is called Sniggling. The fishermen make a certain difference in the mode of placing their eel-pots when they are desirous of catching Snigs; finding by long experience that the Snigs get into those pots the mouths of which are set in the opposite direction, in reference to the stream, to others in which the common Eels are taken.

The Hampshire Snig differs from our other Eels in its habit of roving and feeding during the day, which other Eels do not. It is considered excellent as an article of food, and of a superior flavour to other Eels : it does not, however, attain a large size, seldom exceeding half a pound in weight.

In the comparative breadth of the nose, the Snig is intermediate in reference to the Sharp and Broad-nosed Eels, but rather more resembles that with the sharp nose; it has a slight but elongated depression extending from the anterior edge of the upper jaw to the upper and back part of the head; the tubular openings of the nostrils are longer, and the mucous pores about the lips larger and more conspicuous; both jaws rounded at their extremities, the lower one the longest; teeth longer and stronger than in the common sharp-nosed species; gape large; the angle and the posterior edge of the eye on the same vertical line; the pectoral fins, the commencement of the dorsal fin, and the vent, are each placed nearer the head than in either of our fresh-water Eels. The general colour olive green above, passing by a lighter green to yellowish white below.

The vignette at the bottom of the next page represents correctly the relative size and power of bone in each of 
our three species of Eel. The cranium on the left is that of the Broad-nosed Eel; that in the middle is from the Snig; the head on the right hand is from the Sharp-nosed Eel, prepared from individuals which were exactly of the same length when alive. It will be seen that, independent of some difference in the length and form of some of the bones, as well as in the size of the head in the middle, belonging to the Snig, as compared with that on either side, there is a characteristic distinction in the form of the bones of the vertebral column. The first five cervical vertebræ are smooth and round, entirely destitute of superior or lateral spinous processes, both of which are possessed by the other two, of a size corresponding to the character of the vertebral bone itself to which it belongs. With this exception, the skeleton of the Snig most resembles that of the Sharp-nosed Fiel; but is somewhat stronger, and particularly so in the processes of the other vertebræ generally.
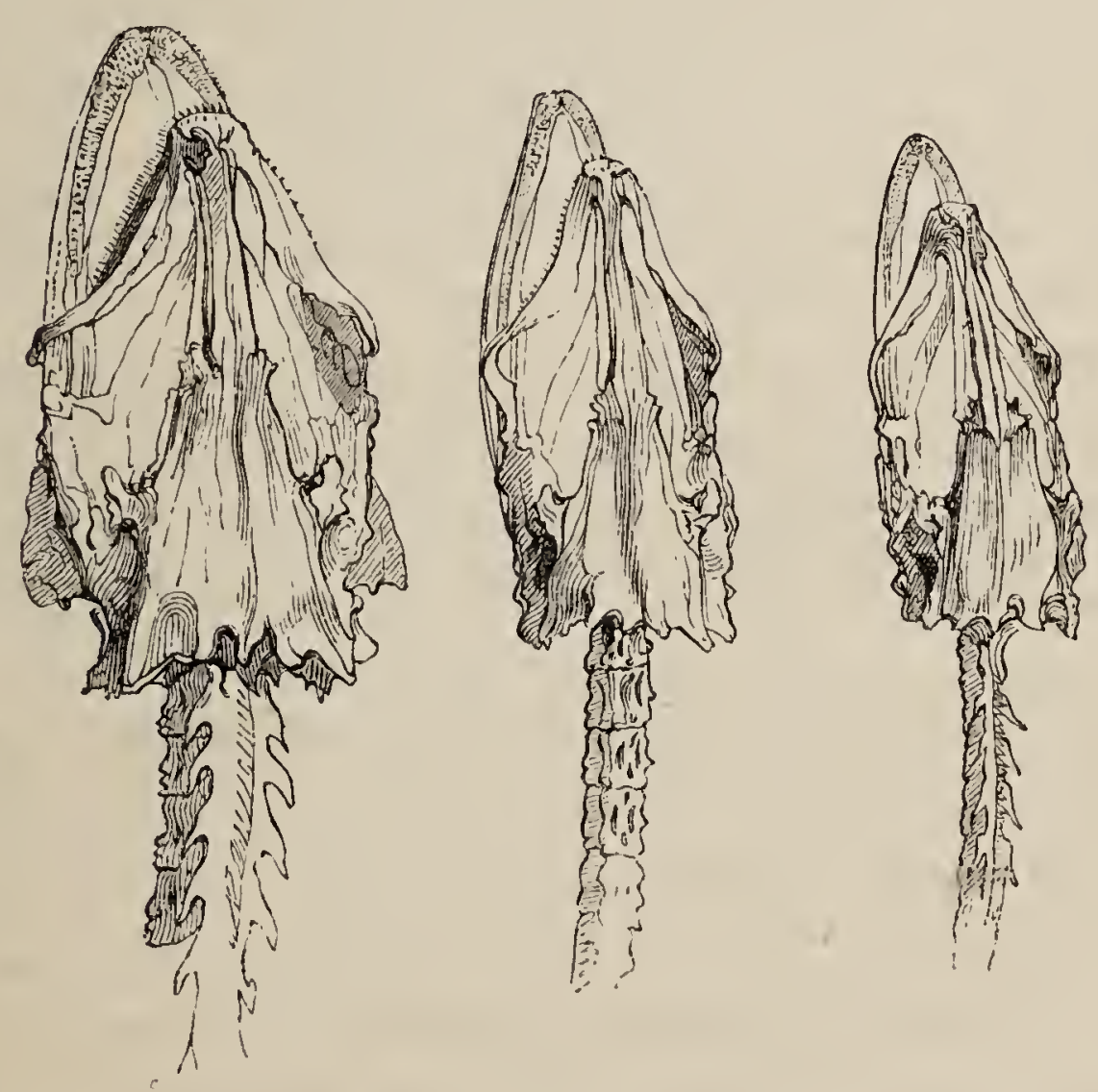

APODES.

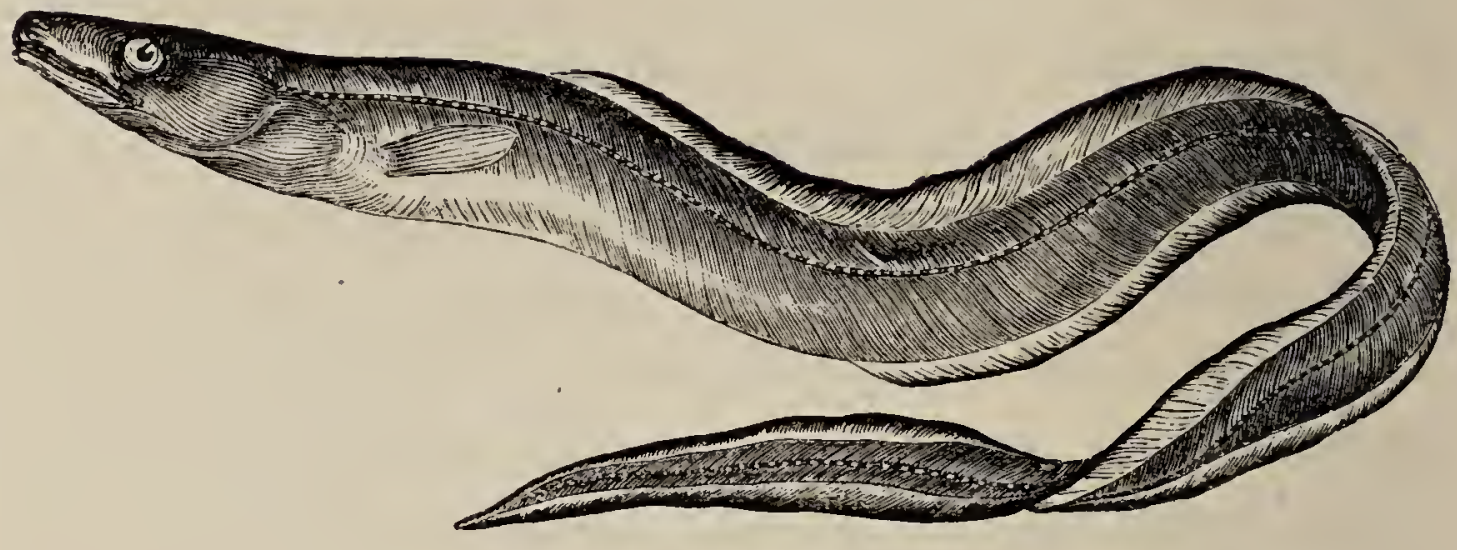

\section{THE CONGER.}

Conger vulgaris, Le Congre, Cưvin, Règne An. t. ii. p. 350.

Conger, Willughis, p. 111, G. 6.

Murcena Conger, ,, Lrinæos. BLoch, pt. v. pl. 155.

$\begin{array}{cccl}, " & , & \text { Conger Eel, Penn. Brit. Zool. vol. iii. p. } 196 . \\ ", & , & , & \text { Don. Brit. Fish. pl. 119. } \\ \text { Anguilla } & , & , & \text { Fuem. Brit. An. p. 200, sp. } 110 .\end{array}$

Congeride. Family Characters.-Dorsal beginning near the head; skin withont scales; snout generally projecting beyond the lower jaw. Pectoral fins absent in some genera, in others present.

Conger. Generic Characters.-Anterior nostrils issuing in short tubes near the end of the snout; posterior nostrils opening before the large eyes. Palatine and vomerine teeth slender, but chisel-pointed and standing closely together, so as to produce an incisorial edge. Skeleton very different from that of Anguilla, the spinous and other vertebral processes being much more complicated.

The Conger Eel is a marine species well known on all the rocky parts of the coast of the British Islands, but nowhere more abundant than on the coast of Cornwall. Mr. Low says, "It is found very frequently round the Orkney Islands : some are caught at the fishermen's lines; but the otter is by far the most successful in killing 
Congers. He brings them ashore, and eats but a very small part, leaving the rest for the next comer; and where his haunts are known, the country people are very careful every morning to search for the remains of the night, and are seldom disappointed, but find Cod, Ling sometimes, but especially Congers, which are oftener seen amongst the deep hollows of the rocks than farther to sea.". Dr. Neill and Dr. Parnell say this species is taken in the Forth, and finds a ready sale in Edinburgh market.

The Conger is frequently caught at various rocky parts of our eastern coast, and I have known specimens of large size taken in winter about the mouth of the Thames. Congers are caught by bulters, or long-lines, and handlines-modes of fishing already described, and the most esteemed bait is the Sand-launce. "So well assured," says Colonel Montagu, "are the French fishermen of the advantage derived from the use of this little fish, that the fishing boats in times of peace run over from the coast about Dieppe to Slapton Bay, on the south coast of Devon, to purchase Launce; and for that alone do some of our fishermen keep fine nets for the purpose of supplying bait to these foreigners, for which they obtain about twenty-pence the bushel. Some principal Conger banks lie off the French coast, from which a prodigious quantity are taken to feed the poorer classes on maigre days."

The principal fishery for Congers in this country is on the Cornish coast; where, according to Mr. Couch, it is not uncommon for a boat with three men to bring on shore from five hundred-weight to two tons, the fishing being performed during the night; for this fish will not readily take a bait by day, and even on moonlight nights it is more shy than when in the dark, except in deep 
water. The most usual bait with the Cornish fishermen is a Pilchard. The Congers that keep among rocks lide themselves in crevices, where they are not unfrequently left by the retiring tide; but in situations free from rocks, Congers hide themselves by burrowing in the ground.

The flesh is not in much estimation, but meets a ready sale at a low price among the poorer classes. Formerly a very considerable quantity was prepared by drying in a particular manner, and exported to Spain: Bayonne also received a part. When thus dried, the flesh was ground or grated to powder, and in this state was used to thicken soup.

Congers spawn in December or January; and the distinction of the sexes is obvious on the examination of the roe during the cold months. Small ones, about the size of a man's finger, are found among rocks, close to land, during the summer. The small Eels which ascend the Severn in such numbers in the spring, and were considered by Willughby and Pennant as the young of the Conger, are in reality the young of fresh-water Eels.

The adult fish is most voracious, not sparing even those of its own species. From the stomach of a specimen weighing twenty-five pounds, I took three common Dabs, and a young Conger of three feet in length. The power of the jaws in this fish is very great: in the stomach of small specimens examined on the coast, I have found the strong testaceous coverings of our shell-fish comminuted to fragments. They are often tempted by the crustacea entrapped in the lobster-pots to enter those decoys in order to feed on them, and are thus frequently captured. •

Congers acquire a very large size. Specimens weighing eighty-six pounds, one hundred and four pounds, and 
even one hundred and thirty pounds, have been recorded, some of them measuring more than ten feet long, and eighteen inches in circumference. They possess great strength, and often prove very formidable antagonists if assailed among rocks, or when drawn into a boat on a line. The tip of the tail is sufficiently prehensile to take hold of the gunwale of a boat, and enable the fish thereby to throw itself over and escape into the sea.

Three measurements taken from the point of the nose, as in the fresh-water species, give the following proportions in reference to the whole length:-the distance to the origin of the pectoral fin is as two to thirteen; to the commencement of the dorsal fin, as one to five; and to the vent, as two to five.

The head is long and depressed: the upper jaw the longest; both jaws furnished with strong teeth, forming a broad band in each: the lips fleshy: the nostrils double; the most anterior near the edge of the lip, and tubular; the other a simple orifice: numerous mucous pores about the parts of the mouth and head: the mouth deeply divided, making the gape long, its angle in a vertical line with the posterior edge of the pupil: the eyes large; body nearly cylindrical; dorsal fin commencing immediately behind the pectorals, extending along four-fifths of the whole length of the body; anal fin commencing immediately behind the vent, and extending along threefifths of the whole, and joining the dorsal fin, forms a pointed tail.

The colour of the upper surface of the body is a uniform pale brown, becoming lighter on the lower part of the sides, and passing into dull white underneath; the dorsal and anal fins whitish, edged with black; lateral line almost white; but the colour varies, depending on the situation from which the Conger has been taken. 
The notion entertained by some, that river Eels on going to the sea remain there and become Congers, scarcely requires a serious remark. No one who looks for specific distinctions can fail to observe them when comparing either of our fresh-water Eels with the Conger. These differences, which extend to colour, form of body, and situation of fins, receive further confirmation on examining their internal structure: independent of comparative difference of relative position of some of the most important of the viscera, the greatest number of vertebræ found in our fresh-water Eels is 116, those of the Conger amount to 156 .

In the beginning of February of the present year, 1841, large quantities of the Sharp-nosed Eel were killed by frost in the river Logan at Belfast, in the Bay at Dundalk, and also in the Lee below Cork: the last were Conger Eels. A similar occurrence took place in January, 1814.- See Annals of Nat. Hist. vol. vii. pp. 75 and 236.

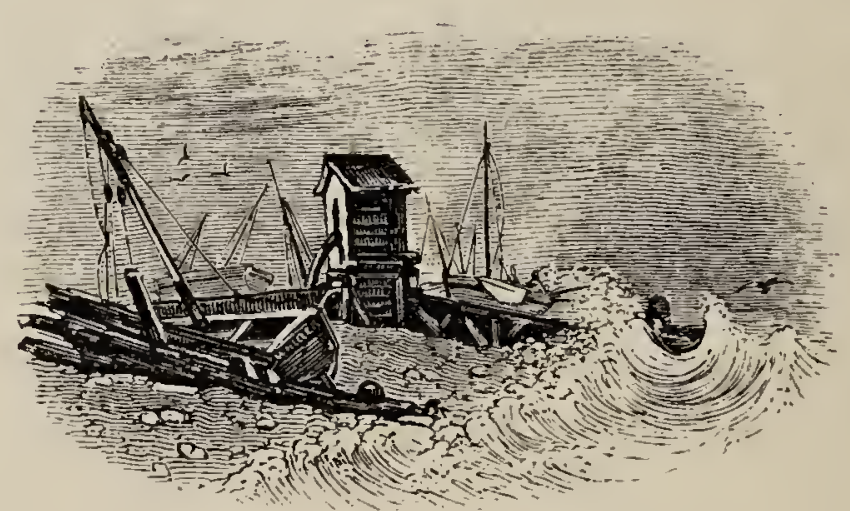




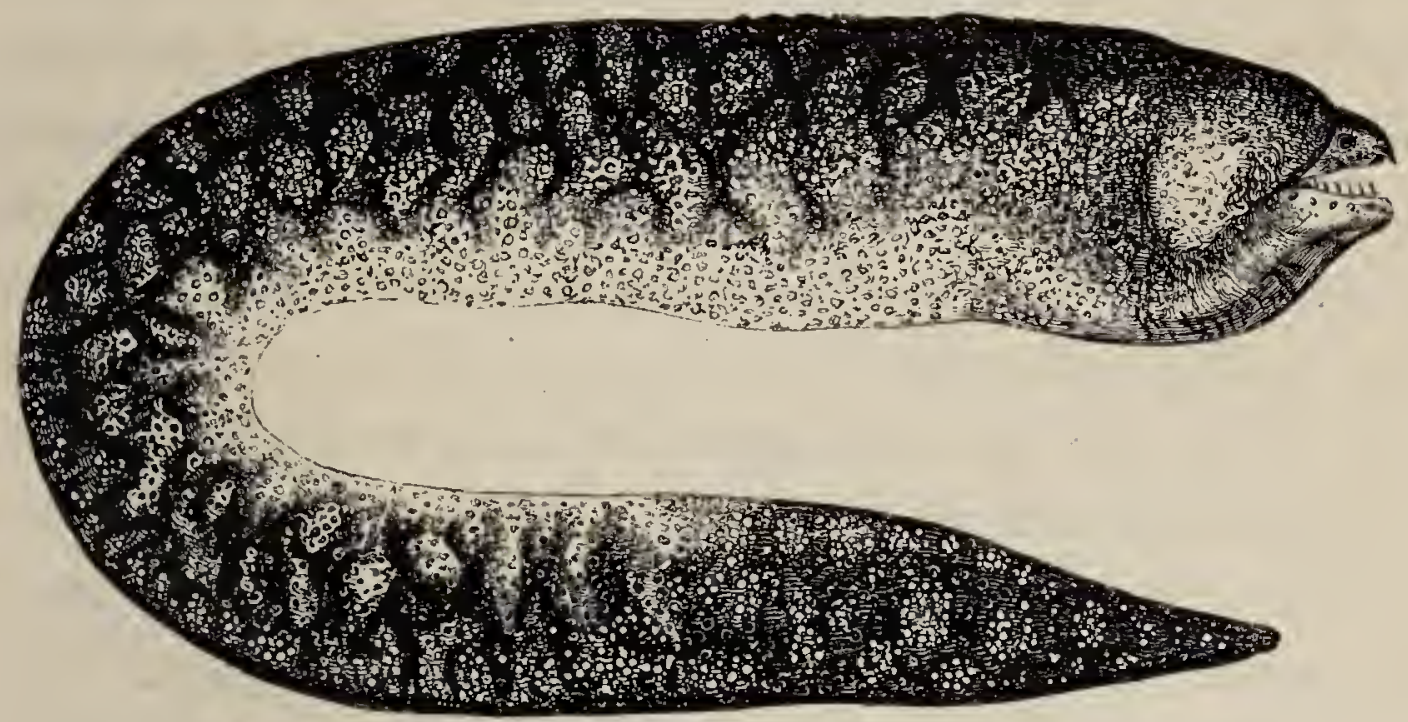

\section{THE MURRY.}

Murcena Helena, Linneus. Bloch, pt. v. pl. 152.

", " La Murène, Cuvien, Règne An. t. ii. p. 352.

", "The Murcene, Covch, MS.

", ", JenYNs, Brit. Vert. p. 479.

Muranides. Family Characters. - No pectoral fins: lateral, slit-like gillopenings. Skin smooth, scaleless.

Murena. Generic Characters. - Uniserial teeth on the nasal bone, three on the mesial line.

Mr. Couch is the only British naturalist I have heard of who has obtained an English example of this beautifully-marked species, which inhabits the seas of both hemispheres. The following is Mr. Couch's account, copied from his MS. :-

A specimen, the first on record as a British fish, was caught by a fisherman of Polperro, October 8, 1834. Its length was four feet four inches; body very flaccid, rounded anteriorly, compressed, and tapering towards the tail: the whole body seemed plump. Before the eyes it 
is slender and sharp; jaws equal; gape moderately large; teeth long, incurved, sharp, separate, in one row, a row on the palate; tongue adherent, scarcely perceptible; a nasal tube on each side of the end of the snout, another a short distance above each eye, and a probe passed down the latter found its way out at the former; large mucous orifices encircle both jaws at equal distances, four on each row. Eye rather small, one inch and one quarter from the snout; irides light bluish grey, having a lively look; cheeks tumid; an extensive depression at the side of the thorax, in which is the simple orifice of the gills; the external appearance of the branchial aperture very much resembles one of the stigmata of the Lamprey: from the snout to the branchial opening, six inches; from the part above the eye the head is much elevated; the skin wrinkled; thorax remarkably protuberant; the distance from the top of the head to the thorax five inches and three-quarters. The vent is exactly half-way between the two ends of the body, from whence proceeds a line to the end of the tail parallel to the anal fin, and half an inch from its base: this line must be the lateral line, since there is no appearance of any other. The dorsal fin begins five inches and a half from the snout, and proceeds round the extremity of the body to join the anal, which begins at the vent; but these fins are thick and fleshy, and not readily distinguished from the margin of the body.

The ground colour of the anterior part of the body is a fine lively yellow, the hinder part a fine purple; but the whole, including the fins, is divided into segments, forming irregularly-shaped spots, which yet have a tendency to regular distribution; towards the tail the yellow spots more resemble irregular rings, with larger spaces between them; the whole is interspersed with innume- 
rable spots of whitish and deep yellow, golden brown, and purple, forming a most beautiful arrangement: under the thorax and to the gill-opening are a few lines marked in the skin as if to facilitate motion, though the skin is exceedingly smooth and soft; it is strong also, and the colours were remarkably slow to fade, contrary to what is observed in most fishes. This specimen was taken with a line, and manifested great strength after it was taken on board the boat.

Of this singular and beautifully-marked fish Mr. Couch very kindly sent me for my use a coloured drawing made from the fresh specimen, from which the figure on the preceding page, carefully reduced in size, was drawn and engraved. The species is distinguished from most of its congeners by both its nostrils being tubular.

This Muræna is considered very common in almost every part of the Mediterranean.' It was a great favourite with the ancient Romans, who preserved large quantities of them in their numerous vivaria, where they were fed with great care. On the celebration of one of his triumphs, Cæsar distributed six thousand specimens of this Muræna among his friends.

The flesh is said to be delicately white, and very agreeable eating. In the Mediterranean it is fished for with lines. It is very voracious, and its bite is very severe, which, from the nature of the teeth, and the large size of the muscles about the head, might be expected.

This fish is said to live with equal facility in fresh or salt water, though generally found at sea, and it is as common in the Chinese and Australian seas and in Polynesia, as it is in the Atlantic and Mediterranean. 


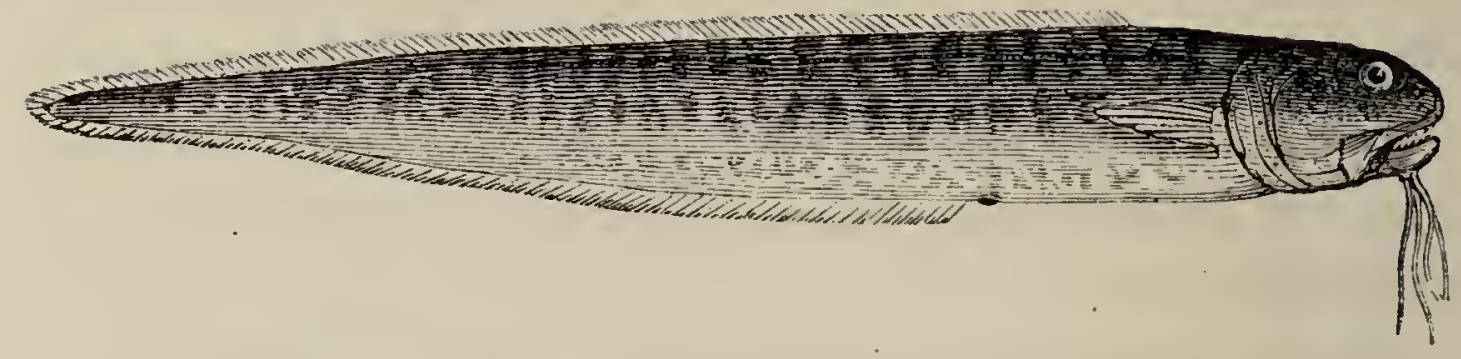

\section{THE BEARDED OPHIDIUM.}

Ophidium barbatum, Linn. BLoch, Ichth. pl. 159, fig. 1.

\begin{tabular}{|c|c|c|c|}
\hline , & , & Bearded Ophidium, & Berken. Syn. vol. i. p. 66. \\
\hline , & , & ," & Turton, Brit. Faun. p. 88. \\
\hline , & $"$ &,,$\quad$, & JenYns, Brit. Vert. p. 481. \\
\hline , & physoce & $\begin{array}{l}\text { Donzelle cornmune, } \\
\text { elum, }\end{array}$ & $\begin{array}{l}\text { Cuvier, Règne An. t. ii. p. } 359 . \\
\text { RAF. carrat. }\end{array}$ \\
\hline
\end{tabular}

Enchelyopus barbatus, KLEIN, Musc. iv. 52.

OpHidiug. Generic Characters. - Anus situated in the middle of the body, or at the end of its proximal third part of the length; two pairs of barbels attached between the limbs of the mandible to the point of the lingual bone. Feebly-developed dorsal and anal fins supported by simple rays. The oviform and thick swim-bladder is attached to three bones, which are suspended to the first pair of ribs, the middle bone being movable by its proper muscle.

\section{The Bearded Ophidium, a well-known Mediterranean} species, has been included by Berkenhout in his Catalogue of British Fishes; but whether on the personal authority of that author, or on what part of the British coast it was observed, or taken, no mention is made.

This fish was the subject of a paper by Dr. Broussonet, communicated by Sir Joseph Banks, read at the Royal Society, July 5, 1781, and printed in the Transactions. The author traces this species from Pliny to Belon, Rondelet, Willughby, Artedi, Klein, Linnæus, Gouan, and Brunnich. 
"The form of the body is seen by the figure. The direction of the mouth is ascending; both maxillary bones are furnished with teeth; the barbel on the chin is single at its origin, is soon divided once, and each division again forking, thus the appearance of four barbels is produced; the dorsal fin commences on a line nearly even with the end of the pectoral fin: the anal fin begins a little further backward; the scales are oval; the fish of a silvery flesh colour, appearing occasionally slightly mottled or spotted."

"This fish commonly grows to the size of eight or nine inches. It is found in most parts of the Mediterranean Sea, and in great plenty in the Adriatic. It is taken by nets in Provence and Languedoc, together with many other small species which are not esteemed-that is, what they call Ravailla. In Languedoc the Ophidium is called Donzella, and this is the most common name for it on the coasts of the Mediterranean. In summer the Ophidium is common; its flesh is not of a good taste, rather coarse, as that of all the species of fishes which, having no ventral fins, are obliged to make great efforts in swimming, and have consequently the muscles harder. The want of ventral fins induces me to believe that it is not a migratory species. It feeds upon small crabs and fishes."

The true position of the Ophidide in the ịchthyological scale has not been fixed by a satisfactory investigation of their structure. Following Cuvier we place them here in the vicinity of the Serpentiform Apodals. In their fins and other cuticular appendages they resemble the Gadidæ or Cod family, and have therefore been ranged by Rüppell and some other ichthyologists among the Anacanths. They have also been classed with the Blennies, to which they have considerable resemblance, especially to the arctic genus Lycodes. Dr. Kaup characterizes the family as 
comprehending apodal fishes having gadoid forms and sword-shaped bodies edged by the dorsal and anal fins, which are continued without a break to the point of the tail. They have a thin oblong stomach, without pyloric cæca, and generally an air-bladder.

His diagnostic character of this species is: "The two anterior barbels shorter. Flesh-coloured body, with black edging to the dorsal and anal fins. No scales on the gillplates." He characterizes four other species.

The vignette was copied from a sketch of a fishing party made by T. Stothard, R.A. about the year 1780 .

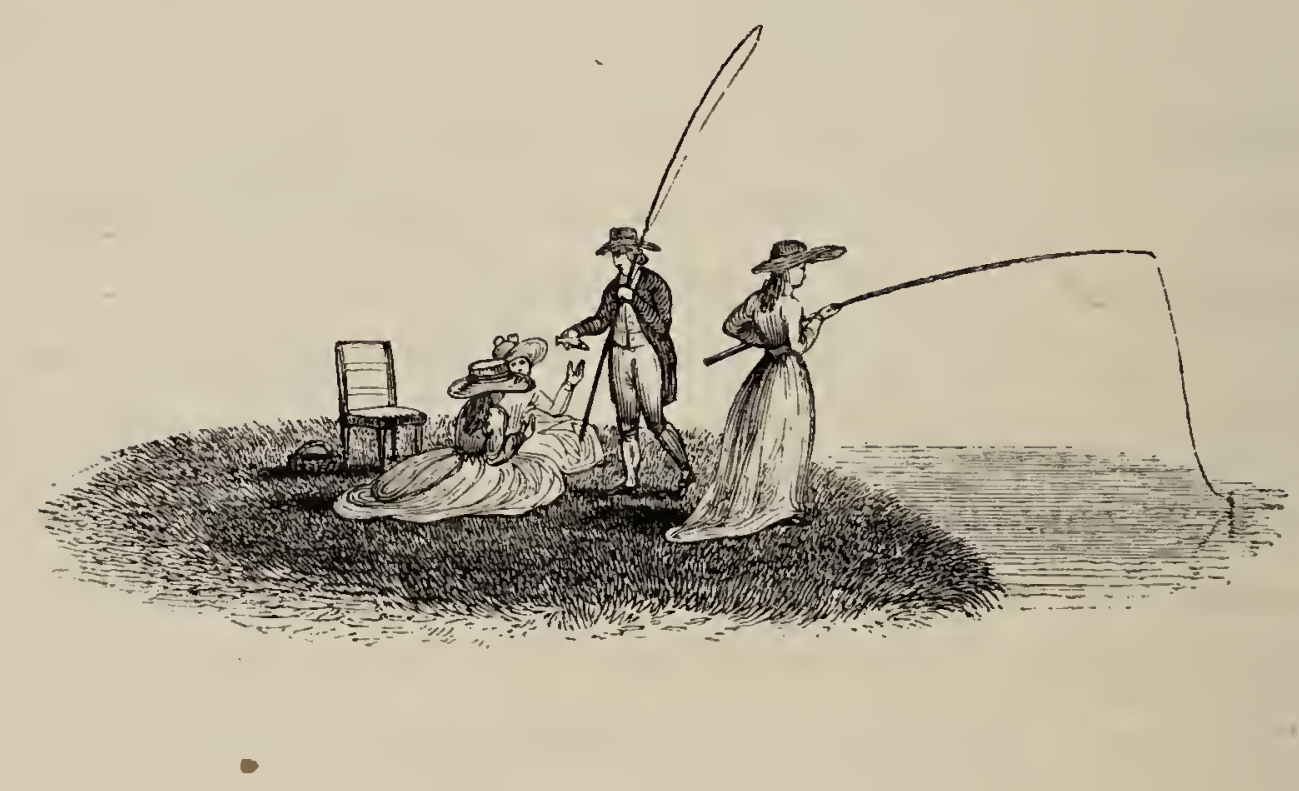




\section{THE BEARDLESS OPHIDIUM.}

Gymnelis (?) ReINIIARDT. KAUP, Cat. of Apodes.

Ophidium imberbe, Linnaus.

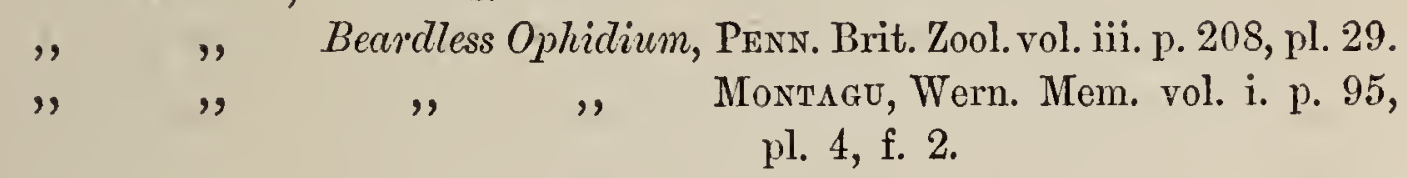

Gruneuis. Generic Character.-Ophidia destitute of barbels and scales.

Six branchiostegals.

The Beardeess Ophidium was first added to the catalogue of British Fishes by Pennant, to whom it was communicated by the Duchess of Portland: the specimen was found near Weymouth. Pennant gave a figure of his fish in the Appendix to the fourth volume of the British Zoology, edition of $177 \%$, but no description. Colonel Montagu afterwards obtained a specimen on the south coast of Devon, which is figured and described in the first volume of the Wernerian Memoirs, as quoted. The editor of the edition of Pennant's British Zoology, published in 1812, left out the figure of the Beardless Ophidium, given in the previous edition, but copied the figure and description of Colonel Montagu.

Never having seen a specimen of this fish, Colonel Montagu's figure and description are here given, with some additions to be hereafter explained.

"Length about three inches; depth about a quarter of 
an inch. The head is very obtuse, and rounded in front: eyes large, placed forward and lateral; irides dark, with a circle of silver round the pupil: mouth, when closed, inclines obliquely upwards; the lips are marginated: the gill-membranes inflated beneath. The body is ensiform, considerably compressed towards the tail, and in shape is not unlike that of Cepola rubescens, hereafter to be mentioned in this work; the lateral line is nearly in the middle, originating at the angle of the operculum to the gills but rather obscure : vent nearly in the middle: the pectoral fin is rounded; the dorsal fin commences immediately above the base of the pectoral, and is at first not so broad, and usually not so erect as the other part: the anal fin commences at the vent, and, together with the dorsal, unites with the caudal fin, which is cuneiform, but obtusely pointed. The colour is purplish brown, disposed in minute speckles; and along the base of the anal fin are about ten small bluish-white spots regularly placed, but scarcely discernible without a lens, and possibly peculiar to younger fishes : all the fins are like the body in colour, except the pectoral and caudal ; the first is pale, the last is yellowish." The fin-rays in number are-

\section{D. $77:$ P. $11:$ A. $44:$ C. 18 or 20 .}

"This fish," Colonel Montagu observes, "does not appear to be very tenacious of life, like some of the Blennies, as it was placed in a tin box with the Crested and Smooth Blenny, covered with wet sea-weed, and although these were lively, the Ophidium was dead before it could be got to his house. It died with its mouth shut, the pectoral fins thrown forward, and the body curved, a little near the vent, throwing the head upwards."

"Little can be said of the natural habits of this fish; 
but as it so rarely occurs, it is most probably an inhabitant of the rocky parts; in such a situation, at low water, the specimen here described was taken."

But little being known either of Montagu's or Pennant's Ophidium, the figure at the head of this subject is taken from Montagu's figure, and the outline at the foot of this page is taken from Pennant's first figure, which Schneider appears to have adopted as the representative of the genus Ophidium and which bears some resemblance to the Gymnelis viridis of the Greenland seas. This has generally one or more black spots edged with white on the dorsal.

Never having seen either of these species, for they are evidently distinct, any information of their appearance on our coast would be interesting to ichthyologists.

The genus Gymnelis differs from Fierasfer which follows, in the vent being pretty far back instead of in the pectoral region, and in the vomerine teeth being nearly even with those on the upper jaw, instead of projecting boldly from the roof of the mouth.

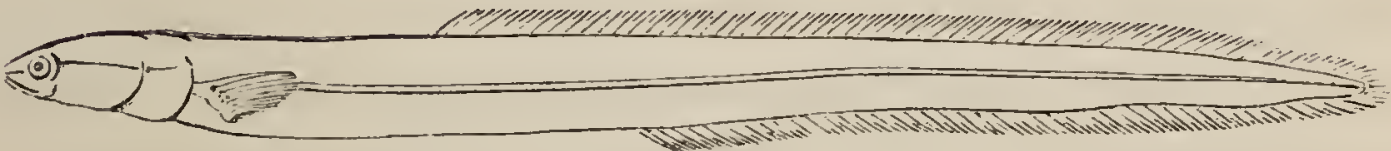

VOL. I. 


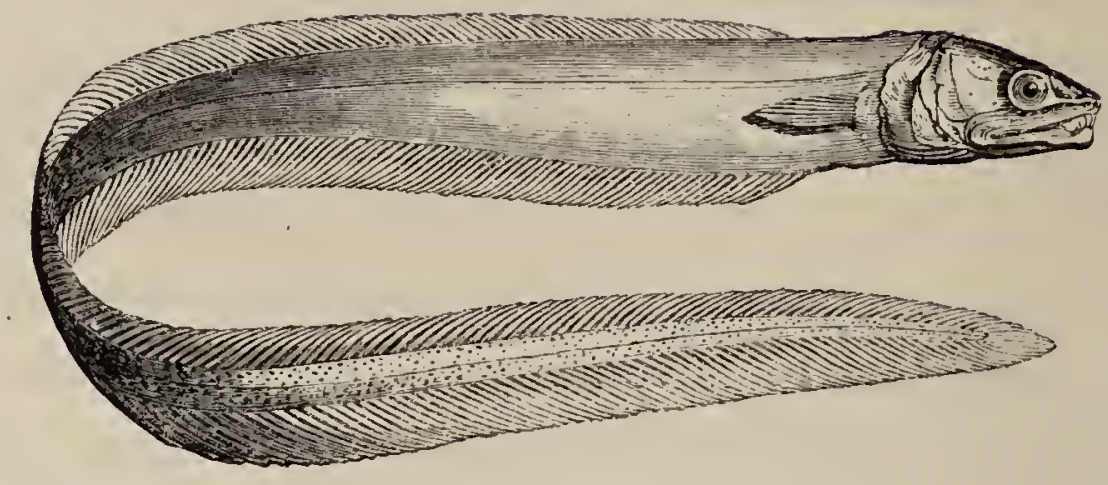

\section{DRUMMOND'S FIERASFER.}

Fierasfer dentatus, Cuvien, Règne An. ii. p. 359.

" , Kaup, Cat. of Apodes, Br. Mus.

Echiodon Drummondii, Thompson, Proceedings Zool. Soc. 1837, page 55.

, ", , Transactions ,, , vol. ii. part iii. p. 207 , plate 38.

Fierasfer. Generic Characters.-Head oval; jaws furnished with large cylindrical teeth in front, other smaller teeth on the palatal bones and on the vomer. Gill-apertures large; branchiostegous membrane with seven rays. Body smooth, without scales, elongated, compressed. Dorsal and anal fins nearly as long as the body; all the rays soft; no ventral fins; anal aperture in the pectoral region.

A DEAD specimen of the fish figured above was found by Dr. J. L. Drummond on the beach at Carnclough, near Glenarm in the county of Antrim, in the month of June 1836, and from its appearance when found it was conjectured that it had been cast ashore by the tide of the preceding night, when a strong easterly wind prevailed. The specimen was given by Dr. Drummond to his friend Mr. W. Thompson of Belfast; and being new in form to him he made it the subject of a communication to the Zoological Society, which appeared in the Proceedings and Transactions of that Society as here quoted.

This specimen, Mr. Thompson observes, "being, so 
far as known to me, unique, I have been unwilling to injure its appearance by dissection. In external characters it is excluded from the Ophidia proper in consequence of not having the barbels; and though agreeing with the Fierasfers in the negative character of wanting these appendages, yet, by having the dorsal fin strongly developed and elevated, it ranges not with them."

"Although when this fish first came into my possession, I saw that it might be classed under the Malacopterygii Apodes, and be placed near Ophidium, I considered that in a natural arrangement it would best constitute a rew genus of the family Trenioidece (Riband-shaped). In being apodal it was not excluded from this family, as two genera belonging to it are destitute of ventral fins. I did not hesitate to place it under the Acanthopterygii, as some genera which are included in this order are, like it, strictly Malacopterygian, their natural connection with genera having fins with spinous rays being considered-and in my opinion most philosophically - to outweigh this character; and further, I felt less reluctance in thus placing it, in consequence of Cepola rubescens, with which it assimilates in some respects, having but one spinous ray, and that in the ventral fin. At the suggestion of John Edward Gray, Esq., F.R.S., I have, however, reconsidered the subject, and have come to the conclusion here advanced."

As a difference of opinion may still exist with regard to the position of this genus, I think it due to $\mathrm{Mr}$. Thompson to subjoin the observations originaliy made. " "Like certain other genera which are comprehended under Acanthopterygii, the first order of the osseous fishes, its fins are altogether destitute of spinous rays; but, like those alluded to, such as Zoarces, \&c., its other character's seem to point out the Tanioides as the family to which it belongs. Of the eight genera of Tanioides already 
known, viz. Lepidopus, Trichiurus, Gymnetrus, Stylephorus, Cepola, Lophotes, Trachypterus and Alepisaurus, the specimen under consideration agrees with Trichiurus and Stylephorus in being apodal, or wanting ventral fins, but in this character only is there any generic accordance. Though considerably more elongated, from the head posteriorly it approaches most nearly to Cepola rubescens in the form of the body, and in the forward commencement of the anal fin which, with the dorsal, is prolonged until it joins the caudal; but it is only in the continuity of these fins until this junction is effected that the resemblance holds, for in my specimen the dorsal rays, the five foremost of which are very short, increase in length posteriorly, and near the caudal fin are about three times as long as the depth of the body beneath them; in the anal fin, which is throughout much deeper than the dorsal, the rays likewise increase posteriorly; and near the caudal are in length four times greater than the depth of the body at the same place. The length of the posterior rays of these fins causes the dorsal, anal, and caudal, to appear as one; whilst, though they do join in Cepola rubescens, the last ray of the dorsal and anal being much shorter than the outer rays of the caudal, may at the same time be said to mark distinctly the termination of each fin. In my specimen the anal fin originates two lines in advance of the dorsal fin."

In the form of the head, and in dentition, it differs so remarkably from the genera named above as to render a comparison with them unnecessary. Its absolute characters must suffice for distinction.

Description.- "Total length eleven inches; greatest depth at one inch four lines from the snout, six lines, thence posteriorly gradually narrowing; greatest breadth of body anteriorly three lines; at the middle of the 
entire length, one line; and thence to the tail becoming gradually more compressed. Head one inch two lines long, or rather more than one-ninth of the entire length; profile sloping forward equally on both sides to the snout, which is truncated, and projects one line beyond the lower jaw; narrow, increasing in breadth very gradually from the snout, its breadth compared to its length as one to three and a half; height half its length, compressed at the sides, and rather flat above from the eyes backward; from the eyes forward a central bony ridge: snout viewed from above somewhat bifid, in consequence of the forward position of the large teeth on each side. A few large punctures extend from the snout below the eye, and are continued just behind it; a series of small ones closely arranged extend from the upper portion of the eye in a curved form posteriorly to near the edge of the preoperculum, and thence a double row extends downwards. Nostrils very large, placed just in advance of, and before the centre of the eye, and in form a somewhat oval transverse aperture. Eye large, occupying the entire half of the depth of the head; its width greater than its height; occupying the place of one in four and a half in the length of the head; its distance from the snout three lines, or equal to its diameter, consequently two and a half of its diameters are contained between it and the edge of the operculum. Operculum rounded at the base, terminating in a minute point directed backwards, strongly radiated, striæ distant; preoperculum ascending vertically; cheeks smooth and soft. Mouth rather obliquely cleft. Teeth, two large strong ones, placed close together, and curving inwards at each side of the extremity of the upper jaw, the inner two one-sixteenth of an inch apart. In the lower jaw one slender rounded tooth, nearly one line long on each side, curving 
outwards at the base, and inwards at the point. Enitire upper and under jaw and vomer densely studded with small bluntish teeth, nearly uniform in size; vomer extending far forward, and very much developed, fitting into a cavity in the lower jaw, and in advance of the tongue when the mouth is closed; a series of rows of teeth similar to those last described on the palatal bones: all the teeth of the upper jaw exposed to view when the mouth is closed. Tongue short, not reaching within two lines and a half of the extremity of the lower jaw, and apparently toothless. On the dorsal ridge, one inch from the snout, or two lines and a half behind the cranium, is a short, stout, bony spine, not very conspicuous, and excepting at its extreme point, covered with skin : it is six lines in advance of the first ray of the dorsal fin. Scales none, but it may have been divested of them during its short exposure on the beach. Lateral line inconspicuous, being a slight depression extending in a straight line along the middle of the sides posteriorly, or throughout the greater portion of its length, but anteriorly nearer to the dorsal than the ventral profile. Vent one inch three lines from the extremity of the lower jaw. Branchiostegous membrane opening forward to rather before the extremity of the gape. Dorsal fin commencing one inch six lines from the snout, low at its origin, but gradually increasing in height to near the caudal fin, which it joins, the two or three anterior rays, which are very short, flexible and simple, the remainder articulated. The anal fin originates just behind the vent, or at one inch three lines from the point of the lower jaw, joins the caudal fin, near to which it increases in depth posteriorly from its origin, deeper, than the dorsal fin throughout; at about one inch and a half from the caudal fin the rays are in length four times greater than the depth of the body at the same place; 
the opposite rays of the dorsal fin being three times the depth of the body; the first and second anterior rays flexible and simple, the remainder articulated. The pectoral fins originate one line behind the head, and are equal to half its length, central rays longest, all very flexible, placed below the middle of the sides. Caudal fin, central rays longest. Articulations of the rays of all the fins very long; no branched rays in any fin.

\section{B. 7 : D. 180 : P. $16:$ A. 180 : C. 12.}

The number of the fin-rays were reckoned with the greatest care; but without injury to the specimen they could not be ascertained with certainty to a single ray. 'The vertebræ, which are distinctly visible through the skin can be reckoned with accuracy, ninety-eight. Colours, anterior half a dull flesh colour, similar to specimens of Cepola rubescens preserved in spirits, hence it is presumed to have been originally red; behind this portion reddishbrown markings appear on the body at the base of the dorsal and anal fins, and suddenly increase in number, until from an inch behind the middle, the whole sides are closely marked and spotted over; the entire top and the sides of the head before the linder line of the eye are similarly spotted; just behind the cranium a few spots also appear; the posterior rays of the dorsal and anal, and the entire caudal fin, blackish. Irides, operculum, and under surface, a short way beyond the vent, bright silver." " The two large teeth, resembling serpents' fangs, which terminate the upper jaw on each side, have. suggested the generic appellation of Echiodon; and the specific name of Drummondii is proposed in honour of its discoverer."

A second specimen has more lately been found on the same coast.

A Tasmanian species of this genus described in the 
Ichthyology of the voyage of the Erebus and Terror under the name of Oxybeles enables us to add one or two particulars of internal structure which Mr. Thompson could not give without mutilating the solitary specimen. Vertebræ 99, of which 19 are abdominal. Stomach a large conical, cæcal sac, with the pylorus near the oesophagus and most of the viscus beneath it. Spleen roundish and rather large attached to the cæcal point of the stomach. Air-bladder long, passing considerably beyond the anus. Bony operculum stellately tripartite. The genus Encheliophis of Müller, which belongs also to this family, is abrachial as well as apodal.

The figures below represent a side view of the head of the Irish fish, the mouth open to show the form and situation of the teeth, enlarged; and a front view of the anterior terminal teeth, also enlarged. The illustrations here used are derived from Mr. Thompson's paper in the Transactions of the Zoological Society already quoted; and I with pleasure avail myself of the opportunity in this instance afforded me of recording my obligations to Mr. Thompson for his kind and zealous co-operation in zoology, and particularly for the loan of this rare specimen, and many other Irish fishes, for examination.
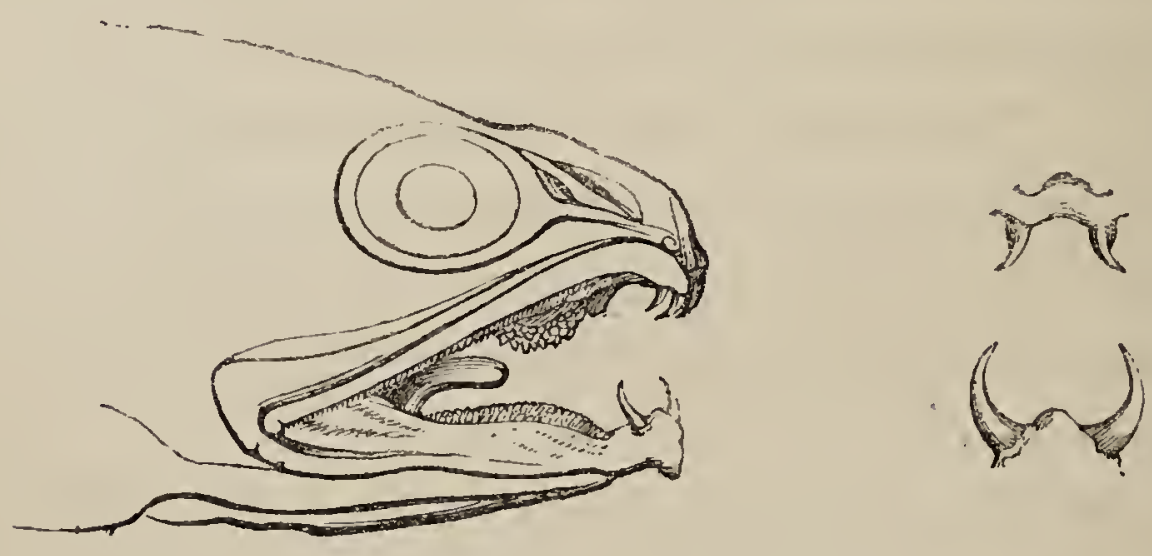


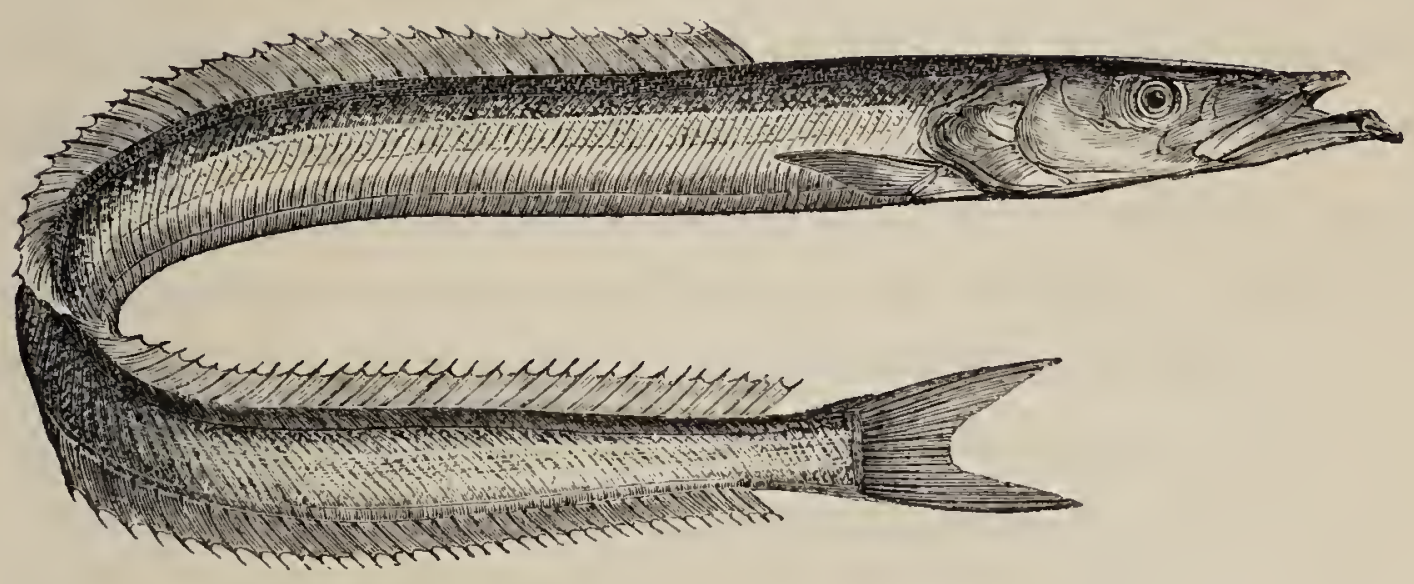

THE SAND-EEL。

HORNELS, (HORNEELS?) Edinburgh.

GREAT LANT, Cornwall.

A mmodytes Tobianus, Le Lançon, Cuvier, Règne An. t. ii. p. 360.

" $\quad$ Linneus. Bloch, pt. iii. pl, 75, fig. 2.

", Anglorum verus, True Sand-Eel, JaGo. RAx, Syn. pl. 2, fig. 12.

", Tobianus, Wide-mouthed Launce, Jenyns, Man. Brit. Vert. p. 482.

"Sand-Eel, Don. Brit. Fish. pl. 33?

Ammodxtes. Generic Characters.-Head and body elongated; gill-openings large; dorsal fin extending nearly the whole length of the back; anal fin of considerable length; dorsal and anal fins separated from the caudal fin. No pyloric cæca : no swim-bladder; vertical fin-rays jointed, not branched.

The true position of Ammodytes in a natural arrangement has not yet been satisfactorily worked out, but authors generally have placed it next the Ophidida, and the Prince of Musignano has considered the genus to be the type of a family which he called Ammodytida.

We are indebted, says Baron Cuvier, to M. Lesauvage, of Caen, for pointing out the true distinctions in the two species of Ammodytes belonging to the shores of the 
Channel, A. Tobianus and A. lancea, the first of which is rare, but the second very common.

Our excellent naturalist and countryman Ray has given us, in his Synopsis, from Jago's Catalogue of Cornish Fishes, a good figure of the true Tobianus; but it was not, I believe, till the recent publication of $\mathrm{Mr}$. Jenyns' valuable Manual of British Vertebrate Animals, that any English Zoologist had admitted two species among British Fishes. Shaw, in his General Zoology, vol. iv. p. 81, plate IX, has figured both species, but with only one name, and but one description.*

Ray, in his short notice from Jago's Catalogue, calls his Ammodytes Anglorum verus the true Sand-Eel; and his figure leaves no doubt that his fish is the same as the $T_{0}-$ bianus of Linnæus, Bloch, and others. In the late Colonel Montagu's copy of Berkenhout's Synopsis of the Natural History of Great Britain, there is a note in Montagu's writing, which states, "That at Teignmouth a distinction is made between the Sand-Eel and Sand-Launce, by the size and superior length of the head and gills in the one; it is also said to be much more rare." The rarity and greater length of the head are both on the side of the Tobianus, or Sand-Eel, which, as far as my own observation goes, is more scarce than the smaller-sized species with the shorter head; I am therefore desirous of preserving the distinctive appellation of Sand-Eel to the longer fish, A. Tobianus, and continuing that of SandLaunce to the smaller species, bearing among naturalists the specific name of lancea. Mr. Couch states that he has seen Cornish specimens of $A$. Tobianus fourteen inches long.

M. Lesauvage gave the name of lanceolatus to the species which had been previously called Tolianus, his

* Both specimens are also figured by Klein. 
trivial name will therefore only be used as a synonym: Willughby's figure, G. 8, f. 1, appears to have been copied from Salvianus, and represents an Ammodytes with two small dorsal fins; I have not, therefore, referred it to either of our fishes.

The Sand-Eel is immediately to be distinguished from the Sand-Launce by its greater size, specimens now before me measuring twelve inches in length; Ray's fish was fifteen inches and a half long. It is further distinguished by the greater length of the head, and particularly. of the lower jaw; by the commencement of the dorsal fin being on a line with the end of the pectoral fin-rays : the dorsal fin of the Sand-Launce beginning in a line with the middle of the pectoral fin, and the head smaller and shorter, as shown in the two representations here given. The Sand-Eel is browner in colour and less transparent in appearance, when in hand, than the SandLaunce.

The habits of the two species are in many respects very similar, and will be more particularly referred to under Sand-Launce, which being exceedingly common on all our sandy shores, has afforded greater opportunities for observation.

Both species of Ammodytes are included by. Professor Nilsson among the fishes of Scandinavia; both species also occur in the Forth. Dr. Neill, in his account of the fishes of that locality, says, the Edinburgh fishermen call the large ones Hornels-probably an abbreviation of Horneels - in reference to the greater length of body and the horm-like elongation of the lower jaw, by means of which they are enabled to bury themselves in the wet sands of the sea-shore, from which they are scratched out with iron hooks for bait or sale.

Stephen Oliver the younger, in his agreeable Rambles 
in Northumberland and on the Scottish Border, when describing the fishing in the Tyne, says, Sand-Eels follow the young fry of the Coalfish into the harbour, and are frequently caught with the same bait as the Poodlers (young Coalfish), which is used in a manner similar to flyfishing for Trout. The common length of the Sand-Eel in the Tyne is from twelve to fourteen inches; and their jaws, by a peculiar conformation, admit of great expansion. They swim rapidly, and dash at a shoal of fry with the voracity and swiftness of a Pike. Mr. Couch says that a large specimen caught on a line by a Cornish fisherman had a small fish of its own species in its stomach. Both species occur on the sandy parts of the coast of Sussex, Hampshire, Dorsetshire, and Devonshire.

Mr. Thompson has recorded the Sand-Eel as taken in the North of Ireland. An Ammodytes is taken at Newfoundland and at New York, but what species it is remains uncertain; Dr. Storer has, however, obtained the Sand-Eel, A. Tobianus, in two localities near Boston in Massachusetts.

From the extreme point of the lower jaw to the posterior end of the gill-cover is to the whole length of the fish as one to four and a half; the depth of the body rather less than one-third of the length of the head; the lower jaw very much elongated, with a strong, indurated projection at the extreme tip; the upper jaw much shorter than the lower, with a strong forked tooth of two points descending from the vomer; the nostrils double; both open on each side on a line, one before the other, about half-way between the eye and the point of the nose: the eyes rather small; the posterior margin exactly half-way between the point of the under jaw and the posterior angle of the gill-cover: the shape of the body very nearly round; covered with small scales: the pec- 
toral fin arises under the posterior angle of the gill-cover, its length one-third that of the length of the head; the dorsal fin placed in a groove, with a prominent line extending along each side; the rays commence in a vertical line over the end of the pectoral fin-rays, and end near the tail; the lateral line indented and straight; the abdomen with three indented parallel lines extending to the anal aperture, which has another orifice behind it; along the whole line of the lower part of each side extends a narrow and slender membrane attached by one edge; the anal fin is about one-third of the whole length of the fish, ending short of the caudal fin, and nearly on the same plane as the dorsal fin; the tail forked.

The fin-rays in number are-

$$
\text { D. 55: P. } 15: \text { A. } 29: \text { C. } 17 .
$$

The irides, cheeks, gill-covers, lower part of the sides, and the abdomen, bright silvery; upper part of the head, back, and sides, light brown, reflecting tints of blue and green when held in different positions.

The vignette below represents the form of rake used to obtain Sand-Eels and Sand-Launce on some parts of the coast. A piece of strong iron wire, bent into the form of a sickle is, however, the more common instrument used.

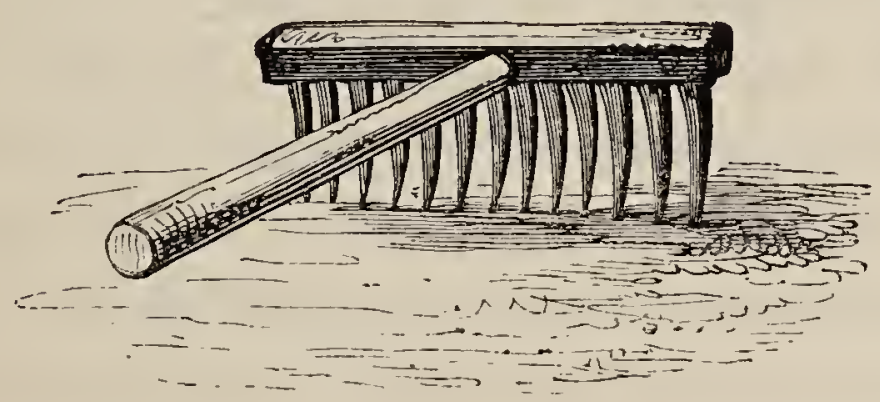




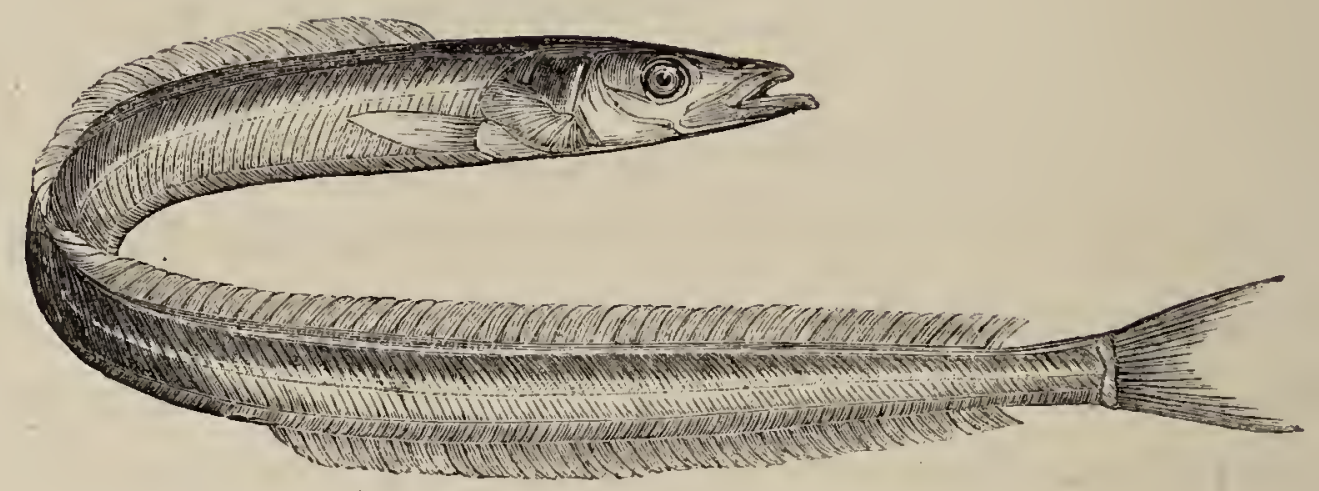

\title{
THE SAND-LAUNCE.
}

\author{
THE RIGGLE, Sussex Coast.
}

Ammodytes lancea, L'Equille, Cuvirer, Règne An. t. ii. p. 360.

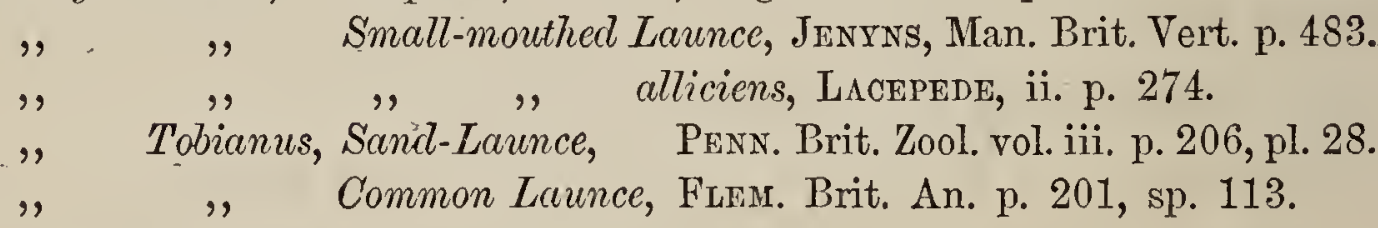

The Sand-Launce, as previously stated, is very abundant on many parts of the shore of the British Islands. On account of its silvery brightness, it is in great estimation and constant use with fishermen as bait for the hooks of their sea and hand lines; and the habit peculiar to the species of burying themselves in the wet sand as the tide recedes affords easy means of capture. The generic term Ammodytes refers to this power of digging in sand. With the projecting portion of the under jaw, aided by the muscular power of the fish, and its slender form, it is enabled to bury itself with rapidity five or six inches deep in the soft sand as the ebbing sea retires, and releases 
itself again on the approach of the ensuing flood-tide, apparently uninjured, though deprived of water for several hours: another instance of a low degree of respiration and great tenacity of life in a genus of fishes having very large gill-apertures.

In Orkney, Mr. Low says it is constantly used as a bait for other fish, and though of good flavour, is very seldom eaten. On the sands at Portobello, near Edinburgh, as well as at other localities in that vicinity, people of all ages may be seen, when the tide is out, diligently searching for the Sand-Launce, and raking them out with iron hooks. Some are used as bait; but many are prepared for table, and considered delicate food.

Colonel Montagu mentions the Sand-Launce as being extremely plentiful at Slapton Sands, on the south coast of Devonshire, where the fishermen employ a small seine with a fine mesh, and are frequently so successful, that six or seven bushels are taken at one haul: these are usually sold to Dieppe fishermen for twenty-pence the bushel. Montagu adds, that on the part of the Devonshire coast here referred to, even the poorest people would not eat the Sand-Launce, while at Teignmouth it was in great request as food, and was counted out for sale by the score.

"It is only of late," says Mr. Couch, "that naturalists have learned to recognise two species, though it has been done long since by fishermen, who have been accustomed to observe that a small species, which keeps in larger bodies, and seldom goes far from land, is more followed by Mackerel than the other, and that its presence is a better sign of good fishing. On a calm evening it is an interesting sight to see the surface of the water broken by the repeated plunges of voracious fishes as they burst 
upon the little schull of Launces from beneath. Their only certain place of refuge from these pursuers is the sand." "It burrows in the sand, and like all fish of our shores with similar habits, it has a pulsating sanguinous sac at the base of the caudal fin."-Zoologist, p. 1972.

I have obtained the fry of the Sand-Launce four inches long in the month of April, and considered them to be the young of the preceding year. May, August, and December, have each been named as the month in which the adult fish deposit their spawn; but the habits and economy of the two species have been greatly confounded hitherto, under the supposition that they were but examples of the smae fish, differing only in size.

The Sand-Launce has been noticed on the coasts of the counties of Londonderry, Antrim, Dublin, and Cork; I learn also from F. C. Lukis, Esq., that both species are found at Guernsey; but that lancea is the most common. The search for them in the sand prevails there, but it is usually made on moonlight nights.

Dr. Richardson includes this species in his Fauna Boreali-Americana, and I have seen a specimen that was brought from Iceland by Mr. Proctor.

The food of the Sand-.Launce is marine worms and very small fishes:

The usual length of this species is from five to seven inches: the length of the head compared to the length of the fish is less than as one to five: the lower jaw shorter in proportion than in the other species; the protractile portion of the upper jaw much more free to move, and when the lower jaw is pressed down, this movable part comes forward and downward: the posterior margin of the eye is less than half-way between the point of the 
lower jaw and the posterior projecting angle of the gillcover, being placed nearer the nose than in Tobianus; the dorsal fin commencing in a line over the middle of the pectoral fin.

The fin-rays in number are-

$$
\text { D. } 51 \text { : P. 13: A. 25: C. } 15 .
$$

The vignette represents a Venetian pleasure-boat.

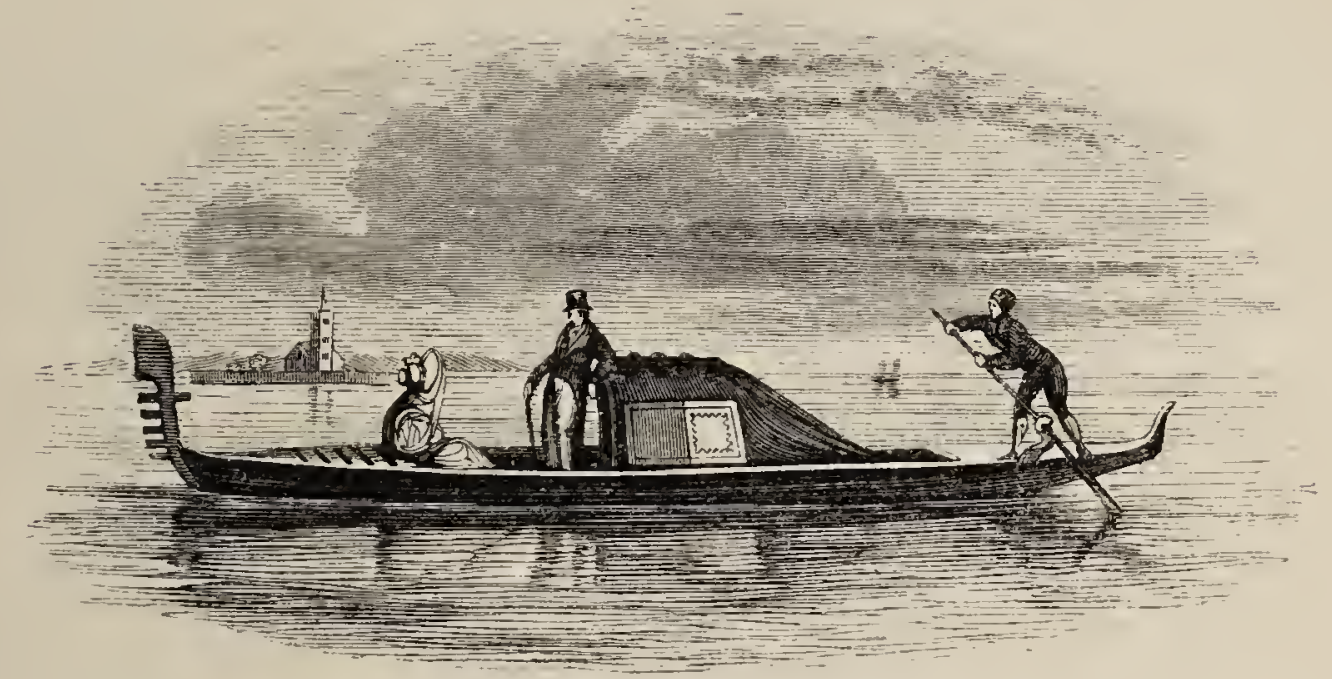


ABDOMINALES

MALACOPTERYGII.

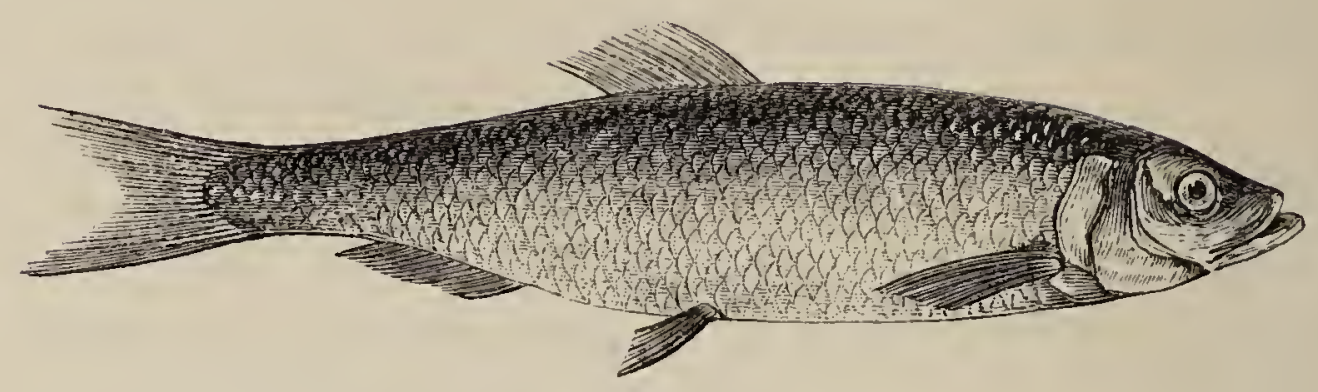

THE HERRING.

Clupea havengus, Linnaus. Bloch, pt. i. pl. 29.

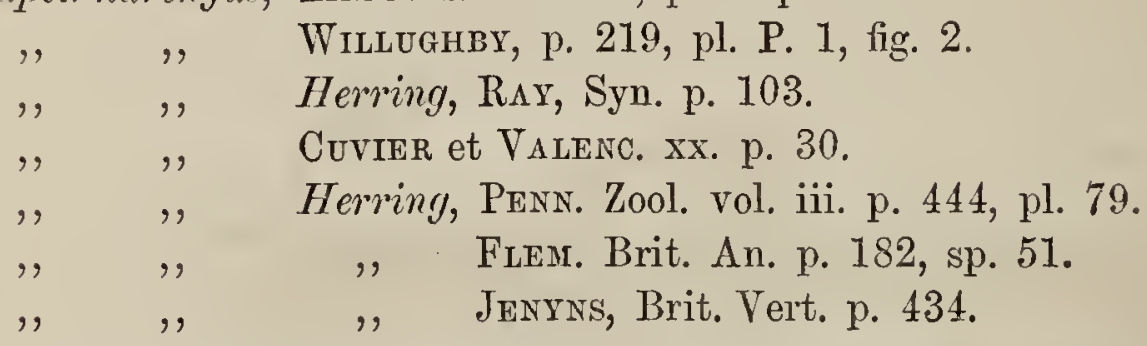

CuUPEID f. Family Characters. - Scaly fishes with a solitary dorsal, and no adipose fin. Body longish, much compressed, with a thin trenchant belly, which is serrated by a series of sharp dermal bones affixed to the points of the ribs; ventral fins situated near the middle of the fish; no spines in any of the fins. Mouth bordered above by the premaxillaries and maxillaries, the latter being divisible into three pieces. Stomach elongated below its orifices into a blind conical sac; pyloric cæca numerous. Air-bladder large, with a simple anterior end, and communicating by a slender tube with the conical bottom of the stomach.

Clupes. Generic Characters. - Small premaxillary teeth; minute teeth also on the part of the mandible which projects beyond the upper jaw ; larger teeth in a longitudinal band on the vomer, others on the tongue, and two or three very small deciduous ones on the edge of the palatines. Belly more or less trenchant, according to the size of the roe or milt.

Anderson and Pennant were certainly mistaken in supposing that the great winter rendezvous of the Herring is within the Arctic Circle: "there they continue," says Pennant, "for many months, in order to 
recruit themselves after the fatigue of spawning; the sea within that space swarming with insect food, in a degree far greater than in our warmer latitudes." "This mighty army begins to put itself in motion in the spring. We distinguish this vast body by that name; for the word Herring is derived from the German Heer-an army, to express their numbers. They begin to appear off the Shetland Islands in April and May.* This is the first check this army meets with in its march southward. Here it is divided into two parts: one wing of those destined to visit our coast takes to the east, the other to the western shores of Great Britain, and they fill every bay and creek with their numbers; others proceed towards Yarmouth, the great and ancient mart of Herrings; they then pass through the British Channel, and after that in a manner disappear. Those which take to the west, after offering themselves to the Hebrides, where the great stationary fishery is, proceed toward the north of Ireland, where they meet with a second interruption, and are obliged to make a second division: the one takes to the western side, and is scarcely perceived, being soon lost in the immensity of the Atlantic; but the other, which passes into the Irish Sea, rejoices and feeds the inhabitants of most of the coasts that border on it. These brigades, as we may call them, which are thus separated from the greater columns, are often capricious in their motions, and do not show an invariable attachment to their haunts."

This is Pennant's account as it regards our own islands. To show that this supposed migration to and from high northern latitudes does not exist, it is only necessary to state, that the Herring has never been noticed, that I am

* In another part of his account, Pennant says the Herrings continue on the Welsh coast till February. (P. 447.) 
aware, as abounding in the Arctic Ocean: it has not been observed in any number in the proper icy seas; nor have our whale-fishers or arctic voyagers taken any particular notice of it. There is no fishery for it of any consequence either in Greenland or Iceland. On the southern coast of Greenland the Herring is a rare fish; and only a small variety of it, according to Crantz, is found on the more northern shore. This small variety or species was found by Sir John Franklin, on the shore of the Polar basin, on his first journey.

"That the Herring is, to a certain degree, a migratory fish," says Dr. M'Culloch,* " may be true; but even a much more limited migration is far from demonstrable. It is at any rate perfectly certain that there is no such progress along the east and west coasts from a central point." There can be no doubt that the Herring inhabits the deep water all round our coast, and only approaches the shores for the purpose of depositing its spawn within the immediate influence of the two principal agents in vivification-increased temperature and oxygen; and as soon as that essential operation is effected, the shoals that haunt our coast disappear: but individuals are to be found, and many are caught throughout the year. So far are they from being migratory to us from the North only, that Herrings visit the west coast of the county of Cork in August, which is earlier than those which come down the Irish Channel arrive, and long before they make their appearance at other places much farther north. "In former times, the fishery of the east coast did not commence till that on the west had terminated. It is remarkable also that the eastern fishery has become so abundant as quite to have obscured the western." And

* See an excellent paper on the Herring in the 32nd number of the Journal of the Royal Institution, for January, 1824. 
Dr. M'Culloch, adducing other facts, confirms a statement previously made, that the fishery has commenced soonest on the southern part of the shore; and, what is also remarkable, that for some years past it has become later every year.

Mr. Couch says, "There is no special fishery for Herring on the Cornish shores, and they rarely appear in sufficient quantities to have a short period of drift-net speculation devoted to them. On the southern parts of Cornwall they are only taken by accident."-(Zoologist, p. 174.1).

The Herring is in truth a most capricious fish, seldom remaining long in one place; and there is scarcely a fishing station round the British Islands that has not experienced in the visits of this fish the greatest variations both as to time and quantity, without any accountable reason.

"Ordinary philosophy is never satisfied," adds Dr. $\mathrm{M}$ 'Culloch, "unless it can find a solution for everything; and is satisfied, for this reason, with imaginary ones. Thus, in Long Island, one of the Hebrides, it was asserted that the fish had been driven away by the manufactory of kelp; some imaginary coincidence having been found between their disappearance and the establishment of that business. But the kelp fires did not drive them away from other shores, which they frequent and abandon indifferently without regard to this work. It has been a still more favourite and popular fancy, that they were driven away by the firing of guns; and hence this is not allowed during the fishing season. A gun has scarcely been fired in the Western Islands, or on the west coast, since the days of Cromwell; yet they have changed their places many times in that interval. In a similar manner, and with equal truth, it was said that they had been driven 
from the Baltic by the battle of Copenhagen. It is amusing to see how old theories are revived. This is a very ancient Highland hypothesis, with the necessary modifications. Before the days of guns and gunpowder, the Highlanders held that they quitted coasts where blood had been shed: and thus ancient philosophy is renovated. Steam-boats are now supposed to be the culprits, since a reason must be found: to prove their effect, Loch Fyne, visited by a steam-boat daily, is now their favourite haunt, and they have deserted other lochs where steamboats have never yet smoked." A Member of the House of Commons, during the session of 1835 , in a debate on a tithe bill, stated, that a clergyman having obtained a living on the coast of Ireland, signified his intention of taking the tithe of fish; which was, however, considered to be so utterly repugnant to their privileges and feelings, that not a single Herring had ever since visited that part of the shore!

Our common Herring spawns towards the end of October or the beginning of November; and it is for two or three monthis previous to this, when they assemble in immense numbers, that the fishing is carried on, which is of such great and national importance. "And here," Mr. Couch observes, "we cannot but admire the economy of Divine Providence, by which this and several other species of fish are brought to the shores, within reach of man, at the time when they are in their highest perfection, and best fitted to be his food." Nearly 70,000 eggs have been counted in one female, quite sufficient to supply the annual breach of numbers by the various enemies of the species.

The mode of fishing for Herrings is by drift-nets, very similar to those employed for taking Mackerel and Pil. chard, with a slight difference in the size of the mesh. 
The net is suspended by its upper edge from the driftrope by various shorter and smaller ropes, called buoyropes; and considerable practical skill is required in the arrangement, that the net may hang with the meshes square, smooth, and even in the water, and at the proper depth; for, according to the wind, tide, situations of their food, and other causes, the Herrings swim at various distances below the surface.

The size of the boat used depends on the distance from shore at which the fishery is carried on; but, whether in deep or in shallow water, the nets are only in actual use during the night. It is found that the fish strike the nets in much greater numbers when it is dark than while it is light: the darkest nights, therefore, and those in which the surface of the water is ruffled by a breeze, are considered the most favourable. It is supposed that nets stretched in the day-time alarm the fish, and cause them to quit the places where that practice is followed; it is therefore strictly forbidden.

$A$ visit to the Herring-fishers on the west coast of Ireland is thus described by the author of Wild Sports in the West:- "Having lighted our pipes, and procured our boat-cloaks, we left the pier-head in the four-oared galley. The night was unusually dark and warm; not a breath of wind was on the water; the noise of the oars, springing in the coppered rullocks, was heard for a mile off, and the whistle of sandpipers and curlews, as they took wing from the beach we skirted, appeared unusually shrill. Other noises gradually broke the stillness of the night. The varied hum of numerous voices chanting the melancholy songs which are the especial favourites of the Irish, began to be heard distinctly, and we soon bore down upon the midnight fishers, directed by sound, not sight. 
"To approach the fleet was a task of some difficulty. The nets, extended in interminable lines, were so frequent that much sliill was necessary to penetrate this hempen labyrinth, without fouling the back ropes. Warning cries directed our course, and with some delay we threaded the crowded surface, and guided by buoys found ourselves in the very centre of the flotilla.

"It was an interesting scene. Momently the boats glided along the back ropes, which were supported at short intervals by corks, and at a greater by inflated dogskins, and, raising the curtain of net-work which these suspended, the Herrings were removed from the meshes, and deposited in the boats. Some of the nets were particularly fortunate, obliging their proprietors to frequently relieve them of the fish; while others, though apparently stretched within a few yards, and consequently in the immediate run of the Herrings, were favoured but with a few stragglers; and the unemployed fisherman had to occupy himself with a sorrowful ditty, or in moody silence watched the dark sea like some dull ghost waiting on Styx for waftage.

"Our visit appeared highly satisfactory; every boat tossed us Herrings on board, until we were obliged to refuse further largess; and these many 'trifles of fish' accumulated so rapidly, that we eventually declined receiving other compliments, or we might have loaded the gig gunnel-deep.

"The darkness of the night increased the scaly brilliancy which the phosphoric properties of these beautiful fish produce. The bottom of the boat, now covered with Herrings, glowed with a living light, which the imagination could not create, and the pencil never imitate. The shades of gold and silvery gems were rich beyond description; and much as I had heard of phosphoric 
splendour before, every idea I had formed fell infinitely short of its reality.

"The same care with which we entered disembarrassed us of the midnight fishing ; every boat we passed pressed hard to throw in a cast of skuddawns (Herrings) for the strange gentleman; and such was the kindness of these hospitable creatures, that, had I been a very Behemoth, I should have this night feasted to satiety on their bounty.

"The wind, which had been asleep, began now to sigh over the surface, and before we had cleared the outer back ropes, the sea-breeze came curling the midnight wave. The tide was flowing fast, and having stepped the mast, we spread our large lug, and the light galley slipped speedily ashore."

In his Prize Essay on the Fishes of the Forth, Dr. Parnell says, "Herrings enter the Frith of Forth about the end of December, or the beginning of January, and remain two or three weeks at the mouth of the estuary before they attempt to ascend. This delay seems greatly to depend on the state of the weather; for in some seasons, when it is mild and fine, they have been observed to swarm in the Frith, off Musselburgh, in the early part of January; whilst, in the rough and stormy seasons, they do not make their appearance so far up the Frith before the middle of February; and always disappear before the end of March. They seem to visit the Frith regularly every winter.* And that season seldom passes without a few being captured, and sent to the Edinburgh market. Some years they appear in much larger shoals than in others, the reason of which is not accounted for. In the year 1816, Pilchards were

* Yarmouth, on the Norfolk coast, and the western coasts of Ireland, have also an autumnal and winter herring fishery. 
taken in the Frith of Forth in great abundance, when not a dozen Herrings were seen during the whole winter. Since that time, not a single Pilchard has been known to enter the estuary." In June, July, and August, Herrings are taken off the Dunbar and Berwick coasts in considerable numbers, from whence the Edinburgh market is abundantly supplied, when scarcely a single Herring is, in these months, to be seen higher in the Frith of a size worth the notice of the fishermen.

The fishery of the herring is named in the records of the Monastery of Evesham as far back as the year 709, and in the annals of the Monastery of Barking the tax levied upon the capture of this fish is called Herringsilver. The Normans appear as Herring-fishers, almost from the earliest notice of that sea-faring people in the history of Europe.

Yarmouth carried on the Herring fishery in AngloSaxon times, and in the reign of Henry I. paid a tax of 10,000 fish; while Dunwich, now sunk beneath the sea, was assessed at 84,000. Noel de la Moriniere states that the most ancient records of the Herring fishery of France carry it back to the year 1030, and in 1088, Robert, Duke of Normandy, granted to the Abbey of the Holy Trinity at Fécamp the right of holding a fair during the continuance of the Herring fishery.

The Herring having spawned, retires to deep water, and the fishing ends for that season. While inhabiting the depths of the ocean, its food is said by Dr. Knox to consist principally of minute entomostracous animals; but it is certainly less choice in its selection when near the shore. Dr. Neill found five young of its own kind in the stomach of a large female Herring; he has also known Herrings to be taken by the fishermen on their lines, the hooks of which were baited with limpets; and they have 
been repeatedly caught by anglers with an artificial fly. They are known to feed upon minute crustacea, small medusæ, and the spawn and fry of fishes. The Rev. Robert Holdsworth wrote me word that in January, 1823, he took a small Bass three inches long from the stomach of a Herring, caught at Kingswear, in the river Dart. The young abound in the shallow water all round our shores during the summer months. I have seen them taken off Brighton in the small-meshed draw-nets which are there used for the capture of Atherine; and they are caught by boys while angling from piers and rocks at various places along the southern coast. They are very abundant on the Yorkshire coast, where they are called Herring sile; ${ }^{*}$ and they swarm among the Orkney and Shetland Islands during the whole of the summer. They remain at the mouth of the Thames during the first autumn and winter : many are caught on the coasts of Essex and Kent in the nets used for taking Sprats. From repeated examinations, I am induced to believe that these young fish do not mature any roe during the first year. A few are occasionally caught by the net in Dagenham Breach, seldom exceeding eight or nine inches in length, and are remarkably mild in flavour.

That the Herring fishery is of great national importance is evident from Parliamentary returns, which state that the Scottish fishery alone cured 766,000 barrels in the year 1855, of which one-half were exported. The fishery was carried on in 11,000 boats, manned by 40,000 seamen, who were assisted by 28,000 curers and labourers-exclusive of the vessels and men bringing salt, barrels, \&c., or engaged in carrying on the export trade. The capture of Herrings in 1855 was ex-

* The Scandinavian hoer or här (in German heer) signifies an army or host, and sill or sild a herring. 
ceeded on two former seasons, and the yearly average number of barrels cured in forty-three years was 416,000 . Each barrel contains about 550 full-grown fish, so that the capture on the Scottish coast alone amounts to 421 millions for curing in a good year, in addition to those consumed in a fresh state. Great quantities are also caught in the English and Irish seas. On the coast of Norway 400 millions are taken in a year, and the fishery. of the Swedes from Gottenburgh yields 700 millions. To these must be added the Herring fisheries of Holland, Germany, France, the United States and Kamtschatka, before we can have a just idea of the quantity of human food derived from this one species of fish.*

The length of the head compared to the length of the body alone, without the head or caudal rays, is as one to four; the depth of the body compared to the whole length of the fish, as one to five; the commencement of the dorsal fin half-way between the point of the upper jaw and the end of the fleshy portion of the tail: the longest ray nearly as long as the base of the fin: the pectoral fin rather large compared to the size of the other fins. The ventral fin arises considerably behind the line of the commencement of the dorsal fin: this fin is small, with elongated axillary scales; its origin halfway between the point of the lower jaw and the end of the short central caudal rays. The anal fin begins halfway between the origin of the ventral and the end of the fleshy portion of the tail, and extends over half the distance between its origin and the end of the fleshy portion, thus occupying the third quarter division of the

* For the statistics of the Herring fisheries, and many particulars of the history of this interésting fish which our restricted limits oblige us to omit, the reader may consult the article Fisheries, in the Encyclopædia Britannica, written by the late James Wilson, Esq., and the twentieth volume of the Histoire des Poissons, by Cuvier and Valenciennes. 
distance between the origin of the ventral fin and the end of the fleshy portion of the tail ; the rays very short. The tail considerably forked; the outer rays as long again as those of the middle. The fin-rays in number are-

D. $17:$ P. $15:$ V. $9:$ A. $14:$ C. 20 . Vertebre 56 ;

varying in some specimens to

$$
\text { D. } 19: \text { P. } 17: \text { V. } 9: \text { A. } 16: \text { C. } 18 .
$$

The lower jaw is by much the longer, with five or six small teeth extending in a line backwards on each side from the anterior point; four rows of small teeth on the central upper surface of the tongue; a few small teeth on the central portion of the upper jaw, and the inferior edges below the gape finely serrated: the eye large, its diameter compared to the length of the head as two to seven, and placed at the distance of its own breadth from the end of the nose: the dorsal and abdominal lines of the body slightly convex; the belly carinated, but not sharply serrated; the scales moderate in size, oval and thin. The upper part of the fish a fine blue, with green and other reflections when viewed in different lights; the lower part of the side and belly silvery white; cheeks and gill-covers silvery, exhibiting the aprearance of extravasation when the fish has been dead twenty-four hours. Dorsal and caudal fins dusky; the fins on the lower parts of the body almost white.

The ribs of the Herring are long and slender, their points mecting at the acute under edge of the belly. There are also still more slender accessory bones termed by Professor Owen epipleural spines which spring from the ribs, and also from the processes of the vertebræ. The gill-openings are very large, allowing of the free exit of the large current of water which flows over the gills, but at the same time permitting the delicate struc- 
ture of these organs to dry rapidly whęn exposed to the air, hence the speedy death of this fish when taken out of the water. The acute edge of the belly is protected by a series of chevronels, or scales bent in form of a chevron, attached to slender ribs. These scales are so closely imbricated that they do not produce conspicuous serratures, but the structure is the same as if their points projected. The absence of streaks on the operculum distinguishes the small Herring from the adult Pilchard.*

* In the Zoologist for 1853, p. 3847, it is stated that Mr. Ffennell, Inspecting Commissioner of Fisheries, mentioned to the Natural History Society of Dublin that he had obtained specimens of the true Herring in the Lakes of Killarney, and that he had learnt that numbers of this fish could be taken there, where they were well known to the fishermen by the name of goureens. It is very desirable that these goureens should be examined by a competent ichthyologist, and compared with young shad and other members of the herring family that are known to enter fresh waters.

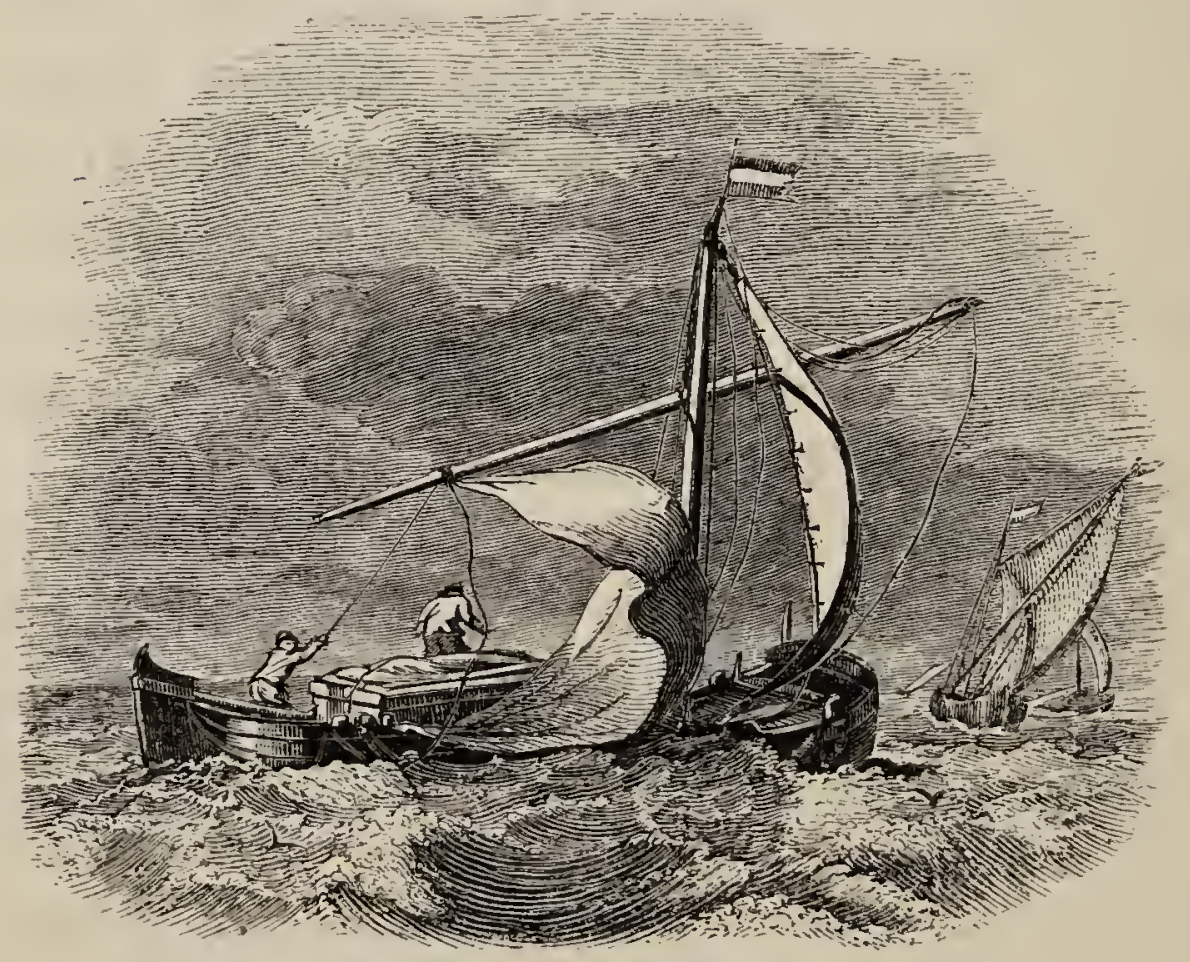




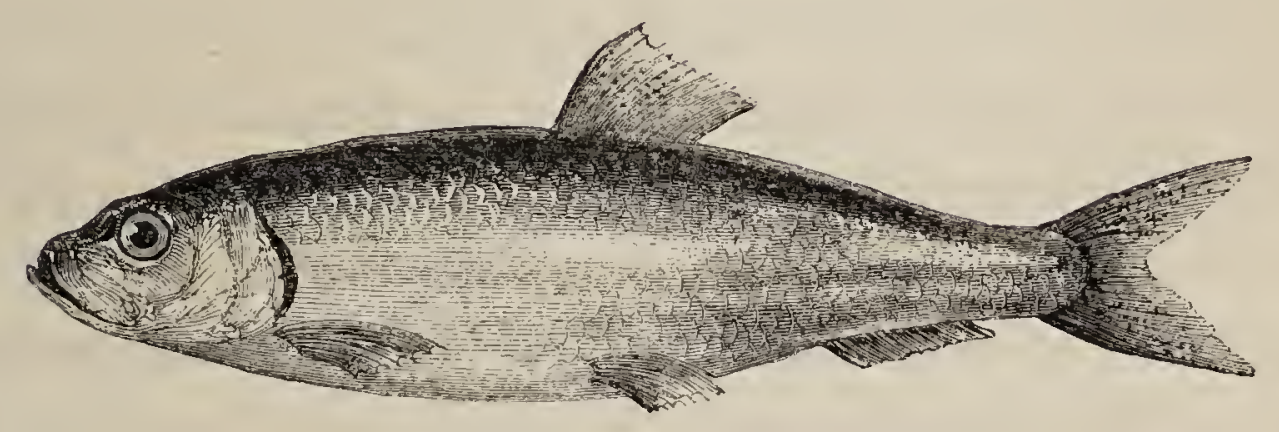

\section{LEACH'S HERRING.}

Clupea Leachii, YARreld, Zoological Journal, vol. v. p. 277, pl. 12.

" " Leach's Herring, Jenyes, Brit. Vert. p. 434.

, ", Valencrennes, Hist. des Poiss. xx. 243.

The examination of considerable quantities of the various sorts of fish caught at the mouth of the Thames during winter by fishermen engaged in taking Sprats, has enabled me to select what I believe to be a second species of British Herring.

The common Herring, when it visits our coast in autumn, is taken heavy with roe, which it deposits towards the end of October. It is certain that the fishing for them is abandoned about that time, as no purchasers could be found for the "shotten Herring ;" and it is also well known that the Herrings, having cast their roe, retire from the shore to deep water. Numbers of the young of the common Herring are taken with the Sprats. These are called Yawlings by some fishermen,-a term probably derived from yearling. But these young Herrings differ materially from the Herring 
which I believe to be new. The yearling fish have the elongated form of the adult common Herring: if seven inches long, which is about their average length, they are only one inch and three-eighths in depth, and are without roe. Having examined them repeatedly during the winter months, I am induced to believe they do not mature any roe during their first year; and the fact of their remaining in large shoals at the mouth of the Thames after the Herrings that have recently spawned have left the shore, may be taken in corroboration; for had they matured and deposited any roe, they would, like the more adult fish of their own species, have experienced the same necessity for retiring to deep water.

The Herring, however, which I now refer to, is found heavy with roe at the end of January, which it does not deposit till the middle of February. Its length is not more than seven inches and a half, and its depth near two inches. It is known that Dr. Leach had often stated that our coast produced a second species of Herring; but I am not aware that any notice of it has ever appeared in print. In order, however, to identify the name of that distinguished naturalist with a fish of which he was probably the first observer, I proposed for it the name of Clupea Leachii.

Dr. Leach's observations on the Herring were made during his visit to the extended line of our southern coast in the year 1808; and Mr. Jesse, in his Gleanings in Natural History, has noticed the superiority and consequent partiality that is said to exist in favour of the Herrings of Cardigan Bay over those that are taken at Swansea.

Of the existence of a second species of Herring on our shores further proof may be adduced in the following extracts. 
"In former times," says Dr. M'Culloch, " the fishery of the east coast of Scotland did not commence till that on the west had terminated. It was then supposed, and not very unreasonably, that the fish had changed their ground, and that these were the western Herrings. Yet it ought to have been plain that this was not the case, as the eastern fish were entirely different in quality from the western, and very inferior. At the same time, they were in that condition as to spawning which proved that they could not have been the same fish. The fact of their being entirely different fish is now at least fully proved, because on both shores the period of the fishery has been the same."-Journal of the Royal Institution, No. 32, for January, 1824, p. 217.

"A smaller but superior kind of Herring is found occasionally in Loch Eribol; but it is chiefly used for home consumption." - Scotch Statistics, Durness.

Three sorts of Herring are said to visit the Baltic, and there are three seasons of roe and spawning. The Strömling, or small Spring Herring, spawns when the ice begins to melt; then a larger Summer Herring; and lastly, towards the middle of September, the Autumn Herring makes its appearance, and deposits its spawn.

M. Valenciennes considers Leach's Herring to be merely a variety of the common species, and to be perhaps the same with the Strömling of the Baltic.

The length of the head compared to that of the body alone, without the head or caudal rays, is as one to three; the depth of the body greater than the length of the head, and compared to the length of the head and body together is as one to three and a half; it is therefore much deeper in proportion to its length than our common Herring, and has both the dorsal and ventral lines much more convex: the under jaw longer than the

vol. I. 
upper, and provided with three or four prominent teeth just within the angle formed by the symphysis; the superior maxillary bones have their edges slightly crenated: the eye is large, in breadth full one-fourth of the length of the whole head; irides pale yellow: the dorsal fin is placed behind the centre of gravity, but not so much so as in the common Herring; the scales are smaller; the sides without any distinct lateral line: the edge of the belly carinated, but not acutely serrated; the fins small. The fin-rays in number are-

D. $18:$ P. $17:$ V. $9:$ A. $16:$ C. 20 . Vertebræ 54.

The back and upper part of the sides are deep blue, with green reflections, passing into silvery white beneath. The flesh of this species differs from that of the common Herring in flavour, and is much more mild.

Intending to make the fishing-boats of several countries the subjects of some of the vignettes, that at page 110 represents a Dutch boat: the vignette below is a representation of a French fishing-boat.

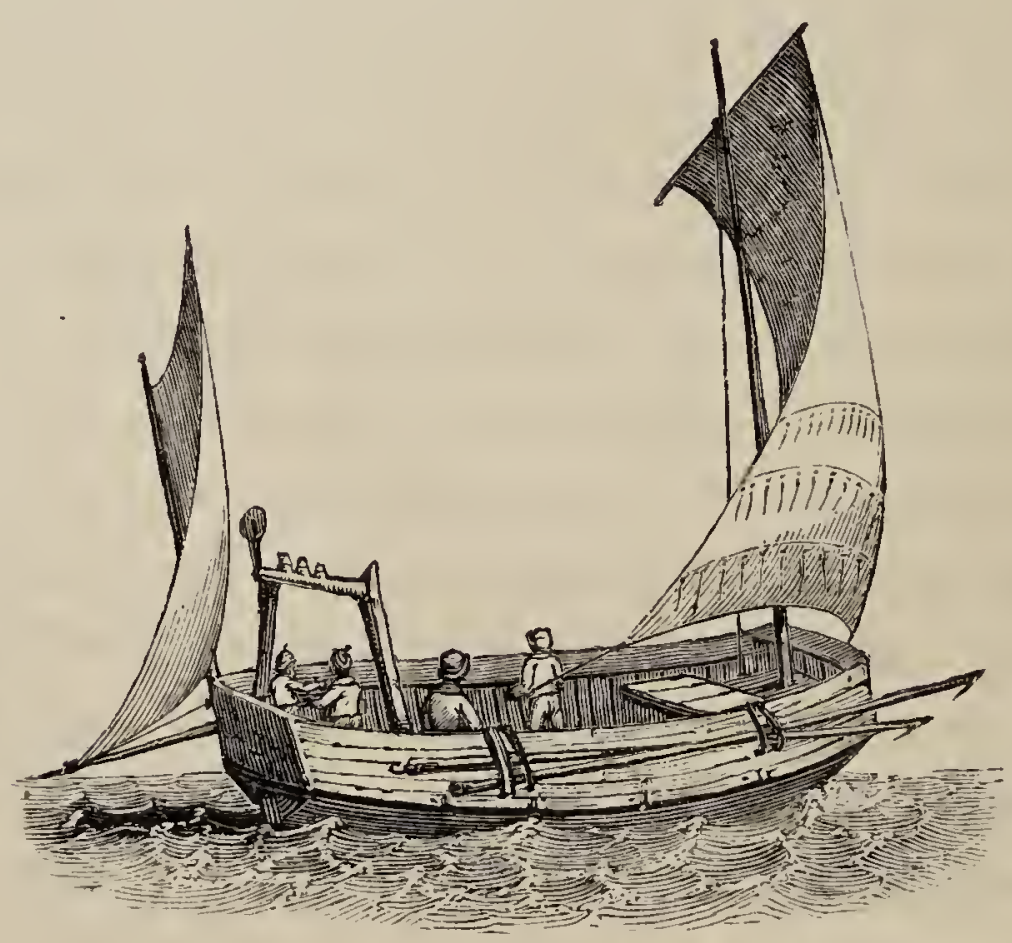




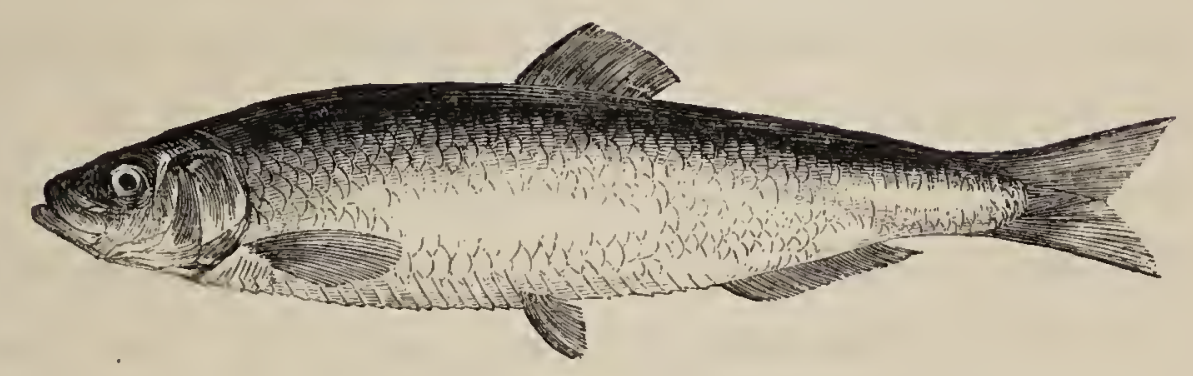

THE SPRAT.

GARVIE HERRING AND GARVIE. Scotland,

Harengula sprattus, Valenciennes, Hist. des Poiss. xx. 285.

Clupea " Linnæus. Bloch, pt. i. pl. 29, fig. 2.

, $\quad$ " Cuvier, Règne An. t. ii. p. 318.

," , Sprat, Penn. Brit. Zool. vol. iii. p. 457.

", , , JENYNS, Brit. Vert. p. 435.

Harengula. Generic Characters. - Teeth on the jaws, tongue, palatines and entopterygoids: no vomerine teeth.

The Linnæan genus Clupea having received a vast accession of species by the researches of ichthyologists, has assumed the rank of a Family, and has been broken up into numerous genera by Valenciennes, who characterizes the various groups chiefly by the position of their teeth.

Willughby and Ray, deceived apparently by the misapplication of the name by the fishermen of Cornwall, with which the latter became acquainted during his journey in that county, considered that the word Sprat was only a name for the young of the Herring and of the Pilchard, and others have been misled by their authority: but so well is this fish distinguished from both by the strongly-serrated edge of the abdomen, that there is 
not a fisherman round those parts of our coast where the Sprat is taken, that cannot immediately distinguish it from either, even in the midst of the darkest night. Its characters being now sufficiently appreciated, it is by some, and ought to be by all, admitted as a good and distinct species.

Though a much less valuable fish than the Herring, it is still a very useful one. Coming into the market in immense quantities and at a very moderate price immediately after the Herring season is over, it supplies during all the winter months of the year a cheap and agreeable food. Large quantities are eaten; and, from their rich quality and flavour, the consumption is not solely confined to the lower classes. They are generally cooked while fresh, but are also preserved in various ways.

The Sprat is included by Linnæus in his Fauna Suecica, and by Professors Nilsson and Reinhardt in their publications on the Fishes of Scandinavia. The Danes name it Sprattè sild, sprced signifying, in their language, brittle or crisp. Dr. Neill says the Sprat is sold in Edinburgh market by the dozen; and I have received specimens that were taken in the Forth, where they are called Garvie Herrings and Garvies. Dr. George Johnston, in his list of the fishes of Berwickshire, says the Sprat is common there, and is a favourite food of the Salmon tribe. Farther south, they are most plentiful on the Norfolk, Suffolk, Essex, and Kentish coasts. I have taken them on the Dorsetshire coast in June, and they were then in roe. They inhabit the deep water round our southern coast during the summer months, and may be found in the stomachs of many of our voracious fishes every month in the year. I have taken three Sprats from the stomach of a Whiting, and have caught young Sprats off Ramsgate, Hastings, and Weymouth, in the months of August 
and September. Like the other species of the genus Clupea, they are wanderer's: the shoals are capricious in their movements, and exceedingly variable in their numbers. "Upwards of a ton weight of Sprats was sold in our market last Saturday."-(Taunton Courier, January, 1832.) "It is nearly fifty years since this useful fish visited the neighbouring coast, and they now appear in exhaustless shoals close in shore on the south coast of Devon." In 1843, the Sprat appeared in such countless multitudes, that the fishermen, merely by dipping their shrimp-nets into the water, took them in such quantities as to be able to sell them at three-pence a bushel. Many of them were infested by the parasitic Lerneonema monillaris, which adhered to various parts of the fish. Twentysix boats found full occupation in this fishery while it lasted.

The Sprat is occasionally taken in Cornwall; and in Ireland, on the coasts of Cork, Dublin, and Belfast.

In Cornwall the true Sprat is, however, very rare; and the name is appropriated, as it was by the old fishermen whom Ray consulted one hundred and fifty-six years ago, to the fry of the Herring and of the Pilchard. An analogous misapplication of a name exists on the eastern coast, where the true Pilchard rarely occurs, and where the name of Pilchard is given to the fry of the Shad and the half-grown Herring. In like manner the Blanquette of the French Mediterranean coasts, a second species of Harengula, has been confounded by many ichthyologists with the true northern Sprat.

The fishing season begins early in November, continuing through the winter months; and the largest quantities are taken when the nights are dark and foggy. A few, and those of the best description, are taken in the same manner as the Mackerel, the Pilchard, and the Her- 
ring, by drift-nets of fine twine and suitably small mesh; a mode of fishing peculiarly adapted for the capture of species which rove in shoals through the water. But the most destructive plan pursued against Sprats is by a mode called stow-boat fishing. The stow-boat net goes with two horizontal beams: the lower one, twentytwo feet long, is suspended a fathom above the ground; the upper one, a foot shorter in length, is suspended about six fathoms above the lower one. To these two beams, or balks, as they are called, a large bag-net is fixed, in the end of which, called the hose, the mesh is fine enough to stop very small fry. The mouth of the net, twenty-two feet wide and thirty-six feet high, is kept square by hanging it to a cable and heavy anchor at the four ends of the beams. The net is set under the boat's bottom; and a rope from each end of the upper beam, brought up over each bow of the boat, raises and sustains the beam, and keeps the mouth of the net always open, and so moored that the tide carries everything into it. A strong rope, which runs through an iron ring at the middle of the upper beam, and is made fast to the middle of the lower beam, brings both beams together parallel, thus closing the mouth of the net when it is required to be raised. In this way an enormous quantity of Sprats, with the fry of many other species, are taken, which are principally sold by measure to manure land near the coast.

From four to five hundred boats are thus employed during the winter. Many thousand tons in some seasons are taken and sold at sixpence and eight-pence the bushel, depending on the supply and demand, to farmers, who distribute about forty bushels of Sprats over an acre of land, and sometimes manure twenty acres at the cost of twenty shillings an acre. In the winter of 1829-30, 
Sprats were particularly abundant: barge-loads, containing from one thousand to fifteen hundred bushels, bought at sixpence a bushel, were sent up the Medway as far as Maidstone to manure the hop-grounds. The coasts of Kent, Essex, and Suffolk are the most productive. So great is the supply thence obtained, that notwithstanding the immense quantity consumed by the million and a half inhabitants of London and its neighbourhood, there is yet occasionally a surplus to be disposed of at so low a price as to induce the farmers even so near the metropolis as Dartford, to use them for manure.

A full-sized Sprat measures six inches in length, and rather more than one inch and one-eighth in depth. 'The length of the head compared to that of the body alone is as one to four ; compared to the whole length of the fish, as one to six: the depth of the body is to the whole length as one to five. The dorsal fin commences exactly half-way between the point of the lower jaw and the end of the caudal rays : the ventral fins arise in a vertical line under the first dorsal fin-ray, and have no axillary scales; the ventral fins in the Pilchard and Herrings begin under the middle of the dorsal fin, and both have axillary scales,- there are two other external distinctions: the under jaw is the longest; the diameter of the eye less than one-fourth of the whole head: considerable convexity of the dorsal and abdominal lines; the latter serrated before the ventral fins, and still more strongly so behind them: the tail deeply forked; the scales large, round, and deciduous; the upper part of the head and back dark blue, with green reflections passing into silvery white on the gill-covers, sides, and belly; the dorsal and caudal fins dusky; pectoral, ventral, and anal fins white. 'The fin-rays in number are-

D. 17: P. 15: V. $7:$ A. 18 : C. 19 . Vertebræ 48. 
By the kindness of Mr. Loudon, I have received some small fish which came from Riga, where they are called Kilkies, and are eaten as a whet before dinner. They proved to be our Sprat. At Reval, and other places in the Gulf of Finland, young Herrings (Strömling), when about the size of Sprats, are prepared with spices, and sent to Petersburgh, London, and other places, for the use of the table. These are also in some estimation as a relish for lunch, from their peculiar flavour, and are sold in small jars, labelled Kilo Strömelein. Mr. Swainson in his treatise on Zoology in Lardner's Cyclopædia, ii. 387, mentions a Large-headed Sprat which he observed at Iiverpool, as a distinct species. It is desirable that ichthyologists who are resident in that town, should make search for it. It will, perhaps, prove to be the Harengula latulus of Valenciennes, or true Blanquette, which frequents the coast of Normandy as well as the Mediterranean shores of France. 


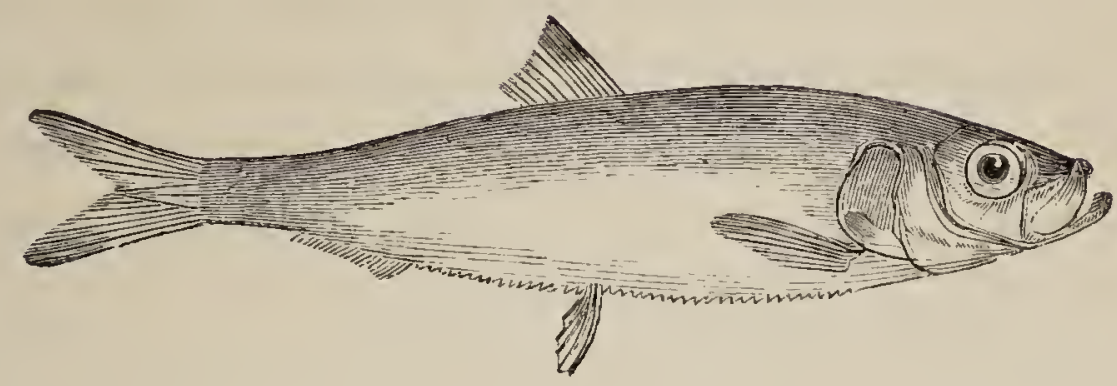

\section{THE WHITEBAIT.}

Rogenia alba, Valenciennes, Hist. des Poiss. xx. 340.

Clupea ," Yarreli, Zool. Journ. vol. iv. p. 137 and 465, pl. 10.

," ,, Whitebait, PenN. Brit. Zool. vol. iii. p. 465, pl. 80.

,, alosa, Young Shad, Don. Brit. Fish. pl. 98.

" alba, Whitebait, JEnyns, Brit. Vert. p. 436.

Rogenia. Generic Characters. - Teeth on the vomer, palatines, entopterygoids, and tongue; teeth also on the jaws, but not easily detected. It has more teeth than any other genus of the family.

Is the papers on the subject of the Whitebait published in the fourth volume of the Zoological Journal, I endeavoured to prove, historically and anatomically, that this little fish was not, as had been supposed, the young of the Shad, but a distinct species. In its habits it differs materially from all the other British species of Clupea that visit our shores or our rivers. From the beginning of April to the end of September, this fish may be caught in the Thames as high up as Woolwich or Blackwall every flood-tide, in considerable quantity, by a particular mode of fishing to be hereafter described. During the first three months of this period, neither species of the genus Clupea, of any age or size, except occasionally a young Sprat, can be found and taken in the same situation by the same means. The young Shad of the year are 
not two inches and a half long till November, when the Whitebait season is over; and these young Shad are never without a portion of that spotted appearance behind the edge of the upper part of the operculum, which in one species particularly is so marked a peculiarity in the adult fish. The Whitebait, on the contrary, never exhibits a spot on the side at any age; and from two inches long up to six inches, which is the length of the largest I have seen, the colour of the sides is uniformly white.

About the end of March or early in April, Whitebait begin to make their appearance in the Thames, and are then small, and apparently but just changed from the albuminous state of very young fry.* During the fine weather of June, July, and August, immense quantities are consumed by visitors to the different taverns at Greenwich and Blackwall. Pennant says, "They are esteemed very delicious when fried with fine flour, and occasion during the season a vast resort of the lower order of epicures to the taverns contiguous to the places where they are taken." What might have been the particular grade of persons who were in the habit of visiting Greenwich to eat Whitebait in the days when Pennant wrote, I am unable to state; but at present, the fashion of enjoying the excellent course of fish as served up either at Greenwich or Blackwall is sanctioned by the highest authorities, from the court at St. James's Palace in the West, to the Lord Mayor and his court in the East, including the Cabinet Ministers + and the philosophers of the Royal

\footnotetext{
* The Shad do not deposit their spawn till the end of June or the beginning of July.

* In the Morning Post of the day on which this account of the Whitebait was written, September 10th, 1835, the following paragraph appeared :--

"Yesterday the Cabinet Ministers went down the river in the Ordnance barges to Lovegrove's West India Dock Tavern, Blackwall, to partake of their annual fish dinner. Covers were laid for thirty-five gentlemen."
} 
Society. As might be expected, examples so numerous and influential have corresponding weight; and accordingly there are few entertainments more popular or more agreeable than a Whitebait dinner.

The fishery is continued frequently as late as September; and speciniens of young fish of the year, four or five inches long, are then not uncommon, but mixed, even at this late period of the season, with others of very small size, as though the roe had continued to be deposited throughout the summer; yet the parent fish are not caught, and are believed by the fishermen not to come higher up than the estuary, where, at this season of the year, nets sufficiently small in the mesh to stop them are not in much use.

The particular mode of fishing for Whitebait, by which a constant supply during the season is obtained, was formerly considered destructive to the fry of fishes generally, and great pains were taken to prevent it by those to whom the conservancy of the fishery of the Thames was entrusted; but since the history and habits of this species have been better understood, and it has been ascertained that no other fry of any value swim with them,-which I can aver, - the men have been allowed to continue this part of their occupation with little or no disturbance, though still using an unlawful net.

When investigating the subject of the Whitebait, I was occasionly engaged in witnessing the mode by which such numbers were taken. The mouth of the net is by no means large, measuring only about three feet square in extent; but the mesh of the hose, or bag-end of the net, is very small. The boat is moored in the tide-way, where the water is from twenty to thirty feet deep; and the net with its wooden frame-work is fixed to the side of the boat, as shown in the vignette at page 126. The tail 
of the hose, swimming loose, is from time to time handed into the boat, the end untied, and its contents shaken out. The wooden frame forming the mouth of the net does not dip more than four feet below the surface of the water ; and, except an occasional straggling fish, the only small fry taken with the Whitebait are the various species of Sticklebacks, and the very common Spotted or Freckled Goby; neither of which are of sufficient value or importance to require protection.* The farther the fishermen go down towards the mouth of the river, the sooner they begin to catch Whitebait after the floodtide has commenced. When fishing as high as Woolwich, the tide must have flowed from three to four hours, and the water become sensibly brackish to the taste, before the Whitebait will be found to make their appearance. They return down the river with the first of the ebb-tide; and various attempts to preserve them in well-boats in pure fresh water have uniformly failed.

The Hamble, which runs into the Southampton Water, is the only other southern river from which I have received Whitebait. But this I believe to be owing rather to the want of a particular mode of fishing by which so small a fish can be taken so near the surface, than to the absence of the fish itself; which, abounding as it does in the Thames, I have very little doubt might be caught in some of the neighbouring rivers on our south and east coasts. In the vicinity of the Isle of Wight, Whitebait, from their brilliancy and consequent attraction, are used by the fishermen as bait on their lines when fishing for Whitings.

\footnotetext{
* The fifteenth printed rule and order of the Lord Mayor and his court is, that "no person. shall take at any time of the year any sort of fish usually called Whitebait, upon pain to forfeit and pay five pounds for every such offence; it appearing to this court that under pretence of taking Whitebait the small fry of various species of fish are destroyed."-Page 11.
} 
The Thames fishermen who live at and below Gravesend know the Whitebait perfectly, and catch them occasionally of considerable size in the small-meshed nets used in the Upper and Lower Hope for taking shrimps called trinker-nets, which are like Whitebait nets, only larger; but these nets, working near the bottom, principally arrest the fry of the ground-swimming fishes.

The Sprat-fishers take the adult Whitebait frequently on the Kentish and Essex coasts throughout the winter.

Dr. Parnell, in his History of the Fishes of the Forth, says, "The Whitebait is not, as it was formerly considered to be, peculiar to the Thames, as I have found it to inhabit the Frith of Forth in considerable numbers during the summer months. From the begining of July to the end of September they are found in great abundance in the neighbourhood of Queensferry, and opposite Hopetown House, where I captured, in one dip of a small net of about a foot and a half square, between two and three hundred fish, the greater part of which were Whitebait of small size, not more than two inches in length; the remainder were Sprats, young Herrings, and fry of other fishes. In their habits they appear to be similar to the young of the Herring, always keeping in shoals, and swimming occasionally near the surface of the water, where they often fall a prey to aquatic birds."

The length of the head compared with that of the body alone is as two to five; the depth of the body compared to the whole length of the fish, as one to five: the dorsal fin commences half-way between the point of the closed jaws and the ends of the short middle caudal rays; the longest ray of the dorsal fin as long as the base of the fin; the ventral fin arises behind the line of the commencement of the dorsal, and half-way between 
the point of the closed jaws and the end of the longest caudal rays; the tail long and deeply forked. The finrays in number are-

D. $17:$ P. $15:$ V. $9:$ A. $15:$ C. 20 . Vertebræ 56.

The head is elongated; the dorsal line less convex than that of the abdomen; the scales deciduous; the abdominal line strongly serrated from the pectoral fin to the anal aperture.

The lower jaw the longest, and smooth; the upper slightly crenated: the tongue with an elevated central ridge: the eye large; the irides silvery: the upper part of the back pale greenish ash; all the lower part, the cheeks, gill-covers, sides, and belly, silvery white: dorsal and caudal fins coloured like the back; the latter tipped with dusky: pectoral, ventral, and anal fins, white. The only food I could find in the stomach were the remains of minute crustacea.

The word Rogen signifies roe, or eggs of fish, and from this M. Valenciennes has framed the generic name Rogenia.

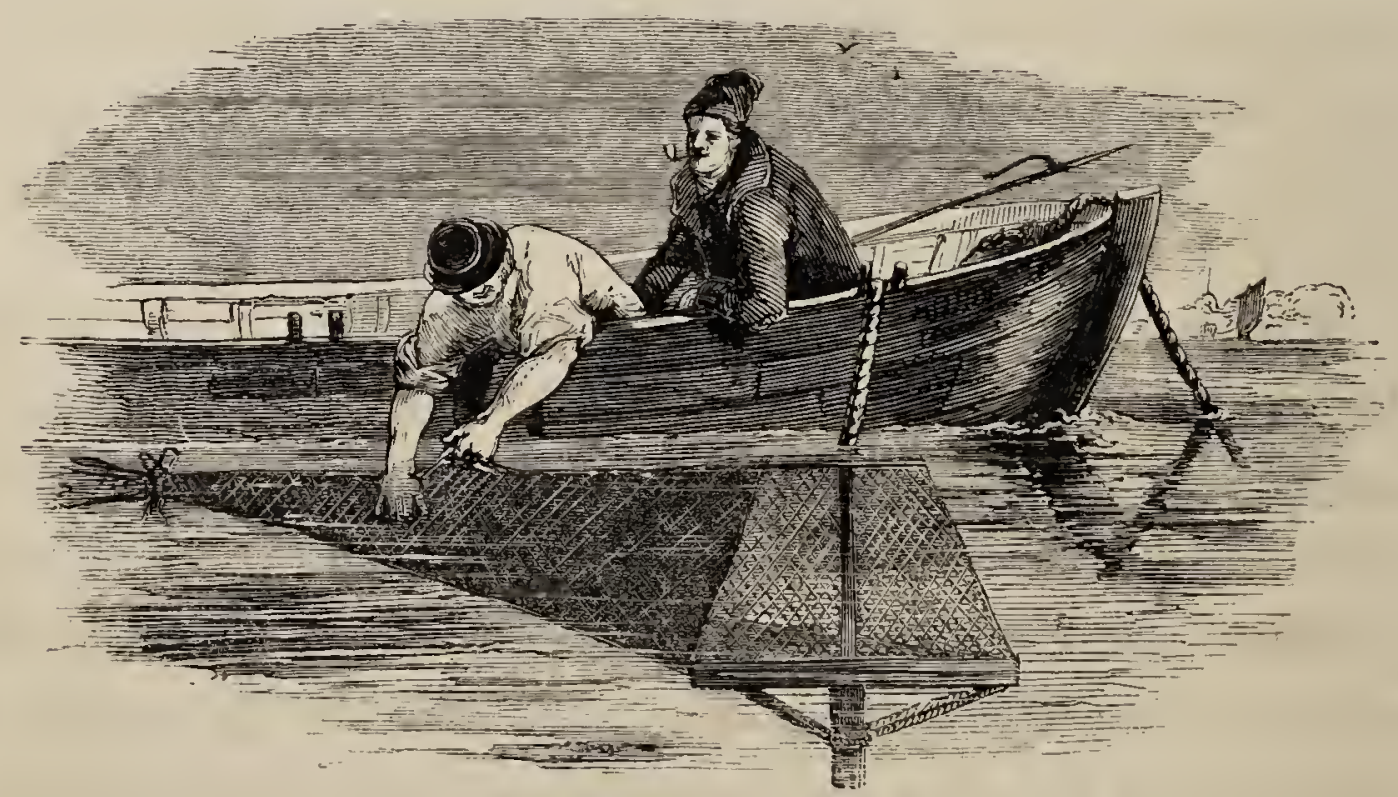




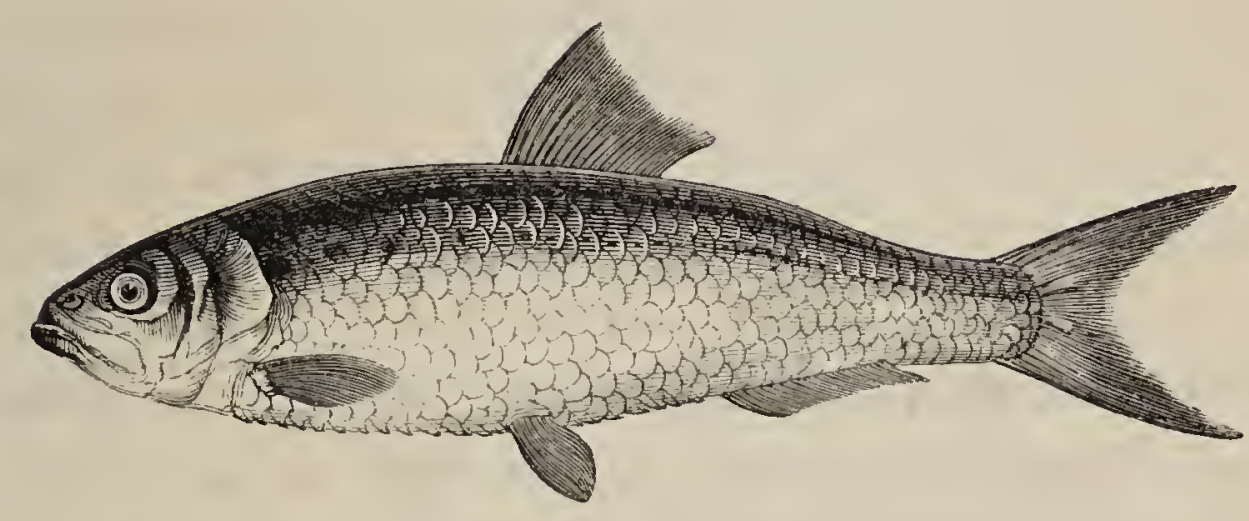

\section{THE TWAITE-SHAD.}

Alausa vulgaris, Valenciennes, Hist. des Poiss. xx. 389.

Alosa finta, Cuvier, Règne An. t. ii. p. 320

\begin{tabular}{|c|c|c|}
\hline & ", & \\
\hline & & La Feinte, Duни mei, sect. iii. pl. \\
\hline & $\cos$ & LINNAUS. BlOCH, pt. i. pl. 30 . \\
\hline & " & $\begin{array}{l}\text { Shad, Penn. Brit. Zool. vol. iii. p. } 46 \\
\text { Don. Brit. Fish. pl. } 57\end{array}$ \\
\hline & $"$ & FLEM. Brit. An. p. 183, sp. \\
\hline & & Jenyns, Brit. Vert. p. 437. \\
\hline
\end{tabular}

Aladsa. Generic Characters. - Upper jaw with a deep notch in the centre; very small and deciduous teeth on the jaws: none on the palate or tongue. Air bladder simple, pointed at both ends.

The genus Alausa, or Shad, is sharply separated from the other members of the Herring family that have an acute and serrated belly by the paucity and feebleness of the teeth. In other respects their organization is the same. They possess a pretty large pointed stomach, with an ascending branch having muscular coats. The pisiform air-bladder does not advance forwards before the third vertebra.

The Alosa of Rondeletius is not described or figured as possessing either teeth or spots; and Cuvier, by his 
usual research, had probably satisfied himself that the fish to which the term alosa had been originally applied was a toothless Shad, and that the toothed and spotted Shad was the true finta. Pennant, in noticing the second British species of Shad taken in the Thames and the Severn, which is without teeth or the row of lateral spots, called it an Allis, a name preferable to Alosa. The old name for the Shads was Lachia; and hence are derived Hallachia, Alachia, Alosa, Alose, and Allis or Allice. Ausonius who wrote A.D. 380, in his poem on the Moselle, calls this fish Alausa, and we follow M. Valenciennes in using this name as it is more euphonious than Alosa.

The differences noticed by Pennant and others in the smaller species of Shad, taken also in the Severn, near Gloucester, called the Twaite, induces the belief that it is our common Thames Shad; and the note by the editor of the last edition of the British Zoology, at the foot of page 463 (vol. iii.), is particularly deserving of notice. "I suspect," says the note, "that the Shad and Twaite are distinct species, and correspond with the Alose and Feinte of Duhamel." This appears to be precisely the case, as a comparison of our two Shads with the representations in Duhamel's work will prove : and Professor Nilsson, in his Prodromus of the Fishes of Scandinavia, which has been frequently referred to, has correctly designated and described our more common shad of the Thames as the finta* of Cuvier.

I venture to propose the names of Twaite-Shad and Allice-Shad for our two species, the better in future to distinguish them; thus combining the generic name Shad

* Page 22.-C. finta, Cuv. C. maxilla superiore antice profunde incisa; inferiore vix longiore; maculis 5-6 lateralibus in serie positis; dentibus utriusque maxillae distinctis. Longit. circa 15 poll. 
with a trivial name by which these two fishes have been hitherto, to some extent at least, locally known.

It is necessary to mention, however, that M. Valenciennes, after careful anatomical examination of all the varieties of Alausa, indicated by authors, took a different view from his master Cuvier, and came to the conclusion that the toothless or variegated Shad, and the Feinte or Venth, with teeth on the jaws constitute but one species. Notwithstanding this high authority we shall continue to describe them separately, as in the former editions of this work, especially as the distinction is recognised by the fishermen on both the French and English coasts.

The Twaite-Shad then, if I may so call it, is a sea-fish which enters our rivers about May, and in consequence of the time of its annual visit to some of the rivers of the European Continent is called the May-fish. The object of its visit to the fresh water is to deposit its spawn; and, that accomplished, it returns to sea by the end of July. Twaite-Shads appear during these three months in abundance in the Thames, from the first point of land below Greenwich, opposite the Isle of Dogs, to the distance of a mile below; and great numbers are taken every season. These fish produce, however, but a small price to the fishermen, having little repute as food, their muscles being exceedingly full of bones and dry. Formerly great quantities of the Twaite-Shad were caught with nets in that part of the Thames opposite the present Penitentiary at Millbank, Westminster. Above Putney Bridge was another favourite spot for them; but the state of the water, it is believed, prevents the fish ascending the river in the same manner as in former years, and but few comparatively are taken. The ordinary size of the adult fish of this species is from twelve to sixteen inches.

VOL. I. 
Shad are not allowed to be caught in the Thames after the 30th of June, that the remaining fish may cast their spawn without interruption from nets.*

The principal spawning-time of the Twaite-Shad in the Thames is about the second week in July, when numbers may be seen and heard frisking at or near the surface. In the language of fishermen, the Shad are said to thrash the water with their tails : they appear to disencumber themselves of the matured roe by violent muscular action; and on a calm still evening or night the noise they make may be heard at some distance. I have obtained the young only two inches and a half long in October; and suspect that they grow slowly, finding them only four inches long, and the young of the larger AlliceShad only six inches long, in the following spring.

The habits and habitat of the two species of Shads have probably been very frequently confounded. Though both are common in the Severn during a particular season, Montagu has not noticed the appearance of either on the coast of Devon: yet the Rev. Mr. Holdsworth sends me word that Twaite-Shad are very common on that coast and in the rivers; he has taken several at one time when whiffing with a light running line for Mackerel in the mouth of the Dart. The bait was a slice of a Mackerel. Both species have been noticed on the Cornish coast by $\mathrm{Mr}$. Couch, and by Mr. Heysham on the west coast of Cumberland. The Twaite-Shad has been caught near Dublin. On the eastern coast it is common in the Thames; is occasionally taken off Yarmouth on the Norfolk coast, with the Herrings, and also in the Tyne. Dr. Parnell says, "On the coast of Scotland, the Twaite-Shad receives the name of Rock Herring. We observe this fish enter the Frith of Forth in tolerable abundance towards the end of July, and

* Whitebait are plentiful throughout May and June. 
dozens are then taken in the Salmon-nets, at almost every tide; but after August we lose sight of them until the following season." It appears to have a considerable range to the northward, both Professors Nilsson and Reinhardt including it among the fishes of Scandinavia. The food of the Shads is small fish and the softer-skinned crustacea.

The length of the head compared to the whole length of the fish is as one to five; the depth of the body rather greater than the length of the head; the distance from the point of the llose to the commencement of the dorsal fin, carried from thence onwards, falls far short of the end of the fleshy portion of the tail; the base of the last dorsal fin-ray is half-way between the point of the nose and the end of the caudal rays; the longest ray of the dorsal fin is as long as the base of the fin; the ventral fins, which have no axillary scales, are placed a little behind the line of the commencement of the dorsal fin; the base of the anal fin, occupying about two-fifths of the space between the ventral fin and the end of the fleshy portion of the tail, is shorter than the anal fin in the Allice-Shad, and has five rays less, beginning also more forward: the tail deeply forked; the caudal rays with two thin membranous appendages on each side, parallel to the seventh and thirteenth caudal rays, about an inch in length by three-eighths deep; all four membranes opening from the centre, being attached by the outer edge only. The scales of the body rather larger in proportion than those of the Allice; the lateral line, as in most of the Clupeida, scarcely perceptible. The abdomen strongly serrated. The lower jaw the longest, with a few teeth anteriorly; the upper jaw with a deep central notch, and a row of small teeth on the edge down each side. The breadth of the eye equal to one-fourth 
of the length of the head; the mucous vessels on the surface of the gill-covers beautifully arborescent; the top of the head and back dusky blue, with brown and green reflections in particular points of view; from the upper edge of the operculum a row of five or six dark spots extend in a line backwards, the last generally the most indistinct, the number sometimes more than six; the irides, sides of the head and body, silvery white, with a tinge of copper colour; dorsal and caudal fins dusky; pectoral, ventral, and anal fins white. This species is immediately distinguished from the Allice-Shad by possessing teeth, by the lateral spots, and the smaller anal fin. The fin-rays in number are-

D. 18: P. 15: V. $9:$ A. 21: C. 19 . Vertebræ 55.

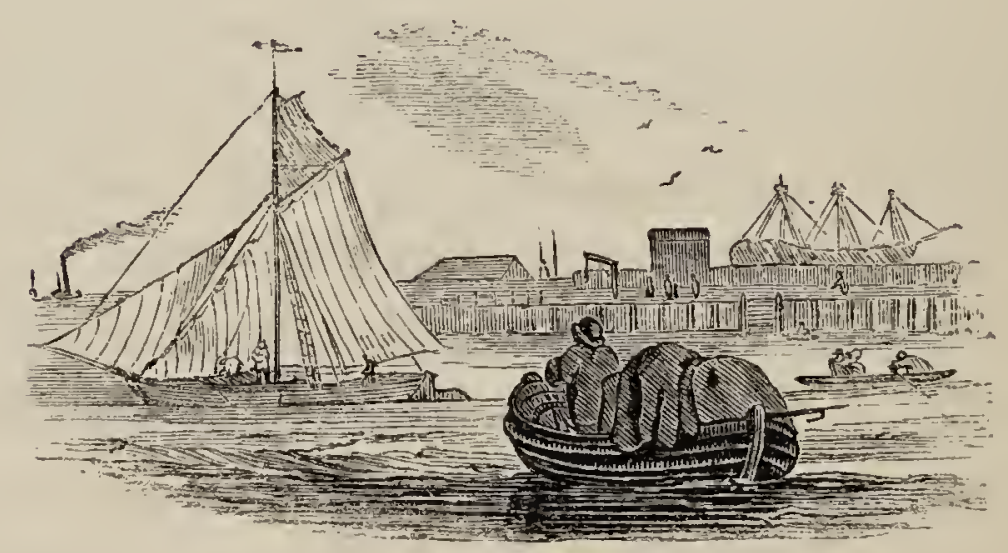




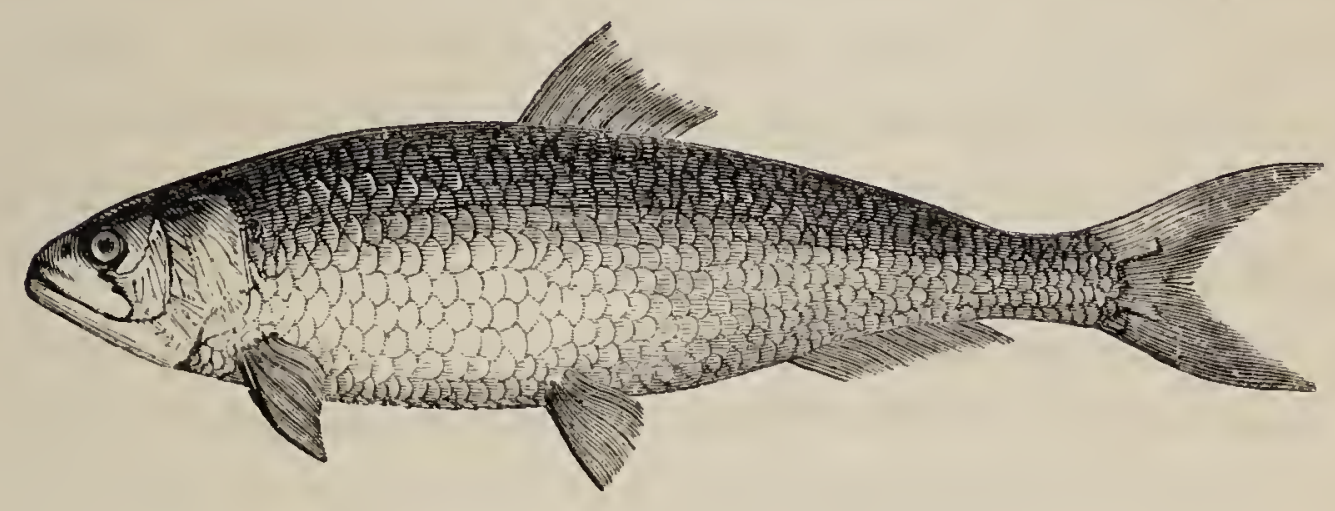

\section{THE ALLICE-SHAD.}

Alausa communis (vulgaris), Valencinnnes, Hist. des. Poiss. xx. 394.

Alosc , , Cuvier, Règne An. t. ii. p. 319.

,, , Willughisy, pl. P. 3, fig. 2.

,, , Allice, Penn. Brit. Zool. vol. iii. p. 463.

," $\quad, \quad$ Alose, Duhamel, sect. iii. pl. 1, fig. 1.

Clupea alosa, Allis, Jenyns, Brit. Vert. p. 439.

The Allice-Shad, by far the larger of the two in size, appears to be much more limited in its localities as a British species. It is represented by Pennant and others as abundant in the Severn, but is much less known elsewhere.

Dr. Hastings, in his Illustrations of the Natural History of Worcestershire, at page $\mathbf{7 7}$ says, "This is another fish which the Severn affords in great perfection. These fish generally appear in May, though sometimes in April. This, however, depends a good deal upon the quality of the water : if it is clear, they ascend early in the spring; but if there happen to be a flood, they wait till the waters are restored to their former purity; and if they meet with a flood in their progress upward, they immediately return, and keep below Gloucester. The weight 
of this Shad (the Allice of Pennant) is seldom less than four pounds. It continues in the river about two months, and is succeeded by a variety called the Twaite, which is less than the Shad, never weighing more than two pounds, and is but little esteemed. Dr. Fleming says, that the celebrated Whitebait of the Thames, which appears near Blackwall and Greenwich during the month of July, is the fry of this fish; but as we hear nothing of the Whitebait in the Severn, although Shad are plentiful there, ${ }^{*}$ further investigation seems to be required on this point."

In the Thames, the Allice-Shad is of rare occurrence. A specimen was brought to me in 1831, that had been caught above Putney Bridge; and another was taken in 1833, which is noticed by Mr. Jesse in the third series of his Gleanings in Natural History, page 147. "This fish was taken June 25th, opposite Hampton Court Palace; and its appearance so high up the river is very unusual. On taking it out of the well of the boat, it was full of spawn, and died immediately." I have had opportunities of examining very fine specimens from the Severn, sent to me by T. B. L. Baker, Esq. of Hardwick Court.

This species is not uncommon on the north-east coast of Ireland. On the north-eastern coast of England, namely, at Berwick,-Dr. George Johnston says it is frequently taken at the mouth of the Tweed in autumn, and sold in the market, but held in no estimation. Dr. Parnell says this species is rare in the Forth. The flesh of this fish is said to be of good flavour, and the quality is considered to improve the higher the fish ascends the river. Ausonius, writing in the fourth century, says, that the Shad was used as food by the common people only.

* This, it may be remembered, was adduced as one of the proofs that the Whitebait were not the young of the Shad. 
AElian says the Shads appear to take pleasure in the sounds of musical instruments; but if it happens to thunder when they are ascending rivers, they return rapidly to the sea.

Both species of Shads have great resemblance, except in size, to Herrings, and have been frequently called the mother of Herrings, and king and queen of the Herrings. The large Herrings of two feet in length, spoken of by Anderson and others, and said to occur in the Northern Seas, and among our Northern Islands, are no doubt to be considered as referring to our Shads.

The specimen described measured two feet in length; the body deep and compressed; the thickness rather less than one-third of the depth. The length of the head compared to that of the whole fish is as one to six; the depth compared to the whole length, as one to four and a half. The length of the base of the dorsal fin three inches: the fourth ray, which is the longest, is one-third shorter than the whole length of the base of the fin: the first and second rays shorter than the third; these three rays simple, all the others branched: the first ray half-way between the point of the nose and the last ray of the anal fin; the last ray exactly half-way between the point of the nose and the end of the tail. Pectoral fin small; the upper ray the longest, strong and simple; the others branched: ventral fin also small; the first ray arising in a vertical line under the first ray of the dorsal fin; axillary scales long, narrow, and pointed: anal fin commencing half-way between the ventral fin and the origin of the lower caudal rays, nearly one-fourth longer in the base than the dorsal fin; the first three rays shorter than the fourth, which is the longest, and only one-third the length of the base of the fin: the tail long and slender, deeply forked; the rays of the middle only one- 
fourth of the length of the longest external rays; the seventh and thirteenth caudal rays furnished with membranous appendages on each side similar to those observed in the Twaite-Shad. The fin-rays in number are-

$$
\text { D. } 19: \text { P. } 15: \text { V. } 9: \text { A. } 26: \text { C. } 20 .
$$

The lower jaw the longest and smooth; the upper jaw with a central notch; the lateral edges crenated: the breadth of the eye rather less than one-fifth of the length of the head, and placed one diameter and a half from the end of the nose: mucous vessels of the gill-covers beautifully distributed; the nape and shoulders rise suddenly; the greatest depth of the body just before the ventral fin; scales of the body rather large, nearly circular, and thin ; no distinct lateral line; abdominal edge strongly serrated, particularly behind the ventral fins. The colours very similar to those of the Twaite-Shad, with a single dusky patch behind the operculum, sometimes scarcely visible.

Figure 1 of plate III. in Dr. Fleming's Philosophy of Zoology is a representation of the Allice-Shad.

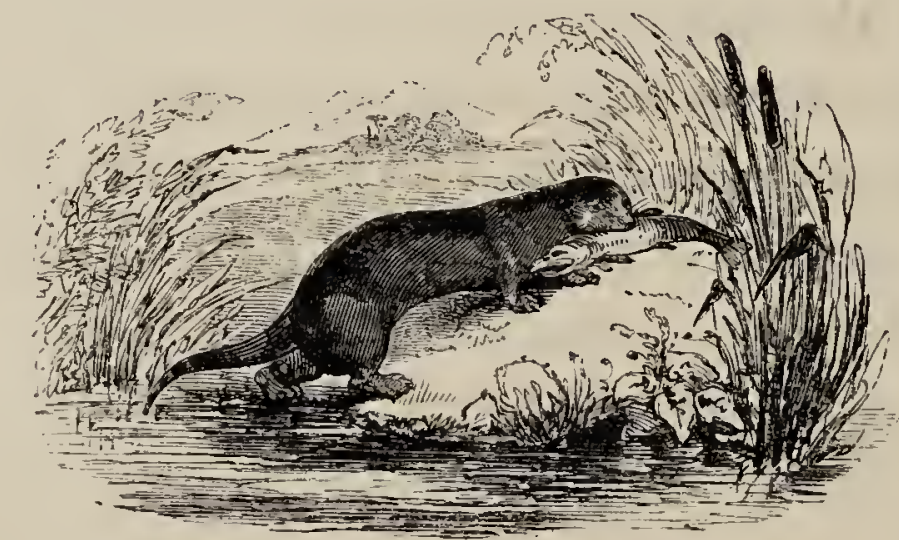




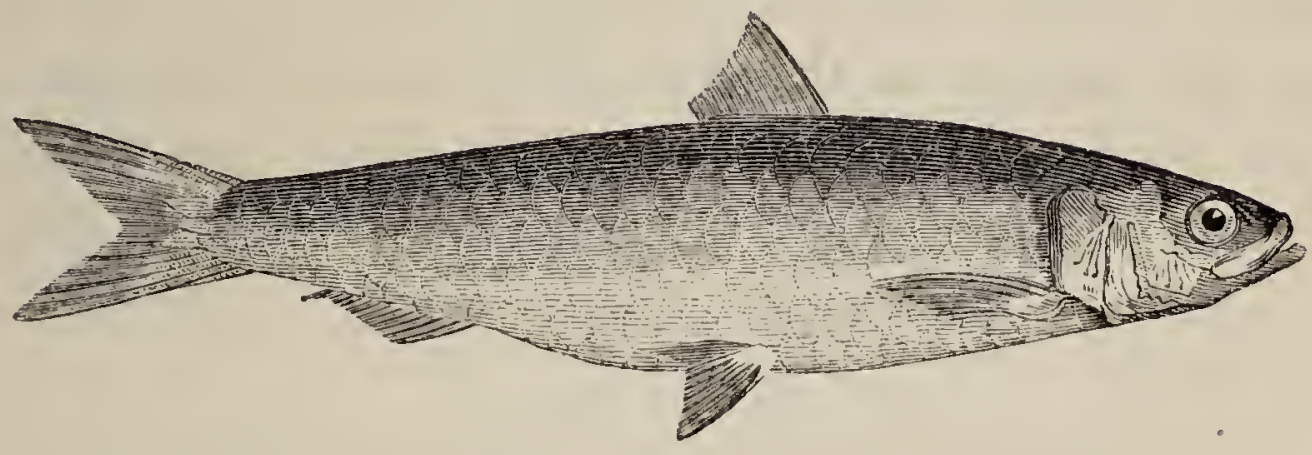

\section{THE PILCHARD.}

Sardinia of Commerce. gipsey or crue herring. Scotland.

Alausa pilchardus, Valenciennes, Hist. des Poiss. xx. 445.

Clupea ," BцоCH, pt. xii. pl. 406.

, $\quad, \quad$ Willughi, p. 223, tab. P. 1, fig. 1.

" , $\quad$ Cuvier, Règne An. t. ii. p. 319.

" $\quad$ " Pilchard, PenN, Brit. Zool. vol. iii. p. 453, pl. 79.

", " ", , Don. Brit. Fish. pl. 69.

", pilcardus, ", FuEM. Brit. An. p. 183, sp. 52.

," , , Jenwns, Brit. Vert. p. 436.

The following account of the Pilchard is derived from the MS. of Mr. Couch, from whose various scientific acquirements, habits of observation and locality, it may be fairly inferred that no better authority could be quoted.

The older naturalists considered the Pilchard, like the Herring, to be a visitor from a distant region; and they assigned to it also the same place of resort as that fish, with which indeed the Pilchard has been sometimes confounded. To this it will be a sufficient reply, that the Pilchard is never seen in the Northern Ocean, and the few that sometimes wander through the Straits of Dover, 
or the Bristol Channel, have evidently suffered from passing so far out of their accustomed limits. It frequents the French coasts, and is seen on those of Spain ; being the Celerin or Ceilan of the French Fishermen, and known on the Spanish coast by the names of Sarda and Sardinia. The peculiarly-shaped boats named "Bean-cods," at Lisbon, are much employed in fishing for Sardinias. It is the Royan of the fishermen of Bordeaux.

On the coast of Cornwall Pilchards are found through all the seasons of the year, and even there their habits vary in the different months. In January they keep near the bottom, and are chiefly seen in the stomachs of ravenous fishes; in March, they sometimes assemble in schulls, and thousands of hogsheads have in some years been taken in seans: but this union is only partial, and not permanent; and it is not until July that they regularly and permanently congregate so as to be sought after by the fishermen.

The sean fishery commences in August, and continues until the shortened days and stormy weather of the equinox render its further prosecution impracticable; but the fish continue to appear, sometimes in great numbers, until the conclusion of the year. The season and situation for spawning, and the choice of food, are the chief causes which influence the motions of the great bodies of these fish; and it is probable that a thorough knowledge of these would explain all the variations which have been noticed in the wanderings of the Pilchard, in the numerous unsuccessful seasons of the fishery. In some years, at least, a considerable body of Pilchards shed spawn in the month of May-perhaps in the middle of the Channel, where I have known them taken, heavy with roe, in drift nets shot for Mackerel; yet it seems certain that they do 
not breed twice in the year, and that the larger body do not perform this function until October, and then at no great distance from the shore. I have known an equally great variation to occur in other fishes, which have in consequence visited us, and been in season, at a time not expected by the fishermen.

They feed with voracity on small crustaceous animals; and their stomachs are frequently crammed with thousands of a minute species of shrimp, not larger than a flea. It is probably when they are in search of something like this, that fishermen have seen them lying in myriads quietly at the bottom, examining with their mouths the sand or small stones in shallow water. The abundance of this food must be enormous, if, as there can be no doubt was the case, all the schulls on the coast were as well fed as the individuals I examined. The Pilchard has been known to swallow a hook baited with a worm; and it is probable that it devours the roe of fish; for a gentleman who resided on the shores of the Bay of Biscay informed me that it is the custom of the French fishermen to throw large quantities of the salted pea-roe of fish about their nets, to attract Pilchards, and that he has seen much of this spawn in the stomachs of Pilchards so taken. Large quantities of the roe of fish are imported into France for this purpose from northern nations.

When near the coast, the assemblage of Pilchards assumes the arrangement of a mighty army, with its wings stretching parallel to the land; and the whole is composed of numberless smaller bodies, which are perpetually joining together, shifting their position, and separating again. There are three stations assumed by this great body, that have their separate influence on the success of the fishery. One is to the eastward of the Lizard, the most 
eastern extremity reaching to the Start Point in Devonshire, beyond which no fishery is carried on, except that it extends on rare occasions to Dartmouth; a second station is included between the Lizard and Land's End; and the third is on the north coast of the county, the chief station being about St. Ives. It is common for one of these districts to be full of fish, while in neither of the others is a schull to be seen; but towards the end of the season they often move from one station to another, or perhaps traverse in succession all the shores of the county. The subordinate motions of the schulls are much regulated by the tide, against the current of which they are rarely known to go; and the whole will sometimes remain parallel to the coast for several weeks, at the distance of a few leagues, and then, as if by general consent, will advance close to the shore, sometimes without being discovered till they have reached it. This usually happens when the tides are strongest, and is the period when the principal opportunity is afforded for the prosecution of sean-fishery.

The fishery for Pilchards is carried on by drift or driving nets, and with seans. The outfit of the former, which somewhat resembles that employed for Mackerel, consists of a number of nets, great in proportion to the wealth of the proprietor and the size of the boat, but commonly about twenty, each from eighteen to twenty fathoms long, and seven fathoms deep; so that a string of driving nets will sometimes reach three-quarters of a mile. These nets are fastened to each other in length, and to a head-line, appropriated to each, along which runs a row of corks; another line runs loosely along the middle of the nets to afford additional strength, but no lead is used at the bottom. The nets are carried in common fishingboats, some of which, as at Mount's Bay, are luggers, 
and most of the others have spritsails: the crews consist each of four men and a boy. The fishery begins a little before sunset, and the nets are drawn in about two hours, to be again shot as morning approaches; for Pilchards enter the nets better at these seasons. A rope from one end of the string is fastened over the quarter of the boat, and the nets are left to float with the tide, no sails being set, except rarely in very calm weather, to prevent the nets being folded together. Within a few years an improvement has been made, derived, it would appear, from the practice of the herring-fishers, by which more fish have been taken, and much of the hazard obviated to which the nets were exposed by ships passing over them. It consists in diminishing the number and size of the corks along the head-line, and in fixing cords at proper distances, each of which has attached to it a stout buoy. These cords are from two to two and a half fathoms long, and consequently allow the upper edge of the nets to sink to that depth below the surface; but even now it is found that the fish are principally caught in the lower part of the net.

The number of fish taken by a drift-boat in a night's fishing varies exceedingly: from five to ten thousand is considered moderate; it often amounts to twenty thousand. For the season's fishing, about one hundred and fifty thousand fish would be deemed favourable.

For the sean-fishing, three boats are provided, of which two are about forty feet long, and ten wide at the beam, with flat timbers and a sharp bow. The first is termed the sean-boat, and is furnished with a sean two hundred and twenty fathoms in length, and twelve fathoms deep, which is buoyed along the head-rope with corks, and weighed down with leads. The second boat is called the volyer, a term supposed to be a corruption of the word 
follower.* This boat has a sean from one hundred to one hundred and twenty fathoms in length, and eighteen fathoms deep at its deepest part, and is termed the tucksean: it differs from the former, called the stop-sean, as well in shape as in dimensions, the middle being formed into a hollow or bunt. A third boat, called the lurker, is less than the others, and has no sean. The crew attending a sean consists of eighteen men and one or two boys. Seven of these are assigned to each of the larger boats, and the remaining four, including the master seaner, to the lurker. This fishery commences in August, three weeks or a month after the drivers, whose success, or the want of it, has much influence. The three boats proceed in the afternoon to some sandy bay, and cast anchor, keeping a good look-out for the appearance of fish, which are discovered either by the rippling of the water, by the stoiting or leaping of the fish, or by the colour they impart to the sea. In these respects, as marks of the difference between the Herring and the Pilchard, fishermen observe that the former rarely springs from the water, or stoits, as it is called, except when alarmed or driven: but the Pilchard does this often, and apparently from wantonness. When alarmed, both these fish will rush along the distance of five or six feet, as marked by the briming; $\psi$ but the Pilchard does this with more celerity than the Herring.

When the presence of fish is discovered, the lurker proceeds to the place to ascertain the magnitude of the schull, and the direction in which it is moving. The depth of water, clearness of ground from rocks and other obstructions, and the force and direction of the tide, enter

* Felge, Dan.; Följe, Swed.-followers, suite.

* The flash of light seen in the sea when disturbed in the night, and supposed to proceed from minute molluscous or crustaceous animals. 
also into the calculation of the master before he makes the signal for preparation. All the proceedings are directed by signs, for the fish are alarmed at noise, and when everything is favourable, a warp from the end of the sean is handed to the volyer, whose place it is to keep all taut; the lurker continuing with the fish to watch their motions, and to point to the sean-boat what is to be enclosed. The sean-boat is rowed by four men, the other three being employed in throwing the net; and such is the vigour exerted on this occasion, that this great body of net, rope, corks, and lead is thrown into the sea in less than five minutes. The sean at first forms a curved line across the course of the fish; and while the two larger boats are employed in warping the ends together, the lurker's station is in the opening, where, by dashing the water, the fish are kept away from the only place of escape. When the sean is closed and the ends are laced together, if the body of the fish be great and the sea or tide strong, the net is secured by heavy grapnels, which are attached to the head-ropes by hawsers. It will appear from this account that it is not more difficult to take a thousand hogsheads of fish than a single hogshead; the only difference being, that with the greater quantity the sean is regularly moored, which with a smaller is unnecessary : it may even be said that the capture of a larger body is most easily effected; for, as its motion is slow, its course is not so speedily altcred.

When the evening has closed in, and the tide is low, they proceed to take up the fish. For this purpose, leaving the stop-sean as before, the volyer passes within it, and lays the tuck-sean round it on the inner side: it is then drawn together so as gradually to contract the limits of the fish, and raise them from the bottom. When disturbed, they become exceedingly agitated; and so great 
is the force derived from their numbers and fear, that the utmost caution is used lest the net should either sink or be burst. When the tuck-sean is thus gradually contracting and the boats surround it, stones suspended from ropes, called minnies, are repeatedly plunged into the water, at that part where escape alone is practicable, until the fish then to be taken up are supported in the hollow or bunt of the sean.

When brought to the surface, the voices of the men are lost in the noise made by the fish as they beat the water. The seaners fix themselves in pairs on the gunwales of the boats, with flaskets to lade the fish on board. When the quantity enclosed in the stop-sean is large, the tuck-sean is made to enclose no more than the boats can carry, of which a master seaner commonly forms a correct judgment by the extent of the briming in his sean, as the fish move in it; and many advantages result from taking up only a portion at one time, for the whole can thus be salted in proper condition, without fatigue or extraordinary expense: thus a week may possibly elapse before the whole of the capture is secured, part being taken up every night.

The description here given of the manner in which the Pilchard fishery is conducted applies to the greater part of the coast, but some variation occurs in particular districts. In Mount's Bay the men and boats employed to take the fish are not the same that convey it to land; a mode of proceeding rendered necessary by the distance from shore at which it is taken. The fishery at St. Ives is regulated by a particular act of parliament, and huers* are employed there and elsewhere to assist the fishermen.

* Huers'are men posted on elevated situations near the sea, who by various concerted signals, made with a bunch of furze in each hand, direct the fishermen how best to surround a schull of fish.-Huie, to shout,--Danish. 
The sean-fishery, as practised formerly, resembled that carried on at St. Ives; and in one of Norden's maps is a representation of the taking of Pilchards by means of a sweep-net, of which one end continues near the shore, as then employed in St. Austle's Bay. The capture was drawn on shore in the mode now used with ground-seans for other fish, and consequently none could be taken unless they approached near to an open beach; one end of the sean is still termed the pole end, from the pole shod with lead then used to elevate and spread the part to which the warp was attached.

Old and experienced fishermen have stated as the result of long observation, that besides the well-known fact of the fish being mostabundantly taken within a few days after the spring-tides, the direction of the tide has great effect on the motions of the schull. Its progress is always towards the same point, and in drift-nets all the heads of the fish point in one way, unless the tide has turned while the nets were afloat. In a bay where the tide comes round a headland and circles the bay, the fish take the same route, and a man aware of this may know in what direction to watch, and whither the schull is proceeding; and as, especially when the tide is rapid, he must be careful that the sean is not carried on the back of the schull, the net must be so shot as to have the benefit of the tide, and yet be laid across the front of the fish. A schull will not turn back directly contrary to its former course, although, when alarmed, its direction may be considerably changed. In the open sea, driftnets are commonly cast in the direction of the tide, because the nets are most easily kept in that course; but when near land, or the entrance of a bay, a favourite position is parallel to it, by which the fish are intercepted in their advance or retreat. I have seen drift-boats shoot 
their nets in the midst of a multitude of fish, one in the direction in which they were going, and another across their course, and in less than two hours the second had taken nine thousand, and the other not a fish; and yet the boats frequently prefer the first plan. The most successful time for the drift-net fishery is during hazy nights, with some motion of the waves, for the fish then enter the nets freely, whereas in clear moonlight they are shy; and in very dark nights, such is the brightness of the briming, that the nets look like a wall of fire, and deter the fish.

As an object of adventure, the Pilchard fishery is popular in Cornwall, and beyond a doubt the community is greatly benefited by it; yet it frequently happens that the success is partial, and the price low; and it may be questioned whether in any year the greater part of the seans obtain more than their expenses : but when there is a profit, it is commonly considerable, and in this lottery every one is led by the hope of being among the fortunate.

The following is a statement, perhaps nearly approach-" ing to the truth where absolute certainty is unattainable, of the amount of property engaged in the Pilchard fishery in the year 1827, when the bounty began to be withdrawn :-Number of seans employed, 186 ; not employed, 130 ; total number of seans, 316 : number of drift-boats, 368: men employed on board drift-boats, 1600 ; number of men employed on seans at sea, 2672; number of persons on shore to whom the fishery affords direct employment, 6350 ; total number of persons employed in the fishery, 10,521: cost of seans, boats, \&c. used in the fishery, 209,840l.; cost of drift-boats and nets, 61,400l. cost of cellars for curing, and other establishments on shore for carrying on the fishery, 
169,175l.; total capital invested directly in the Pilchard fishery, 441,215l. The outfit of a sean amounts to about $800 l$. ; a string of drift-nets will cost about $6 l$. the net; and the boat from $100 l$. to $150 l$. ; but this is used throughout the year for the other kinds of fishing. The nets are supposed to last about six years, and ought, of course, to produce their own value within that time, together with an adequate profit; but it is the complaint of the fishermen that this is not the case. The profit of the men depends on the share of the fish, which is divided into eight parts, of which the boat has one-eighth part, the nets three, and the men four : a boy that accompanies them is rewarded with the fish that may fall into the sea as the nets are drawn, to secure which he is furnished with a bag-net at the end of a rod, termed a keep-net. At St. Ives, 250,000 Pilchards have been caught in a single draught.

The quantity of Pilchards taken is sometimes incredibly large. A fisherman now alive was present once at the taking of two thousand two hundred hogsheads of Pilchards in one sean; but the greatest number heard of as taken at one time is stated by Borlase at three thousand hogsheads; in reference to which Pennant has made an astounding error, in reckoning by mistake thirty-five thousand fish to a hogshead, instead of three thousand five hundred. The number since allowed has been three thousand, and is now two thousand five hundred fine fish; but it is scarcely necessary to say that they are not counted. An instance has been known where ten thousand hogsheads have been taken in one port in a single day, thus providing the enormous multitude of twenty-five millions of living creatures drawn at once from the ocean for human sustenance.

The different modes of curing the fresh fish are de- 
tailed elsewhere. The various ports on the northern shore of the Mediterranean are the principal places to which the preserved fish are exported. M. Valenciennes gives an account of the modes of taking this fish on the coasts of France in his Histoire des Poissons.

Our term Pilchard is said to be derived from Peltzer, a name by which this fish was known to some early Northern Continental authors. A few Pilchards make their appearance occasionally in the Forth about October, generally preceding the Herrings; but the great shoals appear to belong almost exclusively to our south-western shores. They are seldom seen east of Devonshire; but in August 1834 a shoal of Pilchards was observed in Poole Harbour, and so many fish were taken that they were sold in the market at a penny a dozen. In May 1838 I obtained one Pilchard in the Thames.

Smith's History of the County of Cork contains a full and interesting account of the Pilchard fishery in Bantry Bay. They have been noticed also on the coast of the county of Cork, and taken at Dublin and Belfast. On our eastern coast, a few are taken every year at Yarmouth with the Herrings. They were more than usually abundant there in the years 1780, 1790, and 1799 .

Specimens of the Pilchard sometimes measure eleven inches in length; the fish described measured nine inches. It much resembles the Herring, but is smaller and thicker. The length of the head is to the whole length as one to five; the depth of the body equal to the length of the head; the transverse thickness of the body equal to half its depth: the form of the head triangular, the upper surface flat; the dorsal and abdominal lines slightly and equally convex; no perceptible lateral line; the body across the back obtusely rounded: the line of the abdomen smooth; the edges of the scales of the two sides 
leave a longitudinal groove from the branchiostegous rays to the vent, along which groove extends a row of scales of a peculiar shape, of which the woodcut here placed is a representation; the two long narrow lateral arms extending on each side under the scales, the shortest projection pointing backward; the scales of the body are very large, deciduous, and ciliated at the free edge.

The distance from the point of the nose to the base of the last ray of the dorsal fin, and from thence half-way along the caudal rays, nearly equal : the commencement of the dorsal fin is therefore anterior to the middle of the fish by the whole length of the base of the fin; the first and second rays shorter than the third, which is equal to the length of the base of the fin ; these first three rays articulated, but simple; all the other rays branched: pectoral and ventral fins small, the latter commencing in a line under the middle of the dorsal fin; the axillary scales very long: the anal fin commencing half-way between the origin of the ventral fins and the end of the fleshy portion of the tail; the first ray short, the second and the last two rays the longest: the tail deeply forked; the scales at the end of the fleshy portion of the body extending far over the bases of the caudal rays, particularly two elongated scales above and below the middle line. The fin-rays in number are-

D. $18:$ P. $16:$ V. $8:$ A. $18:$ C. 19 . Vertebræ 55.

The mouth is small, almost without teeth, the under jaw the longest, as it is in all the preceding genera of this family: the breadth of the eye one-fourth of the 
length of the head, and placed at rather more than its own breadth from the point of the nose; the irides yellowish white: the cheeks and all the parts of the gillcovers tinged with golden yellow, and marked with various radiating strix: the posterior edge of the operculum nearly vertical and straight: the upper part of the body bluish green; the sides and belly silvery white; the dorsal fin and tail dusky. Mr. Couch says the Pilchard is sometimes found with a row of spots on the side, like the Shad; which seems to be the result of disease, these fish being small, soft, and unfit for curing.

While this sheet was going through the press for the second edition, the London newspapers noticed the appearance of numerous large shoals of Pilchards on the south coast of Ireland, which the poor fishermen were unable to take advantage of from the want of proper nets and salt.

The vignette represents the harbour of Polperro, where Mr. Couch studied the habits of the Cornish fishes for many years.

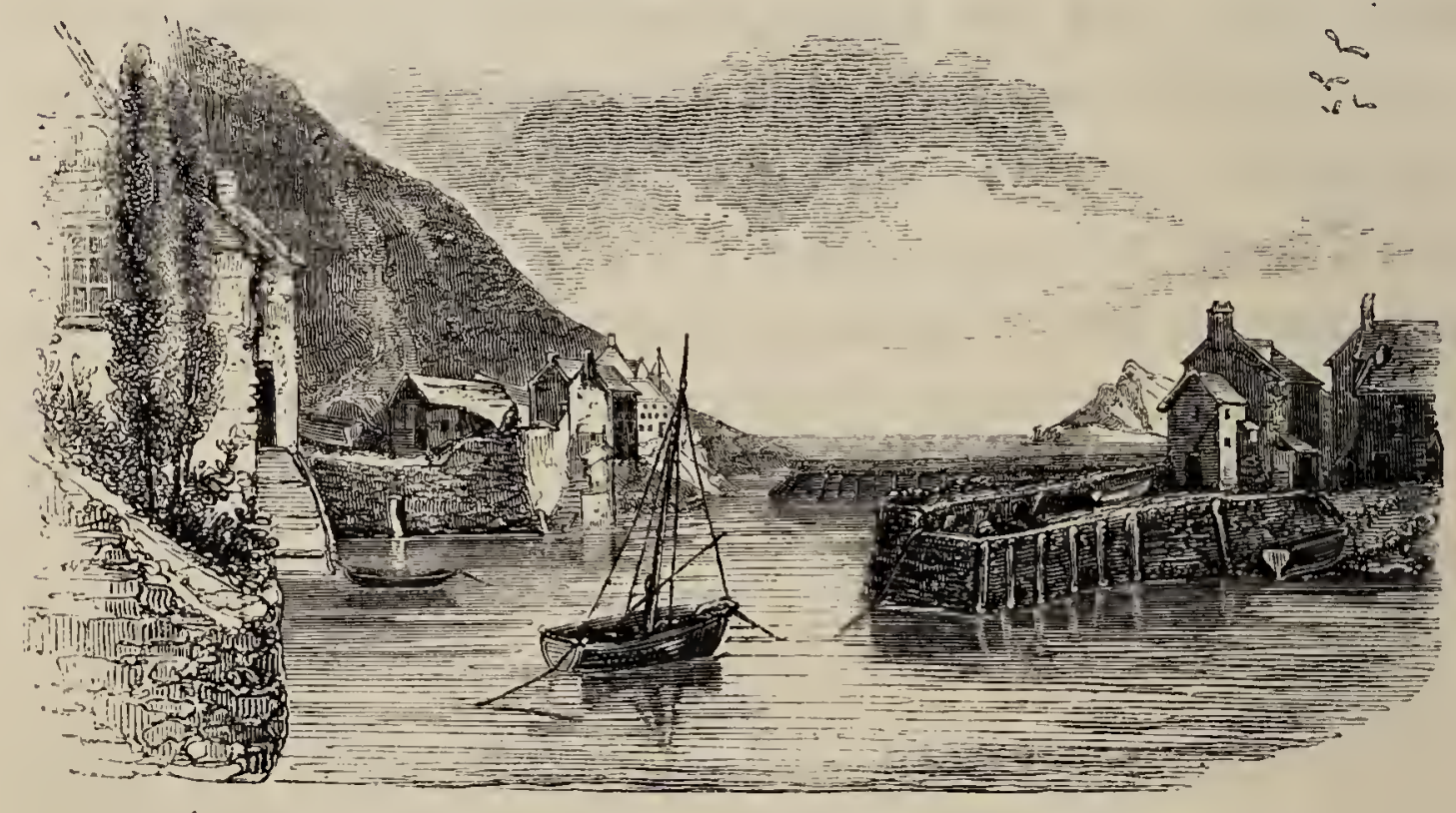




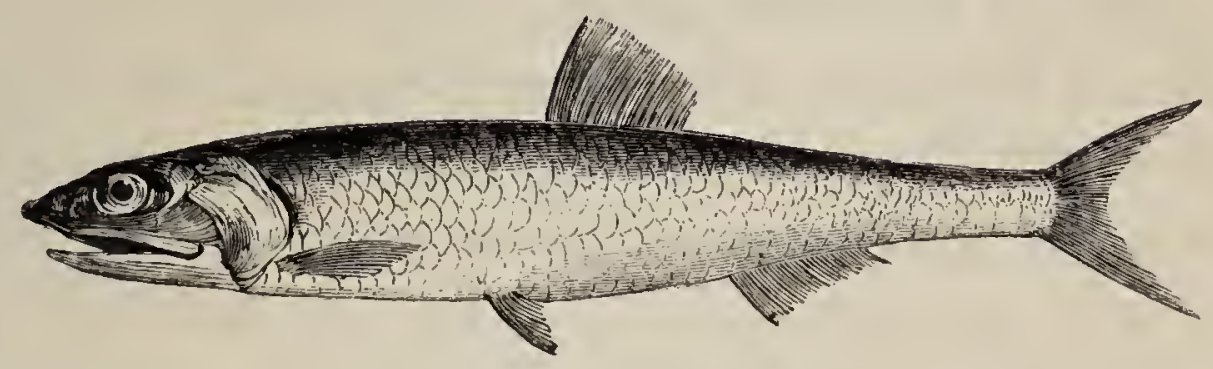

THE ANCHOVY.

Engraulis encrasicholus, Anchovy, Fuem. Brit. An. p. 183, sp. 54.

", vulgaris, Cuvier, Règne An. t. ii. p. 322.

," $\quad$ Willughis , p. 225, P. 2, fig. 2, App. 27.

Clupea encrasicholus, Linneus. Broch, pt. i. pl. 30, fig. 2.

, " $\quad$ Anchovy, PenN. Brit. Zool. vol. iii. p. 459, pl. 78.

" $\quad, \quad$ Don. Brit. Fish. pl. 50.

Engraulis encrasicholus, ", JENYNS, Brit. Vert. p. 439.

Engradurs. Generic characters. - Gape large; snout projecting. Nasal bone advancing beyond the jaws and concealing the small premaxillaries; maxillaries slender, their tips not passing back beyond the angle of the mouth; vomer, palatines, and entopterygoids narrow, armed with teeth, which are sometimes very minute. Gill-openings large. Body generally rounded; caudal forked. Pectorals low down. Ventrals small. Air-bladder communicating with the entrance of the stomach by a tube.

I have followed Dr. Fleming in preserving to the Anchovy the old name by which it was formerly known. It was called Lycostomus from the form of its mouth; and Encrasicholus Engraulis, because from its bitterness it was supposed to carry its gall in its head. For this reason the head as well as the entrails are removed when the fish is pickled.

The Anchovy is a common fish in the Mediterranean from Greece to Gibraltar; and was well known to the 
Greeks and Romans, by whom the liquor prepared from it, called Garum, was in great estimation. Its eastern range is extended into the Black Sea. It is the Roqueron or Anchoa of the Catalan fishermen and is common on the coasts of Portugal, Spain, and France; it occurs, I have no doubt, at the Channel Islands, and has been taken on the Hampshire coast. A century ago it was plentiful on the coasts of Brittany, though it is not so now.

The fishing for Anchovies is carried on during the night, and lights are used with the nets.

The Rev. Robert Holdsworth wrote me word that Anchovies had been taken in a Herring seine-net during autumn in the river Dart; and Mr. Couch, in his Cornish Fauna, says that "this fish abounds towards the end of summer, and if attention were paid to the fishery, enough might be caught to supply the consumption of the British islands. Bloch informs us that the fishery in the Mediterranean is carried on from May to July, at which period this fish enters that sea for the purpose of shedding its spawn; and that when this function is performed it returns to the Atlantic. I have not found it upon our coast until the autumnal equinox; and the fishery would be chiefly followed in October and November, when the fish are in fine condition; but some are met with through the winter, and until the month of March." The Anchovy is taken in the Bristol Channel. In the Appendix to Willughby's work, it is mentioned as having been taken on the coast of Wales; Mr. Bicheno has very recently obtained several on the coast of Glamorganshire; and Mr. Dillwyn, in his contributions towards a History of Swansea, says, "The late Charles Collins, Esq. showed me six pounds of Anchovies which he had purchased in Swansea market for a shilling; and 
I have since ascertained, that in some summers, if a net with proper meshes were used, a vast quantity of these fish might be taken in our bay." Pennant obtained the Anchovy near his own residence at Downing, in Flintshire; and it is said to be sold frequently in Liverpool market. It has not, that I am aware, been recognised on the coast of Ireland.

The Anchovy is reported to be at this time an inhabitant of the large piece of water below Blackwall, called Dagenham Breach; and in May 1838 I received one that was caught in the Thames, where, however, this species is so little known, that the specimen referred to was sent to me with a request to know what fish it was.

In a series of notes on the occurrence of rare fish at Yarmouth and its vicinity, with which I have been favoured by Dawson Turner, Esq. there is mention of a specimen of the Anchovy, taken on the beach, which measured six inches and a half in length. Mr. Couch says he has seen it in the Cornish seas of the length of seven inches and a half: additional proofs of the large size acquired by this fish on our shores. Dr. George Johnston does not mention this species as occurring on the coast of Berwickshire, nor does Dr. Parnell include it in his Fishes of the Forth: yet its range to the North is extensive, as it is occasionally taken on the coast of Norway and in the Baltic; but is not included by Linnæus in his Fauna Suecica.

The Anchovy is immediately recognised among the fishes of the family to which it belongs, by its sharppointed head, with the upper jaw considerably the longest. The length of the head compared with the length of the body alone is as one to three; the depth of the body but two-thirds of the length of the head, and compared to the length of the whole fish is as one to 
seven: the first ray of the dorsal fin arises half-way between the point of the nose and the end of the fleshy portion of the tail; the third ray of the dorsal fin, which is the longest, is of the same length as the base of the fin: the pectoral fin small; the ventral fins arise, in a vertical line, in advance of the commencement of the dorsal fin, which is over the space between the ventral and anal fins: the base of the anal fin is as long as the distance from its commencement to the origin of the ventral fins; the rays short: the tail deeply forked. The fin-rays in number are-

$$
\text { D. } 14 \text { : P. } 15 \text { : V. } 7 \text { : A. } 18 \text { : C. } 19 .
$$

The breadth of the eye is one-fifth of the length of the whole head; the peculiarity in the comparative length of the jaws has been previously noticed; this genus differing from the other British Clupeidx, in the mandible being shorter than the snout; the gill-covers are elongated; the scales of the body large and deciduous : the colour of the top of the head and back blue, with a tinge of green ; irides, gill-covers, sides, and belly, silvery white; the fins delicate in structure, and greenish white; the membranes connecting the rays almost transparent.

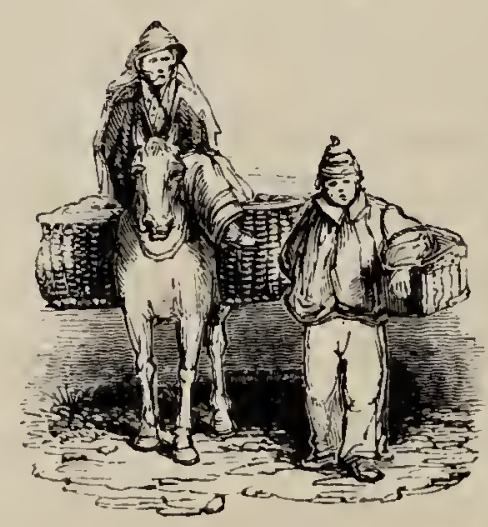




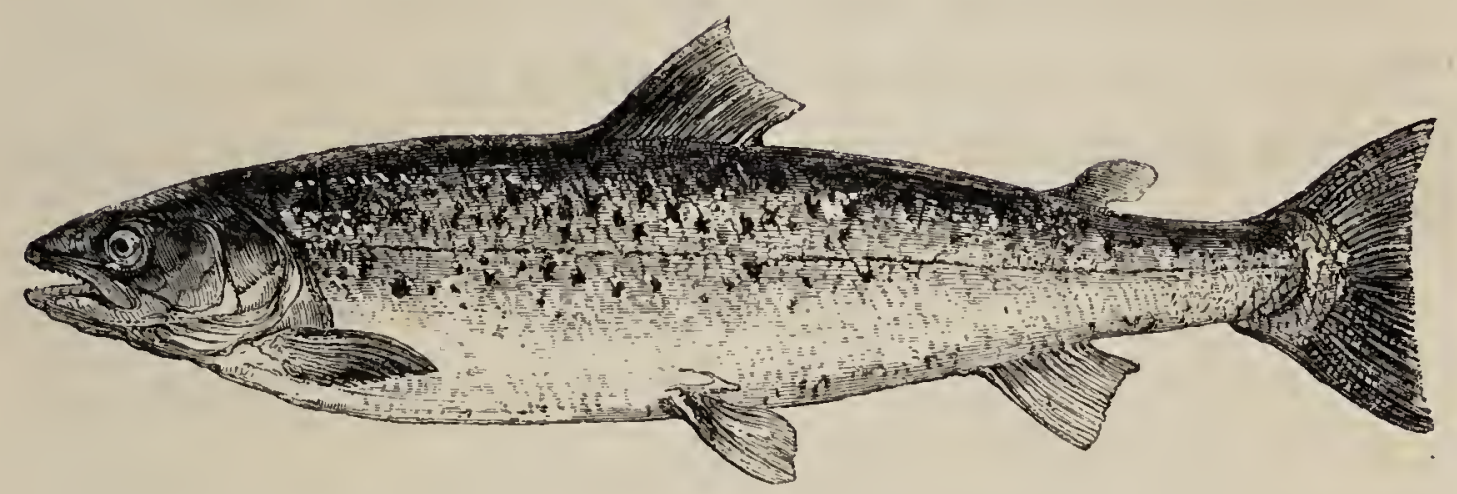

\section{THE SALMON.}

\section{SMOLT, young. GRILSE, first return from sea.}

Salmo salar, Linneus. Valienc. Hist. des Poiss. xxi. p. 182.

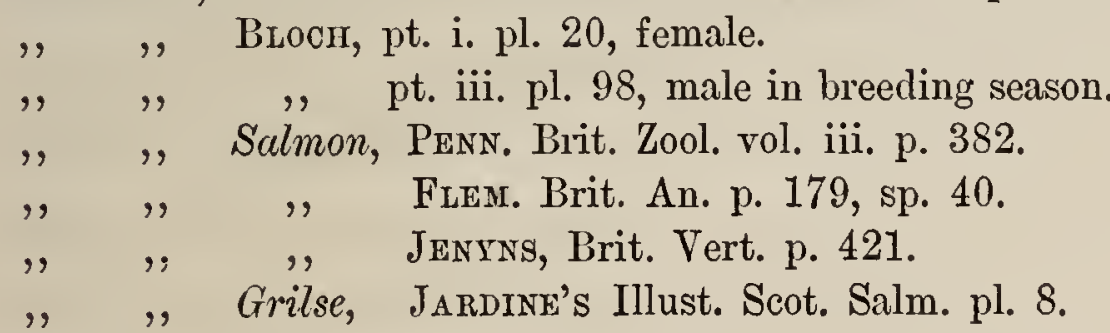

", , , , , , , , , , 1 \& 2 .

", ", Salmon, ", ", ", , , ", state.

SALMONIDF. Family Characters. - Scaly fishes with an adipose fin. Upper border of the mouth formed by the premaxillaries and maxillaries; branchiostegals numerous; supplementary gills ; air-bladder large and simple, without contractions; pyloric cæea numerous.

Salmo. Generic Characters. - A few teeth on the front of the vomer; but none extending backwards along the mesial line of that bone. Body fusiform. Head moderately large; maxillaries articulated to the end of the short premaxillaries, and not compound. Mandible strong; its symphyses swelling, in some species into a knob, which is largest in the males. Teeth on the jaws strong and conical or subulate; one row on the palatines, entopterygoids, and on each side of the tongue, together with the small group on the end of the vomer: in some there are two rows on each half of the tongue. Stomach capacious, bent into a siphonal form. Eggs of the roe, as they are detached from the ovary, falling into the cavity of the abdomen before they are excluded in spawning. Air-bladder opening almost directly into the pharynx, or without the intervention of a distinct tube. 
The Salmon is so well known for its quality as an article of food, as well as for the immense quantities in which it is taken, that it requires no other claims to recommend it strongly to our notice; and probably, in no country of the world, in proportion to its size, are the fisheries so extensive, or so valuable, as in the United Kingdom.

The history of the Salmon, and of the species of the genus Salmo, in this work, will extend to a considerable length; and some doubts existing as to the extent of their identity with the species of the Salmonida generally which are taken in the rivers or lakes of other countries of Europe, from the want of specimens with which to make actual comparative examination, the account of the species here inserted will be confined more particularly to a detail of what is known of them in this country only.

Of the species existing in this country, the characters and specific distinctions admit of considerable detail: too much reliance has been placed upon colour, without resorting sufficiently to those external indications, founded on organic structure, which may with greater certainty be depended upon.

In the scale of the relative value of parts affording characters for distinction, the organs of digestion, respiration, and motion are admitted by systematic authors to hold high rank; and in the hope to induce sportsmen to become zoologists-so far at least as to enable them to determine the various species they may meet with by a reference to those external characters which are the most important,-the specific distinctions in the genus Salmo will be illustrated by referring to the number and situation of the teeth, the form of the different parts of the gillcovers, and the size, form, and relative situation of the fins. The outlines here introduced represent a front view of 
the mouth, and a side view of the head, of a common Trout. Of the first figure on the left hand, No. 1 marks the situation of the row of teeth that are fixed on the central bone of the roof of the mouth, called the vomer: Nos. 2, 2, refer to the teeth on the right and left palatine bones; and the row of teeth outside each palatine bone on the upper jaw are those of the premaxilliary and maxillary bones: No. 3, refers to the row of hooked teeth on each side of the tongue, outside of which are those on the limbs of the mandible. The Trout is chosen as showing the most complete series of teeth among the Salmonida; and the value of the arrangement, as instruments for seizure and prehension, arises from the interposition of the different rows, the four lines of teeth on the lower surface alternating when the mouth is closed with the five rows on the upper surface, those on the vomer shutting in between the two rows on the tongue, \&c.
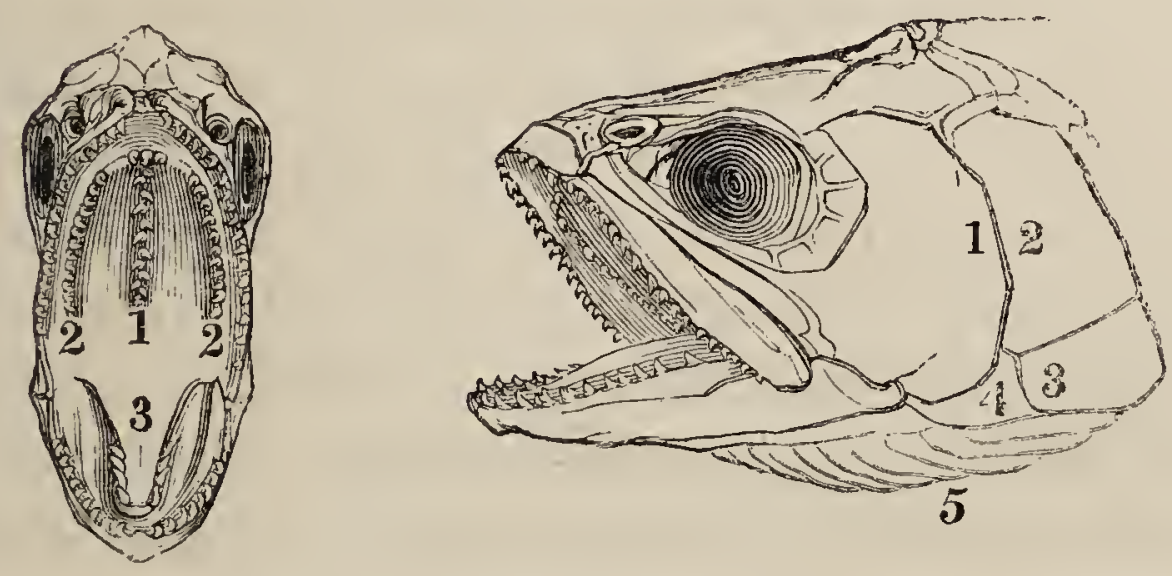

The second figure represents, in outline, a side view of the head, of which No. 1 is the preoperculum; No. 2, the operculum; No. 3, the suboperculum; No. 4, the 
interoperculum; No. 5, the branchiostegous rays: the four last parts together forming the moveable gill-cover. The different fins are sufficiently indicated by being coupled, when referred to, with the name of the part of the body of the fish to which they are attached.

The external appearance of the adult Salmon during the summer months, when it is caught in the estuaries of our large rivers, is too well known to require much description. The upper part of the head and back is dark bluish black; the sides lighter; the belly silvery white; the dorsal, pectoral, and caudal fins dusky black; the ventral fins white on the outer side, tinged more or less with dusky on the inner surface; the anal fin white; the small, soft, fleshy fin on the back, without rays, called the adipose, fat fin, or the second dorsal fin, is of the same colour nearly as the part of the back from which it emanates. There are mostly a few dark spots dispersed over that part of the body which is above the lateral line, and the females usually exhibit a greater number of these spots than the males.

These colours, differing but little, are, however, in a great degree common at the same period of the year to the three species that are the most numerous, as well as the most valuable; namely, the true Salmon, the Grey Trout, and the Salmon Trout; which are also further distinguished from the other species of the genus Salmo by their habit of moving from the pure fresh water to the brackish water, and thence to the sea, and back to the fresh water again, at particular periods of the year. Further specific distinctions are therefore necessary; and those that will be pointed out as existing constantly in these species will, it is hoped, enable observers to identify not only each of them, but also the other species of the genus, at any age or season. 

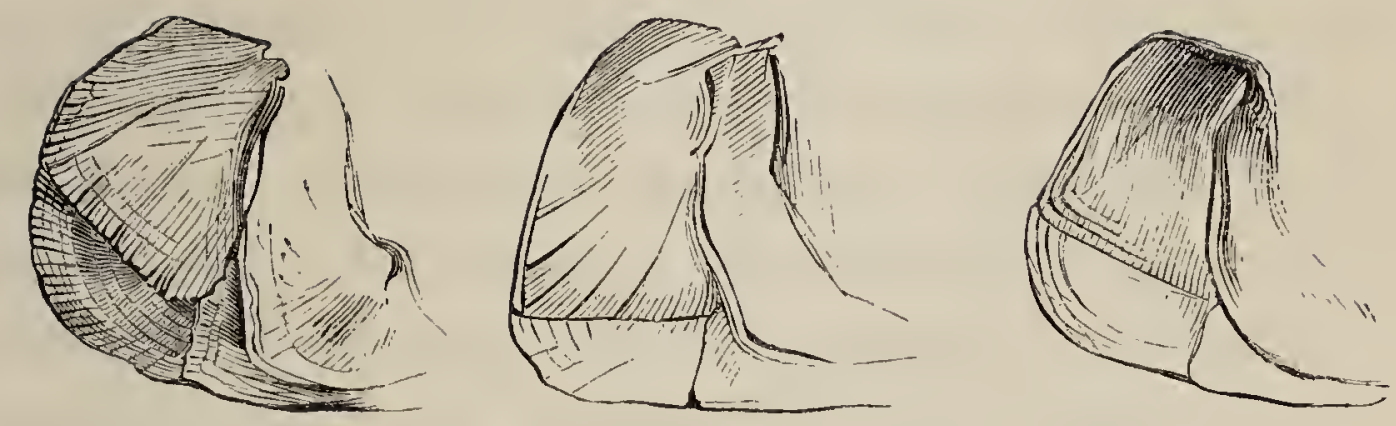

The vignette above represents the form of the different parts of the gill-cover in the three species just named; of which the figure on the left hand is that of the Salmon, the middle one is the gill-cover of the Grey Trout, and that on the right hand is the gill-cover of the Salmon Trout: the differences are immediately apparent when thus brought into comparison.

In the Salmon, the posterior free edge of the gillcover, as shown in the left-hand figure, forms part of a circle; the lower margin of the suboperculum is a line directed obliquely upwards and backwards: the line of the union of the suboperculum with the operculum is also oblique, and parallel with the lower margin of the suboperculum; the interoperculum is narrow vertically, and its union with the operculum is considerably above the line of the junction between the suboperculum and the operculum. The teeth of the Salmon are short, stout, pointed, and recurved: as stated in the generic characters, they occupy five situations at the top of the mouth; that is, a line of teeth on each side of the upper jaw, a line on each palatine bone, with one line on the 
vomer between the palatine bones when young, but the Salmon loses a portion of the vomerine teeth during the first visit to salt water. I have observed that some specimens of the migratory or Sea Trout carry their vomerine teeth longer than the Salmon; and the Trout which do not migrate appear to carry their vomerine teeth longer than those which do migrate. The teeth on the vomer of the Salmon, when the fish is old, seldom exceed two or three in number, sometimes only one, and that placed on the most anterior part. The Salmon has, besicles these, two rows of teeth upon the tongue, and one row along the outer upper edge of each limb of the mandible.

The inner surface of the pectoral fin is in part dusky: the tail very much forked when young; by the central caudal rays growing up, the tail becomes less forked the third year, and in the fifth year it has become nearly or quite square at the end.

The descriptions of the gill-covers of the other species will be given in the accounts of the fish to which they belong; but it may be remarked here, that looking, at the form of the three gill-covers, it will be obvious that a line drawn from the front teeth of the upper jaw to the longest backward projecting portion of the gill-cover, in either species, will occupy a different situation in respect to the eye; that the line will fall nearest the centre of the eye in the first, that of the Salmon, and farthest below it in the second, that of the Grey Trout.

As further specific distinctions in the Salmon, I may add that, according to Dr. Richardson, the cæcal appendages are in number from sixty-three to sixty-eight; and several 'observers have stated the number of vertebræ to be sixty, which I have repeatedly found to be correct.

Commencing, then, with the true Salmon, which ascend 
the rivers, in the state as to colour before mentioned, sooner or later in the spring or summer months, it is observed that some rivers are much earlier than others, the fish in them coming into breeding condition and beginning to spawn at an earlier period.

Rivers issuing from large lakes afford early Salmon, the waters having been purified by deposition in the lakes; on the other hand, rivers swollen by melting snows in the spring months are later in their season of producing fish, and yield their supply when the lake rivers are beginning to fail. "The causes influencing this," says Sir William Jardine, to whom I am indebted for much valuable information on the Salmonida, as well as many specimens, "seem yet undecided; and where the time varies much in the neighbouring rivers of the same district, they are of less easy solution. The Northern rivers, with little exception, are, however, the earliest,-a fact well known in the London markets; and going still farther north, the range of the season and of spawning may be influenced by the latitude." Artedi says, " in Sweden the Salmon spawn in the middle of summer." "It has been suggested that this variation in the season depended on the warmth of the waters; and that those Highland rivers which arise from large lochs were all early, owing to the great mass and warmer temperature of their sources,- that the spawn there was sooner hatched. There are two rivers in Sutherlandshire which show this late and early running under peculiar circumstances. One, the Oikel, borders the county, and springs from a small alpine lake, perhaps about half a mile in breadth; the other, the Shin, is a tributary to the Oikel, joins it about five miles from the mouth, but takes its rise from Loch Shin, a large and deep extent of water, and connected to a chain of other 
deep lochs. Early in the spring all the Salmon entering the common mouth diverge at the junction, turn up the Shin, and return as it were to their own and warmer stream, while very few keep the main course of the Oikel until a much later period."

Dr. Heysham, in his Catalogue of Cumberland Animals, has supplied similar evidence. "The Salmon," it is there observed, "is plentiful in most of our rivers, in all of which they spawn; but they evidently prefer, during the winter and spring, the Eden to the Esk, the Caldew, or the Peteril. Although the Esk and the Eden pour out their waters into the same estuary, and are only separated at the mouths by a sharp point of land, yet there is scarcely an instance of a new Salmon ever entering the former until the middle of April or beginning of May. The fishermen account for this curious fact from the different temperature of these two rivers; the waters of the Eden, they allege, being considerably warmer than the water of the Esk; which is not altogether improbable, for the bed of the Esk is not only more stony and rocky than the Eden, but is likewise broader, and the stream more shallow; consequently its waters must be somewhat colder in the winter season. It is an undoubted fact, that snow water prevents the Salmon from running up even the Eden : it is probable that this circumstance may have considerable effect in preventing them from entering the Esk till the beginning of summer, when the temperature of the two rivers will be nearly the same. The Peteril joins the Eden a little above, and the Caldew at Carlisle; yet up these rivers the Salmon never run unless in the spawning season, and even then in no great numbers."

Mort and Spod are names applied in Cumberland indiscriminately to the Salmon and Salmon Trout, the former 
term being used for fish weighing between two and five pounds, and the latter to smaller fish.--(Dr. Davy, Angler in Lake District.) Willughby informs us that the fishermen of the Ribble call Salmon, when one year old, Smelts, next year they are Sprods, in the third Morts, * in the fourth Fork-tails, in the fifth Half-fish, and in the sixth Salmon. These names must be taken as merely indications of size, for the rapid growth of the Salmon had not been clearly ascertained in Willughby's time.

The number of fish obtained in the spring in a proper state for food is small compared with the quantity procured as the summer advances. During the early part of the season, the Salmon ascend the river, advancing with the flood, and generally retiring with the ebb, if their progress be not stopped by any of the various means employed to catch them which will be explained hereafter. It is observed that the female fish appear before the males ; and the young fish on their first return from the sea, called Grilse till they have spawned once, ascend earlier than those of more adult age. As the season advances the Salmon ascend higher up the river beyond the influence of the tide, they are observed to be getting full of roe, and to be more or less out of condition according to their forward state as breeding fish. Their onward progress is not easily stopped; they shoot up rapids with the velocity of arrows, and make wonderful efforts to surmount cascades and other impediments by leaping, frequently clearing an elevation of eight or ten feet, and, on gaining the water above, pursue their course. If they fail in their attempt and fall back into the stream, it is only to remain a short time quiescent, and thus recruit their strength to enable them to make new efforts.

* Mört is the appellation of the Roach in Sweden, and refers to its dusky red colour. 
These feats of the Salmon are frequently watched with all the curiosity such proceedings are likely to excite. Mr. Mudie, in the British Naturalist, describes from personal observation some of the situations from which these extraordinary efforts can be witnessed. Of the fall of Kilmorac, on the Beauly, in Inverness-shire, it is said, "The pool below that fall is very large; and as it is the head of the run in one of the finest Salmon rivers in the North, and only a few miles distant from the sea, it is literally thronged with Salmon, which are continually attempting to pass the fall, but without success, as the limit of their perpendicular spring does not appear to exceed twelve or fourteen feet: at least, if they leap higher than that they are aimless and exhausted, and the force of the current dashes them down again before they have recovered their energy. They often kill themselves by the violence of their exertions to ascend; and sometimes they fall upon the rocks and are captured. It is indeed said that one of the wonders which the Frasers of Lovat, who are lords of the manor, used to show their guests, was a voluntarily-cooked Salmon at the falls of Kilmorac. For this purpose a kettle was placed upon the flat rock on the south side of the fall, close by the edge of the water, and kept full and boiling. There is a considerable extent of the rock where tents were erected, and the whole was under a canopy of overshadowing trees. There the company are said to have waited until a Salmon fell into the kettle, and was boiled in their presence. We have seen as many as eighty taken in a pool lower down the river at one haul of the seine, and one of the number weighed more than sixty pounds."

At the meeting of the British Association, held at Glasgow in September 1840, Mr. Smith, of Deanston, in the Carse of Stirling, exhibited a model, which is thus 
noticed in the Report of the Proceedings of the Natural History Section in the Literary Gazette. "Mr. Smith gave an interesting account of a stair which he had invented, whereby Salmon might be enabled to ascend streams, notwithstanding the existence of natural or artificial obstructions, and so constructed as not to diminish the power of the water, or lessen the supply to mills; it being understood that the disputes between the owners of mills and of salmon-fisheries had hitherto led to much disagreement and inconveniency. He illustrated his observations by the model of an experimental erection which he had constructed on the Teith, near Doune, the result of which had been so successful, that numerous applications had been made from various quarters for erections of the same kind. Mr. Smith mentioned that in connection with this invention, he had in contemplation the construction of an apparatus, or index, whereby the exact number of fish that passed up the stream by the stair might be accurately ascertained, together with the time of their so passing up, and the size and thickness of the fish. It is difficult to give a perfect idea of this ingenious contrivance without a model. It consists of one side of the river, under a weir or ' cauld,' being separated from the main stream, and intersected by transverse pieces of wood, or stone, from each side, crossing, perhaps, two-thirds of the width, and with considerable intervals between the opposite intersections. The fish, it seems, both from the experience on the Teith, and at another dam at Blantyre, on the Clyde, immediately adopt this staircase in ascending the rivers, and, finding resting-places between the intersecting materials, abandon the other parts of the stream for this contingency. Some amusing remarks were made on this communication, which is one of infinite value to local mill and fishing interests." 


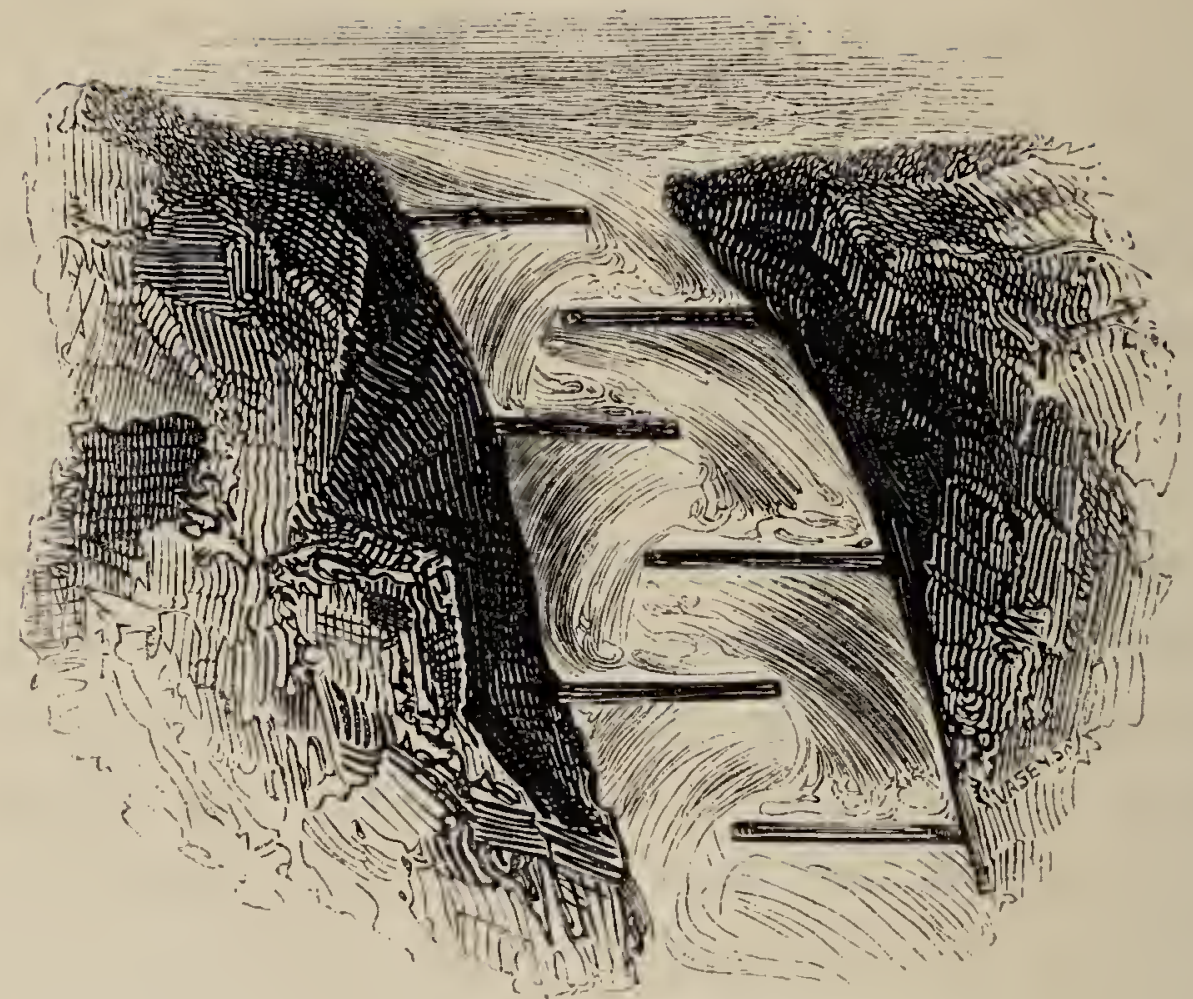

The fish having at length gained the upper and shallow pools of the river, preparatory to the important operation of depositing the spawn in the gravelly beds, its colour will be found to have undergone considerable alteration during the residence in fresh water. The male becomes marked on the cheeks with orange-coloured stripes, which give it the appearance of the cheek of a Labrus; the lower jaw elongates, and a cartilaginous projection turns upwards from the point, which, when the jaws are closed, occupies a deep cavity of the upper jaw between the premaxillary bones; the body partakes of the golden orange tinge, and the Salmon in this state is called a Redfish. The females are dark in colour, and are as commonly called Black-fish; and by these terms both are designated in those local and precautionary regulations intended for the protection and preservation of the breeding fish.

The process of spawning has been described by various 
observers. "A pair of fish are seen to make a furrow, by working up the gravel with their noses, rather against the stream, as a Salmon cannot work with his head down stream, for the water then going into his gills the wrong way, drowns him. Whell the furrow is made, the male and female retire to a little distance, one to the one side, and the other to the other side of the furrow: they then throw themselves on their sides, again come together, and rubbing against each other, both shed their spawn, into the furrow at the same time. This process is not completed at once; it requires from eight to twelve days for them to lay all their spawn, and when they have done they betake themselves to the pools to recruit themselves. Three pairs have been seen on the spawning-bed at one time, and were closely watched while making the furrow and laying the spawn."*

The following extracts are made from a paper by Dr. Knox, published in the Transactions of the Royal Society of Edinburgh:-

"November 2.-Salmon are observed to be spawning in the various tributary streams of the Tweed which join that river from the north, and a pair are watched. The ova observed to be deposited near the sources of the stream on the 2nd of November, and covered up with gravel in the usual way." "February 25 , or a hundred and sixteen days after being deposited, the ova, on being dug up, are found to be unchanged." "March 23.-The ova now changing; the outer shell cast; the fry are lying imbedded in the gravel, as fishes somewhat less than an inch in length, being now twenty weeks from the period of their deposition." "April 1.-On reopening the spawning-bed, most of the fry had quitted it by as- 
cending through the gravel. During a former series of observations I have found the ova imbedded in the gravel unchanged on the 10th of April, and as fry or fishes, but still imbedded in the gravel, on the 17th: they were taken that year with $\mathrm{fly}$, as Smolts, on the 22nd of April, about the size of the little finger."

Some specimens of Salmon fry now before me, with a portion of the ovum still attached to the abdomen of each fish, measure one inch in length: the head and eyes are large; the colour of the body pale brown, with nine or ten dusky grey marks across the sides. These dusky patches, longer vertically than wide, are common, I have reason to believe, to the young of all the species of the genus Salmo. I have seen them in the young of the Salmon, Grey Trout, Sea Trout, Common Trout, and Charr. In a specimen of the young of the Salmon six inches long, these transverse marks are still observable when the fish is viewed in a particular position in reference to the light: and if the scales are removed, the marks are much more obvious. They are also very distinct in the Common Trout and in the Charr for a considerable time.

There are striking examples in other animals of this similarity in the markings, or family likeness, in the young of the various species of the same genus, however different may be the colours of the parent animals. The young of the lion and the puma are as much marked for a time as the young of the tiger and leopard, or, indeed, of any of the other cats, whether striped or spotted; and the young of all deer are said, and many are known, to be spotted, though it is also known that the greater number of the adult animals are perfectly plain.

I am now enabled, through the kindness of Thomas Lister Parker, Esq., to offer some remarks on the growth 
of the young Salmon in fresh water, and in order to prevent any misconception of the terms employed, I shall speak of the young Salmon of the first year as a Pink; in its second year, till it goes to sea, as a Smolt; in the autumn of the second year as Salmon Peal, or Grilse; and afterwards as adult Salmon.

In the autumn of the year 1835, Thomas Upton, Esq., of Ingmire Hall, situated between Sedbergh and Kendal, began to enlarge a lake on his property, and in the spring of 1836, some Pinks from the Lune, a Salmon river which runs through a valley not far from the lake, were put into it. This lake, called Lillymere, has no communication with the sea, nor any outlet by which fish from other waters can get in, or by which those put in can get out. The Pinks when put into Lillymere did not certainly exceed three inches and a half in length. Sixteen months afterwards, - that is, in the month of August 1837, Thomas L. Parker, Esq. then visiting his friend, fished Lillymere, desirous of ascertaining the growth of the Pinks, and with a red palmer fly caught two Salmon Peal in excellent condition, silvery bright in colour, and measuring fourteen inches in length, and weighing fourteen ounces. One was cooked and eaten, the flesh pink in colour, but not so red as those of the river: wellflavoured and like that of a Peal. The other was sent to me in spirit of wine, and a drawing of it immediately taken. In the month of July 1838, eleven months after, another small Salmon was caught, equal to the first in condition and colour, about two inches longer and three ounces heavier. No doubt was entertained that these were two of the Pinks transferred to the lake in the spring of 1836, the first of which had been retained sixteen months, and the other twenty-seven months, in this fresh-water lake. 
Desirous of ascertaining the appearance of the young Salmon at periods intermediate between the states as Pinks and Salmon Peal, other experiments were tried. Pinks in the river Hodder in the month of April are rather more than three inches long, and are considered to be the fry of that year: at this time, Smolts of six inches and a half are also taken. The Smolts are considered as the fry of the previous year, and are distinguished by the blue colour on the upper half of their body, the silvery tint of the lower half, and the darker hue of the fins generally as compared with those of the Pink. In this state as to colour, the Smolts are said to have assumed their migratory dress, and go down to the sea in May. In June the young Pink in the Hodder measures about four inches; in July it measures five inches, and no Smolts are then found in the river. To be further convinced of this change, and the length of time required to produce it, a Pink put into a well at Whitewell, in the forest of Bowland, in November 1837, was taken out in the state of a Smolt of six inches and a quarter in July 1838. In another instance more Pinks, by Mr. Upton's directions, were put into Lillymere in September 1837, and Mr. Parker caught five or six in the state of Smolts of seven and a half inches in August 1838. In referring to the particular size of the Pinks, in the river Hodder at stated periods, it may be necessary to remark that the Pinks of different rivers, and even in the same river, will be found to vary in size, depending on the time at which the spawn was deposited, the temperature of the season, and other causes. I may here observe that I am indebted to the kindness and liberality of Mr. Parker for a variety of specimens, as well as for the requisite information concerning them. Of the various fishes, when received, accurate drawings 
were immediately made, and coloured representations of the natural size of six examples at different ages, in illustration of this subject, were published.*

A knowledge of the growth of young Salmon in a fresh-water lake, as here described, and the experiment has succeeded elsewhere, may be useful to those gentlemen who possess lakes near Salmon rivers from which they can supply them with Pinks: whether the Salmon thus prevented going to salt water will still retain sufficient constitutional power to mature their roe, and by depositing it in the usual manner, as far as circumstances permit, produce their species, would be a subject worthy of further investigation. That the rate of growth in young Salmon has some reference to the size of the place to which they are restricted, receives further confirmation in these river, lake, and well specimens. The Smolt taken from the well in July 1838, where it had been confined for eight months, was rather smaller in size at that time than the Smolts in the Hodder in the preceding April, though both were Pinks of the same year, namely, 183\%. The Smolt taken from the lake in August 1838, which then measured seven inches and a half, had also grown more rapidly than that in the well, but had not acquired the size it would have gained had it been allowed to go to sea. Further, it may be observed, that the Salmon Peal from the lake in August 1837, then eighteen months old, though perfect in colour, is small for its age; while that of July 1838, or twenty-nine months old, is comparatively still more deficient in growth, supposing both fish to have resulted from Pinks of the year 1836, and been put into the lake at the same time; of which there was no doubt, since the lake,

* On the Growth of the Salmon in Fresh-water.-John Van Voorst: London, 1839. 
though its formation commenced in the autumn of 1835 , was not finished till February 1836, soon after which the first Pinks were put in.

In another experiment, a large landed proprietor in Scotland, whose name I do not know that I am at liberty to mention, wrote as follows:- "In answer to your inquiry about the Salmon fry I have put into my newlyformed pond, I must tell you, the water was first let in about the latter end of 1830, and some months afterwards, in April 1831, I put in a dozen or two of small Salmon fry, three or four inches long, taken out of a river here, thinking it would be curious to see whether they would grow without the possibility of their getting to the sea or salt water. As the pond, between three and four acres in extent, had-been newly stocked with Trout, I did not allow any fishing till the summer of 1833, when we caught with the fly several of these Salmon, from two to three pounds' weight, perfectly well shaped, and filled up, of the best Salmon colour outside, the flesh well-flavoured and well-coloured, though a little paler than that of new-run fish."

I have purposely adverted to the growth of the fry of the Salmon in fresh water, as stated by Dr. Knox, Mr. Parker, and others, in order to introduce the important experimental observations of Mr. John Shaw, on the development and growth of Salmon fry, from the exclusion of the ova to the age of two years; and that I may do justice to so interesting a subject, I include a large portion of Mr. Shaw's paper as it appeared in the Transactions of the Royal Society of Edinburgh :-

"That the facts which I communicate regarding the natural history of the Salmon in its earlier stages, may not appear altogether undeserving of consideration, I may premise that my remarks have not proceeded from 
hasty or imperfect observation, but from the experience of many years sedulously devoted to the subject, the whole of my life, with the exception of a few seasons, having been spent on the banks of streams where Salmon are in the habit of depositing their spawn, and where of course the Parr is likewise abundant. My opportunities of observation have thus been as ample, as my efforts have been unremitting and laborious, to discover the true history of this invaluable species. I shall here present a brief abstract of my earlier proceedings in relation to the subject.

"I had long been of opinion, in opposition to the sentiments entertained by the majority of authors, that the fish commonly called Parr, was the natural produce of the Salmon, and that all recorded attempts to trace the history of the latter fish were fanciful in their nature, and delusive in their results. To enable me to watch the progressive growth of Parr, I caught seven of these small fishes on the 11 th of July 1833, and placed them in a pond supplied by a stream of wholesome water. There they contirued to thrive remarkably well, and were seen catching flies and other insects, and sporting on the surface in perfect health. In the month of April following (1834), they began to assume a different aspect from that which they exhibited when first put into the pond, and this change was evident enough, even while they continued swimming at large in the water; but wishing to examine them more particularly, and at the same time to convince others of the fact of their having changed their external character, I caught them with the casting-net on the 17th May 1834, and satisfied every individual present that they had assumed the usual appearance of what are called Salmon smolts or fry. They were now of a fine deep blue upon the back, with a delicate silvery 
appearance on the sides, and the abdomen white; these silvery scales came easily off upon the hand. A circumstance occurred about the first week of May, which it may be proper to mention, as illustrating in some manner what may be deemed the migratory instinct of these fishes. They seemed to me at this time to be decreasing in numbers, and I found, on examination, that some had leapt altogether out of the pond, and were lying dead at a short distance from its edge.

"In March 1835, I again took twelve Parrs from the river of a larger size, that is, about six inches long; they then bore the perpendicular bars, and other usual characters of that fish. These I also transferred to a pond prepared for the purpose, and, by the end of April, they too assumed the characters of the Salmon-fry,the bars becoming overlaid by the new silvery scales, which Parrs of two years old invariably assume before departing towards the sea. From these experiments I had no doubt that the larger Parrs observable in rivers in autumn, winter, and early spring, were in reality the actual Salmon-fry advancing to the conclusion of their second year, and that the smaller summer Parrs (called in Dumfriesshire May Parrs), were the same species, but younger as individuals, and only entering upon their second year. This, then, I conceived to be the detection of the main error of preceding observers, who had uniformly alleged that Salmon-fry attain a size of six or eight inches in as many weeks, and after the lapse of this brief period take their departure to the sea. It is the rapidity with which the two-year old Parr assumes the aspect of the Salmon-fry that has led to this false conclusion; and superficial or hasty observers, taking cognizance, 1 st, of the hatching of the ova in early spring, and, 2dly, of the seaward migration of Smolts soon afterwards, have imagined 
these two facts to take place in immediate or speedy succession. I may now mention what actually becomes of these young fishes for some weeks after they are hatched.

"'That the fish in question should not be found in the river in an earlier state than that in which it is named the May or summer Parr, had long appeared to me to be an extraordinary and perplexing circumstance. I therefore made a minute examination of the streams where the old Salmon had spawned the preceding winter, and I there found in vast numbers a very small but active fish, which I concluded to be the young Parr or Samlet of the season. To prove the fact, I scooped up with a gauze-net two or three dozen of them, on the 15 th of May 1834. They measured about an inch in length; their heads were large in proportion to their bodies, and the latter tapered off towards the tail, in the form of a wedge. The small transverse bars, characteristic of the Parr, were already distinctly marked. I placed them in two ponds, each provided with a run of water, where they throve well. In the course of the succeeding May (1835), that is, when they were more than a year old, and had been twelve months in my possession, I took a few of them from the pond for the purpose of examination. They had increased to the length of three and a half inches, on an average, and it is important to remark, that they corresponded in every respect with the Parr of the same age which occurred in the river; but neither as yet indicated any approach to the silvery aspect of the Smolt. Being satisfied, however, from the result of my former experiments on the Parr, that they would ultimately assume that silvery aspect, I continued to detain them in the pond, and accordingly, in May 1836, they were transmuted into Smolts or Salmon-fry, commonly so called. At this time they measured six and a half inches in 
length, their colour on the back a beautiful deep blue, the sides bright and silvery, the dorsal, caudal, and especially the pectoral fins, tipped with black; the abdomen, ventral, and anal fins white. The undoubted Smolts of the river were at this time descending seawards, and the most careful comparison of these with those in my possession did not elicit the slightest difference between the two. Mine had completed their second year, and is it likely that those in the river which so identically resembled them, were only a few weeks old?

"The minute but active fish above alluded to, is at that early period to be nowhere found except in those streams (or their immediate vicinity) in which the old Salmon had deposited their spawn during the preceding winter. Early in April 1835, I discovered them in one of these streams, but so young and weak, owing to their very recent emergence from the spawning-bed, as to be unable to struggle with the current where it flowed with any strength or rapidity. They therefore betook themselves to the gentler eddies, and frequently into the small hollows produced in the shingle by the hoofs of horses which had passed the ford. In these comparatively quiet places, and covered by a slight current of a few inches in depth, they continued with their little tails in constant motion, till such time as my near approach was perceived, when they immediately darted beneath the stones. They remain with these habits, and in the situations just mentioned, during the months of April, May, and even June; but as they increase in size and strength, they scatter themselves all over the shallower parts of the river, especially wherever the bottom is composed of fine gravel. They continue, in truth, comparatively unobserved throughout the whole of the first summer, being seldom taken by the angler during that season. But 
when the two-year-olds have disappeared (as Smolts) in spring, these smaller fishes, now entering their second year, become bolder and more apparent, and constitute the May and summer Parr of anglers. But their timid habits during the first few months of their existence, and their consequent concealment in the shingle, greatly screen them from observation during that period, and have led to the erroneous belief, that the silvery Sinolts were the actual produce of the season, and were only a few weeks old. It certainly seems singular that it should never have occurred to any intelligent angler to inquire what had become of the older generation of Parr, that is of the comparatively large individuals which he might have captured late in autumn and in earliest spring, but none of which he can detect after the departure of the so-called Smolts. If the two are not identical, how does it happen that the one so constantly disappears simultaneously with the other? Yet no one alleges that he has ever seen Parr, as such, performing their migration towards the sea. They cannot do so, because they had been previously converted into Smolts.

"I shall here aliude briefly to three different occasions on which I have had an opportunity of witnessing the first migration of Smolts or converted Parr, that is their descent in small shoals towards the sea. The first of these was in the first week of May 1831. I was able deliberately to inspect them as the several shoals arrived behind the sluices of a salmon-cruive, and while they yet remained in the water, and were swimming in a particular direction, indistinct transverse lateral bars might still be seen, but as they changed their position, these became, as it were, lost in the silvery lustre. I also examined many of them in the hand, and could there also, by holding them at a certain angle in relation to the eye, produce

VOL. I. 
the barred appearance, but when the fish were held with their broad side directly opposed to view, the character alluded to could not be seen. Its actual existence, however, could be easily proved by removing the deciduous silvery scales, when the barred markings became apparent, and, of course, continued so to whatever light exposed. My next opportunity occurred on the 3rd of May 1833. The appearance was exactly the same as that which I have just described. They passed down the river in small family groups or shoals of from forty to sixty and upwards, their rate of progression being about two miles an hour. The caution which they exercised in descending the several rapids they met with in the course of their journey was very amusing. They no sooner came within the influence of any rapid current than they in an instant turned their heads up the stream, and would again and again permit themselves to be carried to the very brink, and as often retreat upwards, till at length, one or two, bolder than the others, permitted themselves to be carried over the current, when the entire flock, one by one, disappeared, and then, so soon as they had reached comparatively still water, they again turned their heads towards the sea, and resumed their journey. The third opportunity to which I shall here refer occurred in May 1836, at which time, as I have stated, I compared a few of the descending Smolts with those which (having been two years in my possession as Parr) had, in the confinement of the pond, assumed the corresponding silvery aspect of the Salmon-fry. The river during this month being remarkably low, I was thus enabled to ascertain more accurately the time during which they continued to migrate, which I found to be nearly throughout the whole of the month, but more especially in the course of the second week, in which the shoals were both larger, 
and more frequent in their successive arrivals. Their external aspect was the same as that of the former shoals, and the average length, as usual, from six to seven inches.

"Having thus traced the progress of the Parr from an inch in length, through its several stages up to the period of migration, I shall now detail my various experiments on the ova of the Salmon, undertaken with a view to prove the identity of these two fish. On the 10th of January 1836, I observed a female Salmon of considerable size (about sixteen pounds), and two males, of at least twenty-five pounds, engaged in depositing their spawn. The spot which they had selected for that purpose was a little apart from some other Salmon which were engaged in the same process, and rather nearer the side, although still in pretty deep water. The two males kept up an incessant conflict during the whole of the day, for possession of the female, and in the course of their struggles, frequently drove each other almost ashore, and were repeatedly on the surface displaying their dorsal fins, and lashing the water with their tails. Being satisfied that these were real Salmon, there being at least ten brace of that fish engaged in the same process on the stream at the time, I took the opportunity of securing as much of the ova as I could possibly obtain. This I did three days after it was deposited, the males and female still occasionally frequenting the bed. The method by which I obtained the egos was by using a thin canvas bag, stitched on a slight frame formed of small rod iron, in fashion of a large square landing-net, one person holding this bag a few inches farther down the stream than where the ova were deposited, and another with a spade digging up the gravel, the current carrying the eggs into the bag, while the greater portion of the 
gravel was left behind. Having thus obtained a sufficient quantity of the ova for my purpose, I placed them in gravel under a stream of water where I could have a convenient oportunity of watching their progress. The stream was pure spring water. On the 26th of February, - that is, forty-eight days after being deposited, I found on close inspection that they had some appearance of animation, from a very minute streak of blood which appeared to traverse for a short distance the interior of the egg, originating near two small dark spots, not larger at that time than the point of a pin. These two dark spots, however, ultimately turned out to be the eyes of the embryo fish, which was distinctly seen resting against the interior surface of the egg a few days previous to its exclusion. On the 8th of April, which makes ninety days imbedded in the gravel, I found on examination that they were excluded from the egg, which was not the case a day or two previous. The temperature of the water at the time was $43^{\circ}$, the temperature of the water in the river $45^{\circ}$, and the temperature of the atmosphere $39^{\circ}$. On its first exclusion, the little fish has a very singular appearance. The head is large in proportion to the body, which is exceedingly small, and measures about five-eighths of an inch in length, of a pale blue or peachblossom colour. But the most singular part of the fish

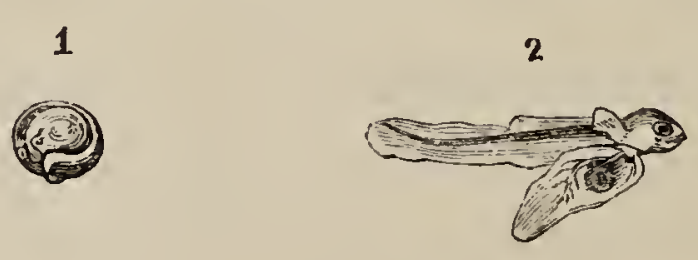

3

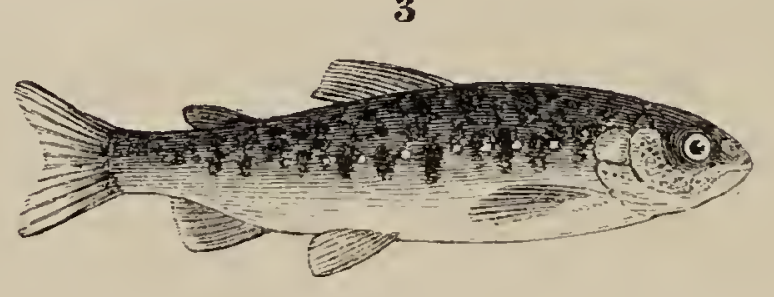


is the conical bag-like appendage which adheres by its base to the abdomen. This bag is about two-eighths of an inch in length, of a beautiful transparent red, very much resembling a light red currant, and in consequence of its colour, may be seen at the bottom of the water when the fish itself can with difficulty be perceived. The body also presents another singular appearance, namely, a fin or fringe, resembling that of the tail of the tadpole, which runs from the dorsal and anal fins to the termination of the tail, and is slightly indented. This little fish does not leave the gravel immediately after its exclusion from the egg, but remains for several weeks beneath it with the bag attached, and containing a supply of nourishment, on the same principle, no doubt, as the umbilical vessel is known to nourish other embryo animals. By the end of fifty days, or the 30th of May, the bag contracted and disappeared. The fin or tadpole-like fringe also disappeared by dividing itself into the dorsal, adipose, and anal fins, all of which then became perfectly developed.* The little transverse bars, which for a period of two years (as I have already shown) characterize it as the Parr, also made their appearance. Thus, from the 10th of January till the end of May, a period of upwards of one hundred and forty days, was re-

* In 1849 Professor Quekett subjected the young of Trout to microscopical examination at successive periods of their growth, in the course of which he observed a pulsating vascular sac in the tail of the embryo, similar to that which occupies the same situation in the Eel. Dr. Davy subsequently, but without having heard of the Professor's observations, noticed a small red mass in the tail of the newly-hatched Charr, through which the veins and arteries passed. The globules of blood were seen to be propelled through this mass by what he considered at first sight to be a proper pulsatory action of the mass (or sac); but on again examining a number of the fish on the following day he came to the conclusion that there was no real muscular contraction in the red mass, and that the blood was propelled through it by the impulse propagated from the true heart, aided by the elasticity of the vessels. - See Zoologist for 1849 , p. 2543. 
quired to perfect this little fish, which even then measured little more than one inch in length, and corresponded in all respects with those on which I had formerly experimented, as well as with such as existed at that same time in great numbers in the natural streams.

"Although I was myself satisfied by the preceding facts that Parr and Salmon-fry were thus identical in kind, and differed only in respect to age, I was informed that my inferences were objected to, in as far as there was not sufficient evidence that the spawn experimented on was actually that of Salmon, seeing that the same streams were accessible to other species of the genus. I therefore felt it incumbent on me to supply this desired link in the chain of evidence, and I accordingly repeated my experiments on ova which I saw excluded, which, in fact, I forced the Salmon to exclude, in the manner after mentioned, preserving at the same time the skins of the parent fish, for the satisfaction of the curious or sceptical.

"Before proceeding to make additional experiments, it was necessary to lay my experimental basins dry, not only for the purpose of removing the young Salmon of the preceding season's produce, but also to enable me to fit them up on such a principle as would exclude any possibility of confusion either from the overflowing of the ponds themselves, or from the flooding of the river Nith, on the banks of which they are situate. Every precaution was used not only to exclude error, but to place the young fry in circumstances as nearly resembling the state of nature as was consistent with their preservation.

"The ponds, which are three in number, are two feet deep, and thickly imbedded with gravel, while they are at the same time supplied with a small stream of spring water in which the larvæ of insects abound. Pond No. 1 
is twenty-five feet in length by eighteen in breadth, and is fed by the stream, which debouches into it at the fall. Pond No. 2 is twenty-two feet in length by eighteen in breadth, and is fed from Pond No. 1, where the communication is carefully grated with wire. Pond No. 3 is fifty feet in length by thirty in breadth, and is fed by the stream, having no communication with either of the other ponds. The waste water from Pond No. 1 is conducted into Pond No. 2, through a square wooden pipe covered at the mouth with a wire grating, the bars of which are about one-eighth of an inch apart. The waste water from pond No. 2 is conveyed under ground to the distance of twenty feet in a square wooden pipe, grated in the same manner as the former. The waste water from pond No. 3 passes down a square wooden pipe two feet deep, covered at the top with wire-gauze, and is conveyed under ground in a small covered drain to the distance of twenty feet from the pond. The water of the whole is then left to find its way to the river.

"To prevent any communication arising from an accidental overflow of the ponds themselves, I raised embankments upon the intersecting walks of two feet in height, so that the several families of fish which the ponds contain can have no access, direct or indirect, to each other. Where the rivulet is divided for the purpose of supplying the several ponds, I have formed an artificial fall in each stream, of a construction to prevent the fish from ascending one stream and descending another. Finally, where the water discharges itself from the ponds, the channels are so secured by wire-grating that it is as impossible for the young fish to escape as for any other fish to have access to them. The whole occupies an area of nearly eighty feet square.

"My experimental basins being thus prepared, my 
next object was to secure the fish, the progeny of which were to form the subject of experiment. With the view, therefore, of securing two Salmon, male and female, while in the very act of continuing their kind, I provided myself with an iron hoop five feet in diameter, on which I fixed a net of a pretty large mesh, so constructed as to form a bag nine feet in length, by five feet in width. I then attached the hoop and net to the end of a pole nine feet long, thus forming a landing-net on a large scale. The weight of the net with its iron hoop being upwards of seven pounds, it instantly sank to the bottom on being thrown into the water.

"Being thus prepared with all the means of carrying my experiment into practice, I proceeded to the river Nith on the 4th January 1837, and readily discovered a pair of adult Salmon engaged in depositing their spawn. They were in a situation easily accessible, the water being of such a depth as to admit of my net being employed with certain success. Before proceeding to take the fish, I formed a small trench in the shingle by the edge of the stream, through which I directed a small stream of water from the river two inches deep. At the end of this trench I placed an earthenware basin of considerable size, for the purpose of ultimately receiving the ova. I then, at one and the same instant, enclosed both the fish in the hoop, allowing them to find their way into the bag of the net by the aid of the stream. In capturing these fish I considered myself fortunate in securing them by one cast of the net, for, in conducting the experiment of artificial impregnation, it appeared to ne to be very desirable that the male should be taken, with the female of his own selection, at the very moment when they were mutually engaged in the continuance of their species. To take a female from one part of the stream and the 
male from another, might not have given the same chance of a successful issue to the experiment. Having drawn the fish ashore, I placed the female, while still alive, in the trench, and pressed from her body a quantity of ova. I then placed the male in the same situation, pressing from his body a quantity of milt, which, passing down the stream, thoroughly impregnated the ova. I then transferred the spawn to the basin, and deposited it in a stream connected with a pond previously formed for its reception. The temperature of this stream was $39^{\circ}$, of the river from which the Salmon were taken $33^{\circ}$, and of the atmosphere $36^{\circ}$. The skins of the parent Salmon are now in my possession.

"On examining the ova on the 23rd of February (fifty days after impregnation), I found the embryo fish distinctly visible to the naked eye, and even exhibiting some symptoms of vitality by moving feebly in the egg. The temperature of the stream was at this time $36^{\circ}$, and of the atmosphere $38^{\circ}$. On the 28th of April (one hundred and fourteen days after impregnation), I found the young Salmon excluded from the egg, which was not the case when I visited them on the previous day. The temperature of the stream was then $44^{\circ}$. The ova, which for some time previous to being hatched, had been almost daily in my hand for inspection, did not appear to suffer at all from being handled. When I had occasion to inspect the ovum, I placed it in the hollow of my hand, covered with a few drops of water, where it frequently remained a considerable time without suffering any apparent injury. The embryo, however, while in this situation, showed an increased degree of activity by repeatedly turning itself in the egg, an action probably produced by the increase of temperature arising from the warmth of the hand. 
"On the 24th of May (twenty-seven days after being hatched), the young fish had consumed the yolk, but in a few days afterwards the whole of this family, with the exception of one individual, were found dead at the bottom of the pond, a circumstance which has occurred more than once in the course of my experiments, arising, I apprehend, from a deposition of mud, the same result having previously taken place, when the pond had not been sufficiently imbedded with gravel.

"To show the effects of increased temperature in hastening the development of the infant fish, I may relate an experiment which I made upon a few of the same ova, from which this family proceeded. On the 20th of April (one hundred and six days after impregnation), finding the ova alluded to unhatched, and the temperature of the stream being $41^{\circ}$, I took four of them and placed them in a tumbler of water, covering the bottom with fine gravel, in which I imbedded the ova. I then suspended the tumbler from the top of my bedroom window, below a large earthenware jar, with a small spigot in its side, from which I easily directed a stream of pure spring water into the tumbler. The waste water was carried out at the window along a wooden channel fitted up for the purpose. As there was no fire in the bed-room, and the windows faced the north, the temperature did not range very high, $47^{\circ}$ being the average, while the average temperature of the water in the tumbler was $45^{\circ}$. During the night, however, the temperature would be very considerably increased, and the consequence was, the young fish in the tumbler were hatched in thirty-six hours, while those remaining in the stream did not hatch till the 28th of A pril, a difference of nearly seven days. At this stage the little fish are so very transparent, that their vital 
organs are distinctly visible, and, when placed immediately under the eye of the observer, they present a very interesting appearance. The pectoral fin is continually in rapid motion, even when the fish itself is otherwise in a state of perfect repose. They also begin to manifest an increasing desire to escape observation, a principle wisely implanted for their better security, during so feeble and helpless a condition. On the 24th of May, (thirty-nine days after their birth), the fish in the tumbler were completely divested of the yolk, and the characteristic bars of the Parr had become visible. At this time they measured nearly one inch in length, and appeared to be in perfect health; but fearing that, after the yolk was consumed, I should be unable to supply them with appropriate food, I returned them to the pond from which I had taken them on the 20th of April, where they perished with the rest of the family.

"This last experiment proves, that by placing the ova under a temporary stream of water in the house, the development of the young may be materially accelerated, while it also shows that they may be kept alive for a considerable time afterwards; at all events, until the yolk, which I presume to be their sole support at this period, is totally consumed.

"The next experiment, the circumstances of which I have to relate, has been attended with more success than those which I had previously made. The process of taking the adult fish, and all the circumstances attending the impregnation, were entirely similar in this case to that already narrated. That the pedigree of the young fish may not be called in question, I have preserved the skins of the parents. The weight of the male when taken was sixteen pounds, and of the female eight pounds. 
"The spawn was impregnated and deposited in the stream immediately below the fall, pond No. 1, on the 27 th of January 1837 ; the temperature of the water in the stream being $40^{\circ}$, and that of the water in the river $36^{\circ}$. On the 21st of March (fifty-four days after impregnation), the embryo fish were visible to the naked eye. On the 7 th of May (one hundred and one days after impregnation), they had burst the envelope, and were to be found amongst the shingle of the stream. The temperature of the water was at this time $43^{\circ}$, and of the atmosphere $45^{\circ}$. It is this brood which I now had an opportunity of watching continuously for a length of time, that is, for more than the entire period which was required to elapse from their exclusion from the egg, until their assumption of those characters which distinguish the undoubted Salmon-fry. I therefore desire, even at the risk of repetition, to describe their progressive growth during these important and usually misconceived stages of existence.

"It has been asserted, with some appearance of truth, in support of the old-school theory, that owing to the comparatively limited range of my experimental ponds, that the young Salmon reared in them have not had a ' supply of food sufficiently varied, or in sufficient quantity, to insure an equally rapid growth to those in the open river.' This objection, I must repeat, is by no means tenable, as the streams and ponds in which they have existed from their birth abound with every species of insect food peculiar to the river, and, at the same time, the fishes themselves (which are certainly the best test) are in the highest possible health and condition, and correspond in every respect with those in the river. I have already stated that the young of the Salmon remain in the river for the first two years after their birth, being 
then known under the various local denominations of Parrs, Pinks, Fingerlings, \&c. However, in order to prevent any misconception of the terms employed in the course of these details, I shall adhere to the name Parr, as being the designation by which this fish is most generally known in Scotland.

"The early or late hatching of the Salmon-spawn in the river is no doubt in a great measure regulated by the temperature which may prevail after its deposition. In severe winters, when the temperature of the river for many weeks barely exceeds the freezing point, the ova remain in the gravel at the bottom of the stream during that period with the living principle comparatively suspended, until the more genial temperature of the spring brings that principle into more active operation. In the course of experiments made in the beginning of 1838, I had an opportunity of observing the different effects of temperature in facilitating or retarding the development of the Salmon-spawn. In ova placed in a stream of spring water, the average temperature of which was $40^{\circ}$, the embryo fish was visible to the naked eye by the end of the sixtieth day, and was hatched on the hundred and eighth day after impregnation. That which the same parent deposited the same day in the river, the average temperature of which during the eight following weeks did not exceed $33^{\circ}$, was not visible to the naked eye until the ninetieth day, and was not hatched until the 10th of May,-that is, one hundred and thirty-one days after impregnation. The temperature of the river, however, during the last forty days of that period, had considerably increased, and on the day on which the fishes were hatched, it had attained an elevation of $60^{\circ}$. Were it, then, the fact that the young Salmon migrate to the sea the same season they are hatched, the effects of a mild or 
a rigid winter would alone regulate the period of their departure from the river. This, however, is not the fact, as the main body of the Salmon-fry regularly quit our rivers about the first or second week in May, whatever may have been the temperature of the previous winter, and in this particular instance they were actually descending the river in shoals on the very day (10th of May) on which that season's produce were only emerging from the ova.

"Owing to the great family likeness which is known to exist amongst the young of the several species of the genus Salmo in their early stages, an idea has been entertained that unscientific observers are in the practice of confounding the progeny of the whole of the migratory species indiscriminately under the too general name of Parr. To obviate this inconvenience, and to mark the distinction of species in their earlier stages, recourse has been had to very fanciful and ill-defined attributes; and I am of opinion that in almost every instance these vague characters have been applied to individuals of the young of the real Salmon, of which the characters had not been so fully developed as those of others, rather than to the young of any distinct species. With the view, therefore, of affording scientific men an opportunity of comparing the young of the Salmon Trout with that of the Salmon, with which they are supposed to have been confounded, I have taken this opportunity of laying before the Royal Society a brood of the former produced by artificial impregnation, and exhibiting five successive stages, from the day on which they were hatched to the age of nine months, accompanied by the skins of the parent fishes. At the age of six months they bear no very marked resemblance to the young of the real Salmon either in the Parr or fry state, and as they advance in age and size, the 
resemblance becomes still slighter. However, on comparing them with the common Trout, the resemblance is very striking, the general outline of the fish being much less elegant than that of the young Salmon or Parr, the external markings being also more peculiarly those of the Trout species, so that, in the absence of the parent skins, it would be a matter of difficulty to determine to which kind of Trout they actually belong. A specimen of the young Common Trout of this season's produce, taken from the Clyde above the falls, is also exhibited; so that the young of the three species most common to this locality (and of corresponding age), viz. Salmo salar, Salmo trutta, and Salmo fario, may be carefully compared. The ova of the Salmo eriox, which is less common in
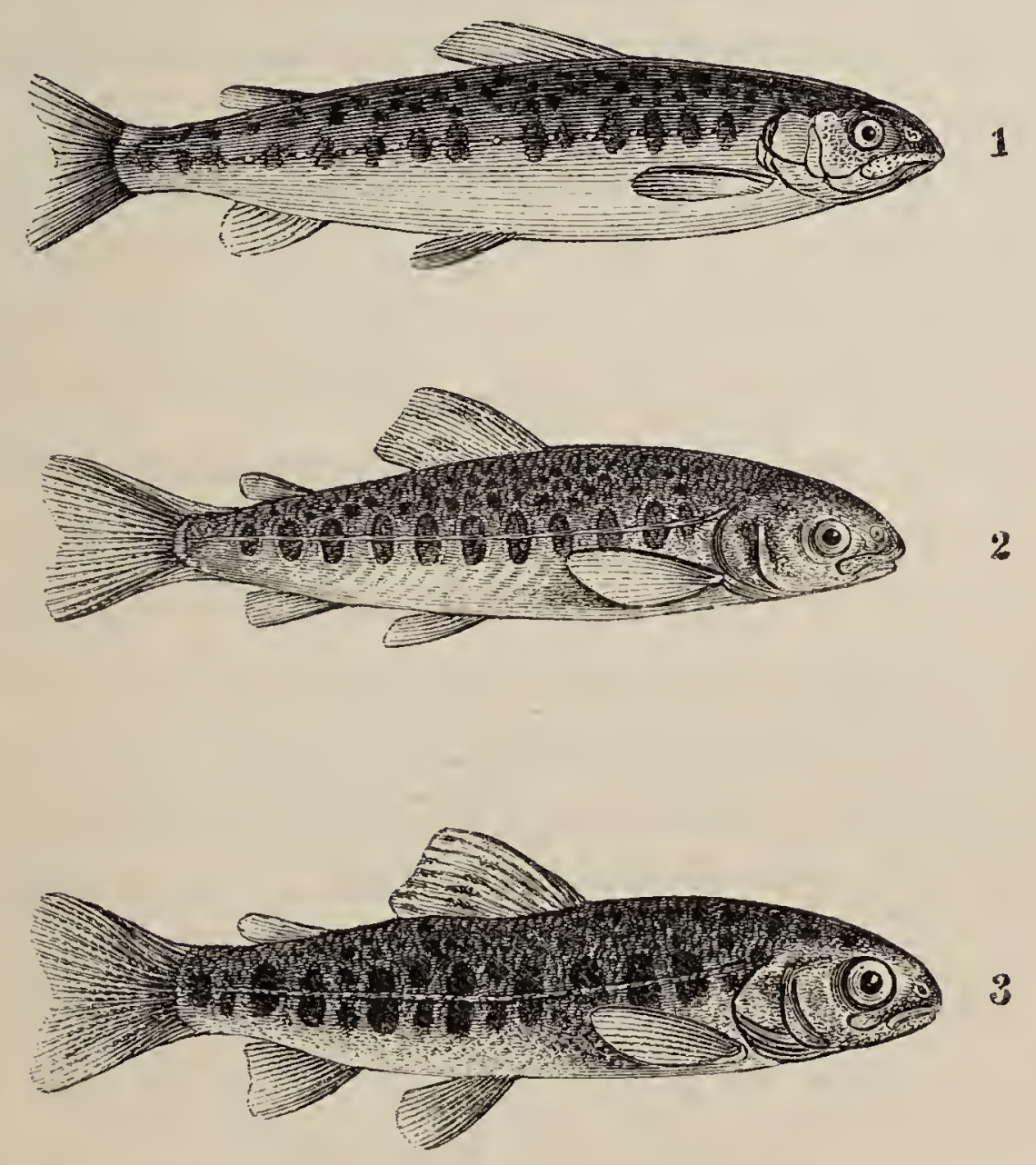

1. Young Salmon. 2. Young Sea Trout. 3. Young River Trout. 
these tributaries, I have not as yet had an opportunity of experimenting upon.

"To resume my history of the so-called Parr. Having brought this series of experiments on the ovum of the Salmon, begun in January 1837, to a satisfactory conclusion, it may be gratifying to those who have taken an interest in this curious inquiry, to be put in possession of the results. I have already detailed the particulars regarding the mode practised in capturing the parent Salmon, the process of fecundating the ovum artificially with the milt from the male, and the appearance it presents from that period up to the exclusion of the young fish from the capsule of the ovum, which took place on the 7th of May,-one hundred and one days after impregnation. A complete series of specimens from the egg until the commencement of the third year, illustrates the following descriptive notes.

"Specimens taken from the pond, when ten days old (16th of May), had still a considerable portion of the vitelline bag attached to the abdomen. Specimens removed when forty-eight days old (24th of June) had no recognisable bag, but the symmetry of the form was as yet but imperfectly developed. After the lapse of two months ( 7 th of July), the shape was found to be materially improved, and to exhibit in miniature much of the form and proportions of a mature fish. At the age of four months (7th of September) the characteristic marks of the Parr were clearly developed. Two months later (six months' old, 7th of November) an accession both of size and strength was apparent, and on comparing the pond specimens with the Parr of the river, no marked difference was perceptible. The average length at this time was three inches.

"During the winter months, the general temperature 
of the rivers is so low, and the consequent deficiency of insect food so great, that the whole of the Scottish Salmonida which inhabit the fresh waters during that season, are well known to lose, rather than gain, in point of condition. The same rule holds in regard to the young Salmon in the experimental ponds, although not to the same degree, they having maintained comparatively a superior condition throughout the winter to those found in the river of a corresponding age and size. The temperature of the ponds, averaging about $40^{\circ}$ during the winter, not only keeps the young fishes which occupy them in a more active condition, but the insects themselves are also more abroad, and thus afford a convenient supply of food not to be obtained by those at that time in the river, the average temperature of which, in ordinary winters, barely exceeds $34^{\circ}$."

"A specimen twelve months old, taken from pond No. 1, on the 10th of May 1838, is much improved in condition, as well as in external appearance, in comparison to those taken in February, and has exchanged its dusky autumnal and winter's coating for that which may be called its summer dress.* It measures about three inches and three-quarters in length, and is denominated, along with those of a corresponding age and size in the river, the 'May Parr.' Immediately after the migration of the two-year old Parr (which the latter always effect about the beginning of May, under the name of Salmon-fry), there is no other Parr, besides such as have been recently hatched, to be found in the river save those which corre-

* "On the approach of autumn, the whole of the Salmonidce, resident as well as migratory, while in fresh water, acquire a dusky exterior, accompanied by a considerable increase of mucus or slime. The fins also become more nuuscular. However, on the return of spring, they resume their wonted beautiful colouring; and the fins, the cartilaginous portions of which are frequently damaged during the winter floods, grow up and acquire their former outline."

VOL. I. 
spond with this specimen, which is the Pink of the river Hodder, alluded to by Mr. Yarrell.* As the summer advances they increase in size, and are actually the little fish which afford the Angler in Salmon rivers so much light amusement with the rod, during the months of August, September, and October. They remain over the second winter in the river, during which period the males shed their milt, and are found continuing their kind along with the female adult Salmon, although still bearing all the external markings of the Parr, as I shall afterwards more particularly mention. A specimen eighteen months old, taken from pond No. 1, on the 14th of November 1838, measures six inches in length, and has now attained that stage when all the external characteristic markings of the Parr are strikingly developed, and, in point of health and condition, cannot be exceeded by any taken from the river. All the males, at the age of eighteen months, of the several broods in my possession, last autumn (1838), attained a most important and corroborative stage, viz. that of showing a breeding state, by having matured the milt, which could be made to flow freely from their bodies by the slightest pressure of the hand. The females of the same broods, however, although in equal health and condition, did not exhibit a corresponding appearance in regard to the maturing of roe. $\uparrow$

* " "Pinks in the river Hodder, in the month of April, are rather more than three inches long, and are considered to be the fry of that year"; at this time Smolts of six inches and a half are also taken.'-See Yarrell's Supplement to British Fishes, p. 6 . The fry of the same year, in mild winters, are only quitting the gravel in April, at which stage they measure not more than one inch."-J. S.

* "I have examined hundreds of Parrs. . . . . Male Parrs I have frequently found with mature milt, but never a female with roe, correspondingly developed ; on the contrary, in the female fisl, without exception, the ovaries lave been so small, that, had they not been sought for carefully, they would have escaped notice."-Dr. Davy On Salmonidce, Transactions, Royal Society of Edinburgh, 1854. 
The male and female Parrs in the river, of a similar age, are found respectively in precisely a corresponding state, which may surely be admitted as most important evidence in support of the fact, that all these individuals are, in truth, specifically the same.

"A specimen, two years old, taken from pond No. 1, on the 20th of May 1839, is six inches and a half long, and has assumed the migratory dress. The commencement of the change, which was perfected by the whole of the broods about the same time,* was first observable about the middle of the previous April, by the caudal, pectoral, and dorsal fins assuming a dusky margin, while, at the same time, the whole of the fish exhibited symptoms of a silvery exterior, as well as an increased elegance of form. The specimen in question, so recently a Parr, exhibits a very perfect example of the Salmon-fry or Smolt.

"When the migratory change takes place in the young Salmon in the ponds, a marked alteration also occurs in their habits. While in the Parr state, they show no disposition to congregate, but each individual occupies a particular station in the ponds, and should any one quit his place with the view of occupying the position already possessed by another, the intruder is at once expelled with an apparent degree of violence. But so soon as the whole brood has perfected the migratory dress, they immediately congregate into a shoal, and exhibit an anxious desire to effect their escape, by scouring all over

* "One or two of each of the three broods assumed the migratory or" Smolt dress at the age of twelve months. This circumstance I am disposed to attribute to the high temperature of the spring-water ponds, which I have no doubt has hastened the change. I am greatly strengthened in this opinion by the fact of no instance of a similar change having occurred with individuals reared in similar ponds supplied with water from a rivulet, the temperature of which throughout the year ranges pretty nearly with that of the river Nith." 
the ponds, leaping and sporting, and altogether displaying a vastly-increased degree of activity."

"I have elsewhere stated that 'the circumstances attending the development and growth of the brood in pond No. 3, so exactly correspond with those of the preceding brood in pond No. 1, that their history would only be a repetition of the former. I may, however, state, that the individuals in pond No. 3 are considerably larger than those in pond No. 1, the difference, at the age of six months, amounting to an inch.' This superiority in point of size, for the first six months, of those in pond No. 3 over those reared in pond No. 1, was not, however, maintained, with the exception of two individuals, much beyond the first six months, as by the period at which they assumed the migratory dress (two years) no difference existed in regard either to size or condition."

"The circumstance of the male Parrs with the milt matured, and flowing in profusion from their bodies, being at all times found in company with the adult female Salmon while depositing her spawn in the river, and the female Parrs being in every instance absent, suggested the idea that the males were probably present with the female Salmon at such seasons for a sexual purpose. And to demonstrate the fact, I took, in January 1837, a female Salmon weighing fourteen pounds from the spawning-bed, from whence I also took a male Parr weighing one ounce and a half, with the milt of which I impregnated a quantity of her ova, and placed it in the stream of pond No. 2, where, to my great astonishment, the process succeeded in every respect as it had done with that which had been impregnated by the adult male Salmon, and exhibited, from the first visible appearance of the embryo fish up to their assuming the migratory dress, the utmost health and vigour. The very extraordi- 
nary results of these experiments, although made with the utmost possible care, induced me to defer giving them publicity until I had repeatedly verified the fact. I, therefore, removed this brood to another pond, apart from all other fish, where they had an abundant supply of insect food and wholesome water; and again, early in the following January (1838), I repeated the experiment by taking another female Salmon, weighing fourteen pounds, and two male Parrs from the same spawning-bed, and impregnated two lots of her ova with the milt from the two Parrs, and afterwards placed them in two different streams inclosed in boxes open at the top, temperature $45^{\circ}$. The extreme severity of the weather which succeeded had, however, nearly proved fatal to the whole. On the evening of the 8th of January, the day on which I took the parents from the river, the frost set in, and continued with such intensity for a succession of many weeks, that the wild fowl generally, and the wild ducks in particular, suffered severe privations, and in the course of their wanderings in search of food, they unfortunately stumbled on my boxes of ova, one lot of which they wholly devoured, to the amount at least of five hundred. My feelings of mortification and disappointment on the discovery of this unforeseen disaster may readily be conceived. However, on examining my other box, I found there were still a few remaining, which I carefully collected, and put into a place of greater safety. The progressive growth of these, from the impregnation of the ova up to the age of eighteen months, has also been uniformly the same as those produced by male and female adult parents, and reared under similar circumstances.

"As a further illustration of the singular economy of the Salmon in their native streams, I have yet to detail another experiment or two, not less interesting than con- 
clusive. In December last (1838) I took a female Salmon from the river weighing eleven pounds, and four male Parrs from the same spawning-bed. After impregnating four different lots of her ova, one lot to each individual Parr, I placed the four Parrs in a pond, where they remained until the following May, at which period they assumed the migratory dress. The ova were placed in streams to which no other fish had access, and where they became mature in a similarly progressive manner to those already detailed, thus clearly demonstrating that the young Salmon of eighteen months old, while yet in the Parr or early state, actually perform the duties of a male parent before quitting the river.*

"While the males of the three several broods which occupy ponds Nos. 1, 2, and 3, continued in a breeding state, which lasted throughout the whole of the winter of 1838-39, I impregnated the ova of three adult female Salmon from the river with the milt of a male taken from each of the three ponds, the whole of which ova matured. This at once removes any doubt which may have been entertained regarding the constitutional strength of individuals reared under such circumstances.

* "As I believe it has been objected to my views, or rather practice, regarding this mode of impregnation, that the generative influence may have been in some othel way effected than through the medium of the Parr, I therefore took every means to prove the truthful results of my experiments by varying in some measure their conditions. Thus, in two instances, I took a portion of the ova from a female Salmon, and placed them, without impregnation, in a stream of pure water. The result was as I anticipated :- - up to the termination of the general hatching season they exhibited no appearance of vitality. The female from which one lot of ova was taken, and placed in water without impregnation, was the female with which the four Parrs above alluded to were spawned. They were placed in the same stream, but in a separate vessel from the four lots impregnated. The other lot was taken from the female with which the male from pond No. 3 was spawned. The unimpregnated lot was placed in the same stream with the former. The impregnated lot was placed in the stream of pond No. 3. To avoid contact the unimpregnated lots were in each case taken first, and removed to a distance." 
"One of the males used in the above experiments is itself the produce between a male Parr and female adult Salmon taken from the river on the 4th of January 1837, and reared in pond No. 2, as already mentioned. The result of the experiment practised with this specimen and the female Salmon from the river, being of the utmost importance in establishing the identity of the species (on a principle recognised by physiologists as a law of nature), every necessary precaution to avoid error or confusion was observed. It was taken from pond No. 2 on the 5 th of January, 1839, being then twenty months old, with the milt flowing from its body. A female adult Salmon weighing twelve pounds was taken at the same time from the river, in the act of spawning in the absence of the male. A quantity of her ova was impregnated in the same manner in every respect as practised in the preceding experiments, and, for the better security of the lot, the whole was placed in a wooden trough, over which a sheet of fine copper-wire gauze was fixed. The trough was then placed in a stream of water previously prepared for its reception, and the results were precisely of a corresponding nature to those already detailed, the embryo fish becoming visible after fifty-five days, and being excluded from the egg at the end of one hundred and nine days after impregnation, under a temperature of $40^{\circ}$.

"It has been maintained by individuals whose opinions are opposed to mine on this question, that the Parr is a distinct species, and that, by a forced connection between it and the female Salmon, I was producing a hybrid. This idea at once brings the importance of the last experiment more immediately into view, from the circumstance of the male parent of the specimen being actually a Parr, while the alleged hybrid, in its turn, became the parent of a numerous brood. 
"Were these two species, then, really distinct, it would follow that the produce would be hybrids, and 'nature herself has provided against the confusion of different species by a conservative law, according to which all hybrids are barren :' consequently, upon this principle-a law in the economy of nature-the Parr and Salmon are really identical in species, as proved by the fact now narrated, of the young produced between them having actually the power of reproducing their kind.

"Apart from these experiments, it was at one time held, that the Parrs found in their native streams were hybrids, from the anomalous circumstance of the males being always found in the autumn with the milt matured, while females, of a corresponding size, could at no season be found exhibiting the least approximation to a breeding state.* However, this idea, if it ever was seriously entertained by scientific men, has now given way to the opinion 'that they are a distinct species, and have no connection whatever with the migratory Salmon.' $\dagger$ Were the Parr a distinct species, the result of their attendance

* "Solitary instances have occụrred of large female Parrs having been found in Salmon rivers with the roe considerably developed, and I find, by detaining the female Smolts in fresh water until the end of the third winter, that individuals are found in this comparatively mature condition. From this fact, therefore, it may be inferred, that the large Parr, either male or female, of nine and ten inches in length, which are occasionally found in rivers, are the young of the Salmon, which, for some natural reason, had not been prepared to migrate at the ordinary period, and had, therefore, remained for another year in the fresh water."

+ "Recent experiments having been made on the young of the Salmon by very competent individuals, it is now admitted that they 'remain one year' in the river before they go to the sea as Smolts.' However, owing to these fishes having escaped the observation of those individuals during the intermediate stage, that is, from the ovum up to the length of three inches, they were actually twelve months old at the commencement of the experiments referred to by Mr. Yarrell, in place of being the "fry of that year.'" - See Mr. Yarrell's Supplement to British Fishes. 
on the female Salmon would have the effect of producing universal confusion among the migratory inhabitants of rivers, from the circumstance of the male Parrs in a breeding state occupying in great numbers the very centre of the Salmon spawning-bed, while the female Salmon herself is at the same instant pouring thousands of her ova into the very spot were they are thus generally congregated.

"Had these extraordinary results proceeded from a solitary experiment, there might have been some ground for believing that I was probably deceiving myself, and, consequently, misleading others, - a fear I myself at first entertained. But after such a series of experiments, made with all possible care, and uniformly ending in the same results, the fact can no longer, I conceive, admit of doubt. Having altogether, within these last two years, made eight distinct experiments by artificially impregnating the ova of the Salmon with the milt of a corresponding number of male Parrs from the river, besides three experiments with those of eighteen-month-old Parrs from the pond-each with perfect success-I trust that I have thrown some interesting light on the breeding of Parrs, - a subject which has hitherto defeated all inquiry when sought after on the principle of their breeding among themselves as a distinct species.

"The fact of the young Salmon propagating its kind while it is yet itself in other respects in an immature condition, is certainly an extraordinary departure from the ordinary laws of nature, so far, at least, as land animals are concerned. From certain observed facts, however, there is reason to believe that the economy of the class of fishes differs in this respect from that of land animals-a disparity which, in consequence of the medium they inhabit, has hitherto escaped the observa- 
tion of the naturalist. As the young of the other migratory species do not quit the river during the first year, it is probable that they also observe a similar economy to that of their more valuable congener.

"It has been generally supposed that the male Salmon, during the spawning season, assists the female in forming the spawning-bed. This idea is, I think, founded in error, as, during the whole course of my experience, I have never been able to detect the male taking any share whatever in the more laborious portion of these parental duties. The only part he performs, beyond the mere sexual function, consists in the unwearied vigilance which he exhibits in protecting the spawning-bed from the intrusion of rival males, all of which he assiduously endeavours to expel. The female, regardless of the occasional absence of the males during these contests, and probably satisfied with the presence of the male Parrs, proceeds with her operations by throwing herself at intervals of a few minutes upon her side, and while in that position, by the rapid action of her tail, , she digs a receptacle in the gravel for her ova, a portion of which she deposits, and, again turning upon her side, she cover's it up by a renewed action of the tail,- - thus alternately digging, depositing, and covering ova, until the process is completed by the laying of the whole mass, an operation which generally occupies three or four days. In the course of these experiments it has been ascertained that the milt of a single male Parr, whose entire weight may not exceed one and a half once, is capable, when confined

* "I am aware it has been a matter of dispute amongst observers as to which of the two extremities of the fish is employed in the formation of the spawning-bed. However, from late opportunities of observation, which rarely occur, owing to the turbid state of the river in the spawning season, I am now satisfied that it is by the action of the caudal extremity alone that the gravel is removed." 
in a small stream, of effectually impregnating all the ova of a very large female Salmon. On the spawn first quitting the body of the female, it is found to be enveloped in a thin coating of viscous matter, which the action of the water does not immediately destroy, but which continues to admit of a partial adherence to the gravel at the bottom of the spawning-bed, where the ova receives the necessary fecundation of the milt, and are afterwards covered with gravel by the instinctive efforts of the female parent, in the manner above described.

"How long these ova will remain excluded from the body of the female, and yet continue capable of receiving with effect the fecundating action of the milt, I have not hitherto ascertained. I have, however, made several experiments on the ova after the parent had been a considerable time dead, and removed from the river. In one particular instance, the female had been dead for nearly two hours without the vital principle of the spawn being in the least degree affected, -as, on being afterwards placed in water, and the milt of a living male poured upon it, it exhibited within the usual period the same healthy and progressing vivification, under a similar temperature as that taken and impregnated the moment it quitted the body of the living parent. I have merely stated this fact as being in part corroborative, so far as relates to the Salmon, of similar experiments made by M. Jacobi on individuals of the same genus.

"The extraordinary nature of the experiments made with the Parr and Salmon, I have no doubt will tend to stagger the belief of many who may be disposed to admit the truth of the facts resulting from the experiments upon the adult fishes. Nevertheless, they are strictly true; and I would strongly recommend that all those interested should immediately turn their attention to a 
subject so curious in a zoological point of view, and so important in its bearings on the history of the most highly prized of all the species which ever sojourn in our river waters."

It will be recollected, then, from these details, commencing with the observations of Dr. Knox, that the young Salmon was believed by some to go down to salt water when only two or three months old, or in its first spring. By others it was considered that the young fish did not go down to the salt water till it was fourteen months old, or in its second spring; and the experiments of Mr. Shaw go to prove that they do not go down to the salt water till they have completed their second year, and are in their third spring. If $\mathrm{Mr}$. Shaw is correct that a Pink of three inches and a half in the month of April is twelve months old-which there is now, from his various experiments, no reason to doubt-it will be found that Mr. Parker's observations, commencing with Pinks from the Hodder in April, then twelve months old, subsequently corroborate the views of Mr. Shaw both as to growth and colour.

In the course of Mr. Shaw's experiments, he found that though the usual duration of the Parr stage was as he has described, yet that some of his young fish smolted when little over a year old; and some naturalists still maintain that all would have undergone that change at the year's end had they been left at large in the river. That excellent man, and sound naturalist, the late James Wilson, Esq., offers some valuable remarks on this point, in his paper on Fisheries, published in the latest edition of the Encyclopadia Britannica, in support of Mr. Shaw's conclusions. The reader is referred to that able paper for important facts and much sound reasoning, our limits not permitting us to extract from it more 
than a single paragraph. "We have repeatedly," says Mr. Wilson, "demonstrated by observations of the easiest kind, that there are three different stages or broods of Parr (that is, young Salmon) in our rivers in early spring. First, those recently excluded from the eggs; as yet small and inconspicuous; Secondly, those which are just completing their first year, and which, from the defect of insect food in the winter, are very little larger than they were at the end of the preceding October-seldom measuring more than three inches. These increase rapidly in size during the summer, and then constitute the obvious and admitted Parr which stock our rivers. Thirdly, for a short time, along with two other broods, the large and as regards the males, sexually-developed Parr, which have completed their second year, and are characterized by their brightness as well as size. In the months of April and May these are converted into silvery Smolts, and depart downwards to the sea." Dr. Davy has ascertained, by chemical analysis, that insect diet furnishes a large supply of the phosphate of lime, which fishes need for the induration of their scales and deposition of nacre which accompanies the lustrous appearance the fish assumes in smolting.* On analyzing the scales of a Trout, he found that they contained twenty per cent. of phosphate of lime. Worms and slugs contain but little phosphate of lime. A writer in the Scotsman newspaper of the 6th of June 1855, states that one-half of the Salmon-fry produced in the river Wharfe in Yorkshire descend to the sea when one year old, and the other half at two years. The facts stated by this writer are very curious, and the reader

* Dr. Davy considers the scales of the Smolt to be new productions, not mere alterations of the former scales.--See Angler in the Lake District, p. 209. 
would do well to consult his letter, which is printed in Mr. Wilson's Fisheries above quoted.

The facts stated respecting the Wharfe accord with experiments made at Stormontfield, near Perth, by Mr. Thomas Ashworth, and reported upon by a Committee of the British Association. It was clearly proved that a part of the Salmon-fry assumed the migratory dress, and descended to the sea shortly after the close of the first year of their existence, and returned again as marketable Grilse, weighing from five to nine and a half pounds, within twenty months from the deposition of the ova. The Parrs left behind in the pond weighed only one ounce, while their brethren, by a visit to the sea, had acquired the weights mentioned above. The female Parrs in the pond had their eggs so immature as to be scarcely discernible through a good lens; but the males had their milt as far advanced as that of the Grilses of equal age, yet of seven pounds' weight. In the following season the Parrs that had remained behind also became Smolts, and went to sea.-Rep. of Brit. Ass. for 1856, p. 451 .

'To return to the Salmon when in a natural state. The adult fish having spawned, being out of condition and unfit for food, are considered as unclean fish. They are usually called Kelts; the male fish is also called a Kipper, the female a Shedder, or Baggit. With the floods of the end of winter and the commencement of spring, they descend the river from pool to pool, and ultimately gain the sea, where they quickly recover their condition, to ascend again in autumn for the same purpose as before; but always remaining for a time in the brackish water of the tide-way before making either decided change; obtaining, it has been said, a release from certain parasitic animals, either external or internal, by each seasonal 
change; those of the salt water being destroyed by contact with the fresh, and vice versâ.

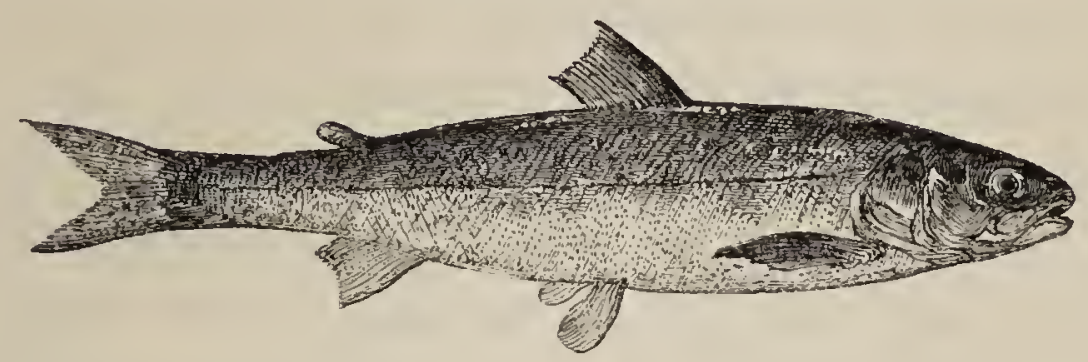

The fry are observed to collect in small pools and milldam heads preparatory to quitting the river. The specimen from which the figure on this page was taken was obtained in the Thames, in which river they are occasionally caught in the season, with other fry of Salmonida, by fishermen who work at night with a casting-net on the gravelly shallows for Gudgeons to supply the London fishmongers.

My own specimens of the young of the Salmon having been preserved in spirits, and the colours thereby affected, the following description is from Dr. Heysham's Catalogue before referred to, premising that some differences in colour may be expected in specimens from different rivers.

"Length seven inches and a half; circumference three inches and one-eighth; head dark green: gill-covers fine silvery white, marked with a dark-coloured spot; belly and sides up to the lateral line of the same silvery colour; back and sides down to the lateral line dusky, inclining to green; sides above the lateral line marked with numerous blackish spots; along the lateral line, and both a little above and beneath it, several dull obscure red spots; dorsal fin has twelve rays, marked with several blackish spots; pectoral fin has twelve rays, of a dusky olive colour; ventral fin eight rays of a silvery white; anal fin ten rays of the same colour. When the scales 
were carefully taken off with a knife, the obscure red spots became of a fine vermilion, and were nineteen in number; and ten obscure oval bars of a dusky bluish colour appeared, which crossed the lateral line. In a young fry these bars are very distinct."

Whether the river be considered an early or a late river, the descent of the fry is said to take place much about the same time in all. It begins in March, and continues through April and part of May. The Smolt, or young Salmon, is by the fishermen of some rivers called a Laspring; and various couplets refer to the fish, as well as to the time and circumstances under which the descent is made.

The last spring floods that happen in May, Carry the Salmon fry down to the sea.

And again,

The floods of May

Take the Smolts away.

But the uncertainty of popular or provincial names is a source of great perplexity to the naturalist. The Laspring of some rivers is the young of the true Salmon; but it must also be recollected that the fry of two other species probably descend to the sea about the same time as those of the Salmon.

The Salmon-fry at first keep in the slack water by the sides of the river; after a time, as they become stronger, they go more towards the mid-stream; and when the water is increased by rain, they move gradually down the river. On meeting the tide, they remain for two or three days in that part where the water becomes a little brackish from the mixture of salt water, till they are inured to the change, when they go off to the sea all at once. There, their growth appears to be very rapid, and many 
return to the brackish water, increased in size in proportion to the time they have been absent. Fry marked early in May have returned by the end of June weighing from two to three pounds and upwards. The London markets during the latter part of June, and the months of July and August, exhibit young fish varying in weight from two to six pounds. I have one, here figured, that weighed only fifteen ounces, which, judging from its appearance when $I$ bought it, that it had been to sea, is the smallest specimen I have ever seen that had been once to salt water.

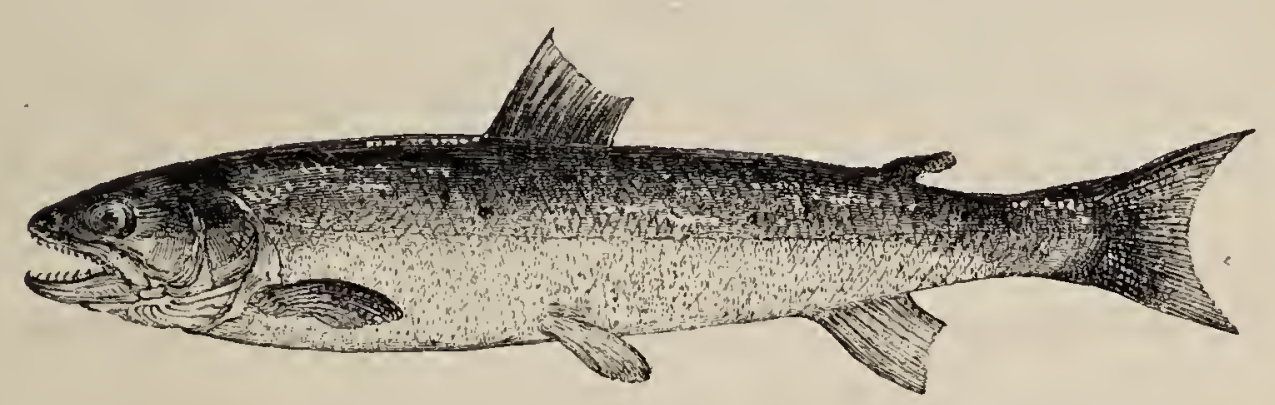

These small-sized fish, when under two pounds' weight, are called by some of the London fishmongers SalmonPeel; when larger, Grilse. They breed during the winter ; and on their return from the sea with the roe enlarged, the ova are of nearly the same size as those of a Salmon, but they mature only a much smaller number. The Grilse visit the estuary, remaining for a considerable time in the brackish water, afterwards in the tide-way above, ultimately pushing up to the sources of the tributary streams, and, as before observed, rather earlier in the season, in the same river, than the more adult fish.

It has been a constantly-received opinion, that all the young fish after their first visit to the sea return to the rivers in which they had been bred; and numbers of marked fish are stated to have been retaken in their 
native rivers: but it is equally certain that some have been taken in other rivers not far off. The difficulty of supposing that they could find and return to the same spot after roving for miles along the coast remains to be solved. That they do thus rove for miles is proved by the thousands that are taken in nets placed in the bays along the coast. Very many Tweed Salmon have been caught opposite Hopetoun House on the Forth; and a very successful fishing there is generally followed by a scarce one in the Tweed. It is therefore very probable, from the remarks of Dr. Heysham and Sir William Jardine, that if the fish happen to have roved far from the estuary of their native river, they run at the proper season up any stream, even the first they encounter, the temperature and condition of which are congenial to them.

The growth of the Salmon from the state of Smolt to that of Grilse has been shown to be very rapid, being from a few ounces to that of four or five pounds in two or three months; and the increase in weight attained during each subsequent year is believed to be equal, if not to exceed, the weight gained within the first.* The increase in size is principally obtained during that part of the year in which the fish may be said to be almost a constant resident in the sea. The food sought for to produce and sustain so rapid an increase of size must be very considerable in quantity, as well as most nutritious in quality; and that the Salmon is a voracious feeder, may be safely inferred from the degree of perfection in the arrangement of the teeth, and from its own habits, of which proof will be adduced, as well as from the

* A table, published by Mr. Young, of twelve carefully-marked Grilses, each weighing four pounds, shows that, when re-captured about six months afterwards, their weights had increased to from nine to thirteen pounds. 
well-known habits of the species most closely allied to it; yet of the many observers who have examined the stomach of the Salmon to ascertain the exact nature of that food which must constitute their principal support few have been able to satisfy themselves. Dr. Knox states "that the food of the Salmon, and that on which all its estimable qualities, and, in his opinion, its very existence, depend, and which the fish can obtain only in the ocean, he has found to be the ova or eggs of various kinds of echinodermata, and some of the crustacea. From the richness of the food on which the true Salmon solely subsists, arises, at least to a certain extent, the excellent qualities of the fish as an article of food. Something, however, must be ascribed to a specific distinction in the fish itself: for though he has ascertained that the Salmon-Trout lives very much in some localities on the same kind of food as the true Salmon, yet under no circumstances does this fish acquire the same exquisite flavour as the true Salmon."

That they occasionally, however, take other food, is also well known. Faber, in his Natural History of the Fishes of Iceland, remarks, "The common Salmon feeds on small fishes, and various small marine animals." Dr. Fleming says, "Their favourite food in the sea is the Sand Eel;" and I have myself taken the remains of Sand-Launce from the stomach. Sir William Jardine says, "In the north of Sutherland a mode of fishing for Salmon is sometimes successfully practised in the firths, where Sand Eels are used as bait: a line is attached to a buoy or bladder, and allowed to float with the tide up the narrow estuaries. The Salmon are also said to be occasionally taken at the lines set for Haddocks, baited with Sand Eels. At the mouths of rivers they rise freely at the artificial fly within fifty yards of the sea; and the common 
earth-worm is a deadly bait for the clean Salmon. All the other marine Salmonoids are known to be very voracious; and there is nothing in the structure of the mouth or strong teeth of the common Salmon, to warrant us in supposing that there is any material difference in their food." The following is an extract from a letter sent me by Sir William Jardine, dated St. Boswell's, 15th April 1835:- "The fisherman who rents this part of the Tweed, fishing with worm one day last week, had his hooks and tackle taken away by a fish. He put on a new set, and again with worm in ten minutes hooked and killed a Salmon with his former hooks and bait in his mouth. This will either prove extreme voracity, or little sensibility in the parts of the mouth. I have often heard fishermen mention a similar fact, but never before knew an instance on which I could depend."

Several observers have borme testimony to the partiality of the Salmon to the Sand-Launce as food; and I have a record by an angler of Salmon caught in the Wye with a Minnow. In a prize essay published in the Transactions of the Highland Society, vol. ii. page 392, Mr. Alexander Morrison says, "I have taken Salmon, within flood mark, some of which had two, and others three, full-sized Herrings in their stomachs."

The London season of 1835 was more than usually remarkable for large Salmon. I saw ten different fish varying from thirty-eight to forty pounds each. A notice appeared in the public papers of one that weighed fiftyfive pounds; and, from the inquiries made, there is reason to believe most of these large-sized Salmon were sent from the Tay. Salmon, however, of much larger size have been occasionally taken. Mr. Mudie has recorded one of sixty pounds. In a note to the history of the Salmon in several editions of Walton, one is mentioned 
that weighed seventy pounds; Pennant has noticed one of seventy-four pounds: the largest known, as far as I am aware, came into the possession of Mr. Groves, the fishmonger of Bond Street, about the season of 1821 . This Salmon, a female, weighed eighty-three pounds; was a short fish for the weight, but of very unususal thickness and depth. When cut up, the flesh was fine in colour, and proved of excellent quality.

The Salmon of the largest size killed by angling, of which I have been able to collect particulars, are,-In the Thames, October 3, 1812, at Shepperton Deeps, Mr. G. Marshall, of Brewer Street, London, caught and killed a Salmon with a single gut, without a landing-net, that weighed twenty-one pounds four ounces.

Sir H. Davy used occasionally to visit the Tweed for the sake of angling for Salmon. This river is famed for affording amusement to the Salmon-fisher, more especially from the middle of March to the beginning of May. "We have heard," says Mr. Stoddart, in his Art of Angling as practised in Scotland, "that on one occasion Sir H. Davy happened by good fortune to hit upon an immense fish, weighing about forty-two pounds, immediately above Yair Bridge, and captured him after a severe struggle. This feat he makes no mention of in his Salmonia, although certainly worthy of some notice."

Mr. Lascelles, in his Letters on Sporting, Part I. Angling, says at page 21, "The largest Salmon I ever knew taken with a fly was in Scotland: it weighed fiftyfour pounds and a half." Sir Hyde Parker with a rod and line killed a Salmon in Sweden that weighed sixty pounds; and the Earl of Home, the uncle of the present Earl, killed a Salmon in the Tweed with a rod, which weighed sixty-nine pounds and three quarters.

It may be stated generally, that Salmon pass the sum- 
mer in the sea, or near the mouth of the estuary: in autumn they push up rivers, diverging to the tributary streams; in winter they inhabit the pure fresh water, and in spring descend again to the sea. The question has frequently arisen, Could Salmon be preserved permanently in fresh water? and from the facts already adduced, it appears that they might, but not without some diminution in size or quality, or both.

Mr. Lloyd, in his Field Sports of the North of Europe, vol. i. p. 301, says, "Near Katrineberg there is a valuable fishery for Salmon, ten or twelve thousand of these fish being taken annually. These Salmon are bred in the lake, and, in consequence of cataracts, cannot have access to the sea. They are small in size, and inferior in flavour. The year 1820 furnished 21,817."

Dr. Davy, from a series of experiments instituted for the purpose of ascertaining how far the vitality of the eggs of Salmon were affected by exposure to air, or changes of temperature, came to the conclusion, that the eggs, when in an advanced stage, died in a short time in a dry atmosphere of the ordinary temperatures, but that they could remain for a considerable time in cool moist air,- the limit in the former case not having exceeded an hour, while in the latter, life extended over many hours. He found the vitality of the egg to be as well preserved in moist air as in water; and that it was not destroyed in ice, unless the cold were lowered many degrees below the freezing point. Both the eggs and the young fish, when in water, bore a heat of $80^{\circ}$ or $82^{\circ}$ Fahrenheit for a moderate time with impunity, but one of $84^{\circ}$ or $85^{\circ}$ proved fatal to life. Water as salt as sea-water speedily killed both the eggs and the young fish; brackish water, having a specific gravity of 1016 , also caused death, but less quickly; but when it was diluted so as to reduce the 
specific gravity to $100 \%$, the advanced ovum was hatched in it, but did not thrive so well as in pure fresh water.*

It would appear, therefore, that in cold weather the eggs of Salmon may, if entangled in the moist hair of an otter, or in the feathers of an aquatic fowl, be carried safely from one river to another, so as to diffuse the species; but that the heat of the stomach of a warmblooded animal would arrest the circulation of the embryo. An instance is recorded of the eggs of a Salmon, taken from the stomach of a Trout, being productive when returned to the water. $\uparrow$ Dr. Davy, in the course of his experiments, had the eggs of Salmon transmitted in moist moss or paper, backwards and forwards between Ambleside and Penzance, some of them surviving four of these journeys. The nearer the eggs were to the period of hatching, the better they bore transmission. The baneful influence of high temperatures on the eggs and young fish, explains why the parallel of $45^{\circ} \mathrm{N}$. Lat. is the southern limit of the Salmon in Europe, and $41^{\circ}$ in America, the mean temperatures of the year in those latitudes, being between $45^{\circ}$ and $52^{\circ}$ Fahrenheit.

Dr. Davy's observations lead one to believe, that the attempts that are making to transfer Salmon and Trout from England to Tasmania, and New Zealand, will not succeed unless the temperature of the water be kept down by ice during the passage through the warm latitudes. In the Zoologist for 1852 (p. 3504), Mr. Daniel Simith, who had charge of the impregnated eggs of the Salmon, and of two kinds of Trout from the Wandle, for conveyance to Hobart Town, mentions, that the eggs

* On the Ova of Salmon in Relation to the Distribution of Species, \&c., by John Davy, M.D., Inspector-General of Hospitals in 1855.-Transactions of the Royal Society of Edinburgh.

+ Treatise on the Propagation of Salmon, by Edm. and T. Ashwortl. London, 1853. 
hatched prematurely, and that many were addled, but that two kinds were growing rapidly when he wrote; the position of the ship being then $1 \frac{1}{2}^{\circ}$ south of the equator. $\mathrm{He}$ does not say whether any precautions were used to moderate the temperature.

It remains to describe the different modes by which the Salmon are taken; and these are as various, and the fisheries are as numerous and as extensive, as the value and quantity of the fish would lead us to expect. The rights of the proprietors, which have arisen in various ways, some by royal grants, others by possession or occupation of the soil, are generally farmed or hired at a rent depending on the extent or value of the local stations. The first attack made upon the fish is in the summer months, when the Salmon rove along the coast in quest of the mouths of the different rivers, in which they annually cast their spawn. "On these expeditions, the fish generally swim pretty close to the shore, that they may not miss their port; and the fishermen, who are well aware of this coasting voyage of the Salmon, take care to project their nets at such places as may be most convenient for intercepting them in their course.".

"It so happens that Carrick-a-rede (the rock in the road), between Ballycastle and Portrush, eastward of Ballintoy, is the only place on this abrupt coast (the northern coast of the county of Antrim) which is suited for the purpose. The net is projected directly outward from the shore with a slight bend, forming a bosom in that direction in which the Salmon come. From the remote extremity of the net a rope is brought obliquely to another part of the shore, by which the net may be swept round at pleasure and drawn to the land: a heap of small stones is then prepared for each person. All things being ready, as soon as the watchman perceives 
the fish advancing to the net, he gives the watchword. Immediately some of the fishermen seize the oblique rope, by which the net is bent round to enclose the Salmon, while the rest keep up an incessant cannonade with their ammunition of stones, to prevent the retreat of the fish till the net has been completely pulled round them; after which they all join forces, and drag the net and fish quietly to the rocks." *

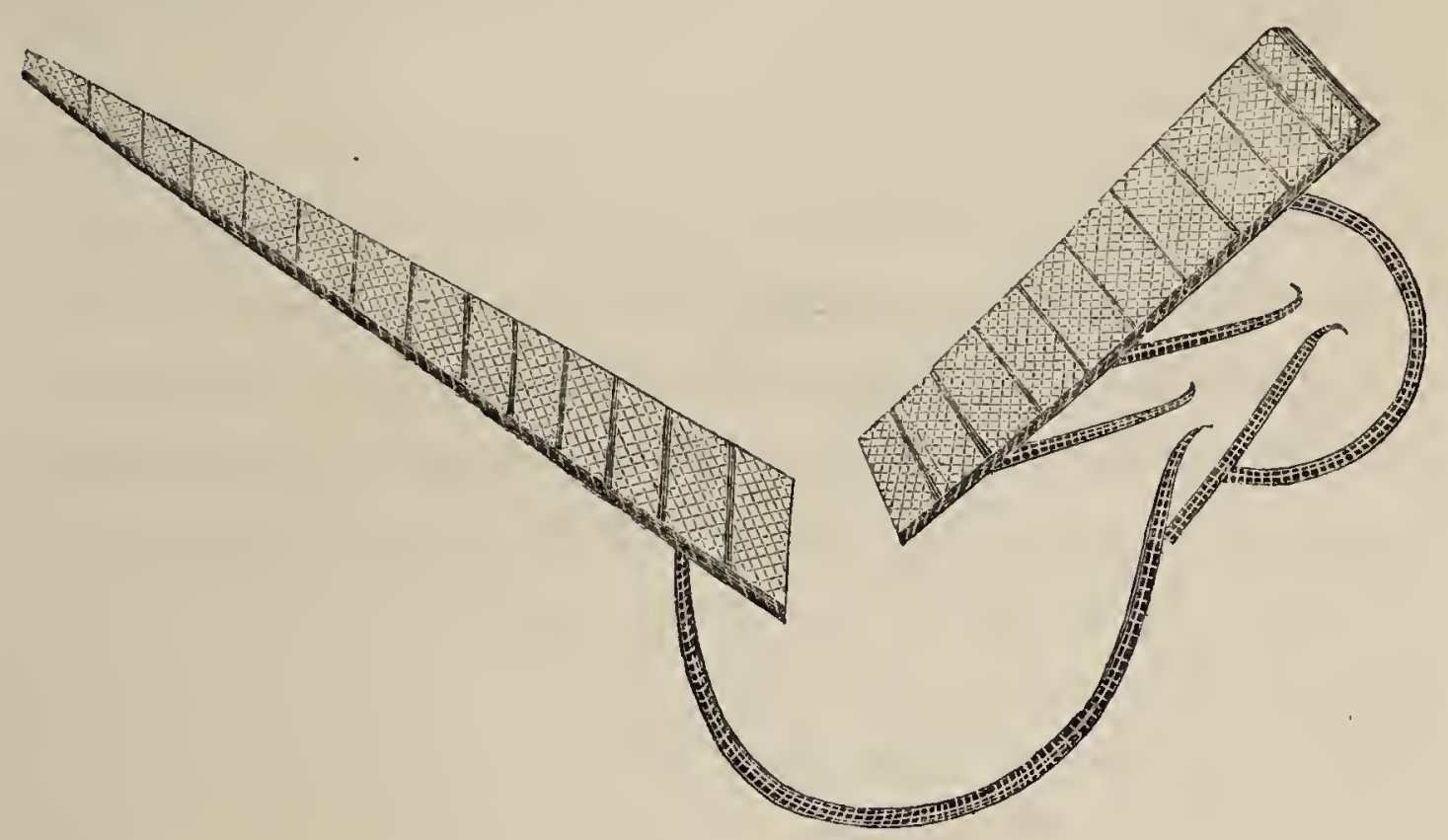

Pursuing a course along the shore and arrived at an estuary, on each side of the mouth, and for miles up on both sides stake-nets are used, of which the engraving above represents the form. The distance between high and low water mark on the shore is the site occupied. The shallow extremity of the net on the left hand in the figure, which is fixed and supported by stakes, is placed on the shore at high-water mark; the deepest part of the net, at low-water mark; the concavity of the sweep of the net between its two ends, called the court, being opposed or open to the flood-tide running up the river, the Salmon which in their passage up along-shore strike

* Letters concerning the Natural History of the Basalts on the Northern Coast of the County of Antrim, by the Rev. William Hamilton, A.B. 
against any part of the net are conducted by its form through the chambers into the trap, from whence they can find no retreat.

Many fish, in the wide part of the estuaries, ascending with each flood-tide and returning with the ebb, it is not unusual to have stake-nets placed in the reverse position, with the courts open to the ebb-tide, on purpose to meet this disposition in the Salmon; and they do actually sometimes catch as many fish in their downward as in their upward course.

The central portions of the streams, many of which are very wide, are worked incessantly by fishermen in boats called cobles, with long sweeping seine-like nets. Another mode of fishing is with a net dropped into the water from the stern of a boat, as the boat is rowed away from the shore. Men are stationed at particular places near the river, where the water is shallow, to watch the fish coming up; and so liabituated are they to this, that they can discover by a ripple on the surface of the water even a solitary fish making his progress upward. When a fish is thus discovered, an alarm or signal is instantly given to the men at the shiel or house where the fishermen lodge : and immediately a boat is rowed off by one man with great celerity, having a net attached to it, and ready prepared for dropping gradually into the water, one end of which is tied to the boat, and the other is dragged with a rope by men on shore ; and by taking a considerable sweep, an endeavour is made to surround the fish. When thus discovered coming up, they seldom escape. Higher up the river, and in parts that are narrow, weirs, or dams, are built across the stream. At certain intervals along these weirs, cruives are placed. Cruives are enclosed spaces formed in the dam wall; the fish enter these spaces, through which the water rushes, as 
they push up the stream, and are prevented by a grating of a peculiar contrivance from returning or getting out. All the wide and open pools of the river between these artificial, or any natural contractions of the stream, are fished with the cable and sweep-net.

In the work by the Rev. William Hamilton already quoted, and in the second series of Mr. Jesse's Gleanings in Natural History, an interesting account is related of the assistance afforded by a water-dog to some Salmon fishermen when working nets in shallow pools. The dog takes his post in a ford or on a scour where the water is not very deep, and at a distance below the net: if a Salmon escapes the net, the fish makes a shoot down the river in the direction towards the sea: the dog watches and marks his approach by the ripple on the water, and endeavours to turn the fish back towards the net, or catch him; if he fails in both attempts, and the fish passes him, the dog then quits the water, in which the pace of the fish is too fast for him, and runs with all his speed down the bank of the river to intercept the fish at the next shallow ford, where another opportunity and a second diverting attempt occurs.-I learn also from Mr. Bicheno, that dogs are occasionally used when trying for Salmon in that part of Glamorganshire where he resided. These dogs appear to take great pleasure in the pursuit, exhibiting by turns the most patient watchfulness, persevering exertion, or extraordinary sagacity, as either quality may best effect the wishes of the master. In some parts of Wales, where the rivers are narrow, and the Salmon are caught in a net drawn by men on each bank, dogs are trained to swim over from side to side with the head and ground lines of the net, as required. From a correspondent in Devonshire I learn that a clever poacher at Totness on the Dart, admitted that he had 
killed many Salmon in the night by setting a trammel, or three-wall net, at the lower end of the deep pools in the river Dart, and by sending in a Dog at the upper end of the pool, which dog he had trained to dive like an otter. The Salmon, as soon as the dog dived, immediately dashed down the stream, and were taken in the trammelnet at the lower end of the pool.

Sir Walter Scott, in his novels of Redgauntlet and Guy Mannering, has described with his well-known skill and effect the animated scenes which occur when parties are engaged in spearing Salmon either by daylight or torchlight, as practised in the North. These works are familiar to all, and repetition would be useless. For the following description of two other modes of taking Salmon I am indebted to the kindness of Dr. Richardson.

A particular kind of fishing is peculiar to the Solway Firth, or at least can be practised with success only where the tide flows, as it does there, over extensive flats. The instrument used is termed a "halve," and consists of a funnel-shaped net ending in a pocket or bag. The mouth of this net is stretched on an oblong frame about three yards wide, to which there is attached a handle or pole. When the tide begins to flow, a number of fishermen proceed over the sands, and range themselves in a close line across the current of the flood, each with the "halve" resting on the bottom, and its pole against his shoulder: as the tide rises, it becomes too deep for the man farthest from the shore, who then raises his net and places himself at the other extremity of the line, where he is shortly succeeded by another and another, the whole thus changing places continually. When the halve is struck by a fish, its mouth is instantly elevated above the surface by the fisherman, so as to prevent the retreat of the fish until it can be carried into shallow 
water and secured. During the ebb a similar plan is pursued in a reversed order; the mouths of the nets are still turned to the current, but the fishermen now move in turn to the end of the line which stands deepest in the water. Flat-fish are the principal returns of this fishing; but prime Salmon are occasionally taken both on the flood and ebb.

This kind of fishing being as yet open to all, and unfettered by parliamentary enactments, there is scarcely a cottage on the shores of the Solway Firth where the halve-net may not be seen suspended. The fishermen have all some other employment by which they maintain their families, being mostly artisans; and they generally consume the produce of the halve-net at home, unless they chance to take a fish whose value is sufficient to compensate them for the time spent in going to market, sometimes tell or twelve miles distant.

Somewhat akin to this is the Salmon fishery in the Frith of Forth. Narrow stages or platforms, supported on wooden pillars, are carried from the shore for a considerable distance into the river. Upon each of these half-adozen or more fishermen station themselves with bag-nets, which are dropped down from the side of the stage with the current of the tide. The owner concealed, and also sheltered by a straw hurdle, such as is used in decoys for water-fowl, watches his net, and on a fish being taken, instantly secures it. When the tide ebbs, the net is shifted to the opposite side of the stage.

"A singular method of taking Salmon is practised at Invermoriston, in the county of Inverness, where the river flows in a narrow chasm between two projecting rocks. The fisherman seats himself on a cleft of this rock, right over the cascade, with a spear in his hand, which has a line fixed to the upper end of the shaft, similar to the practice of fishing for whales with harpoons. When- 
ever the Salmon makes a spring to gain the ascent over the cataract, the spearman strikes the fish and lets the shaft go, holding only by the line until the fish has exhausted its strength; then the spear and fish are thrown ashore by the stream, and taken out at the lower side of the pool."

The mode of fishing for Salmon in the Severn, and other rivers of Wales, with coracles and nets, requires a short and concluding notice. The coracle is a small boat constructed with. willow twigs in the manner of basket work, or with split slips of elastic wood, both the form and the material varying in different countries. In the neighbourhood of Shrewsbury, the framework is covered with canvas and painted; in Cardiganshire it is covered with flannel, and afterwards with a coating of tar. The boat is something less than six feet long, and about four feet wide, with a seat across the middle. The form of the paddle with which this little boat is impelled and guided along is also varied: in the Severn, the blade is square, but a more elongated blade is the form in use on the Dee. The boat, which in appearance is not unlike one-half of a walnut-shell, is so light and portable that the fisherman carries it to and from the water on his back. These coracles,* so called, it is said, from corium, the hide of the beast with which they were formerly covered, are of great antiquity: they were known in Cæsar's time, and are described by Lucan to be very nearly the same as in our own days.

"With twisted osiers the first boats were made, O'er which the skins of slaughter'd beasts were laid;

With these the Britons on the oceans row, And the Venetians on the swelling Po."

* This word is sometimes written coriacle, and may be derived from coriago, hide-bound. 
The custom of alternately carrying or being carried, as practised by the fisherman and his boat, is whimsically alluded to in the following lines, extracted from an old MS. history of Shropshire.

"Some sportsmen in pursuit of prey,

Their horses on their shoulders lay;

But seizing of their booty, then

They sit their steeds like other men.

Returning home when all is o'er,

Their steeds they carry as before."

The coracle is in frequent request with fly-fishers, * the banks of the rivers being in some places very rugged and steep, in others overgrown with wood to the water's edge.

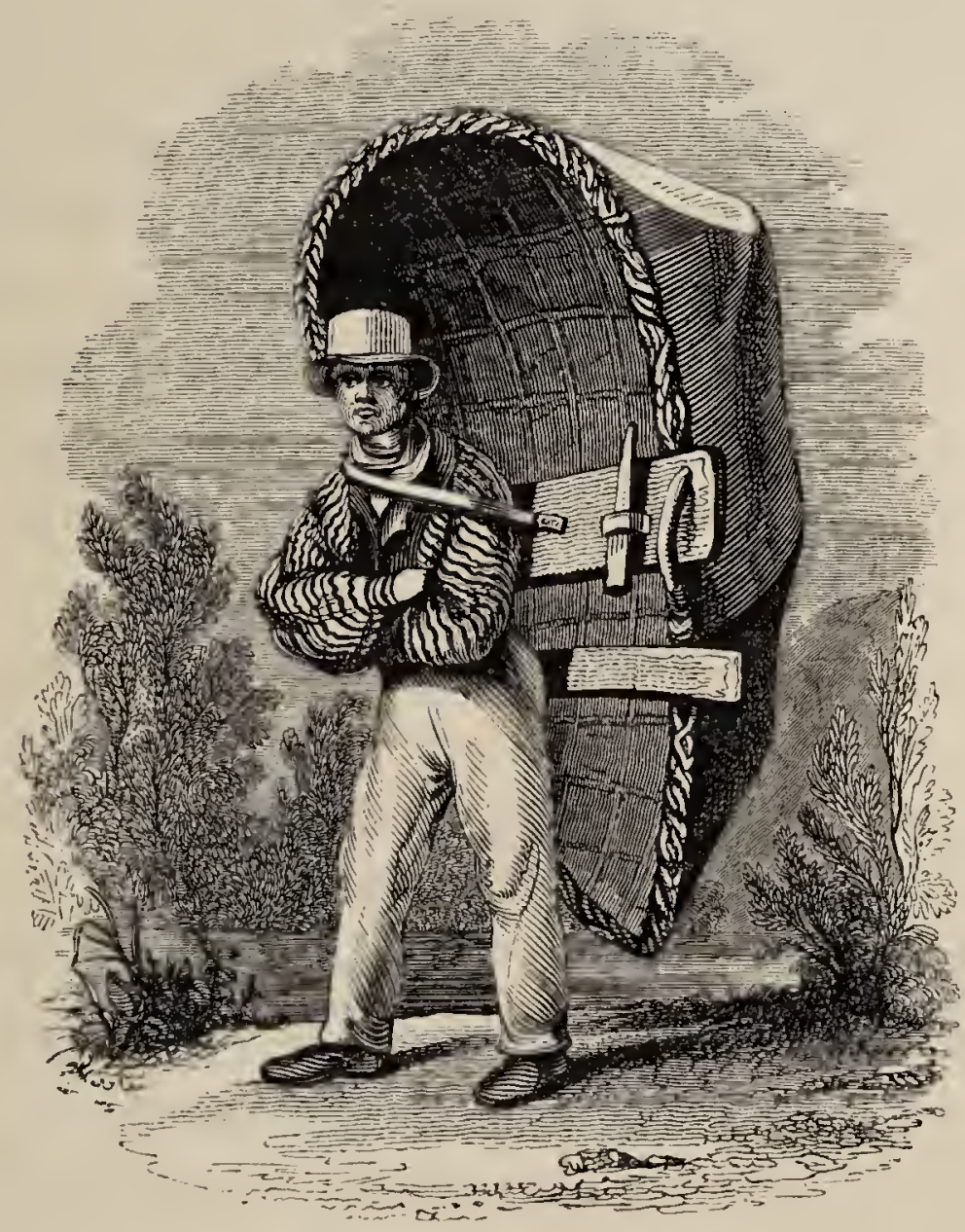

The fishing for Salmon in coracles is performed by two

* Ilansard's Trout and Salmon Fishing in Wales, pp. 145 and 184. 
men, each in his little boat, drawing between them down the stream a single-walled trammel, called there a hornnet, from its sliding by means of rings of horn, instead of corks, along the top. Through these rings runs a line, the end of which is held by one of the fishermen. By pulling upon this running line, which is distinct from the drag-line, the net is quickly closed when a fish strikes it. Various modifications of this sort of net occur in different rivers. Captain Medwin, in his Angler in Wales, says, "We stood on the bridge at Machynlleth for some time, to watch the operations of two fishermen in coracles. They were about to drag for Salmon; and it must have been difficult to preserve the balance in such frail and fragile machines. The net was attached to the two boats, and connected them. When all was clear, the fishermen made with their paddles a considerable circle, and then re-united, drawing in cautiously the sweep. They seemed very dexterous in the management of their canoes, and perfectly unconscious of danger. The first essay was a failure; a Salmon of ten or twelve pounds' weight leaped over the corks."-Long doubly-walled trammel-nets are now in use near Shrewsbury.

The length of the head of the Salmon, as compared to the whole length of the fish, is as one to five: the eye rather small, placed nearer to the point of the nose than to the posterior edge of the gill-cover: the peculiarities of the teeth and the parts of the operculum have been already described; the origin of the last ray of the dorsal fin about half-way between the point of the nose and the end of the tail; the first two rays simple and shorter than the third, which is the longest and branched; all the other rays of this fin branched; the last ray double, but, arising from a single origin, is only counted as one: the posterior edge of the base of 
the adipose fin is half-way between the origin of the last dorsal fin-ray and the end of the tail, and over the origin of the last ray of the anal fin. The pectoral fin twothirds of the length of the head: ventral fin in a vertical line under the middle of the dorsal fin, with an axillary scale two-fifths of the length of the ventral fin itself; the anal fin commences about half-way between the origin of the ventral fin and the commencement of the lower caudal fin-rays, the third ray the longest, the first two rays simple, the others branched: the form of the tail has been already noticed. The body is elongated; the dorsal and abdominal line about equally convex; the lateral line near the middle of the body, dividing it equally; the fleshy portion of the tail slender, and ending in the form of one-half of a hexagon; the scales moderate in size, oval and thin, easily removed when young, adherent when old. The fin-rays in number are-

\section{13: P. $12:$ V. $9:$ A. $9:$ C. 19 . Vertebræ 60.}

Salmon, and indeed all the Salmonida, like other fish that swim near the surface of the water, cannot be eaten too fresh; its fine Havour, and its money value, diminish rapidly after capture. In London a Thames Salmon commands the highest price: the next is that sent up either from Woodmill or Christchurch in Hampshire; then those fish received from the Severn, which are usually brought up by the mail from Gloucester.

A Thames Salmon is a prize to a fisherman, which, like other prizes, occurs but seldom. The last Thames Salmon I have a note of was taken in June 1833. The appearance of the Common Tern, or Sea-Swallow, which on its arrival in May wings its flight for miles up the Thames, is the signal to the fishermen to keep a good look-out for a Salmon : the occasionally coincident reap- 
pearance of a Tern and a Salmon has induced some of the Thames fishermen to apply to the former the name of the Salmon-bird.

Soon after the publication of the History of British Fishes the Earl of Home did me the favour to write various comments and notes on the Salmonida of the Tweed, in the form of a letter to the Earl of Montague, dated January 10, 183\%, and has since been kind enough to give me permission to use them. The following refer to the Salmon :-

"Mr. Yarrell is correct as to the time of the spawning of the Salmon in the Tweed. I must, however, be allowed to make a remark on this subject: that in the Tweed a very great change has taken place within these twenty or thirty years: a considerable portion of the breeding-fish not coming into breeding condition till long after the time they had formerly been in the habit of doing so. On the 2nd of November 1835, I killed, with fly, fourteen Salmon, "from ten to twenty pounds' weight, every one of which was in as fine condition as fish caught in the end of July.

"It is singular enough that in the early part of the season, when the first show of young Salmon comes up the Tweed, however small they may be, they are all denominated Salmon. I have killed them under three pounds: yet that fish was called a Salmon, and the fishermen,-I mean those above Berwick or Norham,-all allege that no Grilses ascend the river till the second great shoal come up about the beginning of June. The Berwick people are, however, now convinced that the Grilse is neither more nor less than a young Salmon, and accordingly call it so.

"I have always considered the Salmon as sea-fish, which enter the river for the sole purpose of spawning. 
That during the period they remain in the fresh water, they are not only nearly stationary as to growth, but lose, and rapidly too, their fine condition, and their flesh its fine and delicate flavour. This I consider chiefly occasioned by their not being able to obtain the more nutritious food of various kinds which they find in the sea.

"The Salmon is no doubt a very voracious feeder at times. The first Salmon I ever caught was with the minnow, in the month of June 1783, when I was a boy of thirteen, fishing for Trout. That fish weighed eighteen pounds; and since that time I have frequently killed ten or twelve Salmon in one day with a minnow; the worm also is a very deadly bait, when the river gets low in summer, and in the upper parts of the river the worm is the principal bait used during the whole of the spring fishing season. In the summer, too, numbers of Salmon are caught with the Parr tail.

"I have often known a Salmon Kelt take away a set of minnow tackle, consisting of three large hooks at least, and caught with another set as soon as it could be put on; but the instances of clean Salmon being so caught are very rare.

"During the latter part of last season, 1836, there were more Salmon in the river than I ever remember to have seen, (with the exception of one season, about twenty years ago,) and certainly an uncommon proportion of very large fish. I observed many oversetting, (the term used when Salmon jump out of the water for their own amusement,) which must have weighed from thirty to forty pounds, and one which I am sure must have exceeded fifty pounds at least. I never, at any other time, saw so large a fish in our streams. It is a curious fact that on both these occasions, when there were such multitudes of fish, they would not take any fly or bait 
that could be offered to them: some few were caught, no doubt, but only here and there one; and this was more or less the case the whole way from the foot of Galawater down to my fishing-ground, where I may say the rod-fishing ends. I may here mention that I have killed, and all with the fly, many hundreds of Salmon weighing twenty-five pounds and upwards. The two largest I ever killed weighed, one forty-five pounds, the other forty pounds. The latter fish was sent to the late Duke of Buccleugh, at Bowhill. The former one weighed fortyfive pounds, was a fresh run fish, with what are called tidelice on it, and the finest I ever tasted. Both were taken in July 1795. My uncle, my father's elder brother, caught a Salmon with a rod which weighed sixty-nine pounds and three quarters.

"For a number of years, however, there has been a great scarcity of large fish in the river, few exceeding eighteen pounds having been caught, and my present fisherman told me he had never seen a clean Salmon above twenty pounds. The reason for this scarcity of large fish was, first, the river down at Berwick was over-fished; and secondly, all the large spawning-fish were killed during close time by poachers in the upper parts of the river, particularly in the small streams to which the fish resort in such numbers to deposit their spawn. Of course very few were allowed to return to the sea, and consequently few of the old or large fish could come back to the river the next season.

"I may here be permitted to mention that in the month of April 1795, I killed thirty-six Salmon in one day, rod-fishing, one of which of eighteen pounds, I took home. Mr. Yarrell may form some idea of the size and quality of the fish when I tell him that the fisherman received twenty-five guineas for that day's work, not 
including the fish I took home. The day after, I caught twenty-six. In the month of June of that year, 1795, I killed in one week, between the Monday morning and Saturday night, eighty-two clean Salmon, all in the finest condition, and many of them large fish, which averages near fourteen per day, all but two Salmon.

"But, alas! those halycon days in Tweed are ended; rod-fishing is all but entirely over, and is now reduced to a few days in spring and a few days in autumn, when the net-fishing ends on the 15 th of October. This change has been brought about by draining the sheep farms on the hills, the effect produced being that a little summer flood which took a fortnight or three weeks to run off previous to 1795 , is now completely run out in eight hours. The rain which formerly filled the bogs or sides of the hills, and yielded a constant and regular supply to the river, is now carried off at once by the drains to the different feeders, causing sudden and violent floods, and short as they are sudden, so that the flood is all run off before the river has had time to clear itself; becoming too low for a Salmon to rise, yet not clear enough for a fish to see a hook, even were Salmon there to take one. But the worst effects produced by these drains, and the consequent diminution in the volume of water, is the advantage it gives to the fishermen near the mouth of the river, who hardly allow a fish to escape; and indeed in summer the river becomes so low that it cannot clear itself of the filth and sludge which is constantly floating backwards and forwards witl the flood and ebb tides, and prevent the Salmon from taking the river at all. Sir Humphrey Davy in his Salmonia compares the Tweed as it was formerly to what it is now, to two houses, the one covered with thatch, and the other with slate; the one dripping for hours after rain 
has fallen, the other ceasing when the rain ceases. In short, Salmon-fishing in the Tweed is quite at an end; except in some particular years when there is rain enough to ruin the crops, and create almost a famine in our harvest time, September, but that is all. What I regret also, almost as much as the loss of Salmon-fishing, is our Trout-fishing, - that, too, is at an end. Last year, 1836, we had not one single opportunity, and in 1835, it was much the same; for, of course, the draining has affected the smaller streams as well as the Tweed itself.

"My uncle, the same who caught the seventy-pound Salmon, had a Newfoundland dog which was celebrated for catching Salmon. He knew the Monday mornings as well as the fishermen themselves, and used to go to the cauld or mill-dam at Fireburn mill on those mornings. He there took his station at the cauld slap, or opening in the dam to allow the Salmon to pass, and has been known to kill from twelve to twenty Salmon in a morning. The fish he took to the side. The then Lord Tankerville instituted a process against the dog. I had a copy of the proceedings, but I regret to say it was lost when the old library was altered. This case was brought before the Court of Session, and the process was entitled, the Earl of Tankerville, versus a Dog, the property of the Earl of Home. Judgment was given in favour of the dog."

The Edinburgh Courant (1856) mentions that the Marquis of Beaumont, while angling in Sprowston water, hooked a Salmon which was judged to be above thirty pounds' weight, and after playing it for between five and six hours, lost it as he was in the act of landing it by the line being cut through on a sharp stone.

With regard to the commercial value of the Salmon 
fisheries in Great Britain, Mr. Wilson, in his treatise on Fisheries already referred to, furnishes ample data. The Salmon fishery of the river Tay, between Perth and Newburgh, produced a yearly rent varying in thirty years from $£ 7162$ to $£ 9683$. That of the Tweed varies from $£ 4000$ to $£ 5400$, and the Spey rents at about $£ 8000$. From these three examples the great value of the innumerable Salmon rivers of Scotland, Ireland, and England, to the landed proprietors will be apparent, as well as the great interest that must be felt in the protection and improvement of the breeding-places.

Anstruther, in Fifeshire, has a Salmon in its coat of arms, indicative of the importance of that fish to the town at some former period.

The vignette below represents the bones of the head in the Salmon.

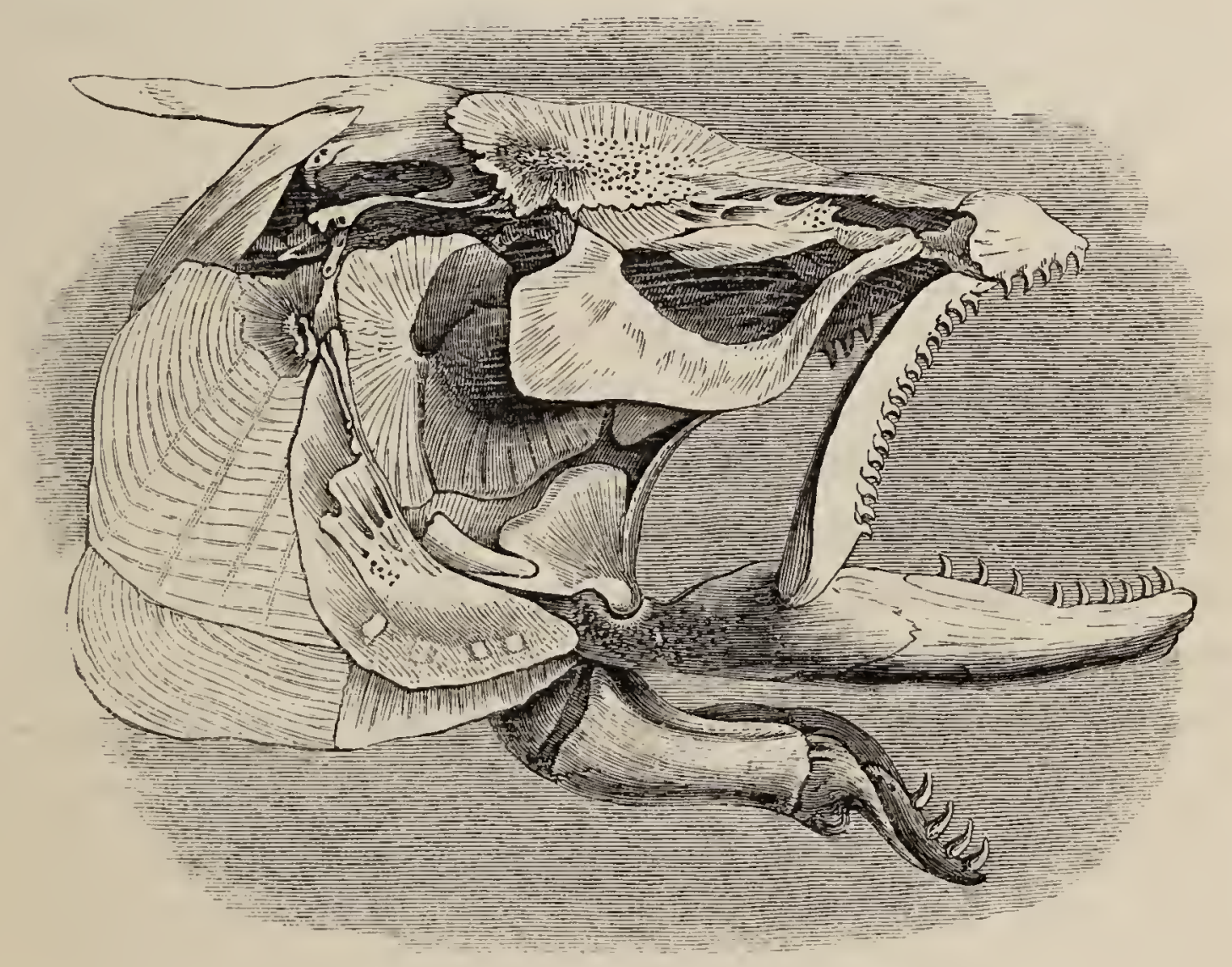


ABDOMINALES

MALACOPTERYGII.

\section{THE PARR.}

Salmo salmulus, Wrludgins, p. 192.

,, , $\quad$ RAY, Syn. p. 63, sp. 2.

, , , Penn. Brit. Zool. vol. iii. p. 404.

This little fish, the smallest of the British Salmonida, has given rise to more discussion than any one species of the genus. Abounding in our Salmon rivers, and conspicuous for the lateral marks which are known to be borne for a time by the young of the Trout as well as the fry of the other Salmonida, and always of small size, it has been generally insisted upon to be the young of the Salmon; and on that account local regulations have as generally been invoked for its preservation.

The fry, however, of the different species of migratory Salmonida are probably even now known accurately to only a few persons: their great similarity when very small, as shown at page 191, has so frequently deceived even those who have lived the greater part of their lives on the banks of Salmon rivers, that the fry marked by them, in their experiments, for the young of the Parr, have been retaken as Grilse, Grey Trout, Salmon Trout, and River Trout. The transverse dusky bars from which this fish has obtained the name of Brandling and Fingerling are family marks, borne for a time by all the species of the genus, and it has been remarked on this subject by the late M. Fries, the Ichthyologist of Stockholm, that the more natural the genus the more difficult it is to characterize the species while young. 
Mr. Shaw's experiments and observations, already given at length in the article on the Salmon, and the reports of other practical fishermen, have convinced most ichthylogists that the Parr, as a distinct species, does not exist.

In Mr. William Thompson's Natural History of Ireland, 1856, the following local names of the Parr are mentioned; Branlin, Guillioge, Jenkin, Ginkin, and Graveling.

The vignettes below represent three states of the Mayfly and two states of the Stone-fly of anglers.
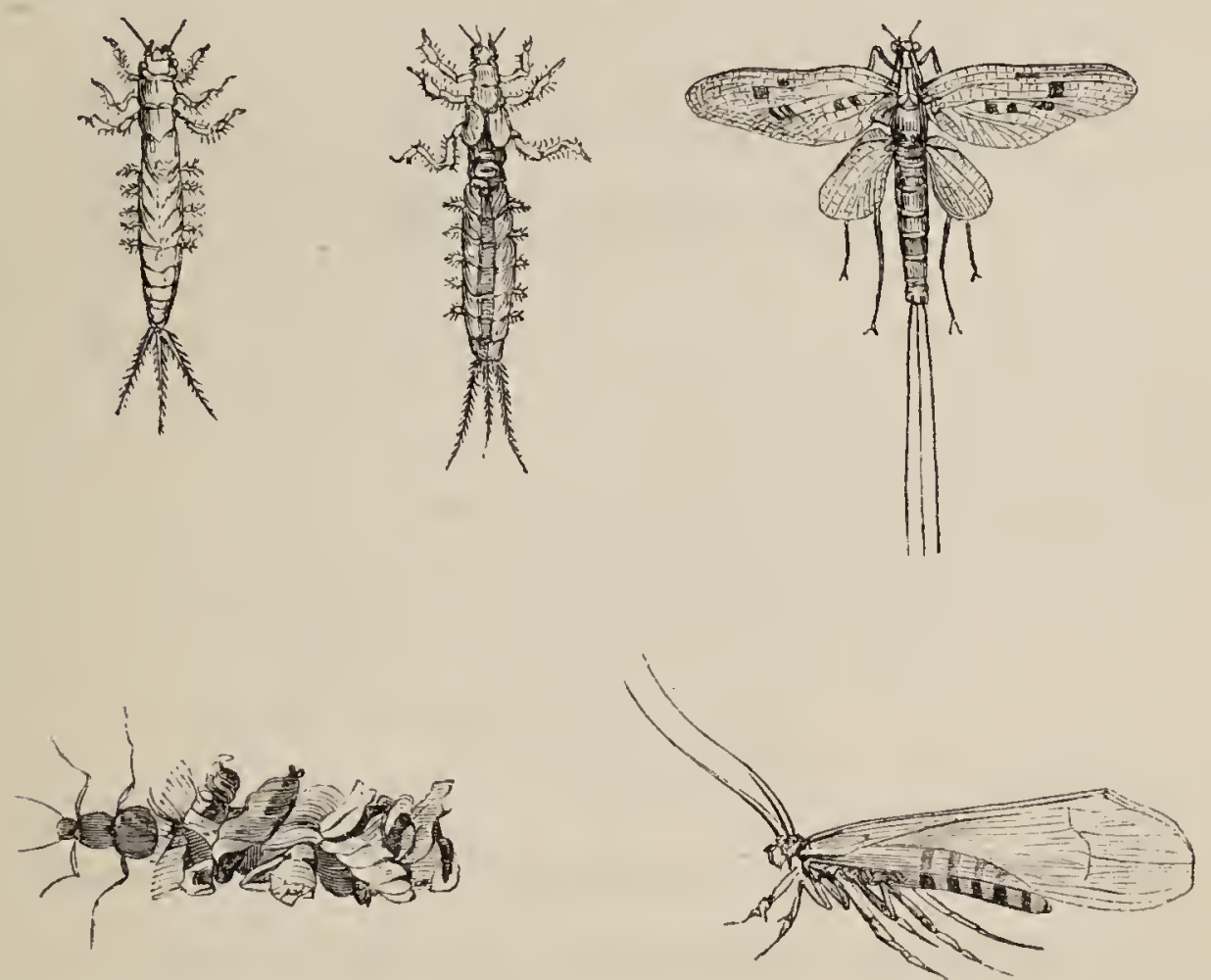


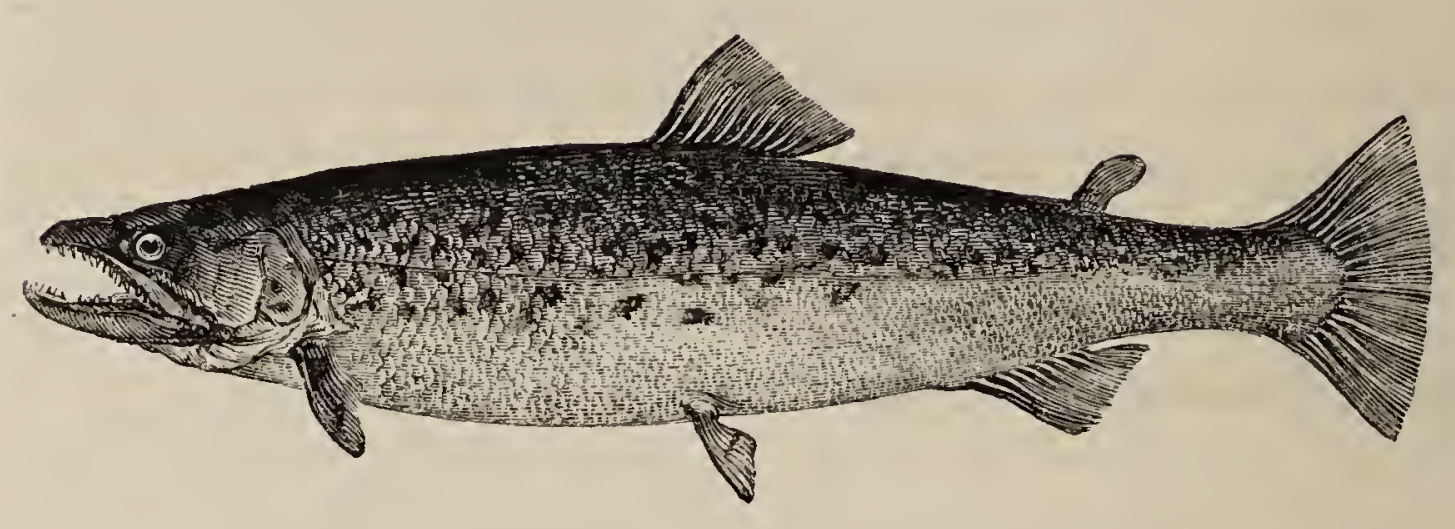

THE GREY TROUT.

THE BULL TROUT, OR ROUNDTAIL, AND SEWIN.

Salmo criox, Linnaus. NiLsson.

,, cinereus aut griseus, Wrlugaribi, p. 193.

", griseus seu cinercus, Rムx, p. 63, A. 3.

," eriox, Grey, Penn. Brit. Zool. vol. iii. p. 394.

," , , Fuem. Brit. An. p. 180, sp. 46.

", , , JENYNS, Brit. Vert. p. 422.

", hamatus, VAlenciennes?

The Grey Trout is distinguished from the Salmon and Salmon Trout by several specific peculiarities, and if M. Valenciennes be correct in his grouping of the Salmonida, by generic differences from the latter. The gill-cover differs decidedly in form, as examination of the central figure of the illustration at page 159 will show. The operculum is larger; the free vertical margin much more straight; the inferior posterior angle more elongated backwards; the line of union with the suboperculum not so oblique, but nearly parallel with the axis of the body of the fish: the inferior edge of the suboperculum 
parallel to the line of union with the operculum: the interoperculum much deeper vertically; the vertical edge

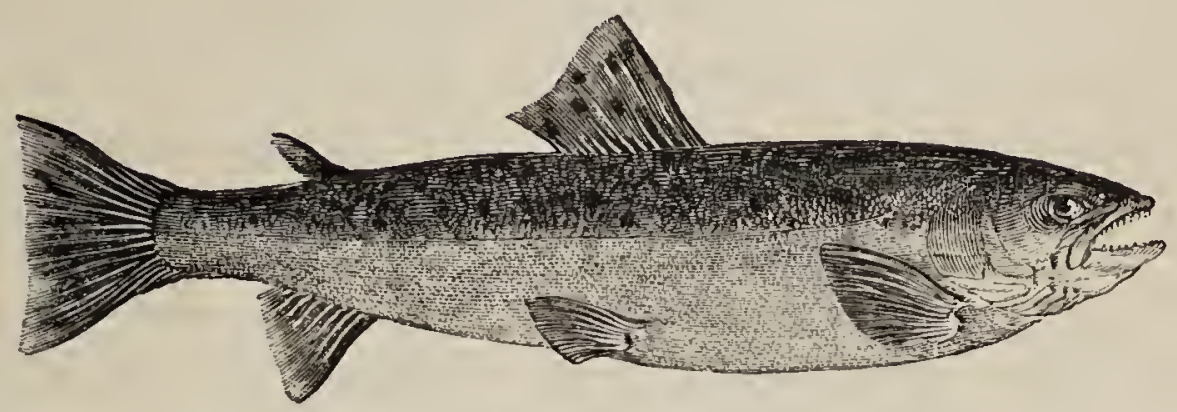

of the preoperculum more sinuous. The teeth in the Grey Trout are longer and stronger than those of the Salmon; but, like the Salmon, the two or three teeth that may be seen on the vomer in the adult fish occupy the most anterior part only. The tail becomes square at the end in this species at an earlier period than in the Salmon; and the central caudal rays continuing to increase with age, the posterior edge from being concave becomes convex. The Warkworth Trout and Coquet Trout of Northumberland and Durham are the young of the Grey Trout.

The Grey 'Trout, in all its stages of growth, is probably better known in the Tweed than elsewhere in Britain, being there as abundant as the Salmon. I have had proof of the existence of this species in some of the rivers of Dorsetshire and Cornwall : it occurs in the estuary of the Severn, and I have seen it from the rivers of South Wales, where it is called Sewin. Dr. Heysham includes it in his list of fish of the rivers of Cumberland that run into the Solway. Sir William Jardine, Bart., mentions it as occurring sometimes in the Annan 
in Dumfries-shire. It is said by Mr. White to be the Norway Trout of the fishermen in the firth of Forth, and the Swedes name it the Graulachs. Artedi states that the Swedes give it also the names of Laxöring and Borting, and that it is known in Northumberland by the appellation of Scurf-Trout. Mr. Low says it is found in the loch of Stenness, Orkney. In Ireland this species occurs on every side of the northern portion of the island; and Mr. Thompson mentions Killala Bay, Donaghadee, Florence Court, Beleek, Crawfordsburn, Nanny Water, Ballyhalbert, Ballywalter, and Dundrum, as places from whence he had obtained specimens.

The Grey Trout appears to be the Salmo maculis cinereis cauda extremo aquali of Artedi, page 23, sp. 2; and probably also, as quoted, the Graia Salmo cinereus seu griseus of Willughby and Ray, whose specific names have precedence of eriox. It is probable, moreover, that the Grey or Bull Trout of English fishermen is the Salmo hamatus or Bécard of Cuvier and Valenciennes. That the Sewin, and consequently the Bull Trout, is the eriox of Linnæus we believe on the authority of Professor Nilsson, since that able Swedish naturalist recognised, figure 2, plate 91, of the Fauna Boreali Americana, a portrait of the head of a Glamorganshire Sewin, as a correct representation of the head of the Scandinavian eriox. A comparison of the English Bull Trout with an authentic hamatus in the Paris Museum would clear up the doubt about synonyms, but this comparison has still to be made. It is to be observed, however, that the Welsh fishermen apply the name of Sewin to the Salmon Trout as well as to the Bull Trout, and that, therefore, care must be taken in the selection of specimens.

This fish sometimes attains the weight of twenty pounds; but it more commonly occurs under fifteen 
pounds' weight. It ascends rivers for the purpose of spawning, in the same manner as the Salmon, but earlier in the season; and the fry are believed to go down to the sea sooner than the fry of the Salmon. This species affords good sport to anglers; and, from its great muscularity, it is a powerful fish when hooked, frequently leaping out of the water. It is not, however, held in the same degree of estimation for the table as the Salmon or Salmon Trout: the flesh, even when the fish is in season, is paler in colour, yet its quality may depend on the particular stream in which the fish has been caught. Sir Walter Scott says, "There is an old rhyme, which thus celebrates the places in Liddesdale, remarkable for game :

\footnotetext{
'Billhope braes for bucks and raes, And Carit haugh for swine, And Tarras for the good bull-trout, If he be ta'en in time.'
}

The bucks and roes, as well as the old swine, are now extinct; but the good Bull Trout is still famous." - Notes to the Lay of the Last.Minstrel, Canto IV.

The following are the Notes of Lord Home on this fish :-

"The Bull Trout has increased in numbers prodigiously within these last forty years, and to that increase I attribute, in a great measure, the decrease of Salmon Trout, which formerly abounded when I was a boy. It is now a rare thing to see a Salmon Trout or Whitling,-for the Whitling in the Tweed was the Salmon Trout, not the young Bull Trout, which now go by the name of Trouts simply. The Bull Trout take the river at two seasons. The first shoal come up about the end of April and May. They are then small, weighing from two to four of five pounds. The second, and by far the more 
numerous shoal, come late in November. They then come up in thousands, and are not only in fine condition, but of a much larger size, weighing from six to twenty pounds. The Bull Trout is an inferior fish, and is exactly what is called at Dalkeith and Edinburgh, Musselburgh Trout. Mr. Yarrell is mistaken when he says these fish afford good sport to anglers; quite the contrary: a clean Bull Trout, in good condition, is scarcely ever known to take fly or bait of any description.* It is the same in the Esk at Dalkeith. I believe I have killed as many, indeed I may venture to say I have killed more Salmon with the rod, than any one man ever did, and yet put them altogether I am sure I have not killed twenty clean Bull Trout. Of Bull Trout Kelts, thousands may be killed. The great shoal of these Bull Trout, not taking the river till after the commencement of close time, are in a great measure lost both to the proprietor and the public:"

The description is taken from an adult male of thirtytwo inches in length, from which the cut at the head of this article was drawn and engraved.

The length of the head compared to that of the body only is as one to four; the teeth and the form of the parts of the gill-covers have been already described; the elongation of the under jaw is peculiar to the males only, but it is not so conspicuous in the Grey Trout as in the Salmon; the dorsal fin commences half-way between the point of the nose and the origin of the short upper caudal rays; the base of the dorsal fin is longer than the longest of its rays: the adipose fin large, and nearer to the end of the tail than to the origin of the last dorsal fin-ray; the.form of the tail at different ages has been noticed; the length of the pectoral fin is very little more

* A mistake as to season, or time of year, not of the species. 
than half the length of the head. The scales of the Salmon are thin in substance, oval, with numerous concentric lines only: the number of scales forming an oblique line from the lateral line up to the base of the anterior part of the dorsal fin, following the oblique arrangement of the scales, are about twenty; and the number in a row from the axillary scale of the ventral fin up to the lateral line about eighteen. The scales of the Grey Trout are rather smaller than those of a Salmon of equal size, the number forming a continuous oblique row from the lateral line up to the base of the dorsal fin being about twentysix; the number in a row from the ventral axillary scale up to the lateral line, whether taking the line that ascends obliquely forward or the one that runs backward is about twenty-five; the axillary scale of the ventral fin is nearly half as long as the fin itself: the anal fin nearer the tail than in the Salmon; and all the fins are muscular.

The fin-rays of this Trout in number are-

\section{11: P. 14: V. $9:$ A. 11: C. 19. Vertebræ 59.}

In six specimens out of seven, the number of vertebræ was fifty-nine; in the other, sixty. Fifty-nine will probably prove to be the normal number in the Grey Trout.

The form of the body of this fish is similar to that of the Salmon, but the nape and shoulders are thicker, the fleshy portion of the tail and the base of each of the fins more muscular: the males are the stronger in the water, but the females are the more eager for bait, and their teeth are rather smaller. The colours of the males in the spawning season are-the head olive brown, the body reddish brown or orange brown, that of the females a blackish grey; the dorsal fin reddish brown, spotted with darker brown; the tail dark brown; the other fins dusky 
brown. The general colour at other times like that of the Salmon Trout.

The Salmo hucho, which is a native of the Danube, is not found in British waters, and Dr. Fleming has erroneously included it in his British Fauna. Its eggs are difficult to transport, as they hatch quickly; and in a very brief time the hucho attains a gigantic size. Those raised at Hunique become enormous in less than three years.*

The vignette below is a view of Rothbury Bridge, over the Coquet, looking from the south.

* M. Caste, the Field newspaper, 9th April 1857.

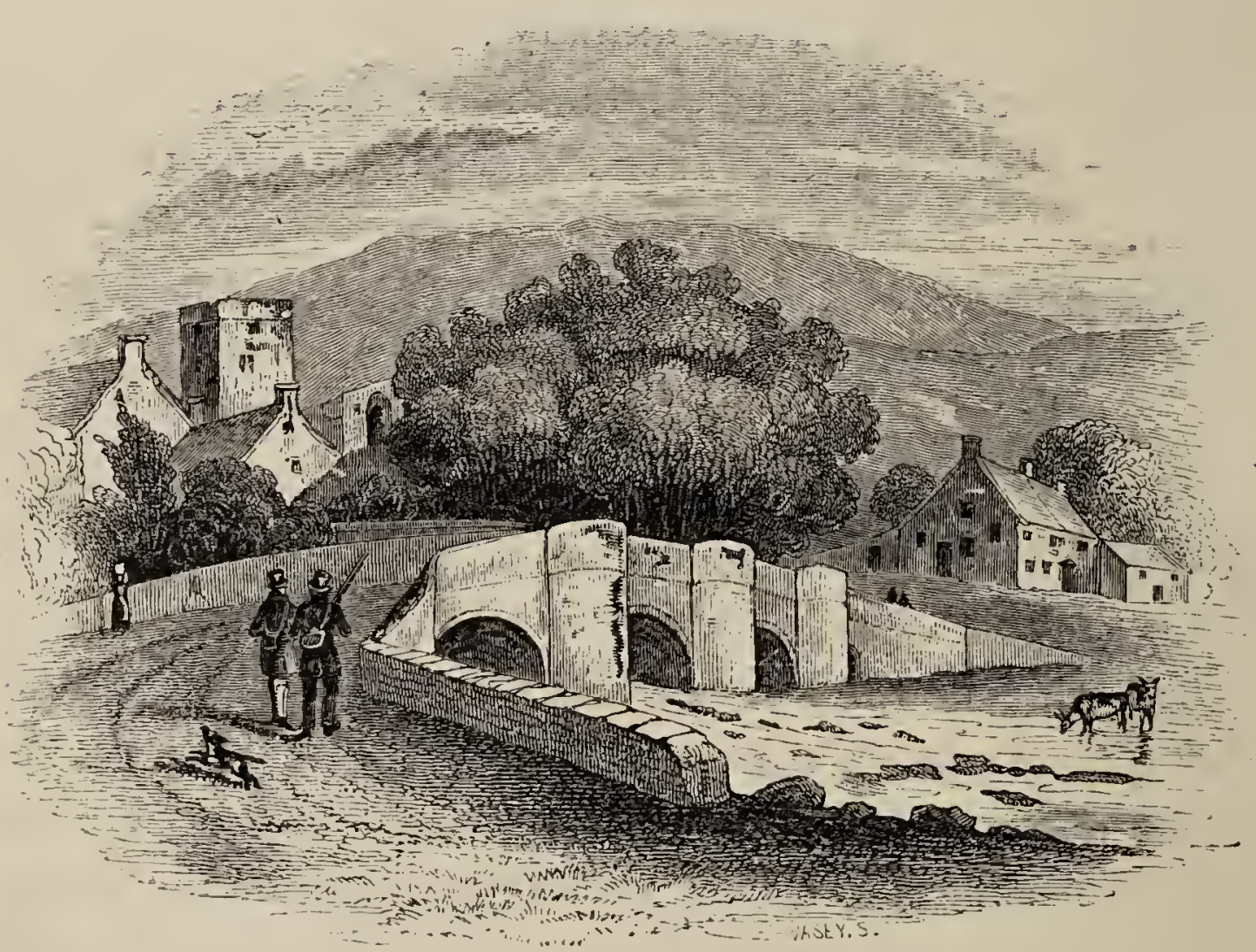




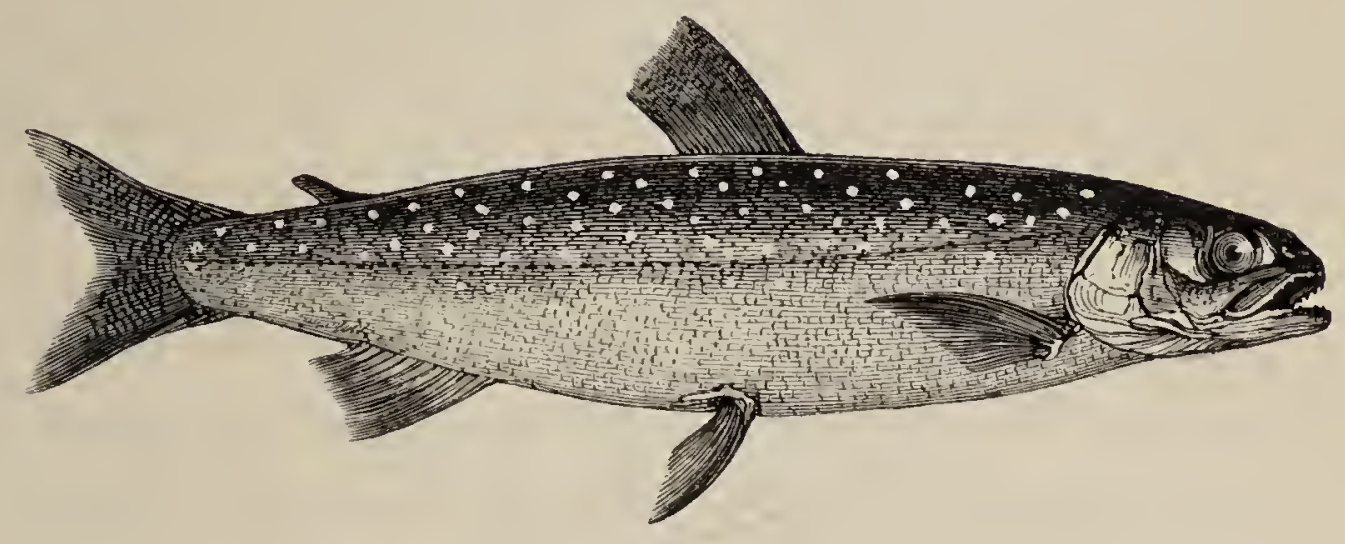

\section{THF CHARR.}

Salmo salvelinus, Linneus. Blocir, pt. iii. pl. 99.

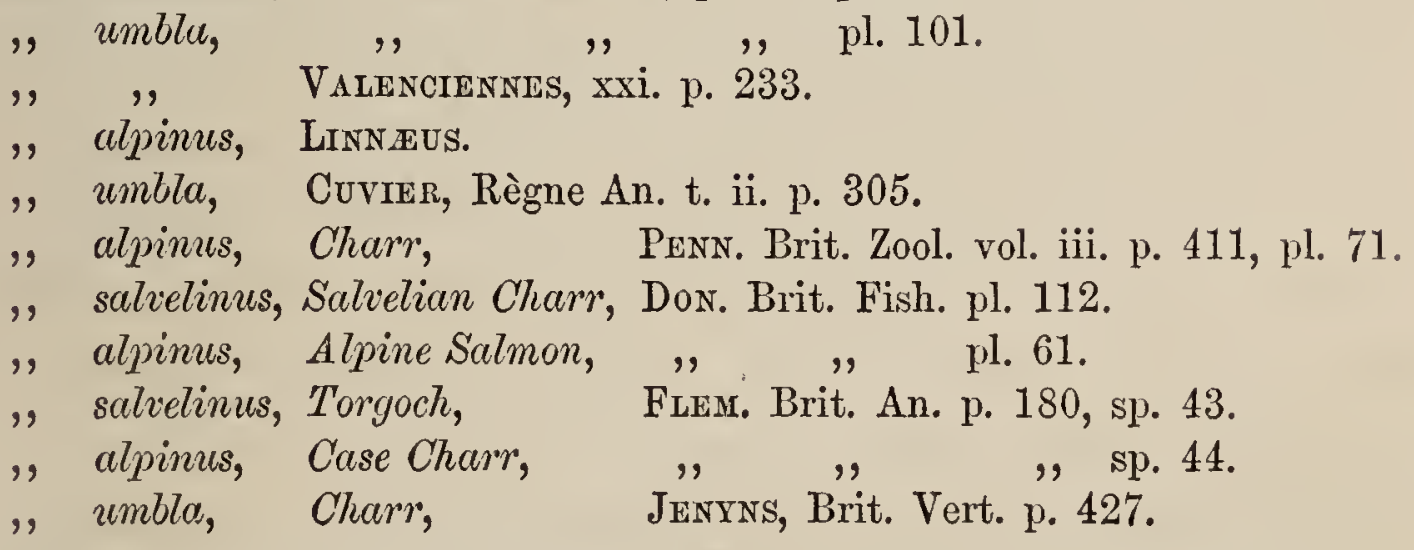

The Charrs are distinguished from the other Salmonida by the smallness of their scales and the bright red or orange tints of the belly in the breeding season. They constitute the group of Salvelini of Nilsson, and are named Rothfohren by the Swedes.

M. Agassiz, when in the North of England in the autumn of 1834, had several opportunities of examining the Charr of the Northern lakes, which he declared to be identical with the Ombre Chevalier of the Lake of Geneva; and in his "Remarks on the different Species of the Genus Salmo which frequent the various Rivers and 
Lakes of Europe," read at the meeting of the British Association at Edinburgh, that gentleman considered the S. umbla, alpinus, salvelinus, and salmarinus of Linnæus as different states only of the same fish.* This is the opinion also of Professor Nilsson, who had access to the original specimens of Linnæus, but he mentions another Scandinavian Charr as quite distinct, viz. the Salmo carbonarius of Ström, described in the Archiven für naturgeschichte for 1849 (p. 310).

Examples of the Charr of the Northern lakes of England agree exactly with the description and figure of the Ombre Chevalier in M. Jurine's paper on the Fishes of Lake Leman, Geneva.

In the former edition of this work I considered the Welsh Charr to be distinct as a species from the Northern Charr, but I have now reason to believe that I had not made sufficient allowance for the variations in appearance produced by local influences; and, assisted by the published notes of W. Thompson, Esq., of Belfast (An. Nat. Hist. vol. vi. p. 439), I am now induced to consider as one species the Charr of England, Scotland, Ireland, and Wales, and that our fish is also the same species as that found in Germany, in the lakes of Switzerland, and in those of Scandinavia.

Mr. Thompson precedes his notes by the following remarks:- "The chief object of my inquiry was to learn whether in the lakes of Ireland, and in those of Scotland, from which I could procure specimens, the S. salvelinus of Donovan was to be found; and at the same time to ascertain, at least for my own satisfaction, whether its characters have sufficient permanency to entitle it to rank as a distinct species. As they are merely crude unfinished

* See the Reports of the Fourth Meeting of the British $\Lambda$ ssociation, p. 617 to $\mathrm{p} .623$. 
notes that are to follow, I shall here give the result of the investigation, that the reader may be in possession of it without entering into the details. In a fresh state I have had the opportunity of examining Charr from three localities,-Windermere (England), Lough Melvin (Ireland), and Loch Grannoch (Scotland); and, either in spirits or preserved dry, from nine other lakes in Ireland and Scotland. The examination of these examples leads me to believe that the $S$. umbla of Linnæus, and the $S$. salvelinus of Donovan, are but one species; one, however, that, like the Salmo fario, is subject to extraordinary variety. In one lake the male fish can at a glance be distinguished from the female either by colour, or by the many characters which are comprised under 'form.' In another, so similar are the sexes in every external character, that, without the aid of dissection, they cannot be determined. In size we find the species ordinarily attains twice the length, and several times the weight, in one lake that it does in another, although both lakes may have an area of similar extent; indeed, in some of the largest lakes, this fish will be found not to attain near the size it does in others which are but as pools in comparison: there, are, however, various influences which account satisfactorily for such differences. In the form of the body, again, we find the species even when in equally high condition, to be in one lake Fierring-like, and in another approximating the roundness of an Eel. So manifold are the differences presented by the Charr now before me from various localities, that it would be tedious, and perhaps useless, to point them out." The Charr of Windermere weigh generally about half a pound, and one weighing ninetecn ounces is uncommon.

The Charr inhabits many of the lakes of Cumberland, Westmoreland, and Lancashire, which are annually visited 
by the admirers of fine scenery. Keswick, Crummock Water, Buttermere, Winandermere, and Coniston are among the localities best known to produce this delicate fish. It occurs in Loch of Moy, Loch Inch, Loch Grannoch, and in several other lochs of Scotland; and also in Loughs Melvin, Corrib, Esk, Egish, Neagh, Dan, Luggelaw, Shessuck, Kindrum, Keel, Lough Erne in Fermanagh, Belvidere lake, Lough Bofin, and probably many other loughs in various counties of Ireland. The Scots name it Red-wame.

Sir William Jardine calls the Charr of the West of Scotland and of Ireland "Southern Charr," and describes their scales as being more orbicular, while "the Northern or Sutherland Charr," he says, have more elongated scales.

The Charr is the Torgoch or Red-belly of Wales, and was formerly to be taken either in Llanberris Lake, or in Llyn Cawellyn, two deep lakes situated on the east and west sides of Snowdon. The waters from a neighbouring copper-mine are said to have destroyed or driven out the Charr from Llanberris, where they were formerly very numerous; and it was remarked that some of these fish were caught in the sea, at the mouths of rivers on this coast, after they disappeared from the lake.

"Llyn Cawellyn," says Mr. Donovan, "is a vast lake of unknown depth, sheltered on one side by an abrupt mountain, which rises immediately out of the water, and in the deep recesses at the base of which the Torgoch is supposed to pass the milder seasons of the year in perfect security. These fish approach the shallower parts of the lake in winter, about the middle of December, appearing in small troops at a short distance from the shores, and are at this season taken in some plenty by a poor cottager - who resides in the vicinity of the lake, and derives a 
small annual profit from the fishery; this delicious fish being in much request for the tables of the neighbouring gentry."

I am indebted to the kindness of the Rev. F. W. Hope for specimens of Charr from a locality near Barmouth in Merionethshire, unnoticed by $\mathrm{Mr}$. Donovan, but recorded by Willughby. The piece of water is called Coss-ygedawl-the lake of the fruitful marsh. The meaning of this term is said to be questionable: the primitive root from which it is derived means gift, relief, or profit. By Willughby it is spelt Casageddor ; by others, Cors-ygedol.

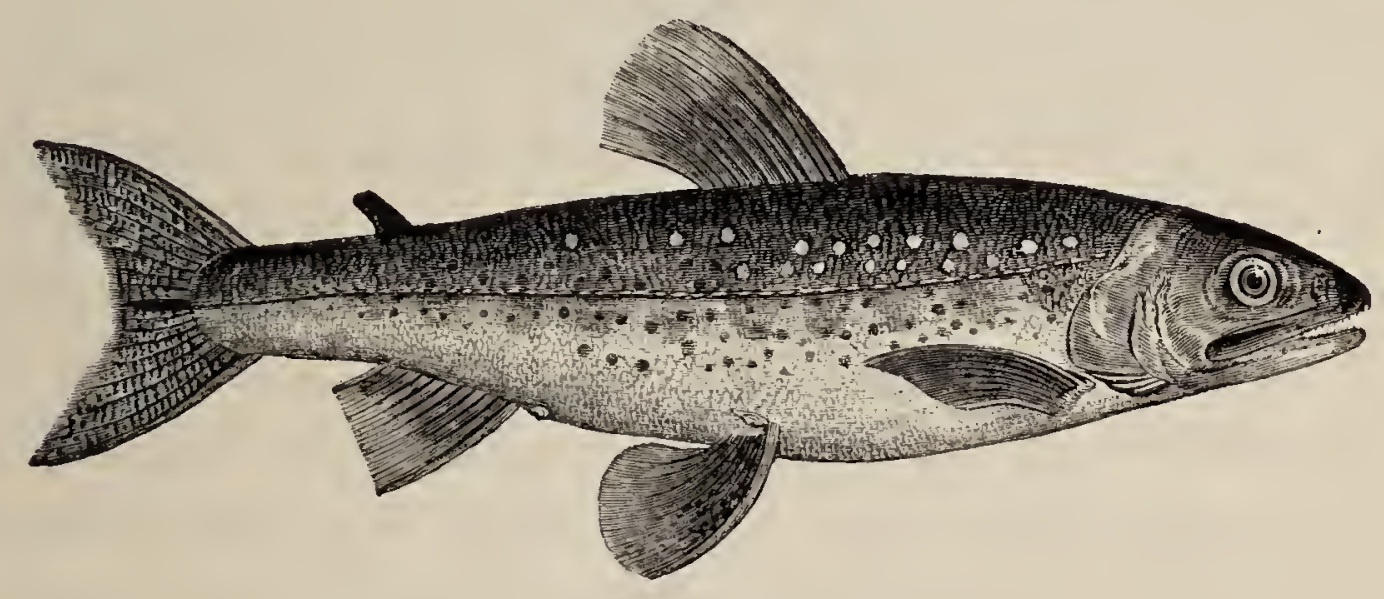

The Charr generally inhabit the deepest parts of those lakes in which they are found, and afford but little amusement to the angler. The most successful mode of fishing for them is to trail a very long line after a boat, using a minnow for a bait, with a large bullet of lead two or three feet above the bait, to sink it deep in the water. By this mode a few may be caught in the beginning of summer, at which time they are in the height of perfection, both as to colour and flavour. The fly-fisher when whipping for Trout, which frequently abound in the same lakes, occasionally takes a Charr; but this does 
not happen often : they are believed to feed principally during the night. The stomachs of those I have examined were empty; but Sir William Jardine has found abundance of minute Entomostraca in the stomachs of some of those examined by him. The forms of two species of these very minute animals will be represented when describing the Vendace.

The Charr are very seldom known to wander into any of the streams by which these lakes are either supplied or drained, except at the season of spawning, and their decided partiality for clear water and a hard bottom is then very conspicuous. Winandermere has two principal feeders, the rivers Rothay and Brathay: the Rothay has a sandy bottom, but the channel of the Brathay is rocky. These streams unite at the western corner of the head of the lake, below Clappersgate, at a place called the Three-foot-brander, and after a short course boldly enter the lake together. 'The spawning season is in November and December; about which time the Charr in shoals make their way up both these rivers, but invariably, before depositing their spawn, those fish which have ascended over the sandy bed of the Rothay return and pass up the rocky channel of the Brathay.* A few Charr also spawn in the lake; and it is observed that they frequent the stony parts only which resemble the bottom of the Brathay.

Charr, even at the same season of the year, exhibit considerable difference in colour, which has been attributed to different causes. M. Jurine, when describing the Salmo umbla of the Lake of Geneva, which fish there is little or no doubt is identical with our Charr, says the females are the finest in colour. Mr. Mascall, in a communication to the Magazine of Natural History

* The Trout, in thoir spawning season, prefer the Rothay. 
for April 1835, states that he found the males of the Charr of Ennerdale Lake in Cumberland superior to the females in colour. It is not improbable that the degree of colour may depend, not so much upon the sex, as upon the constitutional vigour of the individual fish; a circumstance observed in the periodical assumption of peculiar tints in other animals. In reference to these variations in the intensity of the colours, several distinctions have been supposed to exist in the Charr of our lakes, and the names of Case Charr, Gilt Charr, Red Charr, and Silver Charr have been applied to them: Pennant, however, states that, after the closest examination, he was unable to discover any specific difference. Dr. Davy says that the Silver Charr of Windermere spawns chiefly in November, and does not haunt the deep parts of the lake, while the Gilt Charr inhabits the deepest water, and does not spawn till the beginning of February.

The most common size of our Charr is from nine to twelve inches in length; they are said occasionally to attain the length of two feet; the largest specimen in my possession measures eighteen inches. The finest-coloured specimen I ever saw was brought me by my friends J. B. Giles and W. C. Hewitson, from Coniston Water, in the month of May. They are considered to be in the greatest perfection as food from July to October.

The length of the head compared to the length of the head and body is as one to five; the depth of the body greater than the length of the head: the commencement of the dorsal fin is half-way between the point of the nose and the adipose fin; the posterior edge of the base of the adipose fin half-way between the origin of the last dorsal fin-ray and the end of the longest caudal ray; the longest dorsal fin-ray but one-fourth longer than the base 
of that fin: the pectoral fin small; the ventral fins originate half-way between the point of the nose and the commencement of the under caudal rays; the ventral axillary scale nearly half as long as the fin; the anal fin small, the longest ray but little longer than the base of the fin; the tail deeply forked, the longest rays more than as long again as those in the centre; all the fins of small comparative size. The fin-rays in number are-

D. $13:$ P. $12:$ V. $9:$ A. $11:$ C. 19 . Vertebræ 59.

The diameter of the eye is less than one-fourth of the length of the whole head; it is placed at the distance of one diameter from the point of the nose: the teeth small; a few on the anterior part only of the vomer; the other four rows above and four rows below, exist as usual in the fishes of this genus. The branchiostegous rays vary from ten to twelve, and frequently differ in number on the two sides of the head of the same fish.

The top of the head and all the upper parts of the back umber brown; the sides lighter; the whole of the belly, the pectoral, ventral, and anal fins, deep reddish orange; the first ray of the ventral and anal fins white; the sides above and below the lateral line marked with numerous red spots; the irides orange; gill-covers yellowish olive; dorsal and caudal fins dark brown, tinged with purple brown; the lateral line straight, but rising gradually from the parallel of the point of the pectoral fin to the top of the operculum; the scales very small, more than thirty in an oblique line from the base of the dorsal fin to the lateral line, and as many from the ventral axillary scale upwards to the lateral line. In this state as to colour, this fish is considered to be the S. salvelinus of authors.

When not in fine condition as to colour, the top of the head and along the back are pale purplish brown, becoming lighter lower down; the sides silvery; the belly 
tinged with pale orange; above the lateral line are numerous small round white spots; irides and gill-covers silvery, with a tinge of yellow; pectoral, ventral, and anal fins, brownish red; dorsal fin brown; caudal fin purple brown. In this state, as to colour, this fish is considered to be the S. alpinus of Continental authors, Bloch excepted, whose S. alpinus, part iii. plate 104, appears to be a Trout.

In the autumn of 1839, T. Upton, Esq., of Ingmire Hall, near Sedberg, put into his lake, the Lilleymere, near the reservoir, some Charr from Windermere, each weighing about half a pound; and, on the 23rd of August 1840, caught two with a fly, full two pounds' weight each, in the finest possible season, well fed, and beautifully coloured. These fine specimens were served at the Queen Dowager's table, at the Rose and Crown, Kirby Lonsdale.

The vignette is a view of Whitewell, in the forest of Bowland, Yorkshire.

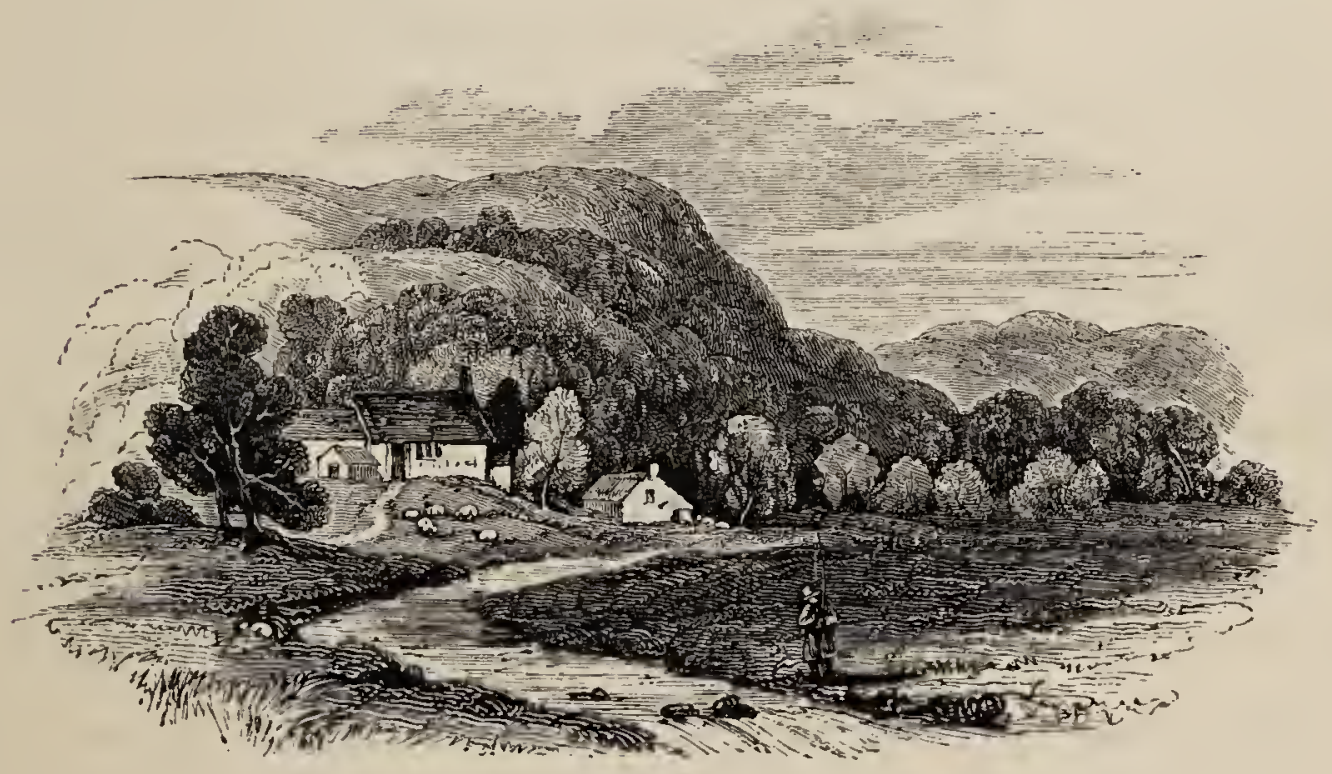


A BDOMINALES

MALACOPTERYGII.

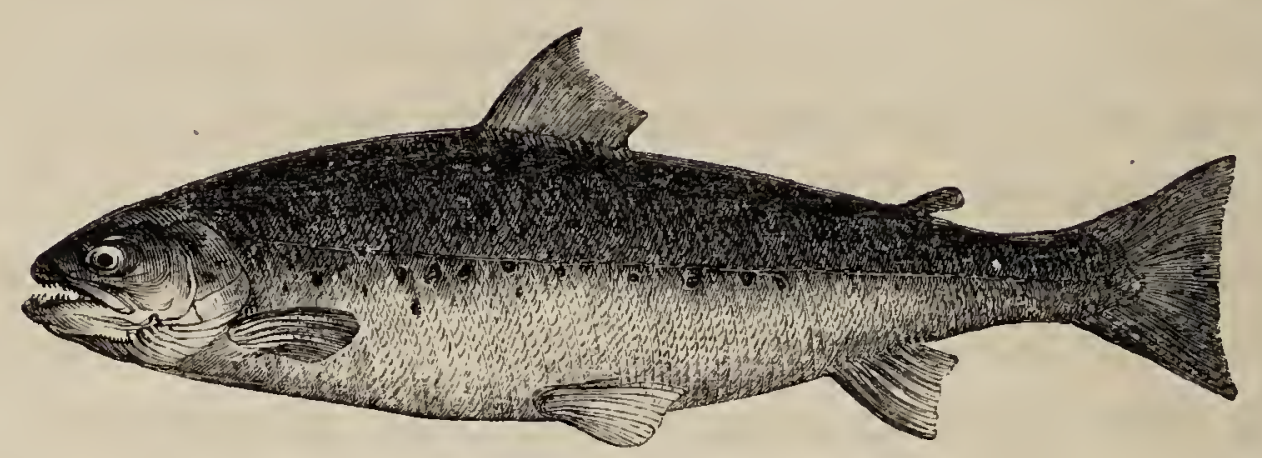

\section{THE SALMON TROU'T.}

Fario argenteus, Valenciennes, Hist. des Poiss. xxi. p. 294.

Salmo irutla,

Linneus.

Trutta salmonata, WrLLdGHBY, p. 193.

Salmo trutta, Salmon Trout, Ray, p. 63.

BLOCH, pt. i. pl. 20, adult.

", schiefermulleri, ", pt. iii. pl. 103, young.

", trutta, Sea Trout, Penn. Brit. Zool. vol. iii. p. 397.

", albus, Phinock, Flem. Brit. An. p. 180, sp. 42.

" trutta, Sec Trout, , , ", , sp. 45.

", , , , Jenyns, Brit. Vert. p. 423.

", JardrNe's Illust. Scot. Salm. pl. 11. 3. 10. 9.*

Fario. Generic Characters.-Salmons with a single row of teeth running along the mesial line of the vomer. (Valenciennes.)

The Salmon Trout is, of the migrating species in this country, the next in value to the Salmon. It is most abundant in the rivers of Scotland, and its flesh is excellent. It is distinguished by the gill-cover being intermediate in its form between that of the Salmon and the Grey Trout. The representation on the right hand

* The numbers of the plates are here arranged according to the age of the specimens figured. 
of the vignette at page 159 is that of the Salmon Trout male. The posterior free margin, it will be observed, is less rounded than that of the Salmon at the left hand,

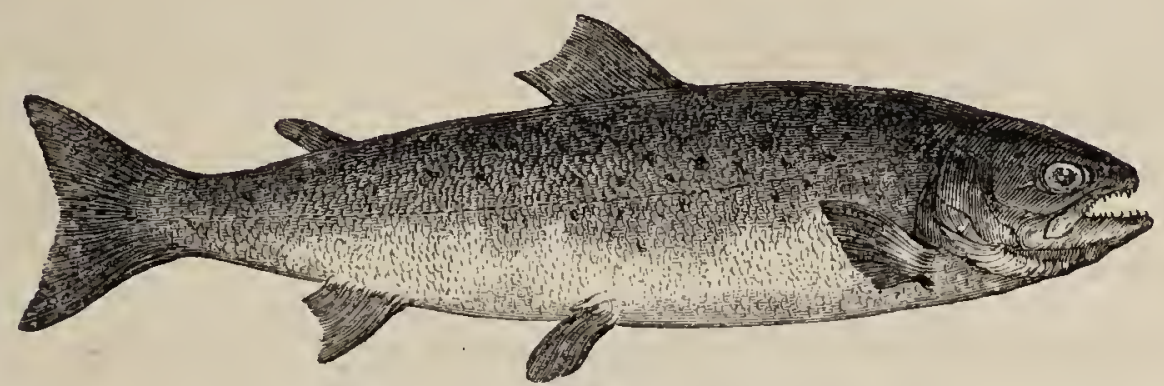

but more so than that of the Grey Trout, which is represented by the middle figure. The line of union of the operculum with the suboperculum, and the inferior margin of the suboperculum, are oblique, forming a considerable angle with the axis of the body of the fish. The posterior edge of the preoperculum rounded,-not sinuous, as in the Grey Trout. The teeth are more slender as well as more numerous than in the Salmon or Grey Trout; those on the vomer extending along a great part of its length, and indenting the tongue deeply between the two rows of teeth that are there placed, one row along each side. The tail is less forked at the same age than that of the Salmon, but becomes ultimately square at the end. The size and surface of the tail also is much smaller than that of the Salmon, from the comparative shortness of the caudal rays. The figure at the head of this article represents the Salmon Trout in its fourth year; the second figure represents this species in its third year.

This fish is the Truff of Devonshire and White Trout of 
Wales and Ireland; it is found in the Severn, in the rivers of Cornwall, and plentifully in the Esk, the Eden, the Annan and Nith, rivers falling into the Solway, where it is called Sea Trout, and in its Grilse stage Hirling. Mr. Thompson states it to be common on every coast of Ireland, and to vary in weight from one pound to eighteen pounds. It is commonly denominated by the Irish fishermen White or Sea Trout.

It is the Salar of the Moselle so named in the fourth century,-

"Purpureisque Salar stellatus tergore guttis."-Ausosius.

The habits of this species are very like those of the Salmon, and the females are said to run up the rivers before the males. Sir William Jardine says, "In approaching the entrance of rivers, or in seeking out, as it were, some one they preferred, shoals of this fish may be seen coasting the bays and headlands, leaping and sporting in great numbers, from about one pound to three or four pounds in weight; and in some of the smaller bays the shoal could be traced several times circling it, and apparently feeding. In these bays they are occasionally taken with a common hang-net stretched across; and when angled for in the estuaries, with the ordinary flies which are used in the rivers of the South for Grilse, rose and took so eagerly, that thirty-four were the produce of one rod, engaged for about an hour and a half. They enter every river and rivulet in immense numbers, and when fishing for the Salmon are annoying from their quantity. The food of those taken with the rod in the estuaries appeared very indiscriminate; occasionally the remains of some small fish, which were too much digested to be distinguished; sometimes flies, beetles, or other insects, which the wind or tide had carried out; but the most general food seemed to be the Talitris locusta, or 
common sand-hopper, with which some of their stomachs were completely crammed. It is scarcely possible to arrive with any certainty at the numbers of this fish. Two hundred are frequently taken at a single draught of a sweep-net, and three hundred have occasionally been counted." They are much more numerous in the Don, the Spey, and the Tay, than in the Tweed.

Great quantities of this Salmon Trout are sent to the London market; those from Perth, Dundee, Montrose, and Aberdeen appear, from their comparative depth of body, to be better fed, are higher in colour, and considered to be finer in flavour than from some other localities. The Fordwich Trout of Isaac Walton is the Salmon Trout; and its character for affording " rare good meat," besides the circumstance of its being really an excellent fish, second only to the Salmon, was greatly enhanced, no doubt, by the opportunity of eating it very fresh. Fordwich is about two miles east-north-east of Canterbury. The stream called the Stour was formerly very considerable; it communicates with the sea opposite the back of the Isle of Sheppy, and from Fordwich one branch going eastward, again enters the sea at Sandwich. The ancient right to the fishery at Fordwich was enjoyed jointly by two religious establishments: it is now vested in six or seven individuals, who receive a consideration for their several interests. It was formerly the custom to visit the nets at Fordwich every morning to purchase the fish caught during the night. I have seen specimens of the Salmon Trout from the Sandwich river exposed for sale in the fishmongers' shops at Ramsgate, during the season for visiting that watering-place; and the Salmon Trout is also occasionally taken in the Medway by fishermen who work long nets for Smelts during the autumn and winter. I have obtained a young specimen in the Thames 
from the men who fish for Shads above Putney Bridge in the months of June and July.

The following are the notes of Lord Home on the Salmon Trout:- "Of this excellent species I can only repeat that in the Tweed they have almost entirely disappeared. They afford good sport to the angler; but I never saw one above seven pounds' weight. Of the Phinock of the Spey, the Hirling of the Nith and Annan, the Whitling or Whiting of the Esk, all one and the same fish, I can say nothing. There is a little fish, however, which makes its appearance about November and December, but in very small numbers, few only being caught, and of course with the hook. They are called here Silver Whites, and also Black Tails, from a dusky blue spot in the centre of the tail fin. They are beautiful little fish, resembling much small Salmon Trout, and if not young Salmon. Trout, I know not what they are. When caught, the scales, which are of a beautiful silvery whiteness, separate so easily from the fish, that on taking it up they stick to the hand, leaving almost the impression behind. The flesh pink-coloured, and the flavour very good."

Dr. Mac Culloch states, that "the Salmon Trout, or Sea Trout, as it is called in Scotland, is now a permanent resident in a fresh-water lake in the island of Lismore, one of the Hebrides, and without the power of leaving it or reaching the sea. There it has been known for a long course of years, perfectly reconciled to its prison, and propagating without any apparent difficulty." *

The length of the head is, when compared with the length of the body alone, as one to four; the depth of the body compared to the whole length of the fish is also

* Journal of the Royal Institution, No. xxxiv. p. 211. 
as one to four: the teeth small and numerous, occupying five rows on the upper surface of the mouth; those of the central row on the vomer extending some distance along it, the points turning outwards alternately to each side; one row upon each side of the under jaw, and three or four teeth on each side of the tongue, strong; sharp, and curving backwards, well calculated to assist in holding a living prey, or to convey food towards the pharynx: the middle of the eye situated half-way between the point of the nose and the posterior edge of the preoperculum: the form of the parts of the gillcover have been already described and figured. The first ray of the dorsal fin is short; the second ray long, equal to the length of the base of the fin; the articulation at the base of the last dorsal fin-ray exactly halfway between the point of the nose and the end of the tail; the fleshy fin on the back being also half-way between the base of the last ray of the dorsal fin and the end of the tail. The body of the fish rather deep for its length; the lateral line very nearly straight, and passing along the middle of the body: the scales adhering closely; in form rather a longer oval than those of the Salmon, and having about twenty-three in the usual line up to the dorsal fin, and twenty-two below it. The fin-rays in number are-

\section{D. $12:$ P. $13:$ V. $9:$ A. $10:$ C. 19 . Vertebræ 58.}

The upper part of the head and back dark bluish black, becoming lighter on the sides, which are marked with numerous spots, somewhat resembling in form the letter $\mathrm{X}$ : these spots are mostly above the lateral line. The lower part of the sides and belly silvery white; cheeks and gill-covers silvery white; the dorsal fin, fleshy fin, and tail, nearly as dark as the colour of the back; 
the pectoral fin rather small and bluish white; the ventral fins white, arising in a vertical line under the middle of the dorsal fin; the anal fin white, the base of the fin one-third shorter than the longest of its fin-rays. When the Salmon Trout is placed by the side of a Salmon, it is, in comparison, darker in colour in the body, but lighter in the colour of the fins.

The specimens of the Phinock or Hirling of the North, the Salmo albus of Dr. Fleming, which I have received, so exactly resemble the young of the Salmon Trout on its first return from salt water that $\mathrm{I}$ am unable to point out any sufficiently distinguishing specific character. The coloured Illustrations of the Scottish Salmonida by Sir William Jardine, Bart., represent this species, and also the Salmon in various stages of growth.

I have made the following notes of large examples of this species. In July 1840, a male Sea Trout was caught at Sandstell fishery in the mouth of the Tweed, which had a length of thirty-seven inches, a girth of twenty-two, and weighed twenty-four pounds and a half. This beautiful and finely-conditioned fish passed into the possession of Sir Chapman Marshall, then Lord Mayor of London, and was presented by him to the Reverend Dr. James, of Peterborough. In November 1846, a male of the same species, having a length of forty inches, and a weight of twenty-one pounds, was caught in the Tame, near Drayton Manor, and was presented by Sir Robert Peel to Professor Owen. 


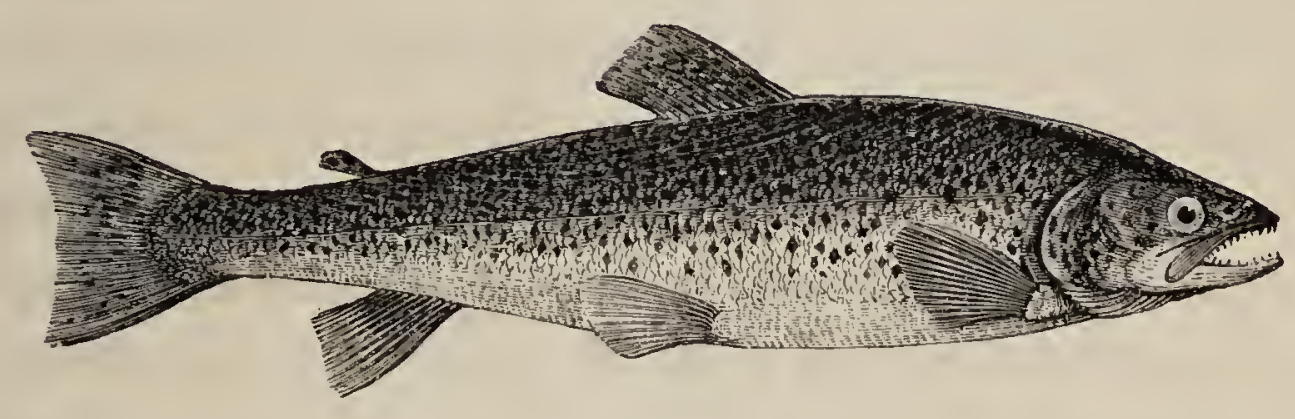

\section{THE LOCHLEVEN TROUT.}

Fario Levenensis.

Salmo Levenensis, WaLKer.

" cacifer, PARNell.

I Am indebted to Dr. Parnell for the loan of a beautiful specimen of this Trout from which the figure was taken, and the following account of it by Dr. Parnell is from the seventh volume of the Memoirs of the Wernerian Natural History Society of Edinburgh.

"This fish is considered by most writers on British Ichthyology to be identical with Salmo fario, the Common Trout, differing from it only in the colour of the flesh, and in having no red spots on the sides. It is true that food and season may have a great share in diminishing or increasing the external markings and colour of the fiesh; * but they can have no effect in shortening or lengthening the rays of the fins, or in adding numbers to the creal appendages."

* James Stuart Menteath, Esq., of Closeburn, caught a number of small river Trout, and transferred them to a lake (Loch Ettrick) where they grew rapidly; their flesh, which previously exhibited a white chalky appearance, became in a short time of a deep red, while their external appearance remained the same from the time they were first put in.

VOL. 1 . 
"The differences that exist between $S$. cacifer and $S$. fario are very striking. The pectorals in S. cacifer when expanded are pointed, in S. fario they are rounded. The caudal fin in S. cacifer is lunated at the end; in S. fario it is sinuous or even. S. cacifer has never any red spots; S. fario is scarcely ever without them. The caudal rays are much longer in cacifer than in fario, in fish of equal length. In S. cacifer the tail fin is pointed at the upper and lower extremities; in S. fario they are rounded. The flesh of S. cacifer is of a deep red, that of S. fario is pinkish and often white. The cæcal appendages in S. cacifer are from sixty to eighty in number; in S. fario I have never found them to exceed forty-six."

"Lochleven (of which the barren isle and now dismantled castle are famous in history as the prison-place of the beautiful Queen Mary) has long been celebrated for its breed of Trout. These, however, have fallen off of late considerably in their general flavour and condition, owing, it is said, to the partial drainage of the Loch having destroyed their best feeding-ground, by exposing the beds of fresh-water shells, the animals of which form the greater portions of their food.* They spawn in January, February, and March."

"The fish described does not appear to be peculiar to this Loch, as I have seen specimens that were taken in some of the lakes in the county of Sutherland with several other Trout, which were too hastily considered as mere varieties of $S$. fario. It is more than probable that the Scottish lakes produce several species of Trout known at present by the name of $S$. fario, and which remain to be further investigated."

Dr. Richardson, who has had opportunities of examin-

* There are two or three varieties of $S$. fario in Lochleven with white and pinkish flesh, which are much inferior in flavour to S. ceecifer.-Encyc. Brit. 
ing very fine specimens of this celebrated Trout, has pointed out some of the differences between it and the Common Trout: the scales are thick, and when dry exhibit a small ridge in the centre of each, not perceived in the common Trout: in its large and strong fins, and in its habit, as stated by Dr. Parnell, of spawning in spring, it differs from $S$. fario, which spawns in autumn, and resembles some of the large species of Trout of the great northern lakes. Three individuals of the Lochleven Trout dissected by Dr. Richardson had each seventy-three pyloric cæca, and in one of them fifty-nine vertebræ were counted. The largest of the specimens measured twenty inches and a quarter, including the caudal fin, and two inches less to the end of the scales. The only difference which he could perceive between it and the Fario lemanus from the Lake of Geneva, was in the larger size of the spots of the Lochleven fish. It is probable, therefore, that the Fario lemanus and levenensis are identical, at all events they are nearly allied. M. Valenciennes counted only fifty-six vertebræ in the $F$.lemanus, of which thirtythree were abdominal, while Dr. Richardson enumerated fifty-nine in one of the Lochleven fish that he examined. The $F$. lemanus spawns in summer, the exact time varying with the temperature of the season.

Dr. Parnell's description, taken from a specimen measuring one foot in length, is as follows: "Head rather more than one-fifth of the whole length, caudal fin included; depth between the dorsal and ventral fins less than the length of the head. Gill-cover produced behind; basal margin of the operculum oblique, preoperculum rounded; end of the maxillary extending back as far as the posterior margin of the orbit. Colour of the back deep olive green; sides lighter; belly inclining to yellow; pectorals orange, tipped with grey; 
dorsal and caudal fins dusky; ventral and anal fins lighter; gill-cover with nine round dark spots; body above the lateral line with seventy spots; below it ten; dorsal fin thickly marked with spots of a similar kind; anterior extremities of the anal and dorsal fins without the oblique dark bands which are so conspicuous and constant in many individuals of $S$. fario. Front of the dorsal fin half-way between the point of the upper jaw aud a little beyond the fleshy portion of the caudal extremity of the body; all the rays branched except the two first; the third ray the longest, equalling the length of the long caudal ray; the seventh as long as the base of the fin; the last considerably more than half the length of the third, equalling the length of the middle caudal ray; fin even towards the end (in many specimens it is concave, with the last ray longer than the preceding one); caudal fin crescent shape, the middle ray rather more than half the length of the longest ray; third ray of the anal fin the longest, equalling the length of the fifth dorsal ray; the last ray as long as the base of the fin, ventral fin equalling the length of the fifth ray of the anal; the third ray the longest; third ray of the pectorals equalling the length of the long caudal ray; the last ray half the length of the fin. Teeth stout and sharp, curved slightly inwards; thirty-two in the upper jaw, eighteen on the lower; twelve on each palatine bone; thirteen on the vomer; and eight on the tongue. Scales small and adlerent; twenty-four in an oblique row between the middle dorsal ray and the lateral line; flesh deep red; cæca eighty. The number of fin-rays-
D. 12 : P. 12 : V. $9:$ A. $10:$ C. $19 . "$ 


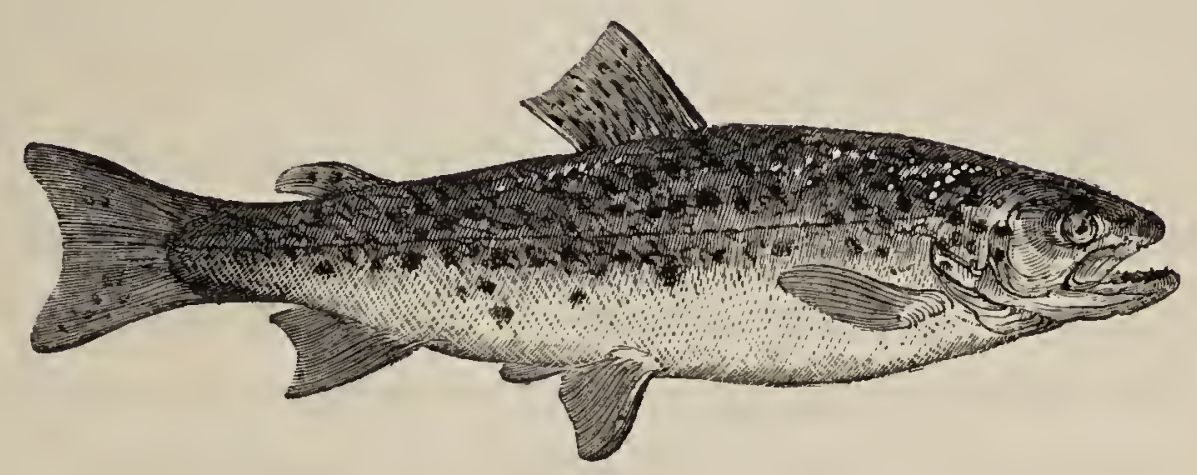

THE COMMON TROU'T.

\section{BREAC-PRECht in the Scottish Highlands.}

Salar Ausonii, Valenciennis, xxi. p. 319.

Salmo fario, LINNeUS.

,, , BLoch, pt. i. pl. $22 \& 23$.

, Goodenii, ,, pt. iii. pl. 102.

" fario, River Trout, Penn. Brit. Zool. vol. iii. p. 399, pl. 70.

", " Trout, Don. Brit. Fish. pl. 85.

", ", Common Trout, Flem. Brit. An. p. 181, sp. 47.

", , , " JENyns, Brit. Vert. p. 424.

", , $\quad, \quad, \quad$ JARDINe, Illust. Scot. Salm. pl. 5 \& 12.

SALAR. Generic Character.- Vomer armed with two rows of teeth, without the remarkable group in front, such as exists in Salmo and Fario. (VaLEno.)

The Common Trout is too widely diffused and too generally known to make any enumeration of particular localities necessary; it is an inhabitant of most of the rivers and lakes of Great Britain, and so closely identified with the pursuits and gratifications of sportsmen, that those landed proprietors who possess streams of water favourable to the production and growth of Trout preserve them with great care and at a considerable expense. The Trout, though a voracious feeder, and thus affording 
excellent diversion to the experienced angler, is so vigilant, cautious, and active, that great skill as well as patience are required to ensure success. During the day, the larger-sized fish move but little from their accustomed haunts; but towards evening and during the night they rove in search of small fish, insects, and their various larvæ, upon which they feed with eagerness. The young Trout-fry may be seen throughout the day sporting on the shallow gravelly scours of the stream, where the want of sufficient depth of water, or the greater caution of larger and older fish, prevent their appearance.

Though vigilant and cautious in the extreme, the Trout is also bold and active. A Pike and a Trout put into a confined place together had several battles for a particular spot, but the Trout was eventually the master.

The season of spawning with the Trout is generally in the month of October, at which period the under jaw of the old male exhibits in a smaller degree the elongation and curvature observed to obtain in the male Salmon, of which an instance will be shown.

Dr. Davy has been in the habit of opening the fish he captures by angling, and finding, that as the spawning season approaches, only about one-half of the female Trout have visible eggs, while in the other half there are no signs of the development of the ova, concludes, that Trout spawn in alternate years only.

Sir Humphrey Davy in his Salmonia particularly alludes to the experiments of $\mathrm{Mr}$. Jacobs, a German gentleman, on the breeding of Trout by artificial impregnation of the ova. The Rev. Dr. Walker, Professor of Natural History in the University of Edinburgh, thus refers to the experiments of $\mathrm{Mr}$. Jacobs in his paper printed in the second volume of the Transactions of the Highland Society. "He found that in Salmon and 
Trouts the roe is not fecundated till after ejection. That when both are extracted from dead fishes, the roe by mixture can be fecundated by the milt, and when placed under water in a proper situation can be brought forth into life. He further discovered that this artificial fecundation can be accomplished with the roe and milt of fishes that have been dead two and even three days."

By the kindness of Mr. Pickering, of Chancery Lane, I am enabled to insert here a translation of Mr. Jacob's paper, which appeared in 1763 in the form of a letter to the editor of the Hanover Magazine.

"SrR,-I have thought it a duty incumbent on me to lay my observations on the breeding of Trouts and Salmon, as well as on other subjects, before the public. It would be needless, and not to my present purpose, to mention every trifling experiment which I made within the last sixteen years, before my discovered invention; and in twenty-four years more afterwards, on the artificial increase of Trout and Salmon, perhaps I may be induced to give a more circumstantial account on this subject. The box, trough, or water-bed in which the eggs, animated with the milt or sperma of the male Trout, are scattered, needs no particular form, yet it will be necessary to give a description how those which I use are made.

\section{"SECTION I.}

" 1. I had boxes made of various woods, but I found oak to be the best, of about twelve feet long, one foot and a half wide, and six inches deep.

"2. At the head of the trough where the water is to run in, is laid a thick board about two and a half or three inches thick, about a foot wide, and as long as the trough is wide; in the middle of this board is made a 
hole six inches long, and about four inches wide in the clear, with a ravet on all the four sides of this hole, about an inch and a half wide and deep, so as to admit a square frame, with an aperture of six inches by four inches, or of the same size as the hole, which frame must be covered with a brass grating of a moderate strength, and close enough to prevent the smallest water-shrew from passing through, otherwise all the spawn and young fry will be in danger of being devoured by them.

" 3. Near the middle of this box or trough lay another piece of thick board across, as long as the width of the trough, and about six inches or more wide, which, when nailed upon the edges of the side pieces, will keep them more steady and firm.

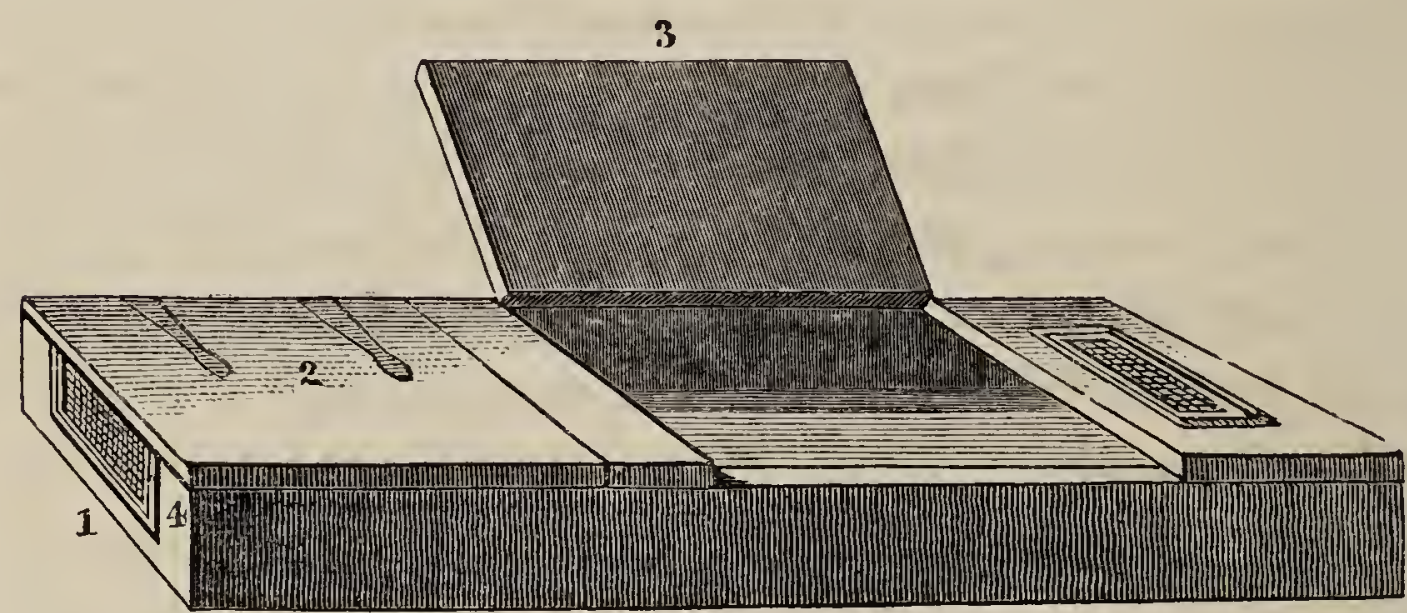

"4. Let the lower end board, where the water is to run off again, be at least three inches thick, as the greatest pressure is against it: have an opening cut at the top six inches wide and four inches deep; have a ravet made on the outside and another on the inside, deep enough to leave at least an inch thick of the solid board in the middle, and wide enough to admit a frame with a brass-wired grate, like No. 2 , on the outside, which can be pushed in from the top; the wires should not be above a line and a half asunder, no more than those at the top, for the same reason as mentioned before. In 
the inside, opposite this opening, push a bit of board downwards into the groove to stem the water either entirely or to regulate its running off, according as you find it necessary, or to pull it entirely out when the whole of the water is to run off.

" 5. There must be two strong covers, one between the two cross pieces described in 2,3 , and the other below the middle cross quite to the lower end, 4 ; both covers must be fastened behind with strong hinges, and before with handles, to lift them conveniently up by; and as these boards are apt to warp, on account of the water within and the air without, it is requisite to have each clamped with two or three cross pieces.

"6. If you think fit to give the young fish more air than what enters at the two brass grates, you may have in each cover a hole made of the same size, and guarded with a brass wire grate, as 3 ; and for the same reasons, I have done this out of precaution, but have found it, in the end, to be unnecessary.

\section{"Section II.}

" 1 . Spring water out of rocks or stony ground is the properest for breeding of Trout or Salmon; but where it is not to be had, other spring water may do, provided the current is strong enough so as not to freeze in hard frosty weather.

" 2. If the spring has not fall enough, you must raise a dam around it, one or two feet higher than the top of your trough; convey the water from thence through a pipe or gutter, to the first grate in the opening, on the head part of the trough, Section I. 2, of one square inch diameter, and determine its length at least two inches above the grate; the remaining water from the spring can be led off sideways. 
"If you have an inclination for more breeding troughs than one, they should be fixed in the same direction as the first, and a larger pipe must be placed to the head of the spring, which must empty itself into smaller pipes, laid across the water troughs, so that each trough may have its proper quantity of water conveyed into it; or it may be managed by means of brass cocks; but this is left to the choice of every one's own pleasure, as the most convenient method will be soon found out.

"3. After the box or trough is properly finished, it must be placed horizontally upon two legs of wood, stone, or brick; and within upon its bottom put some clean washed gravel, about the size of peas and beans, two inches high; afterwards sprinkle some coarse gravel or pebbles over it, the smallest of them of the size of beans, and some larger than hazel-nuts. This last is done, that upon the surface of the smaller gravel many deep holes may be formed, that the continual motion of the water may not carry away the eggs, but that they may remain where they were at first sprinkled in.

" 4. Then let the water run into the trough as directed in 2, and raise it higher or lower, according to the instructions, Section I. 4, so that the water covers the gravel always one or two inches.

"This done, you have accomplished all that is necessary to the apparatus for breeding Trouts and Salmon.

\section{"Section III.}

" 1 . The time of spawning begins the latter end of November, and commonly ends the latter end of January, or beginning of February. But the spawning time of each separate Trout continues only about eight days, as the eggs of the female and sperma of the male become in some sooner, in others later ripe. 
"Trouts meet in rivulets in great numbers, in the before-mentioned months, and such as are ready for spawning fix upon a place where there is large gravel, and where the water has a quick current; there they rush and rub their bellies against the stony bottom, and so violently, that they often make great holes; and by means of this motion both female and male get rid of their spawn and sperma.

"As a single drop of sperma contains vast numbers of animalcules sufficient to animate hundreds of eggs, and as the water is loaded at this time with the sperma, it is no wonder that almost every egg becomes a fish.

"Every egg or spawn in the female comes to its perfection and ripeness at the same time and day; but it is not so with the sperma of the male, for the sperma, or white roe, lies like a solid substance divided into two parts in its body close to the back, and grows gradually liquid, and dissolves itself into a creamy fluid, beginning at the lowest part, and discharges about the sixth part of each division every day, so that within eight days all the sperma becomes liquid and runs off.

\section{"Section IV.}

"1. To breed young Trouts, according to this invention, you must have some Trouts taken out of the rivulet in December and January when they gather together to spawn; as in some rivulets their spawn becomes later ripe, you may in the latter end of January let part of the water drain off, by stemming the water above, that you may take as many out as you want; if after stroking their bellies with the fingers, some spawn or sperma goes off, it is a sign that both are ripe, and those must be put into a large pail or tub for use.

"2. Then take a wooden, earthen, or copper bowl, 
put into it a pint, quart, or more of clear water; take out of your pail one fish after another, stroke them with the hand or fingers downwards till the spawn discharges into the bowl: you need not fear that it will hurt them, for they can without danger bear great pressing; then rub the belly of the male Trout in the same manner till some of its milk discharges into the water,-a little is sufficient, - then stir the whole with your hand so as to mix it well, and all the eggs and spawn will be fructified; then mix more clear water with them to disperse them more asunder: after the eggs are impregnated with the sperma they are apt to clog together, which hurts them in the end; it is therefore necessary to thin them with more water, and to sprinkle them into the breeding trough.

"A small space will receive a great quantity of spawn, yet they must not lie too thick; otherwise, when many touch each other too closely, they will get in a few days into putrefaction, and have the appearance as if a fine downy wool was spread over them; if they remain in this state they are unfit. To prevent this, take a thin slice of wood, or a paddle about the breadth of a hand, and paddle with it backwards and forwards on the spot where the spawn lies too thick, to spread by this motion the spawn asunder.

" 3 . It will be necessary to repeat this manœuvre twice a week, or at least once a week, and by paddling with your wooden slice in all parts, you will bring the water upon the eggs in motion; for let the water be ever so clear, there will adhere to the eggs in a few days a subtle filth, which lays the foundation of their corruption, even, when the young fish is already alive in the egg; therefore it is necessary to clean them by this gentle means. 
"4. After the eggs have been about three weeks in this state, one may perceive through the hard skin a divided black spot, which are the eyes of the young fish; the body is too transparent to be seen with the naked eye, but after four weeks, if you squeeze one of the eggs between your fingers, you will see the fish make a motion and turn within,- - then you perceive his form.

"At last, after lying five weeks in this state, and under a continual current of running water, the young fishes will bore their heads through the shell of the egg, and under motion with their bodies will, in about half an hour, free themselves entirely from the shell, with the yolk of the mother egg hanging to their bellies like a small bag; so soon as they are out of the egg, they will still be in the cavities between the gravel, and have then the appearance as if the head of a pin was fastened to a reddish field pea, on account of these hanging bags. For three or four weeks they receive their nourishment from the substance contained in this bag, till by degrees, as the fishes grow larger, the bag disappears; then they begin gradually to assume the shape of fishes, and having no further sustenance from this bag, they will seek for food themselves. But as in so small a compass as this breeding trough, there cannot be a sufficient quantity of small insects to be found for their sustenance, they seek for more room where they may meet with them in greater abundance; they follow then the current of the water, and slip through the brass grate at the end of the box, where you should have a large wooden tub, like a brewer's cooler, or a small clean fish pond, covered with gravel to receive them, in which they will grow in about six months considerably.

"Section V.

"To instruct my readers as much as possible, I shall 
add several observations on the formation of these young Trouts.

"1. After an egg has been fructified by the sperma of the male, which slips through an invisible opening into it, it lodges in the white liquor under the shell and round the yolk, which last is liquid and transparent, tending to a yellowish colour, and seems to fill up the greatest space in the egg, except the little white round it.

"2. So soon as this little animalcule has assumed the nature and form of the fish, it appeareth that the yolk in the egg is separated by a very thin skin from the outward hard membrane.

" 3 . The fish itself, except the eyes, is very transparent, and as liquid as a little mucilaginous water, yet in shape longish; it lies bent within the outward harder membrane of the egg, and round the thin skin that covers the yolk.

"4. From this time the fish is to be considered as one body grown to the yolk from the gills downwards to the outlet, which is in length about the quarter part of the inward circumference of the egg; this yolk, which looks like a bag, becomes a belly, and without entrails.

" 5 . On this expanded belly, especially in the Salmon Trout, are to be seen many blood-vessels, divided into smaller branches, and so plain, that the arteries may be distinguished from the veins with the naked eye. And it is no wonder, for as it has been mentioned that this hanging belly is larger in proportion to the fish, so the blood-vessels are in proportion expanded, and are to be seen very plainly, so long as the fish remains in a state of transparency like water.

"6. If you open one of these bags with a needle, a liquor runs out of a yellowish colour, which is the nutriment of the fish, then the bag shrinks in like an empty bladder; and the fish dies. 
"After the fish has been out of its egg about a fortnight, a thin skin separates from the inward coat of this hanging belly, and then it shrinks so much that it appears as entirely vanished. After the belly is entirely shrunk to its proportionable size, this inward skin shrinks likewise, and becomes the intestines; from the mouth it forms a passage into the stomach, and continues more narrowly contracted and formed into intestines which lay one over another to the outlet in the belly.

"It is farther to be observed that the heads of the Trout, when they first have the shape of fishes, have not yet all the usual shape of form,-they look as if the snout was chopped off near the eyes; but as their bellies shrink, their heads grow, the mouths are formed, and after about three weeks the heads get their proper shape.

"Lastly, I shall make a few additions, which flow from the former observations, and are the result of experiments, which at this present occasion I have no inclination to publish.

\section{"Section VI.}

"1. According to the course of nature, no Trouts or Salmon are generated in ponds or standing waters.

“2. They cannot be bred there. if millions of pregnant eggrs were put into them.

"3. The young Trouts have, in the first two or three weeks, great tenacity of life, for after the head is dead, the body will live two days before they are quite dead; this is to be understood of healthy fish, kept in a current of fresh running water.

"4. Although the young Trout love to swim with the current within the six weeks out of their breeding trough, yet they can be kept within them six or more weeks longer, by particular management.

"5. They are not easily caught, on account of their 
small size and rapid motion, notwithstanding they may be collected in a pail.

"6. They may then be put into proper water, or can be put through a funnel into bottles, and carried to any part, provided the water don't freeze.

"7. The ripe eggs of a Trout, after they are four or five days apparently dead, and gone into a kind of putrefaction, so that the stench is intolerable, may yet be recovered and bred out into fishes.

"8. The eggs of Trouts will not produce fishes so long as they remain connected with the egg stock.

"9. The natural causes, why it is possible that a hen may bring a live chicken into the world may very easily be accounted for, from observations I have made in the breeding of Trouts.

"10. The natural disposition of the animalcule of the sperma, which enters the egg, may be considerably increased.

" 11 . I have made many experiments, in which I found that two animalcules had slipt into the egg, and that double fishes have been generated; and although they had two bodies, they had but one common stomach: how this happens, see Section V. 1.

"12. Of these monstrous productions the most of them were opposite to one another, and had their stomach in common between them : yet, in a strict sense, the stomach only; the rest of the intestines divided in about three weeks separately.

"13. Some of these double fishes were fixed by their sides together, when two animalcules of the sperma enter the egg in a direct line $90^{\circ}$ one from another.

"14. I have seen only one of these double fishes where the backs were crossed nearest the tail in a direct angle, so that this fish formed a kind of cross. This happens 
when two animalcules enter one egg, and are placed opposite each other from their direct line to $90^{\circ}$.

"The monsters of paragraphs 12 and 13 were grown together from the head to the opening in the belly, and that of 14 had in some degree a joined body, but the backs were distinguished one from another.

" 15 . All these kinds of monstrous productions die in four or five weeks, after their joint bag or belly is emptied; for as each endeavours to follow its own direction in pursuit of food, and both hinder one another, neither of them is capable of fulfilling its intention; it is impossible that either head can receive its proper nourishment, therefore they must starve.

"16. All monstrous productions in the human and other animal creations, with a joint stomach, are produced when an egg is fructified by more than one spermatic animalcule.

"17. All observations made on the Trout, and its artificial method of breeding, hold good with regard to Salmon.

$$
\text { (Signed) “S. L. JACoBs." }
$$

The Trout varies considerably in appearance in different localities; so much so, as to have induced the belief that there are several species. It is, indeed, probable that more than one species of River Trout may exist in this country; but when we consider geologically the various strata traversed by rivers in their course, the effect these variations of soil must produce upon the water, and the continuous influence of water loaded with peculiar solvents upon the fish that inhabit it;-when we reflect also on the great variety and quality of the food afforded by different rivers, depending likewise on soil and situation, and the additional effect which these

voL. I. 
causes combined in various degrees are likely to produce; -we shall not be much surprised at the variations both in size and colour which are found to occur. That two Trout of very different appearance and quality should be found within a limited locality in the same lake or river, is not so easily explained; and close examination of the various parts which afford the most permanent characters should be resorted to, with a view to determine whether the subject ought to be considered merely as a variety, or as entitled to rank as a species. In these examinations the character of the internal organs also, and the number of the bones forming the vertebral column, should be ascertained. The normal number of vertebræ in Salmo fario, our Common Trout, I believe to be fiftysix.

The remarks of Lord Home on the Common Trout are as follows:- "I am much inclined to think there is but one kind of River Trout; the large Lake Trout may be different, but of that I can be no judge, having never caught or seen them; but to the variation in size, colour, and appearance of the River Trout I can speak. It has often happened to me, when fishing in the height of the season for Trout in the Tweed, that, out of two or three dozen I have caught, there should be five or six differing not only from the Common Tweed Trout, but from each other. The reason of this difference in my opinion is easily explained. These Trout come down into the Tweed during the winter and spring floods from its different feeders, viz. the Ettrick, Yarrow, Jed, Kale, Eden, Leet, \&c.; all differing completely from each other. They retain enough of their original appearance to distinguish them from Tweed Trout, which, with the exception of the Whitadder Trout, are the leanest and worst-flavoured of any in this part of the country; but, 
after a few months' stay, the Trout from the small burns gradually lose their original marks and excellence of flavour, and become like the Common Tweed Trout in every respect. There can be no doubt that the nature of the soil through which the different streams flow is the cause of the difference of appearance, not only as to colour and size, but also particularly in the superior excellence of their flesh to that of the Tweed and Whitadder Trout. For example, the Eden and Leet, flowing through a rich loamy and often marly soil, afford Trout of very superior size and quality; their bodies beautifully marked with bright red spots, their fins orangecoloured, as well as their sides, and their flesh fully a deeper red than that of the Salmon, and almost as highflavoured, particularly the Leet Trout, which I have killed weighing seven pounds. The largest Tweed Trout I ever saw was one I caught with a Salmon fly; it weighed just five pounds.

"There are two considerable streams in this county which take their rise at no great distance from each other, the Whitadder and the Blackadder, the latter tributary to the former. The Whitadder from head to foot flowing along a very rocky and gravelly bed: while the Blackadder (Blackwater) rises in the deep mosses near Wedderlea and the Dorrington laws (High hills), and flows for about half its course through mosses; the rest of its course through a rich and highly-cultivated district. The Trout of Whitadder (Whitewater) are a beautiful silvery fish, but good for nothing; those of the other dark, almost black, with bright orange fins, and their flesh excellent. Nothing can be more different than the appearance of the Trout of these two rivers; and surely nothing can be more easy than at once to see the cause of this difference. The Trout in neither of these 
streams are of a great size. In the Blackadder they would attain a large size,-say three or four pounds; but the river is overfished, and poached to perfection.

"I have ascertained that the Tweed Trout, after having. been a month or two in the Leet, change their colour, and soon assume the appearance of those of the Leet: while again, not only the Leet Trout, but those of the other small burns, soon lose their beauty and other good qualities after they have been any time in the Tweed. I may mention that the food in the two little rivers Leet and Eden afforded to the Trout, is the principal cause, in my opinion, of their superior size and excellence. This food consists of small shells, cadis bait, \&c., and clouds of flies produced by the marl on the sides of the brooks and the woods on their banks.

"Once, while fishing in the Tweed for Trout, with Minnow, a Trout rose and missed. I threw the Minnow over him at least twenty times; each time the fish rose eagerly and made the most unfishlike (if I may use the expression) attempts to seize the Minnow; at last a tailhook took hold of him, and I got him out. It proved to be a Trout with the upper jaw formed exactly, or very. nearly, like that described and figured in the 59th page of vol. ii. of the first edition of Yarrell's British Fishes.* This Trout was lank and thin, but weighed a pound and a half. Unluckily I did not preserve it."

Sir William Jardine, Bart., in a paper on the Salmonida, published in the Edinburgh New Philosophical Journal for January 1835, has described at considerable length the variations observed in the Trout of some of the lochs of Sutherlandshire. Other lochs abound with Trout which are reddish, dark, or silvery, according to the clearness of thé water. Mr. Neill, in his Tour, has noticed

* See p. 286 of the present volume. 
the blackmoss Trout of Loch Knitching, and Loch Katrine is said to abound also with small black Trout; an effect considered to be produced in some waters by receiving the drainings of boggy moors. In streams that flow rapidly over gravelly or rocky bottoms, the Trout are generally remarkable for the brilliancy and beauty of their spots and colours. Trout are finest in appearance and flavour from the end of May till towards the end of September; an effect produced by the greater quantity and variety of nutritious food obtained during that period. Two specimens of the Common Trout taken early in January were unusually fine in colour for that season of the year; their stomachs on examination were distended with ova of large size, which, from circumstances, were known to be the roe of the Bull Trout. The albuminous nature of this sort of food, which the Trout availed themselves of, was believed to be the cause of their colour; since other Trout, procured at the same time from localities where no such food could be obtained, were of the usual dark colour of that season of the year.

The author of Wild Sports in the West of Ireland refers particularly to the differences observed in the Trout of that country in his 35th letter:- " The fishing party had been successful, and returned late in the evening with two baskets of Trout, which, although of small size, were remarkable for beautiful shape and excellent flavour.

"It is a curious fact, that the loughs where the party angled, though situate in the same valley, and divided only by a strip of moorland not above fifty yards across, united by the same rivulet, and in depth and soil at bottom, to all appearance, precisely similar, should produce fish as different from each other as it is possible for those of the same species to be. In the centre lake, the 
Trout are dull, ill-shaped, and dark-coloured; the head large, the body lank, and though of double the size, compared to their neighbours, are killed with much less opposition. In the adjacent loughs, their hue is golden and pellucid, tinted with spots of a brilliant vermilion. The scales are bright, the head small, the shoulder thick, and from their compact shape they prove themselves, when hooked, both active and vigorous. At table they are red and firm, and their flavour is particularly fine; while the dark Trout are white and flaccid, and have the same insipidity of flavour which distinguishes a spent from a healthy Salmon. The red Trout seldom exceed a herring-size; and in looking through the contents of the baskets, which amounted to at least twelve dozen, I could only find two fish which weighed above a pound.

"The dark Trout, however, from their superior size, are more sought after by the mountain fishermen. They rarely are taken of a smaller weight than a pound, and sometimes have been killed, and particularly with a worm, or on a night-line, of a size little inferior to that of a moderate Salmon.

"I never observed the effect of bottom soil upon the quality of fish so strongly marked as in the Trout taken in a small lake in the county of Monaghan. The water is a long irregular sheet of no great depth; one shore bounded by a bog, the other by a dry and gravelly surface. On the bog side, the Trout are of the dark and shapeless species peculiar to moorish loughs; while the other affords the beautiful and sprightly variety, generally inhabiting rapid and sandy streams. Narrow as the lake is, the fish appear to confine themselves to their respective limits; the red Trout being never found upon the bog moiety of the lake, nor the black where the under surface is hard gravel." 
Mr. Stoddart, in his Art of Angling as practised in Scotland, mentions an interesting experiment made with Trout, some years ago, in the south of England, in order to ascertain the value of different food. "Fish were placed in three separate tanks, one of which was supplied daily with worms, another with live Minnows, and the third with those small dark-coloured water-flies, which are to be found moving about on the surface under banks and sheltered places. The Trout fed with worms grew slowly, and had a lean appearance; those nourished on Minnows, which, it was observed, they darted at with great voracity, became much larger; while such as were fattened upon flies only, attained in a short time prodigious dimensions, weighing twice as much as both the others together, although the quantity of food swallowed by them was in nowise so great." *

Of four Trout fed in a stew together, three of them weighed fifteen pounds each, the fourth attained the weight of seventeen pounds; but neither the food nor the time consumed was recorded.

A writer on fishes and fishing in the New Sporting Magazine for November 1840, says, page 975, "An acutely-observing friend of mine, who has paid close attention to the growth of Trout, having regard to Mr. Shaw's experiments on Salmon, concludes that Trout are rarely visible the first year; that they congregate with Minnows, and other fry, the second; are found on shallows the third summer, about seven or eight inches long, and subsequently increase rapidly to a pound or a pound and a half, dependent on the quantity and quality of their food, the season, and other circumstances. This gentleman has, for years, kept Trout in a kind of store

* Dr. Davy has remarked that insects contain much phosphate of lime, and that the droppings of swallows are very rich in that ingredient. 
stream, and, having fed them with every kind of food, has had some of them increase from one pound to ten pounds in four years. I found, says he, that one of the Trout I had fed and weighed regularly for the last six years, was not improving in size and colour: I therefore killed it. The fish is a female, and weighed exactly seven pounds. The accompanying schedule will show its gradual increase.

\begin{tabular}{|c|c|c|c|c|c|c|c|}
\hline Date of weighing. & $\begin{array}{l}1835 . \\
\text { lb. oz. }\end{array}$ & $\begin{array}{l}1836 . \\
\text { lb. oz. }\end{array}$ & $\begin{array}{l}1837 . \\
\text { lb. } 0 z .\end{array}$ & $\begin{array}{l}1838 . \\
\text { lb. oz. }\end{array}$ & $\begin{array}{l}18 \\
\text { lh. }\end{array}$ & & $\begin{array}{r}1840 . \\
\text { lb. oz. }\end{array}$ \\
\hline April 1st & 012 & 112 & 34 & 54 & 7 & 0 & 74 \\
\hline October 1st & 14 & 20 & 5 & $\begin{array}{ll}512 \\
12\end{array}$ & 7 & 8 & 7 \\
\hline
\end{tabular}

Littlecot, Oct. 1840."

Stephen Oliver the younger, in his agreeable Scenes and Recollections of Fly-fishing, mentions a Trout, "taken in the neighbourhood of Great Driffield, in September 1832, which measured thirty-one inches in length, twentyone in girth, and weighed seventeen pounds." A few years since, a notice was sent to the Linnæan Society of a Trout that was caught on the 11 th of January 1822, in a little stream, ten feet wide, branching from the Avon, at the back of Castle Street, Salisbury. On being taken out of the water, its weight was found to be twentyfive pounds. Mrs. Powell, at the bottom of whose garden the fish was first discovered, placed it in a pond, where it was fed and lived four months, but had decreased in weight at the time of its death to twenty-one pounds and a quarter.

The age to which Trout may arrive has not been ascertained. Mr. Oliver mentions, that in August 1809, "a Trout died which had been for twenty-eight years an inhabitant of the well at Dumbarton Castle. It had never increased in size from the time of its being put in, when it weighed about a pound; and had become so tame, that it would receive its food from the hands of the 
soldiers." In August 1826, the Westmoreland Advertiser contained a paragraph stating that a Trout had lived fifty-three years in a well in the orchard of $\mathrm{Mr}$. William Mossop, of Board Hall, near Broughton-inFurness.

The Thames at various places produces Trout of very large size. Anong the best localities may be named Kingston, opposite the public-house called the Angler,

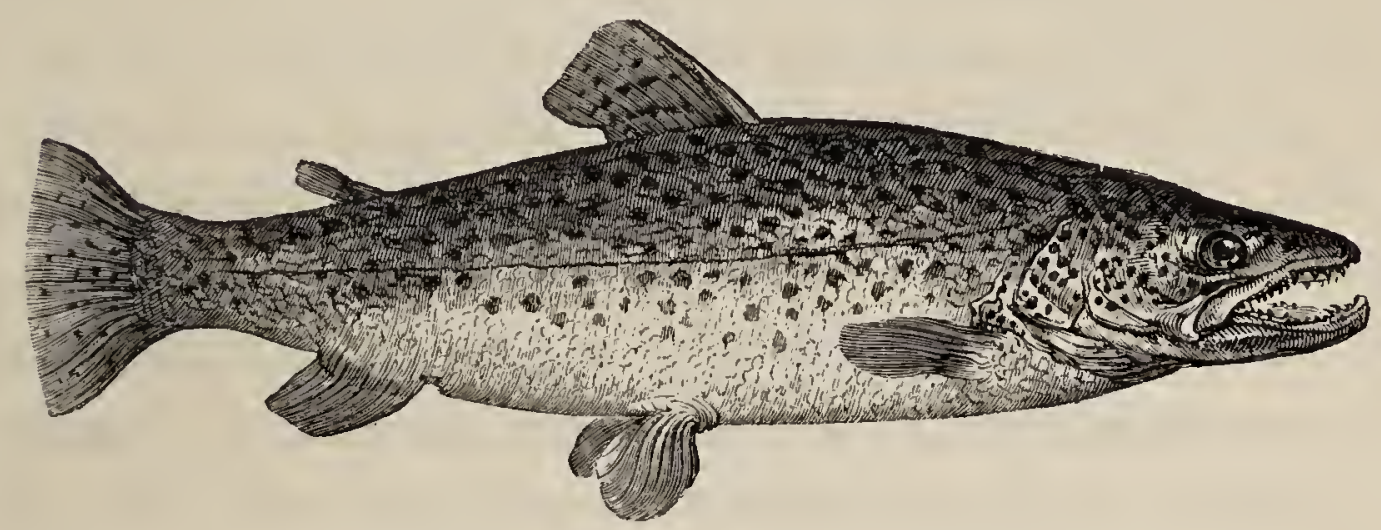

Hampton Court bridge and wear, and the wears at Shepperton and Chertsey. These large Trout are objects of great attraction to some of the best London anglers, who unite a degree of skill and patience rarely to be exceeded. The most usual mode practised to deceive these experienced fish is by trolling or spinning with a small Bleak, Gudgeon, or Minnow; and by these baits Trout of fifteen pounds' weight are occasionally taken.

On the 21st of March, in the year 1835, a male Trout of fifteen pounds' weight was caught in a net. The length of this fish was thirty inches. On the 14th of April following, a male Trout of eleven pounds' weight, and measuring twenty-eight inches in length, was also caught in a net. From this second fish the representation above shown was taken, by permission of 
Mr. Groves, who allowed a drawing to be made, which was engraved for this work.

On the 4th of November 1848 a Trout, measuring twenty-one inches and a half, and weighing above twentyone pounds, was captured at Drayton Manor, in a small tributary of the Trent. Sir Robert Peel employed Mr. Waterhouse Hawkins to take a portrait of this fine fish.

Several deep pools in the Thames above Oxford afford excellent Trout, and some of them of very large size. I have before me a record of six, taken by Minnow spinning, which weighed together fifty-four pounds, the largest of them thirteen pounds. Few persons are aware of the difficulty of taking a Trout when it has attained twelve or fourteen pounds' weight, and it is very seldom that one of this size is hooked and landed except by a first-rate fisherman: such a fish, when in good condition, is considered a present worthy a place at a royal table.

The Botling of Wastwater in Cumberland, which has been taken of the weight of twelve pounds, is probably a large Trout, as Dr. Davy conjectures.* It ascends the feeding streams of the lake in the autumn, and is described by the intelligent yeoman farmer or "statesman" of Wasdale Head, Mr. Ritson, as a fierce, powerful, and voracious fish, which attacks the other Salmonida, when they are in the act of spawning. It is of a short, thick make, and when of full size, its girth considerably exceeds its length. Its spots resemble those of the ordinary Lake Trout, and its dentition is said to be of the same kind. Its under jaw is much hooked. The Botlings of Wasdale Head are all males. We have not succeeded in obtaining specimens, and all our information respecting the fish, comes indirectly from $\mathrm{Mr}$. Ritson.

* The Angler in the Lake District, p. 98. 1857. 
Among performances in Trout-catching, the following may be mentioned, as found in the MS. of the late Colonel Montagu.

"Mr. Popham, of Littlecot, in the county of Wilts, was famous for a Trout fishery. The fish were confined to a certain portion of a river by grating, so those of a moderate size could not escape. To the preserving and fattening these fish, much trouble and expense were devoted, and fish of seven and eight pounds' weight were not uncommon. A gentleman at Lackham, in the same county, had a favourite water-spaniel that was condemned to suffer death for killing all the Carp in his master's ponds, but was reprieved at the desire of Mr. Popham, who took charge of him, in the belief that so shy and so swift a fish as a Trout was not to be caught by a dog. However, in this he was mistaken, for the dog soon convinced him that his largest Trout were not a match for him." Mr. Stoddart also, in his Scottish Angling, page 119, has recorded the propensities of a fish-catching dog.

I am indebted to William Thompson, Esq., of Belfast, for a very fine specimen of the Gillaroo Trout of Lough Neagh, measuring twenty-two inches in length, from which fish the representation at the top of the following page was taken. The internal surface of the stomach presented an indurated cuticle, but the parietes were not thicker than those of other Trout; the cavity was filled with some dozens of the Paludina impura of Lamarck. The fin-rays and vertebræ were-

\section{12 : P. 14 : V. 9 : A. 11 : C. 19 . Vertebræ 56.}

So little difference appeared to exist between this and English specimens of $S$. fario, as to induce the belief that the Gillaroo is only a variety of the Common Trout, as stated by Pennant. 


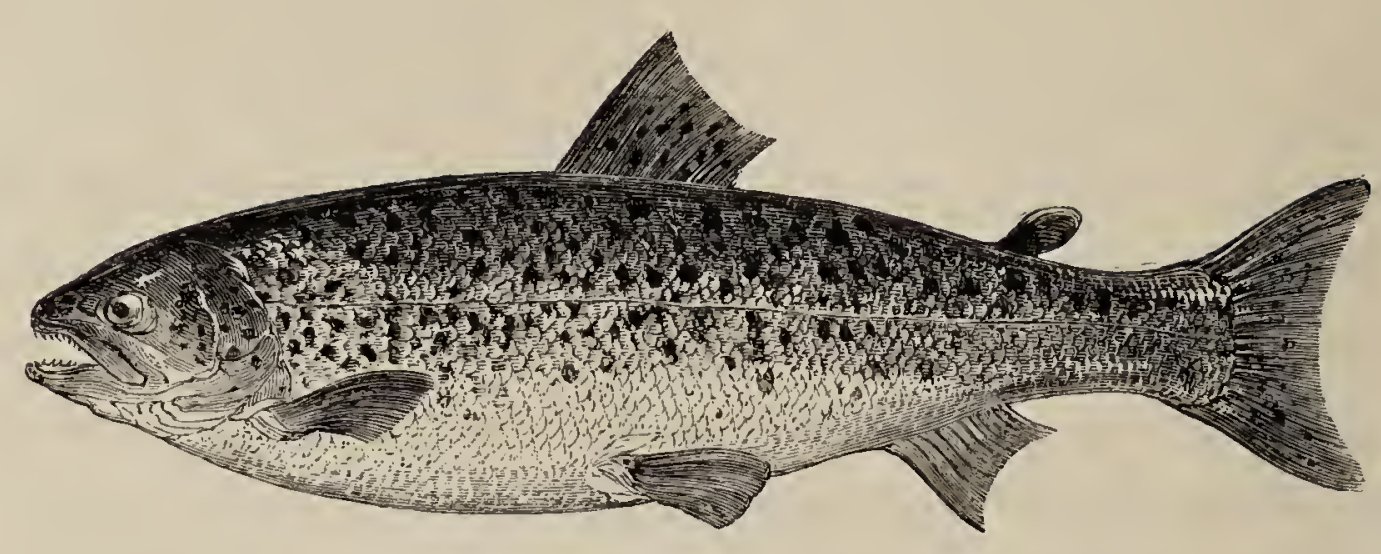

Several loughs in Ireland produce this fish, among others Lough Bofin, Lough Corrib, Lough Mask, \&c. (Thompson). It sometimes attains the weight of ten or twelve pounds. The teeth are remarkably small, but in number and situation like those of $S$. fario. It is partial to a rocky bottom, and takes a worm bait, but may also be captured with an artificial fly.

A male fresh water, non-migratory Trout, from Lough Neagh, was cooked at Brooke's Club-house on the 13th October 1852. It was beautifully spotted, and its flesh of good colour and flavour. Its length was forty inches, girth twenty-four inches, and weight thirty pounds.

The figure of the Trout at the head of this article, and the following description, were taken from a Hampshire fish of twelve inches in length.

The length of the head compared to the length of the head and body, not including the caudal rays, was as one to four; the depth of the body rather more than the length of the head; the dorsal fin commenced half-way between the point of the nose and the commencement of the upper caudal rays; the third ray of the dorsal fin, which is the longest, is longer than the base of the fin : the origin of the adipose fin half-way between the commencement of the dorsal fin and the end of the upper half of 
the tail; the pectoral fin two-thirds of the length of the head; the ventral fins under the middle of the dorsal fin, and half-way between the origin of the pectoral fin and the end of the base of the anal fin; the anal fin begins half-way between the origin of the ventral fin and the commencement of the inferior caudal rays. The tail but slightly forked, and growing slowly up to square in old fish, or even very slightly convex, as seen in the figure of the large Thames Trout represented on page 281 .

The fin-rays in number are-

D. $14:$ P. $14:$ V. $9:$ A. $11:$ C. 19 . Vertebræ 56.

The form of the head blunt; the eye large, placed one diameter and a half from the end of the nose; the irides silvery, with a tinge of pink: the lower jaw in the Salmonidae appears to be the longest when the mouth is opened, but it shuts within the upper jaw when the mouth is closed; the teeth numerous, strong, and curving: inwards, extending along the whole length of the vomer; the disposition of the teeth and the form of the gill-cover are shown in outline at page 15\%; but throughout the Salmonida the teeth of the males are larger than those of the females: the convexity of the dorsal and ventral outline nearly similar; the colour of the back and upper part of the sides made up of numerous dark reddish-brown spots on a yellow brown ground; eleven or twelve bright red spots along the lateral line, with a few other red spots above and below the line; the lower part of the sides golden yellow; belly and under surface silvery white; the spots on the sides liable to great variation in number, size, and colour; dorsal fin and tail light brown, with numerous darker brown spots; the adipose fin brown, frequently with one or two darker brown spots, and edged with red; the pectoral, ventral, and anal fins uniform pale orange brown. The number of scales in a 
row above and underneath the lateral line about twentyfive.

Deformed Trout are not uncommon. "In 1829," says the writer of the article on Angling in the seventh edition of the Encyclopædia Britannica, "we received some very singular Trouts from a small loch called Lochdow, near Pitmain, in Inverness-shire. Their heads were short and round, and their upper jaws were truncated, like that of a bull-dog. They do not occur in any of the neighbouring lochs, and have not been observed beyond the weight of half a pound." Such a Trout from Lochdow was presented to the Museum of the Zoological Society by the Honourable Twiselton Fiennes: the figure below is a representation of the head of that specimen.

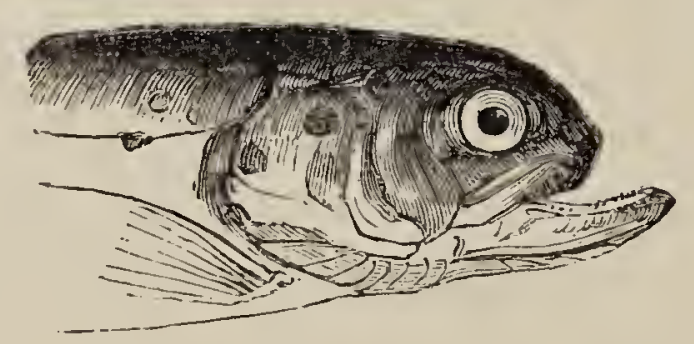

Mention of deformed Trout, as occurring in some of the lakes of Wales, is also made by Pennant, Oliver, and Hansard. I am indebted to the kindness of P. Buckley Williams, Esq., of Pennant House, Montgomeryshire, for a notice of the Hog-backed Trout of Plinlimmon, which is taken occasionally in Bagail Lyn, Shepherd'spool, about one-third up the Plinlimmon mountains, on the Machynllaith, or western side. This Trout, of which a figure is given in the Cambrian Quarterly Magazine for July 1833, is not unlike the form which Perch sometimes assume.

L. W. Dillwyn, Esq. sent me a copy of the following paragraph, which appeared in a Cambrian newspaper of the 28th of November 1829. "As Abraham Harries 
and George Stephens, who reside at Llangattock, Carmarthenshire, were fishing with their nets in the river Towey on Friday last, they caught a fine fish of the Salmon species, which had two heads and two tails. The heads are joined on one neck, and the tails meet about the centre. This fish is now to be seen alive in a small pool at Llangattock."

I have seen one very young specimen of our common Small Spotted Shark with two distinct heads: the whole fish was only about six inches long. Malformations from deficiency in the number of bones of the mouth, or of other parts of the head, are not uncommon.

The vignette represents the castle and the island in Lochleven, mentioned in page 258.

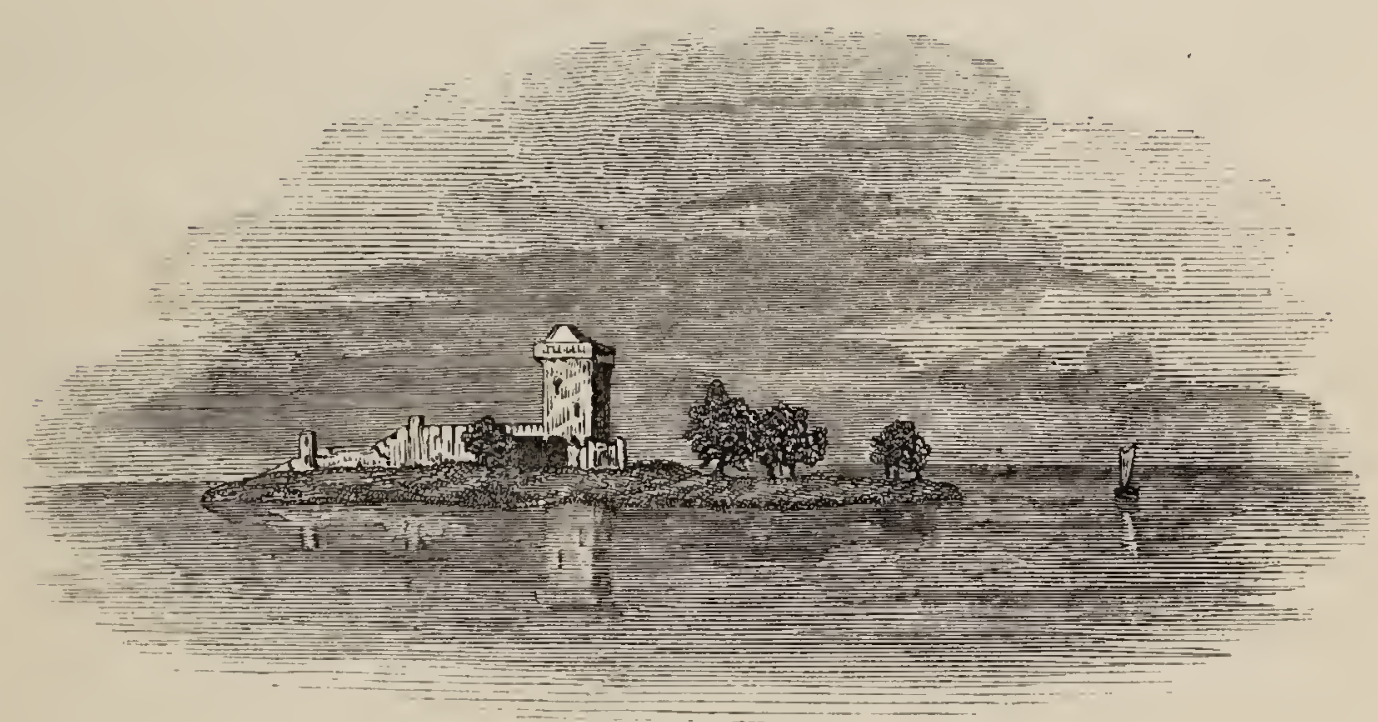




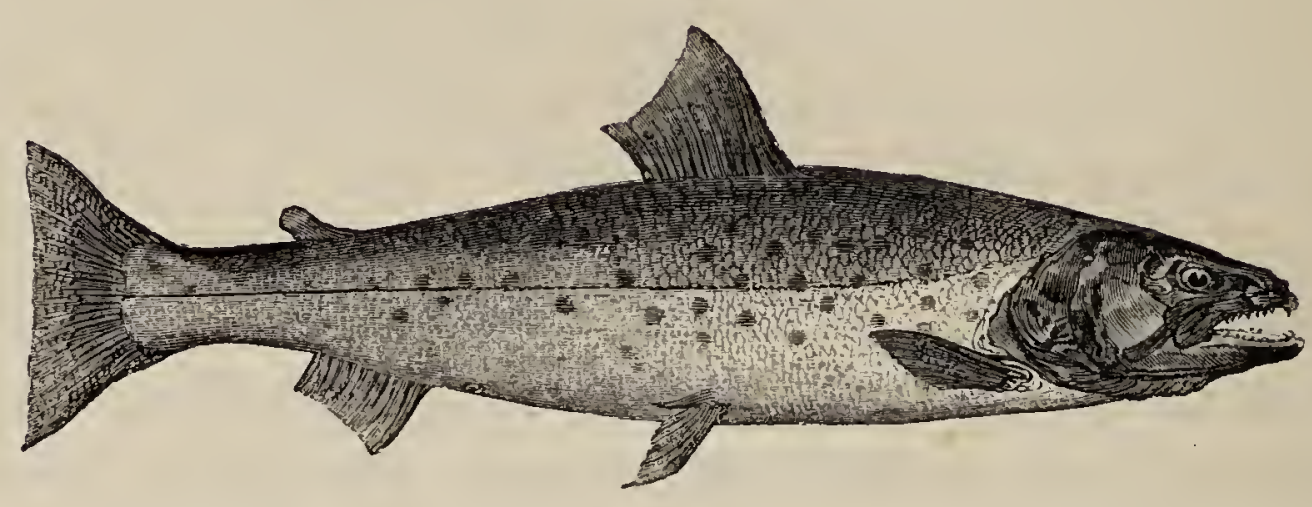

THE GREAT LAKE TROUT.

\section{BUDDAGH.}

Salar ferox.

Sulmo ferox,

Great Lake Trout, JARdine's Illust. Scot. Salm. pl. 4.

, lacustris, Lake Trout, Berkenhout's Syn. 1795, i. p. 79, sp. 3.

" ferox, Great Lake Trout, Jenyns, Brit. Vert. p. 425.

The Great Lake Trout of I Loch Awe, to which attention has been drawn by the various notices that have appeared in print of the fish, as well as of the beauties of that locality, was shortly noticed by Pennant, in the editions of the British Zoology, as a native of Ullswater Lake in Cumberland, and of Lough Neagh in Ireland, and was erroneously considered to be identical with the Great Trout of the Lake of Geneva. Berkenhout includes this fish in his Synopsis of the Natural History of Great Britain and Ireland, as quoted above. Dr. Heysham records it in his Catalogue of Cumberland Animals as the Ullswater Trout and Grey Trout, some specimens of which were said to weigh between fifty and sixty pounds; and the Rev. Mr. Low, in his Fauna Orca- 
densis, mentions a Trout of thirty-six pounds' weight or more, which, along with the Common Trout, occurs both there and in Zetland. Mr. William Thompson of Belfast, when at the meeting of the British Association at Edinburgh in 1834, saw a specimen of the Great Trout of Loch Awe, and recognised it as identical with the Great Trout, or Buddagh, of Lough Neagh. Two fine examples, each of them about thirty-five inches in length, were exhibited by him at the Zoological Society. * They were obtained from Lough Neagh, where the younger and smaller-sized fish of this species are called Dolachans; and he has since learned that this fish exists in Lough Corrib in the county of Galway, and also in Lough Erne in the county of Fermanagh, thus proving it, to use his own words, to be an inhabitant of the three largest lakes in Ireland; it is found also, he says, in Lough Melvin and Lough Mask, and it will probably yet be discovered in most of the lakes of any considerable extent in that country. Mr. Thompson has very kindly supplied me with a young fish of this species from which the representation below was taken, and which, differing from specimens of large size in having the spots more numerous, may be an acceptable addition.

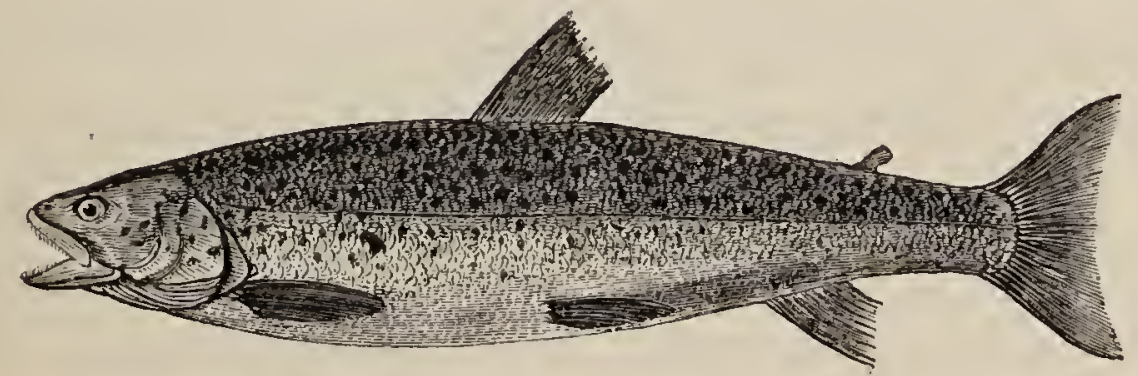

* See the Report of the Proceedings of the Society for June 9, 1835.

VOL. I. 
According to Sir William Jardine, this fish seems, as far as can be traced, to have been first noticed about the year 1790 by the late Mr. Morrison of Glasgow, who used to exhibit examples of it to his friends as the trophies of his expeditions. The first specimens taken in Loch Awe by Mr. Selby and Sir William Jardine were considered as belonging to a species new to Britain, and the specific name of ferox was given to it, as descriptive of its extreme voracity and rapacious habits. M. Agassiz, who saw specimens of it when he was in Edinburgh, pronounced it to be different from any of the large Continental species.

"In Scotland this fish appears to be generally distributed in all the larger and deeper lochs. Loch Awe, Loch Laggan, the upper end of Loch Shin, Lochs Loyal and Assynt it certainly inhabits, roving indiscriminately, and feeding almost entirely upon the smaller fish. By persons residing on the banks these Great Trouts are caught by night-lines, few rising at the artificial fly; but they may always be taken by strong trolling tackle, baited with a small Trout. They are extremely voracious, and, having seized the bait, will allow themselves to be dragged by the teeth for forty or fifty yards; and when accidentally freed, will immediately again seize it."

This Great Trout is almost entirely confined to the lochs, seldom venturing far either up or down any of the streams communicating with them, and never descending to the sea. It is known to spawn in September.

The most usual mode of fishing for this Great Lake Trout is from a boat, which is rowed gently through the water; the bait, as before mentioned, a small Trout, guarded by six or eight large hooks; the rod and line of great strength; for this fish is considered to be even stronger than a Salmon of the same size, but not so 
active. Young fish from one to two pounds' weight rise freely to the usual Trout flies.

For the drawing of this fish, I am indebted to the kindness of Mr. Selby and Dr. Richardson.

The length of the head is to the whole length of head, body, and tail, as one to four and a half; the depth of the body not equal to the length of the head: the teeth large, strong, and numerous, arranged in five lines above and four below, thus extending along the length of the vomer : the free edge of the gill-cover is rounded in the female, and more angular below in the males; the inferior edge of the suboperculum, and the line of its junction with the operculum, oblique. The commencement of the dorsal fin is half-way between the point of the nose, and the origin of the first upper caudal ray; the third dorsal fin-ray, which is the longest, equals the length of the base of the dorsal fin; the soft fleshy fin stands half-way between the last dorsal fin-ray and the end of the caudal rays, and directly over the origin of the last ray of the anal fin : the ventral fins have each an elongated axillary scale; the fins generally are rather small in size, but very muscular. The fin-rays in number in the specimen from Loch Awe were-

$$
\text { D. } 13: \text { P. } 14: \text { V. } 9: \text { A. } 11: \text { C. } 19 .
$$

The specimens from Lough Neagh that were examined had one ray less in the dorsal, pectoral, and anal fins, and one ray more in the caudal fin. For an excellent account of this fish, see the article Angling in the seventh edition of the Encyclopredia Britannica, from which I derive the following description of the colours of this species, which was evidently taken from a recent specimen.

"When in perfect season and full grown, it is a very handsome fish, though the head is always too large and long to be in accordance with our ideas of perfect sym- 
metry in a Trout. The colours are deep purplish brown on the upper parts, changing into reddish grey, and thence into fine orange yellow on the breast and belly. The whole body, when the fish is newly caught, appears as if glazed over with a thin tint of rich lake colour, which fades away as the fish dies, and so rapidly, that the progressive changes of colour are easily perceived by an attentive eye. The gill-covers are marked with large dark spots; and the whole body is covered with markings of different sizes, and varying in number in different individuals. In some these markings are few, scattered, and of a large size; in others they are thickly set, and of smaller dimensions. Each spot is surrounded by a paler ring, which sometimes assumes a reddish hue; and the spots become more distant from each other as they descend beneath the lateral line. The lower parts of these fish are spotless. The dorsal fin is of the same colour with the upper part of the fish ; it is marked with large dark spots; the pectoral, ventral, and anal fins are of a rich yellowish green colour, darker towards their extremities. The tail is remarkable for its breadth and consequent power. In adults it is perfectly square, or might even be described as slightly rounded at its extremity: in the young it is siightly forked, and appears to fill up gradually as the fish advances in age."

"The flavour of this great lacustrine species is coarse and indifferent. The colour of the flesh is orange yellow, not the rich salmon-colour of a fine Common Trout in good season." Pennant states from experience that it is but an indifferent fish. The stomach is very capacious, and is almost always found gorged with fish. I have not had an opportunity of ascertaining the number of vertebræ. Mr.'Thompson, on reckoning the pyloric cæca of several male specimens, found that the number varied 
from thirty-four to forty-nine. In none are they as numerous as in Salmo salar, or Salar argenteus.

The scales are decidedly different in form from those of the Trout, and more circular than those of any of the migrating species: they are thin, flexible, and covered with a delicate membrane.

I have reason to believe that this same species of Great Lake Trout is an inhabitant of some of the large lakes of Scandinavia.

Sir Thomas Maryon Wilson, Bart. visited Sweden in the summer of 1840, and ascending the Gota River in his yacht, the Siren, and passing through the celebrated sluices of Tröllhattan, cruised, fished in Lake Wenern, and visited his friend Mr. Lloyd, who resided near the southern extremity of this noble lake. He brought back with him five or six skins of the Great Trout of the Lake, which he had caught by spinning with a Bleak, and, from their large size, they must have afforded him excellent diversion. The largest of these specimens measured forty-two inches in length, and weighed about thirty-four pounds : the next largest weighed thirty-two pounds: the third twenty-seven pounds; the others were of smaller size. These large Trout, and larger than these are seldom seen, were males; the females, according to Mr. Lloyd, who resided for some years on the borders of the lake, rarely exceed twenty or twenty-two pounds.

The number of fin-rays in these specimens averaged-

$$
\text { D. 13: P. 14: V. 9: A. 11: C. } 19 .
$$

Among other fish taken by Sir Thomas Wilson was a large specimen of the Ide, Leuciscus idus of authors. This fish, which resembles our English Chub, he caught in the Gota Elf, a short distance above the falls of Tröllhattan, whilst trolling for pike on a windy day : its weight was between four and five pounds. The skins of these 
various specimens were effectually preserved and were mounted afterwards in England.

Sir Thomas did me the favour to show me numerous sketches of scenery, taken during this trip, which include views of the Gota River, the cities and country on its banks, the celebrated falls of Tröllhattan and parts of Lake Wenern at different points of view; very kindly allowing me the use of a coloured drawing, from which the vignette below, on a reduced scale, was taken. This view represents Mr. Lloyd's cottage on the eastern bank of the Gota, with Sir Thomas's yacht lying at anchor immediately opposite; and the remarkable and finely-wooded hills of Hunneberg and Halleberg, celebrated for the peculiarity of their geological structure, bounding the distance.

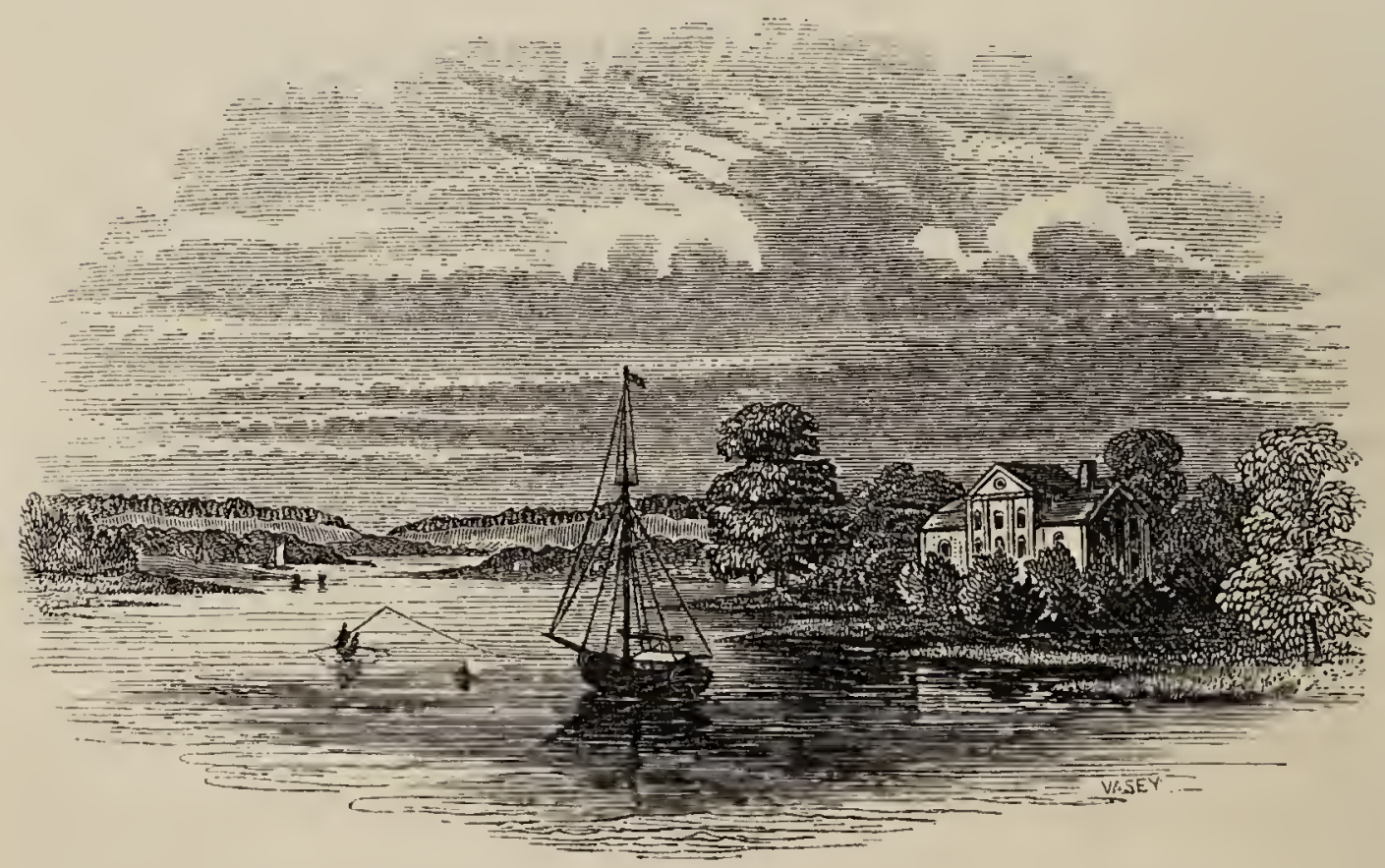




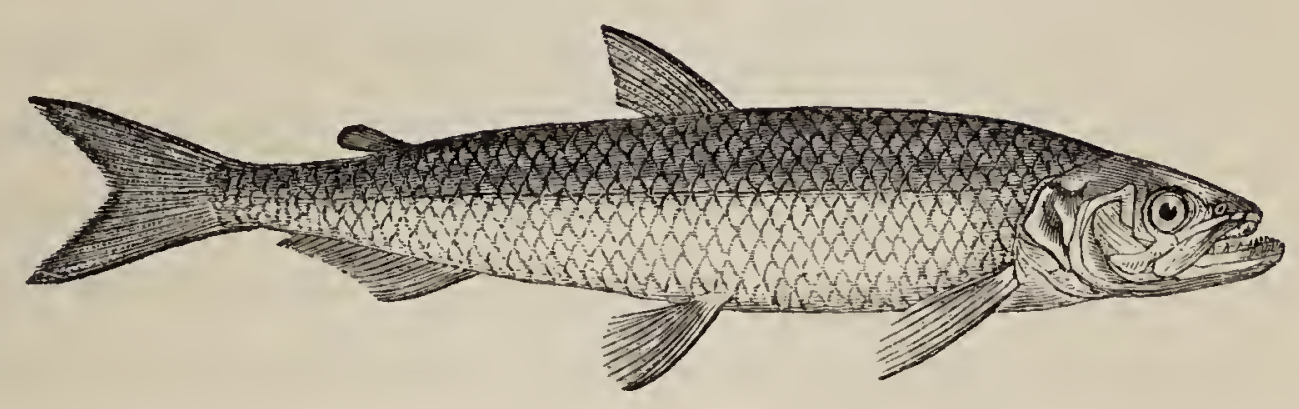

THE SMELT.

SPURLING, SPIRLING, AND SPARLing. Scotland.

Osmerus eperlanus, Smelt, Fuem. Brit. An. p. 181, sp. 48.

$\begin{array}{lll},, & \text {, } & \text { Cuvier, Règne An. t. ii. p. } 305 . \\ , & \text { Cuvier et VAlienc. xxi. } 374 .\end{array}$

Eperlanus Rondeletii, WILLdGHBт, p. 202.

,, Schonfeldii, , Willughis, tab. N. 6, fig. 4.

Salmo eperlanus, Linnzus. Bloch, pt. i. pl. 28, 2.

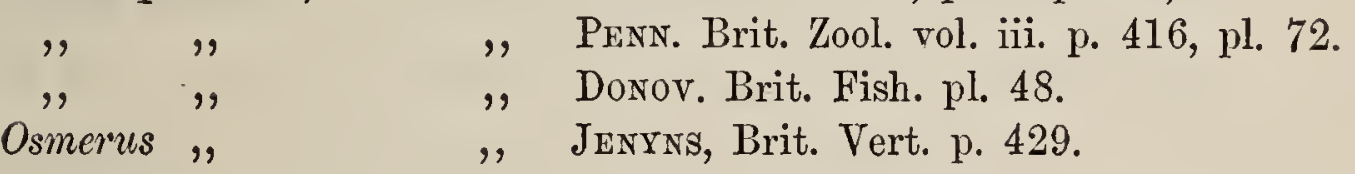

Osmerus. Generic Characters. - Teeth on the jaws, small and curved, the maxillary ones minute; vomerine teeth stout, advancing to the front edge of the mouth: teeth also on the outer edges of the palatines and inner border of the entopterygoid. Ventrals under the front of the-dorsal; gill-openings large; air-bladder having thin nacry coats, and communicating by tube with the gullet. Eggs dropping into the cavity of the abdomen; and general structure as in the other members of the family.

The Smert, as a British fish, is most common on the eastern and western coasts of Great Britain, and I am not aware of any good authority for its appearance between Dover and the Land's End.* The fish called Smelt and Sandsmelt along the extended line of our southern coast is in reality the Atherine, which will be described hereafter.

* Mr. Salter, in his Angler's Guide, page 169, says he has canght very fine Smelts by angling in Portsmouth harbour; but there is very little doubt that the Sandsmelt, or Atherine, which is there abundant, is the fish alluded to. 
On the eastern side of our island, the Smelt occurs in the Tay, in the Frith of Forth, and in the Ure on the Yorkshire coast; it is taken in abundance in the Humber, on the Lincolnshire coast, in the Yare of Norfolk of large size, in the Thames, and in the Medway. On the western side, the Smelt is taken in the Solway Frith, especially in the Bay of Wigtown, and may be traced as far south as the parallel line which runs by the Mersey, the Dee, Conway, and Dublin Bay.

The Smelt is a common fish on the Parisian fish stalls, and is taken abundantly in the Seine, as high as Rouen. It is the Slom of the Swedes, the Slomme or Gern-lodde of the Norwegians, and the Smelt of the Danes. The Scottish name of Spirling is evidently either a corruption of the French Eperlan, or, at least, has a common origin with it. Caudebec on the Seine carries three Eperlans on its armorial shield, as an indication that its chief commercial importance depends on its Smelt fishery. It is the Spiring of the Dutch according to Artedi, and that name may perhaps have a similar origin with Spirling.

The Smelt inhabits fresh water from August to May. After spawning in March or the beginning of April, it returns to the sea. The ova are small and yellowish in colour. The fry are found about three inches long, swimming near the surface in shoals in the rivers in the month of August, ascending and descending with the tide, when the adult fish are again visiting the fresh water. Its food is small fish, with crustaceous and testaceous animals: Dr. Fleming says, the principal food of the Smelt in the Tay is the shrimp.

Two modes of fishing for Smelts are in practice; one on the sandy shallow shores of the sea, on the eastern coast, particularly Lincolnshire, where large quantities are taken in spring; the other is the river fishing within 
the tide-way. The excellence of the Smelts of the Medway is well known. The Thames and Medway fishing with small-meshed nets for Smelts is permitted, under the jurisdiction of the Lord Mayor of London, from the 28th of August (St. Augustine) till Good Friday. Formerly, the Thames from Wandsworth to Putney Bridge, and from thence upwards to the situation of the present suspension bridge at Hammersmith, produced abundance of Smelts, and from thirty to forty boats might then be seen working together; but very few are now to be taken, the state of the water, it is believed, preventing the fish advancing so high up. The strong cucumber-like smell of this fish is well known, and it is considerably more powerful when they are first taken out of the water.

The Smelt regularly ascends the river Wensum in Norfolk in the spring to spawn, and has a rendezvous in the pool at the New Mills in Norwich. It is there taken by a large casting net, and the Norwich "sinelters" are said to excel in the use of this particular net. This is a nocturnal occupation, and the earliest captures sell in the city at five or six shillings a score. It is curious that other fish desert for a time the spawning places of the Smelt, and remove further down the river until that operation is over.**

Mr. Thompson never met with it in Ireland.

The Smelt is generally in great request from its delicate and peculiar flavour. This quality, coupled with the circumstance of the fish passing six or seven months of the year in fresh water, has induced two or three experiments to retain it in ponds, one of which was attended with complete success, and the attempts might be multiplied with advantage. Colonel Meynell, of Yarm in Yorkshire, kept Smelts for four years in a fresh-water pond

\footnotetext{
* Rev. Richard Lubbock, Fauna of Norfolk. 1845.
} 
having no communication with the sea: they continued to thrive, and propagated abundantly. They were not affected by the water freezing; as the whole pond, which covered about three acres, was so frozen over as to admit of skating. When the pond was drawn, the fishermen of the Tees considered that they had never seen a finer lot of Smelts. There was no loss of flavour or quality.

From the point of the lower jaw to the end of the gill-cover, the length, as compared to the body alone, is as one to three; the depth of the body does not equal the length of the head: the dorsal fin commences half-way between the point of the nose and the end of the fleshy portion of the tail; the first ray of this fin has less than half the length of the second, which is as long as the third; the second and third are the longest rays in the fin, and are nearly as high as the body of the fish is deep, and as long again as the base of the fin; the two first rays are simple, all the others branched; the anterior edge of the adipose fin is half-way between the base of the last ray of the dorsal fin and the end of the fleshy portion of the tail, and stands in a vertical line over the middle of the anal fin; pectoral fins long and narrow; the ventral fins commence on the same plane as the dorsal fin; the base of the anal fin is long, commencing half-way between the origin of the ventral fins and the end of the fleshy portion of the tail ; the third ray the longest, but not so long as the base of the fin; the other rays diminish in length gradually: the tail slender and deeply forked. The fin-rays are-

\section{D. $11:$ P. 11: V. $8:$ A. $15:$ C. 19.}

The lower jaw much longer than the upper; the gape deeper than wide : the teeth long, and curving inwards; those on the anterior parts of the tongue and palatine bones being the longest: the breadth of the eye 
about one-fifth of the whole length of the head, the irides silvery white; the gill-cover triangular; the upper part of the head flat; the nape and back rising; the form of the body elongated and slender; the dorsal and abdominal lines slightly convex: the colour of the upper part of the body pale ash-green; all the lower parts, cheeks, and gill-covers, brilliant silvery white: the scales oval, small, and deciduous: all the fins pale yellowish white: the ends of the caudal rays tipped with black.

The specimen described measured seven inches in length. Occasionally Smelts may be seen in the London markets ten and eleven inches long, but this is an unusually large size. Pennant mentions having seen one that was thirteen inches long, and weighed eight ounces.

M. Valenciennes describes and figures an Osmerus microdon from the coast of Norway, which he thinks may be identical with the fish indicated by Daines Barrington in Pennant's British Zoology, as differing from the common Smelt in the smallness of its teeth. He also describes a third species, the Osmerus spirinchus of Pallas, which inhabits the Harlem meer, and also some of the waters of Prussia. It is figured by Bloch, pl. 28, f. 1, and is the species called Nors by the Swedes, and Sildlodde by the Norwegians. It is common in Livonia, and Mr. Lloyd states that the Smelt inhabits Lake Wenern in Sweden.

Sir Robert Sibbald, in his Scotia Illustrata, applies the trivial name of Spurling to what he calls Apua vera. Apua or Aphya were names that used to be given to a Goby. 


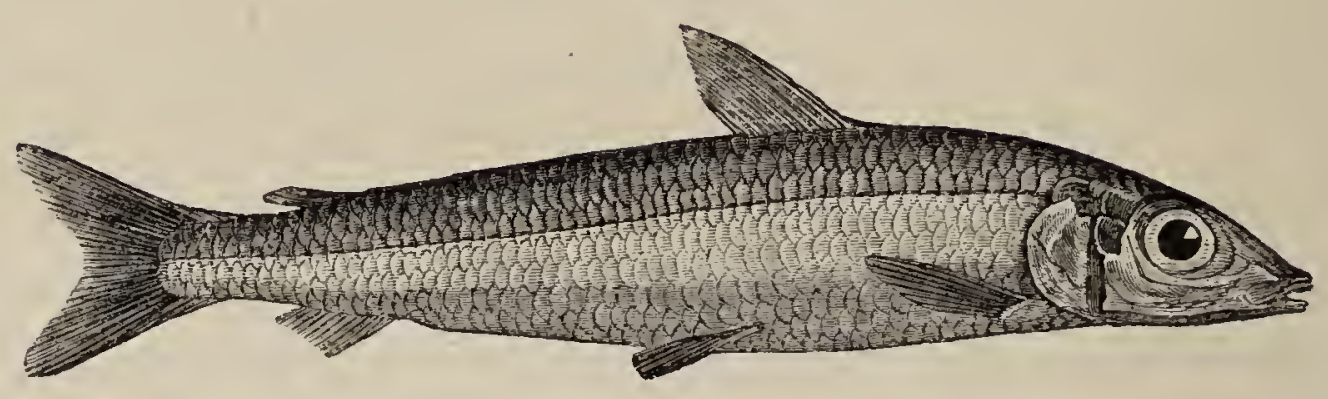

\section{THE HEBRIDAL ARGENTINE.}

Argentina Hebridica. (Yarellii.) Valenc. Hist. des Poiss. xxi. 418. Osmerus Hebridicus, Hebridal Smelt, Yarredr, Suppl. to Brit. Fish. 2 ed. ii. p. 133.

Argentina. Generic Characters.- Upper border of the mouth formed by very short premaxillaries, with the maxillaries extending along its sides: mouth small, without teeth on the jaws; a crescentic band of villiform teeth on the front of the vomer, with a narrow dental stripe prolonged from the horns of the crescent along the edges of the palatines; lingual teeth varying in different species. Gill-openings large, six branchiostegals. Stomach moderately large, with a cæcal elongation: numerous short pyloric cæca: intestine straight. Air-bladder having a thick nacry coat, which is used in the manufacture of artificial pearls; but having no pneumatic tube leading to the alimentary canal : in this the genus departs from the general cha: racter of the family and order. Eggs falling into the cavity of the abdomen as in other Salmonidce. Lining of the abdominal cavity black, or blackishbrown, inclining to chocolate colour.

I AM indebted to Mr. William Euing of Glasgow for the opportunity of making known this hitherto undescribed fish, which that gentleman did me the kindness to send to me in the month of November 1837. It is at once clearly distinguishable from our long known and highly-esteemed favourite, the common Smelt, by the generic characters above given. Mr. Euing passed part of the summer of 1837 near Rothsay in the Isle of Bute; and the Smelt in question was brought to him by a fish- 
erman, who stated that he caught it on a hand-line in the bay of Rothsay, about two hundred yards from the shore, in twelve fathom water; and that it was, though well known, but rarely seen. This specimen ineasured six inches and a half; but another example of the same sort, measuring eight inches in length, that was taken near the same place in June 1836, was full of roe, and when first caught the cucumber-like smell, so strong in the Smelt, was in this Argentine also very apparent.

The Paris Museum possesses two specimens of this fish, presented to it by Professor Nilsson of Stockholm; and Mr. J. S. Rudd obtained another British specimen at Redcar in May 1852.

The proper genus of this fish has been pointed out by M. Valenciennes in the Histoire des Poissons. In the former editions of the British Fishes it was included with the true Smelt in the genus Osmerus, but the position of the dorsal before the ventrals will at once distinguish it, exclusive of the characters derived from the mouth, dentition, and shut air-bladder. Another species of Argentina, the silus of Risberg, remarkable for its extraordinarily large eye, frequents the Norwegian coast, where the Bergen fishermen name it Sil, or Val-sil. It is also called Blankesten and Gullax. The Argentina Cuvieri of the Mediterranean has not been detected in the northern seas. The genus Argentina is widely different from the supposed Argentine of Pennant, which is a Scopelus, and belongs to the family of Scopelida.

The specimen sent me by Mr. Euing, measuring six inches and a half in length, is one inch and one-eighth deep at the commencement of the dorsal fin, at which part the body is deepest; the thickness of the body compared to the depth is as one to two, or exactly half: the length of the head is one inch and three-eighths, and is, 
in reference to the whole length of the head and body, without the tail, as one to four. The jaws are nearly equal in length without teeth upon either; but there are four long teeth upon the tongue; the eye is very large, the diameter almost equal to one-third of the whole length of the head, and placed at a distance of little more than its own diameter from the point of the nose: the upper surface of the head is flattened, descending by a rapid slope to the nose; the line of the lower jaw straight; the posterior edge of the operculum rounded; the back of the fish, or its dorsal outline, slightly arched; the abdominal line nearly straight; the sides compressed. The dorsal fin commences half-way between the point of the nose and the anterior edge of the adipose or rayless dorsal fin, the longest ray nearly twice the length of the base of the fin; the last dorsal fin-ray but three has the same length as the base of the fin. The adipose fin is placed very near the tail; the tail itself is deeply forked. The pectoral fin reaches to the plane of the commencement of the dorsal, and its length, if turned forwards, would reach to the centre of the eye. The ventral fin is in a vertical line under the last ray of the dorsal fin; there is a slender axillary scale; but the ends of the ventral fin-rays being injured, the length of the fin cannot be mentioned. The anal fin has its last ray underneath the posterior edge of the adipose fin; but the rays of the anal fin are also broken. The formula of the fin-rays is as follows :-

D. $11:$ P. $14:$ V. $12:$ A. $12:$ C. 19.

The scales are large and deciduous, the lateral line prominent and nearly straight. Below the lateral line for the whole length of the body two rows of the scales are silvery white, forming a conspicuous elongated band; 
the rest of the body and fins dull amber colour, the gillcovers silvery and iridescent.

The vignette below represents a fishing cottage on the Inny, in Cornwall, the property of Georgiana, Duchess of Bedford.

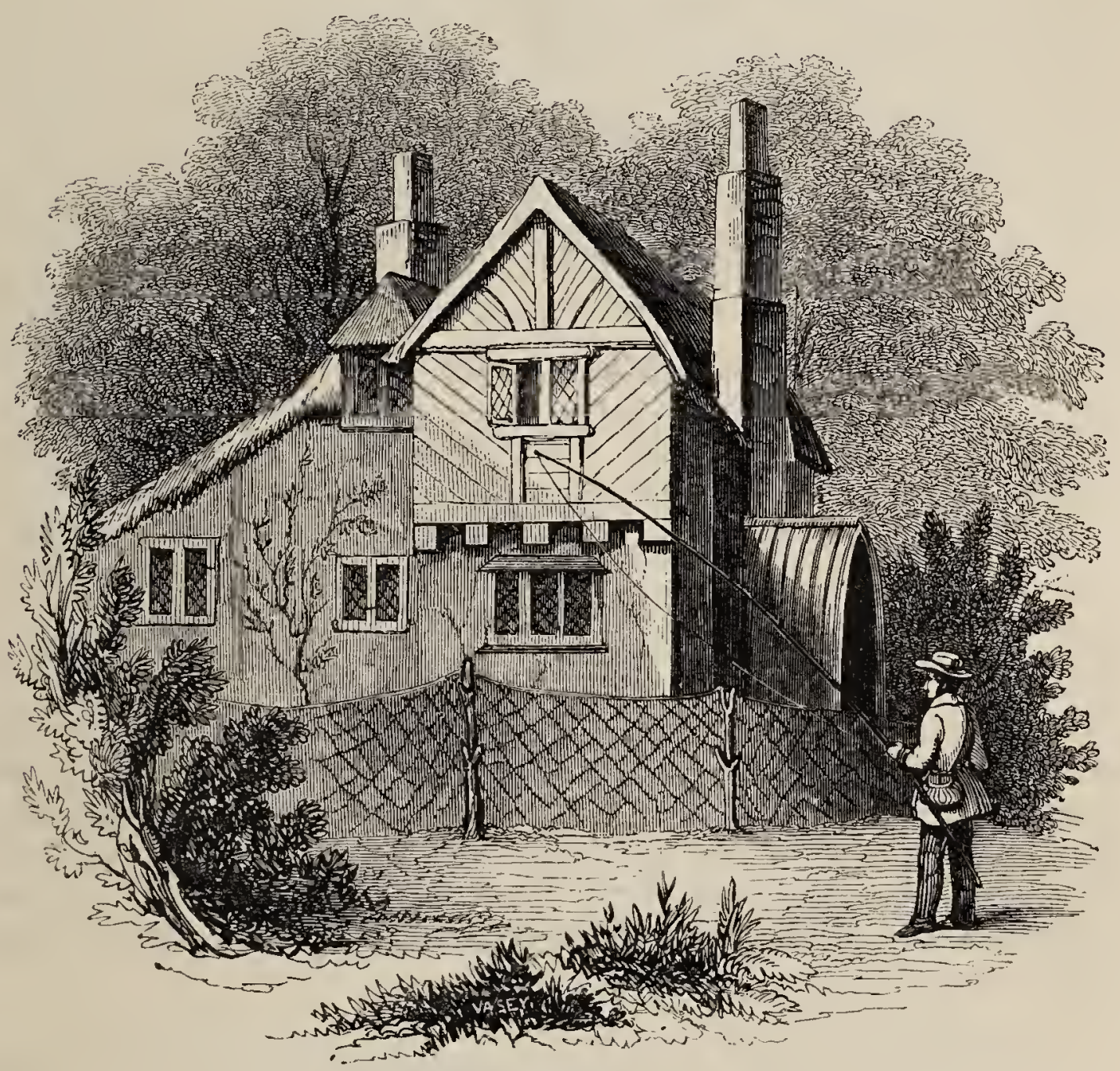


ABDOMINALES

MALACOPTERYGII.

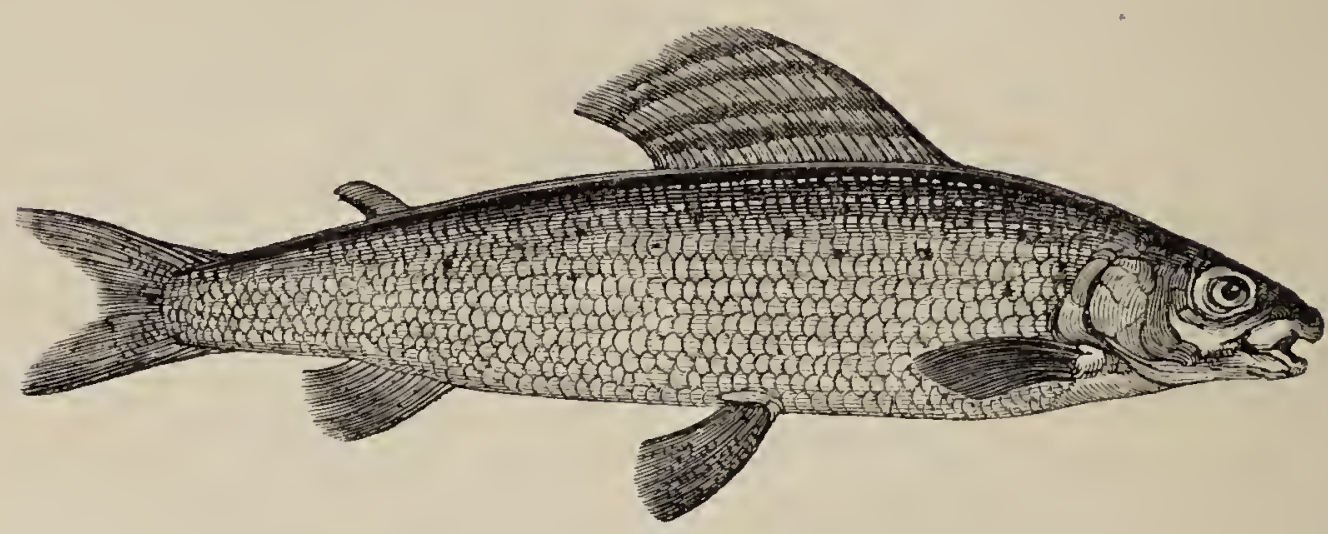

\section{THE GRAYLING.}

Thymallus vulgaris, Cuvier, Règne Àn. t. ii. p. 306.

,, vexillifer, AGass., Cuv. et Vameno. xxi. p. 438.

",$\quad$ Willugaghis, p. 187, N. 8.

Salmo thymallus, Linneus. Bloch, pt. i. pl. 24.

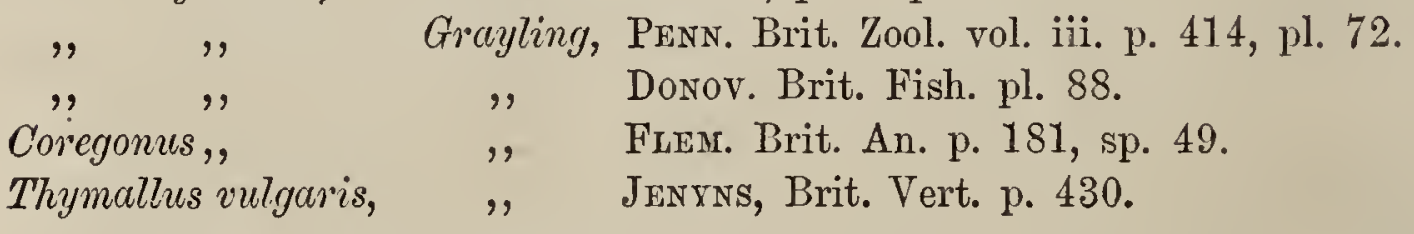

Thymaluus. Generic Characters. - Mouth small; teeth small, conical, uniserial on the jaws, front of the vomer, and fore-part of the palatines. Intestinal tube like that of the Trouts. Air-bladder large, communicating with the œsophagus by a very small tube. Scales extending further down the lobes than on the central rays of the caudal, being forked in their distribution, instead of showing the squarish termination of Salmo, Fario, Salar, \&c.

The Grayling, though abundant in some streams, is yet a very local fish. Similar in many respects to the Trout in its habits and wants, there are numbers of rivers abounding with Trout that do not produce Grayling. In the southern counties of Hampshire and Wiltshire, the Grayling is found in the Test and both the Avons. In 
Herefordshire, in the Dove, the Lug, the Wye, and the Irvon. In Shropshire, in the Teme and the Clun. In Staffordshire, in the Hodder, the Trent, the Dove, and the Wye. In Derbyshire, in the Dove. In Merionethshire, in the Dee, between Curlen and Bala. In Lancashire, in the Ribble. In Yorkshire, in the Derwent, the Ure, the Wharfe, and the Wiske, near Northallerton. Dr. Heysham says it is occasionally taken in the Eden and the Esk in Cumberland. It is not found, that I am aware, either in Ireland or Scotland; Mr. Low, however, includes this fish in his Fauna Orcadensis, and it is known to be plentiful in Sweden, Norway, and Lapland. The peculiarity of the local distribution in this country gave rise to the supposition that the Grayling had been originally introduced by the monks, as a fish worth cultivating; many of the rivers containing the Grayling being near the remains of great monasteries. But two circumstances affect this solution: it would be very difficult to bring this fish alive from the Continent to this country; and it is not found in the rivers of Kent, Dorsetshire, Devonshire, or Cornwall, where monastic establishments were formerly numerous : nor according to Mr. Thompson does it exist in Ireland.

The Grayling thrives best in rivers with rocky or gravelly bottoms, and seems to require an alternation of stream and pool. According to Sir Humphry Davy, who has given a good history of the Grayling in his Salmonia, this fish was introduced into the Test, in Hampshire, from the Avon; and the former river, in particular parts, appears to suit it the better of the two. Large Grayling are, however, occasionally taken in both these waters, which are constantly resorted to by the southern anglers. Three Graylings, weighing together twelve pounds, were caught by Thomas Lister Parker, VOL. I. 
Esq., in the Avon, near Ringwood. A Grayling of four and a half pounds' weight has been killed in the Test, and one of five pounds is recorded to have been caught near Shrewsbury.

However fastidious in the quality of the water, or the choice of situation in the stream, the Grayling is known to be, experiment has proved that this fish will live in ponds that have been newly made in hard soil, or in such as have been very recently and carefully cleaned out; but in these situations the Grayling does not breed, and it dies off in old muddy ponds. The ova of this fish are numerous, large, and of a deep orange colour; the spawning season is in April or the beginning of May; differing in time from that of the other Salmonide, most, if not all, of which spawn towards the end of the year, and generally in cold weather. The Grayling, however, is in the finest condition in October and November, when Trout are out of season, not having then recovered the effects of their recent spawning.

The food of the Grayling, besides the various fliesimitations of which are successfully used by anglersconsists also of the larvæ of Phryganea, Ephemere, and Libellula; the remains of the cases of the former, and the tough skins of all of them, being frequently found in their stomachs. I have found also several small shells, examples of the genus Physa, and of Neritina fluviatilis; together with dead shells and small pebbles; but whether these last are taken up by the fish to serve any useful purpose, as by gallinaceous birds, or have only formed part of the cases of the Phryganea, may be questioned.

Some English authors have considered the Grayling to be a migratory fish, passing the winter in the sea, and the summer in fresh water. "Early in spring," says Mr. Donovan, "they ascend the rivers, where they remain 
till autumn, and then return to their former element." This may apply to Grayling on some parts of the European continent, $*$ but is not the case certainly with our fish in this country, in the rivers of which it is found in the most perfect condition, and in consequence most eagerly sought after, in October and November. The finest specimens I ever saw were taken in November; and Sir H. Davy states in his Salmonia, that he had proved the Grayling of England could not bear even a brackish water without dying.

The term Thymallus is said to have been bestowed upon this fish on account of the peculiar odour it emits when fresh from the water, which is said to resemble that of thyme; and from its agreeable colour and smell, St. Ambrose is recorded to have called the Grayling the flower of fishes. To be eaten in perfection, it cannot be dressed too soon. The name Grayling is supposed to be a modification of the words gray-lines, in reference to the dusty longitudinal bars along the body.

It has been thought that the large dorsal fin of the Grayling enabled it to rise and sink rapidly in deep pools; but this power would rather seem to be afforded by the large size of the swimming-bladder. The very large dorsal fin, compared to the small size of all the other fins, renders the Grayling unable to stem rapid currents; it is much more prone to go down stream than up, and is never seen leaping at a fall, like the Trout.

In a Grayling of ten inches long, the length of the head is to the body alone as one to four; the depth of the body rather more than equal to the length of the head: from the point of the nose to the commencement of the dorsal fin is equal to one-third of the length of the whole fish to the end of the fleshy portion of the tail; the pos-

* Bloch says the Grayling descends to the Baltic in autumn. 
terior edge of the dorsal fin is half-way between the point of the nose and the end of the longest caudal rays; the adipose fin stands rather nearer the dorsal fin than to the end of the tail: the height of the dorsal fin equals half the height of the body, the first ray short, the next five increasing gradually in length; the sixth ray nearly as long as the seventh, and, as well as the five anterior rays, articulated and simple; the seventh ray and all the rays behind it articulated, branched, and nearly of the same height; the length of the base of the fin not equal to twice the length of its longest ray: the pectoral fin small, narrow, and pointed: the ventral fins commence directly under the middle of the dorsal fin and the ventral axillary scale equals one-fourth of the length of the fin: the anal fin commences half-way between the origin of the ventral fin and the end of the fleshy portion of the tail, and ends on a line with the adipose fin; the longest ray is but little longer than the base of the fin: the tail forked; its middle rays being rather more than half as long as the longest. The fin-rays in number are-

\section{D. $20:$ P. $15:$ V. $10:$ A. $13:$ C. 20 . Vertebræ 58.}

The head is small and pointed, flattened at the top: the breadth of the eye equal to one-fourth of the length of the whole head; irides golden yellow, pupil blue, pearshaped, the apex directed forward: the opening of the mouth, when viewed in front, square; the teeth small, incurved, numerous; none on the tongue, and only a few on the most anterior part of the vomer and adjoining ends of the palatines; behind the head, the nape and back rise suddenly: the body is deepest at the commencement of the dorsal fin, then tapers off to the tail; abdominal profile but slightly convex; the scales rather large; the lateral line in the middle of the body not very con- 
spicuous, with seven rows of scales on an oblique line above it, and seven rows below it; the sides marked with about fifteen dusky longitudinal bands. The general colour of the body light yellow brown, beautifully varied with golden, copper, green, and blue reflections when viewed in different lights, with a few decided dark spots: the head brown; on the cheeks and gill-covers a tinge of blue: all the fins somewhat darker than the colour of the body; the dorsal fin varied with square dusky spots on the membrane between the rays, the upper part of the fin spotted and streaked with reddish brown. The Grayling appears to become darker by age, and the pectoral fins are reddish about spawning time, with small black spots.

Switzerland also produces Grayling; I have therefore selected for the vignette a view of Mont Blanc.

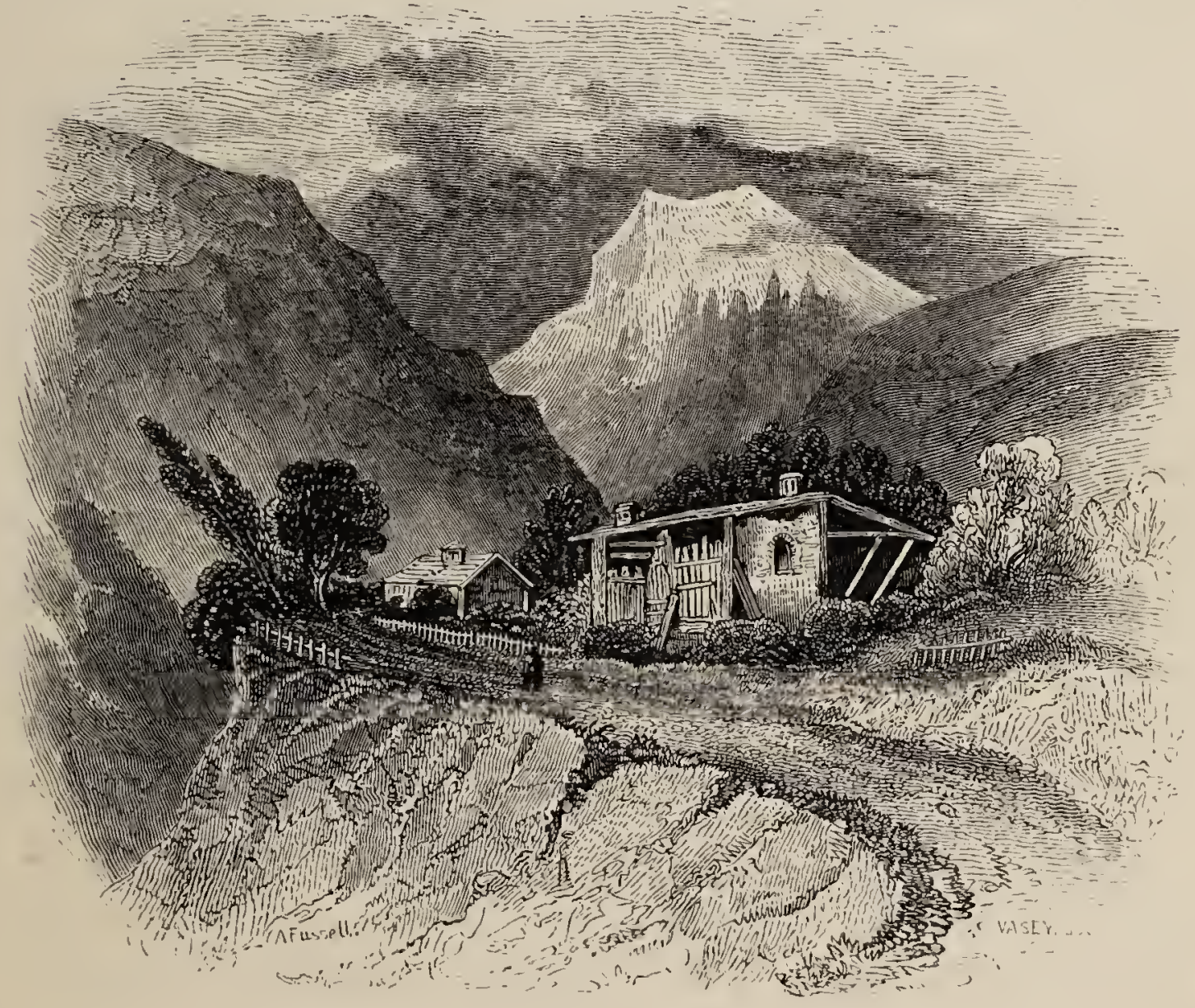


A BDOMINALES

MALACOPTERYGII.

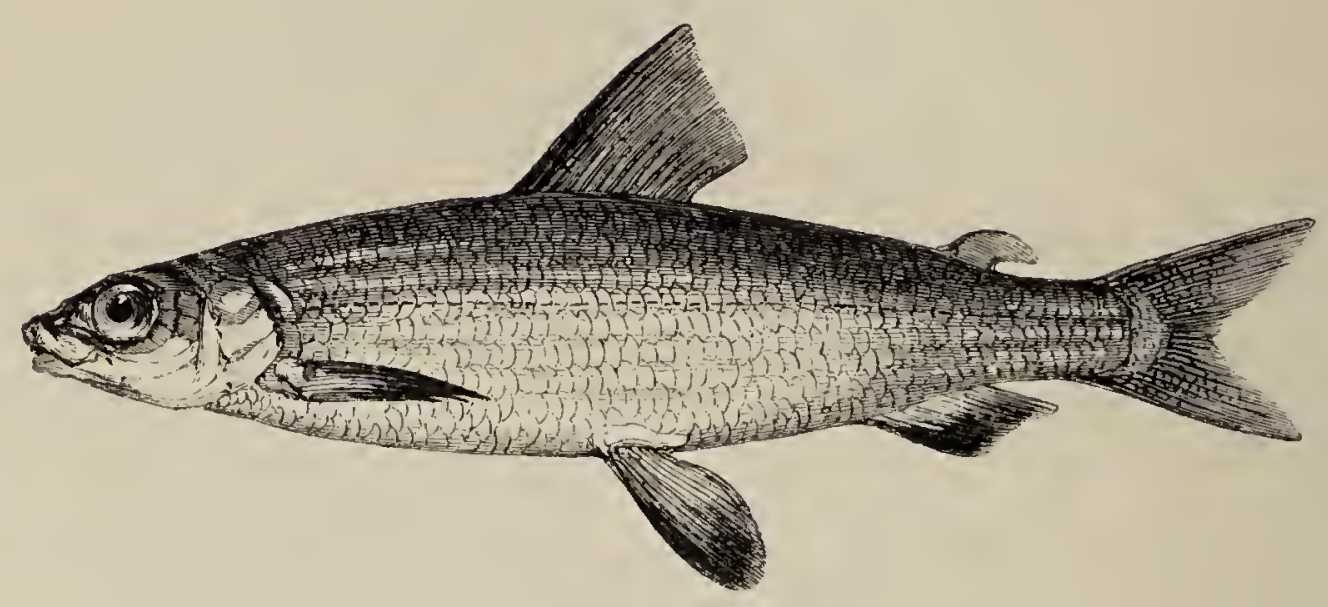

THE GWYNIAD.

sCHELly. Ullswater.

Coregonus Pennanti, Valenc. Hist. des Poiss. xxi. p. 507.

Salmo lavaretus, Groyniad, Penn. Brit. Zool. vol. iii. p. 419, pl. 73.

Coregonus ,, ,, Flem. Brit. An. p. 182, sp. 50.

", , " Jenyis, Brit. Vert. p. 431.

Coregonus. Generic Characters. - Premaxillaries lying across the front of the mouth, thin and varying in depth in different species; maxillaries on the sides of the mouth, generally oval. Teeth small or wholly absent. Dorsal fin commencing before the ventrals. General aspect, that of a herring; but distinguished by the adipose fin, and the absence of ventral serratures.

The species of the gellus Coregonus are numerous in Europe, and several of them are so similar to each other, that, without the power of comparing those of this country with foreign specimens, an appropriation of synonymes is at least doubtful. Some authors have even considered the Vendace of Lochmaben as the same with the Powan of Perthshire, the Schelly of Ullswater, the Gwyniad of Wales, and the Pollan of Ireland: but it will be found that this is not the case; and, from recent observation, there is good reason to believe that the 
Pollan of Ireland is distinct from the two species of Coregonus found in Great Britain.

The Gwyniad of Wales was formerly very numerous in Llyn Tegid (Fair Lake), of Bala, until the year 1803, when Pike were put into the Lake, which have very much reduced their numbers. Pennant considered the Gwyniad as the same with the C. fera of the Lake of Geneva, following in this the opinion of Willughby; and in the manuscript notes of a fishing tour in Wales, by two excellent fishermen, who had also pursued their amusement abroad, an opinion is given to the same effect; but all these authorities were in error, as M. Valenciennes has shown. Neither is it the Lavaret of Switzerland.

The Gwyniad is very numerous in Ullswater and other large lakes of Cumberland, where, on account of its large scales, it is called the Schelly. It occurs also abundantly in the neighbouring lake of Haweswater, and is probably the Coregonus, which is known to inhabit the Red Tarn,'a small piece of water near the summit of Helvellyn, and elevated more than 2600 feet above the sea. We have failed in procuring a specimen of this Alpine fish, so as to verify the conjecture of its identity with the Ullswater fish, but as the Tarn discharges its waters into the lake we think that they will prove to be the same. Dr. Heysham, the natural historian of Cumberland, and Pennant also, in his British Zoology, have recorded that many hundreds are sometimes taken at a single draught of the net. They are gregarious, and approach the shore in vast shoals in spring and summer. Pennant says, they die very soon after they are taken out of the water, are insipid in taste, and must be eaten soon, for they will not keep long. The poorer classes, who consider and even call them the Fresh-water Herring, preserve them with 
salt. The fish is not unlike a Herring in appearance, and the Welsh term Gwyniad has reference to their silvery white colour. They spawn towards the end of the year, and the most usual length of the adult fish is from ten to twelve inches.

The length of the head is about one-fifth of the whole length of the fish, the depth of the body rather exceeding the length of the head: the dorsal fin commences about half-way between the point of the nose and the end of the fleshy portion of the tail; its longest ray is onethird longer than the base of the fin, and is equal to threefourths of the depth of the body: the adipose fin is rather nearer to the end of the tail than to the posterior edge of the dorsal fin; the pectoral fins, narrow, pointed, and a little shorter than the head, are inserted low down on the body: the ventral fins are attached under the middle of the dorsal fin, and the ventral axillary scale equals onethird the length of the fin: the anal fin commences halfway between the origin of the ventral fin and the end of the short middle rays of the tail, and ends on a line with the adipose fin ; the longest anterior ray about equals the length of the base of the fin; the other rays diminish gradually: the tail is forked. The fin-rays in number are-

\section{D. $13:$ P. $17:$ V. $11:$ A. $16:$ C. 19 . Vertebræ 58.}

The head is triangular; the snout rather truncated; the jaws nearly equal, the lower just shutting within the upper; a very few minute teeth on the tongue and jaws: the eyes large, the breadth more than one-fourth of the length of the head; the form of the body very like that of a Herring; the dorsal and abdominal profiles but moderately convex; the scales large ; the lateral line very near the middle of the side. The irides silvery, the pupils dark blue; the upper part of the head and back dusky 
blue, becoming lighter down the sides, with a tinge of yellow; cheeks, gill-covers, lower part of the sides and belly silvery white; all the fins more or less tinged with dusky blue, particularly towards the edges.

According to Mr. Thompson of Belfast, the Pollan, or Lough Neagh Coregonus, differs from the Gwyniad of Bala in the following particulars: in the snout not being produced; in the dorsal fin being nearer the head; in having fewer rays in the anal fin, and in its position being rather more distant from the tail; in the dorsal, anal, and caudal fins being of less dimensions; in the third ray of the pectoral fin being the longest, the first being of the greatest length in the Gwyniad, and in the ventral axillary scale being longer.

In September 1840, the Earl of Lonsdale's fisherman took 800 Schellies, besides Perch and other fish, at a single sweep of the net in Hawes-water.

The vignette represents the bones of the head in the genus Coregonus.

* Reports of Proceedings of the Zoological Society of London for 1835, p. 77.

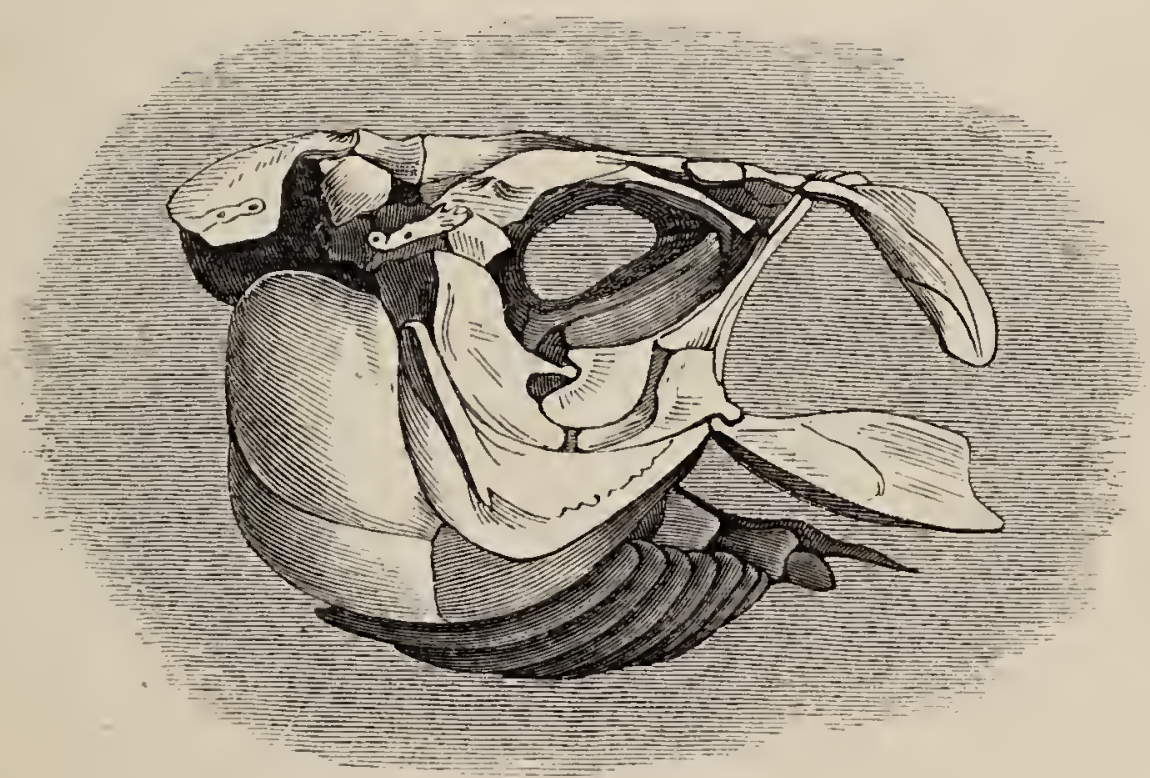




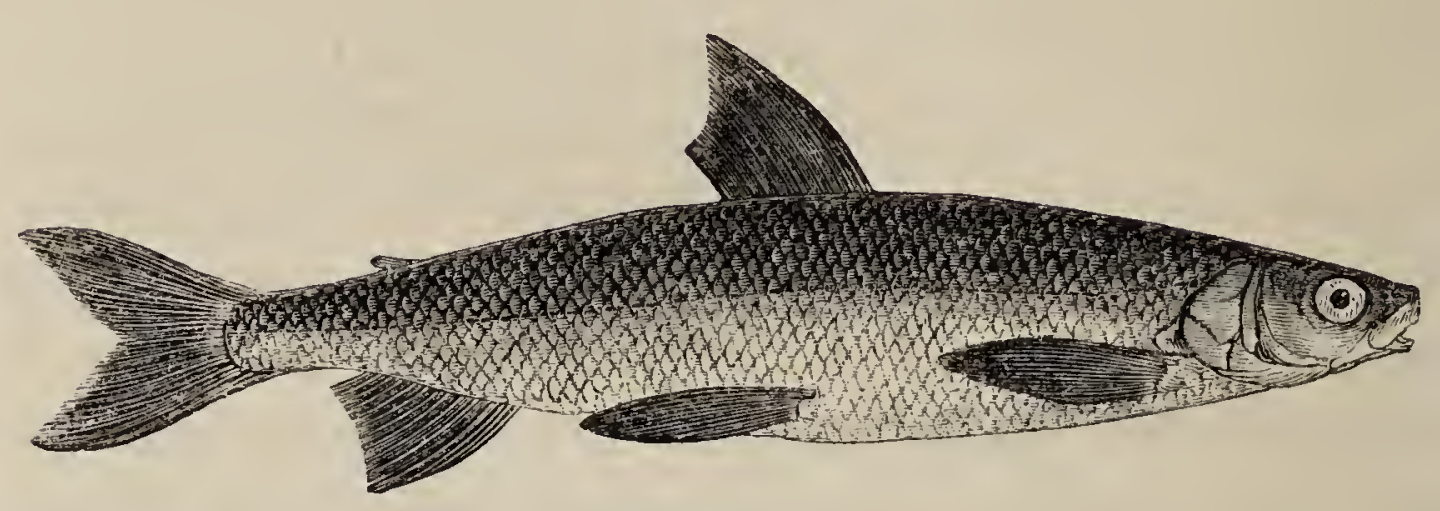

THE POWAN.

Coregonus Cepedei, The Powan, Parneld, An. Nat. Hist. vol. i. p. 161.

", clupeoides, The Herring-like Coregonus, Lacepede, Hist. Nat. des Poiss. 8vo edit. tom. x. p. 386 .

Dr. Parnell, whose Ichthyological investigations in Scotland have not been confined to the Fishes of the Forth only, has described in the first volume of the Annals of Natural History a species of Coregonus, to which he has attached the name of Lacépède; this species having been first described by this celebrated French naturalist. This fish is found in Loch Lomond, one of the largest and most picturesque lakes in the west of Scotland, and thither M. Noël de la Morinière, in August 1802, went to see it, having heard that freshwater Herrings abounded in the lake. By him specimens were communicated to Lacépède. The Latin specific name of clupeoides used by the latter having been previously employed by Pallas to designate a different fish, must give place to Dr. Parnell's newer name. It is not unlikely that some of the species of Coregoni found in. the northern lakes of England, Scotland, and Ireland, may exist in the lakes of Scandinavia; M. Nilsson, Pro- 
fessor of Natural History at Lund, describing in his Prodromus Ichthyologia Scandinavica no less than eight species as belonging to that country: but from a certain general agreement in the characters of the Coregoni, it is difficult to refer our species with certainty in the absence of foreign specimens with which to make actual comparison; and M. Valenciennes, who has had a larger number of European Coregoni in his hands than any other ichthyologist, thinks that the Powan is not a continental species.

In the posthumous edition of Thompson's Irish Fauna, a small Coregonus, locally named Cunn, is mentioned as having been taken at Killaloe, which Mr. Thompson thought might be the clupeoides of Nilsson; whether it be the same with the Powan of Loch Lomond can be decided only by a comparison of specimens, which has not yet been made. The latter is thus described by Dr. Parnell, from a specimen fourteen inches in length :-

"Head long and narrow, of an oval form, about onefifth the length of the whole fish, caudal fin included; depth of the body between the dorsal and ventral fins less than the length of the head. Colour of the back and sides dusky blue, with the margin of each scale well defined by a number of minute dark specks; belly dirty white; the lower portion of the dorsal, pectoral, ventral, and anal fins dark bluish grey; irides silvery, pupils blue. First ray of the dorsal fin commencing half-way between the point of the snout and the base of the short lateral caudal rays; the first ray simple, the rest branched; the second and third the longest, equalling the length of the pectorals; the seventh ray as long as the base of the fin; the last ray one-third the length of the fourth; adipose fin large and thin, situate midway between the base of the fourth dorsal fin-ray and the tip of the long 
upper ray of the caudal fin; anal fin commencing halfway between the origin of the ventral fin and the base of the middle caudal ray; the first ray simple, the rest branched; the second rather the longest; the third as long as the base of the fin; the last ray half the length of the fifth; ventral fins commencing under the middle of the dorsal; the third ray the longest, equalling the length of the same ray of the dorsal; pectorals Jong and pointed, one-sixth the length of the whole fish, caudal fin included; the first ray simple; the second and third the longest, the last short, not one-fourth the length of the first; tail deeply forked, with the long rays of the: upper portion curving slightly downwards, giving the fin a peculiar form. Gill-cover produced behind; the basal line of union between the operculum and suboperculum oblique; the free margin of the latter slightly rounded; preoperculum angular; snout prominent, somewhat of a conical form, extending beyond the upper lip; jaws of unequal length, the lower one the shortest. The maxillary bone broad, the free extremity extending back to beneath the anterior margin of the orbit. Teeth in the upper jaw long and slender, about six in number; those on the tongue shorter and more numerous. Eyes large, extending below the middle of the cheeks; lateral line commencing at the upper part of the operculum, and rumning down the middle of the sides to the base of the middle caudal ray. Scales large and deciduous, eighty-four. forming the lateral line, eight between the dorsal fin and. lateral line, and the same number between the lateral line and the base of the ventrals." The numbers of the fin-rays, including the two short rays at the commencement of the dorsal and anal fins, are
D. 14: P. 16: V. 12: A. 13: C. 20. Cæca 120.

"This fish grows occasionally to the length of sixtecn 
inches. In the stomach of one of the specimens examined were found several species of Entomostraca, larvæ of insects, a few Coleoptera, a number of small tough red worms, little more than half an inch in length, and about the thickness of a coarse thread, besides a quantity of gravel, which the fish had probably accumulated when in search of the larvæ.

"These fish are found in Loch Lomond in great numbers, where they are called Powans or Freshwater Herrings. They are caught from the month of March until September with large drag-nets, and occasional instances have occurred in which a few have been taken with a small artificial fly: a Minnow or bait they have never been known to touch. Early in the morning and late in the evening large shoals of them are observed approaching the shores in search of food, and rippling the surface of the water with their fins as they proceed. In this respect they resemble in their habits the Vendace of Lochmaben and the saltwater Herring. They are never seen under any circumstances in the middle of the day. From the estimation these fish are held in by the neighbouring inhabitants, they are seldom sent far before they meet with a ready sale, and are entirely unknown in the markets of Glasgow. In the months of August and September they are in best condition for the table, when they are considered well-flavoured, wholesome and delicate food. They shed their spawn in October to December, and remain out of condition until March."-Thompson.

Although agreeing in the number of fin-rays with the Pollan of Ireland, this Loch Lomond fish is at once distinguished from it by the peculiar form of its mouth, a representation of which, in two points of view, inserted as a vignette, and contrasted with the same parts in the Pollan, both of the natural size, will, better than descrip- 
tion, convey the appearance in proof of distinction; the Loch Lomond fish being remarkable for the depth of the upper lip, and the large size of the lateral free portions of the superior maxillary bones.

Dr. Parnell has described a second species of Coregonus found in Loch Lomond, which differs from the first in having a smaller head, yet agreeing exactly in the number of all the fin-rays; but as I learn by communication with Dr. Parnell that since the publication of his paper he has obtained many specimens from Loch Lomond, the characters of which are intermediate in reference to the two fishes described, and appear to connect them, I have not figured it as a distinct species.

Powan.
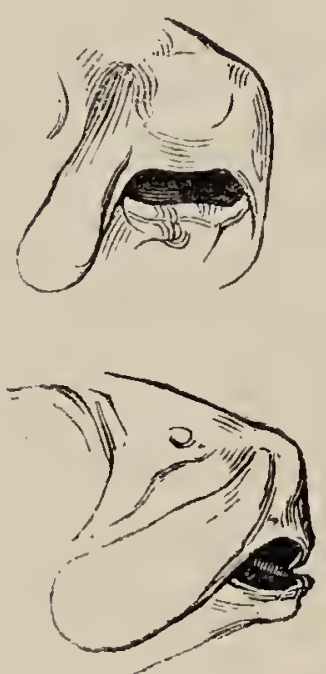

Polilan.
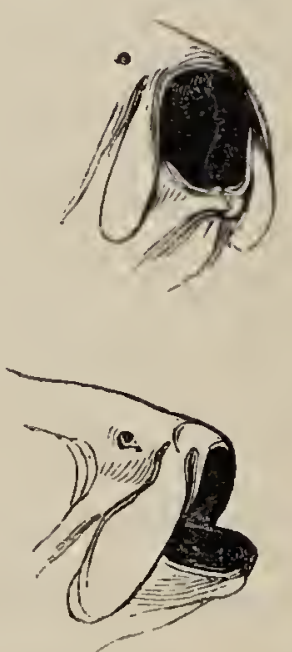


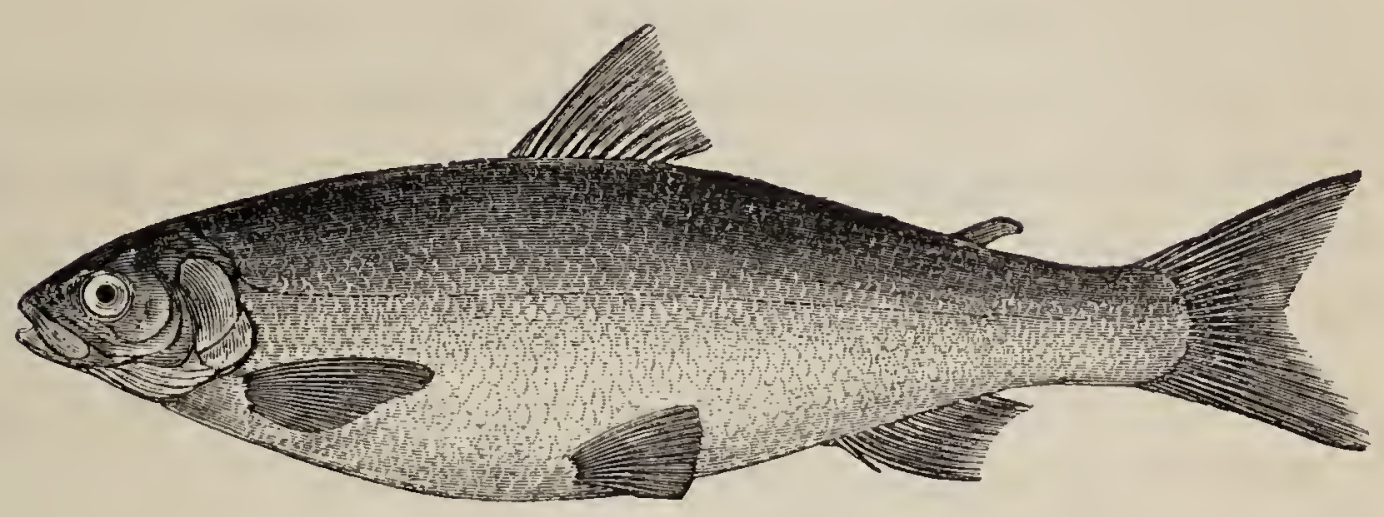

THE POLLAN.

Coregonus Pollan, The Pollan, Thompson, Proceedings Zool. Soc. for 1335, p. 77 ; and Magazine of Zool. and Bot. vol. i. p. 247. Valenciennes, Hist. des Poiss. xxi. 502.

A short notice of the Pollan of Ireland, as made known by Mr. Thompson of Belfast in 1835, was inserted in the History of British Fishes, 1st ed. vol. ii. p. 88; and that gentleman having most zealously followed up his zoological investigations in that country, I am now enabled to add from his researches various further particulars.

"The earliest notice of the species that I have seen," says Mr. Thompson, "is in Harris's History of the County of Down, published in the year 1744, into which, as well as into the statistical surveys of the counties of Armagh and Antrim, it has been introduced as one of the fishes of Lough Neagh, under the name of Pollan: but, as may be expected in works of this nature, little more than its mere existence is mentioned."

"The habits of this fish do not, with the exception of 
its having been in some instances taken with the artificial fly, differ in any marked respect from those of the Vendace of Scotland or the Gwyniad of Wales, and are in accordance with such species of Continental Europe as are confined to inland waters, and of whose history we have been so fully informed by Bloch. The Pollan approaches the shore in large shoals, not only during spring and summer, but when the autumn is far advanced. The usual time of fishing for it is in the afternoon, the boats returning the same evening. On the days of the $23 \mathrm{rd}$, 24th, and 25th of September 1834, which I spent in visiting the fishing stations at Lough Neagh, it was, along with the Common and Great Lake Trout, Salmo fario and Salmo ferox, caught plentifully in sweep-nets, cast at a very short distance from the shore. About a fortnight before this time, or in the first week in September, the greatest take of the Pollan ever recollected occurred at the bar-mouth, where the river Six-mile-water enters the lake. At either three or four draughts of the net, one hundred and forty hundreds,-one hundred and twentythree fish to the hundred,*-or 17,220 fish were taken; at one draught more were captured than the boat could with safety hold, and they had consequently to be emptied on the neighbouring pier. They altogether filled five one-horse carts, and were sold on the spot at the rate of 3s. 4d. a hundred, producing 23l. 6s. 8d. From 3s. $4 d$. to $4 s$. a hundred has been the ordinary price at the lake side, or directly from the fishermen; some years ago it was so low as $1 s$. $8 d$. the hundred, but at that time the regular system of carriage to a distance, as now adopted, did not exist. At the former rates they are purchased by carriers, who convey them for sale to the more populous parts of the neighbour-

\footnotetext{
* The English long hundred is six score, or one hundred and twenty.
} 
ing country, and to the towns within a limited distance of the lake. They are brought in quantities to Belfast; and when the supply is good, the cry of 'fresh Pollan' prevails even to a greater extent than that of 'fresh Herring,' though both fishes are in season at the same period of the year. In the month of June 1834, fifty hundreds - six thousand one hundred and fifty individuals-of Pollan, and one hundred and twenty-five pounds' weight of Trout, were taken at one draught of a net, at another part of the lake near Ram's Island, which was the most successful capture made there for twenty-four years. In 1834 this fish was more abundant than ever before known. Like the Giwyniad and Vendace, the Pollan dies very soon after being taken from the water, and likewise keeps for a very short time. It is not in general estimation for the table, but is, I think, a very good and well-flavoured fish."

"Though permanently resident, the Pollan is very far from being generally diffused throughout Lough Neagh. It rarely occurs between the river Mayola and Toone; while from the Six-mile-water to Shane's Castle is so favourite a resort, that a few houses that formerly stood near the latter locality, were dignified with the name of Pollan's Town."

"In the months of November and December, this fish deposits its spawn where the lake presents a hard or rocky bottom. On the 4th of December 1835, a quantity of the largest Pollans I have seen were brought to Belfast market. Several were thirteen inches in length, and all on dissection proved to be females just ready to deposit their roe. On the 11 th of the same month several male specimens of full size that I procured, and which contained milt most prominently developed, measured but eleven inches and a half,--thus showing that in maturity

voL. I. 
the female fish exceeds the male in length in the proportion of thirteen to eleven and a half. Its average weight when in season is about six ounces. One specimen, mentioned to me as the largest taken within the last ten years, weighed two pounds and a half. The only food that, without resorting to the microscope, I have detected in the stomach of the Pollan, was a full-grown specimen of the bivalve shell Pisidium pulchellum. A pebble of equal size was also found with it." In the stomach of a specimen given me by Mr. Thompson, I found a species of Gammarus. That gentleman, in more recent examinations, found mature individuals of Gammarus aquaticus, and the larvæ of various aquatic insects; some shells of the genus Pisidium, one of the fry of the three-spined Stickleback, and a few fragments of stone. Others were found to contain minute Entomostraca, two Pisidia, and a Limneus pereger; this last was three lines in length.

Besides inhabiting Lough Neagh, the Pollan has also been found in Loch Corrib and in Lough Derg, an expansion of the Shannon; and Lord Cole, who has interested himself in the History of British Fishes, had the kindness to send me a jar full of Pollan from Lough Erne in the county of Fermanagh, from one of which specimens our figure was taken. The Pollan of Lough Erne are rather deeper for their length than those of Lough Neagh. His lordship has also sent me numerous Charr from Ireland; some from Lough Eask very much like the Charr of the Cumberland Lakes; while those from Lough Melvyn are short and deep fish with large fins exactly resembling the Charr found in two or three lakes in Wales, the particulars of which have been already described.

To return to the Pollan of Ireland. Mr. Thompson's 
description is as follows:- "The relative length of the head to that of the body is about as one to three and a half; the depth of the body equal to the length of the head; the jaws equal in length, both occasionally furnished with a few delicate teeth; the tongue with many teeth; the lateral line sloping downwards for a short way from the operculum, and thence passing straight to the tail. Nine rows of scales from the dorsal fin to the lateral line, and the same number thence to the ventral fin, the row of scales on the back and that of the lateral line not included. The third ray of the pectoral fin the longest. The fin-ray formula is as follows--

\section{B. 9 : D. 14 : D. $16:$ V. $12:$ A. $13:$ C. 19 . Vertebræ 59.}

Of these, the first two rays of the dorsal fin, and the first two rays also of the anal fin are short.

"The colour to the lateral line dark blue, thence to the belly silvery; dorsal, anal, and caudal fins, towards the extremity, tinged with black; pectoral and ventral fins of crystalline transparency, excepting at their extremities, which are faintly dotted with black. Irides silvery, pupil black."

In a number of these Pollan from Lough Erne as well as from Lough Neagh, the base of the last ray of the dorsal fin is exactly half-way between the point of the nose and the extreme end of the longest upper caudal ray. Nine rows of scales exist between the base of the first ray of the dorsal fin and the lateral line, and the same number between the lateral line and the origin of the ventral fin, with eighty-eight scales forming the lateral line. The finrays in number on several specimens exactly as stated by Mr. Thompson. 
ABDOMINALES

ILALACOPTER YGII.

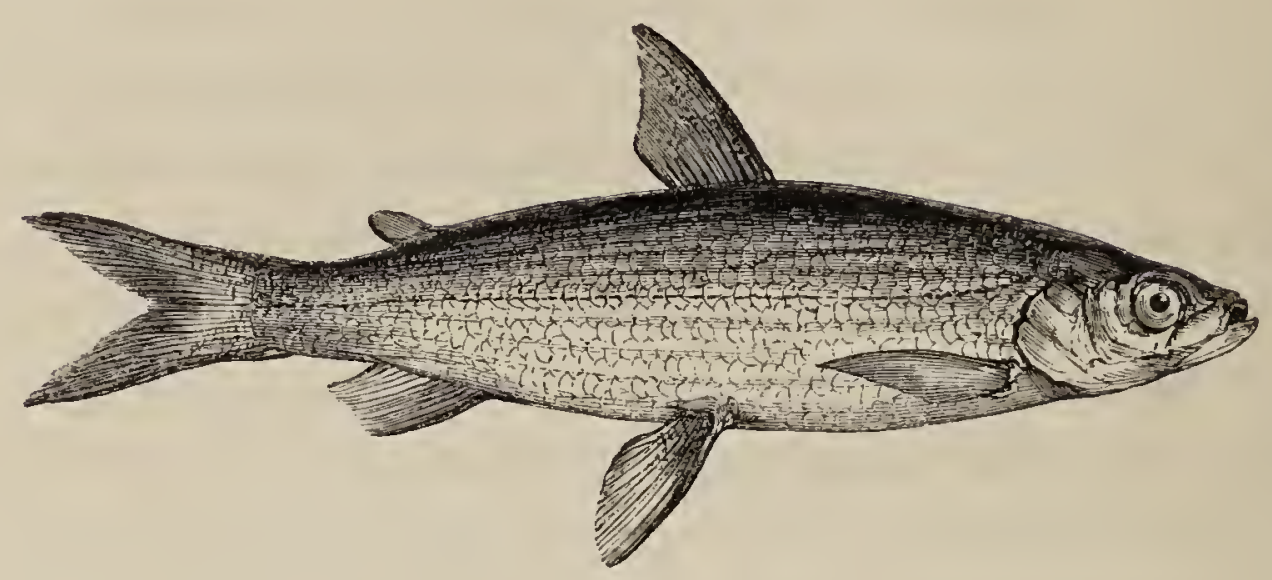

THE VENDACE, OR VENDIS.

Coregonus albulu, Valencrennes, Hist. des. Poiss. xxi. 520.

Vundesius ,, SibBaLd, Scotia Illust. p. 26.

Coregonus Willughbii, Vendace, JARDrNE's Illust. Scot. Salm. pl. 6.

", " Vangis and Juvangis, Pens. Brit. Zool. vol. iii. p. 420.

,, , $\quad$ Vendace, KNox, Trans. R. S. E. vol. xii. p. 503.

,, Marcenula, Jenyss, Brit. Vert. p. 432.

But little is known of this delicate fish beyond what has been published by Sir William Jardine, Bart., in the third volume of the Edinburgh Journal of Natural and Geographical Science, and by Dr. Knox, in the Transactions of the Royal Society of Edinburgh. Sir William Jardine, in his original communication, considered this species to be very closely allied to the Salmo albula of Linnæus; but the difficulty of fixing synonymes satisfactorily from the short descriptions of the older authors has since led to a request from him that the name of our distinguished British naturalist should be attached to it, and I with pleasure adopted this suggestion. I believe, however, that our Vendace is the C. Marcenula and C. albula of Continental authors. It is the Vemme of Ascanius, and M. Valenciennes identifies it with the 
Blitka of Lac Siljan in Sweden ; while Professor Nilsson recognises it as the true albula of Linnæus.

In Scotland the Vendace is only found in the lochs in the neighbourhood of Lochmaben, in Dumfriesshire; and in that district some traditions and curious opinions exist regarding it.

"The Vendace is well known," says Sir William Jardine, "to almost every person in the neighbourhood; and if, among the lower classes, fish should at any time form the subject of conversation, the Vendace is immediately mentioned, and the loch regarded with pride as possessing something of great curiosity to visitors, and which is thought not to exist elsewhere. The story that it was introduced into these lochs by the unfortunate Mary Queen of Scots, as mentioned by Pennant in his description of the Gwyniad,- -and it is likely that his information was derived from this vicinity, -is still in circulation."

The same species exists in Windermere and Bassenthwaite lakes in Cumberland, * a fact which disposes at once of the above tradition, which is evidently a legend of recent origin. The Vendace occasionally descends the Annan to the Solway Firth, and has been taken in the stake nets placed in that estuary.

"An idea," Sir William goes on to say, "prevails that this fish, if once taken from the water, will die, and that its immediate return will be of no avail; and it is also believed that it will not exist in any other water except that of the Castle loch. These are of course opinions which have gradually, from different circumstances, gained weight, and have at last been received as facts. The fish is of extreme delicacy; a circumstance which may have given rise to the first notion; and the intro-

\footnotetext{
* Dr. Davy, Angler in the Lake District, p. 262.
} 
duction of it must have taken place by means of the spawn : the fish themselves, I am confident, could not be transported alive even a few miles. As to the second opinion, they are not confined to the Castle loch, but are found in several other neighbouring ones, some of which have no communication with that where they are thought to be peculiar."

"In general habits the Vendace nearly resemble the Gwyniad, and indeed most of the allied species of the genus. They swim in large shoals; and during warm and clear weather retire to the depth of the lakes, apparently sensible of the increased temperature. They are taken with nets only, a proper bait not being yet discovered; and the fact that little excrement is found in their intestines has given rise to another tradition, that they are able to subsist without food. They are most successfully taken during a dull day and in a sharp breeze, as they then approach near to the edges of the loch, and swim in a direction contrary to the wind. They spawn about the commencement of November, and at this time congregate in large shoals, frequently rising to the surface of the water, in the manner of the common Herring, and making a similar noise by their rise and fall to and from the surface. The sound may be distinctly heard, and the direction of the shoal perceived, during a calm and clear evening. They are very productive. The Lochmaben lochs abound with Pike, of which they are a favourite food; but their quantity seems in no degree to be diminished, notwithstanding that immense numbers must be destroyed. They are considered a great delicacy, resembling the Smelt a good deal in flavour ; and, though certainly very palatable, the relish may be somewhat heightened by the difficulty of always procuring a supply. During the summer, fishing-parties are frequent, introducing 
some stranger friend to this Jochmaben Whitebait; and a club, consisting of between twenty and thirty of the neighbouring gentry, possessing a private net, \&c., meet annually in July, to enjoy the sport of fishing, and feasting upon this luxury."

While enjoying the hospitality of Sir William Jardine in the autumn of 1840 , I had the gratification of seeing some Vendace caught in the morning, and afterwards partaking of them at dinner. I considered the fish quite entitled to their high character for excellence.

The circumstance that this fish is never caught by anglers made a knowledge of its food a matter of interest in several points of view. Dr. Knox ascertained that this consists principally of very minute entomostracous animals, not exceeding seven-twelfths of a line in size. I have been favoured with specimens of the Vendace by Sir William Jardine and T. S. Bushnan, Esq., which have afforded me several opportunities of examining the contents of the stomach and intestines. The contained mass, which is frequently in considerable quantity, has a brownish-yellow colour, appearing slightly granulated to the unassisted eye. A very small portion being placed on a slip of glass, and agitated gently in conjunction with a drop of water, which separates the particles, on placing the slip of glass under a good microscope two species in various states of perfection are almost constantly found. The vignette at the end of the description of this fish represents these two forms. The first and second figure on the left hand are a back and side view of a species of the genus Lynceus of Müller and others ; the third and fourth figures are a back and side view of a species of Cyclops of Müller. On one occasion, I found a very small coleopterous insect, the tough skin of a red worm not much thicker than fine thread, and 
what appeared to be a portion of the wing of a dipterous insect.

Dr. Knox found that the females of the Vendace were more numerous as well as larger than the males, and frequently exceeded eight inches in length; the males not measuring more than seven inches, which was the length of the specimen here described. They are seldom seen of larger size.

The length of the head compared to that of the body only was as two to seven; the depth of the body at the commencement of the dorsal fin not quite equal to onefourth of the length of the body without the caudal rays: the body elegantly shaped; the convexity of the dorsal and abdominal lines about equal; the lateral line passes straight along the middle of the side, with six rows of scales in an oblique line between it and the dorsal fin, and the same number between the line and the ventral axillary scale: the dorsal fin commences half-way between the nose and the origin of the upper caudal rays; the longest ray is double the length of the base of the fin: the adipose fin very near the tail; pectoral fin not quite equal to the length of the head; the ventral fin commences in a line under the first ray of the dorsal fin, and the ventral axillary scale is one-third of the length of the fin; the anal fin commences half-way between the origin of the ventral fin and the end of the fleshy portion of the tail; the longest ray being about equal to the base of the fin : the tail is deeply forked; all the fins are large. The fin-rays in number are-

\section{11: P. 16: V. 11: A. 15: C. 19. Vertebræ 52.}

In form the under jaw is the longest; the mouth small, the opening square; a few very minute teeth on the tongue only : the breadth of the eye one-third of the 
whole head, the posterior part of the iris the broadest; the colour silvery tinged with yellow, the pupil blue: the upper parts of the body of a delicate greenish brown, shading gradually towards the belly into a clear silver; the dorsal fin a greenish brown; the lower fins are all bluish white.

LTNOEUS.

Crolops.
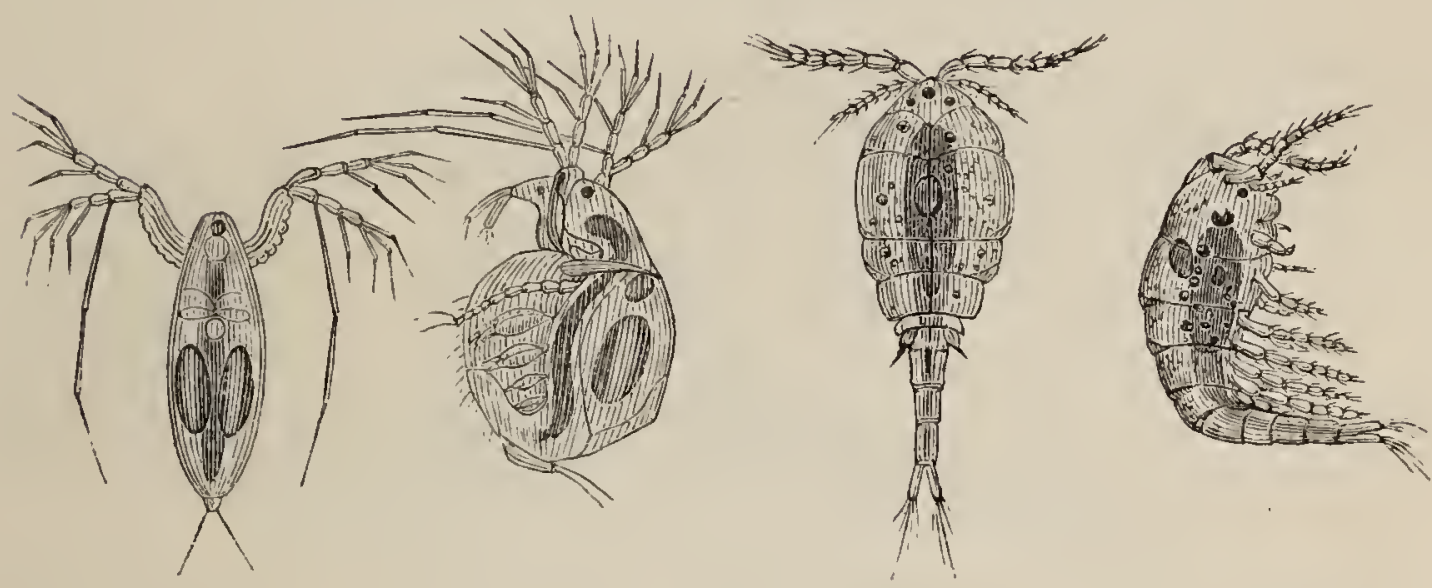


\section{THE PEARL-SIDE.}

Scopelus Pennanti, Valenc. Hist. des Poiss. xxii. 436.

Scopehus Humboldtii, Argentine, British Fishes, 1st and 2nd edit.

Argentina sphyrcena, , PenN. Brit. Zool. vol. iii. p. 432, pl. 76.

Scopelide. Family Characters.-Scaly or scaleless fishes, with an adipose fin; the mouth bounded above from corner to corner by the premaxillaries, the maxillaries lying behind, and in a few genera touching the corner of the mouth. Pseudo-branchie present. Swim-bladder generally absent. Eggs discharged through an ovarian tube, and not falling loose into the abdomen, as in the Salmonida.

Scopeuus. Generic Characters. - Small teeth, almost all of one size, arm the mandible and premaxillaries; behind lie the toothed or toothless maxillaries : the palatine teeth very minute; no vomerine teetl. The species are remarkable for spots of metallic brilliancy on the body, and often for luminous excrescences on the head.

At the time of publishing the first edition of this work, Pennant, and the Rev. Mr. Low of Orkney, appeared to be the only British observers who had met with examples of this genus of brilliant though little fish on our coast.

Pennant's specimen was taken in the sea near Downing in Flintshire: Mr. Low's fish was brought to him by a boy, who said he found it at the edge of the water among sea-weed. The receipt of an additional portion of MS. confided to me by William Walcott, Esq., furnished a notice, written by his late father, of a third instance of the occurrence of the Pearl-side, which was 
found stranded on the shore near Exmouth: length two inches and a half. Pennant's description is, "Length two inches and a quarter; the eyes large, the irides silvery; the lower jaw sloped much; the teeth small; the body compressed, and of an equal depth almost to the anal fin; the tail forked: the back was of a dusky green; the sides and covers of the gills as if plated with silver; the lateral line was in the middle, and quite straight: on each side of the belly was a row of circular punctures; above them another, which ceased near the vent." The formula of the fin-rays appears to be-

D. $9:$ P. $17:$ V. $8:$ A. $15:$ C. 19.

A copy of Pennant's figure immediately follows.

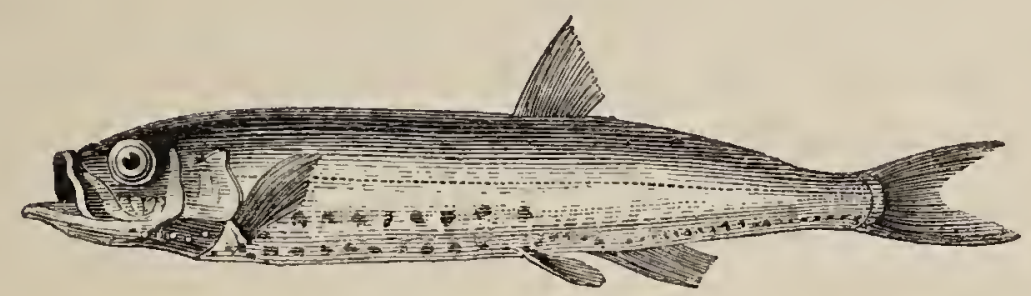

Pennant unfortunately referred his fish to the genus Argentina, which is a totally distinct form, and British ichthyologists, in repeating his observations on a species which none of them had seen, retained the generic name. To prevent further mistake, the designation of Pearl-side is now substituted for that of Argentine.

In March 1841, I received a letter from the Rev. I. Newsam, of Redcar, on the Yorkshire coast, informing me that a specimen of the Argentine (Pearl-side), had been found by one of his children amongst sea-weed on the shore, about high-water mark, the colours of which were most brilliant, and both rows of spots very distinct. This gentleman also sent me word that one or 
two other specimens had been obtained, at different times, in the same vicinity, near Redcar. The specimen preserved was given to me by Mr. Newsam, and I beg to record my thanks for his kindness in sending me the first example of the fish I ever saw. From this specimen the representation at the head of this article was carefully drawn and engraved, exactly of the natural size.

In May of the same year I received a letter from the Rev. T. S. Rudd, also of Redcar, stating that he had found a brilliant specimen of the Argentine (Pearl-side), of which a fisherman, when it was shown to him, observed, that he had seen several like it cast up on the shore. This which Mr. Rudd sent for my inspection, with a request that I would keep it if of any use to me, exactly agreed with the specimen already in my possession. Prince Canino said, on seeing this fish, that he had not found the same species among the Mediterranean Scopeli, most of which are figured and described in the 27 th part of his Fauna Italica.

Both the specimens from Redcar having suffered some slight mutilation, I was unable to decide the number of rays in the dorsal, ventral, or anal fins; which would have assisted in determining the species. In the character of the fins, the Yorkshire specimens most resemble Pennant's figure; in the number and situation of the spots, and in colour, they correspond with Dr. Clarke's fish mentioned below; and there is a general resemblance in all three, except in size. By endeavouring to represent the steel-blue appearance along the lower edge of the fish, the silvery spots are rendered more apparent. Other examples, I have no doubt, will hereafter occur to decide the question, whether only one, or more species, inhabit our shores.

Other specimens have actually been taken since the 
preceding passage was printed in 1841. In December 1850, Mr. Rudd found a third mutilated Pearl-side at Redear, and in the following February, as he reports in the Zoologist, p. 3058, he picked up four more on the beach of the same place, and perceived that they had that smell of cucumbers which is so remarkable in the Smelt. The fishermen of the neighbourhood told him that the Pearl-side visits Redcar only in the season of from January to May.

M. Valenciennes, in his account of the Scopeli, has named the British species after Pennant, who first made it known, as it is undoubtedly distinct from the Scopelus Humboldtii, to which it was referred in the former editions of British Fishes, and from which it may be distinguished by the smaller eye, by the expanded and longer maxillaries, by the much smaller cleft of the mouth being more nearly vertical, and wholly anterior to the eye, and by the more backward position of the dorsal and ventrals. The uniserial teeth of Pennanti furnish a less obvious distinguishing character. Through the kindness of Dr. Gray, the editor of the present edition of this work has been permitted to examine Mr. Rudd's two specimens, which are now in the British Museum. They have evidently suffered from friction among the gravel of the beach where they were found, and the dorsal and anal fins being very brittle are much mutilated, but referring to them, as each clause of Dr. Clarke's description quoted below, was read over, nothing pointing to a difference of species could be detected. Dr. Clarke's figure is longer in the body than the Redcar fish, and the anal fin is too short in the wood-cut at the head of this article, there being the stumps of about twenty rays to be ascertained in the specimens by the aid of a good lens. Neither figure 
represents the form or great extent of the maxillary, and in fact that bone is so transparent, and allows the parts beneath to appear so distinctly through it, that the artist has shown the underlaying glandular spots instead of the contour of the bone, which can be seen best by moving the jaw. The soft parts on the forehead and crown, which are luminous in the dark in some, perhaps in most or all Scopeli, decay and shrink rapidly after death; hence the comparative height and boldness of the forehead will depend on the perfect state of the specimen, whose portrait is taken, and some allowance must be made for the injury the Redcar specimens had sustained, when describing their profile: doubtless the crown of the head should be more arched, and the forehead more rising than in the wood-cut. As to Pennant's figure, the absolute necessity of minute accuracy was scarcely recognised in his day, and the pencil of his servant-artist, Moses Griffith, was scarcely adequate to the correct delineation of so small an animal: it would, therefore, be altogether unsafe to found a species merely on the differences that may be elicited between his figure and the more recent ones, and we are justified in assuming that as yet only one British species has been detected.

We now proceed to describe some parts of the structure of Mr. Rudd's specimens, as supplementary to Dr. Clarke's details quoted further on. The most anterior point of the fish, when the mouth is closed, is a little chin or prominent point of the mandibular symphysis : from this minute peak, to the extremity of the caudal fin, one specimen measured 1.48 inch, and the other 1.45 inch, the relative proportions of parts being the same in both. The ventrals are distant from the mandibular symphysis 0.68 inch, and are attached under the 
third and fourth rays of the dorsal. They are, therefore, considerably before the middle of the fish if the caudal is included in the measurement, and a little behind it if that fin is not taken into the account. The head is exactly a fourth part of the whole length including the caudal, and its height at the nape is equal to its length. The diameter of the perfectly round orbit is as nearly as possible a third of the length of the head, from the point of the mandible to the gill opening: its border approaches, but does not encroach on the upper profile, and is visibly nearer to the cleft of the mouth than to the gill-opening. The interval between the eyes on the forehead scarcely equals the diameter of the orbit. The mandible shuts up in front of the premaxillaries, and then the cleft of the shut mouth is not far from being vertical, and it is wholly in front of the eye even when the mandible is depressed. The whole upper border of the mouth is edged by the very slender finely-tapering premaxillaries, whose fine tips correspond to the corners of the orifice. Behind, and extending far beyond them to beneath the middle of the orbits, move the scalene-shaped maxillaries, having a breadth of little less than half their length. The inferior edge of each maxillary is a convex curve, equal to its almost vertical front edge, or to the premaxillary in length: it joins by a rounded tip the postero-superior edge, which slopes up to the premaxillary symphysis, having merely a small incurvature in the lower third of its length. On the disk of the maxillary, some way within its edge, there is a triangular elevation, occupying fully half its surface, but whether the bone is separable into segments or not, could not be ascertained without damaging the specimens. The bone plays up and down below the front of the eye, covering the articulation of the mandible, and closing up against 
the infra-orbitar scale-bones, while the inferior convexlycurved edge completes the under profile of the face. This lower edge of the maxillary is armed by a single and not crowded series of very short, acute, microscopical teeth. Similar teeth, but slightly longer, also in single rows, exist on the edges of the premaxillaries and mandible, and there are likewise a few small teeth on the palatines. The vomer and tongue are smooth.

The gill-cover is clothed with a silvery integument, which renders it difficult to perceive at first the parts of which it is composed, but a careful inspection showed that the preoperculum is narrow, and the operculum large and nearly rectangular, its height considerably exceeding its length. The suboperculum is also rectangular, but its height, which is equal only to about a third of that of the operculum, does not exceed half its own length. Scales large, thin, and scomberoid in appearance, covering the sides of the body with a smooth silvery band, having a bright metallic lustre. The scales are irregular in outline, the concentric lines of structure are very faint, and there are no basal furrows. There are only three scales in the height at the vent and posteriorly, but they appear to be smaller, and much more easily detached on the top of the back. There they have mostly come off in the specimens, leaving a narrow dorsal stripe of yellowish brown, thickly and irregularly mottled with dark umber brown. The mesial line of the back, from the nape to the tail, is acute and slightly raised, but otherwise the back is rounded though narrow, owing to the compressed form of the fish. On the top of the head there is an acute mesial ridge, with a finer lateral one running immediately over each orbit, behind which the ridges vanish. These bound a deep furrow on each side, all most likely entirely concealed by the soft parts 
in the recent fish. The pectoral fins contain seventeen rays, the lower ones very slender; and the rays of the caudal divide into two groups, an upper and a lower, separated by a small middle space at their insertion. The dorsal and anal rays could not be counted from the injury they had received, but the numbers do not differ above a ray or two, at most, from Dr. Clarke's enumeration.

The pearly spots are glandular-looking bodies, seated in depressions of the integument, and enchased in a very fine black ring. The inferior row passes backwards near the mesial line of the belly, makes a curve over the ventrals, and then runs close to the base of the anal, ending at the insertion of the caudal. It is composed of forty-six or forty-seven perfectly orbicular spots, larger and a little more remote anteriorly, smaller and nearly contiguous on the tail: smaller still where the row rises over the ventrals. This row meets its fellow under the angle of the operculum. Above this, another row of about sixteen runs from the vent along the lower part of the side, rises over the pectoral, and meets the corresponding row of the other side between the articulations of the mandible. All these spots are round. There are besides six or more considerably larger oblong spots, lying obliquely between the corner of the mouth and the scapular arch.

The mouths of both of Mr. Rudd's specimens were filled with minute quartzose sand, among which no infusorial shells could be detected.-(Edit. 3rd Ed.)

In the volume of the Magazine of Natural History for the year 1838, Dr. W. B. Clarke, who had found a specimen of the Pearl-side at Portobello, near Edinburgh, in April, has published a notice of his fish, of which the following is an abstract. 
"I discovered this highly elegant little fish, whilst looking amongst the various bodies cast up by the water, and observed it lying entangled in some sea-weed, which had been accumulated in masses, and left by the retiring tide. The fish was dead; but from its freshness could not long have been so."

After quoting Cuvier's account of the Scopeli from the Règne Animal, Dr. Clarke goes on to say :-

"Pennant's description agrees, in many respects, with my fish; but as the figure contained in Mr. Yarrell's work, which was taken from Pennant's, differs very materially about the head and tail, although it resembles it in the shape of the body, I have sent an exact figure of my own specimen, to show the precise forms of the bones of the opercula and sides of the head, together with a full description; which may assist future observers in determining whether more than one species visits our shores. If Pennant's figure be an exact representation, the fish it was taken from was certainly a different species to the one under description.

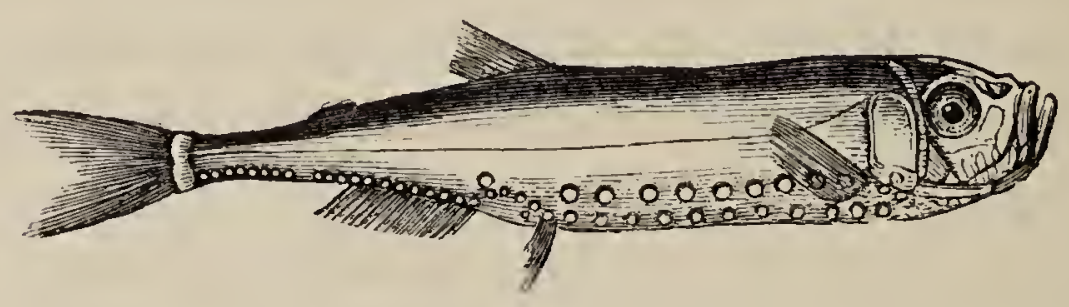

“My specimen would correspond with Pennant's description except in the following particulars: viz. length one inch $\frac{15}{16}$ : the back of a dense blue black, presenting, in certain lights, a brownish tinge; lateral line central 
and straight, but inclining upwards, at about its anterior sixth, towards the upper angle of the operculum.

"The number and arrangement of the guttæ in the specimen under consideration are as follows: viz. on each side, upper series between os hyoides and origin of pectoral fin, five; upper abdominal series between base of pectoral and a spot perpendicularly over the ventral, nine; lower abdominal series, from a spot perpendicularly beneath the posterior margin of orbit, to base of ventral, twelve; between base of ventral and commencement of anal, six; the two anterior directed downwards and backwards; the four posterior forming an arch from a little above the second gutta to the commencement of the anal fin; one large gutta, in a line with the upper abdominal series, is placed slightly anterior, but above the commencement of the anal fin: between the anterior commencement of anal and base of caudal, twenty-four; but between the eighth and ninth from the caudal fin, there is a space where a spot appears to have been obliterated.

"About midway between the anterior commencement of the dorsal and base of caudal, but rather nearer the latter, there is a slight elevation, where, apparently, the fleshy fin has its origin; but in the specimen under description it is scarcely perceptible, being, even with the aid of a lens, only like a slight membranous ridge.

"The formula of the fin-rays appears to be-

$$
\text { D. } 9 \text { : P. } 17 \text { : V. } 8 \text { : A. } 20 \text { : C. } 18 .
$$

"Mr. Yarrell remarks, "the portrait of the Serpes Humboldtii, referred to in Risso's work, represents the anal fin as containing many more rays than are shown in the figure by Pennant.' The fish obtained by me possesses more anal rays than Pennant's would appear to have had, judging from the figure which he has published. 
"Length of head compared with whole length of fish, as one to four : diameter of eye to length of head, as one to three : first dorsal fin commences midway between end of nose and tail : depth of body to whole length of fish, as one to five and a half: nostrils double, situated in a depression midway between the eye and centre of intermaxillary bone. The operculum is extremely large, and appears to be developed at the expense of the preoperculum, which is very small, and joins the former by a straight movable suture, running in a line perpendicularly downwards, from the posterior margin of the orbit; it forms an obtuse-angled triangle, with the obtuse angle pointing downwards and backwards: the sub-orbital bone occupies nearly the anterior inferior half of the orbit, and is of a beautiful argenteous lustre, like the operculum. There are five oval spots, forming a fan-shaped figure, occupying the space between the anterior edge of the superior maxillary bone, and the anterior inferior angle of the preoperculum, beneath the sub-orbital bone, and distinctly seen through the transparent intermaxillary (maxillary) bone, which is very large. There is one gutta upon the preoperculum, at its anterior inferior angle, and the appearance of another at the anterior inferior angle of the suboperculum: there are no branchiostegous rays visible whilst the opercula are closed.

"The sides of this elegant little fish are of the most resplendent argenteous lustre; the guttæ are of a dense opaque white, and round their margin, especially along the infra-caudal series, there is a steel-blue tinge, giving that part of the body a very beautiful appearance. The upper abdominal series have an arched figure, from this tinge not being continued round the inferior margin of the guttæ. The back of the specimen under descrip- 
tion, which has been in spirits ever since its capture, is of a dense blue black, presenting, in certain lights, a brownish tinge.

"From specimens of this fish having been found in the sea near Flintshire, on the shore in Orkney, in Devonshire, and, lastly, in Edinburghshire, we may infer that it is generally, although sparingly, diffused through the British seas. Probably, ere long, we may hear of other examples of its occurrence upon our shores, or in our seas."-Dr. Clarke.

The Scopeli are generally diffused throughout the ocean, both in the northern and southern hemispheres, and the species are numerous. The Mediterranean nourishes many, and the Chinese, Indian, and Australian seas are also enlivened by these gems of the ocean. The southern groups that have been figured, have mostly more horizontal well-cleft mouths, with narrow maxillaries. The habits of the Scopeli are nocturnal, and they are most easily taken in the night by a surface drag-net, sufficiently fine in the mesh. Ström, in the Naturhistorien selskabet Skrifter, 2nd Band, p. 15, t. 1, f. 2, describes and figures a Scopelus, which has been called borealis by Nilsson. It inhabits the Northern Atlantic, but differs from the English species in having a larger eye, and the ventrals farther from the anal and nearer the pectorals. Professor Reinhardt also mentions a Scopelus glacialis in his Fauna Grœnlandica, but, excepting that he points out some particulars in which it differs from borealis, he says little to enable us to judge of its resemblance or dissimilarity to Pennanti. 


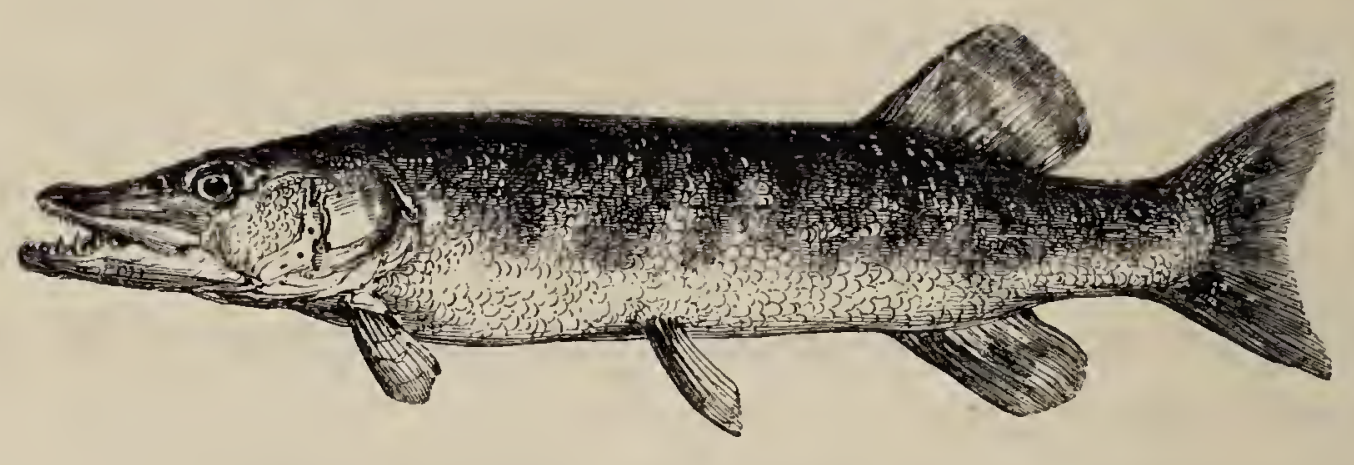

THE PIKE.

PICKEREL. JACK. LUCE.-GEDD. Scotland. GÄDDA. Scandinavia. PENHWYAD. Wales.

Esox lucius, Linneus. Bloch, pt. i. pl. 32.

," , Pike, Penn. Brit. Zool. vol. iii. p. 424, pl. 74.

" " Brochet, Cuvier, Règne An. t. ii. p. 282.

", ", Pike, Donov. Brit. Fisl. pl. 109.

", ," , $\quad$ Flem. Brit. An. p. 184, sp. 55.

" " ", ", JENYs, Brit. Vert. p. 417.

Esocidx. Family Characters.-Scaly fishes, without an adipose fin, and possessing covered glanduiar pseudo-branchiæ. Upper border of the mouth formed by the point of the vomer on the mesial line, by the transverse premaxillaries, and by the lateral toothless fmaxillaries. The teeth are formidable; the vomer, the premaxillaries, the very movable palatines, the mandible, tongue, and the pharyngeals above and below being dentiferous. Simple swim-bladder opening by canal into the gullet. Stomach bent in form of a siphon; no pancreatic cæca. Peculiar vascular ramifications on the inner surface of the skin. Fresh-water fishes, inhabiting the northern hemisphere only.

Esox. Generic Characters. -The same as those of the family, there being but one genus.

LinNeus ranged groups of fishes round certain European species, linking them together by some conspicuous external character, but not requiring any general conformity in the more essential internal structure. He had, 
however, an aptness in perceiving natural affinities, and most of his genera have become, in the advancement of ichthyology, types of families, or have been broken up to form several families. Thus his genus Salmo, corresponding to the family appellation Salmonida of a later time, comprehended the abdominal soft-rayed fishes that have an adipose fin on the tail, and included the members that were then known of the groups now named Characinida, and Scopelida, with others of less importance as to numbers. Cuvier attended more to structure, and, in defining his Salmonide and Clupëida, drew attention to the upper border of the mouth, which in these families is formed by the premaxillaries and maxillaries, while the presence or absence of an adipose fin distinguishes the one family from the other. M. Valenciennes has more lately defined the Clupeoids or Herring family, so as to exclude all which are destitute of serratures on the belly. In like manner this expert ichthyologist has restricted the Esocida (Lucioids), or Family of Pikes, to the single genus $E s o x$, by removing from it many foreign groups, differing from it in internal structure, though associated with it in previous ichthyological writings. He also points out, that in this genus the vomer, carrying teeth, projects between the premaxillaries, so as to edge a portion of the oral orifice. Like the Carps, the Pikes have an intestinal canal, destitute of pyloric cæcal appendages; and on the inside of the gill-covers, there are vaso-ganglionic pseudo-branchiæ, which are covered by the mucous lining of the gill-chamber. These false gills receive not venous blood needing oxygenation, but arterial blood, which has already undergone that process in passing through the true gills, and is transmitted from the pseudo-branchiæ to the eye. In many fishes the pseudo-branchix are not covered up by the mucous 
membrane, and then they bear so close a resemblance to the proper gills, that they used to be described as halfgills, on account of their having only one layer of pectinated processes, or as opercular gills from their position, their function being erroneously considered to be the same as that of the gills. They must not be confounded with the accessory branchiæ which actually have that function, but are found only in a few fishes.

The Pike is a well-known inhabitant of the principal rivers and lakes of Europe; and although probably introduced into this country, and for a long time rare, it is now exceedingly common in many of our rivers, as well as in almost all the lakes and large ornamental waters of England, Scotland, and Ireland.

That Pike were rare formerly, may be inferred from the fact that, in the latter part of the thirteenth century, Edward the First, who thought fit to regulate the prices of the different sorts of fish then brought to market, that his subjects might not be left to the mercy of the venders, fixed the value of Pike higher than that of fresh Salmon, and more than ten times greater than that of the best Turbot or Cod. In proof of the estimation in which Pike were held in the reign of Edward the Third, I may quote a couplet from the prologue to Chaucer's Canterbury Tales :

"Full many a fatte partricke hadde he in mewe, And many a Breme and many a Luce in stewe."

Halliwell says that the Pike was called according to its age, first a Jack, then a Pickerel, thirdly a Pike, and last of all a Luce. He quotes Piers of Fulham for the use of the words "Lucys or Pykys," and an ancient MS. for "Luonus a Lewse."

Pike are mentioned in an Act of the Sixth year of the reign of Richard the Second, 1382, which relates to the 
forestalling of fish: and they were served up in the year 1466, at the great feast given by George Nevil, Archbishop of York. They are also mentioned in the famous Boke of St. Albans, in the treatise on the art of fishing with an angle; the first edition of which is said to have been printed at St. Albans in 1481, and again at Westminster, by $W^{T}$. de Worde, in 1496.* Pike were so rare in the reign of Henry the Eighth, that a large one sold for double the price of a house lamb in February, and a Pickerel, or a small Pike, for more than a fat capon.

The Pike is a common inhabitant of almost all the waters of Scandinavia, and Fries and Ekström say that it grows in Sweden to the length of four feet, and that rare examples occur measuring six feet, and weighing thirty pounds. The Swedish fishermen believe that it turns its head towards the shore on St. Gregory's day, i.e. 12th of March, and that, six days later, it has approached the beach of the lake it inhabits, near the influx of some stream, where the ice first breaks up. They also report that the phases of the moon influence its rapacity, and that it is more voracious than common in the dog-days. The same species is plentiful throughout Rupert's Land, and extends southwards to the great Canadian Lakes, but in the latter it is not so abundant as some other species which do not exist in Europe.

The Pike is strong, fierce, and active; swims rapidly, and occasionally darts along with the rapidity of lightning. Its spawn is deposited among weeds in March or early in April; and at this season the spawning fish will be found in narrow creeks or ditches that are connected with the larger waters which they at other times inhabit. The Rev. Revett Sheppard has noticed " an annual migration

* At the sale of the library of the late Duke of Roxburgh, an imperfect copy of this edition produced $147 l$. 
of this fish which takes place in spring in the Cam, " into which river," he says, "they come in great shoals, doubtless from the fens in the neighbourhood of Ely, where they are bred."

Bloch says the young reach the length of eight or ten inches the first year; twelve or fourteen the second; eighteen or twenty inches the third; and there are proofs on record, that from this last size, if well supplied with food, they will increase in weight at the rate of four pounds a year, for six or seven successive years. Rapid growth requires to be sustained by a corresponding proportion of food, and the Pike has always been remarkable for extraordinary voracity. "Eight Pike, of about five pounds' weight each, consumed nearly eight hundred Gudgeons in three weeks: and the appetite of one of these Pikes," says Mr. Jesse, "was almost insatiable. One morning I threw to him, one after another, five Roach, each about four inches in length: he swallowed four of them, and kept the fifth in his mouth for about a quarter of an hour, when it also disappeared." Digestion in the Pike goes on very rapidly, and they are therefore most expensive fish to maintain. In default of a sufficient quantity of other fishes to satisfy them, moorhens, ducks, and indeed any animals of small size, whether alive or dead, are constantly consumed. Their boldness and voracity are equally proverbial. Dr. Plot relates, that at Lord Gower's canal at Trentham, a Pike seized the head of a swan as she was feeding under water, and gorged so much of it as killed them both: the servants perceiving the swan with its head under water for a longer time than usual, took the boat, and found both swan and Pike dead. Gesner relates that a Pike in the Rhone seized on the lips of a mule that was brought to water, and that the beast drew the fish out before it could 
disengage itself. Walton was assured by his friend $\mathrm{Mr}$. Segrave, who kept tame otters, that he had known a Pike, in extreme hunger, fight with one of his otters for a Carp that the otter had caught, and was then bringing out of the water; and he quotes the old adage, "it is a hard thing to persuade the belly, because it hath no ears." A woman in Poland had her foot seized by a Pike as she was washing clothes in a pond; and the same thing is said to have happened at Killingworth pond near Coventry. The head-keeper of Richmond Park was once washing his hand over the side of a boat in the great pond in that park, when a Pike made a dart at it, and he had but just time to withdraw it. Mr. Jesse adds, that "a gentleman now residing at Weybridge in Surrey, walking one day by the side of the river Wey, near that town, saw a large Pike in a shallow creek. He immediately pulled off his coat, tucked up his shirt sleeves, and went into the water to intercept the return of the fish to the river, and to endeavour to throw it out upon the bank by getting his hand under it. During this attempt, the Pike, finding he could not make his escape, seized one of the arms of the gentleman, and lacerated it so much that the marks of the wound are still visible."

Many keepers and fishermen pretend, that notwithstanding the extreme voracity of the Pike it will not feed on the Tench, from a respect to the general character of that fish, as the physician of the finny tribe. That this popular notion is as unfounded as many others of the kind, is fully shown by several communications to the Zoologist for 1853, in which instances are cited of the Pike feeding greedily on Tench.

The lakes of Scotland have produced Pike of large size, one taken in Loch Ken in Galloway weighed sixtyone pounds, and one from Loch Lomond seventy-nine 
pounds. Mr. Thompson in his Natural History of Ireland, mentions that Mr. O'Flanagan, when seventy years of age, killed one with a single rod and bait, in the county of Clare, that weighed seventy-eight pounds. The largest Mr. Thompson had seen in the Belfast market weighed thirty-six pounds, though greater sizes are common in Lough Neagh and other large sheets of water; but it is observed, says honest Isaac Walton, "that such old or very great Pikes have in them more of state than goodness; the smaller or middle-sized Pikes being, by the most and choicest palates, observed to be the best meat." The flesh of the Pike is of good quality; and those of the Medway, when feeding on the Smelt, acquire excellent condition, with peculiarly fine flavour. In Lapland, and some other northern countries of Europe, large quantities of Pike are caught during the spawning season, being then most easily taken, and are dried for future use.

Among the various localities in England remarkable for the quality as well as the quantity of their Pike, Horsea Mere and Heigham Sounds, two large pieces of water in the county of Norfolk, a few miles north of Yarmouth, have been long celebrated. Camden, in his Britannia, first printed in 1586, says, "Horsey Pike, none like;" and Horsea Pike still preserve their former good character. I have been favoured, by a gentleman of acknowledged celebrity in field sports, with the returns of four days' Pike-fishing with trimmers-or liggers, as they are provincially called-in March 1834, in the waters just named; viz. on the 11 th, at Heigham Sounds, sixty Pike, the weight altogether two hundred and eighty pounds; on the 13th, at Horsea Mere, eighty-nine Pike, three hundred and seventy-nine pounds; on the 18th, again at Horsea Mere, forty-nine Pike, two hundred and 
thirteen pounds ; on the 19th, at Heigham Sounds, fiftyeight Pike, two hundred and sixty-three pounds; together, four days' sport, producing two hundred and fifty six Pike, weighing altogether eleven hundred and thirty-five pounds. Pike have been killed in Horsea Mere weighing from twenty-eight to thirty-four pounds each.

M. Valenciennes has entered into a critical examination of the legends respecting an enormously large and aged German Pike, which have been repeated in different ways by many writers on European ichthyology, but which he clearly shows to be either in part or wholly apocryphal. Marquard Freher says that the Pike was taken at Kaiserlautern, in a lake still called the Kaiserwag, and that a gilt brazen collar which it bore had an inscription, stating that it was put into the lake by the hand of the Emperor Frederick the Second, in the year 1230. It was taken out, and carried to Heidelberg in 149\%, and it had therefore lived in the lake 267 years. Its picture was seen in the palace of Heidelberg by Maynard, and a black line, drawn on the wall, purporting to be the measure of its length, was seventeen feet long. Gesner, who lived nearer the time at which this fish was said to have been taken, says that it was captured in a lake near Heilbronn in Suabia, and that the inscription on the ring was in the Greek language, but to the same purport as that quoted by Maynard; and Lehman reports that in 1592 its portrait and also a sketch of the ring were preserved in a castle erected on the road leading from Heilbronn to Spires. Other conjectures and versions of the story are mentioned by M. Valenciennes.

As a testimony to the truth of the legend, the skeleton of the Emperor's monstrous Pike was long shown in the Cathedral of Manheim, but an eminent German anatomist found, from the number of its vertebræ, that the 
bones of more than one fish had been used in its composition. It is to be observed, however, that it was customary in those ages to put rings in the gill-covers of fishes, and Bock states that in 1610 a Pike was taken in the Meuse, bearing a copper ring, on which was graven the name of the city of Stavern and the date of 1448 .

The meres, or broads, as they are called in Norfolk, are of great extent: Horsea Mere and Heigham Sounds, with the waters connected, are calculated to include a surface of six hundred acres. As the mode of fishing for Pike with liggers on these extensive waters is considered to be peculiar, and affords great diversion, I may state that the ligger or trimmer is a long cylindrical float, made of wood or cork, or rushes tied together at each end: to the middle of this float a string is fixed, in length from eight to fifteen feet; this string is wound round the float except two or three feet, when the trimmer is to be put into the water, and slightly fixed by a notch in the wood or cork, or by putting it between the ends of the rushes. The bait is fixed on the hook, and the hook fastened to the end of the pendent string, and the whole then dropped into the water. By this arrangement, the bait floats at any required depth, which should have some reference to the temperature of the season; Pike swimming near the surface in fine warm weather, and deeper when it is colder, but generally keeping near their peculiar haunts. When the bait is seized by a Pike, the jerk looses the fastening, and the whole string unwinds; the wood, cork, or rushes, floating at the top, indicating what has occurred. Floats of wood or cork are generally painted, in order to render them more distinctly visible on the water to the fishers who pursue their amusement in boats. Floats of rushes are preferred to other forms of the ligger, as least calculated to excite 
suspicion in the fish. The same methods of taking the Pike are mentioned by Fries and Ekström in their Skandinaviens Fiskar.

Sir Robert Sibbald, Physician and Geographer to Charles the Second, gravely states that the heart of the Pike is a remedy in ague, that the gall is powerful in affections of the eyes, and that the jaws dried and powdered cure pleurisy, gravel, and calculus of the bladder.

The body of the Pike is elongated, nearly uniform in depth from the head to the commencement of the dorsal fin, then becoming narrower; the surface is covered with small scales, the lateral line indistinct: the length of the head compared to the whole length of head, body, and tail, is as one to four : the dorsal fin, placed very far back, commences in a vertical line over the vent; the first ray short; the second and third increasing in length, but shorter than the fourth; and the length of the base of the fin about equals the length of the longest of its rays: the dorsal and anal fins terminate on the same plane. From the point of the nose to the origin of the pectoral fin, from thence to the origin of the ventral fin, thence to the commencement of the anal fin, and from the vent to the end of the fleshy portion of the tail, are four nearly equal distances : the pectoral and ventral fins are small; the rays of the anal fin are elongated, exceeding the length of the base of the fin; the first three rays being shorter than the fourth: caudal rays long and forked. The fin-rays in number are-

$$
\text { D. } 19: \text { P. 14: V. } 10: \text { A. } 17: \text { C. } 19 .
$$

The head is elongated, depressed, and wide; the gape extensive: the teeth on the vomer small; on the very movable palatine bones the teeth are larger and longer, particularly those on the inner edges: none exist on the premaxillary bones: the lower jaw is the longest, and has 
numerous small teeth round the front; on its sides there are five or six, at a distance from each other, very long and sharp; the nostrils open in a groove at three-fourths of the distance between the point of the nose and the eyes: the upper surface of the head exhibits various mucous orifices, placed in pairs; the eyes are near the frontal line, and half-way between the point of the nose and the end of the gill-cover; cheeks and upper part of the operculum covered with scales; preoperculum and operculum smooth and silvery, closing upon a corresponding smooth, circular, silvery humeral disk. The colour of the head and upper part of the back dusky olive brown, becoming lighter and mottled with green and yellow on the sides, passing into silvery white on the belly; pectoral and ventral fins pale brown; dorsal, anal, and caudail fins darker brown, mottled with white, yellow, and dark green; irides yellow.

The Pike of the fisherman is the Lucie of heraldry, - a term derived from the Latin or old French name.

Three silver Pikes in a red field were the arms of the ancient baronial families of Lucie of Cockermouth and Egremont.* The character of Justice Shallow, it is well known, was drawn for Sir Thomas Lucy of Charlecote in Warwickshire; but in the following line,

"They may give the dozen white Luces in their coat," †

Shakspeare has somewhat amplified the charge; for the arms of Lucy, according to the heralds, were, gules crusilly or, three lucies or Pikes hauriant, argent; numerous instances of which bearing may be seen in the windows of the hall.

* Egremont, the Mount of Sorrow, derived its name, according to local tradition, from a lady of the Lucy family having been devoured by a wolf on a part of the domain, still distinguished by a cairn of stones, and called the "Woful Bank." The barony, previous to this doleful occurrence, bore the name of Caupland or Kopeland.

+ Merry Wives of Windsor, Act $i$. scene $i$. 
The word esox, which occurs once in the works of Pliny as the name of a fish equalling the Tunny in size, was employed by Artedi and Linnæus, to be the generic appellation of the Pikes. The specific name of lucius, applied by them to the common European species, is used by Ausonius in his poem on the Moselle to indicate a fish which from its haunts is evidently the Pike, called by him Lucius cultor stagnorum.

Armorial bearings of the Lucies.

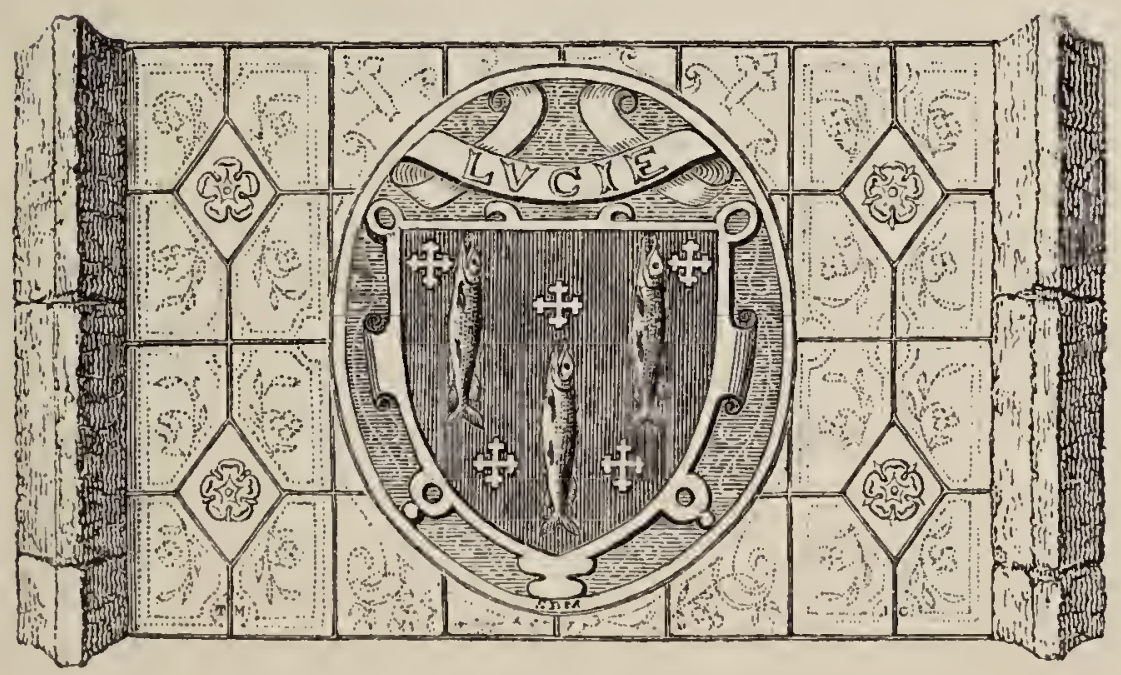


ABDOMINALES

MALACOPTERYGII.

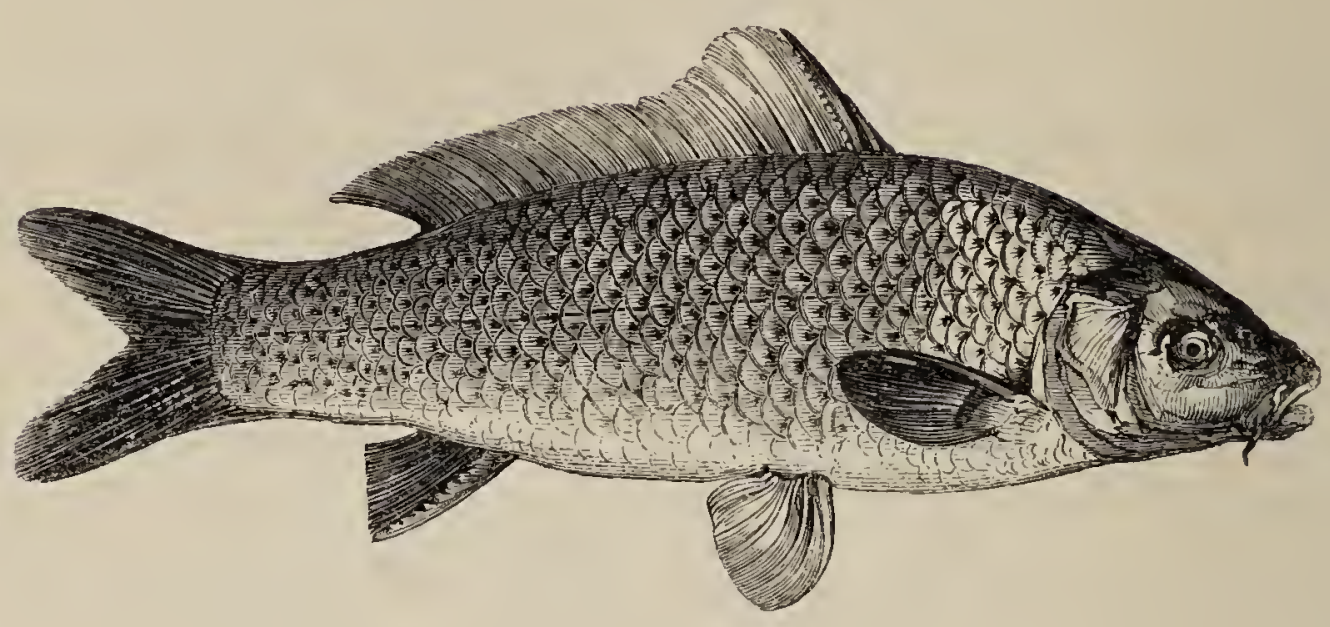

THE COMMON CARP.

CIPPYSG. Wales.

Cyprinus carpis, Cuv. et Valenc. Hist. des Poissons, xvi. 23.

" carpio, Linnaus. Bloch, pt. i. pl. 16.

, " $\quad$ Carp, Penn. Brit. Zool. vol. iii. p. 467, pl. 81.

, , , $\quad$ Dovov. Brit. Fish. pl. 110.

Cyprinids. Family Characters. -One dorsal. Oral orifice soft, small, and toothless, its upper half bordered by the premaxillaries, with the maxillaries lying behind them; no teeth, except on the inferior pharyngeals, which are opposed to a plate covering a cartilaginous or bony process of the basioccipital. Soft palate thick, pulpy, granular, and sensitive. Cycloid scales, which are absent in one or two genera only: none on the head. Branchiostegals three. Four biserial gills. Deep-seated vaso-ganglionic pseudobranchiæ. Swim-bladder divided by one or more narrow necks into chambers, the foremost of which is enclosed in a soft, fibrous capsule, and is connected to the acoustic organs by chains of small bones; the second chamber communicates with the gullet by a long tube.

Cyprinus. Generic characters.-A long dorsal, with two or three stiff, pungent, anterior rays, incumbent on a stout one which is often denticulated behind; anal having two solid rays and a shorter base than the dorsal. Pharyngeal teeth in three rows, the inner row composed of three with broad flat crowns, which are furrowed; the single tooth in each of the outer two rows being small. A short barbel to each premaxillary, and one at the comer of the mouth on each side.

The Cyprinida are more exclusively inhabitants of fresh waters than any other large family group of fishes, 
a few species only descending occasionally to the brackish tides of estuaries, but none living habitually in the ocean. They predominate also in numbers. Their head-quarters as to variety of form and multitude of individuals is the peninsula of India. They are nearly as abundant in the Chinese Empire, and are common throughout the temperate and warmer parts of Asia and Europe. In African ichthyology they are less conspicuous; none, as far as we know, have been detected in Australia, nor in tropical America; but one group exists in almost every river and lake of North America. They are not, however, altogether excluded from the southern hemisphere, as they inhabit the waters of Java and other large islands of the Malay Archipelago. In Australia, and in the southern extremity of America, the Galaxida are the only representatives of the typical Salmonide and Cyprinida.

The Carp family are among the least carnivorous fishes, their food being chiefly soft vegetables or decaying organic matters, and at times worms and insects. Mud is often found in the stomach of these fishes, having been swallowed probably on account of the minute worms or vegetable débris it contained. A few species attack small fishes. Some of the Cyprinida are solitary in their habits, others assemble in sculls, and M. Valenciennes has ascertained that several of the common European species pass the cold winter season in sleep.

A few particulars of the structure of fishes of this family are worthy of notice. In the Salmon and Herring families, the openings between the gills are equal in extent to the length of the branchial arches, but in the Cyprinidee they are partially closed by membrane, which, by retaining moisture, keeps the gills longer in a condition to absorb oxygen from the air than in the above-mentioned groups, and enables the fish to live much longer 
out of water. In the Common Carp, and some other species, the interior support of each leaf of the gills is bony; in the Tench it is partly bony, partly cartilaginous; while the Bream and the Barbel resemble the Pike in this part, being wholly cartilaginous. The leaflets of a gill vary in number with the species. In the Gudgeon there are about fifty-five in a row, in the Tench ninety-six, in the Barbel one hundred and six, and in the Carp one hundred and thirty-five.* The Carps have four biserial gills, and also pseudo-branchia, covered like those of the Pike by the mucous lining of the gill-chamber, but still more deeply hidden, owing to the extraordinary thickness of the pulpy palate.

In the Carps the teeth are confined to the pharynx, the organs of mastication being the inferior pharyngeals, which support teeth varying in number and form with the genera and even species. These teeth work against a cartilaginous plate adhering to the base of the skull (a tubercle in an alveolus of the basioccipital). Before this plate, and forming the roof of the palate, there is a remarkable, thick, soft, minutely-granular, and very. sensitive mass, which thins off towards the orifice of the mouth. This is popularly named "Carp tongue," but the real tongue belonging to the hyoid bone, and placed as usual between the limbs of the mandible, is small and inconspicuous.

The air-bladder in the Cyprinida is large, and is divided by narrow and very short necks into two or more chambers. Weber, about the year 1825, discovered that the acoustic labyrinth was connected by a chain of small bones with the anterior chamber. In the Loach, a member of the family, the air-bladder is considered by Professor Owen to exist chiefly in subserviency to the organ

\footnotetext{
* Milne Edwards, Leçons, vol. ii. p. 234.
} 
of hearing, being so small as to be enclosed by processes of the second and third vertebræ. In the Cyprinidee and Silurida a part of the acoustic chamber is formed by the first vertebra.

Though the Cyprinida are ranged among the soft-finned fishes, many members of the family have one or more of the dorsal or anal rays strong and pungent, or even toothed behind. These rays, though stout, are not so dense and translucent as the spines of the Acanthopterous fishes, and the joints of which they were primordially formed, often remain obscurely visible in the adult fish. These spinous rays, however, and the still more bony ones of the Silurida, form connecting links between Malacopteri and Acanthopteri, two important divisions noted in the table given in the introduction.

The scales of the Cyprinoid fishes are cycloid, that is, sub-orbicular, with no teeth on their posterior edges, and their lines of structure are also generally smooth and without indentations. These cycloid scales are covered with a thick mucous skin or epidermis in the Common Carp and its nearest allies: to this group Prince Charles Bonaparte gave the name of Cyprinini, and Dr. John M'Clelland that of Paonomina, or vegetable-eaters. Another section of the family, named by the former of these naturalists Leuciscini, and by the latter Sarcoborine, possesses more brilliant cycloid scales, their lustre not being obscured by a thick epidermis. The name invented by Dr. M'Clelland means "flesh-eaters," and has reference to the members of the section being keen pursuers of insects and other soft animal matter.

Prince Charles Bonaparte and several other modern ichthyologists seek for characters of the genera in the form and arrangement of the pharyngeal teeth: in the present edition of this work Heckel and Kner's history 
of the Fresh-water fish of Austria has been consulted in drawing up the generic characters of the Cyprinida. The Carp is noticed by Aristotle and Pliny, but appears not to have been held in such estimation formerly as at the present day. It is found in most of the lakes and rivers of Europe in general, and in those of Russia and Eastern Siberia; but the climate of the southern and temperate parts is most congenial to it, and it is observed to decline in size when transported to the higher northern districts. It thrives in brackish water, and is said to attain an extraordinary size in the Caspian, where it is, according to M. Valenciennes, very abundant. Its economical cultivation is, however, particularly attended to in Austria and Prussia, and considerable traffic in Carp prevails in various parts of the European continent, where an acre of water will let for as much yearly rent as an acre of land, and where fresh-water fishes, as articles of food, are held in higher estimation than in this country. Carp are said to live to a great age, even to one hundred and fifty, or two hundred years; but they lose their rich colour,-their scales, like the productions of the cuticle in some other animals, becoming gray and white with age.

Neither the exact period when, nor the particular country from whence, Carp were first brought to England, appear to be distinctly known. Leonard Mascall takes credit to himself for having introduced the Carp, as well as the Pippin; but notices of the existence of the Carp in England occur prior to Mascall's time, or 1600. In the celebrated Boke of St. Albans, by Dame Juliana Barnes, or .Berners, the Prioress of Sopewell Nunnery, already referred to in page 345 , Carp is mentioned as a "deyntous fisshe;" and in the Privy Purse expenses of King Henry the Eighth in 1532, various entries are 
made of rewards to persons for bringing "Carpes to the King." **

The old couplet is certainly erroneous which says-

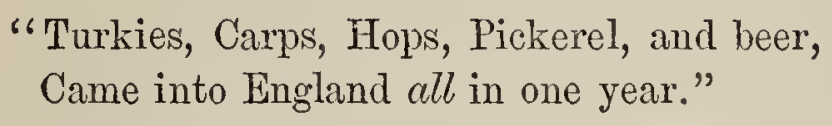

Pike or Pickerel were the subject of legal regulations in the reign of Edward the First. Carp are mentioned in 1496 ; in the Boke of St. Albans, turkeys were brought to England from North America about 1521; but hops were unknown till 1524, previous to which wormwood and other bitter plants were used to preserve beer, and the Parliament of 1528 petitioned against hops as a wicked weed. Beer was licensed for exportation by Henry the Seventh in 1492, and an excise on beer existed as early as 1284, also in the reign of Edward the First. The Rev. Joseph Hughes of Meltham, whose reputation as a. Welsh scholar is widely known, says in a letter,-" I have read most of the works of our Welsh poets from Aneurin down to the last century, and in none have I found the Welsh name for the Carp; but I do not think that this is conclusive evidence of its non-existence in our waters in times far remote."

The Aristotelian names of Kuprinos, or Kuprianos, are evidently the originals of the Latin term Cyprinus, used by Pliny, and perhaps also of the modern appellations, Karp among the Swedes and Germans, Carp, Karpe, and Carpe among the English, Danes, and French, Carpa among the Spaniards, and Carpena in use among the inhabitants on the banks of the Po. The Venetians give it the widelydifferent name of Rayna.

In this country the Carp inhabits ponds, lakes, and rivers; preferring in the latter parts where the current

* Pickering's splendid edition of Walton, p. 207, note. 
is not too strong, and thriving best on soft marly or muddy bottoms. It is very prolific, breeding much more freely in lakes and ponds than in rivers. Bloch found six hundred thousand ova in the roe of a female of nime pounds' weight, and Schneider seven hundred thousand in a fish of ten pounds' weight. It spawns towards the end of May or the beginning of June, the time depending on the temperature of the water and the season; and the ova are deposited upon weeds, among which the female is followed by two or three males, and the fecundation of a large proportion of the ova is by this provision of nature effectually secured; but it both breeds and grows much more freely in some waters than in others, without any apparent cause. Only a few Carp exist even in preserved waters in Scotland, and these breed but slowly, and in some instances not at all.

Carp are said to have been introduced into Ireland in the reign of James the First. Mr. Thompson, in his Natural History of Ireland, mentions Montalto and Killyleagh in the county of Down and Market Hill in the county of Armagh, as localities where it is now found. It exists also in the counties of Galway, Sligo, Kilkenny, and Dublin. The great Earl of Cork introduced it into the south of Ireland.

The larva of insects, worms, and the softer parts of aquatic plants, are the food of the Carp. It probably eats little or nothing during winter, and it is supposed to bury itself in mud. White, in his Natural History of Selborne, says, "in the gardens of the Black Bear Inn in the town of Reading, is a stream or canal, running under the stables, and out in to the fields on the other side of the road; in this water are many Carps, which lie rolling about in sight, being fed by travellers, who amuse themselves by tossing them bread: but as soon as 
the weather grows at all severe these fishes are no longer seen, because they retire under the stables, where they remain till the return of spring." It feeds well in stews; and Mr. Jesse says of some Carp and Tench, so kept by him, that " they were soon reconciled to their situation, and eat boiled potatoes in considerable quantities; and the former seemed to have lost their original shyness, eating in my presence without any scruple."

The Carp is exceedingly tenacious of life out of water. Several authors have stated that it is a common practice in Holland to keep them alive for three weeks or a month by hanging them in a cool place, with wet moss in a net, and feeding them with bread steeped in milk; taking care to refresh the fish now and then by throwing fresh water over the net in which it is suspended.

Though not so rapid in their growth as some fish, Carps have attained three pounds' weight by their sixth year and six pounds' weight before their tenth year. The largest I can refer to are thus noticed in Daniel's Rural Sports :- "Mr. Ladbroke, from his park at Gatton, presented Lord Egremont with a brace that weighed thirtyfive pounds, as specimens to ascertain whether the Surrey could not vie with the Sussex Carp. In 1793, at the fishing of the large piece of water at Stourhead, where a thousand brace of Carp fit for killing were taken, the largest was thirty inches long, upwards of twenty-two inches in girth, and weighed eighteen pounds."

At Weston Hall, Staffordshire, the seat of the Earl of Bradford, the painting of a Carp is preserved which weighed nineteen and a half pounds. This fish was caught in a lake of twenty-six acres, called the White Sitch, the largest of three pieces of water which ornament this fine estate. M. Valenciennes mentions a Carp which was taken at Dertz, and presented to Frederick 
the Great, which weighed thirty-eight pounds, and he quotes reports of some of much greater weight, but seems scarcely to believe in them.

Carp are difficult to take by angling, or rather very uncertain,-great success one day, and little or none another, happening to the same angler at the same water. They manage to avoid a net, burying themselves in the mud, and allowing a heavily-loaded ground-line to pass over them without their moving; but if disturbed from their hiding-places, they frequently endeavour, like the Grey Mullet, to escape over the corked head-line. Carp are in season for the table from October to April, and are greatly indebted to cooks for the estimation in which they are held.

The mouth is small without apparent teeth; a barbel exists at the upper part of each corner of the mouth, and a second smaller one above it: the nostrils are large, and are pierced at the second third of the distance between the lip and the eye; the eye is small; operculum marked with striæ radiating from its anterior edge; nape and back rising suddenly. The fin-rays are-

D. 4 | 19: P. $17:$ V. 9: A. 3 |5: C. 19 . Vertebræ 36.

The fourth dorsal fin-ray tall, bony, and strongly serrated on the posterior surface; the three anterior ones graduated, also bony; the first soft branching ray is the longest in the fin; the last one is double: the dorsal and anal fins end on the same plane, and the last has three stiff rays like the anterior ones of the dorsal, the third being serrated and the last soft one double. The pectoral fin arises immediately behind the free edge of the operculum, its origin being semicircular, concave forwards; the upper ray is the longest, and all the rays are flexible. The ventral fin commences under 
the fourth ray of the dorsal fin. The tail is forked, the longest rays being as long again as those of the centre. The body is covered with large scales, in about twelve rows between the ventral and dorsal fins. The general colour golden olive brown, head darkest; irides golden ; belly yellowish white; lateral line interrupted, straight; the fins dark brown.

M. Valenciennes, in his Histoire des Poissons, commends the figure at the beginning of this article as the best representation of the Carp that he had seen. The cranium is shown by the vignette below. It has no mesial, lateral, or temporal ridges, and the bony septum between the orbits is complete, the chamber for lodging the brain being more closed than in most other families of osseous fishes.

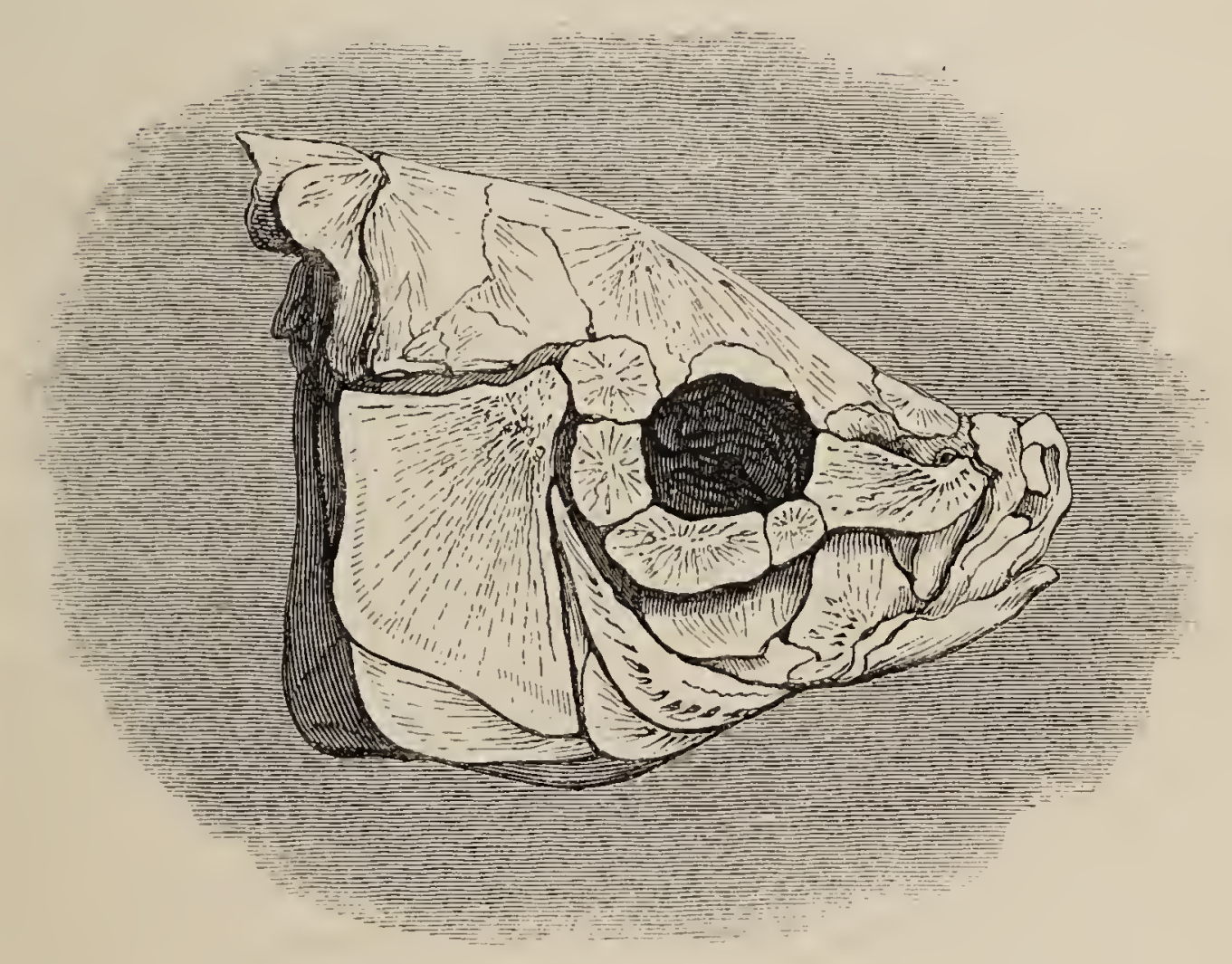


ABDOMINALES

MALACOPTER YGII.

CYPRINIDE.

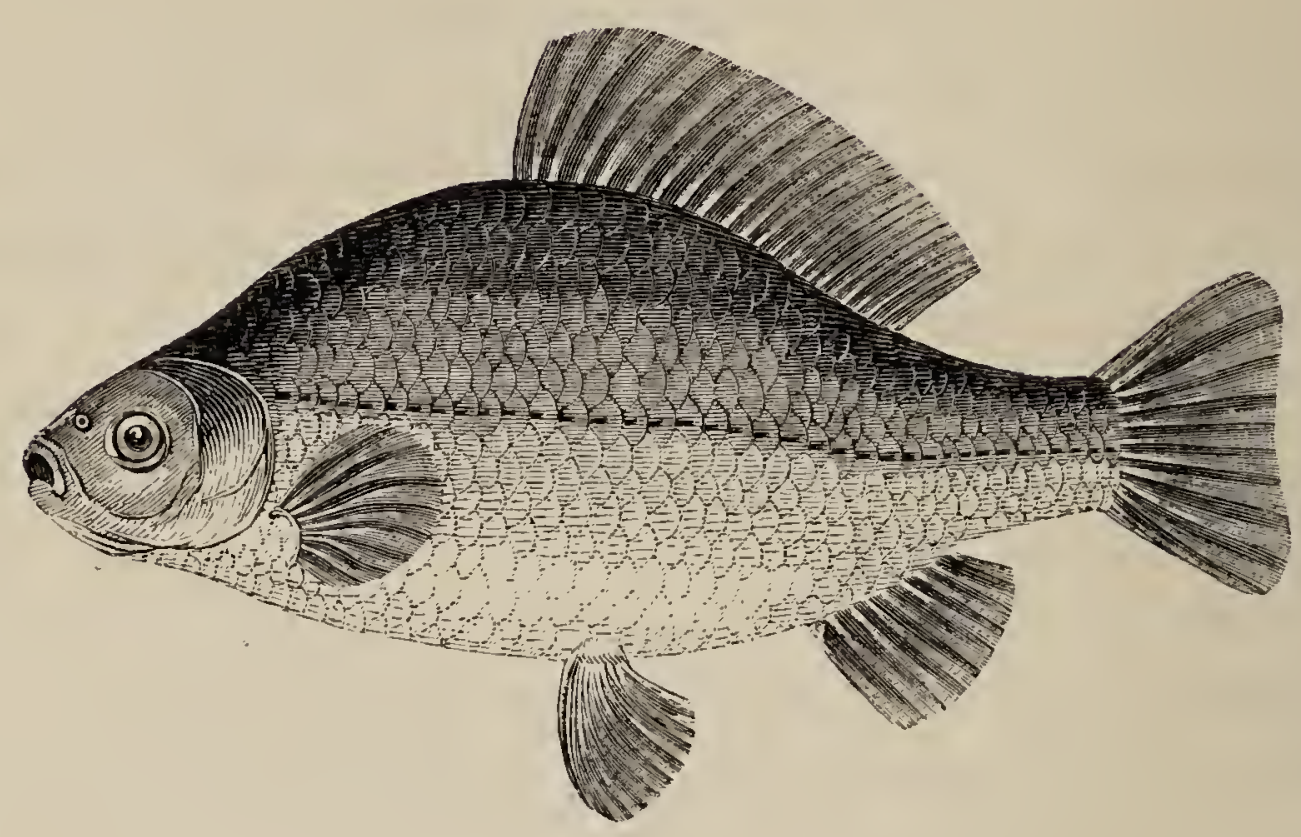

THE CRUCIAN CARP.

THE GERMAN CARP. BYRBYSG, Wales.

Carassius Linncei, Bonaparte, Cyprinidæ Europæ.

Cyprinus carassius, Blocr, pt. i. pl. 11. Valenc. Hist. des Poiss. xvi. 82.

, $\quad$, Ruda, Fries och Eкsтröm, Skand. Fisk. pl. 31.

Carassius. Generic characters. - Aspect of Cyprinus. Dorsal rays about twice as numerous as the anal ones; the fins of similar structure to those of Cyprinus. Mouth terminal. No oral barbels. Pharyngeal teeth, four on each bone, uniserial and spud-shaped (scalpriformes).

M. Valenciennes includes the Carps without barbels on the upper jaw in the genus Cyprinus, but Nilsson separated them under the generic appellation of Carassius, corresponding to Cyprinopsis of Fitzinger. The pharyngeal armature is termed by Prince Charles Bonaparte dentes scalpriformes, in contradistinction to the molars of the Carps. By this term he means to designate, compressed teeth with narrow or thin-edged crowns, and more slender necks, bearing a resemblance to a garden spud, or ploughman's pattle.

Since the publication of the first edition of this work, 
I have obtained another specimen from the Thames of what I believe to be the true Cyprinus carassius; and on the authority of various authors, as well as from a close examination of examples of that and of Cyp. gibelio, I have considered them to be distinct, and have separated them accordingly.

With reference to the systematic term carassius, and the French name carassin, it may be observed that this species is called karussa in Scania and Bohusland, districts of Sweden. The late Dr. Jacobs, an ichthyologist of Berlin, says it is there called carouche; and I have very little doubt that our well-known term Crucian is a modification of one or other of these names, and probably of the word carouche. In Sweden, generally, it is named Ruda. It is called the Hamburgh Carp by Lacépède, and the German Carp by some of our Thames fishermen. Like our Common Carp, it is thought not to be indigenous to England, perhaps without sufficient authority in either case.

This particular Crucian Carp, for two species have hitherto been included under this name, is by far the rarer fish of the two. I have never obtained it except from the Thames between Hammersmith and Windsor, where it attains considerable size, sometimes weighing a pound and a half; in one instance a specimen, brought to me in October 1829, weighed two pounds eleven ounces. The example I last obtained, measured ten inches in length and four inches and a half in depth, without including the dorsal fin; it weighed one pound. The Crucian Carp is stated by Ekström in the Skandinaviens Fiskar to be common in all parts of Scandinavia, except the most northern, and to affect particularly shallow, muddy, and grassy lakes, and he says that except the Gasterosteus it is the only fish of the 
country that breeds freely in ponds. This it does so readily that it is looked upon as a domestic animal. These remarks apply also to the Prussian Carp, which Ekström considers to be merely a variety of the Crucian. The Crucian Carp, he further says, is indolent, and never quits its native spot unless compelled to remove. It habitually keeps to the bottom, and rarely comes to the surface, unless when tempted thither by the rays of a warm sun. It spawns in June, but the time varies according to the fineness of the season, being earlier in a warm summer. During this operation the fish collect in dense crowds, and move about quickly. The eggs are deposited among the water plants, and are in favourable weather quickly hatched, but the growth of the fry is slow. The food of the fish consists of insects, worms, grass, and mud. Its flesh is considered to be excellent in Sweden, but its flavour depends much on the way in which it is cooked.

Pallas, in his Zoographia, mentions the Crucian Carp as inhabiting all the lakes and marshes of Russia and Siberia, and as yielding the inhabitants of those countries a delicious food. It is taken with nets in the vicinity of Jakutsk in the winter time, and is then quite torpid. The fishermen select the largest, and return the others into the water, where they revive on the advent of spring. Even when the lakes freeze to the bottom, it survives, and when a thaw comes issues from the mud, in which it had buried itself.

The length of the head is to the depth of the body as one to two; and to the whole length of head, body, and tail, as one to five; the depth of the body, compared to the whole length, as two to five; the tail nearly square at the end. The fin-rays are-

D. $4 \mid 17:$ P. $14:$ V. $9:$ A. $3 \mid 6:$ C. 19. 
The lateral line is straight, containing thirty-four punctured scales; with seven scales above it to the dorsal edge at the base of the first ray of the dorsal fin; and six scales below the lateral line to the origin of the ventral fin. Three short spines anterior to the elongated bony ray of the dorsal fin, are included in the enumeration of the rays, to make twenty-one; the long stout ray is slightly serrated on both edges of the posterior groove, all the rays behind it branched. The first ray in the pectoral and ventrals, and three rays of the anal fin are also simple or bony; all the other rays of the fins are branched.

The scales are large, the concentrie striæ thereon very strongly marked. The colour of the body above the lateral line is a rich golden brown, becoming lighter and more yellow on the sides below the lateral line and on the belly; the fins dark brown; the mouth small; the irides golden yellow.

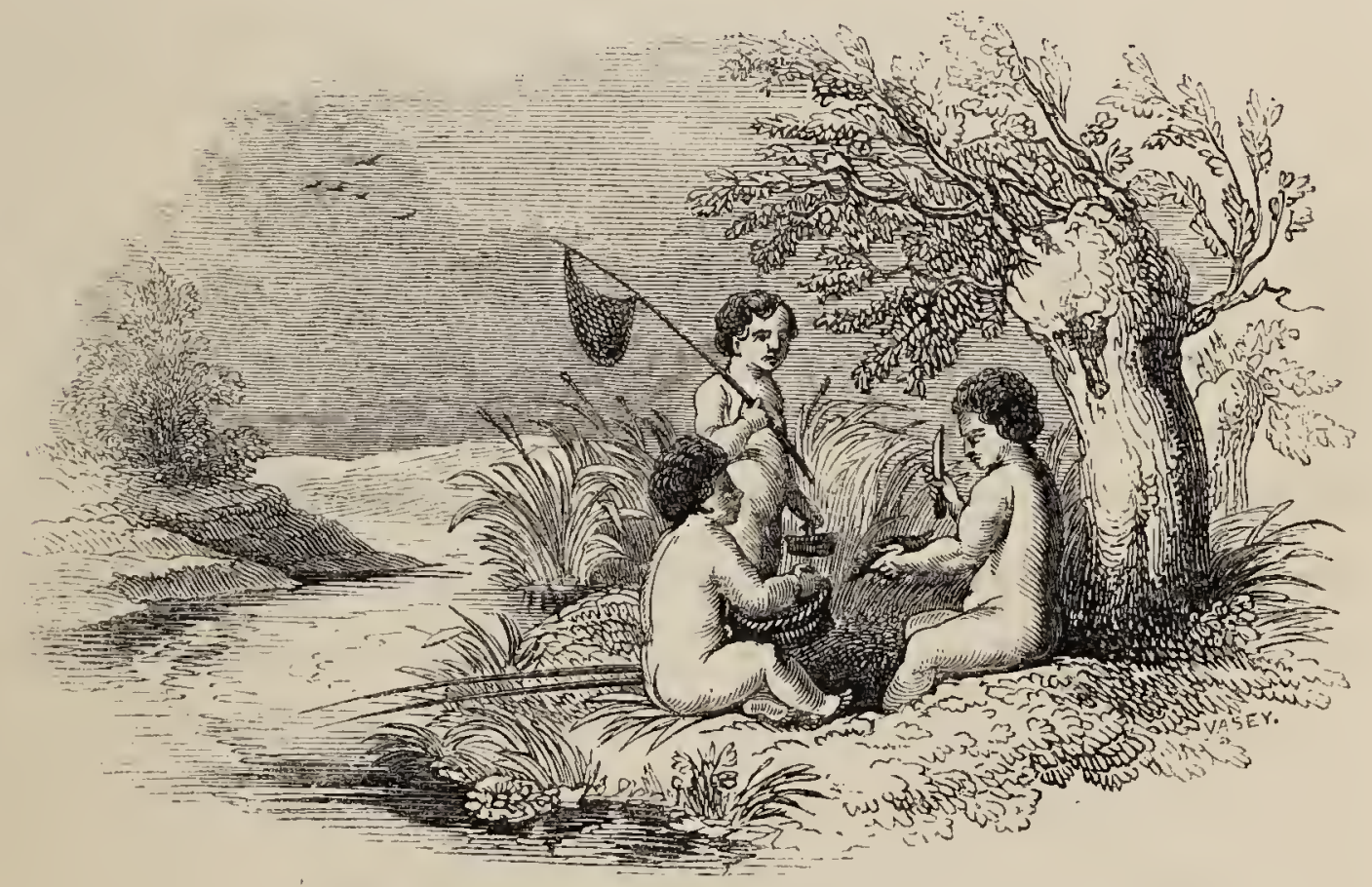

SECUS RIVOS AqUARUM. 
A BDOMINALES

MA LACOPTER Y Y II.

CYPRINIDAR.

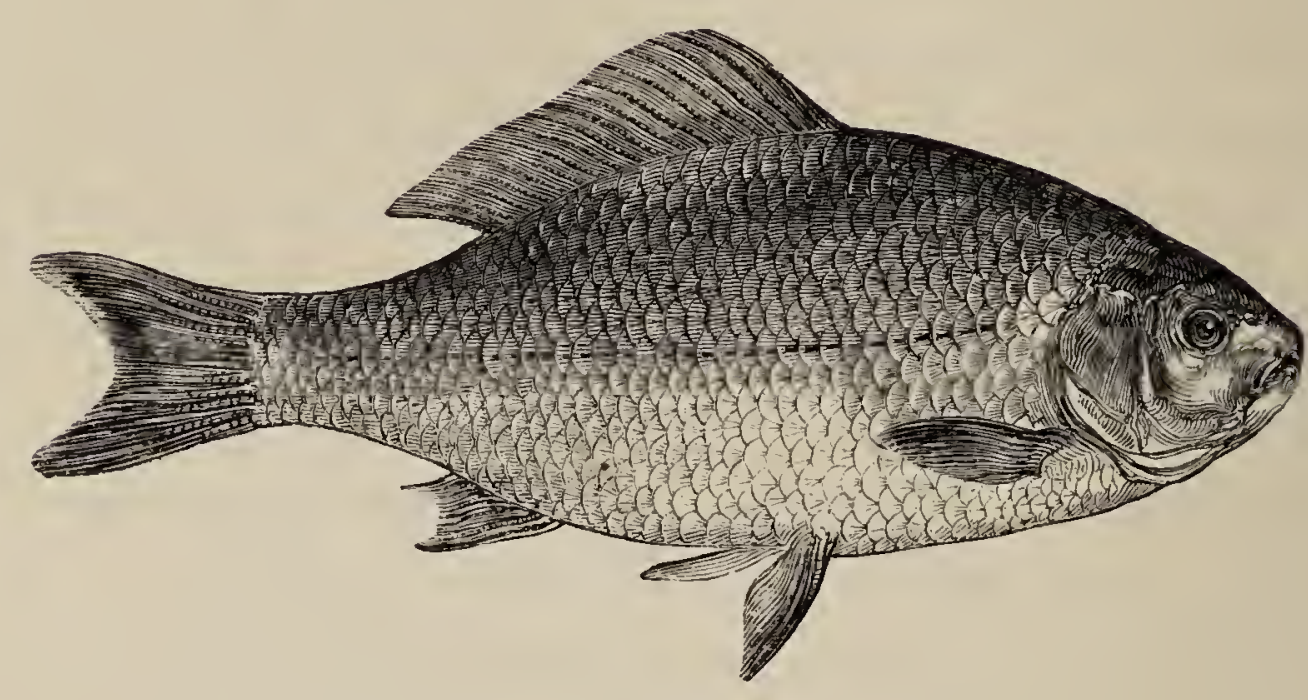

THE PRUSSIAN CARP. GIBEL CARP.

Crouger, Warwickshire.

Curassius gibelio, Nilsson. Bonap. Cyprinidæ Europæ.

Cyprinus gibelio, BLoch, pt. i. pl. 12.

, ", Cuv. et Valeno. xvi. 90.

" $\quad$ Gibele Carp, Penn. Brit. Zool. vol. iii. p. 480, pl. 83.

,, ,, Damm-Ruda, Fries och Eкsтröм, Skand. Fisk. pl. 32.

The Prussran Carp is found in some of the ponds about London, particularly in the vicinity of the Thames, a few miles upwards to the west of the metropolis; it is also known to be very common in several counties of England, and probably exists in most of them. This fish spawns about the end of April, or early in May: it is very prolific,-the roe containing a great quantity of eggs. Though known to be very numerous in some situations, but little success attends the angler for Gibel Carp, as it seldom bites freely. The flesh is white and agreeable. This fish is exceedingly tenacious of life, and $\mathrm{I}$ have known it recover and 
survive after having been kept out of water thirty hours. The numbers of the fin-rays are-

\section{D. $4 \mid 16:$ P. $14:$ V. $9:$ A. $3 \mid 6:$ C. 19. Vertebræ 30.}

The length of the head, compared to the length of the head and body without the tail, is as one to four; including the tail, as one to five; the caudal rays being as long as the head, and one-fifth of the whole length. The body is deepest on the line of the commencement of the dorsal and ventral fins; and the depth, compared to the whole length, including the tail, is as one to three.

The head is obtuse; the mouth and eyes small; the body rather short and thick: the scales large; seven scales occupy an oblique line between the base of the first dorsal fin-ray and the tubular scale of the lateral line, and six scales between the lateral line and the origin of the ventral fin; thirty-four or thirty-five scales form the lateral line, which descends by a gentle curve from the upper free angle of the operculum to below the middle of the body, and from thence straight to the tail: the pectoral fin commences directly under the posterior point of union of the operculum with the suboperculum; the dorsal and ventral fins commence opposite to each other; the length of the base of the dorsal fin nearly equals the depth of the body; anal fin small, commencing immediately under the origin of the last ray of the dorsal fin; the stronger bony ray of the dorsal and anal fin finely serrated. The first ray of both these fins is so short as not to be easily detected. The tail is forked, divided into two nearly equally pointed halves, the longest rays about one-third longer than the short rays of the middle portion; the upper part with ten rays, the lower portion with nine; the numbers in the halves being unequal as is usual in the Carp family. 
The top of the head and back is olive brown; the sides lighter in colour; the belly almost white; the whole fish shining with a brilliant golden metallic lustre: irides golden; cheeks and gill-covers brilliant golden yellow; the dorsal fin and upper part of the tail brown, tinged with orange; pectoral, ventral, and anal fins, orange red; lower part of the tail tinged with the same colour.

This fish has been considered here as the C. gibelio of Bloch; but in one circumstance it does not agree with his fish. Bloch says the $C$. gibelio has but twenty-seven vertebræ; but the specimens examined for the description now given had thirty vertebræ.

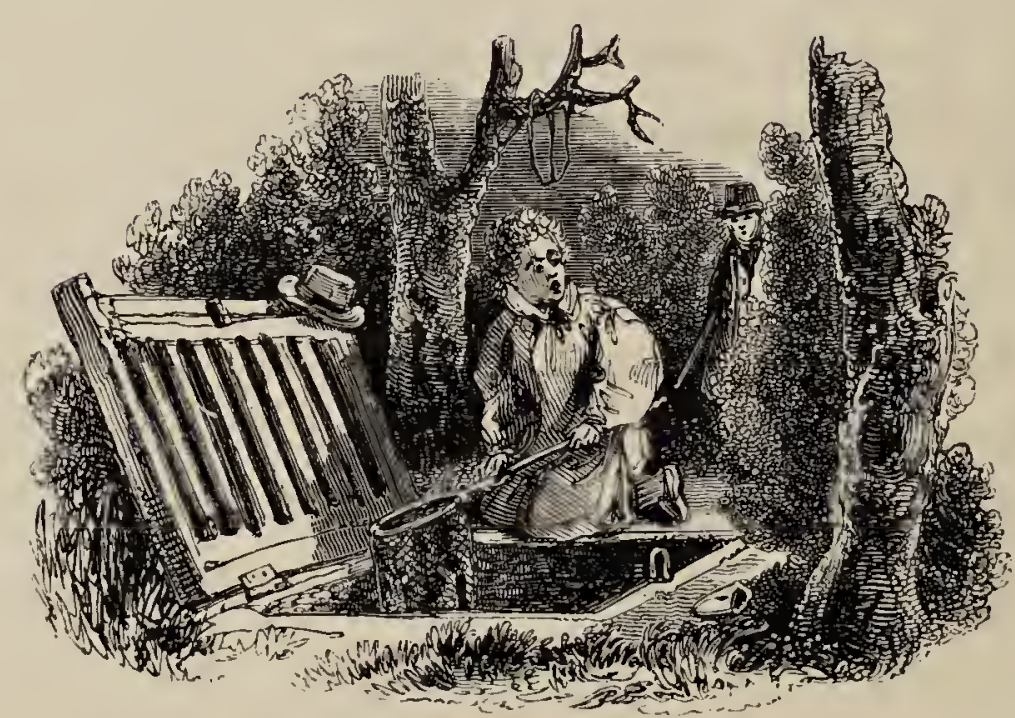




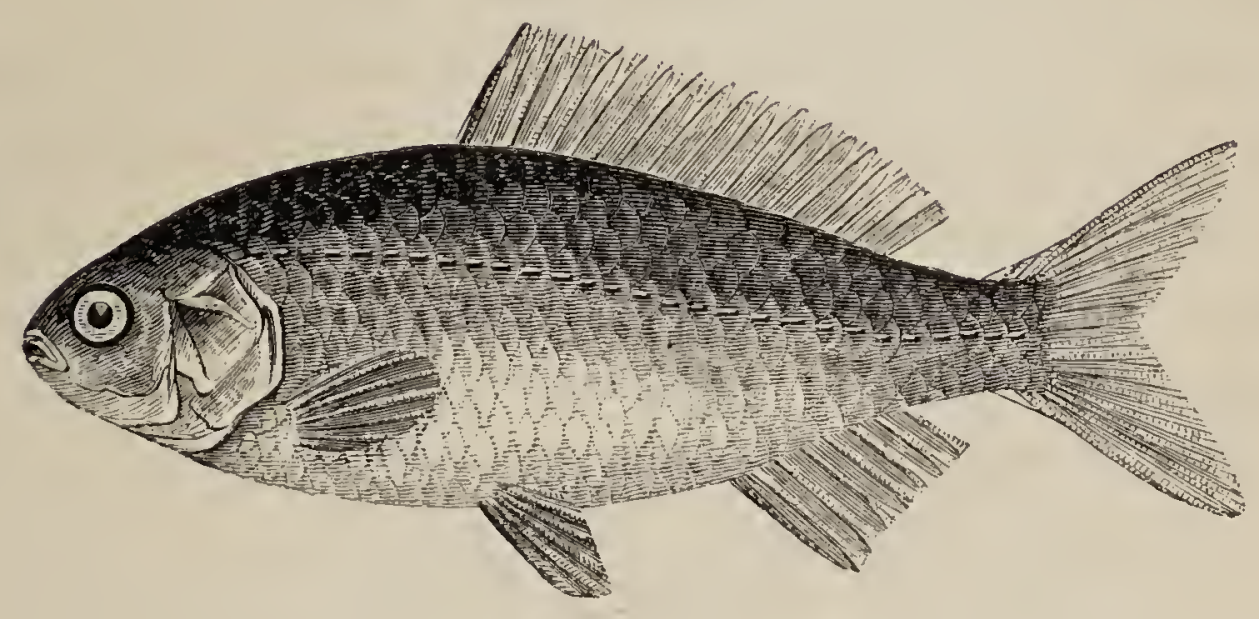

\section{THE GOLD CARP.}

Carassius auratus, Cuv. et VArenc, xvi. 101.

Cyprinus auratus, Linnæus.

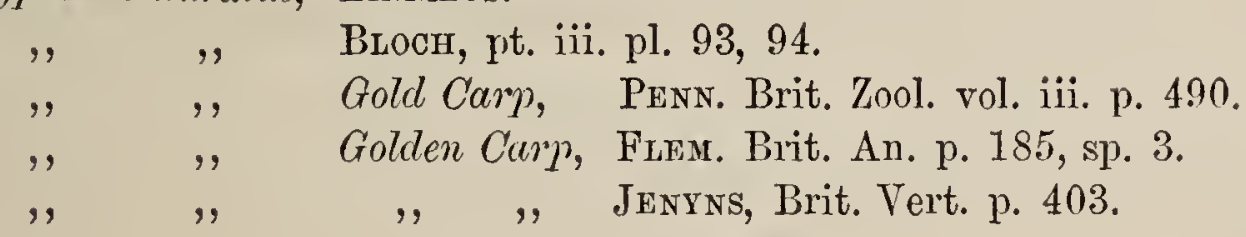

The date of the first introduction of the Golden Carp, or Gold and Silver fish, as they are more frequently called, is differently stated by authors; 1611, 1691, and 1728, are each recorded as the particular year in which they were first brought over. The earliest seen in France were sent to Madame Pompadour.

Pennant says, "In China the most beautiful kinds are taken in a small lake in the province of Che-Kyang. Every person of fashion keeps them for amusement, either in porcelain vessels, or in the small basins that decorate the courts of the Chinese houses. The beauty of their colours, and their lively motions, give great entertainment, especially to the ladies, whose pleasures, from the policy of that country, are extremely limited." 
The Chinese call their fish with a whistle to receive their food.*

A correspondent in Loudon's Magazine of Natural History, vol. iii. page 478, considers " that Gold Carp were probably introduced into Portugal at an early period, after the people of that country had discovered the route to the East Indies by the Cape of Good Hope, as they appear to be now completely naturalised there, and abound in many of their streams, whence they are brought to us by trading vessels, from Lisbon, St. Ubes, \&c., in large earthen jars, and may be had at a very easy rate before they get into other hands. They have also been introduced and naturalised in the Mauritius by the French, where they now abound in fish-ponds and streams, and are served up at table as agreeable food, with the other fresh-water fishes, to the brood of which they are thought to be very inimical, by destroying their spawn and young fry. The extreme elegance of the form of the Golden Carps, the splendour of their scaly covering, the ease and agility of their movements, and the facility with which they are kept alive in very small vessels, place them amongst the most pleasing and desirable of our pets. They even recommend themselves by another agreeable quality-that of appearing to entertain an affection for each other. A person who kept two together in a glass, gave one of them away; the other refused to eat, and showed evident symptoms of unhappiness till his companion was restored to him." -Jesse's Gleanings.

This fish breeds freely in small ponds or even in tanks in this country; and very freely if the temperature of the

* I think it was Sir Joseph Banks who used to collect his fish by sounding a bell; and Carew, the Cornish historian, brought his Grey Mullet together to be fed by a noise made with two sticks. 
water can be maintained at an elevation above the ordinary mean. It is well known that in manufacturing districts, where there is an inadequate supply of cold water for the condensation of the steam employed in the engines, recourse is had to what are called engine-dams or ponds, into which the water from the steam-engine is thrown for the purpose of being cooled: in these dams, the average temperature of which is about eighty degrees, it is common to keep Gold-fish ; and it is a notorious fact, that they multiply in these situations much more rapidly than in ponds of lower temperature, exposed to the variations of the climate. Three pairs of this species were put into one of these dams, where they increased so rapidly, that at the end of three years their progeny, which were accidentally poisoned by verdigris mixed with the refuse tallow from the engine, were taken out by wheelbarrowsfull. Gold-fish are by no means useless inhabitants of these dams: they consume the refuse grease, which would otherwise impede the cooling of the water by accumulating on its surface.

A few authentic notices of the power of fishes in bearing extremes of high and low temperature may not improperly be introduced here.

"Desfontaines found a Sparus of Lacépède, the Chromis of Cuvier, in the hot waters of Cassa in Barbary, in which Reaumur's thermometer rose to thirty degrees, equal to eighty-six of Fahrenheit: and Shaw saw small fishes of the Mullet and Perch kind in these springs." -Travels in Barbary, folio edit. Oxford: 1738, p. 231.

Saussure, speaking of the hot springs of Aise in Savoy, says, "I have frequently examined the temperature of these waters at different seasons, and have always found it very nearly alike (about $113^{\circ}$ Fahr.). Notwithstanding the heat of these waters, living animals are 
found in the basins which receive them. I saw in them Eels, Rotifera, and Infusoria, in 1790."

"At Feriana, the ancient "Thala," says Bruce, "are baths of warm water without the town; in these were a number of fish, about four inches in length, not unlike Gudgeons. Upon trying the heat by the thermometer, I remember to have been much surprised that they could have existed, or even not been boiled, by continuing so long in the heat of this medium."

"The facts mentioned by Sonnerat and other travellers induced Broussonnet to make some experiments on the degree of heat which river fish are capable of enduring. The details of the degrees of heat are not stated, but many species lived for several days in water which was so hot that the hand could not be retained in it for a single minute."

The five preceding notices are from Dr. Hodgkin's additions to the translation of Dr. W. F. Edwards's French work "On the Influence of Physical Agents on Life."

"In the thermal springs of Bahia in Brazil, many small fishes were seen swimming in a rivulet which raises the thermometer eleven and a half degrees above the temperature of the air."

"Humboldt and Bonpland, when travelling in South America, perceived fishes thrown up alive, and apparently in health, from the bottom of a volcano, in the course of its explosions, along with water and heated vapour that raised the thermometer to two hundred and ten degrees, being but two degrees below the boiling point." .

Dr. Davy, in his History of Ceylon, describes the hot springs of Cannea about seven miles from Trincomalee, as having a temperature varying with the different wells, 
of which there are seven, from $86^{\circ}$ to $106^{\circ}$ Fahrenheit, but subject to fluctuation, as other observers had recorded a heat of $110^{\circ}$ Fahrenheit in the hottest spring. All the springs Dr. Davy thinks flow from one source, and he suggests that the lower temperatures of the less copious wells are occasioned by the cooling effects of great discharges of azotic gas. In one of the wells, whose temperature was $91^{\circ}$, he saw small fishes, but M. Reynaud, a correspondent of M. Valenciennes, discovered fishes (Nuria thermoicos, Valenc., xvi. 239) in one of the hotter springs, which caused the mercury in the thermometer to rise to 40 centigrammes, or $104^{\circ}$ Fahrenheit. The biggest of the fishes was scarcely two inches long. Leuciscus thermalis, also from Cannea, was taken by M. Reynaud from water in which his thermometer stood at 1220 Fahrenheit.

Dr. John M'Clelland, in his History of the Fishes of Assam, states that Dr. Cumberland took a fish from a spring at Pooree, which had a temperature of $112^{\circ}$ Fahrenheit; when the heat of the water was increased to $120^{\circ}$ Fahrenheit, the fish died. This was also a Cyprinoid fish, and of the same genus with the preceding, being the Nuria thermophylos of Valenciennes.

The power of fishes to sustain a low temperature is equally extraordinary; "for that these," says John Hunter, in his Animal Economy, "after being frozen, still retain so much of life as when thawed to resume their vital actions, is a fact so well attested that we are bound to believe it."

"Perch have been frozen, and in this condition transported for miles. If, when in this state, fishes are placed in water near a fire, they soon begin to exhibit symptoms of reanimation; the fins quiver, the gills open, the fish gradually turns itself on its belly, and moves slowly 
round the vessel, till at length, completely revived, it swims briskly about."*

But to return to the fish before us: I need not occupy space by attempting to describe a species so well known, and of which the variations in colour, fin-rays, and even in the fins, are so numerous, as to appear to bear some proportion to the degree and extent of the domestication. M. de Sauvigny, in his Histoire Naturelle des Dorades de la Chine, published at Paris in 1780, has given coloured. representations of eighty-nine varieties of this Carp, exhibiting almost every possible shade or combination of silver, brilliant orange, and purple. I have referred to variations in the fins themselves. These fishes are sometimes seen with double anal fins, and others with triple tails : when this occurs, it is generally at the expense of the whole or part of some other fin: thus the specimens with triple tails are frequently without any portion of the dorsal fin, and such specimens have been figured by Bloch and others. Among two dozen Gold-fish for sale in London, were some with dorsal fins extending more than half the length of the back: some, on the contrary, had dorsal fins of five or six rays only, and one specimen without any dorsal fin whatever; yet this fish appeared to preserve its perpendicular position with the same ease as any of the others. This induced me to make an experiment, in order to ascertain whether the sudden privation of the dorsal fin would produce any more apparent inconvenience than was observable in the specimen just referred to.

For this purpose I attended at the Zoological Society's Garden a short time before the hour at which the Otter was fed daily with his accustomed meal of living fish. Nine or ten Roach and Dace were placed with plenty of

\footnotetext{
* T. S. Bushnan's Introduction to the Study of Nature.
} 
water in a large tub of three feet diameter. Five or six of these fish I took from the tub one after another, and with a pair of scissors cut off the whole of the dorsal fin close to the back, returning each fish to the water. They were but little or scarcely at all affected, and each fish appeared to preserve its perpendicular position, or to ascend or descend in the water with the same ease and certainty as before the privation; the mutilated, swimming among the unmutilated, seemed to possess the same powers. I did not carry the experiment beyond ascertaining this point, and in a few minutes the fish were consigned to the Otter.

When Gold-fish breed in ponds or tanks under favourable circumstances, the young attain the length of five inches in the first twelve months, but their growth afterwards is much less rapid. I have not seen any specimen that exceeded ten inches in length. The young are dark-coloured at first, almost black, changing inore or less rapidly according to constitutional power. 


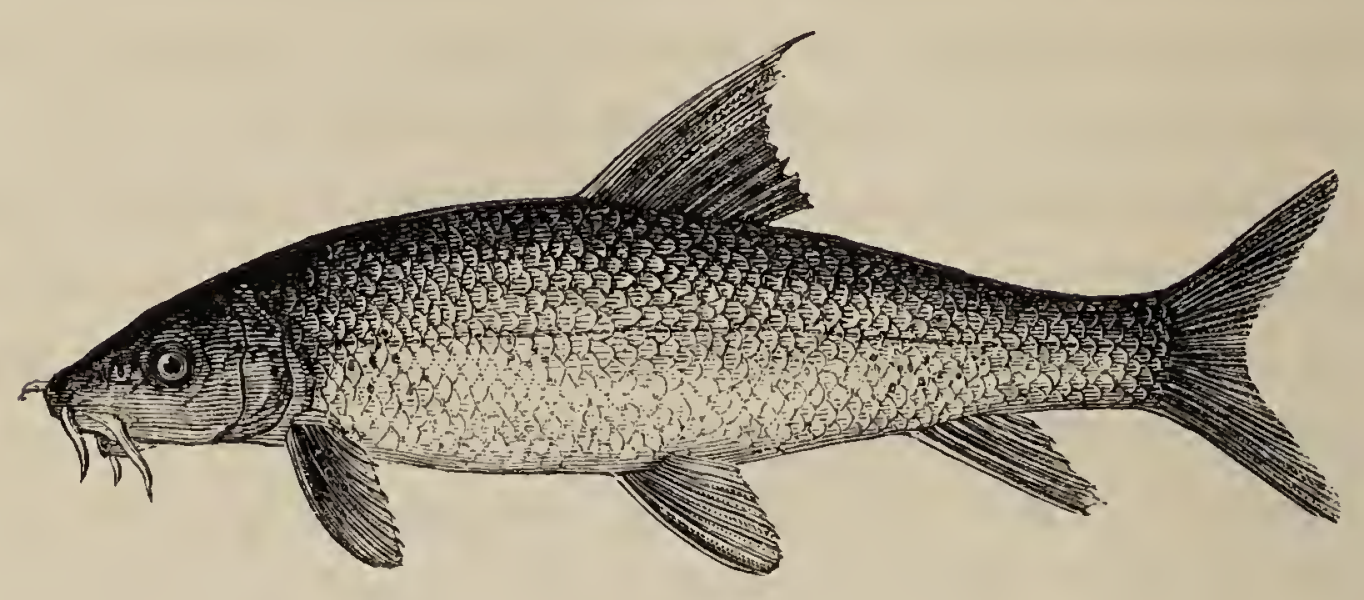

\section{THE BARBEL.}

BARFOGN, Wales.

Barbus fluviatilis, Valenciennes, Hist. des Poiss. xvi. p. 125.

," vulgaris, Flem. Brit. An. p. 185, sp. 58.

Cyprinus barbus, Linneus. Bloch, pt. i. pl. 18.

, ", Barbel, Penn. Brit. Zool. vol. iii. p. 472, pl. 82.

", " , Donov. Brit. Fish. pl. 29.

Barbus. Generic Characters.-Body fusiform. Dorsal short, with three graduated rays incumbent on the fourth, which is strong and often denticulated, but in some Asiatic species smooth. Anal also short, and always with fewer rays than the dorsal. Four barbels on the upper lips. Pharyngeal teeth spoon-shaped, in three rows, curved at the point (dentes cochleariformes, Bonap.); numbers in the rows, two, three, five, sometimes only two in the second row. Snout, in one group, projecting.

The Barbel is said to have been so called from the barbs or wattles attached about its mouth. It is readily distinguished by these appendages, in conjunction with the great extension of the upper jaw beyoud the lower. This genus and Cyprinus are the only European forms in the family, which have three rows of pharyngeal teeth. The teeth swell out into an oval and are concave on one side, or spoon-shaped.

This fish was well known to the older ichthyologists. The warm and temperate parts of Europe appear to be 
its natural locality, and it is abundant in the Rhine, the Elbe, and the Weser. It is also a plentiful fish in the Crimea, and in all the rivers that flow into the Black Sea.

Near London, the Thames, from Putney upwards, produces Barbel in great quantities, and of large size; but they are held in little estimation, except as affording sport to the angler. During summer this fish frequents the weedy parts of the river in shoals, but as soon as the weeds begin to decay in autumn, it seeks the deeper water, and shelters itself near piles, locks, and bridges, where it remains till the following spring. The Lea, in Essex, also produces this fish. It has not been found in Ireland.

The Barbel feeds on slugs, worms, and small fish: when boring and turning up the loose soil at the bottom, in expectation of finding food for itself, small fish are seen to attend it to pick up the minute animalculæ from the removed earth. The Barbel spawns in May or June: the ova, amounting to seven or eight thousand in a fullsized female, are deposited on the gravel, and covered by the parent fishes. These are vivified in a warm season between the ninth and fifteenth day.

Mr. Jesse, when describing the habits of the different sorts of fishes kept in a vivarium, says, "the Barbel were the shyest, and seemed most impatient of observation: although in the spring, when they could not perceive any one watching them, they would roll about and rub themselves against the brick work, and show considerable playfulness. There were some large stones, round which they would wind their spawn in considerable quantities."

So numerous are the Barbel about Shepperton and Walton, that one hundred and fifty pounds' weight have 
been taken in five hours; and on one occasion it is said that two hundred and eighty pounds' weight of largesized Barbel were taken in one day. The largest fish I can find recorded weighed fifteen and a half pounds. Mr. Jesse, and other anglers, have occasionally caught Barbel when trolling or spinning with Bleak, Gudgeon, or Minnow, for large Thames Trout. The longevity of the Barbel is celebrated by Ausonius, in the lines quoted at the foot of the page.*

Barbel appear to be in a torpid state in very cold weather, so much so that they may be taken up by the hand. The fishermen provide themselves with a net fastened to an iron hoop, having a handle to it, which they place near the fish, and with a pole push it into the net, so perfectly inanimate is it at this season. Shoals of them also congregate under the lee of a sunken boat, lying one upon the other, and are often taken by letting a hook down amongst them, and then pulling it up.

M. Valenciennes has observed that many of the cyprinoids have the power of emitting a guttural sound under water, but has not as yet discovered the mechanism by which it is effected; no air bubble escapes from the mouth of the fish at the time. The Barbel is particularly noted as producing these sounds.-Hist. des Poiss. xvi. 14.

The length of the head is, to the whole length of the fish, as one to five; the head the same length as the longest of the caudal rays: depth of the body not equal to the length of the head, and compared to the whole length of the fish as one to five and a half. The head elongated, wedge-shaped; nose produced; upper jaw

* "Tumelior pejore cevo ; tibi contigit omni

Spirantum ex numero non inlaudata senectus." 
much the longest; under jaw very short; upper lip fleshy, forming three-fourths of a circle round the under jaw ; opening of the mouth horizontal, admirably adapted to feeding on the ground; one pair of cirri or barbels at the front of the nose, and a single one at the end of the upper lip on each side, near the angle of the mouth; nostrils about one-third nearer the eye than to the end of the nose : form of the body elongated: dorsal fin commencing half-way between the point of the nose and the end of the fleshy portion of the tail; the base of the fin shorter than the third ray, which is the longest as well as the strongest, and is denticulated on its hinder surface; pectoral fin half as long as the distance between its origin and the attachment of the ventral fins; the ventrals situated directly under the fourth ray of the dorsal fin; anal fin commencing half-way between the origin of the ventral fins and the end of the fleshy portion of the tail: its base half as long as its longest ray: the tail deeply forked, the longest rays three times as long as the middle short ones.

The general colour of the upper part of the head and body is greenish brown, becoming yellowish green on the sides; cheeks, gill-covers, and scales tinged with bronze; belly white; irides golden yellow; lips pale flesh colour; dorsal and caudal fins brown, tinged with red; pectoral ventral, and anal fins, flesh red; the lateral line nearly straight throughout its whole length.

The numbers of the fin-rays are-

\footnotetext{
D. $4 \mid 8:$ P. $16:$ V. $9:$ A. $3 \mid 5:$ C. $19:$ upper half 10 , lower 9 with 4 shorter graduated rays above and below.
}

The Barbel, in the coat of Bar, forms one of the quarterings of the arms of Margaret of Anjou, queen of Henry the Sixth, and founder of Queen's College, Cam- 
bridge. She was daughter of René, Duke d'Anjou, titular King of Jerusalem. These arms are very beautifully painted in glass in the windows of a curious old manor-house at Ockwells, in Berkshire, near Bray, on the banks of the Thames; well-known to antiquaries from the engravings in Lysons' history of that county.

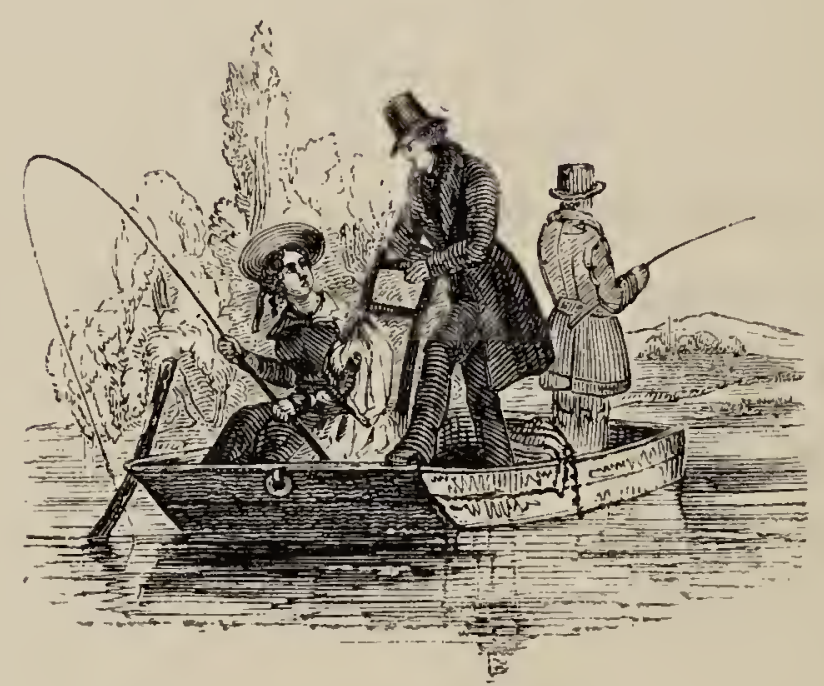

DUM CAPINUS CAPIMUR. 


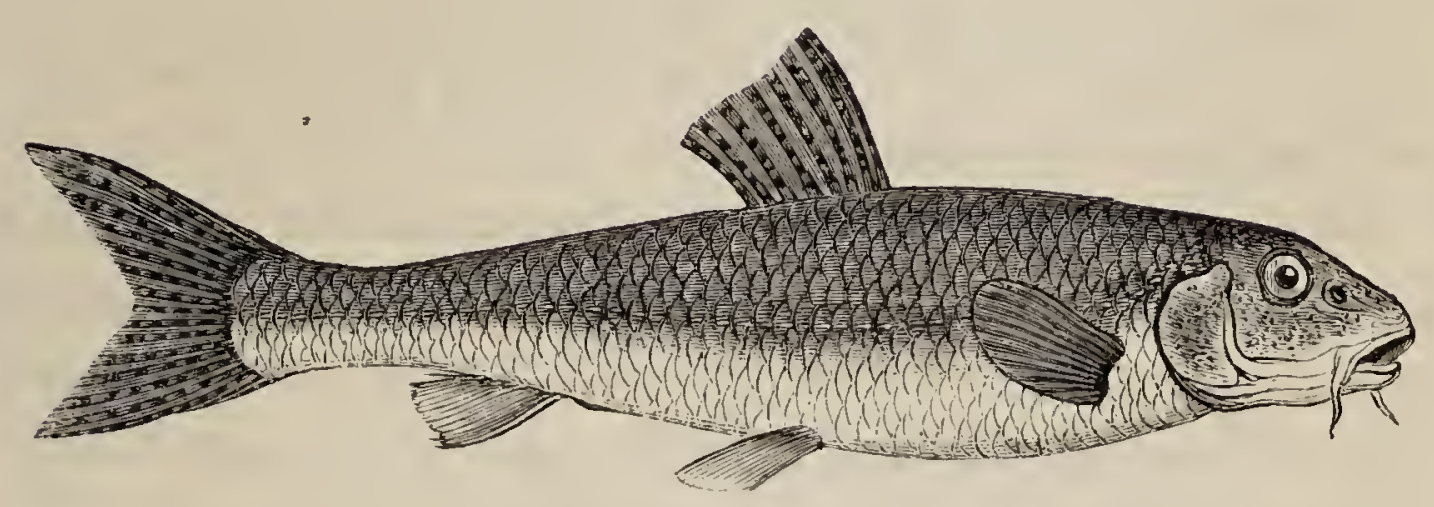

\section{THE GUDGEON.}

Gobio furiatilis, Cuv, et Valenc. xvi. 340.

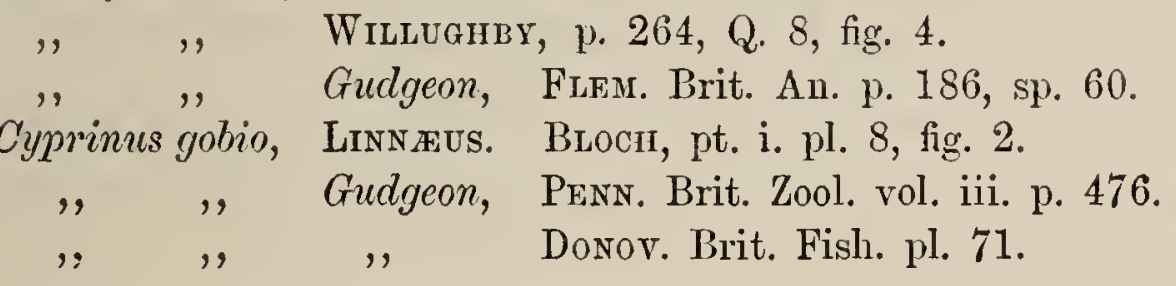

Goвio. Generic Characters.-Body fusiform; scales large. Dorsal and anal short; the former without a serrated spine, and having generally, but not in some foreign species, a ray or two more than the latter. A barbel at the corner of the mouth on each side. Pharyngeal teeth in two rows, numbering three and five respectively but sometimes fewer on one side; individual teeth tapering, curved at the tips (dentes raptatorii, Bonap.), adapted for seizing a prey. Air-bladder divided into two, the front one truncated before, rounded behind, and bigger than the narrow, cylindrical, posterior one.

The Gudgeon is found in many streams that in their course flow over gravelly soils : it appears to delight in slow rivers that have shallow scours over which the current of the water is increased. The Thames, Mersey, Colne, Kennet, and the Avon, produce abundance of the finest Gudgeons. Daniel, in his Rural Sports, says they thrive well in ponds that are supplied with fresh water from brooks running into them. The Gudgeon is known to inhabit the following localities in Ireland:-Lough 
Neagh, and the River Lagan; the Liffey, and Royal Canal; the Barrow, the Shannon Canal, and the Streams of Tuam. A dog kept at Newforge bleach-green, on the Lagan, was in the habit of fishing for Gudgeons in the "tail-race," and devouring them in great quantities. - Thompson Nat. Hist.

Gudgeons swim together in shoals, feeding on worms, aquatic insects, their larvæ, small molluscous animals, ova, and fry, and affording excellent amusement to such anglers as are satisfied with numbers rather than weight-Gudgeons rarely exceeding eight inches in length, and being seldom so large. When angling for them, it is usual to scratch the gravel at the bottom of the water with an iron rake, the Gudgeons resorting to the newly-moved ground for the sake of the small living animals that are exposed by this operation. They bite freely, even to a proverb, at a small portion of a red worm; and many dozens may be caught, in some situations, in a few hours.

The Gudgeon spawns in May, generally among stones in shallow water, in which situation the deposit is exposed to the vivifying influence of the sun's rays; the fry are about an inch long by the beginning of August. The Thames fishermen take them in shallow water with a casting net, keeping them in their well-boats till wanted. The London fishmongers are also able to keep Gudgeons alive several weeks in leaden or stone tanks, which are constantly supplied with fresh cold water; and Colonel Montagu says that a very considerable quantity of these fishes are taken with the casting net in the Avon near Bath, long famous for its Gudgeons, which are exposed for sale alive in shallow tubs of water, and are thus obtained in the highest perfection for invalids, being considered easy of digestion. 
M. Valenciennes having obtained Cyprinoids from the elevated lake of Titicaca, where the mercury does not stand seventeen inches high in the barometer, was induced to make some experiments on Gudgeons and Loches by placing them in water under the bell of an air-pump, and gradually reducing the aerial pressure. When this was diminished to a half or a quarter, the fish suffered little, and permitted bubbles of air to escape from them very seldom. But when the reduction of pressure was rapid and carried far, much air escaped from them, and when the mercury stood very low, the gas in their intestines expanded, the belly was blown up, and the fish floated on the surface back downwards. In this case the air-bladder was found to be quite empty. The Gudgeons, however, continued to live, and when replaced in a vessel under the ordinary atmospheric pressure, they resumed their normal position with the back upwards in the course of twenty-four hours, but remained quiet at the bottom, and with the belly so hollow as to appear to be channelled. They recovered their bulk slowly, but in six hour's acquired their ordinary aspect and the swim-bladder was again filled with air, which on being tested was found to be azote.-Hist. des Poiss. xvi. 15.

The length of the head is, to the whole length of the head, body, and tail, as one to five; the depth of the body, which is greatest at the commencement of the dorsal fin, does not equal the length of the head; the lower jaw is broad, shorter than the upper, and the mouth is wide, with a barbel at the angle on each side; the nostrils are in a circular depression, and the eye is placed high up on the side of the head, and about half-way between the point of the nose and the free edge of the operculum; the dorsal fin, commencing rather before the ventrals, has slender rays, and the connecting membrane is thin and transVOL. I.

C C 
parent; the base of the fin is one-third shorter than its longest ray: the distance from the point of the nose to the origin of the pectoral fin, from thence to the origin of the ventral fin, again to the anal fin, and from thence to the end of the fleshy portion of the tail, are four very nearly equal distances; the caudal fin is deeply forked, the outer rays nearly as long again as those of the centre; all the fins are rather long, the rays slender, and the connecting membranes thin and transparent; the lateral line is straight from the middle of the base of the caudal forward till near the operculum, then suddenly rising to its upper edge; the scales of the body are moderate in size, about ten rows, completing the oblique line of their arrangement between the base of the dorsal and the origin of the ventral fins. The fin-rays in number are-

D. $9:$ P. 15 : V. 8 : A. 7 : C. 19 : Upper half 10 , with five or six graduated incumbent rays above and below.

The second ray of the dorsal and anal is branched, and is the tallest in the fin, and the last ray of both is double, while the first ray is simple, almost bony, and only half the length of the second one.

The colour of the upper part of the head, back, and sides is olive brown spotted with black ; irides orange red, pupil large and dark; gill-covers greenish white; all the under surface of the body white: pectoral, ventral, and anal fins nearly white, tinged with brown; dorsal fin and tail pale brown spotted with darker brown.

The following anecdote is copied from a little book entitled Friendly Contributions for the Benefit of the Royal Schools of Industry.

"The late Mr. Baron Thompson was very curious in all matters of and concerning eating; and was, moreover, somewhat selfish and uncommunicative when he had made any gastronomic discovery, to the pursuit of which he 
frequently made his summer and spring circuits subservient: and it was known that he often jockeyed his less eager brethren out of the Oxford circuit that he might get the best sausages and brawn at Oxford, and eat the first stewed and potted lampreys at Worcester, and finish with Simnel cake at Shrewsbury.

"One day, looking over the bridge at Carlisle, he saw a man fishing with what he fancied was a new bait (boiled cheese); and as the judge was in a logical mood, he considered that the using of a new bait was all in favour of catching a new fish. He smoothed down his wig; and, as well as he could, smoothed the wrinkles of his face into a smile, and asked the man 'what he was fishing for?' - Allmacks!' was the answer : the judge was right ; new baits caught new fish; he had never before heard of a piscine Almacks. His curiosity and his generosity were at once excited, and slipping into the fisher's hand a retaining fee of half-a-crown, bound him over to bring up the bodies of all the Allmacks caught that day before him at his inn, in time then and there to be dressed for dinner; in fact, a sort of piscatory habeas corpus was issued. The judge trotted nimbly home; prepared for court-first, however, imparting to his marshal that he should dine alone, and confiding to him that a certain man would bring a certain new kind of fish, which he desired should be carefully dressed in three different ways,plain boiled, fried, and broiled. The court rose : it is not pretended that any injustice was done, neither did the guilty escape, nor were the innocent convicted, that the judge might dine; but those who were accustomed to the judge's manner, saw that as the hour of dinner crept round, a slight cloud of impatience passed over his brow, and there was less sifting of the evidence, and less subtlety of logic than usual. The judge got back to his 
lodging; the dinner came up; the judge, with his mouth watering, was all impatience: the inaster led the way with a sinall dish, in which were four fried Gudgeons, two Miller's Thumbs, and a Bream; and the next two dishes contained a boiled Perch, a boiled Eel, and a Samlet. The judge stared; and then, to his mortification, first learned that Allmacks meant all sorts*-what one can catch."

* Allmacks, all sorts._Brockett's Glossary of North-country Words, p. 131.

Virginia Water.

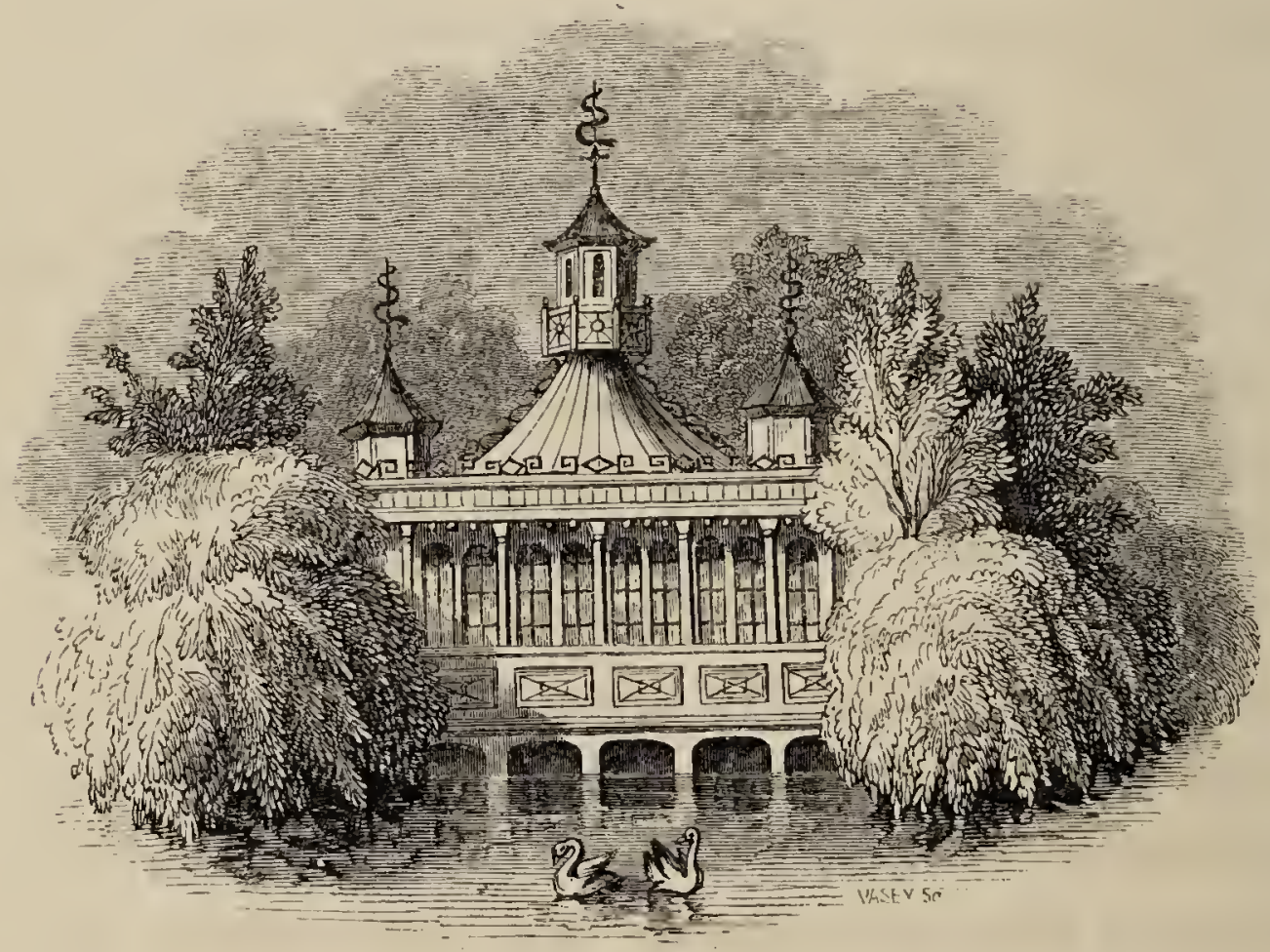




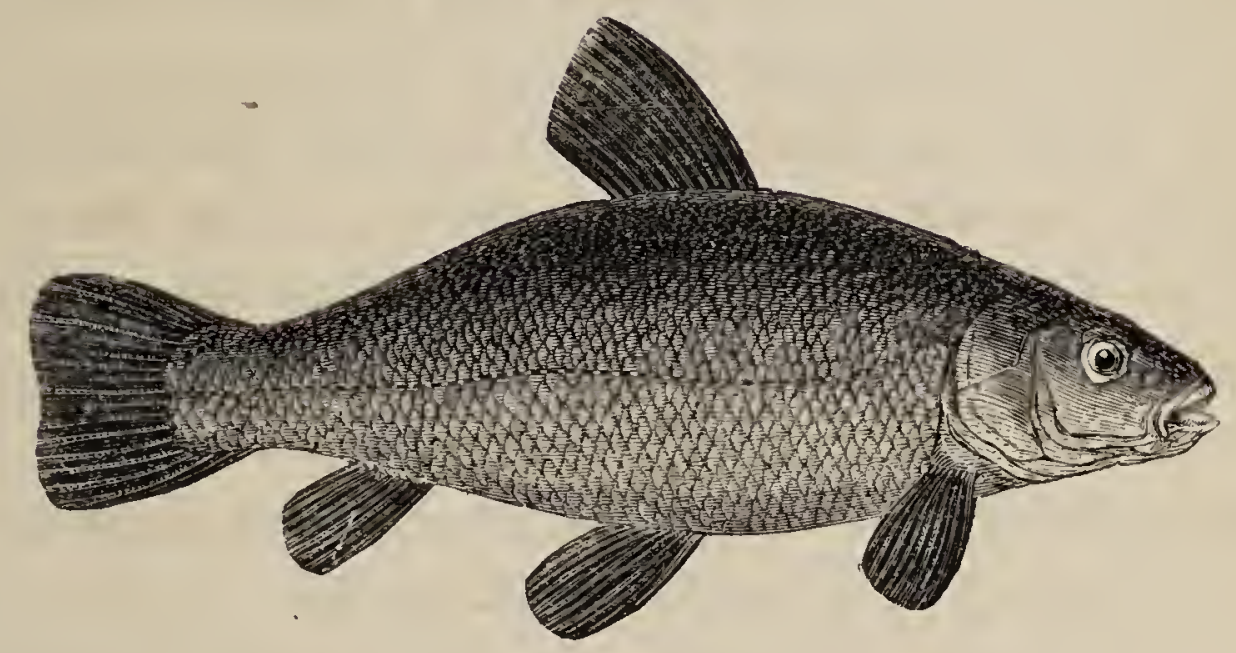

THE TENCH.

YSGRETEN, Wales. sutare (Cobbler), Sweden. sCHLEIHe, Germany.

Tinca vulgaris, Curmer et Valenc. xvi. 322.

", , Tench, Fuem. Brit. An. p. 186, sp. 61.

, , , Willughis, p. 251, Q. 5, fig. 1.

, , ," Heckel und KNER, fig. 34.

Cyprinus tinca, Blocir, pt. i. pl. 14.

", " Tench, Penn. Brit. Zool. vol. iii. p. 474.

,, , , Dowov. Brit. Fish. pl. 113.

Tincs. Generic Characters. - Pharyngeal teeth club-shaped, uniserial, four on the right side, five on the left. Mouth terminal, with a barbel at each corner. Body compressed, high; scales small, not in conspicuously regular rows; skin very mucigenous. Dorsal and anal short, destitute of bony rays.

M. Valenciennes is inclined to deny generic rank to the Tenches, and to consider them to be merely Gudgeons with small scales. There are many extra-European species, he says, which might be placed indifferently in either group. Perhaps a strict attention to the pharyngeal teeth might facilitate the arrangement of the foreign species. 
The Tench was known to the older writers, but was not held in much estimation. In the present day it inhabits most of the lakes of the European continent. Though frequent in ornamental waters and ponds of this country, it is but sparingly found in the generality of our rivers. There is some doubt whether, like the Carp, its origin be not foreign, and whether those rivers that can now boast of it are not indebted to the accidental escape of fish from the preserved waters of neighbouring gentlemen. Of rivers it is mostly the slow and deep in which this fish is found, and in such situations it does not appear to be so prolific as in ponds. In deep pits, from which clay for bricks has been dug out, Tench are often abundant; broad shallow waters on muddy bottoms frequently produce great quantities; some very extensive tracts of water a few miles north of Yarmouth in Norfolk, not far inland from a point called Winterton Ness, abound with Tench, which, when removed to stews, feed and thrive on a mixture of greaves and meal till fit for table: their flesh is nutritious and of good flavour.

The Tench appears to decline in numbers in proportion as we proceed northward. In a communication from Carlisle on the subject of fish, obligingly supplied to me by T. C. Heysham, Esq., that gentleman states that the Tench is only now and then taken in the Eden ; and occasionally he has known of one being caught in the Solway Firth. A few Tench exist in preserved waters in the neighbourhood of Edinburgh, but they are not very prolific. In a paper by Mr. Whyte, land-surveyor at Mintlaw, which obtained one of the Highland Society's prizes, it is stated, that in some ponds belonging to $\mathrm{Mr}$. Fergusson of Pitfour, in Aberdeenshire, the Tench thrives well; and the Carp, although not very prolific, breeds. This is owing, it is said, to a particular softness in the 
quality of the water where these fish exist; in fact, it is allowed by $\mathrm{Mr}$. Whyte, in allusion to the Carp-ponds, that they are wholly kept up by rain water, a very different fluid from that produced by the hard springs of the country.* Dr. George Johnston, in his list of the Fishes of Berwickshire, includes the Tench as an inhabitant of Hirsel Lough.

In Ireland the Tench is noticed as existing in ponds in the counties of Cork, Dublin, Kilkenny, and Down. Thompson's Natural History of that island states, that on a pond at Belvoir bursting, many Tench escaped into the Lagan, in which river numbers of them were subsequently taken.

Tench are exceedingly tenacious of life; and experiments have shown that a Tench is able to breathe when the quantity of oxygen is reduced to the five-thousandth part of the bulk of the water: ordinary river-water generally containing one per cent. of oxygen. The fact, as Dr. Roget has observed, shows the admirable perfection of the organs of this fish, which can extract so minute a quantity of air from water, to which that air adheres with great tenacity. This power is strongly illustrated in the instance about to be quoted, which is selected on account of its reference to other points in the history of the Tench.

"A piece of water which had been ordered to be filled up, and into which wood and rubbish had been thrown for years, was directed to be cleared out. Labourers were accordingly employed; and, almost choked up by weeds and mud, so little water remained, that no person expected to see any fish, except a few Eels, yet nearly two hundred brace of 'Tench of all sizes, and as many Perch, were found. After the pond was thought to be quite

* The Art of Angling as practised in Scotland, p. 99. 
free, under some roots there seemed to be an animal which was conjectured to be an otter; the place was surrounded, and on opening an entrance among the roots, a Tench was found of most singular form, having literally assumed the shape of the hole, in which he had of course for many years been confined. His length, from eye to caudal fork, was thirty-three inches; his circumference, almost to the tail, was twenty-seven inches; his weight eleven pounds nine ounces and a quarter; the colour was also singular, his belly being that of a char, or vermilion. This extraordinary fish, after having been inspected by many gentlemen, was carefully put into a pond, and at the time the account was written, twelve months afterwards, was alive and well." *

"Tench are said to love foul and weedy, more than clear water; but situation does not always influence their taste. Tench were taken out of Munden Hall Fleet, in Essex, belonging to Mr. Western, which was so thick with weeds that the flew-nets could hardly be sunk through them, and where the mud was intolerably fetid, and had dyed the fish of its own colour, which was that of ink, yet no Tench could be better grown, or of a sweeter flavour; many were taken that weighed nine, and some ten pounds the brace. In a pond at Leigh's Priory, a quantity of Tench were caught, about three pounds' weight each, of a colour the most clear and beautiful; but when some of them were dressed and brought to table, they smelt and tasted so rankly of a particular weed, that no one could eat them. Some that were collveyed alive and put into other water, soon recovered themselves from this obnoxious taint: an experiment that will always answer in this kind of fish, when it is suspected that there is a necessity for cleansing them; and the cir-

* Daniel's Rural Sports. 
cumstance is recited to show that no decisive judgment of the flavour of the fish can be formed from the external appearance of the Tench, however prepossessing that may be."

The vulgar opinion which ascribes to the Tench healing qualities is said by $\mathrm{Mr}$. Couch not to have been entertained by the ancient Greek and Roman naturalists, but to have originated in a fact vouched for by Hollinshed, that Tench will crowd round a wounded Pike, and nibble at the sore.-Zoologist, p. 4171.

As the Tench is one of our most useful fresh-water fishes, from the ease with which it may be preserved and its increase promoted, the facility of transportation from its great tenacity of life, and the goodness of its flesh,which is not, however, generally held in the estimation which I think it deserves, - as the Tench is also, like the Carp, one of those species first selected as stock for ornamental waters, I venture to recommend that large and fine fish be chosen as breeders, as the most certain mode of obtaining sizeable fish for table in the shortest space of time. Two males to one female, or not less than three to two, should be the proportion of the sexes; and from the pond, which is found by experiment favourable for breeding, the small fish should be in part withdrawn from time to time, and deposited elsewhere to afford more space for all. The male of the Tench is recognised by the large size of the ventral fins, which reach far enough to cover the vent, and are deeply concave internally: in the females the ventral fins are smaller, shorter, and less powerful.

In other fishes, besides the occasional external sexual distinctions in particular species, it may be stated, as a general law, that the males have the head sharper and longer; the latter effect being produced by a greater 
backward dilatation of the operculum, and the body less deep in proportion to its length than in the females, the abdominal line nearly straight, in accordance with the general law, that in males the respiratory cavity, and in females the abdominal cavity, has the greater proportional size. In measuring the length of the head with reference to the length of the body, the sex causes little or no difference, the female obtaining in depth what is wanting in length, and her shorter body and head affording the same comparative proportions.

The Tench spawns about the middle of June, with some variation depending on the season. Willughby says it happens when wheat is in blossom. Such coincident circumstances in the seasonal progress of animals and vegetables particularly deserve to be studied, recorded, and remembered; they may be made subservient to many useful purposes; one, which has a direct reference to fishing will serve as an illustration. Some London friends, who are enthusiastic fly-fishers, know exactly when to leave home and find the May-fly on the water in different counties of England by the flowering of certain shrubs and plants in the neighbourhood of London.

The female Tench, when ready to spawn, is usually attended by two males, who follow her from one bunch of weeds* to another, upon which the ova are deposited; and so engrossed are they at this time in the fulfilment of the Divine command, that I have frequently dipped out all three fish by a sudden plunge of a landing-net. The ova are very numerous, Bloch says near three hundred thousand in a fish of four pounds' weight. The food of the Tench consists of the various soft-bodied animals

* The Broad-leaved Pondweed, Potamogeton natans, is in some countries called Tench-weed. 
which inhabit fresh-water, with some vegetable matter, as the contents of the intestines seem to indicate; and the best bait for them is the dark red meadow-worm, which they take very readily early in the morning throughout the summer. They are said to bury themselves in soft mud during winter, and certainly they move very little in the colder months of the year.

Opinions vary as to the qualities of the Tench as an article of food. Ausonius speaks of it as in his time coveted only by the common people. Ekström, in Skandinaviens Fiskar, says that in Sweden it is considered to be a delicacy, and that its flesh is white and firm, but difficult of digestion. By washing the mucus off with warm water before cooking, the muddy taste which it is apt to have is removed.

The length of the head, compared to the length of the head and body without including the caudal rays, is as two to seven, and the depth of the body compared to the length of the head and body as one to three; the head is rather large and blunt; the mouth small, with a very small barbel at each corner; the tongue short; the lips flesh colour; the eyes small, the irides are golden yellow; a row of mucous pores runs down the preoperculum, and thence forwards towards the mouth. The body is covered with small scales, about forty-eight, in an oblique row between the base of the dorsal fin and the origin of the ventral. The fin-rays in number are-

\section{11 : P. 17 : V. 10 : A. 10 : C. 19.}

The dorsal fin commences about the middle of the body; the first ray is buried in the skin, the second half as long as the third, which is one-third longer than the whole base of the fin, and more than half as long as the body is deep; the front line of the fin is straight, the upper and hinder edges rounded; the pectoral fins large 
and rounded; the ventral fins arise have their origin before the commencement of the dorsal, and exhibit the sexual indication already noticed; the anal fin commences half-way between the origin of the ventral fin and the end of the fleshy portion of the tail; the caudal rays are not so long as the head; the posterior edge of the tail is in young specimens concave, afterwards straight, and finally convex.

The general colour of the body is greenish-olive and golden; lightest along the whole line of the under surface; the fins darker brown; the lateral line elevated, distinct, descending by a curve from the top of the operculum to the middle of the body, then passing straight to the centre of the tail.

The vignette represents the left pharyngeal bone, looking from behind, of the Carp, Tench, Roach, and Barbel. The crowns wear differently in different genera, and the numbers of rows are various. In the middle figures they are uniserial, in the extreme ones triserial.

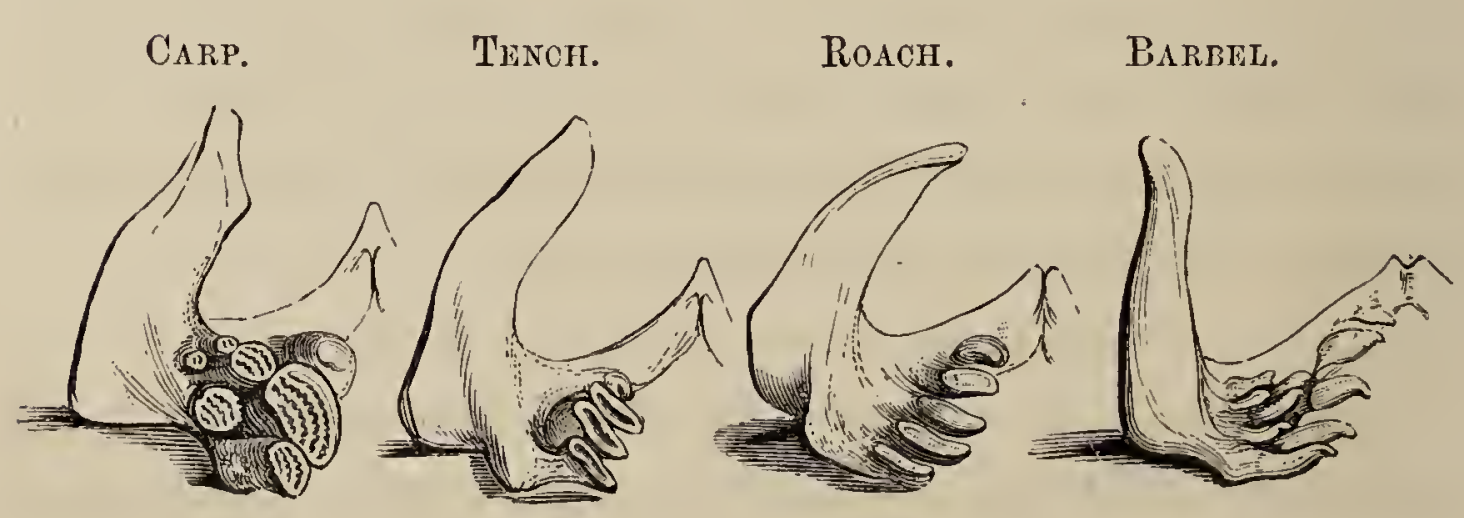




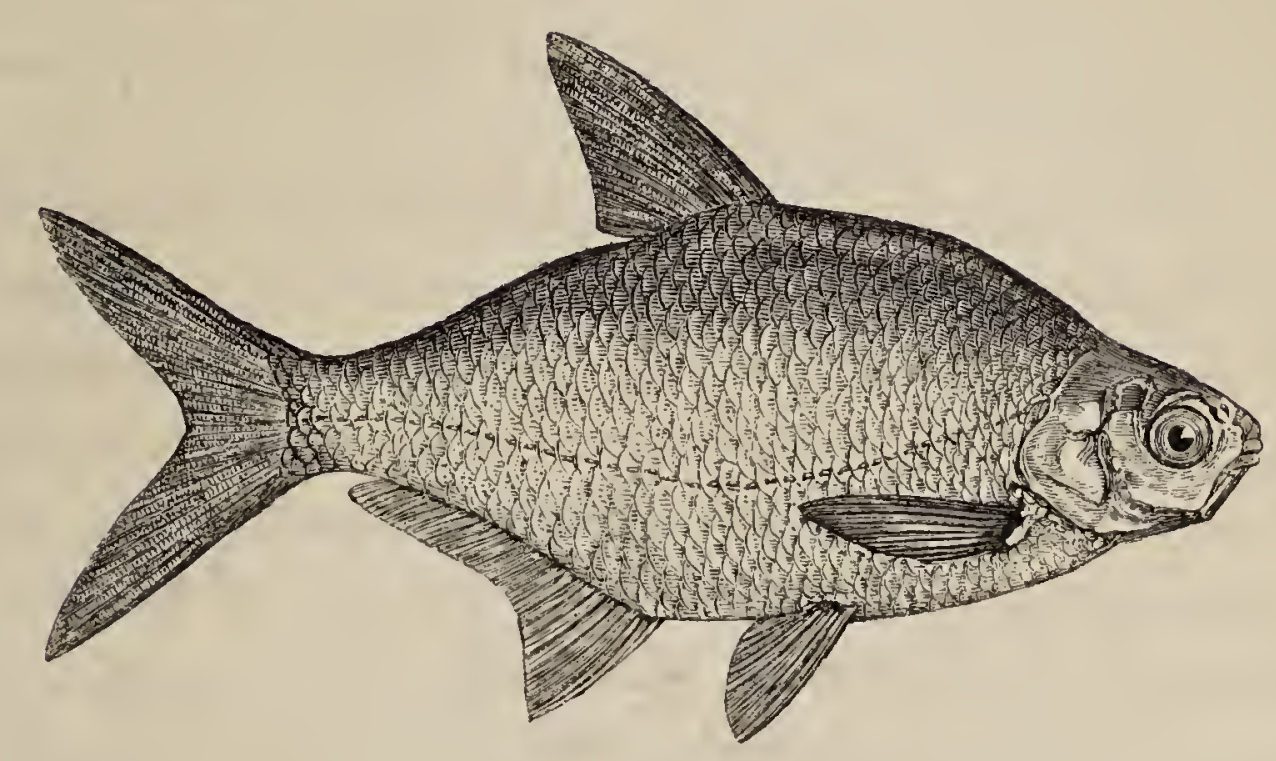

\title{
THE BREAM. 'THE CARP-BREAM.
}

\author{
Y Merfog, Wales.-Braxen, Sweden. \\ brasem, Denmark.-brachen, Germany.
}

Abramis brama, Cuvier, Règne An. t. ii. p. 274.

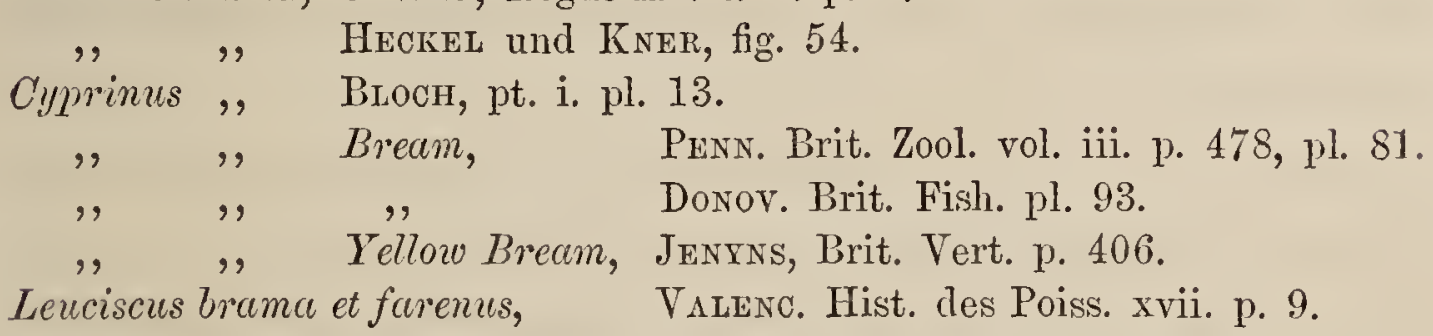

Aвrumis. Generie Charaeters.-Pharyngeal teeth cylindrical, with compressed, smooth crowns adapted for bruising (dentes contusorii), uniserial, five on each side. Mouth oblique, without barbels. Dorsal short; anal long; body high and compressed; scales placed in curves on the fore-part of the back ; a naked space behind the ventrals on the edge of the belly.

M. Valenciennes, who disapproves generally of many of the modern dismemberments of the genus Cyprinus of Iinnæus, does not admit Abramis to be a generic group distinct from Leuciscus, the length of the anal, which is the most apparent differential character, varying so gradually in different species as to cause the 
groups to pass imperceptibly into each other. The Cyprinoids of the preceding pages all belong to the Cyprinini of Bonaparte, and the Bream commences the Leuciscini, distinguished by their bright, nacry scales from the thicker-skinned Carps.

The Bream is an inhabitant of many of the lakes and rivers of the continent of Europe generally, even as far north as Norway and Sweden. In this country it appears also to thrive best in large pieces of water, or in the deep and most quiet parts of rivers that run slowly, being found in many counties, and particularly in some of those that contain lakes and canals of considerable extent. The lakes of Cumberland, and some of the most extensive lakes in Ireland, produce large quantities of Bream of great size. Of the rivers near London producing Bream, the Mole and the Medway are the most noted; to which may be added the Regent's Canal. Bream are said by the Rev. Richard Lubbock, in his Norfolk Fauna, to exist in immense shoals in all the broads or meres of Norfolk, but not to be often taken of a greater weight than four pounds.

Bream swim in shoals, feeding on worms, and other soft-bodied animals, with some vegetable substances; and if the water they inhabit suits them, which is generally the case, as they are hardy in their nature, they grow rapidly, and spawn in May. At this season one female is frequently followed by three or four males, and they bear at this time a whitish tubercle on their scales, which causes them to feel rough to the hand: this has been considered by some as a disease, but is in fact only a periodical production, which, as in others of the Cyprinida, disappears when the season of reproduction is past. Bloch states the number of ova in the female roe at one hundred and thirty thousand. 
Bream being generally considered to have insipid and bony flesh, are not in great estimation for table, though the breeding of them is cultivated, or rather permitted, as useful to feed Pike, and other voracious fishes. They afford great amusement to the angler; and the more the ground is baited to collect them at a particular spot, the greater the sport. The flesh is in more request on the Continent than in this country, if we may credit the French proverb quoted by Isaac Walton, which says, "he that hath Bream in his pond is able to bid his friend welcome."

It may also be inferred, from the couplet in Chaucer's Prologue to the Canterbury Tales, already quoted in speaking of the Pike, that the feeding and eating of Bream was more in fashion in the days of Edward the Third than at the present time.

Daniel, in his Rural Sports, refers to a pleasant day of Bream-fishing at New Hall Pond in Essex. "The weather was cloudy, and the wind brisk: there were seven rods used by the party, and very frequently there were bites at them all at the same time. When a fish was hooked, and played on the top or near the surface of the water, numbers were seen to follow him, and so soon as the hooks were fresh baited, were alike greedily taken. Some few Perch and Tench were caught, but principally Bream, which averaged at least two pounds a fish; and of these, from six in the morning till dark in the evening, some hundred-weight were taken. The bait used was the large red worm, and the spot had been baited on the morning and evening previous to the day of fishing: the ground-bait used was boiled wheat and tallow-melters' greaves mixed together."

In some of the lakes of Ireland great quantities of Bream are taken, many of them of very large size, some- 
times weighing as much as twelve or even fourteen pounds each. A place conveniently situated for the fishing is baited with brewers' grains mixed with potatoes in the form of balls for ten days or a fortnight regularly, after which great sport is usually obtained. The party frequently catch several hundred-weight, which are distributed among the poor of the vicinity, who split and dry them with great care to eat with their potatoes. The Bream, as food, is best in season in spring and autumn.

As the fish next to be described after the present Bream is a Cyprinoid nearly allied to the Bream, I shall follow the example of Cuvier, in describing the Common Bream closely, and when the new species is treated of point out more particularly the differential characters.

The whole length of the fish was five inches: a small one was chosen in order to contrast it the better with the specimen of the White Bream which follows: the length of the head, compared with the length of the body, was as one to three; the head small, the nape depressed; the diameter of the eye, compared to the length of the head, as two to seven, or considerably less than one-third, leaving the space between the eye and the edge of the preoperculum broad; the irides yellow; the body deep and flat, the dorsal and abdominal lines very convex; the head and the fleshy portion of the tail being small and acuminated, producing an appearance of neatness in shape: the scales of the body are comparatively small; of the two representations of scales forming the vignette to the White Bream, that on the right hand belongs to this species; the number of scales forming in succession the lateral line, varying from fifty-two to fifty-eight in different examples; the lateral line itself low down on the 
side, two-thirds of the space below the dorsal line; the number of scales in an upright direction nineteen, of which one punctured scale is on the line itself, with twelve above it, and six below it ; the first ray of the dorsal fin arises at half the distance between the point of the nose and the end of the short central rays of the caudal; the first ray being shorter than the secoud, and the second frequently the longest in the fin, both simple,-that is, not divided or branched; the third ray is nearly or quite as long as the second, and about twice as long as the whole base of the fin; this and the eight other rays of this fin are branched.

The fin-rays in number are-

$$
\text { D. } 11 \text { : P. } 17: \text { V. } 9 \text { : A. } 29 \text { : C. } 19 .
$$

The first ray of the pectoral fin is the longest and is simple, all the others are branched; the ventral fins are placed in advance of the dorsal fin, the first ray being simple, the others branched; the anal fin begins beneath the last ray of the dorsal; the first ray is short, the second longer or half as long as the third, which is the longest; these three rays are simple, all the other anal rays are branched, diminishing in length, the form of the fin being falcate; the tail is long and deeply forked.

The general colour is yellowish white, becoming yellowish brown by age, and the fish is called Carp-Bream from its colour resembling that of the Carp; the irides are golden yellow; the cheeks and gill-covers silvery white; the fins are light-coloured, the pectoral and ventral fins being tinged with red; the dorsal, anal, and caudal fins with brown.

With respect to the geographical distribution of the Carp-Bream, Heckel and Kner state that it is spread throughout all the middle districts of Europe, and VOL. I.

D D 
extends northwards to St. Petersburg, Finland, and Scandinavia.

The subjoined vignette, which was cut for the second edition of British Fishes, is commended in the Histoire des Poissons as a correct representation of the skull of the Carp-Bream. On comparing it with the figure of the cranium of the Common Carp on page 363, it will be perceived that the top of the skull is less vaulted in the Carp-Bream, and the borders of the frontal more elevated; the crest or spine also of the occiput is larger and more triangular and oblique. Other differences are very obvious. M. Valenciennes states that this species has forty-four vertebræ, of which twenty-one are caudal, and fifteen support ribs, the three vertebræ next the skull being without these appendages.

Skull of Carp-Brean.

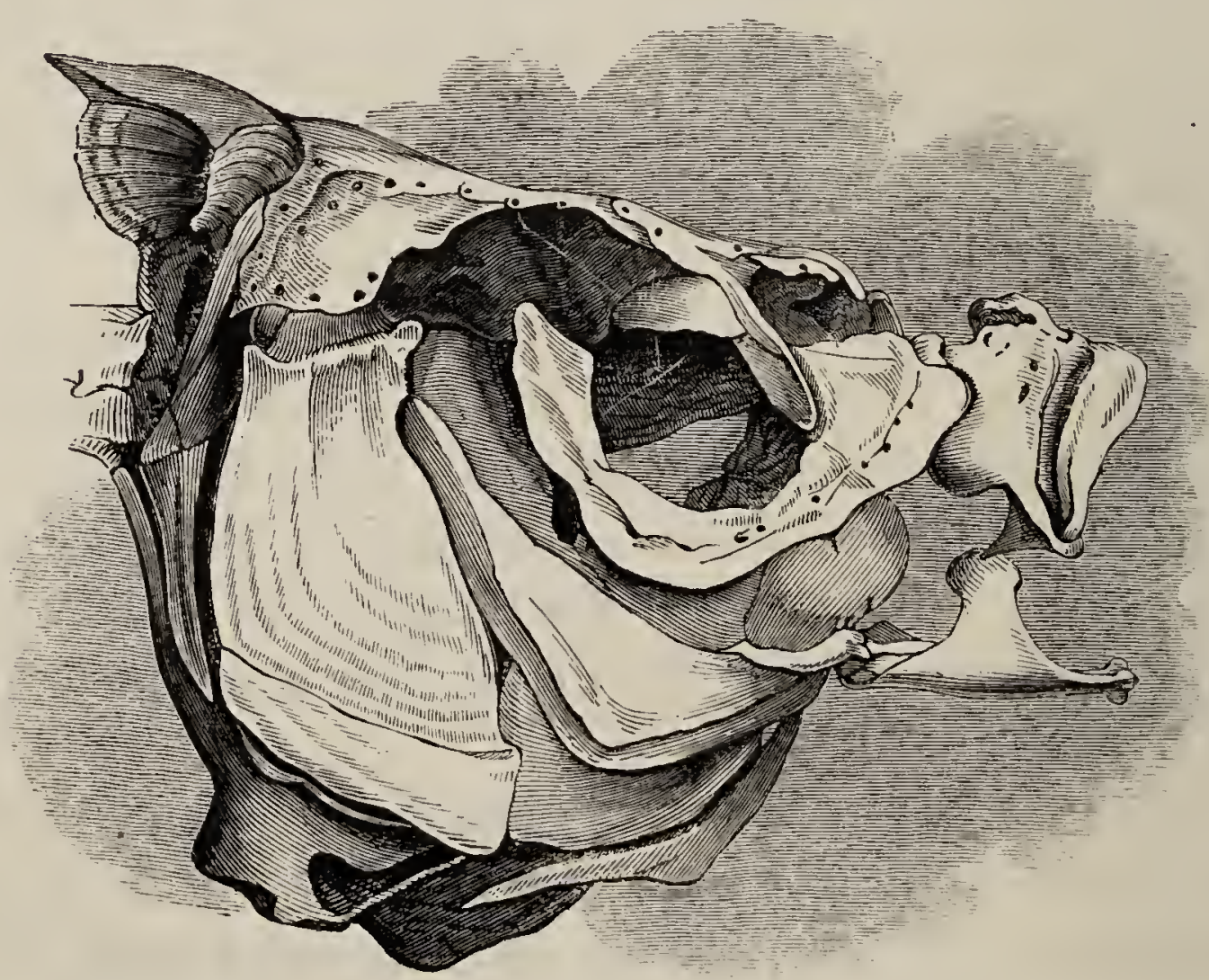




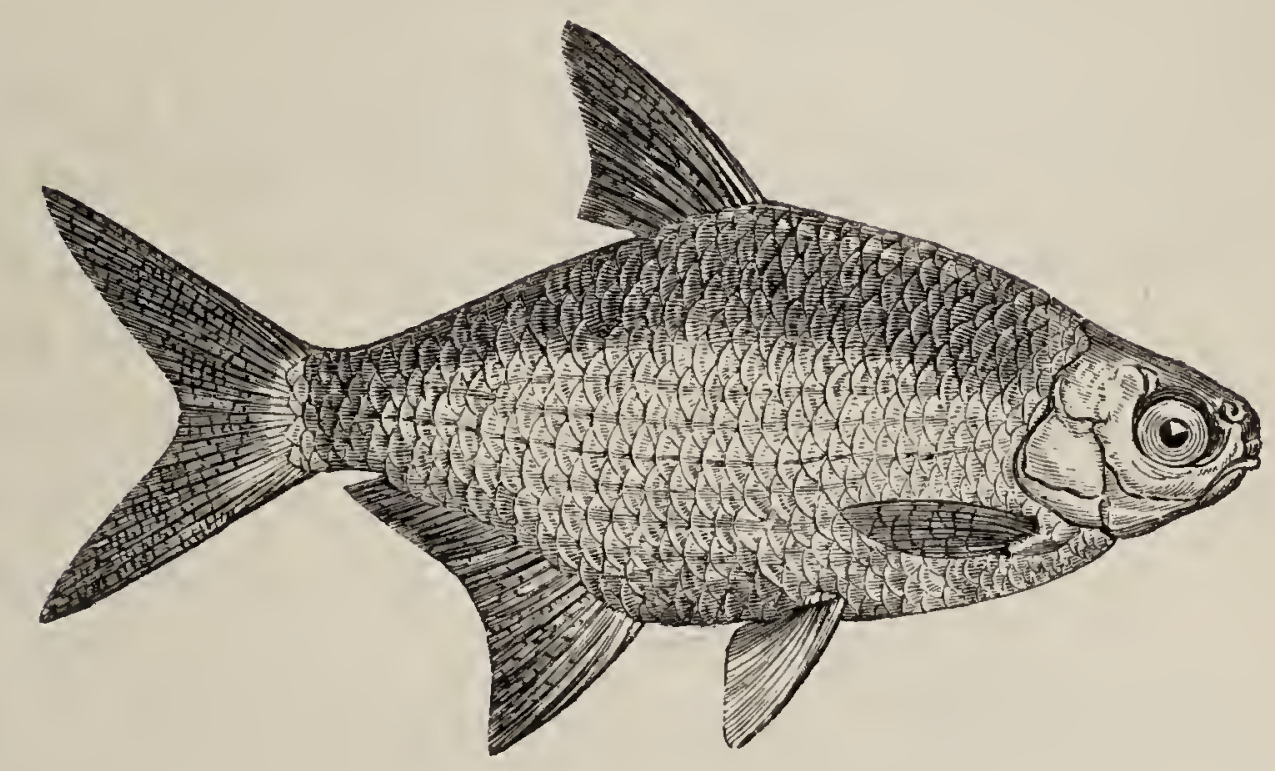

\section{THE WHITE BREAM, OR BREAMFLAT.}

\section{Y MERFOG ANGHRION, Wales.-BJORKNA, BLECKA, Sweden.-zobel Pleinze, Germany.}

Blicca argyroleuca, HeckeL, Süsswasserfische der Östreich. Mon. p. 120.

Abramis blicca, Cuvier, Règne An. t. ii. p. 274.

Cyprinus bjcerkna, LINN. ARTEDI.

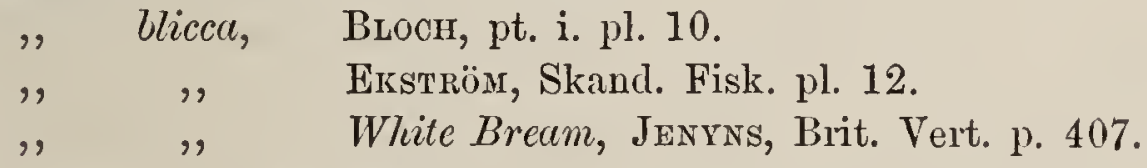

Bucca. Gencric Characters. - Pharyngeal teeth with compressed, hooked, prehensile cusps, biserial, the rows numbering two and five on both sides. Mouth terminal. Characters, in other respects, those of Abramis.

In November 1824, the Rev. Revett Sheppard made a communication to the Linnæan Society, of which the following is an extract taken from the Transactions of that Society, vol. xiv. page 587 :- “'There exist in the river Trent, in the neighbourhood of Newark, two species or varieties of Bream. The common one, Cyprinus brama, is known there by the name of Carp-Bream, from its yellow colour, and has been taken of nearly eight pounds"

$$
\mathrm{D} \mathrm{D} \mathcal{Q}
$$


weight. The other species or variety, which I believe to be nondescript, never exceeds one pound in weight: it is of a silvery hue, and goes by the name of White Bream."

The Rev. L. Jenyns subsequently discovered that this second species of Bream inhabits the Cam; and I am indebted for a specimen of the fish to that gentleman, who informs me that it is called by the fishermen of the Cam the Breamflat; that it rarely exceeds ten or twelve inches in length; and is probably the Cyprinus blicca of Bloch.

I have been also favoured by the Rev. Richard Lubbock, of Tombland, near Norwich, with a communication which states that this fish is occasionally met with in some of the broads and rivers in that part of the county of Norfolk; but that it is limited both as to its location and numbers. Its mode of biting, when angled for, is singular: it appears more prone to rise than to descend; and the float, consequently, instead of being drawn under water, is laid horizontally on the surface, by the attack of the fish on the bait. A specimen of the Carp-Bream and one of the Breamflat sent to me by Mr. Lubbock, differed much less in colour than those previously received from Cambridgeshire. The example of $A$. blicca had two rays less in the anal fin than the fish from the Cam.

That this fish is distinct from the well-known CarpBream, the description will evince. Bloch says of it that it is very common on the Continent, being found generally in lakes and slow rivers; that it is tenacious of life and breeds fast, but is not in any esteem for table, though encouraged as supplying food for Pike and other voracious fishes. He found 108,000 eggs in one that weighed only eight ounces and a half. Ekström says that it is the most voracious of the family and devours grass, insects, and worms. It also takes the 
hook readily, but is too indolent to swallow it. The Swedish fishermen call it Aetare, or the glutton.

Both this species and the Carp-Bream are said to be common in the Lochmaben Lochs. According to Messrs. Nilsson and Ekström, the White Bream is found in most of the lakes of Sweden, and is especially abundant in Uplandia and Sundermannia.

The subject of the present article is called blicca on account of the brightness of its colour compared with the Carp-Bream which is usually more yellow, and when old and large of a yellowish leather-brown. In the Bavarian dialect Blicke is a term applied to fishes that have a silvery glitter in the water.-Heckel und Kner.

The length of the head compared to that of the body alone is as one to three; the head is larger, and the fleshy portion of the tail deeper, than in the Carp-Bream of the same size, and the fish in consequence has a more bulky and less neat appearance: the diameter of the eye compared to the length of the head is as two to six, occupying a full third; it is therefore larger than in the other, leaving the space between the eye and the edge of the preoperculum narrower in comparison, and affecting the proportions of the various parts of the head: the irides are silvery-white tinged with pink, in the other fish they are yellow: the nape is without any depression, the curve of the shoulder being uniform : the scales of the body are larger, and the pointed scaly lappet in the axilla of the pectoral is longer; the vignette on the following page shows the comparative differences, both in structure and size, of two scales, one from the lateral lines of two fish of very nearly the same length; the colour of the scales is bluish white: the lateral line is not quite so low down on the body as in the Carp-Bream, and has fewer scales; the number being from forty-six to fifty; a row up the voL. 1. 
side consists of fifteen, of which nine are above the punctured scale lying on the line itself, and five below it; the character and relative position of the fins are not very dissimilar in the two fishes, except that the dorsal fin, in the White Bream, begins rather nearer the head; but the numbers of the rays in the pectoral and anal fins differ considerably, the pectoral fin of the White Bream having three rays, and the anal fin five rays, less in number than the same fins in the Carp-Bream.

The fin-rays in number are-

\section{D. $10:$ P. $14:$ V. $9:$ A. $23:$ C. 19.}

The general colour of the sides is silvery bluish-white, without any of the yellow golden lustre observable in the Carp-Bream; the fins in my specimen, which has been some time in spirit, are dusky blue, particularly the dorsal, anal, and caudal fins : the pectoral and ventral fins are tinged with red.

Carp-Brean.

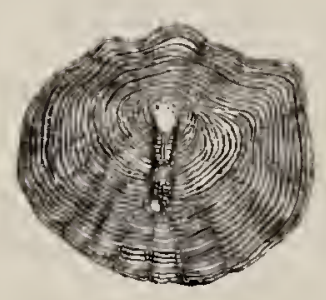

Brfamflat.

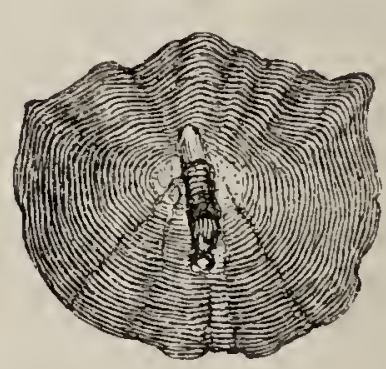




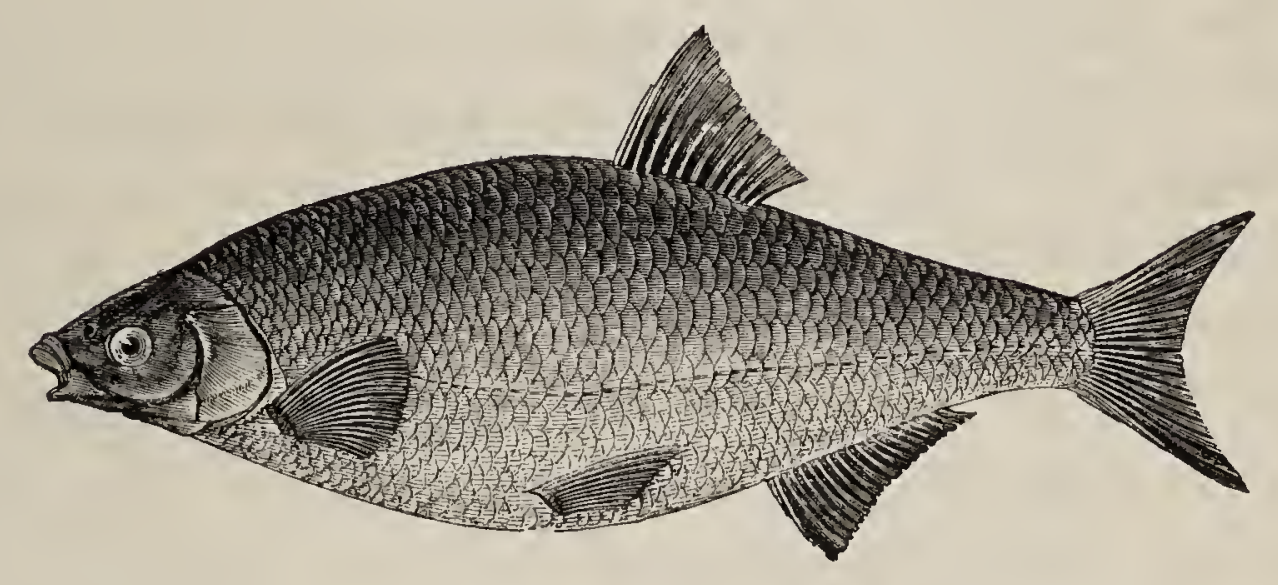

\section{THE POMERANIAN BREAM.}

Bliccopsis Buggenhagii, НRokel und KNeR, p. 125, in note. Cyprinus Buggenhagii, Carpe de Buggenhagen, BLoch, vol. iii. pl. 95. Abramis ", Large-scaled Bream, Triompson, Zool. Proc. 1837. Leuciscus ", Valencrennes, Hist. des Poiss. xvii. 53.

Burccopsis. Generic Characiers. - Pharyngeal teeth biserial, five and three ; the five of the front row compressed, denticulated, with a hooked tip. Belly keeled between the ventral and anal fins; top of the back as in Abramis.

I AM indebted to Mr. Daniel Brandon of Chancery Lane for a fine specimen of this fish which was sent to me in the year 1836 from Dagenham in Essex. Mr. Brandon, who is the renter of the waters at Dagenham Breach, so well known to the London Anglers, and who has frequently favoured me with examples of other species from this locality, having taken this Bream in his net with other fish, very kindly sent it to me with a note stating that it differed from the Bream he had usually caught in that water; and finding when he reached home and made closer examination, that it did not accord with the characters of either of the Bream figured and described in the British Fishes, he begged my acceptance of it, hoped it might prove of some interest, and re- 
quested to know what it was. I understand from Mr. Brandon that he has since at different times taken from twenty to thirty of the same sort.

The characters of this species are so decided, that I had no difficulty in identifying it as the Cyprinus Buggenhagii of Bloch; and on the next visit to London of my friend William Thompson, Esq. of Belfast, who has devoted such unwearied attention to the Zoology of Ireland, I found that he had also obtained an example of the same species of Bream from the River Lagan, near Belfast, which circumstance was made public in the printed Proceedings of the Zoological Society for 1837, page 56 , as quoted on the preceding page.

Since the publication of the Supplement to the History of British Fishes, in which this species was first mentioned as a British Fish, the Rev. L. Jenyns has ascertained that it exists also in Cambridgeshire; an example, ten or twelve inches long, having been caught in the piece of water which ornaments his father's park at Bottisham. In November 1843 also a specimen was sent to me from Wolverhampton by G. Edwardes, Esq., Surgeon.

This species of Bream is at once distinguished both from the Carp-Bream and Breamflat, by the greater thickness of its body, which is equal to half its depth; while in either of the other two the thickness of the body is only equal to one-third of its depth; the scales of this species are also larger in proportion, although the figure here given, not having been drawn on a comparative scale with them, does not exhibit this peculiarity. The anal fin is shorter and has a smaller number of rays than that of Blicca argyroleuca, which in its turn has its anal fin smaller, and with fewer rays than that of the more common Abramis brama. 
This Bliccopsis was first described by Bloch from specimens found in the river Pene, and in the lakes communicating with it, in Swedish Pomerania. The specimens were sent to Bloch by M. Buggenhagen, and hence the name which has been devoted to it for specific distinction. I have also called it the Pomeranian Bream, considering it not improper to attach to this fish the name of the country in which it was first discovered, although it may happen to have been afterwards found elsewhere. The fish attains to the length of twelve or fourteen inches in that country, according to Bloch; the flesh is white, but not much in request on account of the number of small bones which are found in it. It is taken in the same manner and by the same means as the Carp-Bream; and Bloch reports that the fishermen are greatly pleased when they take this fish in their nets: as they have learned by experience that when it appears they shall have a successful fishery: they believe that the other Breams follow this fish, and the name they have accordingly bestowed upon it in that country signifies guide or conductor. Dr. Kner found two specimens in the Bukowine. According to M. Valenciennes it is rare in France, having been received by him from the Somme only, but it exists also, he was told, in the Moselle.

The specimen of this fish from Dagenham, from which the following description was taken, measured fifteen inches in length, of which the head was three inches, or, compared to the whole length of the fish, as one to five; the depth of the body a little in advance of the dorsal fin, where the body is deepest, measuring five inches or one third of the whole length; the thickness of the body was two inches and a half, equalling half the depth, or one-sixth of the whole length; the head is 
rather small and pointed, the mouth is also small; the diameter of the eye is about one-fifth of the length of the head, the iris silvery, and nearly of the same breadth with the pupil; the operculum rather large and angular; the pectoral fin rather small : half the ventral fin is in advance of the first dorsal fin-ray which stands exactly half-way between the point of the nose and the end of the caudal fin; but the base of the dorsal fin in this fish is longer than the base of the same fin in either the CarpBream or Breamflat: the anal fin is shorter than that of the shortest of the other two, and has three rays less; it is also less falcate in form, or more equal in the length of its rays; the caudal fin at its posterior edge is lunate, the outer rays elongated; the formula of the fin-rays is-

\section{12 : P. $17:$ V. $9:$ A. 19 : C. 19 . Vertebræ 41.}

The number of punctured scales forming the lateral line is fifty two; from the anterior edge of the dorsal fin to the lateral line, following the oblique direction of the scales, there are eleven scales; from the lateral line downwards to the base of the pectoral fin, four scales, not including in either enumeration the punctured scale of the lateral line itself. Upper part of head and back dark blackish-blue, becoming lighter on the upper part of the sides, and passing into silvery white on the lower part of the sides and belly; pectorals, dorsal fin and tail, bluish brown, tinged with pale red; ventral and anal fins shewing less brown and more pale red. 


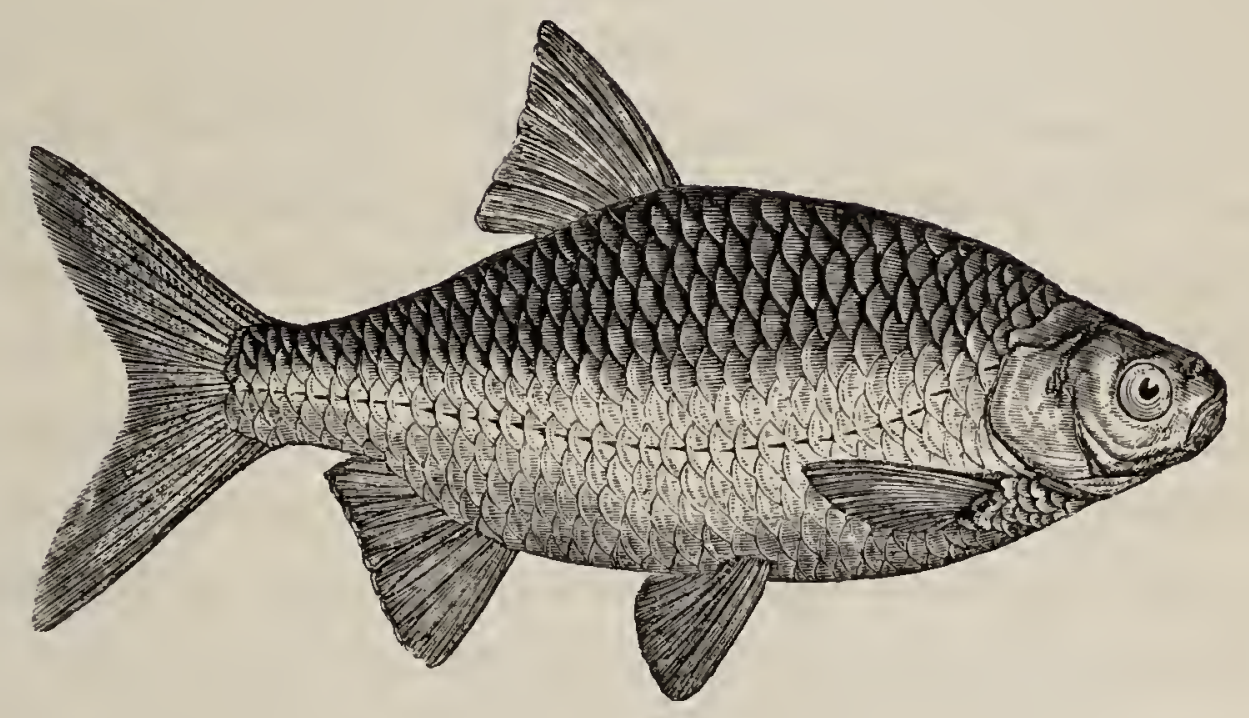

THE RED-EYE. RUDD.

FINSCale. Shallow. ROUd. Norfolk.-Y RHUDdBys, Wales.-Sarf, Sweden.-FLaLl roje, Norway.rödskalle, Denmark.-rothauge, Germany.

Scardinius erythrophthalmus, BonaP., Heckel und KNer, fig. 79.

Leuciscus

Cyprinus

,

,

,

,
Cuvier et Valenc. xvii. 107.

Recl-eye, Fuem. Brit. An. p. 188, sp. 66.

, Linndius. Blocil, pt. i. pl. 1.

, Jenyns, Brit. Vert. p. 412.

Rudd and Shallow, Penn. Brit. Zool. pl. 83.

Recl-eye, Donov. Brit. Fish. pl. 40.

,W Wllughis, $249 \& 252$, Q. 3, f. 1.

Scardinius. Generic Characters.-Pharyngeal teeth raptorial, biserial, two and five; their cusps deeply curved, compressed, and serrated. Mouth terminal, oblique. Dorsal behind the ventrals, and, like the anal, containing few rays, none of them bony.

The RudD, or Red-eye, is a very common fish in Europe, as well as in various localities in this country. It is found in the Thames, and other waters near London; and I have seen some dozens together for sale in Hungerford fish-market. It is found in Oxfordshire and Warwickshire. It is the Shallow of the Cam in Cam- 
bridgeshire, and is abundant in the broads of Norfolk, where it is called Roud, a name that occurs in Willughby; it is also common in Liricolnshire and Yorkshire; is recorded as occurring in Scotland; and I have seen specimens from Lough Neagh in Ireland, where it is universally called a Roach. According to Thompson, it occurs in every part of Ireland where there are suitable waters.

The name of Rudd attached to this species is derived from the prevailing golden-coppery tint which ornaments the whole surface: the term Red-eye refers to the colour of the irides; it is also a translation of the trivial name applied to this fish, which is further distinguished in several countries of Europe by names that have reference to the red colour of its scales or of its eyes.

The Rudd, in addition to its vivid colours, is also tenacious of life, and is on that account preferred by trollers as a bait for Pike. It breeds freely without requiring any care to be bestowed upon it, and is therefore useful food for large Perch, Trout, or Pike. It is said to be a much better fish to eat than the Roach, but does not attain more than two pounds' weight. The largest example of it that I have seen was sent to me on the 13th of August 1856 by Mr. James Cordery, and weighed very nearly two pounds. The food of the Rudd is worms, molluscous animals, and insects, with some vegetable matter; it spawns in April, or early in May, on or about aquatic plants, and the scales at this period are rough to the hand.

The length of the head compared to the length of the head and body is as two to seven: if measured to the forked centre of the caudal rays, as one to four: the depth of the body is to the same length as one to three : the head is small; the nose rather blunt; the diameter of 
the eye one-fourth of the length of the whole head; the nostrils are placed in a circular depression half-way between the point of the nose and the anterior edge of the orbit; the nape and back rise suddenly, and the whole dorsal profile is very convex; the fleshy portion of the tail is narrow; and the ventral profile is convex, the depth of the body decreasing suddenly from the commencement of the anal fin. The scales are large; the series forming the lateral line numbering about forty; an oblique line ascending to the dorsal fin contains seven, and the descending line to the ventral fin four; the scales have numerous concentric striæ, and but few radiating lines. The dorsal fin is placed very far back; the first ray arises half-way between the point of the nose and the end of the short central caudal rays; the base of the dorsal fin stands over the space between the ventral and anal fins, and equals the length of its sixth ray. From the point of the nose to the commencement of the pectoral fin, from thence to the origin of the ventral fin, and thence to the anal aperture, are three very nearly equal distances; the anal fin commences but little behind the origin of the last ray of the dorsal fin, the base of the fin being equal to the length of its second or longest ray; the caudal rays are rather long, the longest as long again as the short central rays. The fin-rays in number are-

$$
\text { D. } 10: \text { P. } 15: \text { V. } 9: \text { A. } 13 \text { : C. } 19 .
$$

The Irish specimens of Rudd from Lough Neagh had one ray more in the dorsal and anal fins.

The irides are orange red; the cheeks and gill-covers golden yellow; the upper part of the back brown, tinged with green and blue: the sides more pale; the belly light golden yellow; the whole surface of the body tinged with a brilliant reddish golden hue, varying when viewed in different positions in reference to the light, 
in a way which it is difficult to describe correctly; the fins are more or less bright cinnabar-red, particularly in those specimens which I have seen from the Thames, the Cam, and Lough Neagh; dorsal and caudal fins not so bright in colour as the fins of the under surface, but more inclining to reddish brown.

Walton says, "There is a kind of bastard small Roach, that breeds in ponds, with a very forked tail, and of a very small size; which some say is bred by the Bream and right Roach; and some ponds are stored with these beyond belief; and knowing-men that know their difference call them Ruds: they differ from the true Roach as much as a Herring from a Pilchard. And these bastard Roach are now scattered in many rivers; but I think not in the Thames." Under the account of the Bream, he adds - "Some say that Bream and Roaches will mix their eggs and melt together; and so there is in many places a bastard breed of Breams, that never come to be either large or good, but are very numerous."

It is probable that the fishes here alluded to were the true Rudd, and the Breamflat, which have been already described; and an opinion apparently prevailed, notwithstanding the numbers in which they existed, that they were hybrids. The instances in which animals in a truly unlimited natural state make selections beyond their own species are probably very rare. Hybrids and permanent varieties are generally the consequence of restriction and domestication, and I confess my doubts of the existence of hybrid fishes. 


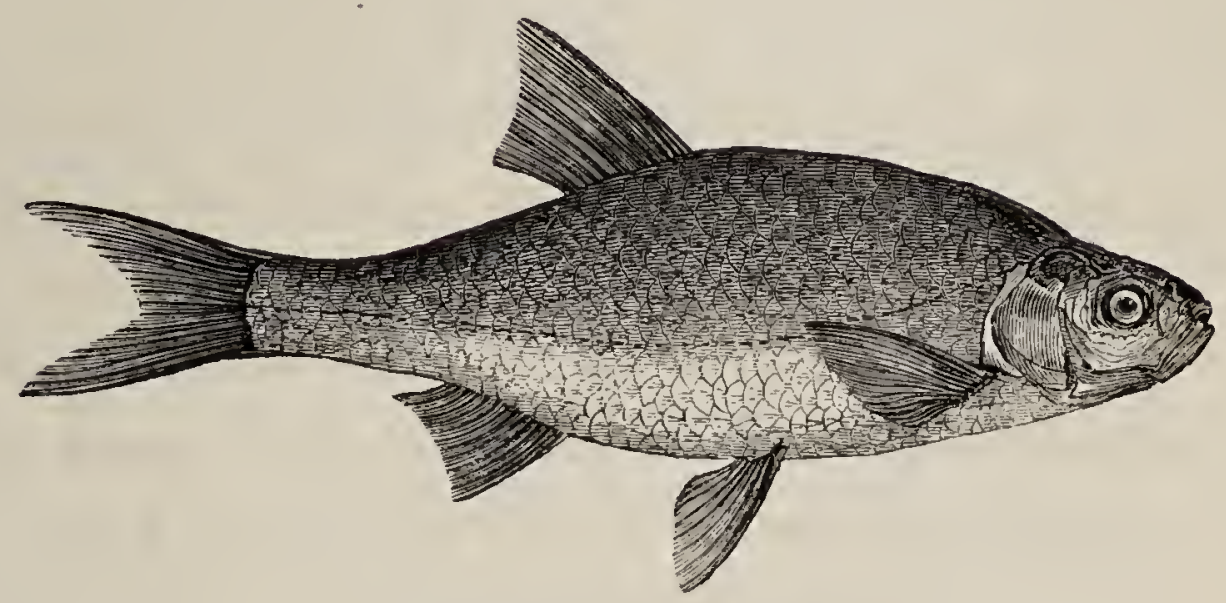

THE AZURINE.

RHUFELL GLAS, Wales.-BLUE RoACH, Lancashire.

Scardinius? cceruleus, Bonap. Cyprinidæ.

Lenciscus cceruleus, Yarreul, Linn. Trans. vol. xvii. pt. i. p. 8. ", $\quad$ Azurine, Jenyns, Brit. Vert. p. 413.

Along with examples of the Graining, Lord Derby sent me specimens of this fish, known provincially by the name of the Blue Roach; which was not only new then to our British Catalogue, but which was not described, as far as I was able to ascertain, in any of the different works of European ichthyologists. M. Agassiz, however, assured me that this fish, like the Graining, is an inhabitant of some of the Swiss lakes.

The localities from which this species is obtained, within the township of Knowsley, are but limited. It is hardy, tenacious of life, and spawns in May. The flesh is said to be firm, of good flavour, and to resemble that of the Perch. The food, and the baits used for its capture, are the same as those taken by the Carp; and 
the largest specimen known was not supposed to exceed one pound in weight.

The depth of this fish is to its length as two to seven; and it is therefore in shape something similar to the Rudd, but is at once distinguished from that species by the slate-blue colour of the back, the silvery whiteness of the abdomen, and also by its white fins, which in the Rudd are of a fine vermilion, or cinnabar-red. The nose is blunt; the mouth small; the nostrils are pierced on the upper surface of the nose, midway between the eye and the upper lip; the eye is moderate in size; the whole head small, and depressed; the back arched, the abdomen also convex; the scales are rather large, and differ in the number of concentric and radiating striæ from those of the Rudd; the number of punctured scales forming the lateral line are about forty-two, with seven in an oblique line from thence to the base of the dorsal fin, and three downwards to the origin of the ventral fin: the lateral line, descending rapidly from the upper edge of the operculum, takes a curve similar to the deep convex line of the abdomen. The fin-rays in number are-

\section{D. $10:$ P. $15:$ V. $9:$ A. $12:$ C. 19.}

The dorsal fin commences half-way between the eye and the end of the fleshy portion of the tail; the first ray is short, the second ray the longest, and the last ray double; the base of the fin equals the length of the seventh ray: the pectoral fin is rather long, reaching nearly to the origin of the ventral fins, which arise considerably in advance of the dorsal fin, thus bringing that fin over the interval between the ventral and anal fins. From the vent the body diminishes rapidly, and the anal fin is situated on the obliquity thus produced. The first ray of the anal fin is short, the second is the longest, and as long as the base of the fin; the last ray 
double. The fleshy part of the tail is narrow and the caudal rays forked, the central rays being only half as long as those which terminate the lobes.

The Azurine has the upper part of the head, the back, and sides slate-blue, passing into silvery white beneath, and both aspects shining with metallic lustre; the irides are white, tinged with pale straw-yellow, and all the fins are white.

In colours and figure, and in the numbers of the finrays, the Azurine agrees with Heckel and Kner's Scardinius plotiza, figure 84 of their Sïswasserfische der Östreichischen Monarchie, p. 159. They call the colour of the back steel-blue. The scales of both Rudd and Azurine correspond with those of Scardinius scardaf $a$ of the same work, a species scarcely differing from plotiza.

THE RuDD.

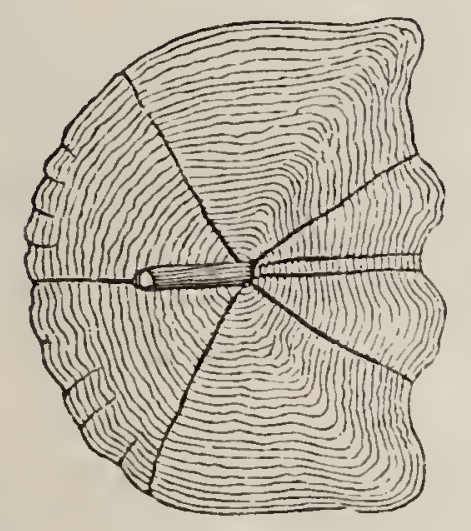

Common Carp.

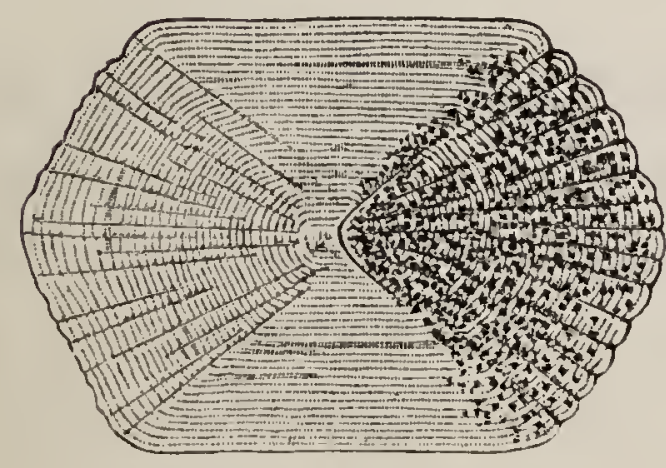

YOL. I.
The Azurine.

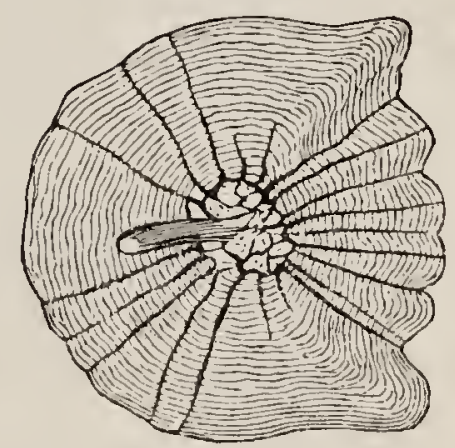

Cructan Carp.

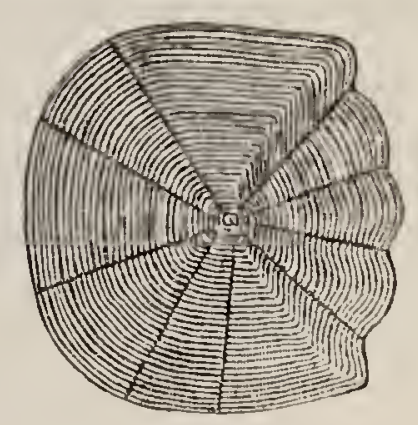

$+\mathrm{EE}$ 


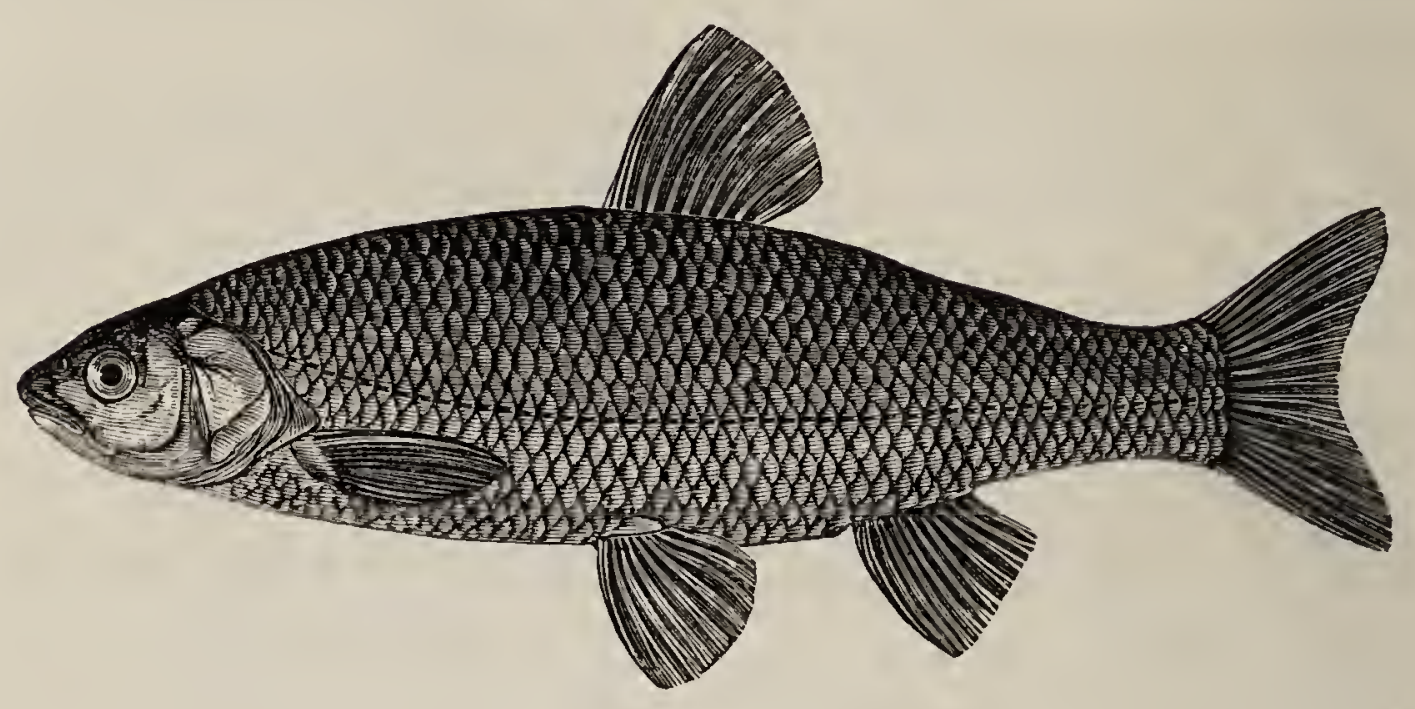

THE IDE.

ID-BARN， ID-PLUGG. SKALL-ID. Sweden.

Idus idbarus, Bonap. Cypr.

, melanotus, Heckei und Krer, p. 147, f. 77.

Leucisus idus, Cuvier, Règne An. t. ii. p. 275.

Cyprinus,, Linnaus. Fries och Ekström, p. 11.

Inus. Generic Characters. - Pharyngeal teeth biserial, three and five, raptorial, with smooth, compressed cusps. Mouth terminal, oblique, withont barbels. Dorsal and anal short, without bony rays. This genus belongs to the subdivision Leuciscini of Bonaparte.

AcCording to Mr. Stuart this species was taken at the mouth of the Nith by the late Dr. Walker ; and a figure from Ekströms' coloured plate was introduced into the first edition of this work, to assist in identifying the species at any future time.

It is found in Pomerania, Westphalia, Sweden, Norway, Lapland, Denmark, and Siberia; and is an inhabitant of the brackish bays of the Baltic, and of large rocky lakes, from which it seeks its way into rivers in the months of April or May, to deposit its spawn in running water among stones. This movement is made on the 
breaking up of the ice in the spring, whence it is locally named Isfisk (Ice-fish). It feeds on vegetables, worms, crustaceans, and insects, but rarely on small fishes. The flesh is said to be white, tender, and of good flavour if carefully cooked. When boiled in salt water it acquires a reddish hue like the flesh of the Salmon.

The head is large, and appears somewhat truncated; the muzzle blunt; the mouth small, without teeth, as is the case also with the other members of this extensive family; the upper jaw rather the longest; the eye of moderate size; the dorsal line convex; the abdominal line almost straight; the scales of the body large; the lateral line curved in its descent from the upper edge of the operculum to the centre of the body: the fin-rays in number are-

\section{11: P. $17:$ V. 11: A. 13 or 14: C. 19. Vertebræ 41.}

Scales on the lateral line about 57 .

In colour the irides are straw yellow, the pupils black; the forehead, nape, and back, very dark bluish black; the sides bluish grey; the belly white; the pectoral fin orange; the ventrals which are situated immediately under the dorsal fin, are red in the middle, the first and last rays being white; the base of the anal fin is white, the other part red; the dorsal fin and caudal gray; all the rays are branched.

Sir Thomas Maryon Wilson, Bart., of Charlton, who visited Sweden in the summer of 1838, and ascended the Gota River in his yacht, the Syren, caught a fine large specimen of the Ide whilst trolling for Pike on a windy day in the Gota Elf, a short distance above the falls of Tröllhattan. The fish weighed between four and five pounds. The skin was effectually preserved and was mounted after it was brought to England.

[The figure, as mentioned above, is copied from the 
Skandinaviens Fiskar, and many of the remarks on the species are from that work. According to Heckel and Kner the Idus and Jeses of Linnæus and Bloch are the same species, and identical with the Idus of Fries and Ekström, and the figure of the Chub in the following page of British Fishes represents their Idus melanotus. That figure and Heckel's have a strong resemblance, closer than that of the Cyprinus Idus of the Scandinavian ichthyologists with either, and there is every reason to believe that Mr. Stewart's fish, captured at the mouth of the Nith, was really a Chub (Idus melanotus). Instead, however, of expunging the article on the Ide from this edition, we have preferred letting it stand, as it gives the northern form of a species which is generally diffused from the middle of Europe to the highest latitudes.-Ed. Third Edition.]

"Swiftly our pleasures glide away, Our hearts recall the distant day With many sighs."

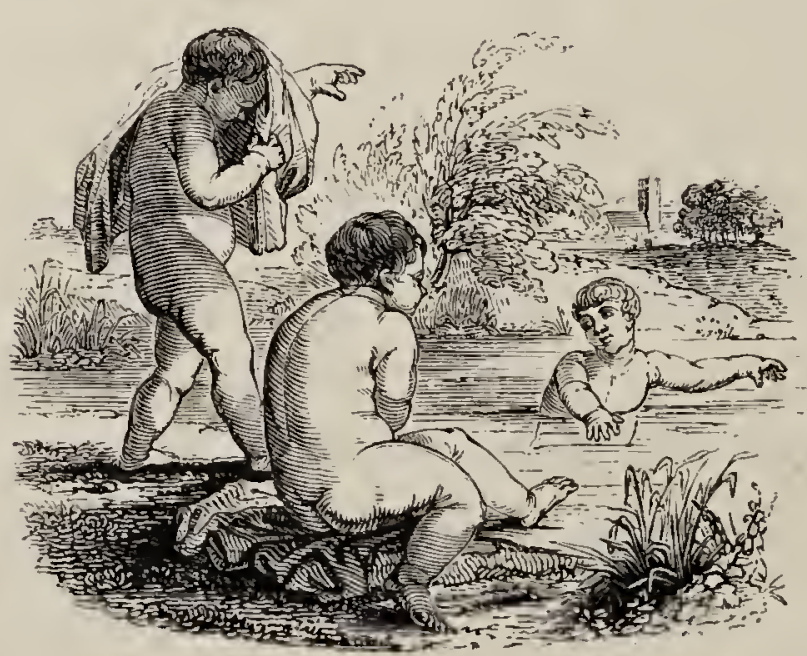




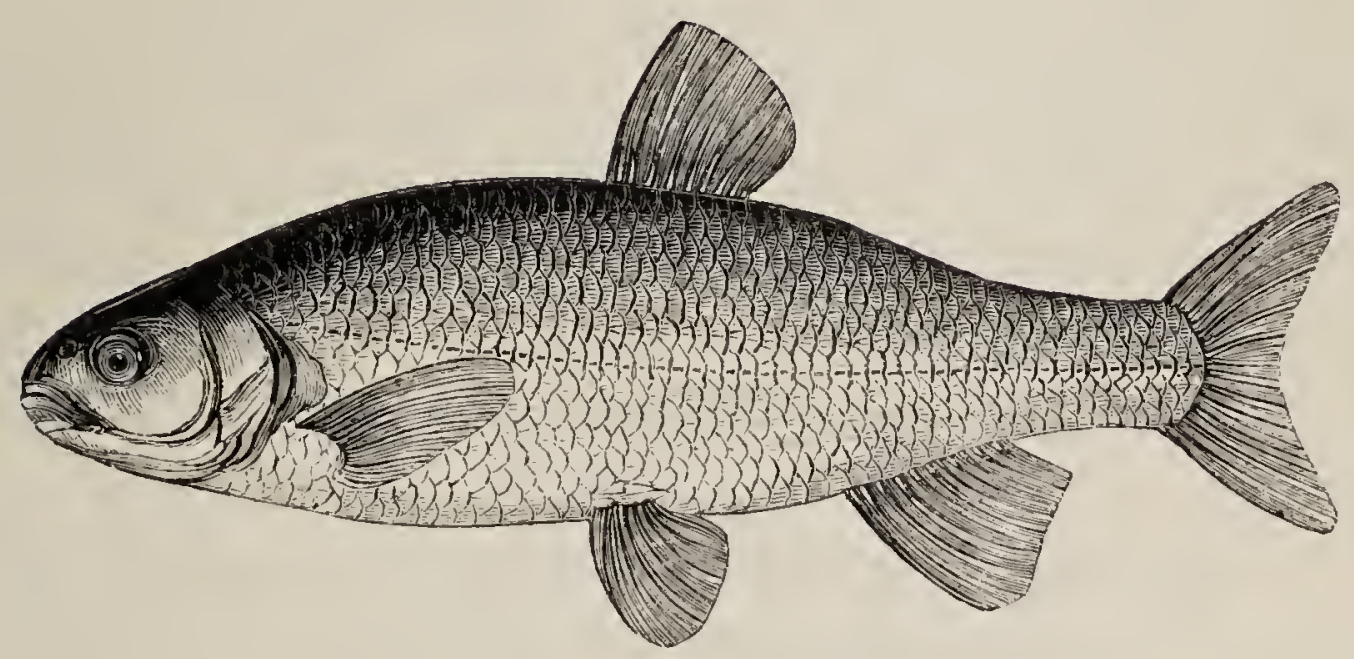

THE CHUB.

THE SKelly, Cumberland.-PENCI or COCHGangen, Wales.-ib-Barn, Sweden.-Gangling, Germany.

Idus melanotus, HECKEL und KNER, p. 147, fig. 77.

Leuciscus cephalus, Chub, FuEM. Brit. An. p. 187, sp. 64.

Cyprinus Jeses, Linnaus. BLoch, pt. i. pl. 6.

, idus, Linnaus, Fries och Eкströs, pl. 11.

" cephalus, Chub, Pens. Brit. Zool. vol. iii. p. 485.

,, , , Jenyns, Brit. Vert. p. 411.

, Jeses, Donov. Brit. Fish. pl. 115.

Leuciscus ,, Valenc. Hist. des Poiss. xvii. p. 160.

The Chub is a well-known fish that is common in the Thames, and many rivers of England: it is said to be plentiful in the Wye, and other rivers of Wales: it is the Skelly of the waters of Cumberland, so called on account of the large size of its scales; but not the Schelly of Ullswater Lake.* It is also recorded as an

* The Chub is the Skelly of the Eden, the Esk, the Caldew, the Irthing, the Petterill, the Line, the Liddel, the Lowther, and the Eamont. Jamieson, in his Etymological Dictionary of the Scottish Language, has, "Skelly, a Chub." The Rev. William Richardson and Dr. Heysham, in their separate accounts of the Natural History of Ullswater and Cumberland, included in Hutchinsou's History of Cumberland, say, the "Chub is called Skelly from 
inhabitant of the Annan, and other rivers in the south of Scotland.

Heckel and Kner in their Siisswasserfische der Ostreichischen Monarchie refer the Idus of Bloch, the Cyprinus cephalus of Fries and Ekström, the Leuciscus frigidus of Valenciennes, and the Gardonius cephalus of Bonaparte, to the Squalius dobula, or Double Roach, which they consider to be distinct from the English Chub and French Chevaine. The Chub is the Jesen and Jentling of Gesner.

In its nature the Chub is timid, frequenting deep holes in the more quiet parts of the sides of the stream, and sheltering itself generally under or near any bush or tree that will screen it from view. It feeds on worms, and on insects in their various stages; and is mostly caught by angler's with a fly or other bait at the surface of the water, by a mode of fishing called dibbing. The 'Thames anglers for Chub "cause themselves to be landed on an ait in the river, from the banks of which, under the shelter of the willows, with a long rod, a short line, and a lively cockchafer, they often have good sport." The insect used as bait, whatever it happens to be, whether large moth or Cockchafer, hangs pendent from the point of the rod, just touching the water; and by repeatedly but gently tapping the butt-end of the rod,

the large scales upon it." The Chub is the Chevin of Ullswater Lake, where the Gwyniad, or Fresh-water Herring, is called the Schelly, pronounced Skelly; but the term Skelly, with reference to scales, belongs, par excellence, to the Chub, whose scales are large, opake, and strong, like those of a Carp ; the scales of the Gwyniad, on the contrary, are thin, semitransparent, and flexible, like those of the Herring. Moreover, the talented author of Rambles in Northumberland, and on the Scottish Border, who is good authority, being a native of Northumberland, a scholar, an antiquary, and an angler, says at page 171 of the work above named, "Whitlings (young Sea Trout) are caught in the Liddel in June and July ; and it also contains a kind of Chub, similar to the fish, which, in the Eden, at Carlisle, is called a Skelly."

See the article "Chub," in Mr. Hofland's British Angler's Manual, p. 153. 
the bait is moved in a manner exactly resembling the struggles of a living insect that had by accident fallen into the water. Mr. Jesse says of Chub, detained with other fish where their actions could be noticed, that they were always restless and shy, but could never resist a cockchafer when thrown to them.

The Chub spawns about the end of April or the beginning of May, but does not acquire a large size; five pounds' weight is the most that I can find recorded. It is considered a coarse fish, and broiling with the scales on is one of the best modes of preparing it for table.

The length of the head, compared to the length of the head and body to the end of the fleshy portion of the tail, is as one to four; the depth of the body is rather greater than the length of the head; the mouth is large; the head wide or chubby; the nostrils lie in a circular depression, one-third nearer the eye than to the end of the nose; the diameter of the eye equals one-fifth of the length of the whole head; the scales on the body are large, the number forming the lateral line being fortyfour, with an oblique row of six scales above it to the base of the dorsal fin; and of three scales below it to the origin of the ventral fin; the lateral line descending by a gentle curve till even with the end of the pectoral fin-rays, then runs straight to its termination.

The dorsal fin commences half-way between the point of the nose and the end of the fleshy portion of the tail; its first ray is short, the second is the longest, both are simple; the others are branched, diminishing in length gradually to the last, which is the shortest; the seventh ray is as long as the base of the fin: the pectoral fin is rather small; the ventral fin is situated immediately under the beginning of the dorsal; the anal fin is large, 
and commences under the end of the dorsal fin when its rays are pressed down: the tail is large and forked. The fin-rays in number are-

$$
\text { D. } 10: \text { P. } 16: \text { V. } 9: \text { A. } 11: \text { C. } 19 .
$$

The colour of the top of the head is blackish brown, with a streak of the same dark colour passing down behind the free edge of each operculum as far as the origin of the pectoral fin : the whole of the upper part of the back is bluish black, the edge of each scale being the darkest part; the sides are bluish white, passing into silvery white on the belly : the dorsal and caudal fins are dusky; the pectoral fins reddish brown; the ventral and anal fins reddish white; the irides are golden yellow, their upper part dusky; cheeks and gill-covers a rich golden yellow.

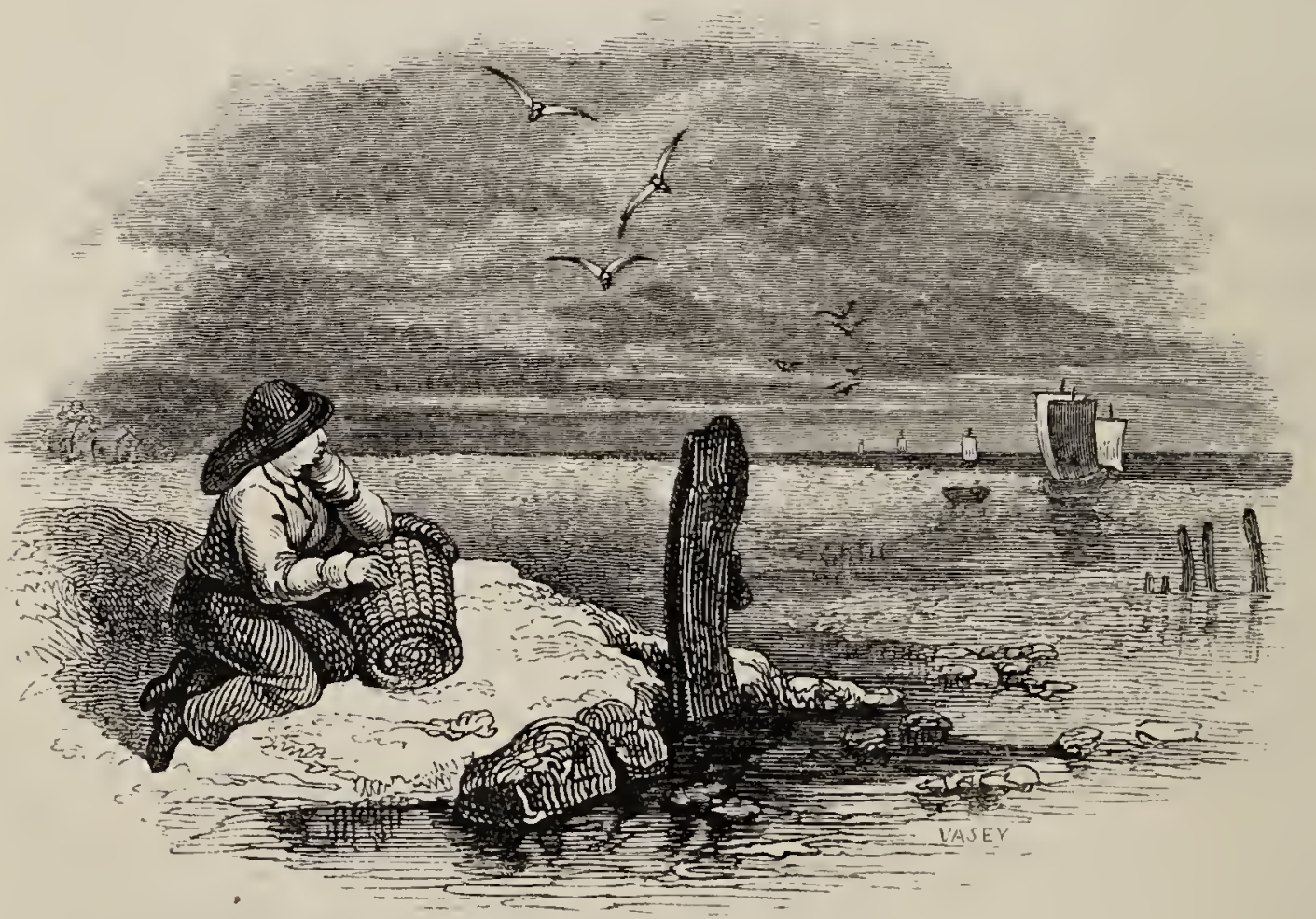




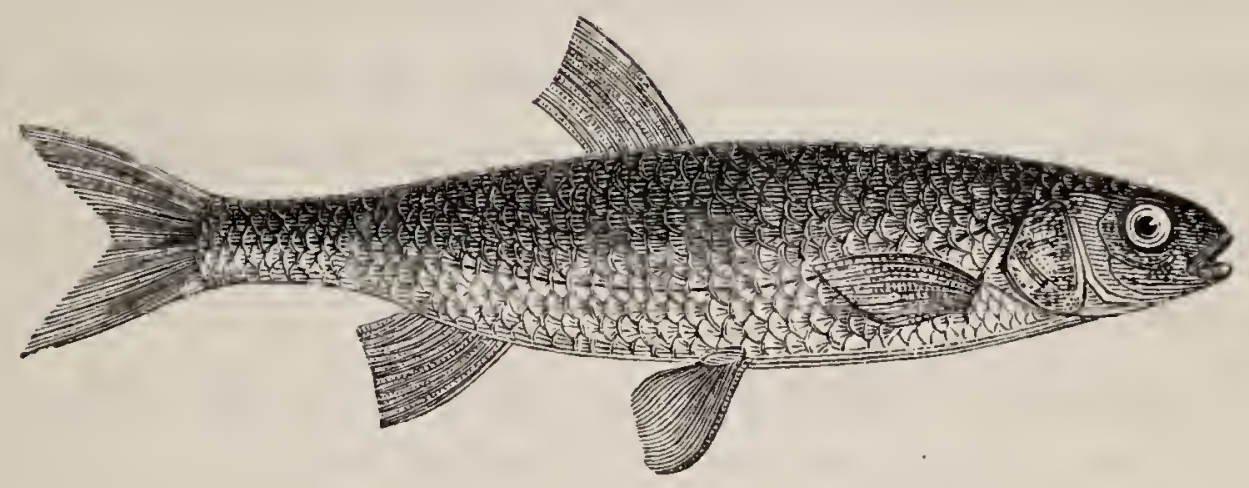

THE DOBULE ROACH.

\section{Altel döbel, Germany.}

Squulius dobula, Bonap. Heckel und Kner, p. 180, fig. 99.

Leuciscus ,, Cuvier, Règne An. t. ii. p. 275.

, ", Yarreld, Linn. Trans. vol. xvii. pt. 1, p. 9.

, , JenYns, Brit. Vert., p. 409.

Cyprinus ," Linneus. Bloch, pt. i. pl. 5.

,, cephalus, Linneus. Fries och Eiströ̀, pl. 13.

, Idus, BLoch, pl. 36 .

Squatius. Generic characters. - Pharyngeal teeth biserial, two and five, raptorial, cusps ending in a strong hook. Mouth terminal, without barbels. Dorsal and anal-short, without bony rays. Body roundish, scales moderately large. Belonging to the section Leuciscini of Bonaparte.

WHILE fishing in the month of August, 1831, in the Thames below Woolwich, with the mouth of a Whitebait net open against a strong flood-tide, I caught a single specimen of the fish above named, but have not been fortunate enough to obtain any more since.

This species inhabits the Oder, the Elbe, the Weser, and the Rhine, as well as the smaller streams that fall into them; also the Danube and the waters of Russia. Like the Ide, just noticed, it inhabits also large lakes, and VOL. I. 
seeks to enter rivers from March till May for the purpose of spawning. The larger and older fish spawn earlier than the younger ones, which exhibit small dark spots on the body and fins at this particular season. The flesh of the Dobule is white, but full of bones, and little esteemed for table: the fish dies soon when taken out of the water, and its food is worms, snails, and small darkcoloured leeches.

The specimen taken was a young male fish six and a half inches long; the body is slender in proportion to its length; the head, compared to the length of the head and body alone, without the caudal rays, is as two to nine; the depth of the body equals the length of the head; the diameter of the eye compared to the length of the head is as two to seven; the nose is rather rounded, and the upper jaw is the longest; the ascending line of the nape and back is more convex than any other portion of the dorsal or abdominal profile; the first ray of the dorsal fin arises half way between the anterior edge of the orbit of the eye, and the fleshy base of the caudal fin; the first ray is half as long as the second, which is the longest, and is as long again as the last ray, which equals the length of the base of the fin: the pectoral fin is rather long and narrow; the ventrals arise just in advance of the first ray of the dorsal fin; the distance from the ventrals to the origin of the anal fin, and from the last ray of the anal fin to the end of the fleshy portion of the tail, are equal; the first ray of the anal fin is nearly as long again as the last one; the tail is considerably forked, the external rays being as long again as those in the centre. The scales of the body are moderate in size, fifty forming the lateral line, with an oblique row of seven scales above it under the dorsal fin, and four below it; the lateral line itself is concave 
towards the back throughout its whole length. The finrays are in this specimen-

\section{D. $9:$ P. $16:$ V. $9:$ A. $10:$ C. 19.}

The colour of the top of the head, nape, and back, is dusky blue, becoming brighter on the sides, and passing into silvery white on the belly; the dorsal and caudal fins dusky brown; the pectoral, ventral, and anal fins, pale orange red; the irides orange; the cheeks and operculum silvery white.

Destgned by Thoritaldsen.

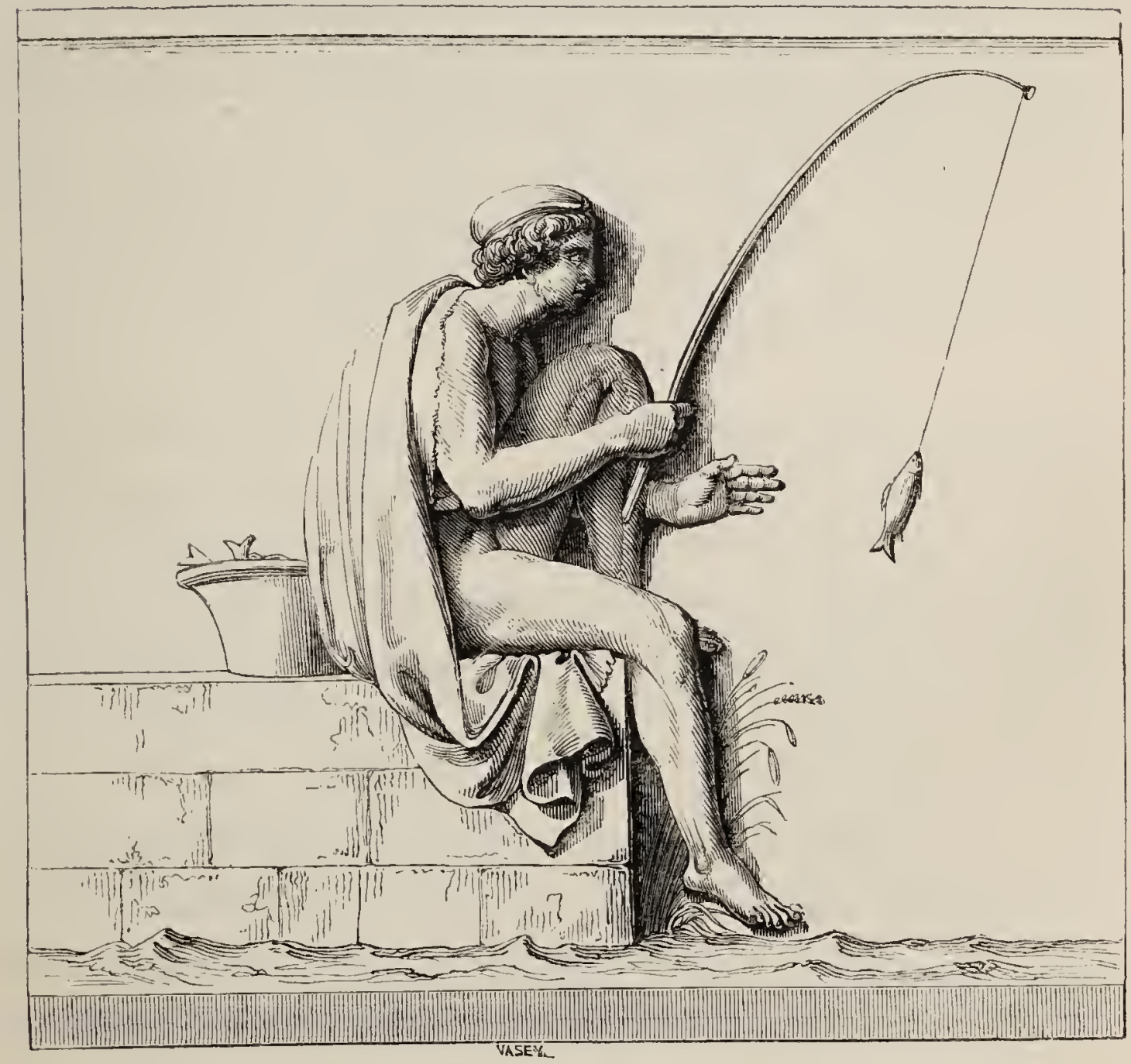




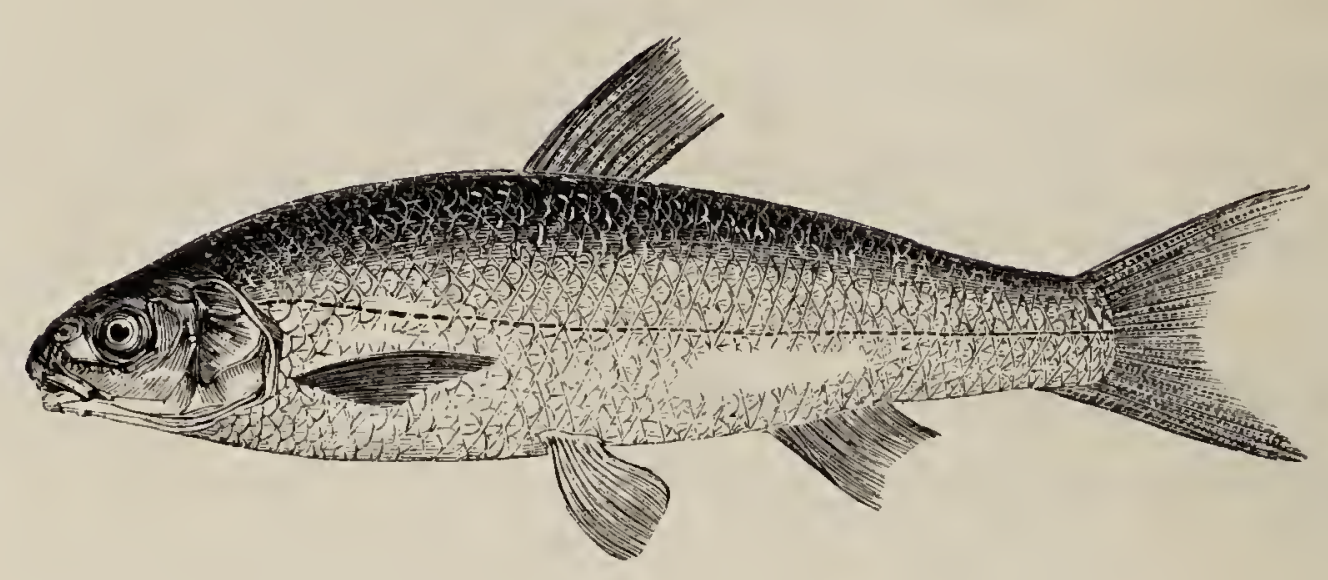

THE DACE, DARE, OR DART.

BRWYNIAD, Wales.-VANDOISE, France.

Squalius lcuciscus, HECKeI und KNER, fig. 191.

Leuciscus vulgaris, Cuvier et Valenc. xvii. 202.

argenteus, Bonap. Cyprinidæ.

Cyprinus leuciscus, Linneus. Bloch, pt. iii. pl. 97.

,, ", Dace, Penn. Brit. Zool. vol. iii. p. 483.

, , , $\quad, \quad$ Dovov. Brit. Fish. pl. 77.

Leuciscus argentatus, Agassiz. Selys.

The DACE and the Roach are somewhat allied in their habits, and a little so in their appearance; but the former is not so plentiful as the latter, nor is it so generally dispersed, being comparatively more local. The Dace inhabits Italy, France, and Germany, and in this country is found in the deep and clear water of quiet streams. Its food is worms and other soft substances; but, like the Trout, it will occasionally rise at an artificial fly, and it is frequently taken by fly-fishers while whipping for that fish. The Dace is gregarious, swimming in sculls, and spawning in June. Its flesh is considered preferable to that of the Roach, but is not generally in much estimation. The Dace seldom exceeds nine or ten inches in 
length, and it is frequently used as bait for Pike in trolling, on account of its silvery brightness; but where live bait are required, as for night looks, Roach are preferable, on account of their being more tenacious of life.

The length of the head, compared with the length of the head and body, without the caudal rays, is as two to nine; the depth of the body, compared to the whole length, as one to five; the muzzle is pointed: the mouth rather large, being more deeply cut than in a Roach of the same size; the nostrils very similar ; the eye is not so large, the diameter of it compared with the length of the head being as two to seven; the back is but slightly elevated: the body is elongated and elegantly shaped; the scales are considerably smaller than those of the Roach in two fishes of the same size; the number of scales composing the lateral line is fifty-two; on an oblique line above it there are eight, and in descending from the line to the origin of the ventral fin four.

"Pharyngeal teeth in two rows, conical, curved in" wards at the point, but neither serrated nor chiselpointed."-Valenc.

The dorsal fin commences rather farther back than in the Roach, the first ray being behind the middle of the body; the ventral fins rather in advance of the line of the commencement of the dorsal fin; in other respects the fins in these two specics are very similar.

The rays in number are-

D. $9:$ P. $16:$ V. $9:$ A. $10:$ C. 19.

The colour of the upper part of the head and back is dusky blue, becoming paler on the sides and white on the belly; the irides are straw-yellow; the cheeks and gill-covers silvery white; the dorsal and caudal fins pale brown; the pectorals, ventrals, and anal almost white, tinged with pale red.

VOL. I. 


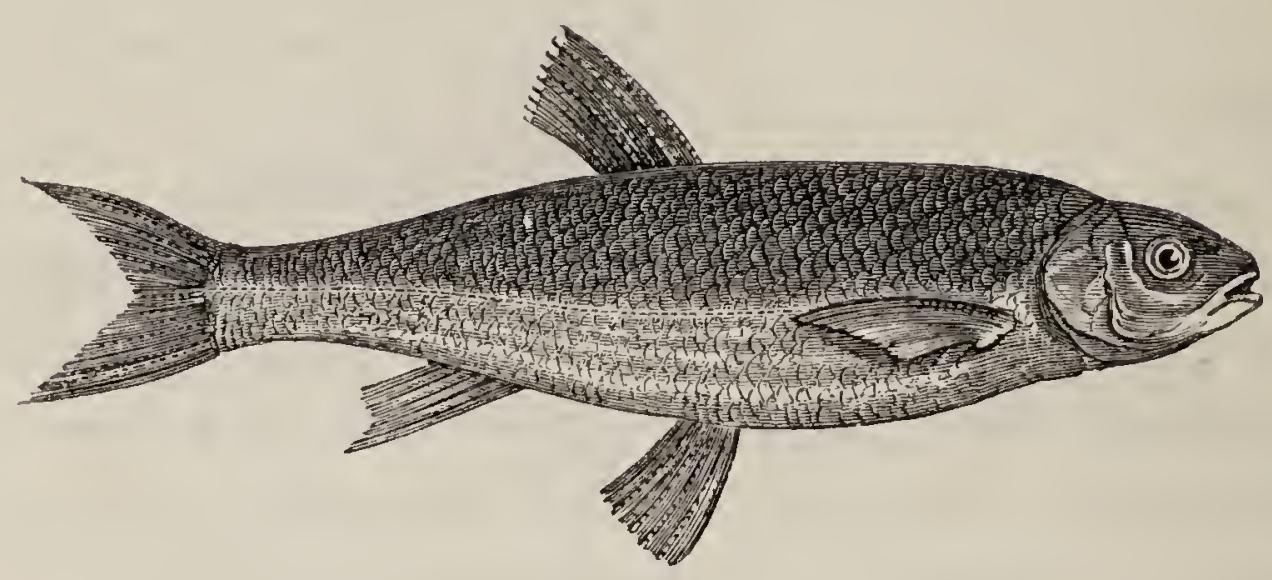

THE GRAINING.

Squalius? Lancastrcnsis.

Leliciscus Lancastriensis, Yarreht, Linn. Trans. vol. xvii. pt. i. p. 5.

, ", Bonap. Cyprinidie.

Cyprinus ," Graining, Sis w, Gen. Zool. vol. v. p. 234.

Leuciscus majalis "Agassiz, Mém. de la S. Nat. de Neuchâtel, pl. 6.

Pennant, in his account of a Tour in Scotland, p. 11, has the following observation:- "In the Mersey, near Warrington, and in the river Alt, which runs by Sephton, Lancashire, into the Mersey near Formby, a fish called the Graining is taken, which in some respects resembles the Dace, yet it is a distinct and perhaps new species." One of the streams here alluded to rises in Knowsley Park; and I have, by the kindness of Lord Derby, the President of the Zoological Society, been most liberally supplied with specimens. Several streams in the township of Burton Wood and Sankey, which flow into the Mersey below Warrington, and others in or near the township of Knowsley, which also form the Alt, produce the Graining in considerable numbers. In its habits and food it resembles the Trout, frequenting both the 
rapid and still parts of the rivers, but is not known to exist in ponds. It is fished for with artificial flies, like the Dace or Trout; and Mr. Bainbridge, an enthusiastic fisherman, in his excellent Fly-fisher's Guide, published at Liverpool, says, that "as they rise freely, they afford good sport to the angler; and when in the humour, it is not difficult to fill a pannier with them. They sometimes, though not commonly, exceed half a pound in weight, and are much better eating than the Dace."

Mr. Thompson of Belfast, mentions that several small individuals of this species occurred to him in the river Leam, near Leamington, in July 1836; and on showing specimens to M. Agassiz, he recognised it immediately as a species inhabiting the lake of Neuchâtel, where it consorts in sculls with the Bleak and Ronzon. It also exists in the Lake of Thun, and is not unlike the Squalius lepusculus, or Hasel of Heckel.

The length of the head, compared to the whole length of head, body, and tail, is as one to six, and the depth of the body, compared to the whole length, is as one to five; the nose is more rounded than in the Dace, the upper line of the head being straighter; the eye is rather larger ; the inferior edge of the preoperculum less angular; the dorsal profile less convex: the dorsal fin commences exactly half-way between the point of the nose and the end of the fleshy portion of the tail; while in the Dace that fin arises behind the middle. The first dorsal fin-ray in the Graining is short, the second ray is the longest; the pectoral fins are longer in proportion than in the Dace; and the ventrals are placed but little in advance of the first ray of the dorsal fin; the anal commences, under the tips of the dorsal fin-rays when that fin is depressed-its first ray is short, the second 
ray is the longest, and the last is double; the fleshy portion of the tail is long and slender, the caudal rays are also long and deeply forked and all the fins are a little longer than those of the Dace.

The scales are of moderate size, rather larger than those of the Dace, their vertical diameter greater, and the radiating lines less numerous: the number of scales forming the lateral line are forty-eight, those in an oblique row up to the base of the dorsal fin eight, and downwards to the origin of the ventral fins four; the lateral line descends from the upper edge of the operculum by a gentle curve to the middle of the body, and runs thence to the centre of the tail in a straight line. The fin-rays in number are-

$$
\text { D. } 9: \text { P. } 17: \text { V. } 10: \text { A. } 11: \text { C. } 19 .
$$

The Graining has the top of the head, the back, and upper part of the sides of a pale drab colour, tinged with bluish red, separated from the lighter-coloured inferior parts by a well-defined boundary line; the irides are yellowish white; cheeks and gill-covers shining silvery white, tinged with yellow; all the fins are pale yellowish white.
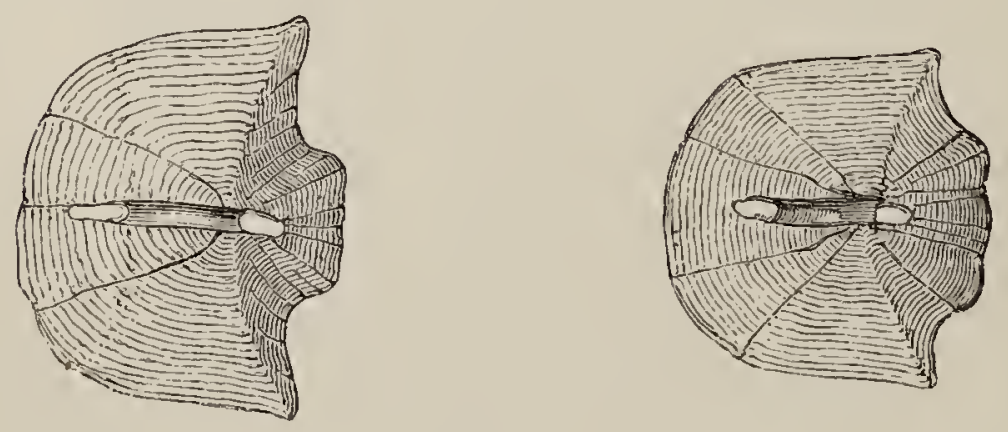


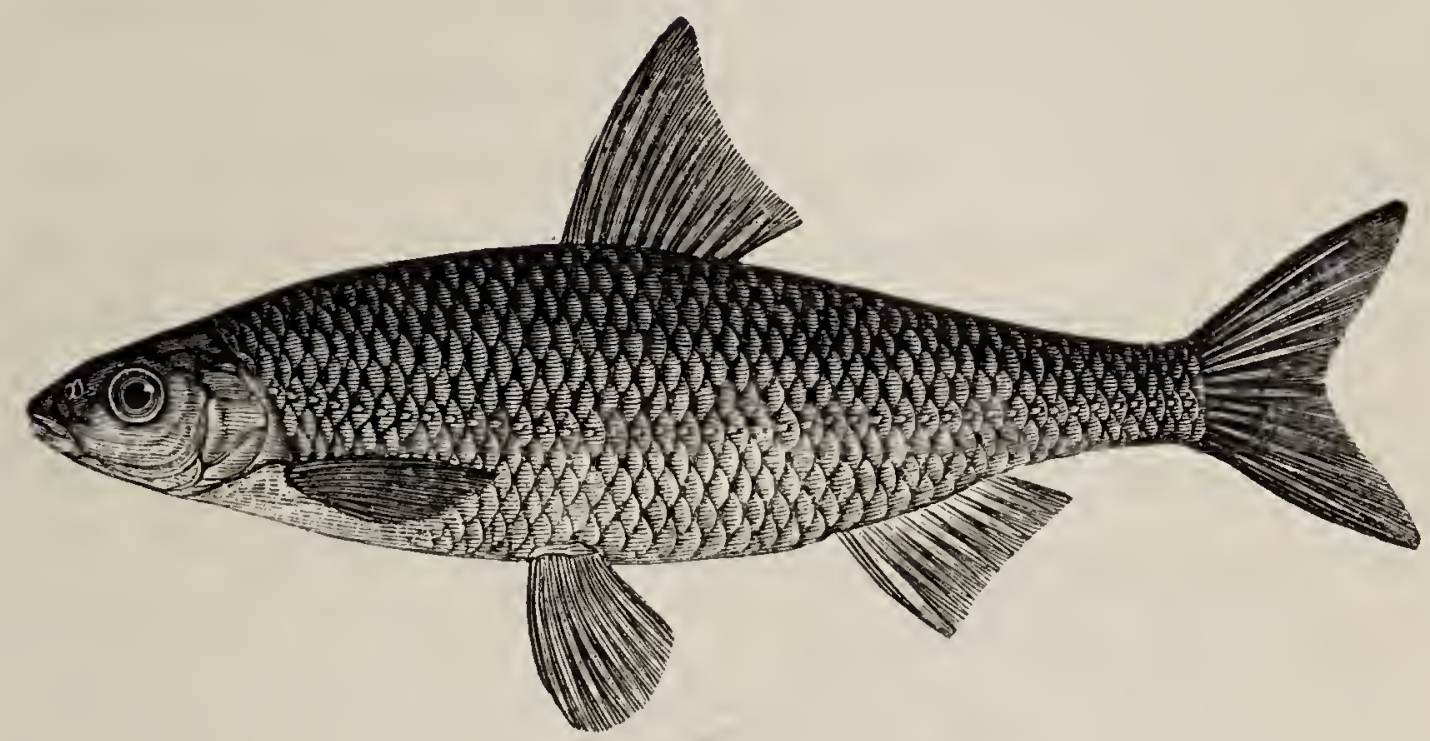

THE ROACH.

TORgOCH, RHYFELl, Wales.-MörT, Sweden.-RotHFLOSSER, Germany.

Leuciscus rutilus, Cuv. et Valenc. xvii. p. 130.

\begin{tabular}{|c|c|c|}
\hline & 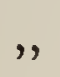 & Flem. Brit. An. p. 188, sp. 65. \\
\hline & , & HECKeL und KNER, fig. 91 \\
\hline yprinus & ", & Linneus. Bloch, pt. i. pl. 2. (Rothauge.) \\
\hline ", & ", & Roach, Penn. Brit. Zool. vol. iii. p. 482. \\
\hline ," & $"$ & Donov. Brit. Fish. pl. 67. \\
\hline & ", & Jenyns, Brit. Vert. p. 408. \\
\hline & ", & FrIEs och ECHSTröm, pl. 15. \\
\hline
\end{tabular}

Leuciscus. Generic Characters.-Pharyngeal teeth uniserial, constructed for pressing; six on the left side, five on the right. Mouth terminal, without barbels. Body compressed. Dorsal and anal similar, short, no bony rays in either.

The RoAch is said to be abundant in almost all the rivers throughout the temperate parts of Europe, and in this country it appears to be a very common fish, inhabiting most of our rivers, but preferring those that are slow in their course, frequenting the deepest parts by day, and by night feeding on the shallows. A specimen sent to me from Scotland, by Sir William Jardine, Bart., was rather

VOL. I. 
shorter and deeper than the Roach of the south. The Rev. David Ure, in a statistical account, when describing the Roach in the parish of Killearn, says, "Vast shoals come up from Loch Lomond, and are caught by nets in thousands: their emigrations from the loch, however, are only for the space of three or four days about the end of May." Mr. Donovan, in his. History of the British Fishes, says, "In the river Thames the finest Roach are caught about the middle of May or early in June, when they come up in sculls from the sea to deposit their spawn in the higher parts of the river ;" but the Roach in this instance come from the direction only in which the sea lies,-not, I apprehend, from the sea itself: the attempt to gain a higher station in the river, where the oxygen is in greater quantity, is analogous to the movement noticed above as occurring in Loch Lomond; but I have never known a Roach to be taken in the sea. Montagu, in his MS. referring to Mr. Donovan's statement of this migration from the sea, states his belief that $\mathrm{Mr}$. Donovan was mistaken, and quotes the following fact which came under his own observation to show that the Roach could not exist in sea-water at all :- In a small river that runs into a large piece of water of nearly two miles in extent, close to the sea, on the south coast of Devon, there is no outlet but by means of percolation through the shingle that forms the barrier between it and the sea: in this situation Roach thrive and multiply beyond all example. About eight or nine years ago the sea broke its boundary, and flowed copiously into the lake at every tide for a considerable time, by which every species of fish therein was destroyed.

The fish of Lough Neagh, in Ireland, called a Roach is in reality the Rudd, or Red-eye, which has the dorsal fin over the space between the ventral and anal fins: 
the Roach has the dorsal fin more forward on the body, and over the ventral fin, not over the space behind it. I may here mention, that the representation of the fish at the bottom of the title-page of the third volume of Pennant's British Zoology is that of a Rudd or Red-eye, and not that of a Roach, as stated; which the position of the dorsal fin sufficiently testifies.

Roach are gregarious, swimming constantly in large sculls, and feeding on worms and herbs. Pennant refers to a Roach of five pounds' weight. Mr. Jesse says the largest he has known to be caught in the Thames weighed three pounds: and Walton considered a Roach of two pounds worthy of particular mention. Mr. Jesse says of the Roach detained in his vivarium, that he has seen a Carp swim among a shoal of them without producing the least disturbance; but if a Pike went near them, they made off rapidly in all directions. The Roach spawns at the end of May or the beginning of June, and the scales are then rough to the touch. It is in little estimation generally for table, but is best as food, as well as finest in colour, in October, - a condition produced, probably, by the variety as well as quantity of nutriment obtained during a long summer ; it is in this month that it is most sought after by the Thames' anglers.

"As sound as a Roach" is a proverb that does not carry with it the degree of conviction that usually attaches to a popular apophthegm. It must, however, be remembered, that in the older ichthyological works this fish was called Roche-a term probably derived from the French. The meaning stands confessed, if we admit the pun upon the word; and we ought then to read, "as sound as a rock."

The French connect the same idea of haleness with the Ide, otherwise the Chub, described already, p. 421, 
which is known to them by the name of Jesse. The English say also, "as sound as a Trout;" and the Italians connect the idea of health with fish generally, è sano como il pésce, or, as Juvenal has it, Sanior es pisce. The Roach was first described by Rondelet.

The length of the head, compared with the whole length of the fish, including the caudal fin, is as one to five; the depth of the body at the commencement of the dorsal fin is to the whole length of the body alone, without the head or caudal fin-rays, as two to five: the muzzle is rather sharp; the mouth small : the nostrils double, both pierced in a circular depression, a little in advance of the anterior superior edge of the orbit; the diameter of the eye equals one-fourth of the whole length of the head, and occupies the second fourth portion; the nape and back rise suddenly; the dorsal profile is much more convex than that of the abdomen: the scales are rather large, and are marked with concentric and radiating lines; the number of punctured scales forming the lateral line is forty-three; the oblique line from the base of the dorsal fin down to the scale on the lateral line contains seven scales; between the lateral line and the ventral fin there are three scales; the lateral line falls by a curve from the upper part of the operculum to below the middle of the body, and from thence runs nearly straight to the tail.

The first ray of the dorsal fin arises exactly half-way between the point of the nose and the end of the fleshy portion of the tail ; its first ray is short, the second is the longest in the fin; both rays are simple, all the others diminish successively in length and are branched; the sixth ray is as long as the base of the fin; the upper ray of the pectoral fin is the longest and is simple, all the others are branched; the length of the fin equals the 
distance from the front of the eye to the free edge of the operculum : the ventral fins arise directly under the first ray of the dorsal fin; their upper ray is the longest and is simple, the others are branched : the anal fin commences under the ends of the rays of the dorsal fin when folded down, its first ray is short, the second ray is the longest, both are simple, the rest are branched; the tail is deeply forked, the central rays are scarcely half as long as the outer ones. The fin-rays in number are-

\section{D. $12:$ P. $17:$ V. $9:$ A. $13:$ C. 19.}

The colour of the upper part of the head and back is dusky green with blue reflections, becoming lighter on the sides, and passing into silvery white on the belly; the irides are yellow; the cheeks and gill-covers silvery white: the dorsal and caudal fins are pale brown tinged with red; the pectoral fins orange-red; the ventrals and anal bright red.

According to M. Valenciennes, the uniserial pharyngeal teeth grind down by use and acquire flat crowns. They are not serrated.

ROACH.

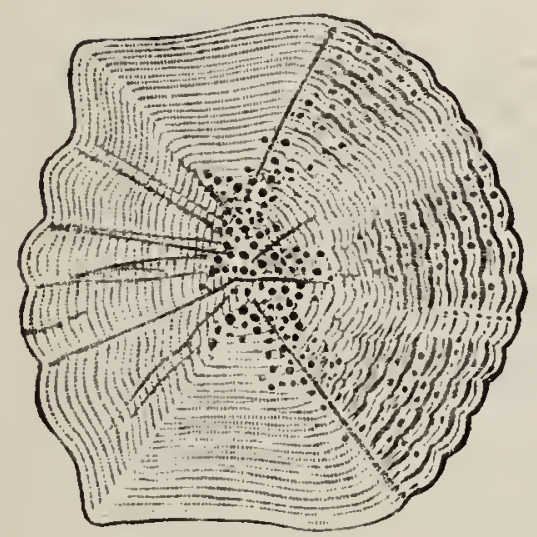

Chus.

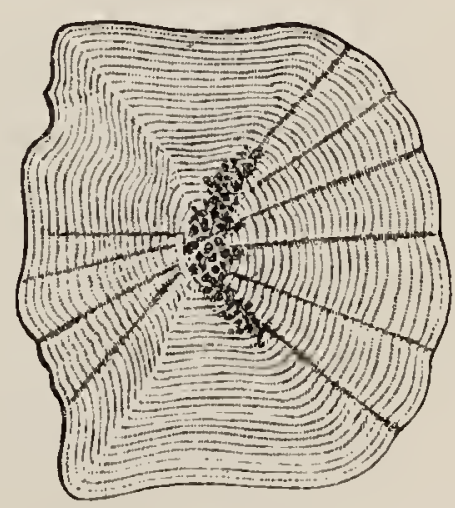


$A B D O M I N A L E S$

MALACOPTER YGII.

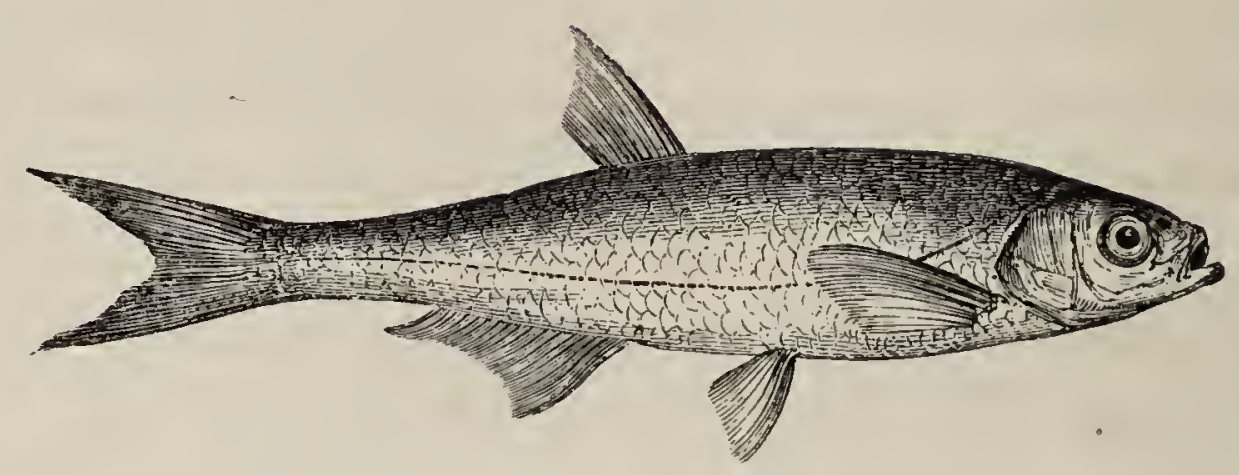

THE BLEAK. BLICK, Merret.

gorwyind, Wales.-Laube, Germany.-BlicCa, Sweden.

Alburnus lucidus, Heckei und Kner, p. 131, fig. 67.

Leuciscus alburnus, Cur. et Valeno. xvii. 272.

Cipprinus ,, Linnæus. Blocir, pt. i. pl. 8, f. 4.

, " Bleak, Penn. Brit. Zool. vol. iii. p. 487, pl. 84.

, $\quad$, $\quad$ Donov. Brit. Fish. pl. 18.

Alburnus. Generic Characters.-Pharyngeal teeth raptorial, biserial, two and five, subulate, curved. Mouth sloping upwards, the point of the mandible fitting into a depression between the slightly-shorter premaxillaries; no barbels. Dorsal few-rayed, behind the ventrals; anal not exceeding the dorsal by more than six rays; no bony ray in either. Body compressed; belly acutely keeled behind the ventrals. The strong silvery scales easily detached.

The Bleak is a well-known small species inhabiting: many of the rivers of Europe, and is found in this country in most, if not all of those which produce the Roach and the Dace. The Thames, the Lea, and the New River produce Bleak in considerable numbers. They swim in large sculls, spawning in May; and at that time the head and gill-covers are rough to the touch. 'Though not of sufficient consequence to claim any attention as an article of food, the Bleak affords excellent amusement to young fly-fishers, rising eagerly to almost any small 
fly, and sporting incessantly on a fine day at the surface of the water. $\mathrm{M}_{\mathrm{r}}$. Jesse, in his Gleanings, says: "But of all the fish confined in a vivarium in Bushy Park, the Bleak were the most amusing and playful. Their activity could not be exceeded; and it gave me much pleasure to see them, on a still summer's evening, dart at every little fly that settled on the water near them, appearing always restless, and yet always happy."

The following lines of Ausonius show that the Bleak was in former times equally the amusement of young anglers as it is in the present:-

\section{"Quis non et virides vulgi solatia Tincas}

Norit, et Alburros predam puerilibus hamis?"

This fish is frequently found to have the intestines partly occupied by a species of tapeworm. I have taken them out of much greater length than that of the whole fish itself : and the name of Mad-Bleak has been bestowed upon those fish that are seen occasionally swimming in an agitated uneasy manner on the surface of the water; -an unnatural action, not observed to occur in other species, and referred to the annoyance or pain supposed to be produced by these internal disturbers.

On the inner surface of the scales of Roach, Dace, Bleak, Whitebait, and other fishes, there is found a silvery pigment, which gives lustre to the scales. This colouring matter is employed in making imitations of the Orienta pearl. When this practice was most in fashion, the manufactured article bore the name of patent pearl, and its use was universal in the bead-trade for necklaces, ear-drops, \&c. At present, it seems confined to ornaments attached to combs, or to small beads arranged with flowers for head-dresses. So great was the demand formerly at particular times, that the price of a quart measure of fish scales has varied from one guinea to five. 
The Thames fishermen gave themselves no trouble beyond taking off the side scales, throwing the fish into the river again; and it was the custom for hawkers regularly before selling any white-fish, as they were called, to supply the bead-makers with the scales.

The method of obtaining and using the colouring matter was, first carrying off the slime and dirt from the scales by a run of water; then, soaking them for a time, the pigment was found at the bottom of the vessel. Into this small glass tubes were dipped, and the pigment was injected into thin hollow glass beads of various forms and sizes. These were then spread on sieves, and dried in a current of air. If greater weight and firmness were required in the beads, a further injection of wax was necessary. Of this pigment, that obtained from the scales of Roach and Dace was the least valuable; that from the Bleak was in much greater request; but the Whitebait afforded the most delicate and beautiful nacre, and obtained the highest price.

This art of forming artificial pearls is said to have been first practised by the French. Dr. Lister, in his Journey to Paris, says, that when he was in that city, a manufacturer used in one winter thirty hampers of Bleak. Our term Bleak, or Blick, according to Merrett, which has reference to the whiteness of the fish, is derived from a northern word, which signifies to bleach or whiten.*

In a specimen seven inches long, the length of the head compared to the length of the head and body, without including the caudal rays, was as two to nine; the depth of the body compared in the same way was as one to four: but in a younger male specimen of five inches long, the depth of the body was merely equal to the length of the head; and both measurements, therefore, were as two

* Blik (Danish), glance ; Blick (Swedish), glimmer. 
to nine. In the large specimen, the body was Dace-like in form and general appearance, but immediately distinguishable by the backward position of the dorsal fin, and the greater length of the base of the aual fin; the body is elongated, with the ventral profile rather more convex than the back; the nose is pointed; the under jaw the longest; the eye rather large: the scales, beautifully striated, of moderate size, the number on the lateral line being about forty-seven; above it, to the base of the dorsal fin, six; and below it, to the origin of the ventral fin, four: the dorsal fin commences half-way between the anterior edge of the eye and the end of the short central rays of the tail ; the first ray is but onethird of the length of the second ray, which is the longest in the fin; the base of the fin is as long as the sixth ray: the anal fin commences under the origin of the last ray of the dorsal fin, and occupies half the space between its commencement and the end of the fleshy portion of the tail; the caudal rays are elongated, and deeply forked.

Rays. D. 10 : P. 17 : V. 9: A. 18: C. 19 . Vertebræ 43.

The colour of the back is a light greenish or ash brown tinged with blue; the sides, belly, cheeks, and gill-covers are shining silvery white; the irides silvery, and in largesized specimens tinged with yellow; all the fins are nearly white.

BARBEL.

BLEAK.
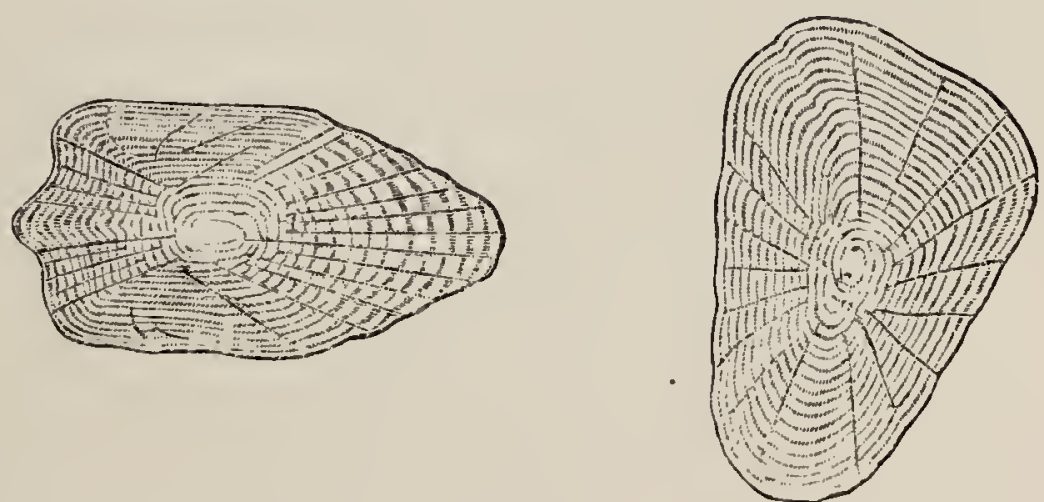
A BDOMINALES

MALACOPTER YGII.

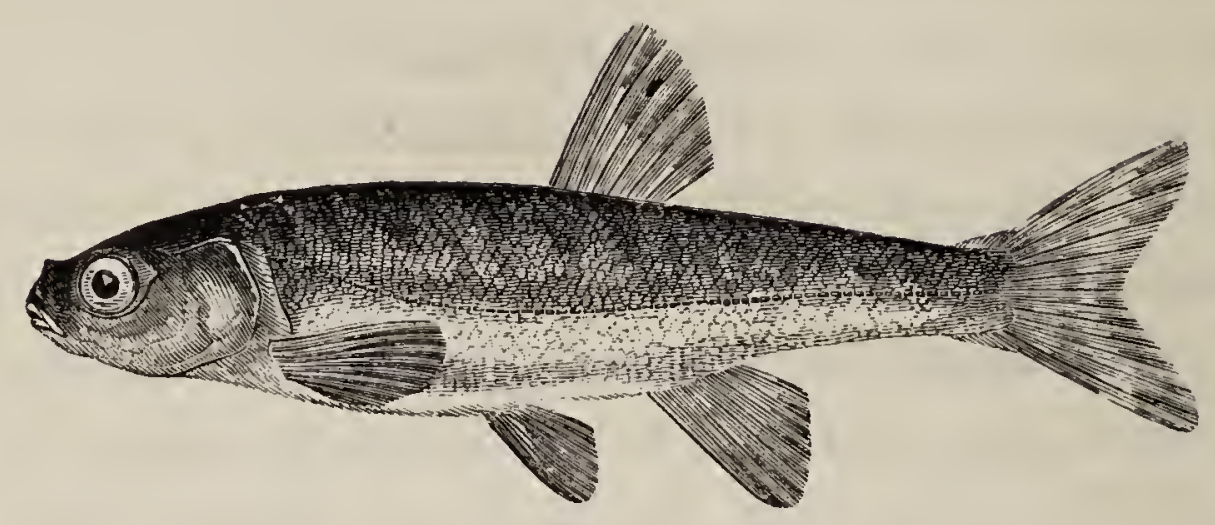

\section{THE MINNOW, MINIM, OR PINK.}

pilcodyn, Wales.-LE veron, France.-ELrizor, Sweden.-pfrille, Germany.

Phoxinus levis, Agassiz. Bonap. Cuv. et Valenc. xvii. p. 363.

Lenciscus phoxinus, Cuvier, Règne An. t. ii. p. 276.

Cyprinus ,, Linnaus. Bloch, pt. i. pl. 8, fig. 5.

" , Minnow, Pens. Brit. Zool. vol. iii. p. 489.

, , , Dovov. Bit. Fish. pl. 60.

, ", , Jenyns, Brit. Vert. p. 415.

Phoxinus. Generic Characters.-Raptorial pharyngeal teeth biserial, generally two and four on both sides, sometimes two and five or four and two. Mouth terminal, without barbels. Dorsal short, behind the ventrals; anal having about as many rays as the dorsal. Scales externally small and tender, often wholly wanting on the throat and belly as far as the anal.

This very prettily-marked species, one of the smallest of the British Cyprinida, rarely exceeding three inches in length, inhabits many of the rivers, brooks, and canals in England; it is also common in Scotland, and in several localities, within the counties of Dublin and Wicklow, where some suppose it to have been introduced. It is generally found in the same streams with Trout, preferring gravelly bottoms, and swimming in sculls. In its habits 
this is an active and amusing little fish; and many persons have tried how long they could keep it in confinement, but none have succeeded in preserving it beyond three years. Its food consists of aquatic plants, worms, and small portions of animal substance. A writer in the fifth volume of Mr. Loudon's Magazine of Natural History relates that, crossing a brook, he "saw from the foot-bridge something at the bottom of the water which had the appearance of a flower. Observing it attentively," he proceeds, "I found that it consisted of a circular assemblage of Minnows: their heads all met in a centre, and their tails diverging at equal distances, and being elevated above their heads, gave them the appearance of a flower half-blown. One was longer than the rest: and as often as a straggler came in sight, he quitted his place to pursue him; and having driven him away, he returned to it again; no other Minnow offering to take it in his absence. This I saw him do several times. The object that had attracted them all was a dead Minnow, which they seemed to be devouring."

M. Valenciennes mentions that M. Rayer had observed many Minnows with oval transparent tumors on the head, about the bigness of a pin's head. Under the microscope, these globules were seen to contain two cells at one end, but M. Rayer could not determine whether they were of vegetable or animal origin. This disease is different from the minute warts that appear on the heads of many of the Leuciscini in spawning time.

The Minnow is very prolific, spawning in June: at that time the head is covered with small tubercles: the young are soon alive, and I have taken them threequarters of an inch long by the first week in August. Dr. Davy having pressed out the roe of a female Minnow in spawning time, mixed it with milt procured in the 
same way, and placing the eggs in water, which he changed daily, they were hatched on the sixth day.

A detailed account of many particulars interesting to the naturalist relating to the habits of this species when spawning will be found in the fifth volume of the Magazine of Natural History, page 681.

A gravelly spot was chosen; each female was attended by two males, one on each side: several ova, nevertheless, it appears, escape fœcundation, which the writer believes takes place at the moment of exclusion : the ova that received the influence of the male were obviously different, when examined under a microscope, from those that were unimpregnated: the membrane forming the investing capsule was more tough, and resisted injury longer, not breaking down so easily when touched: some attempts at artificial impregnation did not succeed. The spawning season with them is short, seldom exceeding two or three days, and the eggs become young fish in a very few days afterwards. The young Minnows are quite transparent, except the eyes, which are large: in this state the larvæ of the angler's May-fly, and other ephemera, were their greatest enemies, and the diminutive fry seemed to be perfectly aware that they owed their safety to concealment; when exposed they immediately buried themselves again in the gravel.

The Minnow affords amusement to young anglers, biting readily at a small piece of a red-worm; it is principally used as a bait for Pike, Trout, and large Perch. The flesh is considered of good flavour; and when a sufficient quantity can be obtained, for which a small casting net affords the best chance, they make an excellent fry.

The terms Minnow and Minnim are said to be derived from the Latin minimus, in reference to the small size of 
the fish : they are called Pink because of the bright red colour that pervades the belly and under parts in summer.

The length of the head compared to the length of the head and body, without including the caudal rays, is as one to four; the depth of the body does not quite equal the length of the head; the body is elongated and slender; the dorsal and ventral profiles are but slightly convex; the surface is smooth, covered with numerous minute scales; the lateral line runs straight from the tail as far as opposite the ventral fin, whence it rises gradually to the upper edge of the operculum. The dorsal fin commences half-way between the anterior edge of the eye and the end of the fleshy portion of the tail: its rays and those of the anal agree in the first ray being short, the second the longest of the fin, both simple, and all the others articulated and branched. The anal fin commences under the origin of the last dorsal fin-ray; the tail is rather large and is forked, the outer rays being double the length of those in the centre. The fin-rays in numbers are-

\section{D. $9:$ P. $16:$ V. $8:$ A. $9:$ C. 19.}

The top of the head and back are a dusky olive, mottled, and lighter in colour on the sides; the belly is white, and of a fine rosy or pink tint in summer, varying in intensity according to the vigour of the fish: the irides and gill-covers are silvery: the dorsal fin pale brown; the pectoral, ventral, and anal fins lighter; the caudal is light brown, with a dark-brown spot at the base of the rays. 
ABDOMINALES

MALACOPTERYGII.

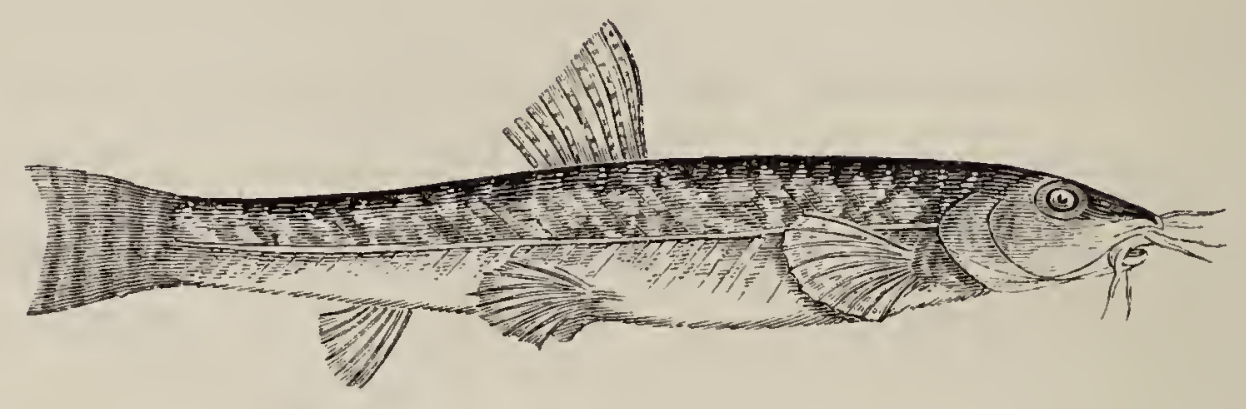

THE LOACH, LOCHE, OR BEARDIE.

BarfWyniad, Wales.-SMerling, Denmark.-Grönling, Sweden.-bartgrundel, Germany.

Crbiti: barbatula, Linnews. Buoch, pt. 1. pl. 31, fig. 3.

$, \quad, \quad$ Valenc. Hist. des Poiss. xviii. p. 14.

, " Loche, Prenn. Brit. Zool. vol. iii. p. 379.

", $\quad$, Bearded Loche, Dovov. Brit. Fish. pl. 22.

," $\quad, \quad$, $\quad$ Flem. Brit. Al. p. 189, sp. 69.

", $\quad, \quad \quad, \quad$, Jenyns, Brit. Vert. p. 416.

Acanthopsids. Family Characters. - Form elongated; head small, and scaleless as far back as the small gill-opening; preorbital scale-bone, and frequently the bony operculum, producing one or more spines. Mouth furnished with suctorial lips and barbels. No bony ray in the short dorsal, which stands over the ventrals. Body covered with sminll scales.

Совгтіs. Generic Characters.-Numerous uniserial, pointed, pharyngeal teeth. Dorsal, and the opposed ventrals, short and far back. Branchiostegals three. Swim-bladder enclosed in a globular cell of bone formed by the lateral processes of two large anterior vertebræ. Pseudobranchia absent.

The Tuach is not uncommon in our rivers and brooks; but its habit of lurking under stones often prevents its being observed. Dr. George Johnston finds it in the Tweed and in the burns of Berwickshire; Mr. Neill says it is frequent in the Water of Leith, and other rivers 
of Scotland; and Mr. Thompson in his Natural History of Ireland, says that it is pretty generally diffused over that island. The Loach delights in small, shallow, clear streams, and swims rapidly when disturbed by the moving of the stone under which it secretes itself. As it is difficult to catch from its slimy smoothness and activity, country boys are in the habit of surrounding any small pool, known to contain some, with a bank of clay, and then making sure of them by lading out the water.

Mr. Booth, in his Analytical Dictionary, considers that our term Loche is derived from the French locher, to be uneasy; alluding to the restless habits of the species of this genus, and their almost constantly moving from place to place. They are said to be particularly restless before and during stormy weather, and have been preserved in vessels, like the leech, as living barometers, * from a notion that certain movements and alterations of position or situation indicated particular changes about to take place in the weather. It is to be observed, however, that the name of La Loche is applied provincially to the Lota vulgaris, also a ground-fish.

The species of this genus are remarkable in having from six to ten barbels about the mouth. Fishes thus provided are known to feed at or near the bottom of the water; and it is stated elsewhere in this work, that those species which reside constantly so near the bottom as to acquire the name of ground-fish, have a low standard of respiration, and a high degree of muscular irritability. In the animals possessing this duration of the power of muscular contractility, as the Eels, Flat-fish, and many others, there is reason to believe there exists also great susceptibility of any change that occurs in the electrical

* The Lake Loche of the European Continent, Cobitis fossilis of authors, is in an old Continental Naturalist's Miscellany called Thermometrum vivum. 
relations of the medium in which they reside; the restless movements of Eels and other ground-fish during thunder receive at least a probable explanation in the belief that no alteration in the weather takes place without some previous change in the electrical condition of the atmosphere, which, by its quality or quantity, may affect the water.

The Chinese, who breed and rear great quantities of Gold Carp, find that thunder does them harm, and even sometimes kills them. Pennant says lobsters fear thunder, and are apt to cast their claws on a loud clap. These effects may be referred to spasmodic action of the muscles induced by electrical influence. If fishes of opposite habits, such as surface-swimmers and ground-fish, are put together into the same vessel of water, and a slight galvanic discharge passed through the fluid, the ground-fish with the lowest degree of respiration will be the most agitated.

Worms and aquatic insects are the food of the Loach. It spawns in March or early in April, and is very prolific, but seldom exceeds four inches in length. The flesh is accounted excellent; and in some parts of Europe these little fishes are in such high estimation for their exquisite delicacy and flavour, that they are often transported with considerable trouble from the rivers they naturally inhabit to waters contiguous to the estates of the wealthy. Linnæus, in his Fauna Suecica, says that Frederick the First, King of Sweden, had them brought from Germany, and naturalized in his own country.

Mr. Newman in the Zoologist (p. 4897) gives some interesting notices of the habits of the Beardie in confinement. "This little fish appears to be entirely incapable of swimming like the majority of fishes: it remains motionless at the bottom of the vessel during the greater 
part of the day, but towards the evening, and also in showery weather, it frequently comes to the surface by a violent wriggling movement of its eel-like body; having reached the surface, it is totally unable to remain there, either by a continuance of its exertions or by that easy floating which many fishes practise so gracefully: the moment the exertion ceases, the fish falls heavily and languidly to the bottom, dropping from rock to rock, or from plant to plant, until it finds a resting-place; where, whether on a stone or a plant, it will remain perched for hours. I have seen it apparently balanced crosswise on the edge of a vertically-placed stone: aquatic progress seems the result of powerful exertion of the vertebræ. It is excessively voracious, and will consume an incredible number of small worms; as soon as it seizes one, it stirs up the sediment in the vessel, making the water so cloudy that the fish becomes invisible. The lid of the nostril stands up like a little horn on each side of the face. It is unconquerably shy."

Some peculiarities in the skeleton of the Loach will be pointed out after the description of its external appearance.

The length of the head compared with the length of the body alone is as one to four; the depth of the body is to the length of the head and body, without the caudal rays, as two to eleven; the nose is rounded, pointing downwards; the top of the head flat; the nostrils double, the most anterior tubular, the second pierced in a depression just before the eye; the lips large; the mouth small, placed underneath, the lower jaw the shortest; the form and situation of the mouth are very similar to that of the Barbel, with four barbels or cirri over it on the upper lip in the front, and one at each lateral angle; the eye is small; the body elongated, smooth, covered with a mucous

vor. I.

G G 
secretion, rounded before the dorsal fin, and compressed behind it; the dorsal fin commences half-way between the point of the nose and the end of the fleshy portion of the tail; the ventral fins are under the dorsal; the anal fin commences half-way between the origin of the ventral fin and the end of the fleshy portion of the tail, and the caudal rays are slightly rounded.

The fin-rays in number are-

\section{9 : P. $12:$ V. $7:$ A. $6:$ C. 19 . Vertebræ 36.}

The head, body, and sides are clouded and spotted with brown on a yellowish-white ground; the belly and under surface white or yellowish-white; all the fins are spotted with dark brown, the dorsal fin and the tail being the most so; the irides are blue.

I am indebted to the kindness of $\mathrm{Mr}$. George Daniell for the knowledge of two peculiarities in the structure of the bones of the Loach, which are represented in the vignette, and also for the use of a skeleton to draw and describe from.

Attached to each outer side of the first and second vertebræ is a hollow sphere of bone, between the pair of which, on the upper surface, the centra of the vertebræ are distinctly seen; but the union of the two spheres underneath hides the centra when looked at from below. These circular capsules are hollow for containing the small air-bladder; and their smooth insides can be seen through a horizontally-elongated aperture that exists on the outer side of each. They have also a function analogous to that of the scapula, since to their outer surfaces the bones of the proximal extremity of the pectoral fins are articulated; and these fins are moved by powerful muscles, which assist in producing the rapid motion observable in this little fish. Another peculiarity existing in the upper 
surface of the head, is the want of union in the two parietal bones at the top, the space between them being, as in the Catastomi and many other Cyprinoids, occupied by cartilage in the recent fish. It is marked in the vignette by the rectangular black patch. A similar deficiency of bone was observed by the late Rev. Lansdown Guilding to occur in the Iguana tuberculata, or common Guana,* and that lamented naturalist applied the term foramen Homianum, to the aperture in honour of Sir Everard Home, observing that the opening did not afford a passage to any nerve or blood-vessel. This structure in the Loach, it will be observed, is an instance of a relation in the organization of the fishes and reptiles, which we shall again advert to.

'The vignette exhibits a magnified representation, four times larger than the natural size of the fore part of the skeleton of the Loach seen from above.

* Zoological Journal, vol. i. p. 130.

Bony Capsules of the Air-blatider.

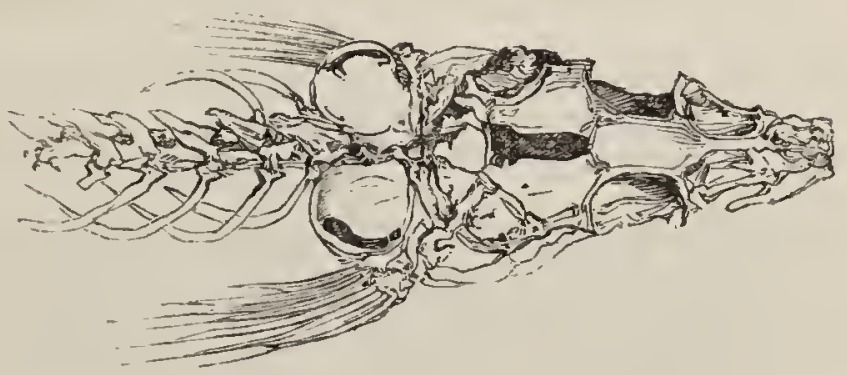




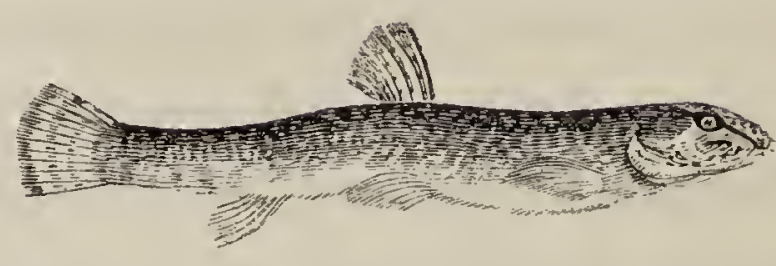

THE SPINED LOCHE. GROUNDLING.

\section{STEInbeisser, Germany.}

Cobitis tenia, Linnwus. Bloch, pt. i. pl. 31, fig. 2.

$, \quad, \quad$ Valenc. Hist. des. Poiss. xviii. p. 58.

", ", Spinous Loche, Pens. Brit. Zool. vol. iii. p. 381.

", ", Groundling, Turton, British Fauna, p. 103, sp. 90.

THE preorbitar spine, which is forked and movable in this species, is the character whereon Agassiz has founded his genus Acanthopsis, which we have not adopted. The Botia of Dr. Gray contains Indian Fishes belonging to a distinct family.

The Spined Loche is much more rare than that last described. Berkenhout, in his Synopsis of the Natural History of Great Britain and Ireland, says it is found in the Trent, near Nottingham; Dr. Turton, in his British Fauna, states that it inhabits the clear streams of Wiltshire; William 'Thompson, Esq. has found it in Warwickshire; and the Rev. Leonard Jenyns has found it in the Lodes, or Leads, as they are called, which run into the Cam. It has not been discovered in Ireland. Its habits are but little known, or have not been distinguished from those of the more common Loach. It is called Groundling from its habit of lurking under stones in search of larvæ 
and insects. When touched it emits a peculiar sound. Bloch says it spawns in April or May, and deposits its ova among stones on the bottom. It seldom exceeds three inches in length. By the kindness of Mr. Jenyns, I possess two specimens from Cambridgeshire, from one of which the representation, of the natural size, at the head of this article, was taken. The fin-rays in number are-

$$
\text { D. } 8: \text { P. } 9: \text { V. } 7: \text { A. } 6: \text { C. } 15 \text {. }
$$

The form of the body is still more elongated, slender, and compressed than that of the Loach; the nose more pointed; the mouth and the eyes smaller in proportion; the pectoral fin longer and narrower; all the fins occupying the same relative situation. The colours are similar, both of the body and fins; but a row of darkbrown spots ranged along the side are the most conspicuous. On the upper lobe of the caudal fin at its base, there is a well-marked crescent of dark brown.

The air-bladder is enclosed in an osseous capsule of the two large vertebræ as in the Beardie.

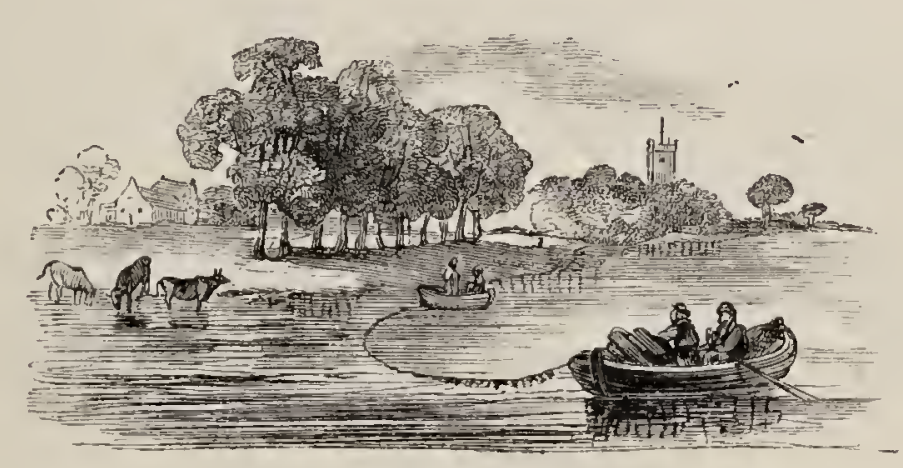




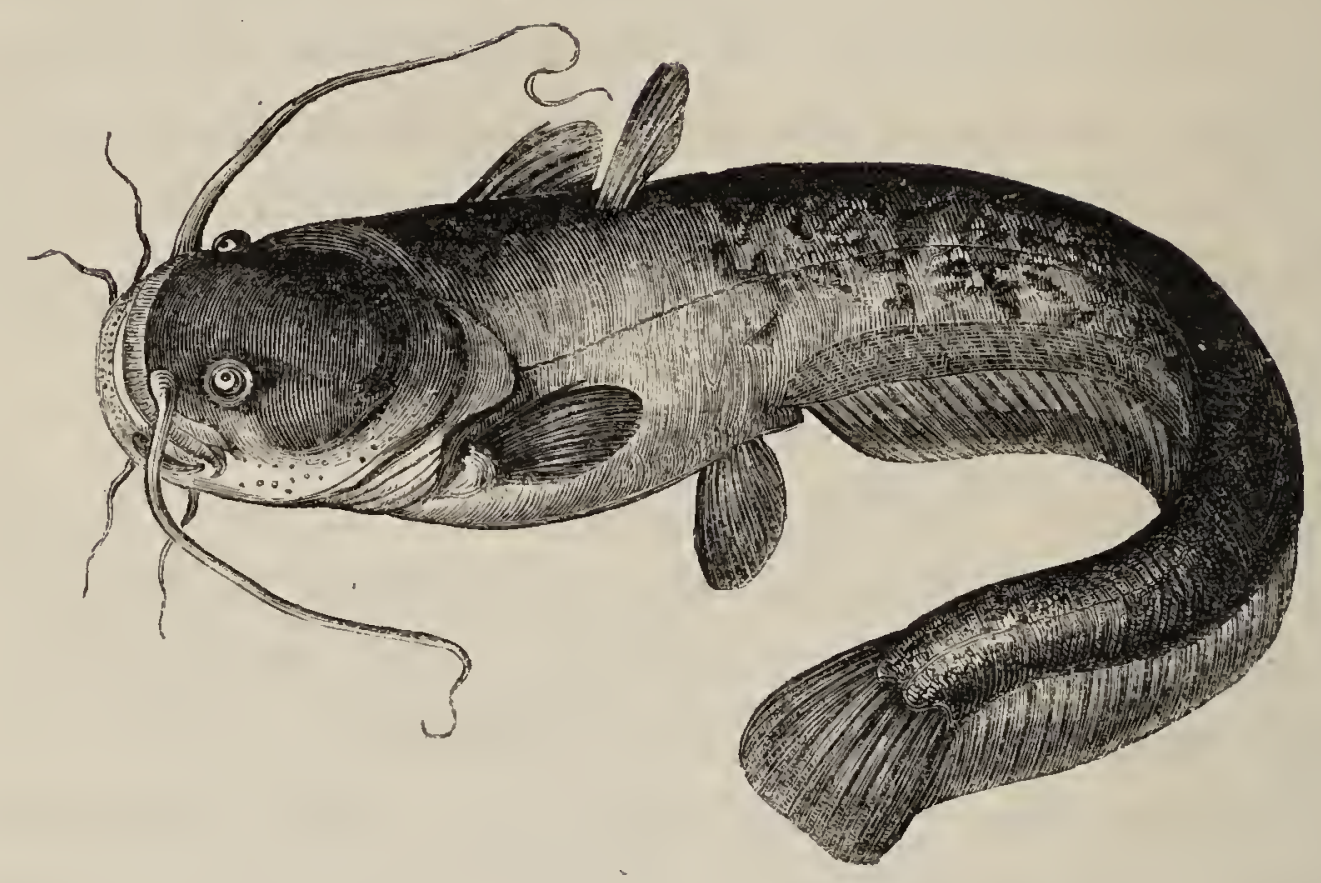

THE SLY SILURUS.

\section{SHEAT-FISH。}

Silurus glanis, Linndus.

,, ,, Sheat-Fish, BlocH, pt. i. pl. 34.

Silurids. Family Characters.-Fishes with oral barbels; skin naked, or armed with bony shields, but no scales of the ordinary kind. Mouth bor. dered above by the premaxillaries, the maxillaries being either rudimentary or elongated into barbels. Suboperculum and epicoracoid wanting. No pseudobranchiæ. Swim-bladder present in most of the members of the family, and connected, by a chain of ossicles, with the acoustic organ. Stomach cæcal; no pancreatic cxca. An adipose fin exists in the majority, and the first pectoral ray is generally a strong serrated bone. Branchiostegals nine to eighteen.

Silurus. Generic Characters. - A short dorsal, without sensible spines, situated well forward on the back; no adipose fin; anal long. Raduliform or card-like teeth on the jaws, with a band of vomerine ones behind the premaxillaries. Some species have four barbels, others only two.

SibBíld, in his Scotia Illustrata, at the end of his list of river fishes adds Silurus sive Glanis, and refers to Atlas novus, pt. 5, p. 148. The Silurus has not been found in the British Islands in modern times, and it has been 
conjectured that Sibbald mistook some other species of fish for it, perhaps the Burbot. It was introduced into the former editions of British Fishes, to enable an observer to identify a specimen, should it perchance be found in our waters, and with the same object it is continued in the present one. As it occasionally descends into brackish or salt water, and has been taken in the Currisch-Haf of Brandenburgh, in the Baltic itself, in the salt lake of Neusiedel, and in the Haarlem Mere, it is possible that in Sibbald's time a stray individual might have wandered to the coast of Scotland; and the existence of the colloquial name of Sheat-fish supplies an argument in favour of its having been known to our fishermen at one time or other. Mr. Thompson, in his Natural History of Ireland, states that in October 1840, William Blair, an experienced fisherman of Florence Court, took in a pool of a tributary of the. Shannon, shortly after a flood, a fish of a kind entirely unknown to him or to those who saw it. It was two and a half feet long, and weighed eight or nine pounds. The skeleton remained on a bush for several years, until it fell to pieces. Blair's description was so graphic and particular that Lord Enniskillen immediately suggested its applicability to the Silurus, and Blair, on being shown the figure in British Fishes of that species, immediately identified it as, in all respects, resembling his fish, except that the head and mouth of the figure seemed too small. None of the people in the district were acquainted with a fish of the kind.

Sheat is an archaic word for a hog.

The Silurus glanis, the largest of European fresh-water fishes, occurs, though but rarely, in the Scandinavian rivers and lakes, but is common in the Danube and its affluents. It has not been found in Ireland or England, 
nor in France, Spain, or Italy. It is named Saluth by the Swiss, Wels and Schaiden or Schade by the Germans; the latter name being probably the origin of Sheat, or having the same derivation. In Prussia it is a common fish, and also in Poland, being most abundant in Styria. One sixteen feet long was taken in the Bug.

Artedi, and after him Cuvier and other's, have supposed that the Glanis of Aristotle was identical with the Silouros of Elian, Athenæus, and Pliny; and Linnæus combined the names to form the generic and specific designations of the fish. This opinion was based on the supposed fact of there being but one kind of Silurus in Europe, and also, as is stated in the Histoire des Poissons, on the appellation of glanos, or glano, being at this day applied in Turkey to the Sheat-fish. M. Agassiz, however, received in $185 \%$ six specimens of a siluroid fish from the Achelous, the chief river of Acarnania, the very quarter from whence Aristotle derived his information about the Glanis. These interesting specimens were labelled in the language of the country, Glanidia (in the singular Glanidi), and M. Agassiz has shown that the descriptive notices to be found in Aristotle of the Glanis do not agree with the Silurus, but correspond in the form they ascribe to the anal fin, and in other particulars to the fish of the Achelous, a genuine siluroid not yet admitted into our systems. The following passages from Aristotle therefore refer to the Glanidi, but in as far as the habits spoken of are generic, they relate also to the Sheat-fish.

"The Glanis and the Perkè give out their spawn in a continuous stream like the frogs, and indeed the spawn is so wound up that the fishermen reel it off, at least that of the Perkè, from the reeds in the lakes. The larger Glanis spawns in deep waters, some at the depth of a 
fathom; the smaller in shallower places among the roots of willows or some other tree, and also among the reeds or the mosses. The growth of the Glanis from the egg is very slow, wherefore the male keeps watch forty or fifty days, that the young may not be devoured by other fishes.

"The male Glanis is conspicuous among river fishes for the great care it takes of its young. For the female having brought forth, departs; but the male remains watching by the deposit of eggs, rendering no other service, but keeping off other fishes. He does this for forty or fifty days until the young are sufficiently grown to escape from their enemies. He keeps off the other fishes by rushing movements, and making a noise and moaning, whereby he is known to the fishermen, who entice him into shallow places by removing the spawn thither, as he does not even then desert it.**

An abridgment of M. Valenciennes' description of this fish, coupled with the figure copied from Bloch, will enable any one who may capture this fish to recognise it. $\downarrow$

"The Silurus of Europe is depressed at the head, rounded at the shoulders, and compressed posteriorly. Its dorsal profile is nearly straight. The mouth occupies the whole breadth of the head, and on both jaws there is a broad band of crowded card-like or coarsely villiform teeth; on the front of the vomer there is a second band parallel to the front one, the rest of the palate being smooth, as well as the tongue, which is merely a flat eminence on the floor of the mouth. The maxillary lying a little before a membranous fold at the corner of the

* Agassiz, Procced. Amer. Ac. of Arts and Sciences, Nov. 12, 1856.

+ A much better figure than Bloch s is given in Heckel und Kner, Süss. wasserfische der Östreichischen Mon. p. 308. 
mouth, has a very short bony stem, but is prolonged into a compressed barbel, which reaches backwards to the pectoral fin. There are, moreover, four barbels on the mandible. The gill-opening commences in the middle of the height of the trunk of the fish, and curves downwards to the throat between the limbs of the mandible. The pectoral is attached low down, and has a very stout spine for a first ray, near whose point there are some fine denticulations internally. The first ray of the ventral is simple, but not spinous. All the rays of the very small dorsal are soft and branched. The vent is a small round hole behind the ventrals; and behind it again there is a fleshy tubercle, with the orifice of an efferent tube in its point. The anal joins the caudal; jts rays are all soft and branched.

$$
\text { Rays: Br. } 16: \text { D. } 4: \text { A. } 90 \text { : C. } 17: \text { P. } 1+16: \text { V. } 12 .
$$

"The skin is soft and smooth throughout without scales. The lateral line is a continuous and nearly straight series of very slender, slightly-elevated lines. The general colour is a brownish olive with deeper and lighter shades." M. Valenciennes gives the internal anatomy and the curious osteology in much detail, which the reader is recommended to study in the original. The Silurus attains a greater size than any other European fresh-water fish. It is very voracious, and the author we quote from gives some remarkable instances of its shark-like propensities. In the year 1700, on the 3rd of July, a countryman took one near Thorn, which had the entire body of an infant in its stomach; and Grossinger relates that a Hungarian fisherman found the corpse of a woman in another, having a marriage ring on her finger and a purse full of money at her girdle! 


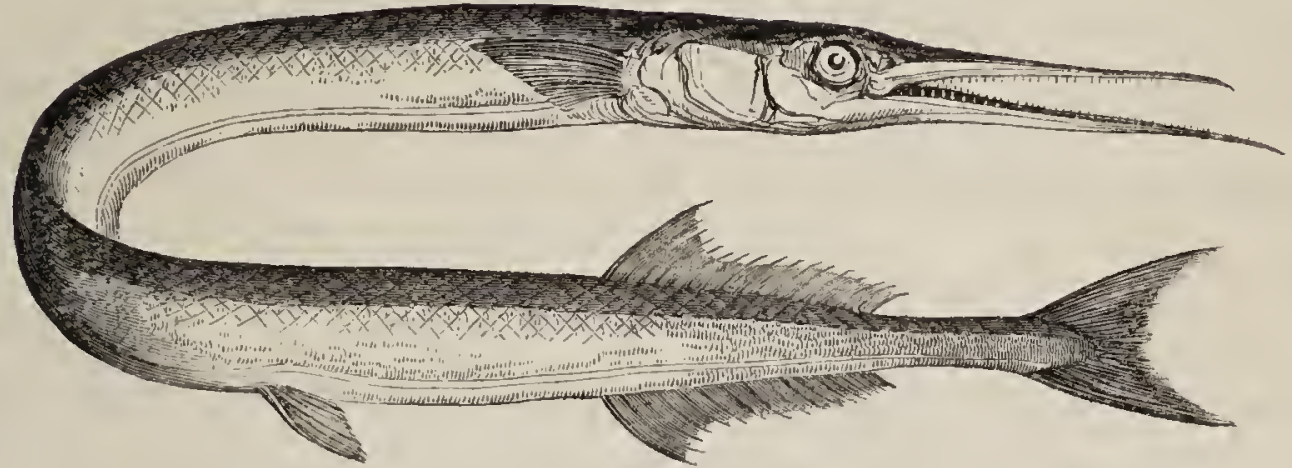

THE GARFISH.

SEA-PIKE. MACKEREL-GUIDE. MACKEREL-SCOUT. GREENBONE. HORNFISH. HORNEEL. LONG-NOSE. GOREBILL. SEA-NEEDLES. MÔR NODYDD, CORNBYSG, Wales.

Belone vulgaris, Cuv. et VALENo. xviii. p. 399.

Esox belone, Linneus. Bloch, pt. i. pl. 33.

, ,

Garpike, Penn. Brit. Zool. vol. iii. p. 429, pl. 74.

, ,

Sea-pike, Garfish, Dovov. Brit. Fish. pl. 64.

Sconberesoctde. Family Characters. - Maxillaries coalescent with or adherent to the elongated premaxillaries at the corner of the mouth, under the nasal, and covered in part or wholly by the preorbitar scale-bone.

BeLone. Generic Characters.-Form elongated, slender; scales very thin, scomberoid, with a row of keeled ones on the sides. Upper border of the jaw composed of the premaxillaries, which, together with the mandible, form a long slender bill; teeth on the jaws disposed in a narrow brush-like band, those of the interior row taller and conical; two small patches of pointed teeth on the upper pharyngeals, opposed to short conical or flattish teeth on the lower pharyngeals. Cranial helmet variously sculptured. Gill-openings large; branchiostegals twelve. Dorsal opposed to the anal, and very far back. No pyloric creca. A large swim-bladder.

The essential character on which Müller established the order of Pharyngognatis, is the coalescence of the two lower pharyngeals into one bone. The swimbladder is destitute of the pneumatic tube which is 
present in the Malacopterous order treated of in the preceding pages. The various groups which compose the Pharyngognath order have very little external resemblance to each other; some of them have cycloid, others have ctenoid scales; some have spinous rays in the fins, others only jointed ones; and in some the ventrals are attached to the thorax, in others to the abdomen.

The Garfish, included by Linnæus in the genus Esox, and thus associated with the true Pike, was called Sea-pike; and, on account of its leaving the deep water in spring to spawn near the shore in the months of April or May, preceding the Mackerel in their annual visit to shallow water for the same purpose, it has received also the name of Mackerel-Guide and Mackerel-Scout; and its most common appellation in Cornwall is, according to Mr. Couch, Garrick. Other names, and they are not a few, have been suggested and bestowed upon it, either in reference to internal peculiarities or external form. It is the Naabgiadda of the Swedes, Horn-igel of the Icelanders, and Nébbe-sild, or Horn-fisk, of the Danes. Its French name is L'Orphie.

The Garfish, Dr. Johnston observes, is occasionally taken off the coast of Berwick in the Mackerel season, and is not unfrequently called a Sword-fish. Dr. Parnell says it is found in the Firth of Forth, with the shoals of Mackerel in July and August; and it is stated by a correspondent in the $Z$ oologist (p. 3461) to be not rare in the Moray Firth. Dr. Neill, in his Tour, mentions having found it also among the islands of Orkney, and it is known to visit the west coast of Norway, the Sound, and the Baltic. Considerable quantities are brought to the London markets in the spring from the shores of Kent and Sussex; on which coasts, however, the fish remains 
but a short time. It is taken every year in greater or lesser numbers off the Isle of Wight. Montagu considered it a rare fish in Devonshire; but it is plentiful on the Cornish coast. It has been taken on the south, the east, and the northern shores of Ireland, from Cork to Londonderry. In Belfast Bay each Mackerel boat generally brings home at least one Garfish. In Strangford Loch numbers are caught in the herring nets. Considerable quantities are eaten in London in the spring; some from curiosity, but the larger portion from the moderate price at which they are sold: the flesh has some of the flavour of the Mackerel, but is more dry: the back-bone is green before as well as after boiling. Great numbers are said to be caught off the coast of Holland; but they are only used as bait for other fish. I have obtained the young of the year seven inches long in December, with the mandibles of equal length; and Mr. Edward Clarke of Edinburgh, sent me word that in June 1839 he procured three extremely minute specimens, not quite an inch long, from a pool at Portobello, in which the upper and under jaws were of equal length.

The Garfish, Mr. Couch says, "is migratory and gregarious, frequently approaching the shores of Cornwall in large sculls in summer, retiring into deep water in winter, though some may be caught in every month in the year. Its motion is rapid, it swims near the surface at all distances from land, and is seen not unfrequently to spring out of its element; its vivacity being such that it will for a long time play about a floating straw, and leap over it many times in succession. When it has taken the hook, it mounts to the surface, often before the fisherman has felt the bite; and there, with its slender body half out of water, it struggles with the most violent contortions, to wrench the hook from its 
jaws. It emits a strong smell when newly taken."-Dr. Ball, as quoted in Thompson's Natural History of Ireland, also describes its manner of leaping. "Its mode of jumping from the water is peculiar and phantom-like; it shoots bolt upright and falls back again tail foremost; when hooked, it makes more efforts to escape than any fish I know. I have seen it, after breaking loose, perform most curious tumblings on the surface for some minutes. Advantage is taken of its habit of jumping over floating substances by the fishermen on the coast of Donegal, where numbers are caught in nets strained on frames of wood by the fish jumping over the sides." At Portrush these fishes have the local name of Spearling.

The elongated, narrow, beak-like mandibles of this fish make a knowledge of its food a subject of some interest; but I have found only a thick mucus in the stomach, without any remains that I could name. In the works to which I have access, I can find no mention of the nature of its food. Mr. Couch, however, sent me word, in reference to its food, that nothing comes amiss to it that has the appearance of life, and is not too large to be swallowed: but it cannot bite a piece out, and is seldom known to swallow an object immediately on seizing it. It is known to hold on to a lask or bait till it drags off a portion, leaving the remainder ragged. Mr. Thompson found a fifteen-spined Stickle-back in the stomach of one. Mr. Couch says that in its effort to disengage itself from the hook it invariably voids the contents of its stomach.

The usual size of this fish is about twenty-four inches; the specimen described measured three inches less. The length from the point of the upper jaw to the end of the operculum, compared to the whole length, was as one to four; the depth of the body compared to the whole 
length, as one to sixteen : both jaws are straight and very much elongated, the under one the most so; the teeth numerous and minute; the eye large, placed at the commencement of the last third portion of the head; the body uniform in depth to the anal fin, then tapering to the tail; dorsal and anal fin beginning and ending nearly on the same vertical lines, the anterior rays of each of these fins being the highest; the pectoral fins are small and are attached immediately behind the free edge of the operculum; the ventral fins, also small, are situated rather behind the middle of the whole length of the body; the vent is immediately in advance of the anal fin; the tail is forked, the external rays being as long again as those of the centre.

The numbers of the fin-rays are-

\section{D. $17:$ P. $13:$ V. $6:$ A. $22:$ C. 15.}

The upper part of the head and back is of a dark greenish-blue or light Mackerel tint, becoming lighter towards the sides, which, with the whole of the belly, are silvery white; irides pale yellow, pupil dark blue; cheeks and operculum brilliant silvery white; dorsal fin and tail greenish brown; pectoral, ventral, and anal fins white. The great length of the upper jaw is produced by an elongation of the premaxillary bones; great flexibility is obtained by ligamentous union; the gape is extensive, both jaws separating simultaneously; and this fish probably seizes its prey with quickness and certainty.

I am indebted to Mr. L. H. J. Tonna, curator of the United Service Museum, for the following account of a mode of fishing for the Belone practised in the Ionian Islands.

"A small triangular raft is formed of three pieces of bamboo, each a foot and a half long; a little thwart is 
inserted in which a small mast is fixed; it is then rigged with a latteen sail, shrouds, \&c., in imitation of the boats of the country. The fisherman takes his station on a projecting rock, with deep water alongside, and when an off-shore breeze blows commits his little raft to the waves, carrying with it a line of thirty or forty fathoms in length; a float is fixed at about every fathom, and from each float depends a finer hair-line with a baited hook (shrimps or chopped fish). When the Belone bites, he draws the float down violently once, and then seems quietly to resign himself to his fate. The fisherman therefore waits till ten or twelve are hooked; he then hawls in his raft, relieves it of its freight, and again launches it for another cruise. The Island of Paxo, twenty miles south of Corfu, is the spot where I saw this mode of fishing employed; and I once saw a boy catch from fifty to sixty in half an hour."

CWrwgle or Coracle.

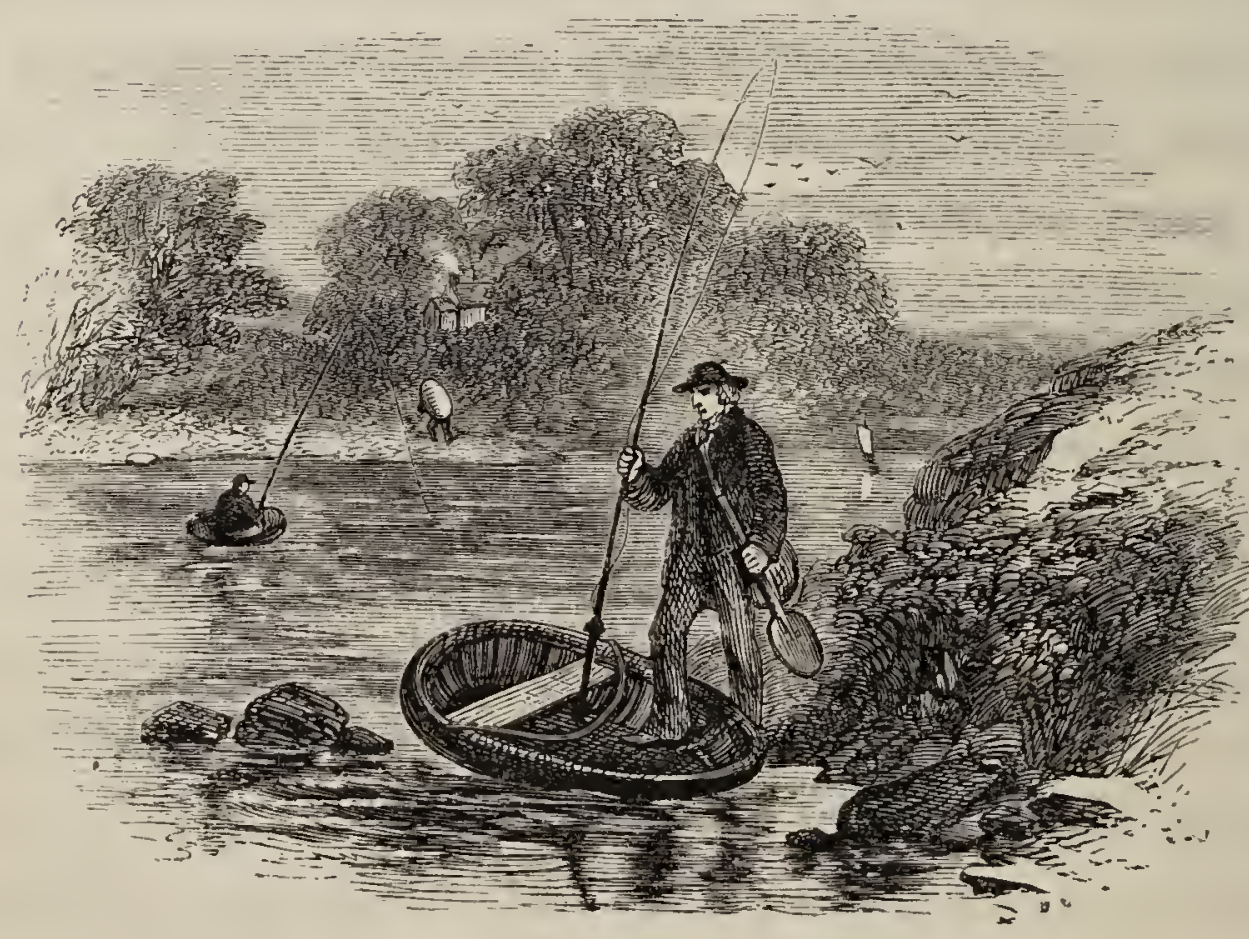




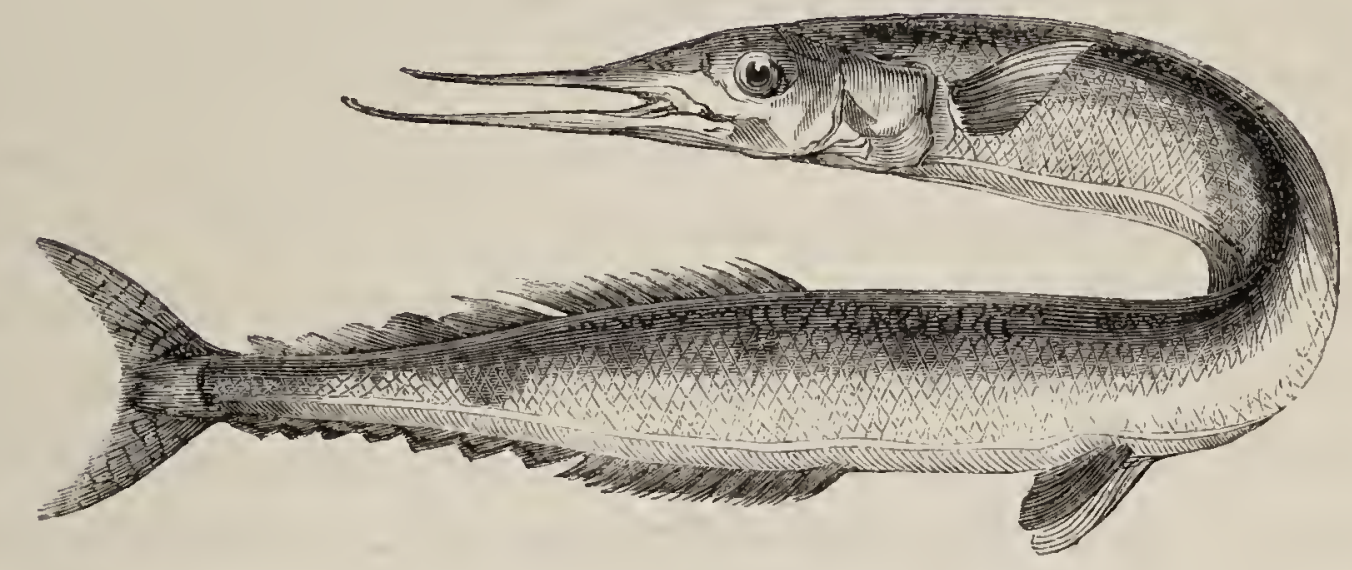

THE SAURY PIKE. SKIPPER.

\section{Mackerel-garrick, Cornwall. Gowdnook, Scotland.}

Scomberesox Camperi, Cuv, et Valenc. xviii. p. 464.

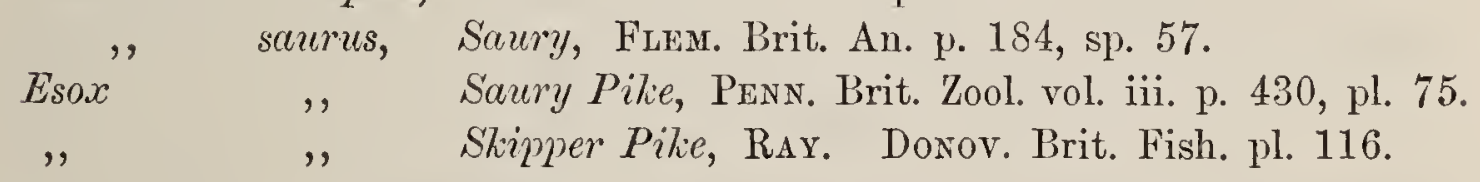

Scomberesox. Generic Characters. - Mandible longer than the premaxillaries, both jaws being long and slender; maxillary not coalescent with the premaxillary, as in Belone, but in contact with it; teeth on the jaws minute, miserial ; palate smooth. Dorsal and anal opposed to each other, and succeeded by detached finlets. The scaly keel becomes obsolete before reaching the caudal fin. Air-bladder wanting in some species. No pyloric creca.

The Saury Pike, or Skipper, was first described as a British species by Ray, and as taken on the Cornish coast. It was also known to Rondelet and Gesner: but was not noticed either by Linnè, Gmelin, or Bloch. Besides the figures of British specimens quoted above, there is one published by Mr. Rackett, in the seventh volume of the Linnean Transactions (pl.5), of an individual that was thrown on the beach of the Isle of Portland, in a gale of wind. The Rev. Mr. Low, in his

VOL. I. 
Natural History of Orkney, says, that the year preceding that in which he wrote his Fauna Orcadensis, such a glut of these fish set into the head of Kerston Bay, that they could be taken by pails-full and numbers were caught, and heaps flung ashore. According to Mr. Neill, the Saury is not at all an uncommon fish in the Frith of Forth, where numbers run up with the flood-tide in the autumin: they do not, like other fishes, retire from the shallows at the ebbing of the tide, but are then found by hundreds, having their long noses stuck in the sludge, and are picked up by people from Kincardine, Alloa, and other places. Mr. Pennant mentions that multitudes of Sauries were thrown ashore at Leith, by a Storm, in November 1768. The Saury has been taken off Berwick and Yarmouth on the east, and off Portland Island on the south; being, on some occasions, even plentiful in Cornwall. Mr. Couch in his MS. says :-

"The Skipper is more strictly than the Gar-pike a migratory fish, never being seen in the Chanuel until the month of June, when it is frequently caught by thousands in the drift-net, and it commonly departs before the end of autumn. It does not swim deep in the water ; and in its harmless manners resembles the Flying Fish, as well as in the persecution it experiences from the ravenous inhabitants of the ocean, and the method it adopts to escape from their pursuit. It is gregarious, and is sometimes seen to rise to the surface in large sculls, and flit over a considerable space. But the most interesting spectacle, and that which best displays its great agility, is when it is pursued by Porpoises, or its still more active and persevering enemies the Tunny and Bonito: Multitudes then mount to the surface, and crowd on each other as they press forward. When still more closely pursued, they singly spring to the 
height of several feet, leap over each other in singular confusion, and again sink beneath. Still further urged, they mount again, and rush along the surface by repeated starts for more than a hundred feet, without once dipping beneath, or scarcely seeming to touch the water. At last, the pursuer springs after them, usually across their course; and again they all disappear together. Amidst such multitudes-for more than twenty thousand have been judged to be out of the water together-some must fall a prey to the enemy; but as many hunt in company, it may be long before the pursuit is abandoned. The form of the fish would scarcely have led us to believe it to be capable of such considerable flights, for the fins, though numerous, are small, and the pectorals far from large, however well fitted to raise the fish by their motions to the surface : the force of its spring must therefore be cliefly ascribed to the tail and finlets. It rarely takes a bait; and when this has happened, the boat has been under sail, the men fishing with a lask, or slice of Mackerel made to imitate a living bait. The Skipper has been less commonly taken since the drift fishermen began the practice of sinking their nets a fathom or two beneath the surface-a circumstance which marks the depth to which they swim."

It does not appear to be common on the Irish coast, but Mr. Thompson mentions seven or eight instances of its capture in or near Belfast Bay.

The specimen from which the representation and description here given were taken, measured fourteen inches and three-quarters; the head and jaws three inches and three-quarters; of this, the narrow portion of the jaws, which curve slightly upwards towards the point, was about equal to the length of the other parts of the head; the lower jaw is the longest : the body, though elongated, 
is considerably deeper for its length than that of the Garfish; the length of the jaws and head, compared to the whole length of the fish, is as one to four ; the depth of the body is two inches, or, as compared to the whole length, as two to seven. Pectoral fins small. A keellike edge commences on each side directly under the lower edge of the gill-cover, and extends the whole length of the body; the ventral space intercepted by this line and its fellow is not wider than one quarter of an inch, except where they diverge a little to include the ventral fins: the dorsal and anal fins are placed far back, and commence opposite each other; the dorsal fin has five finlets behind it and the anal fin seven; the tail is deeply forked, the two portions being divided as far as to the posterior point of a scale-like appendage, with which the fleshy portion of the tail terminates.

The numbers of fin-rays are-

$$
\text { Br. 13: D. 12.-V : P. } 13: \text { V. } 6: \text { A. 12.-VII : C. } 19 .
$$

The cheeks and gill-covers are brilliant silvery white; the irides golden yellow, the pupil rather elongated vertically; the upper part of the head, and the back throughout its whole length, are of a fine dark blue, lighter on the sides below, and tinged with green; the lower part of the sides and the belly silvery white; all the fins are dusky brown.

M. Valenciennes remarks the wideness of the gillopenings, and the length of the pectinated rakers on the branchial arches resembling those of the Herring. $\mathrm{He}$ observes also that this fish has a long air-bladder, though the very similar Mediterranean Scomberesox Rondeletii has not a vestige of one. The kidneys of the Skipper are supported by a curious network of the peritonæum. 


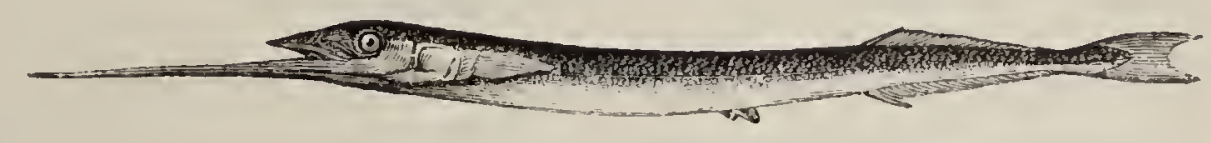

\title{
THE EUROPEAN HEMIRAMPHUS,
}

\author{
OR HALFBEAK.
}

Hemiramphus Europceus, European Hemiramphus, Mag. Nat. Hist. 1837, p. 505.

Hemirampins. Generic Characters.-Upper jaw abbreviated, formed of the premaxillaries soldered together, and joined, at the corner of the mouth, to the maxillaries, which widen and emit a spur that is concealed by the preorbitar scale-bone. Granular teeth on both jaws, in a narrow band. The edentate mandibular symphysis is elongated and pointed, resembling lialf a bill, whence the generic name. No pancreatic cæca. Air-bladder long and cellular, protected by a tense arch of peritonæum.

In a valuable communication on the Fishes of Cornwall, made to the Linnean Society some years ago by Jonathan Couch, Esq., of Polperro, which was published in the fourteenth volume of the Transactions of that Society, the author thus expresses himself in reference to a small fish which appeared to him to be a species of the genus Hemiramphus:- "I have met with a species which I have never seen described. It was taken by me in the harbour at Polperro, in July 1818, as it was swimming with agility near the surface of the water. It was about an inch in length, the head somewhat flattened at the top, the upper jaw short and pointed, the inferior jaw much protruded, being at least as long as from the extremity of the upper jaw to the back part of the gill-covers. The mouth opened obliquely downwards; but that part of the under jaw which protruded beyond the extremity of the 
upper, passed straight forward in a right line with the top of the head. The body was compressed, lengthened, and resembled that of the Garpike, Esox belone. It had one dorsal and one anal fin, placed far behind and opposite to each other. The tail-fin was straight; the colour of the back was a bluish green, with a few spots; the belly silvery."

In August 1837, Dr. Clarke of Ipswich favoured me with a letter, of which the following is an extract:" My brother, Mr. Edward Clarke of Ipswich, who is particularly interested in the study of British Fishes, was examining the sea-shore in the vicinity of Felixtow, a village in Suffolk, between Harwich and Orford, a few days ago, August 7, 1837, when he observed a shoal consisting of myriads of small fish, which, upon a nearer examination, he supposed to be the young of the Garfish. As he had previously not found any so small, he secured a few specimens; and, upon bringing them home and examining them, they were found not to be the young of the Garfish, but those of a species of Hemiramphus. From their being so very young, it probably may be difficult to determine whether they belong to a described species; but from the circumstance of their having been seen in great abundance in a small pool left by the retiring tide, it is, I think, pretty evident that the ova must have been deposited and vivified in the neighbourhood of our shores. I send you the fish, thinking that an examination of the specimens themselves will be far more satisfactory than any figures or description of my own. One specimen was taken-about double the size of those now sent to you."

The representation of this fish on the preceding page is half as large again as the natural size. It can scarcely be doubted, from the quantity of fry seen, as well as from their 
very small size, that the spawn from which they were produced must have been deposited on our shores by the parent fish; and yet, as far as we are aware, these parent fish have hitherto escaped capture. 'This might not appear very extraordinary: but the circumstance that the size attained by the fry in the months of July and August, as well as the general similarity in the form and appearance of the Hemiramphus to our well-known Garfish and Saury-pike, would lead to the belief that the Hemiramphus visited our shores about the same time of the year as these fishes. The Garfish appears on the coast in April, and spawns in May; the Saury-pike makes its first appearance in June. For these fish, but particularly for the former, nets are worked on various parts of the coast, and considerable quantities are taken; but no adult specimens of Hemiramphus, unless we are to suppose they have remained hitherto unrecognised by the fishermen. It is also not a little singular, that, with the exception of the small specimens already referred to, as taken at two places very distant from each other, no example of any species of Hemiramphus has been found, either in the Mediterranean, the Channel, or in the North seas. I have had an opportunity of conversing with two eminent foreign naturalists, to whom I showed the specimens, who agreed with me that no adult species of Hemirampinus had been recorded as found in the seas of Europe.

The question hazarded in a former Supplement,-Is this fish, with its unequally-developed jaws, the very young state of our common Garfish (Belone vulgaris)? - would seem to be answered, that it is not, by Mr. George Clarke, who has found the fry of the Garfish so small as only to measure one inch, with both the jaws of equal length, as mentioned previously in page 461 . 
The two examples obligingly sent me by Dr. Clarke, are too young and too minute to make any attempt to define specific characters desirable, beyond such as the remarks of $\mathrm{Mr}$. Couch, and the representation here given will supply; and I only propose, for distinction's sake, that it should be called provisionally Hemiramphus Europaus.

M. Valenciennes, in commenting on a supposed Hemiramphus pusillus, an inhabitant of the Mediterranean at Nice, which was an inch or an inch and a half long, decides that it is the young of the Orphie or Garfish whose jaws had not attained the relative length they possess in the adult. He observed the germs of biserial teeth on the projecting limbs of the mandible. Mr. R. Q. Couch in the Zoologist for 1848 (p. 1978), says, "The Hemiramphus Europaus was first made known as British by my father, and has since been taken by Mr. Clarke of Ipswich in the estuary of the Thames, and by myself in Mounts Bay. The fishermen call it the young of the Belone vulgaris, which it greatly resembles, and has similar fins similarly placed. It has much the habits of the Garfish, and like it swims about in companies." He then proceeds to describe another species-obtusus, half an inch long, whose lower jaw also is short, though not so much abbreviated as the upper one: and adds "I have seen the young of the Belone vulgaris, about six or seven inches long, and though both jaws were not equal, yet they were sufficiently so as not to produce the deformity so characteristic of Hemiramphus."

These notices would lead us to believe that the Hemiramphus Europaus is in truth the fry of the Belone, and that $H . \cdot$ obtusus is an early stage in the growth of the young fish. The ventral fins are nearer the middle of the distance between the corner of the mouth, and end 
of the tail than in the Garfish, but they do not agree more exactly in position with those of any Hemiramphi that have been figured. The only Hemiramphus of European seas correctly known is the Hemiramphus Picarti (Hist. des Poiss. xix. p. 25), which was captured at Cadiz.

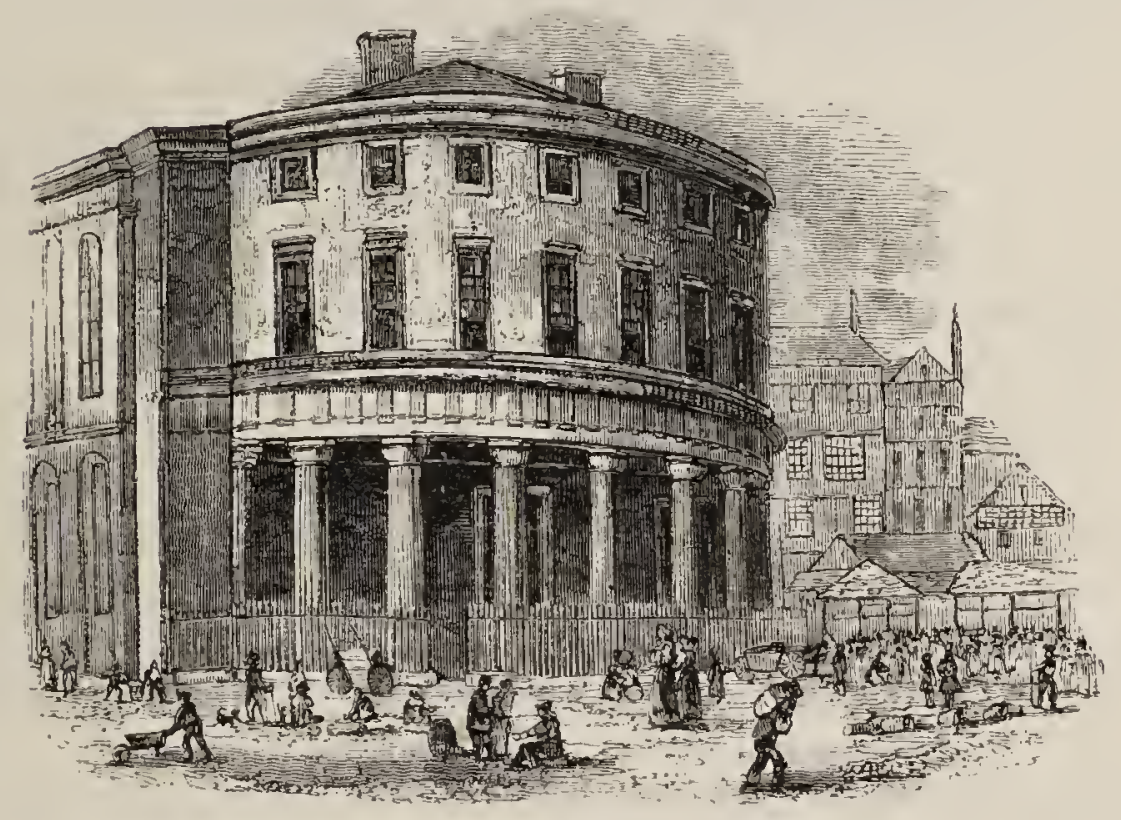




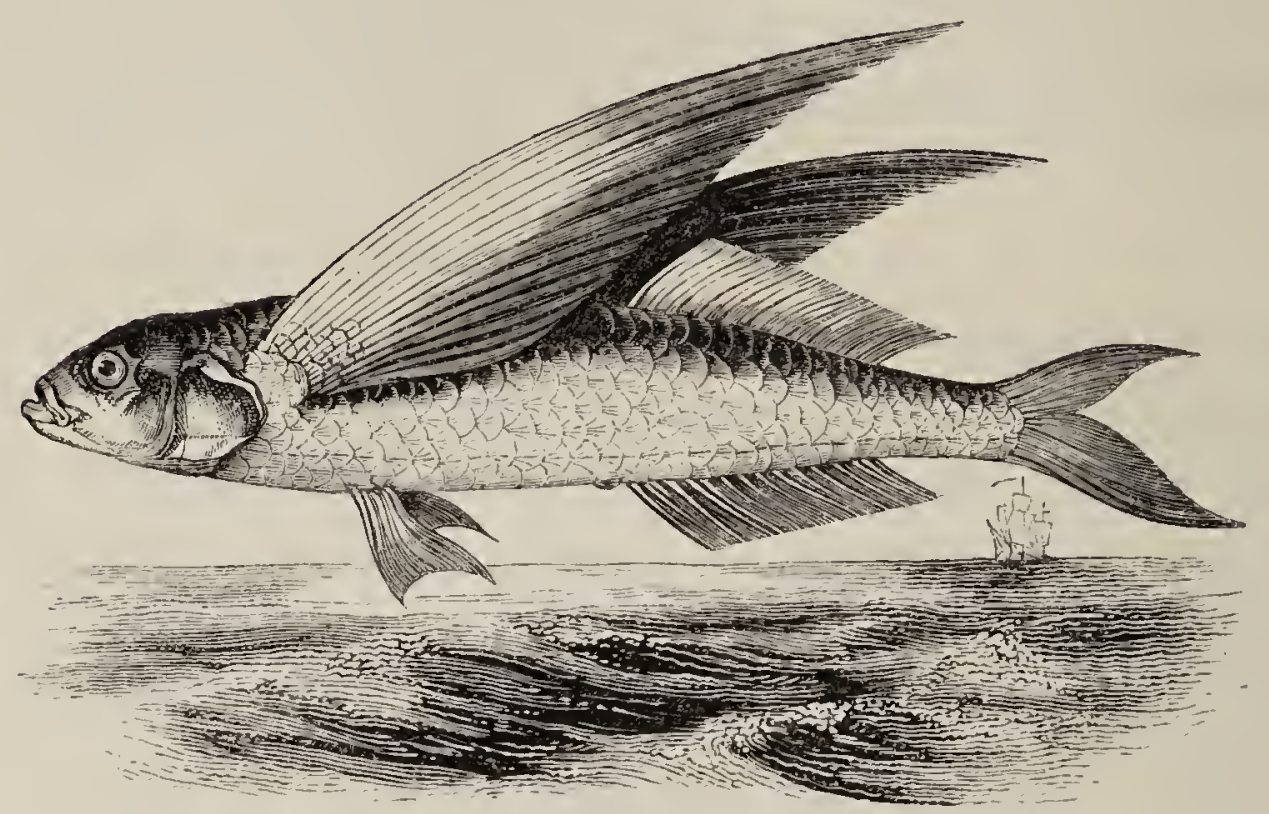

THE FLYING FISH.

Exoccetus evolans, Linnaus. Cuv. et Valenc. xix. p. 138.

,, Winged Flying Fish, Penn. Brit. Zool. vol. iii. pl. 78.

, Common Flying Fish, Dovov. Brit. Fish. pl. 31.

Exocerus. Generic Characters. - Pectorals large, organized for short flights in the air. Eyes large. Head and body scaly, with a scaly keel on each flank. Dorsal opposed to the anal. Maxillary gliding under the preorbitar scale-bone, and not soldered to the premaxillary, which forms the upper borier of the mouth. Jaws armed with small pointed teeth composed of osteo-dentine; and the pharyngeals, with crowded teeth having compressed crowns and several cusps. Branchiostegals ten or twelve. No pyloric creca. Air-bladder large. Caudal lobes unequal.

Several instances being on record of a species of Flying Fish having been either captured or seen at different parts of our coast, the subject requires to be noticed here; although the exact species has not as yet been positively decided, nor yet whether more than one species may not have occurred. Pennant states, that in June 1765 one was caught at a small distance below Carmarthen, in the river Towy, being brought up by the tide, which flows as far as the town. 
Di. Heysham, in his Catalogue of Cumberland Animals, prefixed to Hutchinson's History of that county, says at page 32-_" Another Flying Fish was seen at Allonby, in September 1796, by Mr. Chancellor Carlyle, when he was bathing: it was near the shore, and upon the surface of the water, and came within a yard of him." According to Dr. Fleming, a third one occurred in July 1823, ten miles from Bridgewater, in the Bristol Channel, a notice of which was communicated to the Linnean Society by the Rev. S. L. Jacob.

The following notice, dated Dec. 2, 1825, appears in the fortieth number of the Royal Institution Journal:-

"In going down Channel on the 23rd of August last, with light winds from the E.N.E. inclinable to calm, when off Portland, we were surprised by the appearance of a rather large shoal of what is commonly called the Flying Fish. They were evidently closely pursued by some one of their numerous enemies, from the frequent and long flights which they took; but it was impossible to discover what that enemy was, though passing close to the vessel. The fact may possibly interest some of your numerous scientific readers.

J. C. W."

From the MS. of Mr. Couch another instance may be quoted of a Flying Fish "which threw itself on shore on the sandy margin of Helford River, near Falmouth, at full two miles from the open sea, where it was found while yet living. I was informed by Mr. Joln Fox, of Plymouth, in whose collection this specimen was in 1828, that it measured sixteen inches in extreme length, and that the pectoral fin was eight and a half inches long: a size which caused me to suppose it might be the E. evolans, of which I possess a specimen twenty and a half inches long. There can be little doubt that this fish had 
been chased out of its usual haunt by some one of those voracious inhabitants of the deep by which they are continually persecuted."

The existence of this particular species in the British seas still rests on the authority of Pennant; subsequent writers having copied from him, or relied on the statements of others. M. Valenciennes, however, has seen examples taken on the coast of Brittany, and it may readily have extended its range from thence into the Channel.

The following observations on the habits and powers of the Flying Fish are by Mr. George Bennett, the author of Wanderings in New South Wales, and other countries, who appears to have devoted particular attention to the subject. "I have never," observes this gentleman, "been able to see any percussion of the pectoral fins during flight; and the greatest length of time that I have seen these volatile fish on the fin has been thirty seconds by the watch, and their longest flight mentioned by Captain Hall has been two hundred yards, but he thinks that subsequent observation has extended the space. The most usual height of flight, as seen above the surface of the water, is from two to three feet; but I have known them come on board at a height of fourteen feet and upwards; and they have been well ascertained to come in to the channels of a line-of-battle ship, which is considered as high as twenty feet and upwards."

"But it must not be supposed they have the power of elevating themselves in the air, after having left their native element; for, on watching them, I have often seen them fall much below the elevation at which they first rose from the water, but never in any one instance could I observe them raise themselves from the height at which they first sprang; for I regard the elevation they take to 
depend on the power of the first spring or leap they make on leaving their native element."

The writer of the supplementary part to the class Fishes in Mr. Griffith's edition of Cuvier's Animal Kingdom agrees with Mr. George Bennett. He states that the Flying Fishes "rise into the air by thousands at once, and in all possible directions. Their flight, as it is called, carries them fifteen or eighteen feet out of the water: but it is an error to call them Flying Fishes; they do not in reality fly-they only leap into the air, where they have not the power of sustaining themselves at will. They never come forth from the water except after a rapid course of swimming. When put alive into a vessel of sea-water, in which there was not sufficient space to acquire momentum, they were only able to rise out of it a few inches. The lines which they traverse when they enjoy full liberty of motion are very low curves, and always in the direction of their previous progress in the water." Some interesting experiments of M. Humboldt on the power of the pectoral fins of the Flying Fish are quoted in the Histoire des Poissons.

The flight of the various species of Flying Fish is of constant recurrence on the tropical seas, and bears no small resemblance to that of a flock of Sand-larks. Just before it terminates, the fish often turn aside by an impulse of the entire scull, and their sides glitter in the sun, much like the white under plumage of the Sandlarks as they wheel round before alighting. This movement is so sudden as to appear to be caused by some voracious fish having headed the Exocœti in their flight just when they could no longer sustain it. There must be great power of adaptation in the eye of a Flying Fish to enable it to see in the air as well as in the water. The size of the organ is probably connected with this double function. 
"The Greeks applied the term Exokoitos to a fish which remained on the rocks when the sea retired, perhaps a Blenny, and its use by Artedi, as a designation of the Flying Fish is not happy."-Hist. des Poiss.

For the reasons before stated, that some doubts exist as to the exact species which have been taken on our coast, no description is attempted, and the attention of Ichthyologists is invited to the subject. The figure is taken from Bloch's representation of Exocœetus volitans.

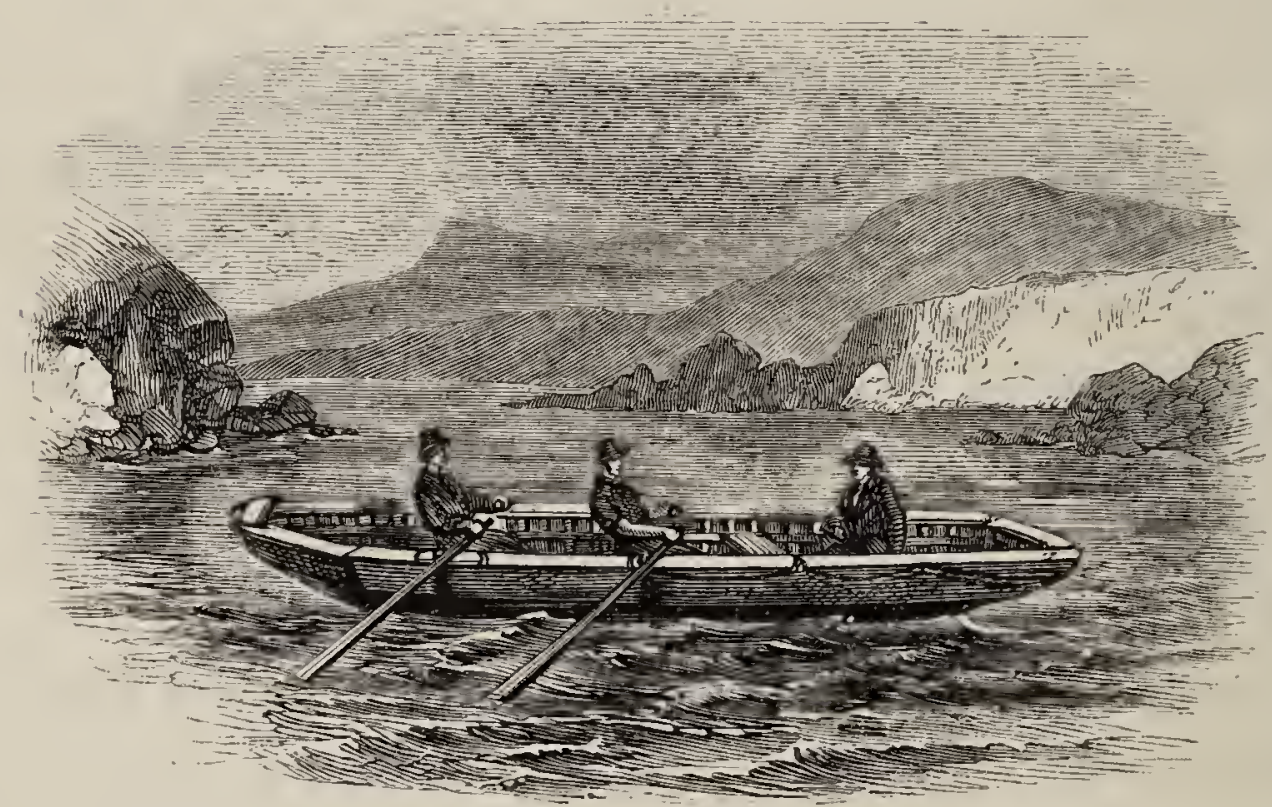




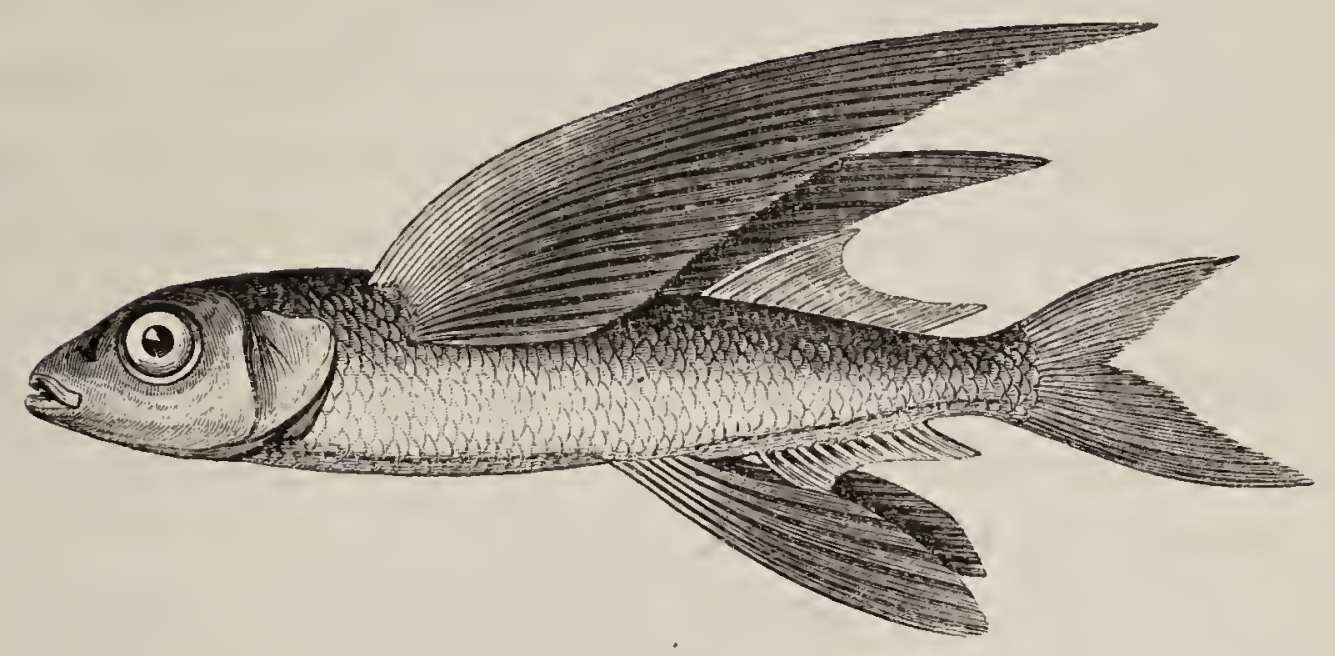

\section{THE GREATER FLYING FISH.}

Exoccetus volitans, Linnaus. Cuv, et Vilenc. xix. p. 83.

Hirondelle de mer, Duhamel, Pt. 2, Sec. 3, pl. 22, f. 2.

Is a Cornish Fauna, by Jonathan Couch, Esq., published for the Royal Institution of Cornwall, Mr. Couch has included a species of Flying Fish which threw itself on to the Quay at Plymouth, and the specimen is still preserved. From an inspection of this example $\mathrm{Mr}$. Couch was enabled to determine that it was the Greater Flying Fish, a well-known species of the Mediterranean ; and he adds, that he has reason to believe, from the dimensions as given to him by the possessor, that the individual Flying Fish, which was found at Helford, where it was discovered on the sand, having just then expired, was of the same species. This specimen, which was in the possession of Mr. John Fox of Plymouth, measured sixteen inches in length. 
In a communication to the Zoologist (p. 1614) Mr. R. Q. Couch informs us that a friend had told him he had seen several Flying Fish in Mount's Bay, and had learnt from the fishermen that their occurrence was not rare. This induced $\mathrm{Mr}$. Couch to look out for them, and at length, in 1845, while about six miles off the shore he saw many start from the water into the air. They were pursued by several huge striped Bonitos. The enormous pectoral fins with the large ventral ones led him to refer the species to the exiliens of Bloch (volitans L.), instead of to the volitans Bl. (evolans L.). They rose, he says, from the water like an arrow to about ten or twelve feet, and then gradually and glidingly fell back into the water again. He examined the heads of two specimens caught near Cape Cornwall, and considered them to belong to this species. The Irish Fishermen see Flying Fish occasionally off the coasts of Waterford and Cork (Ball apud Thompson).

The elongated ventral fins, placed very far backwards, readily serve to distinguish this species. The specimen represented in the work of Duhamel was taken in the Channel, and measured sixteen inches. That author mentions that, besides being an inhabitant of the Mediterrannean, it has also been taken in the ocean. Its flesh is rich, and is said to be more delicate than that of the Herring.

M. Valenciennes identifies the Exocotus exiliens of Gmelin with the fasciatus of Le Sueur, and says, that it is readily recognisable by the broad irregular brown bars on the pectorals and ventrals. The Fx. Rondeletii of the Mediterranean has black ventrals, which distinguish it from volitans, which has bluish ventrals.

The head is wide and flat on the top, but somewhat angular underneath; the mouth is small, the lower jaw 
rather longer than the upper; both jaws are furnished with pointed teeth, those in the lower jaw being the smaller of the two; the eyes are large, the irides silvery, the pupil dark blue; the nostrils large, and placed rather nearer to the eye than to the point of the nose; the operculum has the appearance of polished steel; the body of the fish is covered with large scales, which adhere but slightly ; the upper part of the body is of a fine blue colour, the lower part of a silvery white; the lateral line is placed very low down and runs throughout its whole length a little above and parallel to the ventral profile; the pectoral fins are very large and of a fine transparent blue colour ; the ventral fins are long, and almost rounded at the end and the dorsal and anal fins are falcate, beginning and ending nearly on the same planes; the tail consists of two unequally-sized lobes, of which the lower one is the larger. The fin-ray formula, according to Valenciennes, is-

$$
\text { B. } 11 \text { : D. } 11 \text { : P. } 15: \text { V. } 6: \text { A. } 9: \text { C. } 22 .
$$

According to M. Risso, the female is heavy with roe in the spring, and is remarkable for the variations that occur in the number of the rays of her fins.

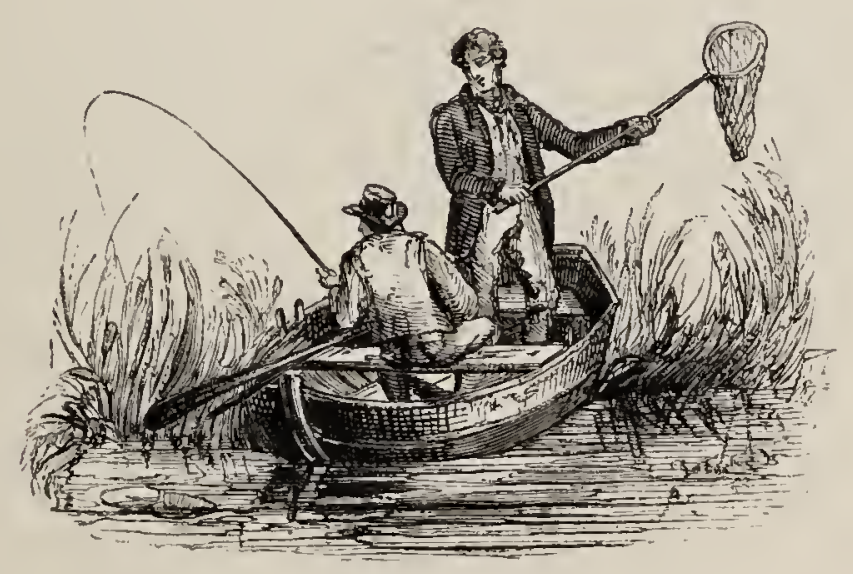




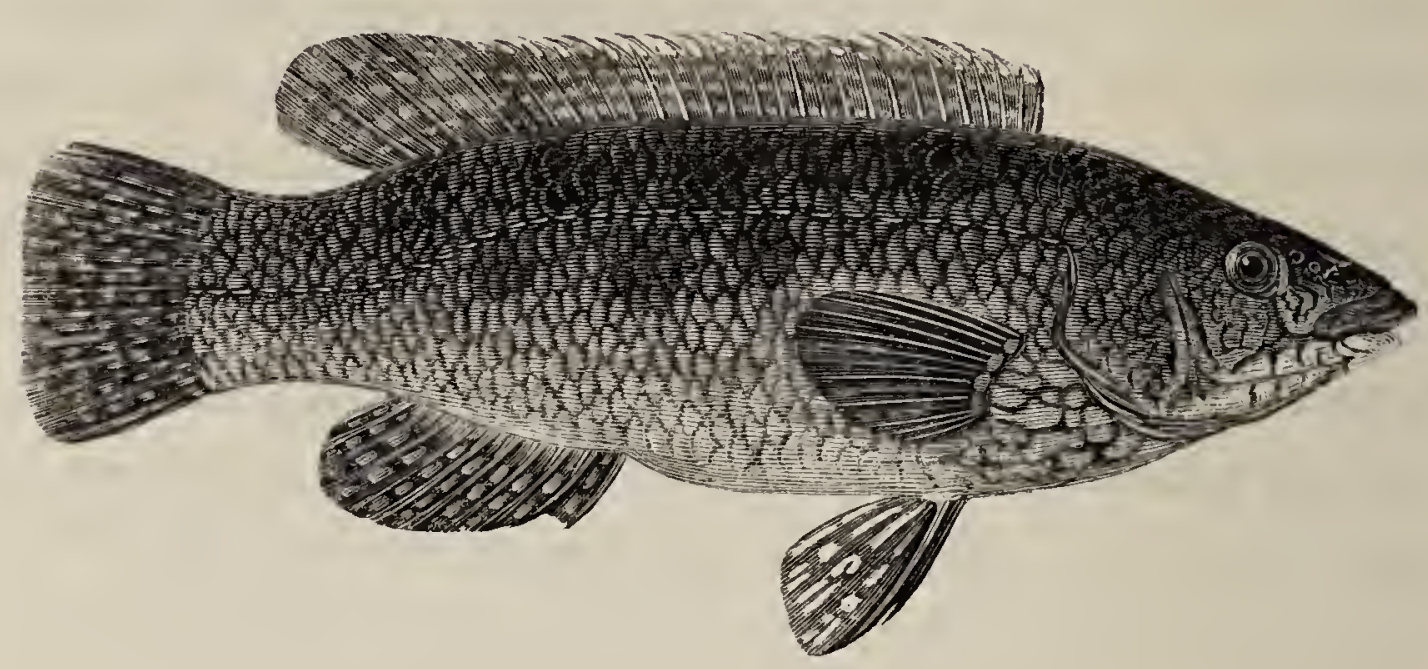

THE BALLAN WRASSE.

GWrach, Wales.-Wrasse conner, Cornwall.-BerG galt, Denmark.-Berg snultra, Sweden.

Labrus bergylta, Ascanius. Cuv. et Valeno. t. xiii. p. 20.

,, maculatus, BLoch, pt. ix. pl. 294.

" $\quad$ ", Ballan Wrasse, Penn. Brit. Zool. vol. iii. p. 334, pl. 55.

", , Fries och Ekström, Skand. Fisk. pl. 2.

", tinca, Ancient Wrasse, or Old Wife, Donov. Brit. Fish. pl. 83. ,, ", Shaw, Misc. pl. 426.

Cyclolabrines. Family Characters.-Oval, elliptical, or oblong fishes, more or less compressed, with the part of the tail bounded by the vertical fins proportionally high and parallel-sided. Scales cycloid, generally large. Dorsal single, with spinous rays anteriorly. Lips fleshy; palate smooth, toothless. Three pharyngeal bones, two above and one below, armed with pavement-like, or lamellated, or pointed teeth. No pancreatic cæca. Airbladder simple, without a pneumatic tube. Ovisacs closed, discharging the eggs by an efferent tube opening behind the anus.

Labrus. Generic Characters.-Lips large, thick, and folded so as to appear double. Upper jaw possessing generally considerable protractility ; teeth on the jaws simple, in one or more rows. Pharyngeal teeth cylindrical, smooth, wearing round on the crowns. Branchiostegals six. Opercular bones smooth-edged. Lateral line continuous, nearly straight. Cheek and gill-plate scaly. Dorsal moderately long, its spines tipped by a tag or tassel of skin. 
The Pharyngognaths hitherto treated of belong to the Malacopterous sub-order, that is, they have no stiff jointless rays in their fins; we have now to describe some members of the second or Acanthopterous sub-order, so named because they have spinous rays. The British species belong to a family whose scales are cycloid.

The species of this family are numerous even on our own shores, and from the variations in colour to which they are liable, they have not been very well determined; red, green, and orange colour being each occasionally predominant: the more permanent characters of the proportions of the head and body, the form of the different parts of the gill-covers, the structure and relative position of the fins, the numbers of the fin-rays, and the dentition afford the best points for specific distinction. There is a tendency in the teeth of the jaws of all the members of this family to coalesce with the bone in which they are implanted, a modification of structure which attains its maximum in the Scari. The vignette (p. 486) exhibits its extent in a Labrus. The Wrasses, or Rock-fish, as they are also called, inhabit principally the rocky parts round our coast, spawning in spring or summer, just previously to which their colours are in the highest perfection. They feed upon soft crustaceans and marine worms. The flesh is said to be soft, and they appear not to be in general estimation as food.

The Ballan Wrasse, Mr. Couch says, "frequents deep gullies among rocks, where it shelters itself among the larger kinds of sea-weeds, and feeds upon crabs and other crustaceans. It takes a bait freely, and fishermen remark that when they first fish in a place, they take but few, and those of large size: but on trying the same spot a few days after, they catch a greater number, and those smaller; from whence they conclude that the large fish 
assume the dominion of a district, and keep the younger at a distance. The spawn is shed in April, and the young, scarcely more than an inch in length, are seen about the margin of the rocks in shallow water through the summer."

A fine specimen, eighteen inches long, and weighing three pounds seven ounces, was taken in January 1831, in Swansey Bay, of which a notice and short description was furnished me by L. W. Dillwyn, Esq. The colour was red, becoming pale orange on the belly; the body ornamented with bluish-green oval spots; the fins and tail green, with a few red spots: the dorsal fin had spots along the base only.

About the same time a specimen of nearly the same size was obtained in the London market, and presented to the Zoological Society by Sir Anthony Carlisle. Both these specimens are referred to in the first volume of the Proceedings published by the Society, pages 17 and 31 . The blue colours of the latter vanished with astonishing rapidity when the specimen was placed in spirits.

I have also seen several specimens of large size from the coasts of Down and Antrim. These fish, with many others, taken on various parts of the Irish coast, were exhibited at the Zoological Society by William Thompson, Esq., of Belfast. Mr. Thompson mentions vivid green with scarlet spots as one dress of this variable species, red as predominating in other individuals, and pale green in others chiefly of smaller size. The Streaked Wrasse he looks upon merely as the younger fish.

It is abundant at Donaghadee, where individuals weighing eight pounds are brought to the market, and being little prized it is sold cheap. Upwards of 500 were thrown up dead on the beach of Holywood in a gale of wind.-Nat. Hist. of Ireland. It is less common in the Orkneys. 
This species occurs along our eastern coast, as well as at various places on the shores of Dorsetshire, Devonshire, and Cornwall. A fine specimen sent to me by Dr. Johnston from Berwick afforded the following measurements, and in its colours had more of the orange-red than the London specimen before mentioned:-The length of the head, compared to the whole length of head, body, and tail, was as one to four; the depth of the body alone equalled the length of the head: the lower edge of the scaly portion of the cheek was rounded, and covered by scales only half as large as those on the operculum; preoperculum without scales, the horizontal and rertical edges forming an angle somewhat obtuse, the ascending line being oblique, the margin entire; operculum broad, covered with large scales, and ending in a membranous projection over the upper part of the origin of the pectoral fin. The pectoral fin was broad and rounded; the membranes connecting the rays of all the fins were spotted with verditer, rather inclining to blue than green; the fin-rays reddish orange, with six or seven scales in succession between each ray of the caudal fin. Back and sides bluish green, paler on the belly; all the scales margined with orange-red, the margins varying in breadth in different specimens, and thus producing the prevalence of the blue or orange colour; six rows of scales between the lateral line and the middle portion of the dorsal fin. Head and cheeks bluish green, reticulated with orange-red lines: lips flesh colour; about eighteen conical teeth in each jaw, those in front the longest; the tail slightly rounded at the upper and under corner, the tip dusky.

The number of the fin-rays are-

D. $20+11$ : P. 15: V. $1+5:$ A. $3+9:$ C. 13 . Vertebræ 20.

The teeth on the jaws are regularly conical and de- 
crease in size as they recede from the mesial line. There are about seven on each premaxillary, and ten on each limb of the mandible, forming the exterior series, behind which there are a few very small ones of similar shape. The palate is smooth. The superior pharyngeal bones are triangular, one on each side armed with strong teeth, the interior ones being blunt and globular, the exterior ones conical and pointed. Similar teeth exist on the inferior pharyngeal, which is a single bone, in accordance with the character of the order, and has a triangular shape. The vent is immediately under the eighteenth spinous ray of the dorsal fin.

Bloch's figure was probably taken from a preserved specimen, the colours of which had faded. A very excellent illuminated figure is given in the Scandinaviens Fiskar.

This fish occurs in the Forth, on the Ayrshire coast, at the Orkneys, and on the coasts of Denmark and Norway, but has not been taken in the Greenland Seas.

The vignette represents the bones of the head in the genus Labrus.

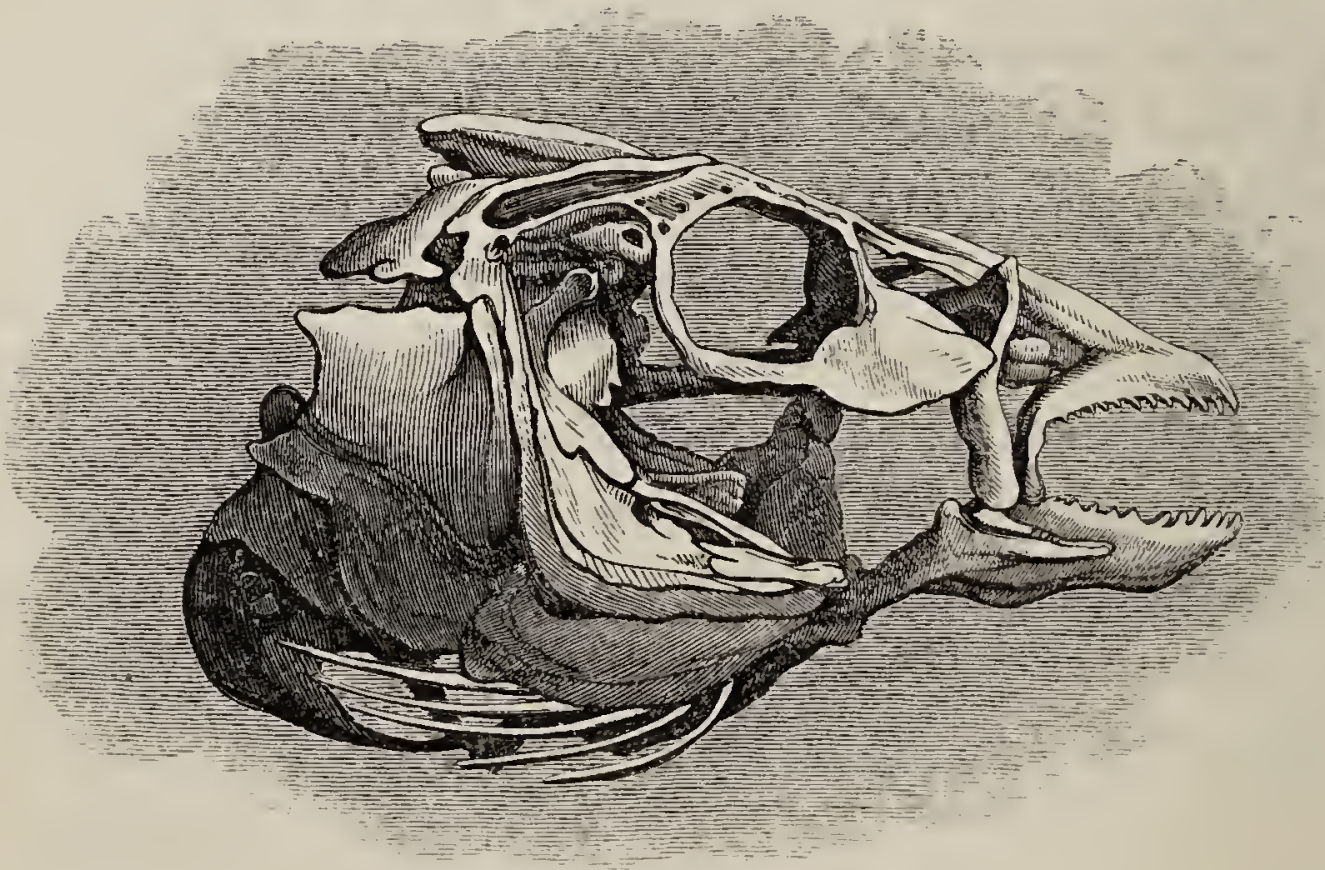




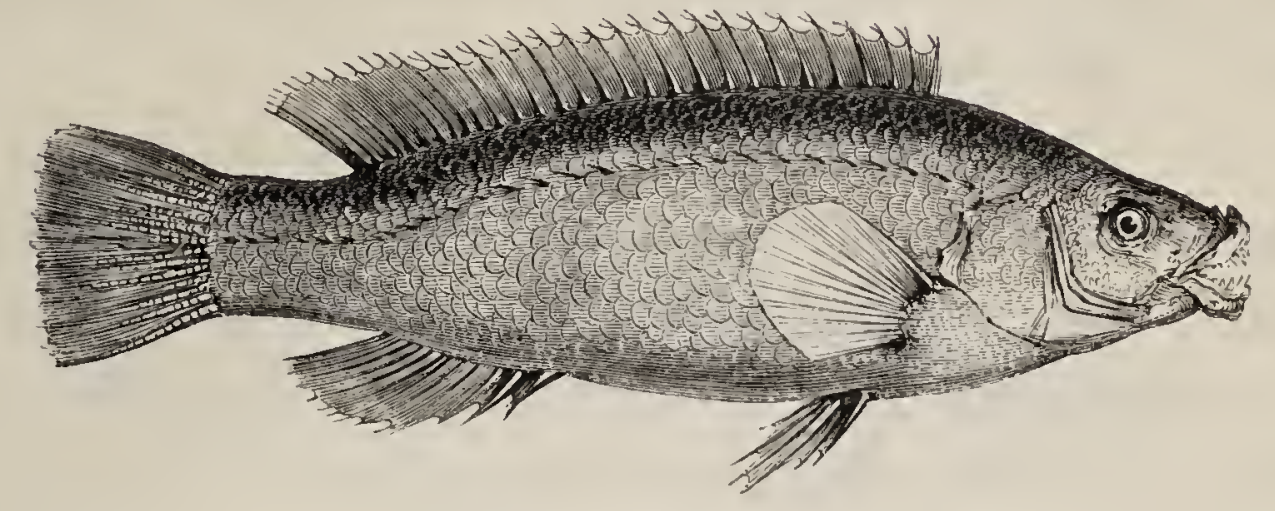

\section{THE GREEN-STREAKED WRASSE.}

\section{Young of the Ballan Wrasse.}

Labrus Donorani, Cuv. et Valenc. Hist. Nat. des Poiss. t. xiii. p. 39.

," lineatus, Streaked Wrasse, Donov. Brit. Fish. pl. 74.

THIs species was introduced into the list of British Fishes on the authority of Mr. Donovan: but according to M. Valenciennes it is not identical with the Labrus psittacus of Risso, I have therefore withdrawn the reference to that author.

"This fish," Mr. Donovan says, "is an occasional visitor, as I was informed, to the coast of Cornwall, where it is provincially known by the name of Greenfish : it usually appears in the summer, and is esteemed the rarest species of its tribe by the fishermen in those parts. The specimen now in our possession, and from which the figure in the plate is delineated, was taken on this coast a few years ago by Captain Bray. This specimen is seven inches long; and having been carefully divested of the flesh while perfectly fresh, and the skin well prepared, the natural colours of the fish are admirably well retained. Besides this genuine British specimen, we 
possess another in excellent preservation from the Mediterranean Sea, that differs only in being smaller, and having the head, back, and sides of the body of a brighter green." The numbers of the fin-rays are-

$$
\text { D. } 20+10: \text { P. } 14: \text { V. } 8: \text { A. } 3+8: \text { C. } 15 \text {. }
$$

This species is represented as having the body elongated, of a fine meadow-green, darker on the back, lighter on the sides, and yellowish green under the throat and belly: the muzzle is rather long, the nape slightly depressed; the upper jaw longer than the lower, both armed with teeth, the longest of which are in front; the operculum angular; the lateral line curved on its approach to the tail; the fins green. The female is of a uniform green colour above, silvery on the belly.

According to his MS. notes, Colonel Montagu, who possessed a copy of Mr. Donovan's History of British Fishes, had taken this species on the Devonshire coast.

From observations made on this fish, which occurs on the south and east coasts of Ireland, Mr. Thompson is inclined to think that it is the young of the Ballan Wrasse. In his Natural History of Ireland (1856) he describes a number of Wrasses having a rich green colour, taken in Lough Larne, which he considers as being certainly the L. lineatus of Donovan, but yet nothing more than a variety, or the young of the Ballan Wrasse. M. Valenciennes does not speak positively of the specimens from St. Malo, which, exclusive of Donovan's plate, are his chief foundation for considering $L$. Donovani as anything more than a variety of $L$. bergylta. 


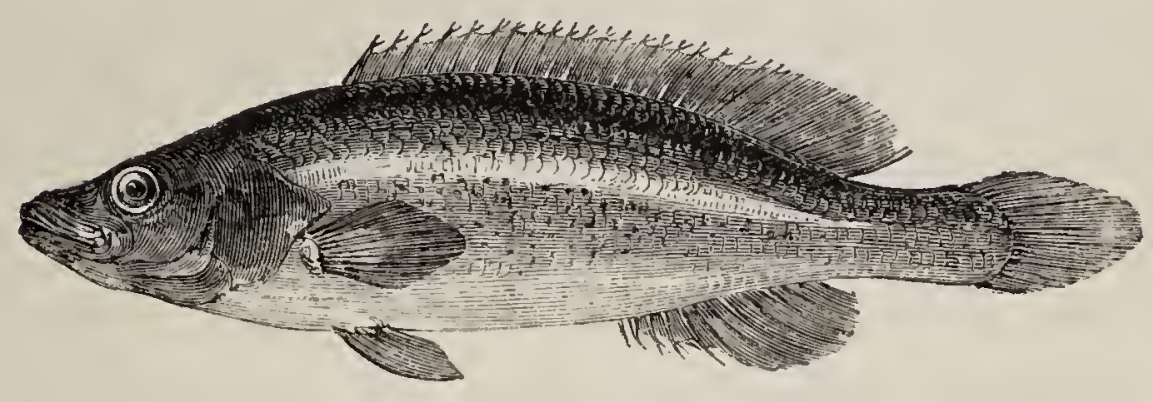

\section{THE COMBER WRASSE.}

\section{Labrus comber, RAY. GMelin.}

", , Comber Wrasse, Pens. Brit. Zool. vol. i. p. 342, pl. 58.

THE Labrus comber was first introduced into our ichthyological lists by Ray, with a specific character which M. Valenciennes characterizes as short and but little characteristic, and he speaks of the figure with as little favour. He considers the species as so doubtful that he has not introduced it into the Histoire des Poissons. Pennant says he received his fish from Cornwall, and supposed it to be the Comber of Mr. Jago, but M. Valenciennes is of opinion that Jago's fish might be mixtus or trimaculatus, and that nothing said of it proves its identity with the Comber of Pennant.

It was of a slender form: the colour of the back, fins, and tail, red; the belly yellow; beneath and parallel to the lateral line ran a smooth even stripe from gill to tail, of a silvery colour. The numbers of the fin-rays were-

D. $20+11$ : P. 14 : V. 5: A. $3+7$ : C. number not given.

$\mathrm{Mr}$. Couch has also met with this fish, and the ac- 
count in his MS. is as follows:- "Compared with the Common Wrasse, the Comber is smaller, more slender, and has its jaws more elongated. The two upper front teeth are very long: a white line passes along the side from head to tail, unconnected with the lateral line. It has distinct blunt teeth in the jaws and palate: the ventral fins are somewhat shorter than in others of the genus." "Such is the note I made," says Mr. Couch, "on inspecting one of this species several years since; but I have not lately had an opportunity of a re-examination; it is consequently scarce."

Mr. R. Q. Couch, son of the writer of the passage just quoted, says, "The Labrus comber is certainly the most elegantly shaped of all the Wrasses inhabiting our seas. It is the most slender and the most graceful. The head is smaller, the lips thinner, and the jaws more prolonged and pointed than any of the others. I have seen only a single specimen, caught off St. Michael's Mount, but I am informed by the fishermen that several are caught every summer."-ZZoologist, p. 1610. The numbers of spines in the vertical fins correspond with those of the Green-Streaked Wrasse (Labrus Donovani), and though the colours are dissimilar, that may prove to be merely a sexual difference. The forms are nearly alike. The thin, prolonged and pointed jaws noted by Mr. R. Q. Couch direct one's attention to $L$. mixtus, but that has fewer dorsal spines.

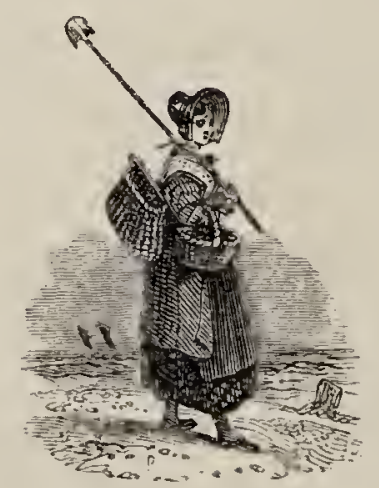




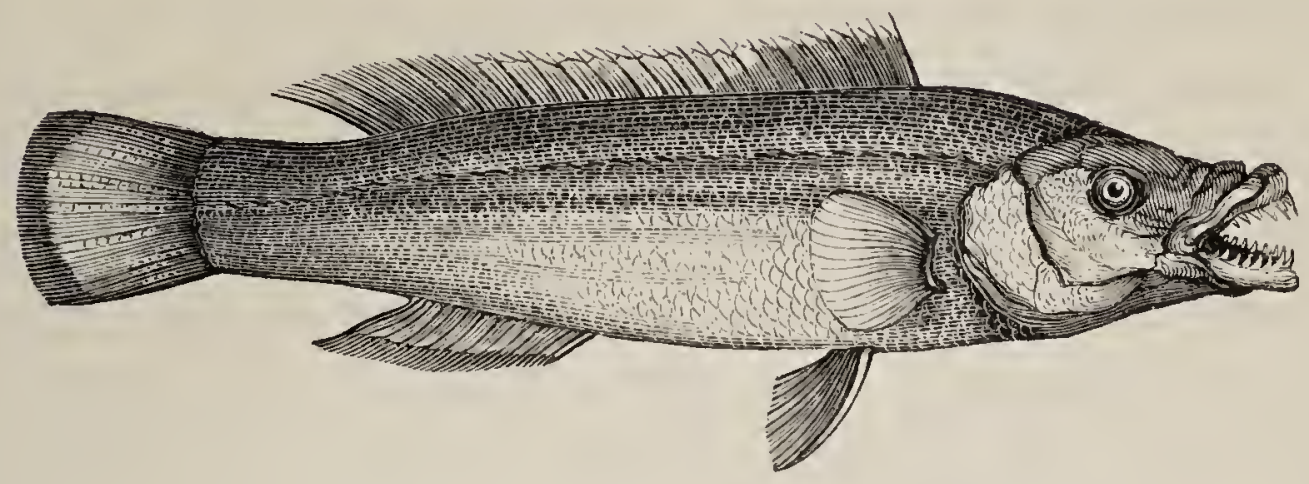

THE COOK WRASSE. The Male.

COOK CONNER, OR BLUE STRIPED WRASSE.

Labrus mixtus, mas, FkIes och Ekström, Skand. Fisk. pl. 37.

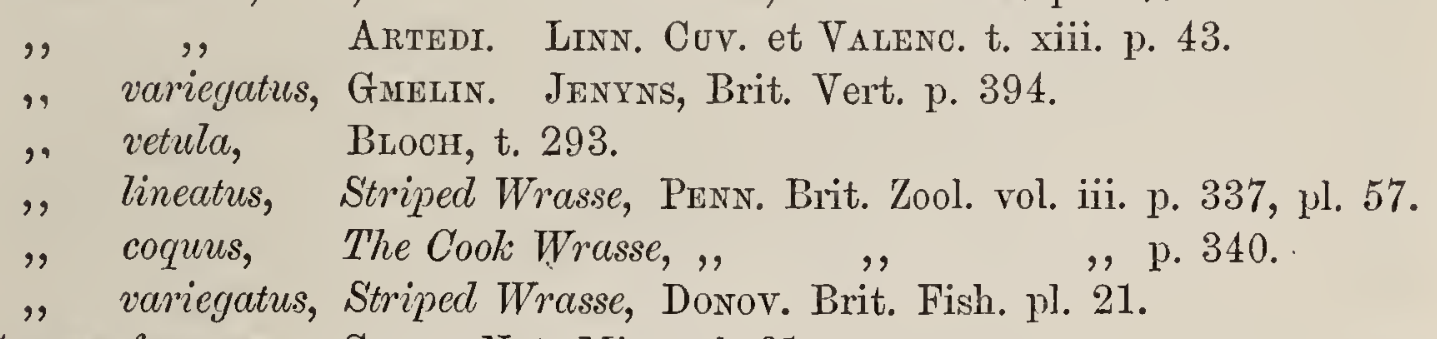

Sparus formosus, SHAw, Nat. Misc. pl. 31.

Labrus pavo, Risso, Hist. t. iii. p. 299, sp. 196.

Fries and Ekström in the Scandinaviens Fiskar state that the male fish only has hitherto been described by icthyologists under the specific names of Labrus mixtus and the other synonyms quoted above. The female is the fish known as the Red or Three-spotted Wrasse. Ekström distinguishes the sexes by the following general tints.

Male. Blackish green, streaked with blue; belly and inferior fins yellowish, with blue spots.

Female. Red with three black spots on the hinder part of the back.

The authors of this work say that the sexes differ in their colour to an extent very unusual among fishes, and that males vary greatly with age, the younger ones 
resembling the females in their dress. The common appellation of the Labri in the Swedish district of Bahus is Snultra, but the males of this kind are called there and in Norway Blåstål, or Blaastak, or Blaaskal, i.e. Blue-scale, and the females Rödnäbba, or Bergnäbba. 'This Wrasse inhabits the Mediterranean as well as the Northern Atlantic. It does not enter theBaltic, nor has it been taken in Iceland or Greenland. No Labrus frequents the coasts of Finmark. Two beautiful illuminated figures in the Skandinaviens Fiskar are the best representations of the species that have been published, and show well the differences between the sexes. They are named Labrus dispar, mas et femina, on plates 37 and 38, but both are included under mixtus in the text.

The Cook Wrasse, first described as British by Pennant, is one of the most beautiful of the Labri, and appears to be much more frequently met with on the southern than upon the eastern shores of England: those from the southern shores are also most conspicuous for the beauty of their appearance. It is liable to much variation in its colours and markings, as the various figures of this fish will show, but the general form of body and fins is permanent. I have obtained two specimens in the London fish-market.

This species is not unfrequent in Cornwall, and has been taken at Cork, Waterford, Dublin, Down, Antrim, and Galway, but not abundantly.

"In its habits," Mr. Couch says, "this Labrus keeps, like the others, among rocks, seeking shelter among the larger sea-weeds, where it feeds chiefly on crustaceous animals, and takes a bait freely. All the Wrasses, however, that have an elongated form, differ from those with deeper and more solid bodies, in changing their quarters according to the season, and that too without much 
reference to the cold or warmth. They enter harbours and frequent the shallower rocks close to land during the summer; but in autumn and winter pass into deeper, but not very deep water. They are but little esteemed here as food, and are chiefly sought after as bait for other fish." Fries and Ekström say that the male attains the length of fourteen inches, while the female scarcely ever exceeds a foot in length.

The whole length of the specimen described is twelve inches; the length of the head, compared with the length of the head and body without the tail-rays, is as one to three; the distance from the teeth in front to the edge of the preoperculum is equal to the depth of the body alone; the depth of the body and dorsal fin included is equal to the whole length of the head: the form of the jaws when the mouth is closed is an isosceles triangle sloping below as well as above; preoperculum somewhat uneven on the edge; lips thin, flexible, and capable of considerable extension; a single row of fourteen teeth stand on each premaxillary, and sixteen on each limb of the mandible conical and slightly curved, the tallest next the symphysis, the others diminishing gradually as they approach the corners of the mouth. Behind the exterior row there is an irregular row of teeth so small as to be visible only when the soft parts are dried up. The pharyngeal teeth are crowded, cylindrical, straight, and obtuse. The dorsal fin commences directly above the short, rounded, pectoral fin; the vent is situated under the sixteenth spiny ray of the dorsal fin and the anal fin ends rather before the end of the soft portion of the dorsal fin; the fleshy portion of the tail and its rays are elongated, the latter slightly rounded: the body deepest in the pectoral region, is elongated ; the scales are of moderate size, disposed in six rows, following the diagonal line 
of their succession between the base of the dorsal fin and the lateral line; and in nineteen or twenty rows between the lateral line and the bottom of the belly. On the cheek behind and below the level of the eye there are seven or eight rows of scales much smaller than those of the Ballan Wrasse in the same situation.

The general colour of the body and head varies in tint from orange-yellow to orange-red, darkest on the back, lightest on the belly; sides of the head and body brownish, or bluish black, striped with fine blue; the irides of two colours, orange and blue; the membrane connecting the first twelve rays of the dorsal fin is blue, its upper edge orange, and the remaining portion orange with blue spots: the pectoral, ventral, anal, and caudal fins, are orange tipped with blue. The numbers of the fin-rays are-

D. $17+13:$ P. $15:$ V. $1+5:$ A. $3+10:$ C. 11 , with 6 graduated incumbent ones above and below.

Pennant's specimen of this fish was taken off the Skerry Isles, on the coast of Anglesey; and Cuvier, in his Règne Animal, tom. ii. page 256 (note), has borne testimony to the excellence of Pennant's representation of this species, by stating that he did not know any good figure of this fish except that in the British Zoology. Some specimens are darker on the upper part of the back than others: and the sides of Pennant's fish are described as having been marked with four parallel lines of greenish olive, and the same number of most elegant blue. Pennant gives Cógwrach as the Welsh name of the male fish and Gwrach rengos as the name of the female fish figured on the succeding page. 


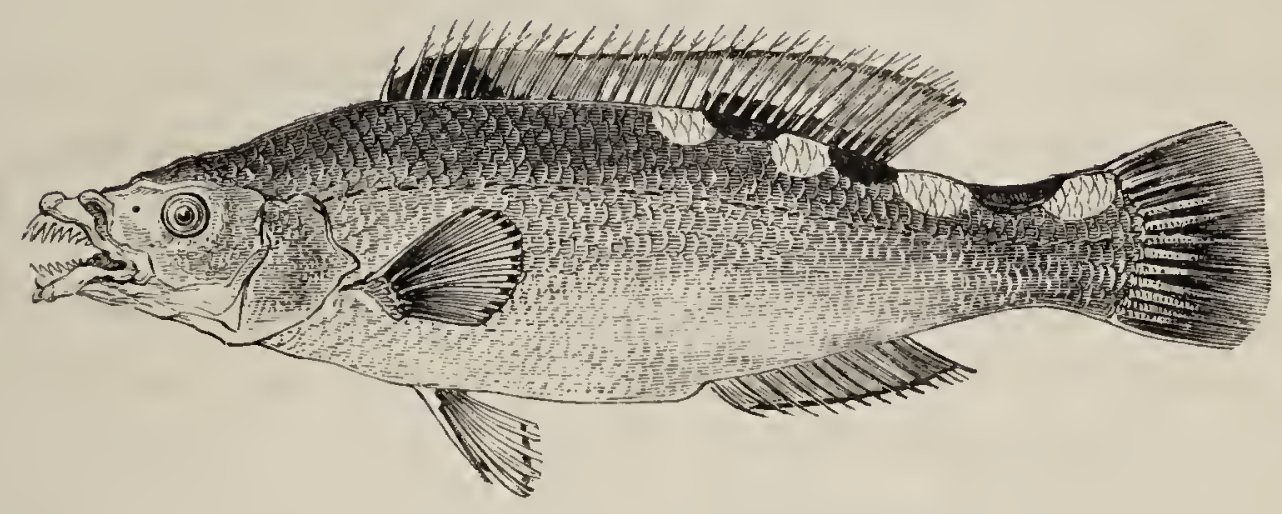

THE COOK WRASSE. The Female.

THE RED WRASSE. THREE-SPOTTED WRASSE. DOUBLYSPOTTED WRASSE. FLESH-COLOURED WRASSE.

Labrus mixtus, foem. Fries och Erströn, Skand. Fisk. pl. 38.

", trimaculatus, Gmedin. Cuv. et Valenc. t. xiii. p. 58.

", carneus, Ascandus, Icon. xiii.

", , Вцосн, pt. ix. pl. 289.

", trimaculatus, Trimaculated Wrasse, Penn. Brit. Zool. vol. iii. pl. 56.

,, ", , , Dovov. Brit. Fish. pl. 49.

,, quadrimaculatus, Rrsso, Hist. t. iii. p. 302, sp. 199.

As mentioned in the preceding article, the Red Wrasse, which had previously been considered to be a distinct species, was ascertained by Fries to be the female of the Cook Wrasse. This ichthyologist while examining the fish frequenting the shores of Bahusland, in the North of Sweden, noticed that all the specimens of $L$. mixtus or lineatus, which he obtained had milt, while those of $L$. carneus or trimaculatus contained roe. He was thus led to believe that as the forms of the two fish were identical, the colours were merely sexual differences, which the subsequent researches of Wilhelm Von Wright and himself fully confirmed. We have preserved part of 
the synonyms, and references to authors of the former editions of this work, under the figures of the male and female fish respectively.

The Red Wrasse was first described by Ascanius, under the Swedish name of Sudernaal, and is met with at various places on our coast. Pennant's fish was taken on the coast of Anglesey. Mr. Donovan, Colonel Montagu, and Mr. Couch, have each described it from specimens obtained in Devonshire and Cornwall. Mr. Neill has recorded his notice of several taken in the Firth of Forth; its capture in the Moray Firth is mentioned in the Zoologist (p. 4171); and $\mathrm{Mr}$. Thompson records its occurrence on the northern, north-eastern, and western coasts of Ireland, specially noticing Donaghadee, Larne, and Roundstone, as localities where it was procured. Two specimens exist in my own collection, one of six inches in length, prepared dry, the second of nine inches, preserved in diluted spirits of wine.

With less variation in its colours than the male, the Red Wrasse is still a beautiful fish. It approaches the shore to deposit its spawn in March or April; and Risso states that in the Mediterranean it is found full of ova twice in the year.

The prevailing colours of the female are a fine orangered over all the upper parts of the body, becoming lighter as it descends the sides, and ending in pale orangeyellow on the belly; pupil of the eye dark, surrounded by three concentric circles of orange, blue, and white; a blue frontal band extends from eye to eye, and is prolonged on each temple; there is also a blue subocular stripe going to the corner of the mouth; all the fins are rich orange, with a tinge of darker colour at the edges of the membranes; between the first two or three spines of the dorsal fin, there is a rich purple mark with two spots at the base of the hinder soft-rayed part of the same fin, 
and one still further back, at the upper part of the fleshy portion of the tail, of the same deep purple colour. Alternating with the last three dark spots are four lightcoloured ones, of a delicate rose colour or fleshy tint, which appear to have given origin to the name of Doubly-Spotted Wrasse. There are occasionally but two dark spots at the hinder part of the body. Risso includes the dark blotch on the anterior part of the dorsal fin in his enumeration of the spots, or refers to the four flesh-coloured spots, and calls the species fourspotted; he also adds, that those specimens which frequent the more rocky districts of the Mediterranean are observed to be most inclined to red in colour. Mr. Couch's coloured drawings of Cornish specimens, which are remarkably red, are in accordance with Risso's remark. The lips and fleshy portions of the under jaw, not covered with scales, are of a delicate flesh-colour.

Since the publication of the first edition of this work I have obtained a fresh red specimen in the London market.

Though the males and females frequent the coast of Norway from the 62nd parallel down to Christiana Fiord, neither have been taken in the Kattegat, nor in the Baltic. They inhabit, according to Ekström, rocky coasts only, and do not enter sandy bays. In summer they are taken in from five to ten fathoms of water, but in winter they resort to deeper parts of the sea. The fin-rays and form of the sexes being alike, we have described only the colours of the female. 


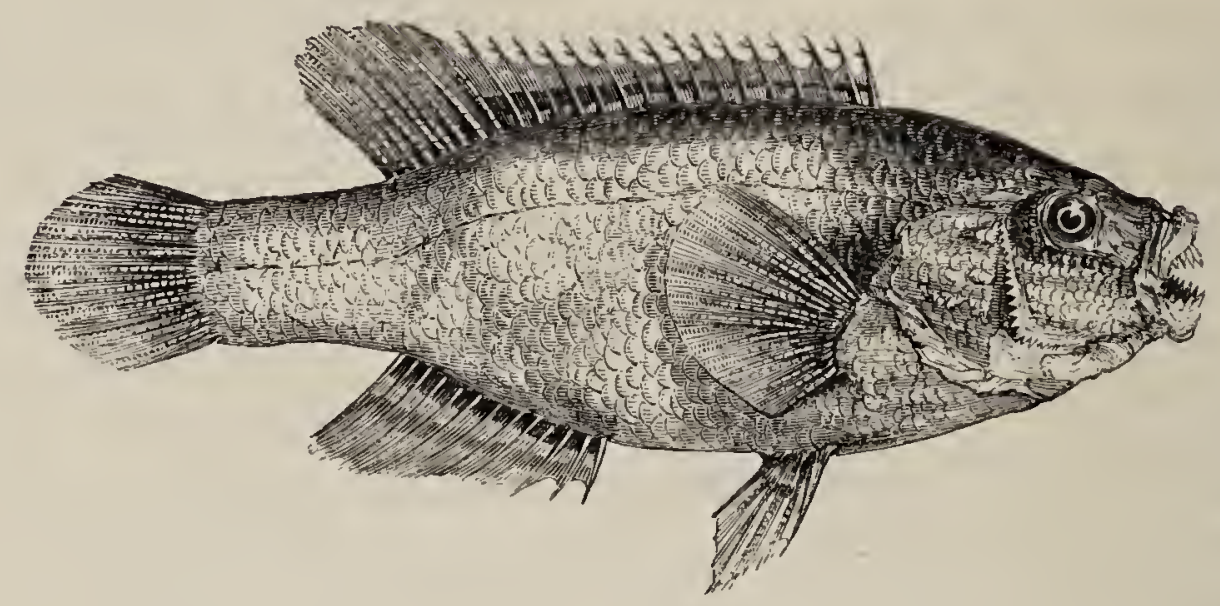

\section{THE CORKWING.}

CONNOR OR GOLDEN MAID, OR GOLDEN WRASSE, OR GILTHEAD. SKäR-SNULTRA, Scandinavia.

Crenilabrus melops, Labrus

, rone

Crenilabrus ,

Lutjanus Norvegicus, Crenilabrus

, tinca,

\section{Labrus}

Crenilabrus ,,
Cuv. et Valenc. xiii. p. 167.

LinN. Kröyer. Fries och Ekströ̀, t. 44.

Ascanios, Icon. 2, t. 14. (1772.)

Cuv, et Valeno. xiii. p. 172.

BLOCH, pl. 256.

Cuv. et Valeno. xiii. p. 176.

Flem. Brit. An. p. 208, \} excluding various Jenxns, Brit. Vert. p. 397, $\}$ synonyms. Risso, Hist. t. iii. p. 315.

Labrus cornubicus, Goldsinny, Penn. Brit. Zool. (4th Ed.) iii. pl. 58, fig. 3. Crenilabrus Pennanti, Cuv. et Valenc. xiii. p. 178.

Labrus cornubius, Goldfinny, Dowov. Brit. Fish. pl. 72.

Crenilabrus Donovani, Cuv. et Valenc. xiii. p. 180.

Crenilabrus. Generic Characters.-Premaxillaries not protractile; preoperculum sharply serrated; lips fleslyy and thick ; teeth conical, uniserial, the largest as usual in the family being next the symplyyses of the jaws and lowering gradually but rapidly towards the corner of the moutli; the posterior granular teeth are not developed. Lateral line continuous. General aspect of Labrus, with tags to the dorsal spines; the body is usually somewhat deeper. The fins do not move in a distinct scaly sheath.

ThE Wrasses are ornamented generally with bright colours, but of patterns by no means uniform in the same species, differing also with the sexes, and changing 
from one determined tint to another speedily after death, or vanishing altogether when the fish is dried or preserved in alcohol; hence many nominal species have been introduced into our systematic works, and the fishermen themselves, who are not to be relied upon as guides in such matters, have applied a variety of names to the same fish in its different garbs. The numerous synonyms quoted above are given on the authority of Fries and Ekström, who tell us that Kröyer in his Danmarke Fiske, first showed that they were all referable to one species; and also that there was reason to believe that the Gibbous Wrasse of Pennant (pl. 56, fig. 1), and the Corkwing of Couch, and also the Labrus cornubius, of Donovan, which is introduced into the Histoire des Poissons (vol. xiii. p. 180), under the name of Crenilabrus Donovani, ought to be all considered as also belonging to Crenilabrus melops. The essential character of the species, according to Ekström, is the black spot behind the eye, which often becomes more conspicuous after death, and remains in the dried specimen; also another spot on the base of the caudal fin below the level of the lateral line, which is not so constant or permanent, and the length of the head, which is shorter than the height of the body. To these specific marks they add the generic character of the serrated preoperculum, which is very conspicuous in this species, the serratures numbering about fifty.

Mr. Thompson, in his able Natural History of Ireland, had already brought together several of the nominal species of British authors, treating the names Gilthead, Corkwing, and Gibbous Wrasse, as different appellations of one species. He says, "In the autumn of 1835, an attentive examination of specimens of the Crenilabrus tinca and Cornubicus, of all sizes, and in a recent state satisfied me of their identity. The depth of 
tinca in proportion to its length being found to vary considerably (though not to the extent described in the Gibbous Wrasse of Pennant), together with the general accordance of other characters, disposed me at the same time to believe that the Crenilabrus gibbus is an accidental variety of it." "The smaller specimens had the black spot on the base of the caudal of $C$. cornubicus, the larger, C. tinca, wanted it ; some specimens of an intermediate size had it of an obscure brown, as if in the act of vanishing." "In not one of the many characters which come under the head of form was there any difference." "The Corkwing is admitted by $\mathrm{Mr}$. Couch to want the black spot on the tail occasionally, and is considered by him to be in this state the Gibbous Wrasse of Pennant, whose greater depth is an individual variety."

The great confusion that has been produced by the introduction of so many synonyms into our lists of British Fishes has induced us to print the above abridgments of the recorded observations of the skilful ichthyologists whose names we have given, and which leave us little ground for doubting the correctness of their opinions.

This polyonomous species is common on all the southern coasts of England and Wales, and also on the coasts of Ireland from Dublin Bay northwards. It frequents the Firth of Forth, and other parts of the Scottish coast, but is stated by Dr. Baikie, in his list of Orkney Fishes, to be rare in that quarter; nor does it appear to be abundant on the Scandinavian shores, though it has been taken on the coast of Norway as high as the 62nd parallel of latitude. It seems to be more plentiful in the Mediterranean, in sandy as well as rocky places, and its chief food consists of small crustaceans. The specimens which I have obtained, or 
seen in the possession of others, have been procured from the fishermen who attend lobster and prawn pots, into which these fish and others are occasionally enticed by the baits, and are in their turn cut up to furnish fresh baits to attract the crustaceans. The Corkwing spawns in April on the English coasts, but not till July on the shores of Norway, according to Kröyer:*

The body is deeper than that of any other of the British Labroids. The liead alone is to the length of the entire fish, excluding the caudal rays, as one to three, or when the caudal fin is included, the head forms rather more than a fourth of the length, but the length of the head is not equal to the greatest height of the body. Eye small, situated near the upper profile, its inferior border not descending to the middle line of height. Mouth also comparatively high up and less deeply cleft than in its congeners, the Acantholabrus exoletus alone of our British Iabroids having a smaller gape. Teeth on the jaws of the usual labroid form, strong, contiguous, diminishing in succession, to the angle of the mouth, numbering five or six on each premaxillary, and seven or eight on each limb of the mandible. The series of teeth, both above and below, are parted by a little space at the symphyses of the jaws. Branchiostegals five, slender. Lateral line parallel to the back, and nearer to it than to the belly, until it reaches the soft rays of the dorsal fin, under which it is deflexed, and then takes a straight course through the middle of the stump of the tail.

* "Hic auctor se observâsse commemorat, unde conjicere liceat, coitum verum unius maris uniusque fœminæe à Labris celebrari. $\mathrm{Ei}$ enim aliquando unus e fucis marinis prosiliens, alterum persequi visus est, moxque ambo subsistentes, ventres componebant, quo in statu aliquamdiu remanebant. Separati inter fucos sese occultebant, quod spectaculum pluries repetitum est. Papilla nigricans, paullo post anum, ad apicem perforata et in fœemina multo major quam in mare, sine dubio vice organi copulatorii in hoc ludo functa est." - Fries och Ekström, l. c. 
Scales large, subpentagonal, with their posterior edge rounded, numbering thirty-seven on the lateral line, with four rows above it and ten below. The dorsal fin commences immediately over the base of the pectoral, and its branching rays are considerably higher than the spinous ones: anal fin exactly opposed to the hinder part of the dorsal, its posterior rays, however, being taller than those of the dorsal : the tips of the ventrals reach the anal aperture, and between the ventrals there is an elongated scale which overlaps their inner margins. The numbers of the various rays are-

$$
\text { D. } 16+9: \text { P. } 15: \text { V. } 1+5: \text { A. } 3+10: \text { C. } 11 \frac{6}{5} \text {. }
$$

Colours beautiful but variable as in others of the tribe. When just taken out of the water the general tint is green, passing into blue on the back, with yellow margins to the scales generally. The head yellow with oblique green lines, and a black space behind the eye. Fins spotted with yellow, green, and blue, without any pure black spots on them. These colours quickly fade, and a general brownish or greyish hue ensues, the black however, behind the eye persists, and sometimes, but not always, the spot on the lower part of the tail.

Further to illustrate this puzzling species, we introduce as a vignette Pennant's figure of his Gibbous Wrasse, pl. 56, fig. 1, (Crenilabrus gibbus of the Histoire des Poissons, vol. xiii. p. 175,) which, though copied into the firstedition of the present work, was suppressed in the second as being merely a variety or nominal species. On Pennant's authority it has appeared in most of the lists of British Fishes. Mr. Thompson has been quoted above as considering it, and we believe correctly, as merely the Crenilabrus melops, somewhat deeper in the body than usual. Most of Pennant's figures were drawn by his 
servant Moses Griffith, and it is creditable to the artist that at a time when Zoology was but in its infancy in England, and minute accuracy not thought necessary, any of his portraits should be recognisable in after times.

Gibrous Wrasse from Pennant.

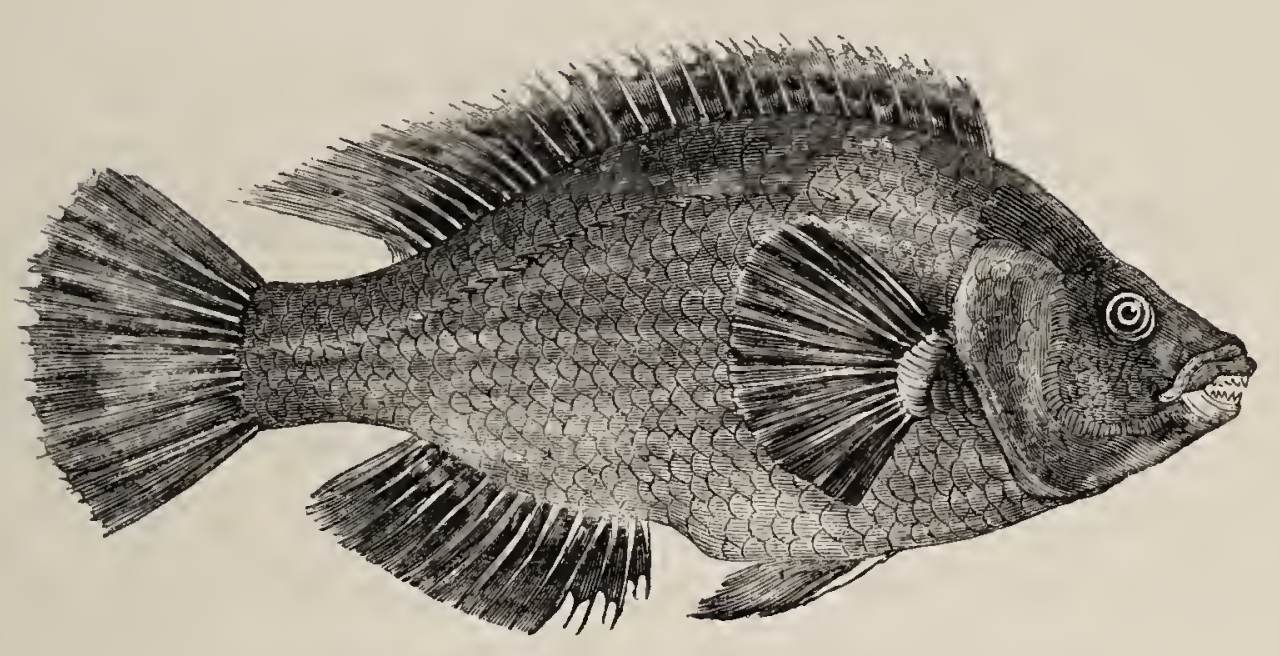




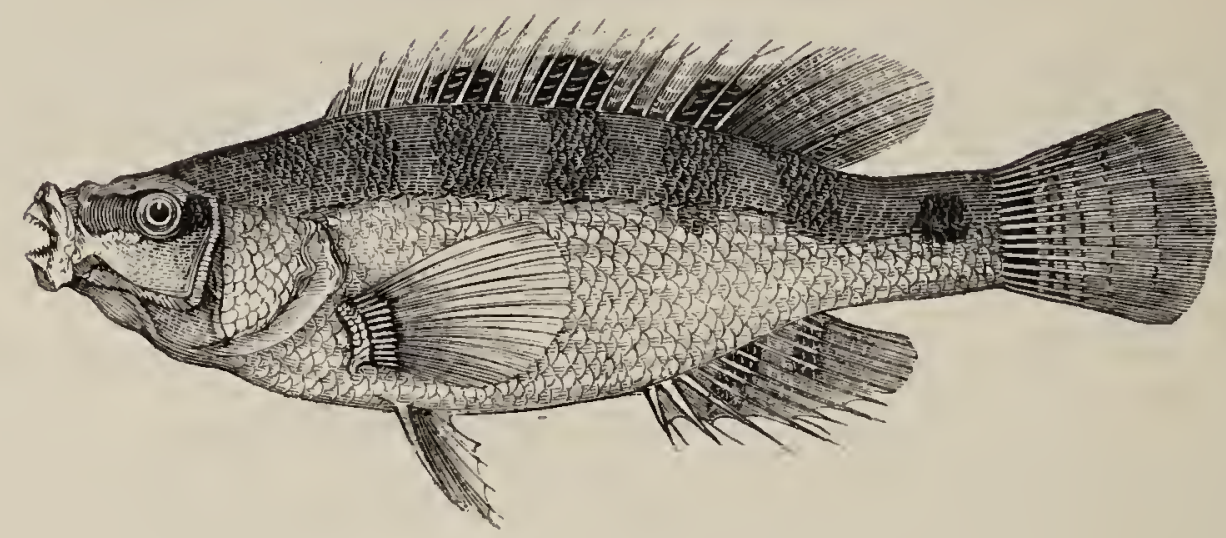

\section{THE CORKWING.}

Labrus comubicus, Goldsinny, Yarreul, Br. Fish. Ed. 1st and 2nd.

WE have no doubt of the accuracy of the observations by which the Scandinavian Naturalists were enabled to refer to the single species of Crenilabrus melops, numerous figures and descriptions published by others under different specific names, which are enumerated in the list of synonyms at the head of the preceding article: but as the history of the species may be illustrated by tracing the mistakes of preceding years, we have reproduced the figures of the nominal species which were introduced into the former editions of this work. Already in the second edition the Gibbous Wrasse of Pennant had been expunged, as mentioned in the preceding page, where the figure recurs as a vignette.

The Corkwing, under the name of Lutganus Norvegicus, was figured by Bloch (pl. 256) from a specimen sent to him by Spengler from Norway, and recognised by Nilsson as frequent on the Norwegian coasts. It was adopted into the Histoire des Poissons, on Bloch's authority, but M. Valenciennes, after stating that he had not been able to procure a specimen, remarks on the similarity of the figure to Crenilabrus melops. Pennant, in speaking 
of a Labroid, discovered by Mr. Jago on the coast of Cornwall, and entered in Ray's Synopsis under the name of Goldsinny cornubiensum,* says distinctly that he had never seen it. Jago's fish is the Ctenolabrus rupestris of the Histoire des Poissons, but the editor of the fourth edition of Pennant's British Zoology has given the figure of a Goldsinny, on plate LVIII. (fig. 3.) which he erroneously refers to Jago's Goldsinny, and on which $\mathbf{M}$. Valenciennes has founded his Crenilabrus Pennanti. This blundering added largely to the confusion of names. Donovan having made the same mistake with Pennant of referring his Goldfinny (Labrus cornubius, pl. 72) to Jago's Goldsinny, has been the cause of the introduction of a Crenilabrus Donovani into the Histoire des Poissons (vol. xiii. p. 810); and Pennant's error was continued by Messrs. Jenyns and Couch, and in the former editions of this work. The Cornish name of Corkwing has been retained for the species, as Gilthead is the name also of a Sparoid fish.

* We believe that Goldsinny is a misprint for Goldfinny, which has a significance which the other wants.

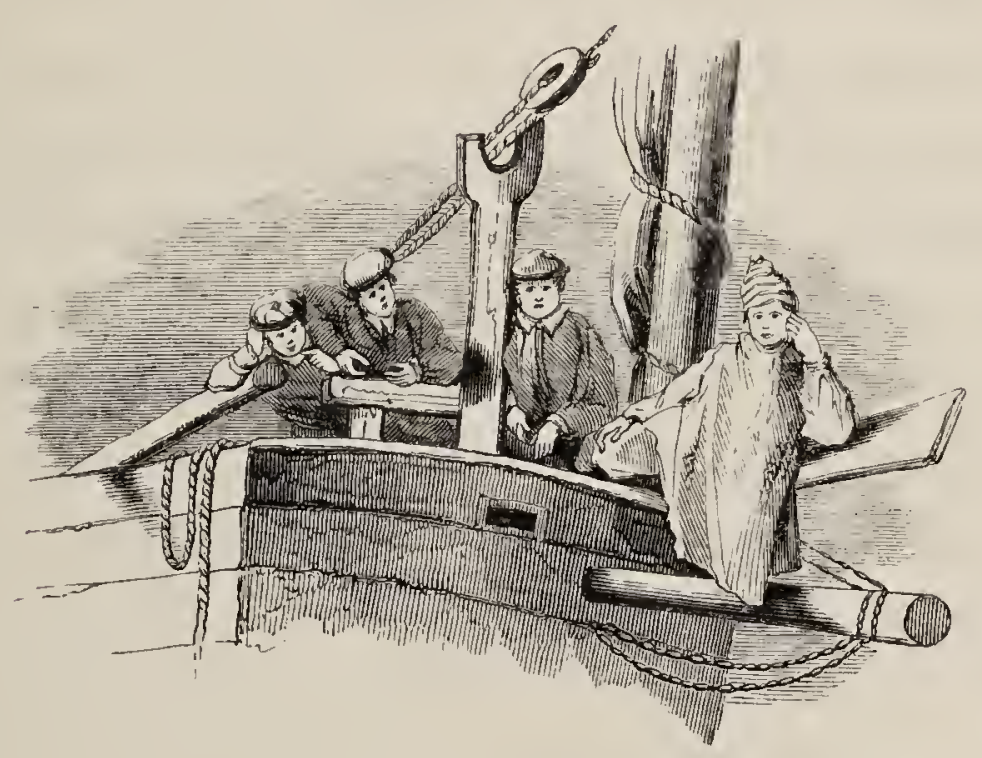




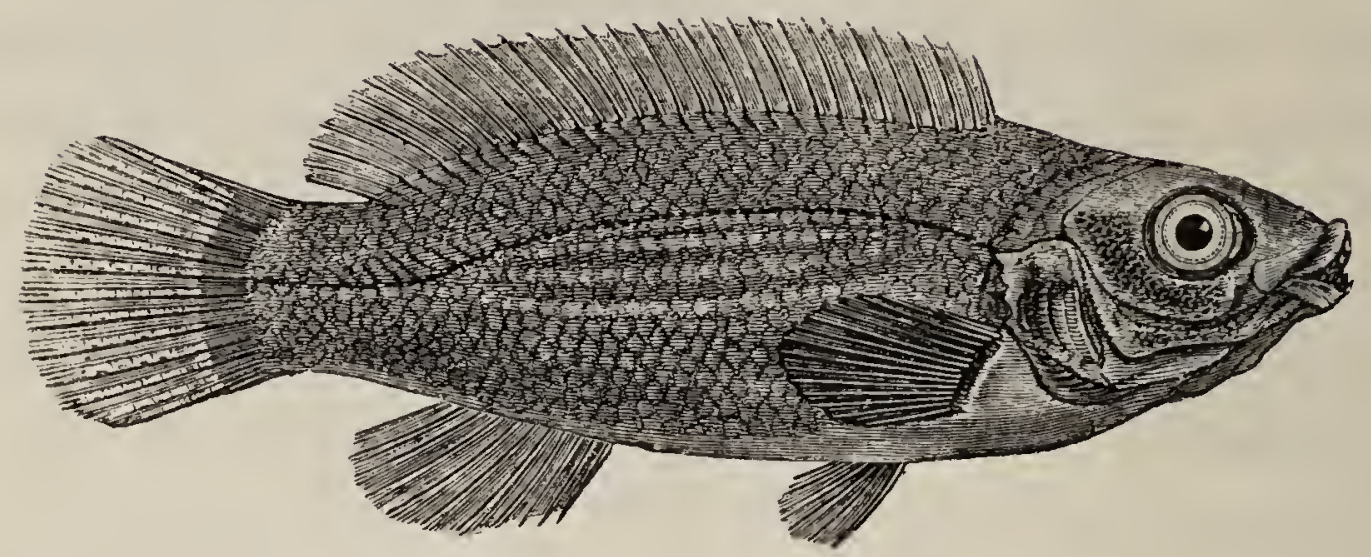

\section{THE CORKLING.}

Crenilabrus (minor vel) pusillus, Corkling, Write, Cat. Brit. Fish. p. 24.

Turdus minor, ,, RaY, Syn. Pisc. p. 165.

Labrus pusillus, , Jenyns, Brit. Vert. p. 392, sp. 70. Crenilabrus multidentatus, Ball's Wrasse, Thompson, Proc. Zool. Soc. 1837.

This species, of which no examples more than four inches in length have been as yet reported, was obtained by Professor Henslow at Weymouth, and four or five specimens are now preserved in the Museum of the Cambridge Philosophical Society. I possess one which was sent to me by Mr. Couch from Cornwall; and Mr. Thompson of Belfast has recorded the occurrence of three others, which were taken at Youghal in Ireland, by Mr. Ball, in the summer of 1835 . Since then it has been obtained on the coast of Cork.

The Youghal specimens were characterized by $\mathrm{Mr}$. Thompson in the Proceedings of the Zoological Society for 1837, page 56-not without some hesitation-as a new species, under the name of Crenilabrus multidentatus; but his subsequent careful comparative examinations of 
the specimens of the two countries show that they are identical, and they are here therefore brought together. *

Mr. Jenyns' description of a specimen, four inches in length, is as follows:- "Distinguished by its small size. Back but little elevated, sloping very gradually towards the snout; ventral line more convex than the dorsal; sides compressed : depth contained about three times and threequarters in the entire length; thickness half the depth, or barely so much; head one-fourth of the entire length: snout rather sharp; jaws equal : teeth of moderate size, conical, regular, about sixteen or eighteen in each jaw : $\downarrow$ eyes rather high in the cheeks, situated half-way between the upper angle of the preoperculum and the margin of the first upper lip; the space between about equal to their diameter, marked with a depression; a row of elevated pores above each orbit: preoperculum with the ascending margin very oblique; the basal angle, which falls a little anterior to a vertical line from the posterior part of the orbit, very obtuse, and remarkably characterized by a few minute denticulations, which further on become obsolete, and in some specimens are scarcely anywhere obvious: lateral line a little below one-fourth of the depth; nearly straight till opposite the end of the dorsal, then bending rather suddenly downwards, and again passing off straight to the caudal : number of scales on the lateral line about forty-five: dorsal commencing at one-third of the length, excluding caudal; spinous portion nearly three-fourths of the whole fin, the spines very slightly increasing in length from the first to the last, which last is not quite one-third of the depth of the body; soft portion a little higher than the spinous, of a

* For Mr. Thompson's latest comparisons and remarks see the postliumous edition of his Natural History of Ireland, p. 131. (1856.)

+ In two rows in the upper, in one in the lower jaw; ten in each outer premaxillary row, thirteen in each limb of the mandible.-Thompson. 
somewhat rounded form, the middle rays equalling nearly half the depth: anal commencing a little anterior to the soft portion of the dorsal, and terminating a little before it; the first three rays spinous, the third being the longest, but the second the stoutest spine; soft rays resembling those of the dorsal: caudal nearly even, with rows of scales between the rays for nearly half their length : pectorals rounded, about two-thirds the length of the head, attached immediately beneath the commencement of the dorsal; all the rays soft and articulated, and, except the first, branched: ventrals a little shorter; the first ray spinous, shorter than the second and third, which are longest; all the soft rays branched; the last ray united to the abdomen by a membrane for half its length.

B. 5 : D. 19 or $20+10$ or 11 : P. 14 : V. $1+5$ : A. $3+9$ : C. $13_{3}^{4}$.

Colours of specimens in spirits yellowish brown, with irregular transverse bands; dorsal irregularly spotted with fuscous ; anal light brown ; the other fins pale."

"It is apparently," says Mr. Jenyns, "quite distinct from any of those described by other authors. Though belonging to the present section (Labrus), which it is convenient to retain, it would seem to form the transition to the Crenilabri, to which its near affinity is indicated by the rudimentary denticulations on the margin of the preopercle."-British Vert.

Mr. Thompson's account of the colours of this fish being drawn up from specimens preserved in spirits, we do not repeat, except that he mentions three blackish spots on the preoperculum, one on the tail at the insertion of the caudal fin, and one on the last dorsal ray at its base, all of which show some resemblance to the distribution of spots in the female Corkwing, which may be distinguished, however, by the number of spines in the dorsal fin. 


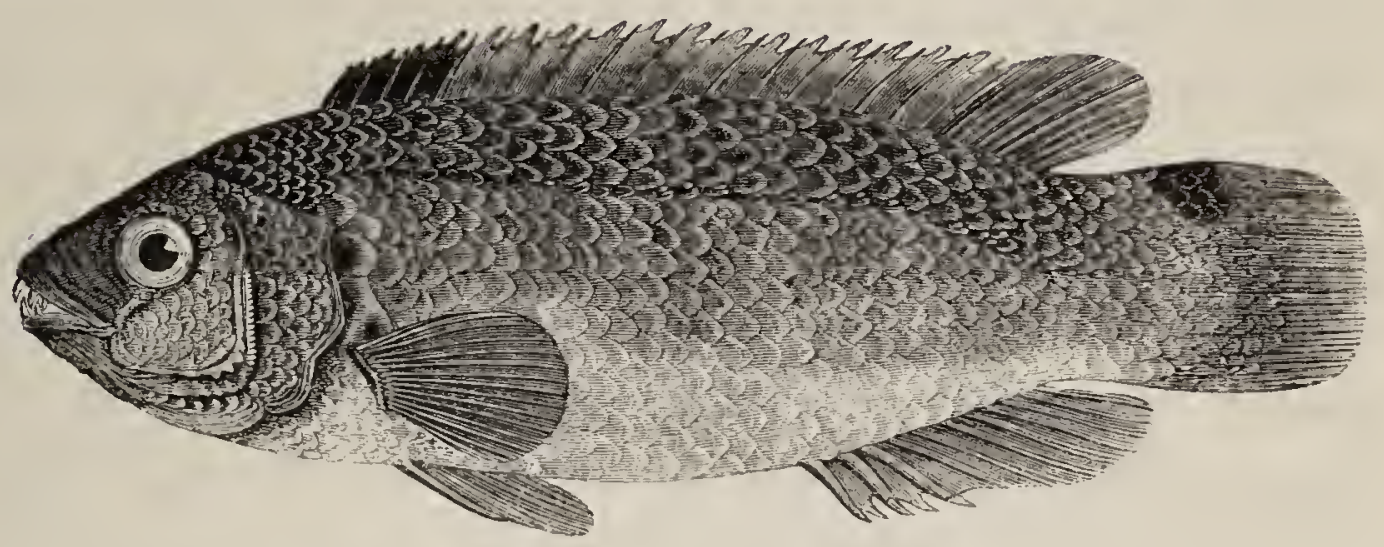

\section{JAGO'S GOLDSINNY.}

\section{sten-snultra, Scandinavia.}

Clenolabrus mestris, Le Ct. des roches, Cuv. et Vaueno. xiii. p. 223.

\begin{tabular}{|c|c|c|}
\hline Scirena & rupestris, & $\begin{array}{l}\text { Jago's Goldsinny, RAx, Syn. tab. 1, f. } 3 . \\
\text { Mus. Adol. Fr. pl. 31, f. } 65 .\end{array}$ \\
\hline Labrus &, & Linn. Sys. Nat. p. 478, sp. 27. \\
\hline & ", & Mulier, Prod. Zool. Dan. p. 45. \\
\hline Perea & ", & Mullek, Zool. Dä. tab. 107. \\
\hline Lutjanus & ," & BlocIr, pt. vii. tab. 250, f. 1 . \\
\hline Labnus & , & Nils. Prod. Icht. Scand. p. 76, sp. 5. \\
\hline Perea & ," & REтz. Faun. Suec. p. 337, sp. 73. \\
\hline Crenilabrus & ,, & Jago's Goldsinny, Seubr, Mag. Zool. \&c. vol. i. p. 167. \\
\hline ,", & , & $\begin{array}{l}, \quad \text { Thompson, Mag. Zool. and Bot. ii. ; } \\
\text { Zool. Proceer. 1837, p. 57 ; Nat. } \\
\text { Hist. of Ireland, iv. p. 130. }\end{array}$ \\
\hline
\end{tabular}

Labrus ", Fries och Ekströn, Skand. Fisk. pl. 3, fig. 1.

Ctenolabrus. Generic Characters.-Crenilabri, except in having a band of villiform teeth on the jaws, behind the outer row of conical ones.

In the month of February 1836, Dr. George Johnston obtained three specimens of the Lutjanus rupestris of Bloch, two of which were picked up in Berwick Bay, and the third near Bamborough; these specimens were 
thrown on shore after a violent storm, and having been sent by Dr. Johnston to his friend Mr. Selby, became the subject of a notice in the first volume of the Magazine of Zoology and Botany, as quoted under the figure of the fish here given. It has also been taken in the Forth.

Mr. Selby most correctly referred the specimens to the Goldsinny of Jago, in the Synopsis of our countryman and naturalist John Ray, who was the first to make it known; but this fish, being also a northern species, was afterwards figured and described in the various works here quoted among the synonyms. Since the occurrence of the specimens on our eastern coast, Mr. Thompson of Belfast has obtained two at Bangor, County of Down, where they were caught by angling boys. Others have since been taken in Belfast Bay by Mr. Drummond and at Roundstone by Mr. Calla. I have received from T. S. Rudd, Esq. two beautifully-coloured examples of this fish, which were taken on the Yorkshire coast, from the finest of which the figure here engraved was drawn; one has also been taken on the coast of North Wales by my friend Mr. Thomas Eyton, and specimens exist in the British Museum, which were captured at Plymouth by Lieut. Spence, and at Brighton by J. G. Children, Esq. Among some Labri supplied me by $\mathrm{Mr}$. Couch from Cornwall, before the occurrence of the specimens in Berwick Bay, was a small fish of this species, but being by accident somewhat discoloured and distorted, and this species differing in colour when young, I did not then recognise it as the Lutjanus rupestris of Bloch, but figured it as a vignette to the Scalerayed Wrasse of the British Fishes, vol. i. p.300. Since that time Mr. Couch has very kindly supplied me with more small specimens, which will enable me to describe this fish as it appears at different stages of its growth, 
premising, however, that I have seen no examples of more than seven inches in length.

The Sten-snultra, say the authors of the Skandinaviens Fiskar, is more common on the coasts of Scandinavia than any other Labroid, being found from Scania round to the northern districts of Norway. It frequents also the Danish coast, where it is sometimes caught by angling from rocks, as in this country. A beautifulcoloured figure of this fish is given in the work of MM. Fries and Ekström, just referred to. These gentlemen mention a curious fact, namely that when this fish is at liberty in the water it shows two rows of spots on the sides, seven above, and as many below, the lateral line. If the fish be disturbed the spots vanish, but return again after it has been allowed to remain quiet for some time. They never observed the spots on a fish when taken out of the water, and have therefore omitted them in their figure. The food of the species consists of small crustaceans, nereides and mollusks.

The length of the specimen here described was six inches and a half. The length of the head one inch and three-quarters; the diameter of the eye three-eighths and a half, or one-fourth of the length of the head; the irides silvery; the teeth long, strong, curved, and pointed, particularly in the anterior part of the upper jaw ; both preoperculum and operculum are covered with scales, and the preoperculum is distinctly crenated throughout the greater part of its ascending edge ; the dorsal and pectoral fins commence on the same vertical line; the membrane connecting the first four spinous dorsal rays is black; the spinous rays are shortest at the commencement of the fin and becoming, very gradually, more elongated towards their union with the soft rays, acquiring a length about equal to one-fourth of the depth of the body of the fish; the 
soft rays are more lengthened; from the base of the last of which to the end of the caudal rays, is about the same length as that of the head, and about one-fourth of the whole length of the fish. Half-way between the base of the last soft dorsal ray and the extreme end of the caudal rays, there is on the upper edge of the body and tail a conspicuous roundish black spot, equally visible on either side; the caudal fin-rays are scaled from their base on a line with this black spot their length half and their ends slightly rounded; the anal fin has three spiny rays in front and ends with elongated soft rays, the last of which stands a little in advance of the last soft dorsal ray; the ventral fin begins a little behind and below the base of the pectoral fin, and the pectoral itself has a length, compared to the length of the fish, as one to seven. The prevailing colour in the largest specimen is orange, the free edge of each scale being of a light golden yellow; the colour is darkest over the three or four lines of scales along the highest part of the back, and lightest on the lower part of the sides and belly; the body is also indistinctly marked with five transverse bands, the first of which descends from below the more anterior spinous rays of the dorsal fin, and the fifth from below the elongated soft rays of the dorsal fin; but I have never seen these bands so strongly marked as they are made to appear in Bloch's coloured figure, the ground colour of the body of which resembles that of one of my specimens. Young examples of this species are of a uniform yellowish fleshcolour; the fins are still lighter; but the black spot at the commencement of the dorsal fin, and on the upper part of the base of the tail, are very conspicuous from the uniform paleness of the body and fins generally, and, except for these two constant spots, are not unlike the Labrus 
pusillus of Mr. Jenyns, which is the subject of the preceding article. These spots appear to be good distinctions: very young specimens of the female Corkwing measuring only one inch and a half in length, are constantly marked with the spot on the middle of the side of the tail.

The fin-ray formula in Jago's Goldsinny is-

$$
\text { D. } 17+9: \text { P. } 14: \text { V. } 1+5: \text { A. } 3+7: \text { C. } 13 .
$$

The number of scales along the lateral line is thirtytwo, and four or five more extend over the base of the caudal fin; there are four rows of scales between the lateral line and the dorsal ridge, and eleven rows between the lateral line and the anal aperture.

M. Nilsson says, this species is liable to variations in colour, and some of the species taken in Northern localities are tinged with green. Fries and Ekström remark that the species may be recognised by its fins being all of one colour, with the exception of a spot on the front of the dorsal, and a few bluish lines between the fourth and seventh rays of that fin. The round black spot on the dorsal edge of the caudal fin is always present.

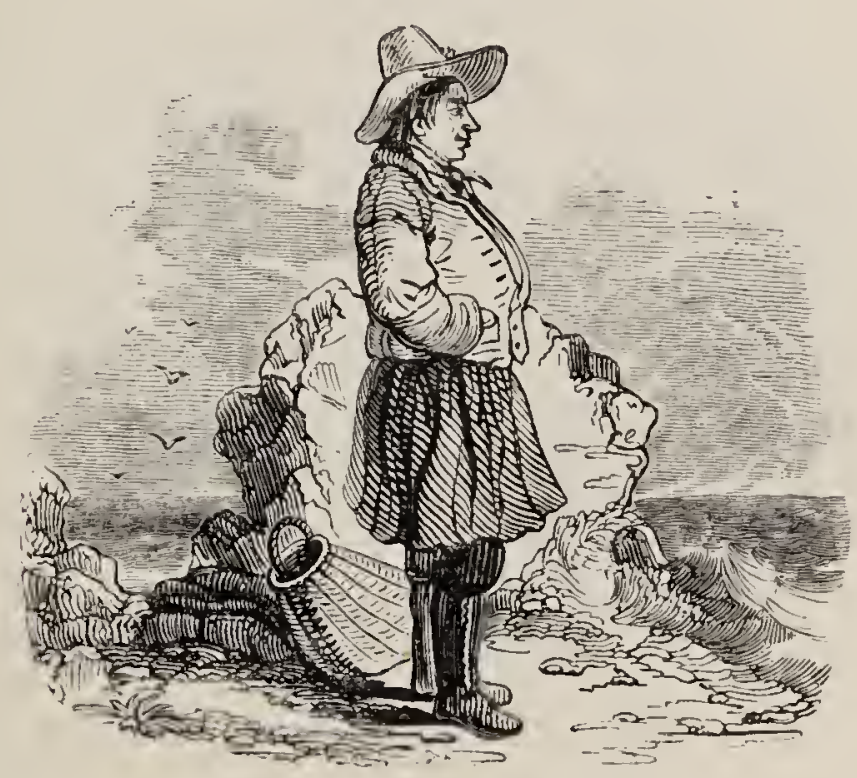




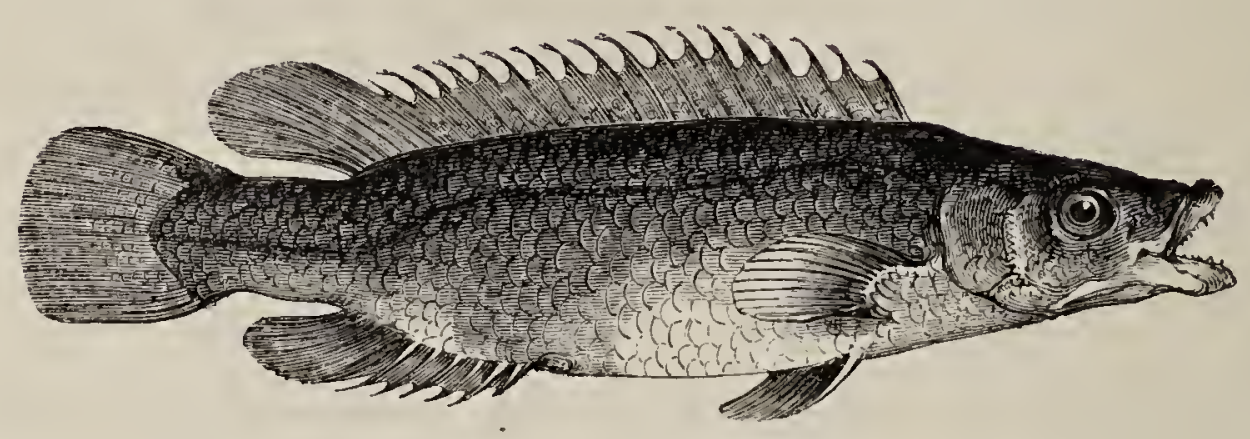

THE SCALE-RAYED WRASSE.

A cantholabrus Couchii, Cuv. et Valenc. Hist. Nat. des Poiss. t. xiii. p. 248.

Crenilabrus luscus,

Labrus , Scale-rayed Wrasse, Covcr, MS.

Couch, Loudon's Mag. Nat. Hist. vol. v. p. 18, and pp. 741, 742, fig. 121.

Acantholabrus. Generic Characters.-The usual Labroid aspect, with the dentition of Ctenolabrus, and more than three (four to six) anal spines.

Of this genus we possess three species, the first of which, named by M. Valenciennes after the describer, has been thus characterized:-

"The specimen was twenty-two inches long; the greatest depth, exclusive of the fins, two and a quarter inches; the body plump and rounded. Head elongated; lips membranous : teeth numerous, in several rows; those in front larger and more prominent, rather incurved. Eye moderately large; anterior gill-plate serrated; six gillrays; body and gill-covers with large scales; lateral line nearer the back, descending with a sweep opposite the termination of the dorsal fin, thence straight backward. Dorsal fin twenty-one firm rays, eight soft rays; the posterior rays when expanded reaching to the base of the tail-fin: pectorals round, of fourteen rays; the ventral of 
six rays, the outermost simple, stout, and firm; between these fins there is a large scale. The anal fin of six firm, eight soft rays. Tail-fin round, of fifteen rays; between each ray of the dorsal, anal, and caudal fins, there is a process formed of firm, elongated, imbricated scales. Colour, a uniform light brown, lighter on the belly; the upper eye-lid is black, and at the upper edge of the base of the caudal fin there is a dark-brown spot. Pectorals yellow and all the other fins bordered with yellow." The numbers of the fin-rays are here repeated for the sake of uniformity-

$$
\text { D. } 21+8: \text { P. } 14: \text { V. } 1+5: \text { A. } 6+8: \text { C. } 15 \text {. }
$$

"I have seen only one specimen of this Wrasse, of the size here mentioned, which was taken in the month of February 1830, at the end of a very cold season."

This is not the Labrus luscus of Linnæus, which, according to M. Valenciennes, has only three spines in the anal fin. The chief difference between the Scale-rayed Wrasse and the longer-known luscus is, M. Valenciennes thinks, in the numbers of the spinous rays.

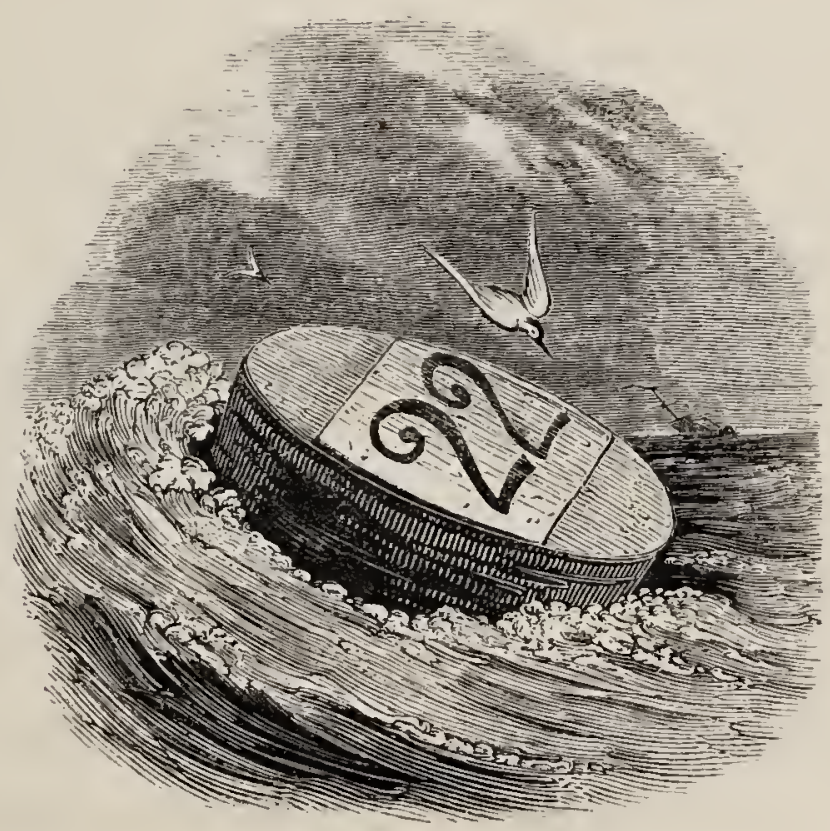

I. T. 2 


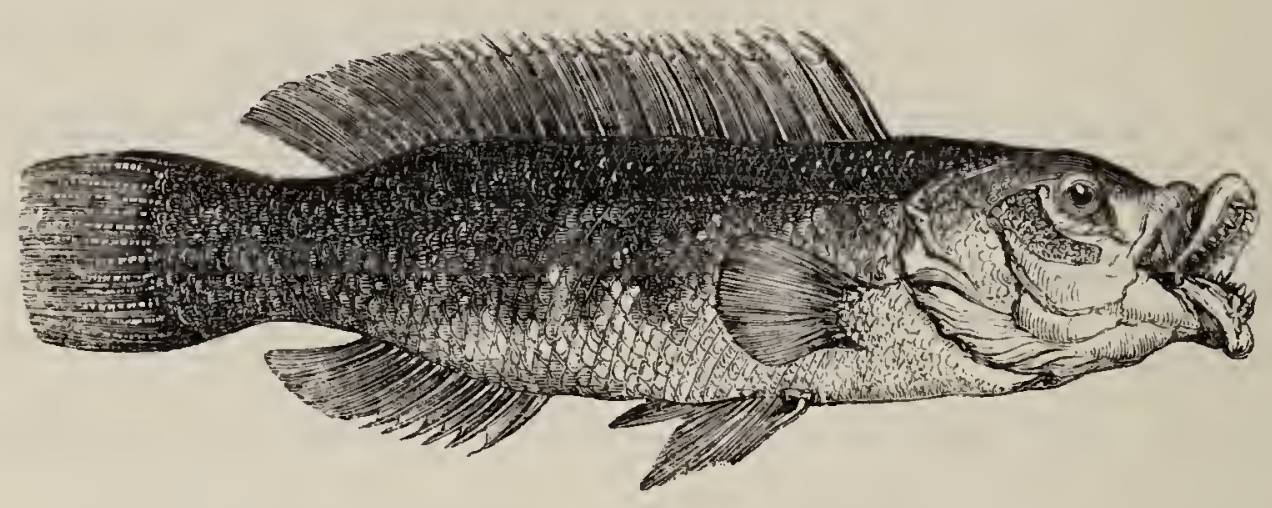

THE SEA-WIFE.

Acantholabrus Yarvellii, Cuv. et Valenc. Hist. Nat. des Poiss. t. xiii. 1) 250.

A specimen of this fish, measuring nine and a half inches in length, I obtained in the London market, and had a drawing of it made at the time, from which the figure above, reduced in size, was taken. In the proportions of the body and its parts, it is intermediate between the Ballan Wrasse and the Cook Wrasse. It is not so short a fish in proportion to its depth as the first, yet shorter and deeper than the second, and distinct, apparently, from both in colour. It is distinguished from the Cook-conner by the ascending line of the preoperculum being much more oblique, forming with the inferior margin a more obtuse angle; by the six spinous rays at the commencement of the anal fin, and the teeth are also, smaller and more numerous, especially in the upper jaw. The length of the head, compared to the whole length of the fish, is as two to seven; the depth of the body is to the whole length of the body without the 
caudal fin, as one to four: the vent is situated immediately under the thirteenth spinous ray of the dorsal fin. The number of fin-rays is-

\section{D. $16+13:$ P. $15:$ V. $1+5:$ A. $6+8:$ C. 12 .}

The whole of the upper part of the back, neck, and sides, have a very dark purplish-black hue, becoming lighter on the belly; the lips and anterior part of the head are flesh-coloured, tinged with purple; irides blue; the teeth have all the characters of those of a Labrus, and the branchiostegous rays are five in number. All the fins are blue; the ventrals being tipped with black.

I could not ascertain from what part of our coast this fish had been brought. M. Valenciennes remarks that it is not the Labrus vetula of Bloch, as he had ascertained from Bloch's own specimen preserved in the Museum of Berlin, and that it differs from the other Acantholabri in the numbers of its dorsal rays, and from the Ac. exoletus in having an anal spine more.

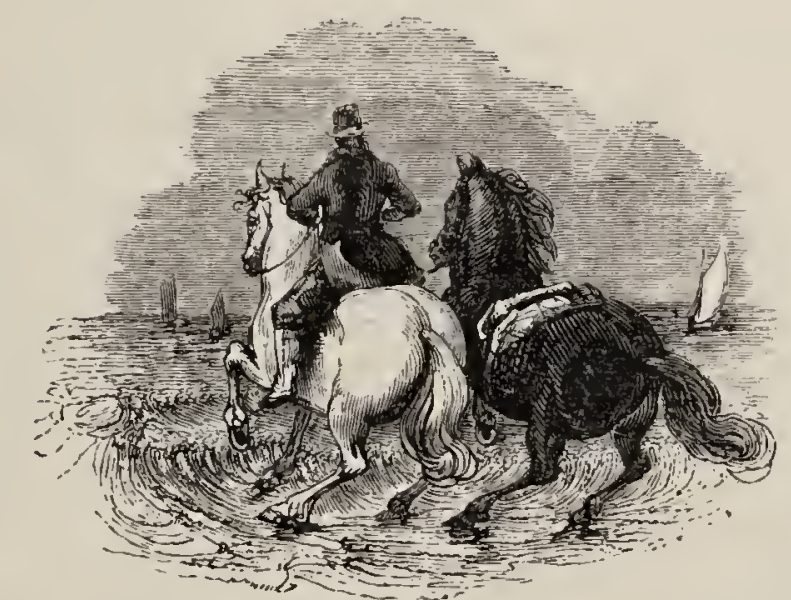




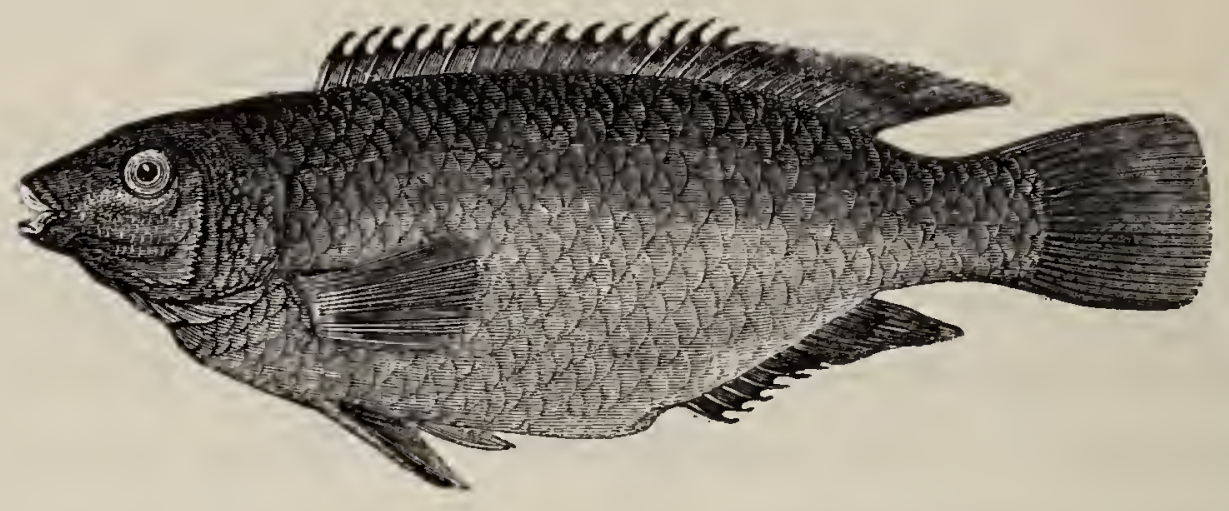

\section{THE SMALL-MOUTHED WRASSE,}

OR ROCK-COOK. GRÄS-SNULTRA, Scandinavia.

Acantholabrus exoletus, Cuv. et Valeino. Hist. Nat. des Poiss. t. xiii. p. 247.

Labrus

,

,

,

,

,

Crenilabrus micr
, Linn. Syst. Nat. p. 479, sp. 33.

" Mulder, Prod. Zool. Dan. p. 46, sp. 386.

, Fab. Faun. Grœnl. p. 166, sp. 120.

,, Retz, Faun. Suec. p. 335, sp. 67.

, Nils. Prod. Icht. Scand. p. 77, sp. 7.

,, Fries och Ekström, Skand. Fisk. pl. 3, fig. 2. Mag. Zool. and Bot. vol. ii. p. 446 , pl. 14 ; Nat. Hist. of Ireland, iv. p. 132.

, ", Rock-cook, Couch, Cornish Faun. p. 39.

Soon after the publication of the first edition of the British Fishes, Mr. Couch very kindly supplied me with two examples of this Small-mouthed Wrasse, a species which I had not till then seen, and which on the Cornish coast is called the Rock-cook, where it is not so common as the Corkwing or female Crenilabrus melops, but is occasionally caught in the pots set for crabs. Since that time Mr. Thompson has recorded the occurrence of this species in two northern localities in Ireland-at Cairnlough in the county of Antrim, and at Lough Foyle in 
the county of Londonderry. At the former place the fish was found by Dr. Drummond, and at both places by Captain Portlock. Mr. M'Calla in 1840 saw a specimen taken at Roundstone.

Although this fish was most appropriately called microstoma, for it may be immediately distinguished when among other Crenilabri by the smallness of its mouth, it proves to be a species long known to more northern naturalists. Mr. Thompson has given a coloured representation of this fish in the second volume of the Magazine of Zoology and Botany, as previously quoted, and the publication at Stockholm of another coloured figure in the second part of the Fishes of Scandinavia, by MM. Fries and Ekström, leaves no doubt of the two fishes being the same, and enables us to identify our species as the Labrus exoletus of Linnæus. It is a fish of small size, seldom exceeding four inches or four inches and a half in length, and is taken occasionally on the coasts of Sweden, Denmark, and Norway, and, according to Fabricius, as far north as Greenland, where, however, it is said to be rare. It does not enter the Baltic.

The specimen from which the figure and description were taken measured four inches in length, and one inch and one quarter in depth; the length of the head compared to that of the whole fish was as one to four, or rather less. This species exhibits a slight elevation over the eye in the line of the frontal profile; the figure here given marks the true position and relative length of the various fins. The teeth are flat, even, and incisor-like, with the corners slightly rounded; some light-coloured lines extend from the mouth to the orbit, and over part of the cheek; the irides are silvery; the colour of the head and body is dark brown on the upper part, passing into pale wood-brown underneath, and on the sides and 
belly; the colour of the dorsal, caudal, and anal fins is dark brown, the pectoral and ventral fins being lighter ; and my specimens having been many months preserved in spirits have lost some of the lighter tints which the coloured figure of $\mathrm{Mr}$. Thompson's fish, and that also of MM. Fries and Ekström exhibit. The formula of the fin-rays is -

D. $19+6:$ P. $13:$ V. $1+5:$ A. $6+7:$ C. 12 , and 2 shorter rays.

The Scales forming the lateral line are thirty-two, with four rows above to the dorsal edge, and eleven below to the anal aperture.

Fries and Ekström describe the colour of the body as olive on the dorsal aspect with the sides yellow, a tint peculiar to the species, and the belly white. The scales of the back and sides tipped with blue, six longitudinal violet-coloured stripes on the head, the ground colour of which is reddish brown. The vertical fins blue and reddish brown, in alternate longitudinal stripes.

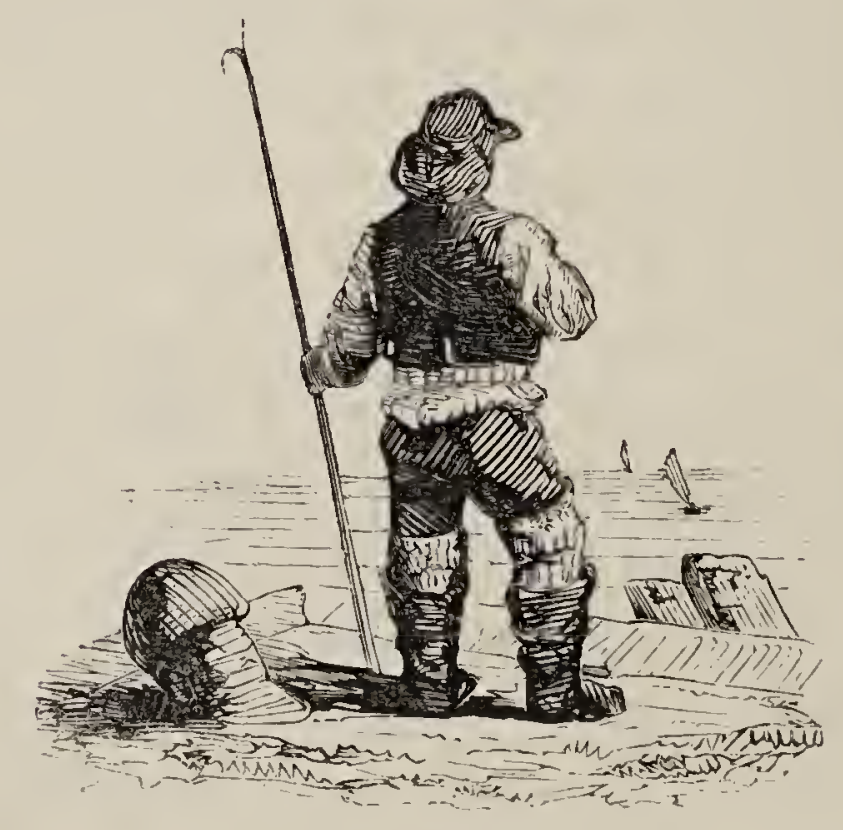




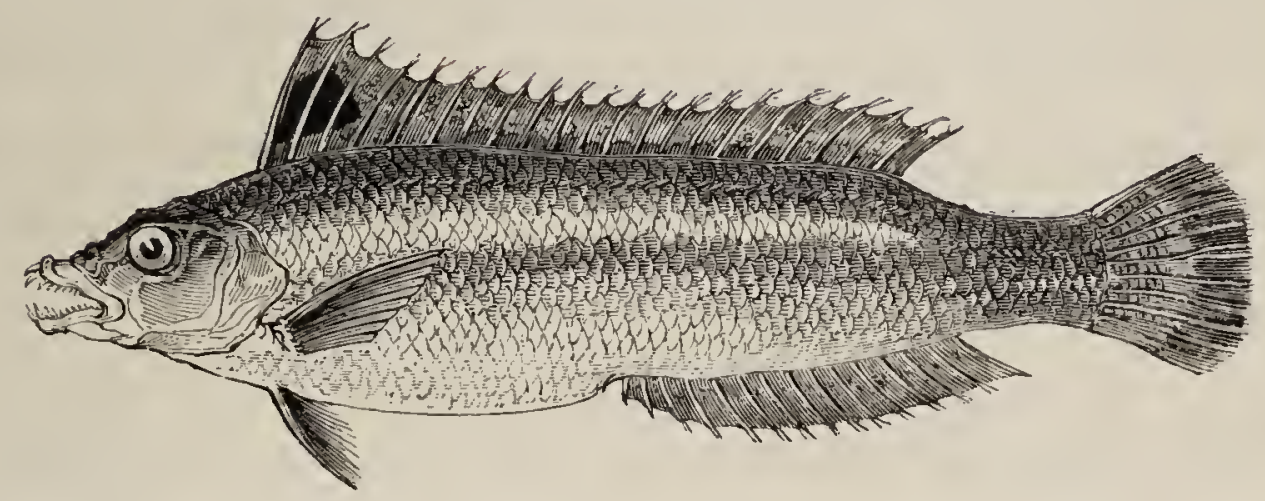

\section{THE RAINBOW WRASSE.}

\section{INDENTED STRIPED WRASSE.}

Julis Mediterranea, Risso, Hist. iii. 309. WiLt. 324, X. 4. f. 1.

Labrus Julis, Artedi. Linnaus. Bloch, pt. viii. pl. 287, fig. 1. Julis, La Girelle, Cưvier, Règne An. ii. 257.

Labrus Julis, $\quad$ Indented Striped Wrasse, Donov. Brit. Fish. pl. 96. ", "Rainbow Wrasse, Penn. Brit. Zool. iii. 343.

Julis rulgaris, Fuen. Brit. An. p. 210, sp. 134.

, , $\quad$ Cuvier et Valeno. Hist. Nat. des Poiss. t. xiii. p. 361.

Juhis. Generic Character's. - Lateral line continuous. Dorsal spines stiff and pointed. The jaws, suborbitar scale-bones, preoperculum, gill-cover, and under aspect of the head, scaleless. Teeth on the jaws conical, longer and stronger the nearer they stand to the symphyses; behind there are some granular teeth, which are largest in the old fish, and are incorporated with the bone of the jaws. Some species have a canine tooth at the corner of the moutli. Pharyngeal teetl as in Labrus.

This very beautiful species, which appears to have been known to the oldest ichthyologists as an inhabitant of the Mediterranean, was first made known as a British fish by Mr. Donovan, in his Natural History of British Fishes, in which he figured and described a specimen taken on the coast of Cornwall in the summer of 1802.

"This specimen," Mr. Donovan observes, "rather ex- 
ceeded the length of seven inches; it was of a slender, or elongated form, and remarkable for the elegant distribution of its colours, which were changeable in various directions of light; but the most striking peculiarity was the broad indented stripe, extending along each side, from the head nearly to the tail, the colour of which was fulvous, and which, with the rest of the colours, produced an effect equally singular and beautiful."

Rays. D. $9+13:$ P. $12:$ V. $1+5:$ A. $2+13:$ C. 13 . Donovan.

B. $6:$ D. $9+12$ : P. $13:$ V. $1+5:$ A. $3+12:$ C. 14 . Valenc.

From other sources we learn that the head is compressed; the lips large; the jaws of equal length, with four pointed recurved teeth in front, and two rows of conical teeth on each side; the palate and tongue smooth; the nostrils pierced near the eyes with four apertures, the anterior ones round, the others oval; the irides orange, the pupil black; the body elongated and narrow; and the back and belly round; the lateral line elevated; the scales of the body adherent, small, and thin.

Risso says an assemblage of beautiful colours pervades the body of this species; the back is greenish blue and the longitudinal band orange, beneath which there are lilaccoloured bands on a silvery ground; the head is varied with brown, yellow, blue, and silver, and the dorsal fin is orange with a purple spot on the membrane connecting the first three spinous rays, which are elongated beyond the others. There are numerous variations of colour.

Although this species is common in the Mediterranean, and frequents all the rocky shores of that sea, but little appears to be known of its habits. A translator of Oppian says :-

" On some thick beds of mossy verdure grow Sea grass, and spreading wrack are seen : below Gay Rainbow-fish, and sable Wrasse resort." 
The food of this fish consists of mollusks, echini, and crustaceans, which it finds most abundantly on coral rocks, and crushes easily with its strong teeth. Alian says the flesh is poisonous: Galen and Bloch consider it to be wholesome.

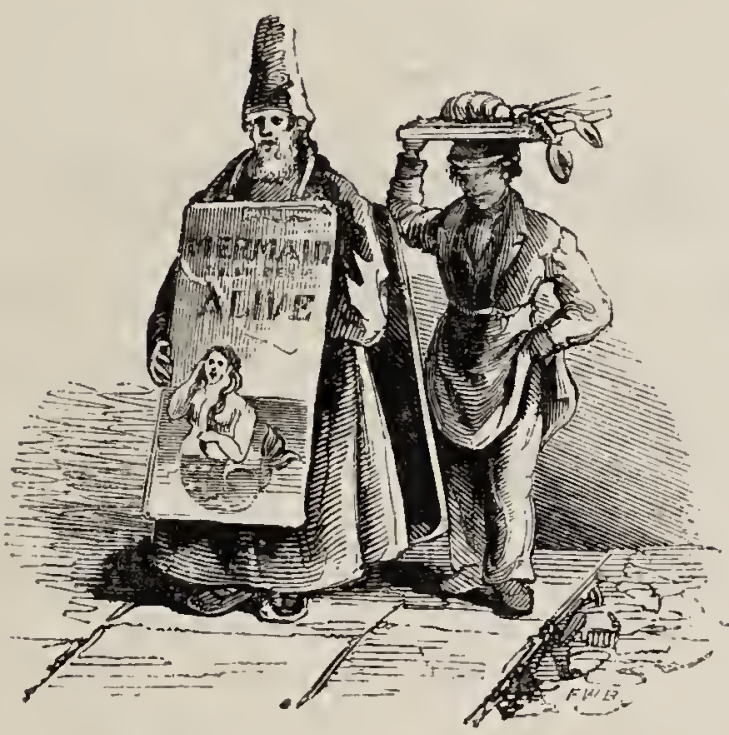

Prima hominis facies, et pulcro pectore virgo Pube tenus; postremo immani corpore pistrix, Delphinun caudas utero commissa luporum.

सENEID iii. 426. 


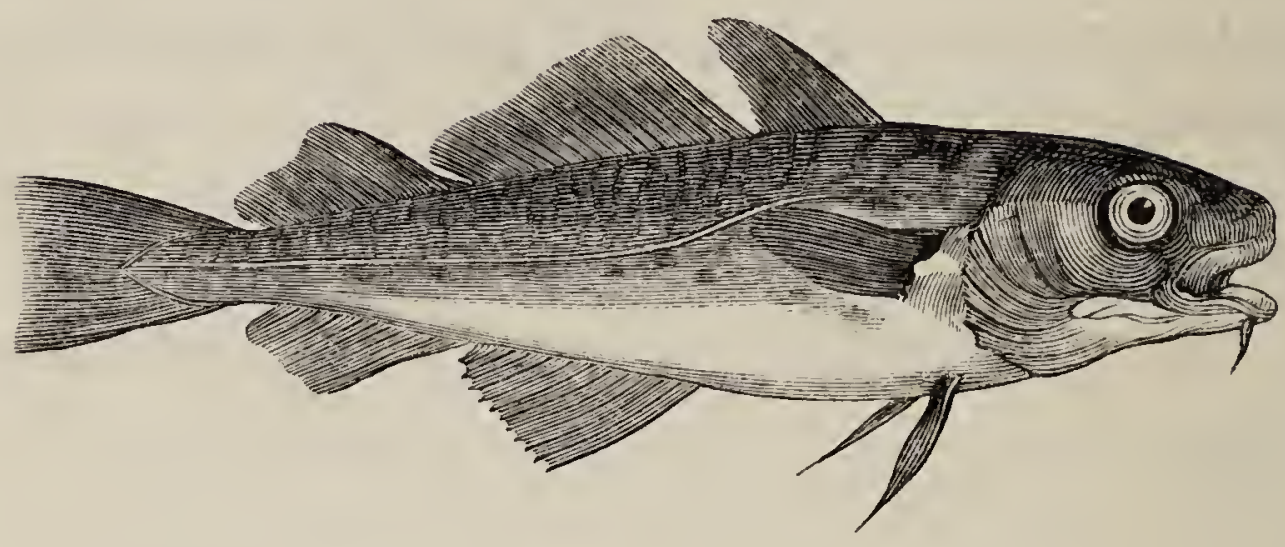

\section{THE COMMON COD.}

\section{THE kEELing. BUdDagh, Ireland.-Torsk, Sweden.}

Morrhua callarias, Fries och Ekströ̈s, pl. 47.

Morrhua vulgaris, Cuvier, Règne An. t. ii. p. 331.

" $, \quad C o d, \quad$ FleMr. Brit. An. p. 191, sp. 76.

", " Codfish, Keeling, Willuandr, p. 165, L. 1, fig. 4.

Gadus morrhua, Linndeus. Bloch, pt. ii. pl. 64.

," , Common Codfish, Penn. Brit. Zool. vol. iii. p. 231.

,, , Codfish, - Donov, Brit. Fish. pl. 106.

,, , Common Cod, Jenyns, Brit. Vert. p. 440.

Gadus callarias, Linneus. BLoch, pl. 63.

$, \quad, \quad$ Willughis, pl. L. 1, f. 1.

, barbatus, Linneus, Syst. 1, p. 437.

GLDID s. Family Characters. - Body more or less elongated, covered with small, soft, cycloid scales; ventrals sub-brachial, dorsals one, two, or three, anals one or two, all anacanthous; jaws and front of vomer and occasionally the palatines armed with card-like or raduliform patches of teeth; branchiostegals seven; stomach capacious, crecal ; pancreatic cæca numerous; airbladder large, often indented, containing a cæliac vaso-ganglion, and without a pneumatic tube.

Gadus. Generic Charucters. - Three dorsal and two anal fins; a symphysial mandibular barbel; caudal distinct from the other vertical fins. Head unarmed. Body scaly.

THE order of Anacanths is so named from the absence of solid pungent rays in the fins. It was introduced into systematic ichthyology by Müller, and the families that 
are grouped together in it are dissimilar in external aspect, and also in many material parts of structure. Some have cycloid scales, others scales with spiniferous disks, and others again ctenoid scales. The swim bladder is absent in most of the fishes of the order, and in the Gadoids, which have this organ of a large size, and with very thick coats, it is closed and destitute of any communication with the stomach or gullet, such as exists in the freshwater fishes we have already described. The ventrals are also absent in most of the families, and, when present, the pelvic bones to which they are affixed are closely connected with the coracoid bones which support the pectorals:-This disposition of the ventral fins has been conveniently referred to by the single term sub-brachial.

The Gadoid family includes some of the fish most valuable to man as articles of food and commerce: among which may be particularly noticed the Common Cod, Haddock, Whiting, and others to be hereafter referred to, all more or less remarkable for the excellence of their flesh, which is white, firm, separates readily into flakes, is agreeable to the taste, wholesome, and cheap.

The old genus Gadus of Linnæus included fishes with one, two, or three dorsal fins, one or two anal fins, with or without barbels or cirri about the mouth, and of very different forms of body. These have been divided by Cuvier, whose first genus includes only those with three dorsal fins, two anal fins, and one barbel at the chin, as specified in the generic characters.

The Common Cod is not only one of those species most universally known, but is also one of the greatest intrinsic value, whether we consider the quality of the fish itself, the enormous numbers in which it is taken, or the extensive range over which it exists. In the seas with which Europeans are best acquainted, this fish is found univer- 
sally, from Iceland very nearly as far south as Gibraltar; but it does not exist in the Mediterranean: it has been taken in abundance on the Newfoundland banks ever since the year 1500, and was fished for on the Labrador coast in the time of Edward the Sixth.

In this country it appears to be taken all round the coast, and among the islands to the north and west of Scotland where it is abundant most extensive fisheries are carried on : it may be traced also as occurring on the shore of almost every county in Ireland. In the United Kingdom alone, this fish, in the catching, the curing, the partial consumption and sale, supplies employment, food, and profit to very many thousands of the human race.

The Codfish is very voracious; a favourable circumstance for the fishermen, who experience little difficulty in taking it with almost any bait whenever a favourable locality is ascertained. As these fish generally inhabit deep water, from twenty-five to forty and even fifty fathoms, and feed near the ground on various small fish, worms, crustaceans, * and testaceans, their capture is only attempted with lines and hooks. Two sorts of lines, adapted for two very different modes of fishing, are in common use. One mode is by deep sea-lines, called bulters, on the Cornish coast: these are long lines, with hooks fastened at regular distances along their whole length by shorter and smaller cords called snoods; the snoods are six feet long each, and placed on the long line twelve feet apart, to prevent the hooks becoming entangled. Near the hooks these shorter lines or snoods, are formed of separate threads loosely fastened together, to guard against the teeth of the fish. . Some variations occur at different parts of the coast, as to the

* Mr. Couch has taken thirty-five crabs, none less than the size of a halfcrown piece, from the stomach of one Cod. 
number of hooks attached to the line, as well as in the length of the snood; but the distance on the long line between two snoods is always double the length of the snood itself. Buoys, buoy-ropes, and anchors or grapples, are fixed one to each end of the long line; the hooks are baited with Sand-launce, Limpet, Whelk, \&c. : the lines are always laid, or, as it is termed, shot, across the tide; for if the tide runs upon the end of the line, it will force the hooks together, by which the whole tide's fishing is irrecoverably lost : they are deposited generally about the time of slack water, between each ebb and flow, and are taken up or hauled in for examination after being left about six hours, or one flood or ebb.

An amendment of this more common plan was some years ago suggested by $\mathrm{Mr}$. Cobb, who was sent to Zetland by the Commissioners appointed for the improvement of the fisheries. He fixed a small piece of cork within about twelve inches of the hook, which suspended and floated the bait so as to prevent its falling on the ground; by which method the bait was more freely shown to the fish through the constant and variable motion produced upon it by the tide. In the old way, the bait was frequently hid from the fish by being covered with seaweed, or was consumed by some of the numerous star-fish and crabs that infest the ground.

The fishermen, when not engaged in shooting, hauling, or rebaiting the long lines, fish with hand-lines, armed with two hooks kept apart by a strong piece of wire : each fisherman manages two lines, holding one line in each hand; a heavy weight is attached to the lower end of the line not far from the hooks, to keep the bait down near the ground, where the fish principally feed. These two modes of line-fishing are practised to a great extent 
nearly all round the coast; and enormous quantities of Cod, Haddock, Whiting, Coalfish, Pollack, Hake, Ling, Torsk, and all the various flat-fish, usually called by the general name of Whitefish, are taken. Of Codfish alone, the number taken in one day is very considerable : from four hundred to five hundred and fifty fish have been caught on the banks of Newfoundland in ten or eleven hours by one man; and a master of fishing-vessels trading for the London market told me that eight men, fishing under his orders off the Dogger Bank, in twenty-five fathoms' water, have taken eighty score of Codfish in one day. These are brought to Gravesend in stout cutterrigged vessels of eighty or one hundred tons' burthen, called storeboats, built for this traffic, with a large well in which the fish are preserved alive; and of these a portion is sent up to Billingsgate market by each night-tide.

Well-boats for preserving alive the fish taken at sea came into use in this country early in the last century. They are said to have been first built at Harwich about 1712. The storeboats remain as low down as Gravesend, because the water there is sufficiently mixed to keep the fish alive: if they were to come higher up, it would kill them. There are now upwards of two hundred and fifty well-boats which bring Cod and Flat-fish to the London market, built at a cost exceeding 275,000l. sterling, and manned by more than two thousand fishermen, who inust earn 140,000l. per annum before any profit accrues to the capitalists.

The oil prepared from the liver of the Cod, and from that of some other members of the family, has been extensively used in medicine, and bears a comparatively high price in the market.

A change has taken place in the fishing grounds of the Cod. Formerly the Gravesend and Barking fishermen 
obtained few Cod nearer than the Orkneys or the Dogger Bank; but the supply for the London market is now obtained by going no farther than the Lincolnshire and Norfolk coasts, and by fishing even nearer London, at stations where formerly very few fish could be obtained. The newspapers have also noticed (in 1858) the discovery of a bank on the Irish coast most abundantly frequented by Codfish.

Cod have been kept in salt-water ponds in different parts of Scotland, and found to maintain their condition unimpaired. Of these ponds there is one in Galloway, another in Fife, and a third in Orkney. That in Galloway is at Logan, the seat of Colonel M'Dowall: it is a basin of thirty feet in depth, and one hundred and sixty in circumference, hewn out from the solid rock, and communicating with the sea by one of those fissures that are common to bold and precipitous coasts. A fisherman is attached to this preserve, whose duty it is constantly to supply the fish with the necessary quantity of food, which several species soon learn to take eagerly from the hand. In the course of the fishing for this daily supply, such fish as are not too much injured are placed in the reservoir; the others are cut in pieces for food for the prisoners. The whelks, limpets, and other testacea, are boiled to free them from the shells; and no sooner does the keeper or his son appear with the well-known basket of prepared food, than a hundred mouths are simultaneously opened to greet his arrival. The Cods are the most numerous of the fish in this preserve; and one which has lived twelve years in confinement, has attained a large size.

Dr. Parnell mentions that Cod are observed to thrive better while under confinement than most of the species of the same family, and that in some instances they are

VOL. I. 
found to improve in the stews. Elias Cathcart, Esq., of St. Margaret's, near North Queensferry, kept for some time a number of marine fishes in a salt-water pond of about two hundred feet in length, and five fathoms deep, in which the tide flows and ebbs twice in the day. The principal fishes preserved were Cod, Haddock, Whiting, Flounders, and Skate, which were retained prisoners by means of an iron grating, placed at that part of the pond which communicates with the Frith. They were fed by the keeper with Sprats, young Herrings, and other small fishes, besides, occasionally, with the intestines of sheep, which the Cod devoured with avidity. All the fish appeared to thrive well, especially the Cod, which were found to be firmer in the flesh and thicker across the shoulders than those obtained from the Frith of Forth, whence the Edinburgh market is supplied. The Cod is abundant in the Orkney and other Scottish Islands.

In a natural state the Cod spawns about February; and nine millions of ova have been found in the roe of one female. The Cod is in the greatest perfection as food from the end of October to Christmas. It may, in fact, be said of the whole of the family of Gadida, that they are in the best condition for the table during the cold months of the year. Young Cod, about six inches long, abound at the mouth of the Thames and Medway throughout the summer: as the autumn advances, they gain size and strength, and are caught from twelve to sixteen inches in length by lines near the various sandbanks in the Channel. When of Whiting size, they are called Codlings and Skinners; and, when larger, Tumbling or Tamlin* Cod.

On the coast of Durham and Northumberland, and at

* Query, Tämlig (Scandinavia), middle-sized. 
the Isle of Man, the Cod acquire a dark-red or reddishbrown colour; and are called Rock Cod, Red Cod, Ware Cod, and Red Ware Cod, when of this particular colour. I saw a considerable quantity in this state in Berwick market, and have had others sent to me by Dr. Johnston. Both the varieties of our Common Cod were equally red. This colour is considered to be the consequence of particular food obtained while lying among weedy rocks. At a short distance only from the situations named, the Codfish are of the usual ash-green colour.

The largest Codfish that I have a record of weighed sixty pounds, was caught in the Bristol Channel, and produced five shillings: it was considered cheap there at one penny the pound. Pennant, however, states that a Codfish of seventy-eight pounds' weight was caught at Scarborough, and sold for one shilling.

There appear to be two well-marked varieties of the Common Cod; one with a sharp nose, elongated before the eye, and the body of a very dark brown colour, which is usually called the Dogger Bank Cod. This variety prevails also along our southern coast. The other variety has a round blunt nose, short and wide before the eyes, and the body of a light yellowish ash-green colour, and is frequently called the Scotch Cod. Both sorts have the lateral line white. I believe the distinction of more southern and northern Cod to be tenable, and that the blunt-headed lighter-coloured fish does not range so far south as the sharper-nosed dark fish. Our fishermen now finding plenty of Codfish near home, the London shops only now and then exhibit specimens of the short-nosed northern Cod: both varieties are equally good in quality, and both are frequently taken on the same ground.

The length of the specimen described was three feet, 
and the weight about twelve pounds. The length of the head compared to the length of the body alone, without the caudal rays, is as one to two and a half; the depth of the body equal to the length of the head: the first dorsal fin commences just behind the origin of the pectorals; the second dorsal commences over the anal aperture, and ends on the same plane as the first anal fin; the third dorsal fin and the second anal fin begin and finish on the same planes; the tail is nearly square; all the rays of the fins are covered with an extension of the skin of the body.

Rays. D. 10. 18. 18 : P. 20 : V. $6:$ A. $20.16:$ C. 26 . Vert. 50. varying to 15.22 .21 .

23. 19.

The head is large; the belly tumid and soft ; the body tapering gradually throughout the latter half; the cavity of the abdomen is extended internally behind the anal aperture, the intestine being recurved: the upper parts of the head, cheeks, back, and sides, are mottled and spotted with greenish ash and the belly is white; the lateral line is also white, becoming broader along the posterior half; all the fins are dusky, the first and second dorsal being rather lighter in colour than the rest : a broad band of short teeth exists on the upper jaw, which is the longest, and on the anterior part of the vomer ; a narrower band arms the lower jaw, and there is one elongated barbel at the chin: the irides are silvery, and the pupil blue; the breadth of the orbit is one-sixth of the length of the head.

Some years since, I obtained from a fisherman at the mouth of the Thames, a fresh-caught example of a species of Morrhua, with the middle dorsal and the first anal fins short; the body as deep for its length as the luscus; the length of the head compared to the whole length of the fish as one to three. Among the fishermen it was by 
some considered to be an accidental deformity, with injury of the spine, and their name for it was Lord-fish; others said it was a fish which they met with occasionally, and believed it distinct from any other. A coloured drawing was made at the time, from which the representation here given was taken, but the fish was not pre-

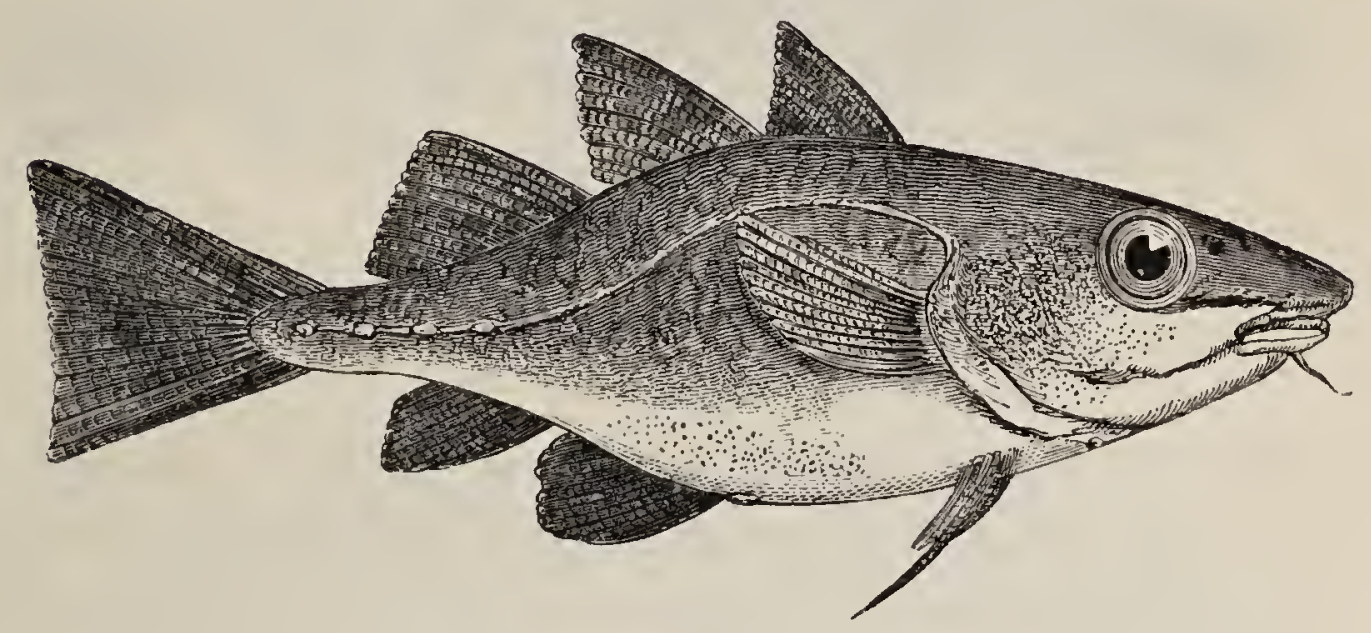

served. The fin-rays were as stated; and it will be observed, on comparing the numbers, that they do not differ very widely from those of the Common Cod.

$$
\text { D. 14. 19. 18.: P. } 14 \text { : V. } 6: \text { A. } 17.11 \cdot \text { C. } 24 .
$$

The figure above is taken from the drawing referred to, but carefully reduced: upper part of the head, back, and fins, mottled with two shades of brown; the sides of the body lighter; the belly white; the lateral line white, arching high over the pectoral fins: the irides reddish orange. It is probable that this is only an accidental deformity, some injury to the spine having prevented the usual growth.

There is reason to believe that the Speckled Cod of Dr. Turton, represented in his British Fauna as fre- 
quently taken in the weirs at Swansea, is only the young of the Common Cod.

We have reproduced here the figure of the Variable Cod which was given in former editions of this work,

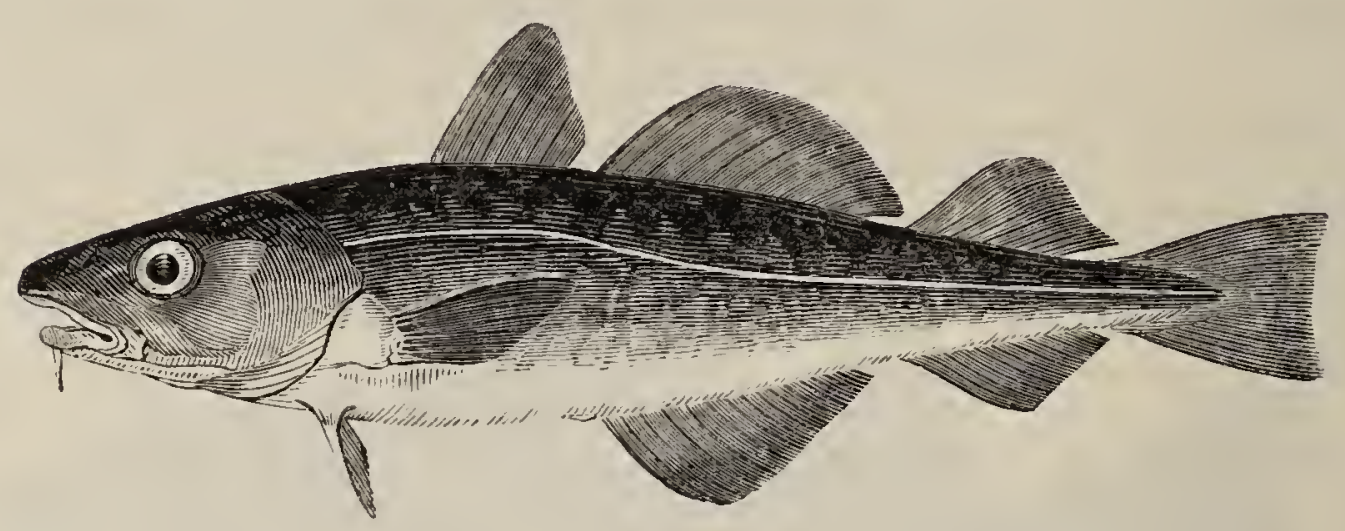

though not drawn from a specimen in the possession of the Author, who had never seen a fish which he could safely name callarias, and consider as specifically distinct from the common Morrhua vulgaris. Ekström identifies the G. callarias of Linnæus as the younger fish of the same species which was designated Gadus morrhua by Linnæus, but erroneously described as having a spinous ray in the dorsal: he therefore adheres to callarias as the proper specific name, and adds that there are three varieties of the Common Cod.

1. The Stor-torsk or Valgild-torsk, a grey or blackishgrey variety, with dusky or blackish-brown spots on the dorsal aspect, and yellowish ones beneath the lateral line.

2. The Gräs-torsk, having a brownish-green colour, with numerous dusky-brown spots.

3. Berg-torsk or Rod-torsk is reddish, with numerous red spots on the back and all the fins. This is evidently the Rock Cod of the English fishermen, which is mentioned in page 531 as an accident of colour, arising 
probably from the nature of its feeding-ground, and is common to both the sharp and blunt-nosed varieties. In some parts of Scandinavia the fishermen designate varieties as the Skrey and Sild-torsk; in Bahusland the names are Slo-torsk and Völgild-torsk, - the differences being, Ekström thinks, similar to those between the Scotch and Dogger-bank Cods, - the young fish resorting to banks less deeply covered by water. Kröyer in his Danmarks Fische has discussed the variations of the Codfish at greater length.

\section{SRUII OF A CoD.}

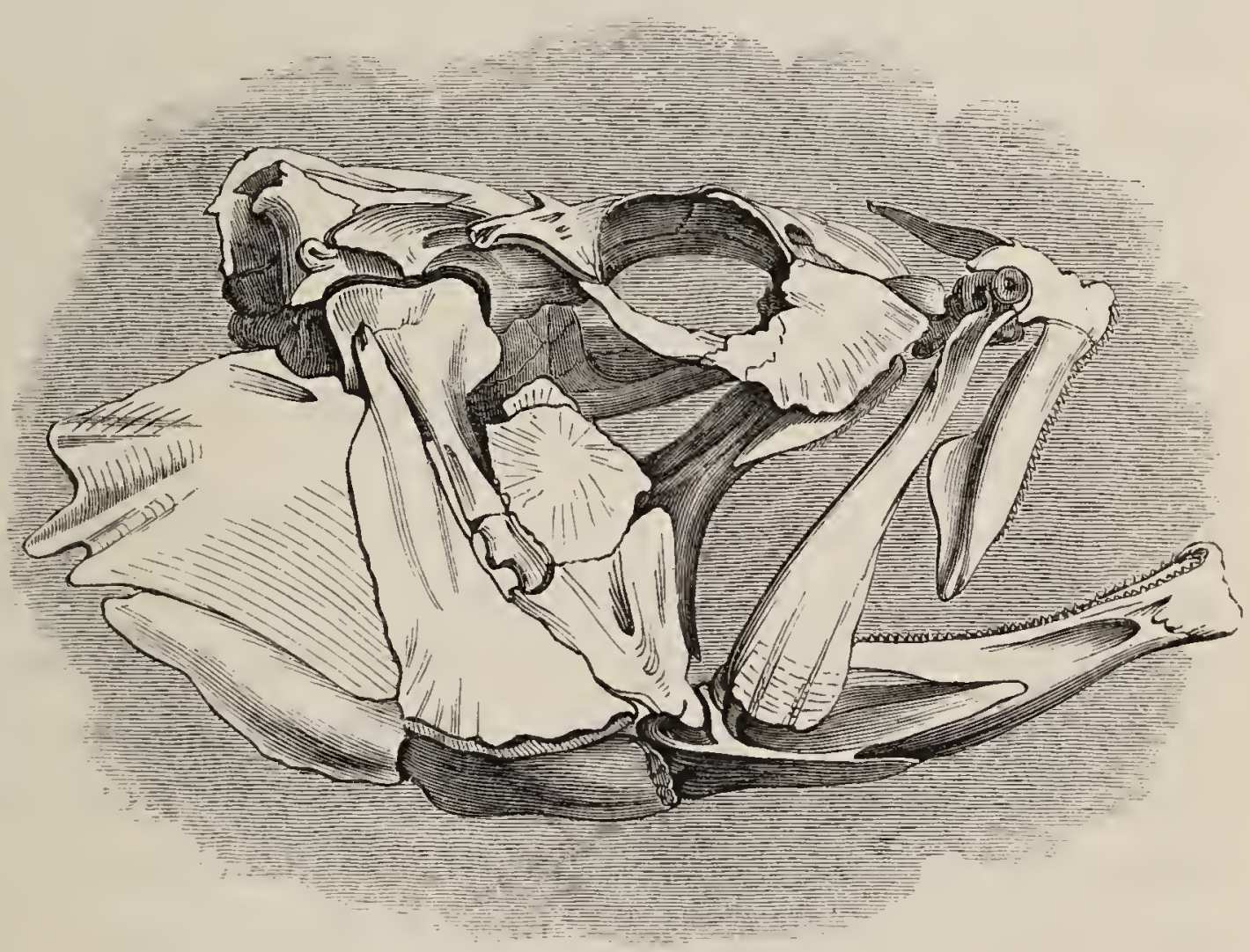




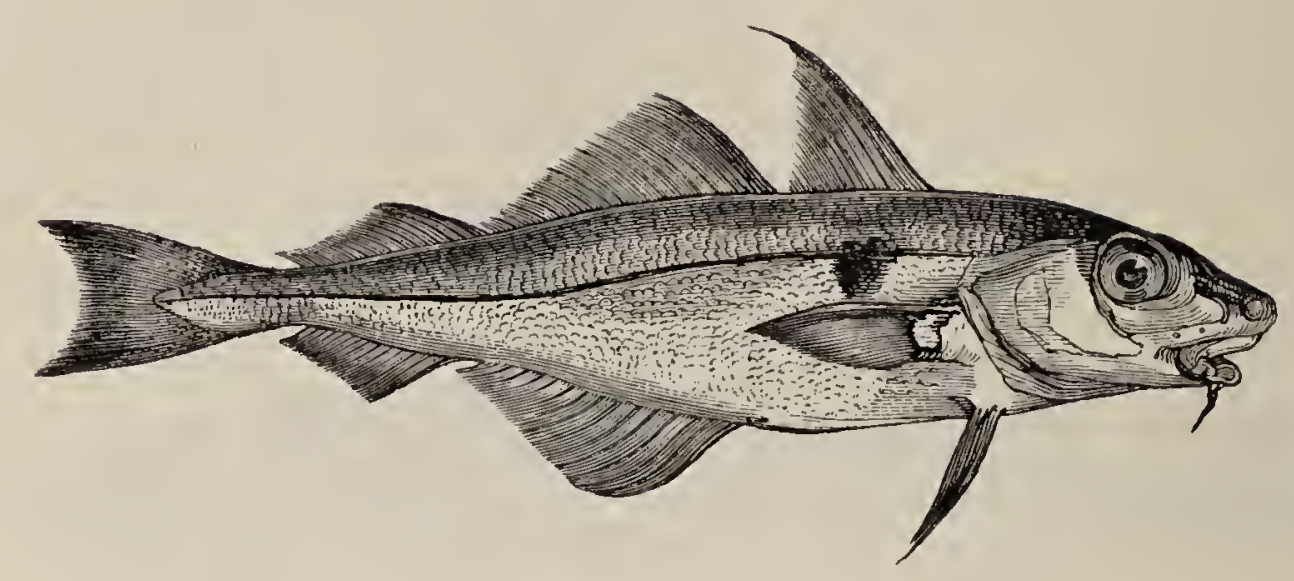

\title{
THE HADDOCK.
}

\author{
Haddie, Scotland. коLJa, Sweden.
}

Morvhua ceglefinus, Cuvier, Règne An. t. ii. p. 331.

\begin{tabular}{|c|c|c|c|}
\hline , & ," & Haddock, & FleM. Brit. An. p. 191, sp. 77. \\
\hline & , & Hadock, & Willughiy, p. 170, L. 2. \\
\hline Gadus & $"$ & LINNAUS. & BlocH, pt. ii. pl. 62. \\
\hline$"$ & , & Hadock, & Penn. Brit. Zool. vol. iii. p. 241. \\
\hline ", & , & Haddock, & Donov. Brit. Fish. pl. 59. \\
\hline ," & ", & ", & JENYNS, Brit. Vert. p. 441. \\
\hline
\end{tabular}

The Haddock is almost as well known as the Common Cod; and from the quantity taken at numerous localities round the coast, and the facility with which the flesh can be preserved, it is a fish of considerable value. Besides frequenting the coast of Great Britain, from the extreme north to the Land's End, the Haddock may be traced nearly all round the shores of Ireland; and the largest examples have been taken in Dublin Bay and off the Nymph Bank. Though ranging over a considerable space of sea both north and south of this country, the Haddock does not exist either in the Baltic or in the Mediterranean.

Haddocks swim in immense shoals, but are uncertain 
as to their re-appearance in places that they have formerly visited, and they are prone to change their ground after having arrived. The enormous consumption of food even in a short space of time, when the number of mouths is considered, may be one powerful reason for seeking new localities. They are probably more abundant along our eastern coast, from Yarmouth to the Tyne, than elsewhere. There they are caught with longlines and hand-lines, and the most attractive baits are pieces cut from the Herring or Sand-launce. Along our southern shore, where the trawl-net is constantly in use, the Haddock, feeding near the bottom, is frequently taken in the trawl. The most common weight of a Haddock is from two to four pounds. I have seen Haddocks of ten pounds' weight in the London market; the Brixham trawling-ground has produced Haddock of fourteen pounds; but the largest seen for many years past weighed sixteen pounds, and was taken in Dublin Bay.

Haddocks spawn in February and March, and the young are six inches long by the beginning of September. When kept in confinement in the salt-water preserve referred to in the account of the Common Cod, the Haddocks were found to be the tamest fishes in the pond, and took limpets one after another from the hand. Their food is small fish, crustacea, and almost any of the inferior animals of the deep, even the spiny Aphrodita. Mr. Thompson examined the stomachs of one hundred and nineteen Haddocks, and in one hundred and two he found fragments of Ophiurce, which in some quite filled the cavity of the viscus. He also found Nereida, Sea-urchins, and small fishes in some of the stomachs. The Haddocks are in the best condition for the table during the last three months of the year.

The French fishermen call the Haddock, Hadou, whence 
probably our name was derived. Pennant says, "Our countryman Turner suggested that the Haddock was the Onos or Asinus of the ancients. Different reasons have been assigned for giving this name to the species, some imagining it to be from the colour of the fish, others because it used to be carried on the backs of asses to market." A different reason appears to me more likely to have suggested the name: the dark mark on the shoulder of the Haddock very frequently crosses the ridge of the back and unites with the patch of the shoulder on the other side, forcibly reminding the observer of the dark stripe over the withers of the ass; and the superstition that assigns the mark in the Haddock to the impression St. Peter left with his finger and thumb when he took the tribute-money out of a fish of this species, which has been continued to the whole race of Haddocks ever since the miracle, may possibly have had its origin, in the obvious similarity of this mark on the Haddock and on the humble animal which had borne the Christian Saviour. That the reference to St. Peter is gratuitous, is shown by the fact that the Haddock does not exist in the sea of the country where the miracle was performed.

The length of the specimen described was twenty inches. The length of the head compared to the length of the body, without including the caudal rays, is as one to two and a half; the depth of the body less than the length of the head: the first dorsal fin commences directly over the origin of the pectorals; the second dorsal fin begins over the anal aperture, and ends nearly on the same plane with the first anal fin; the third dorsal fin, and the second anal fin, commence nearly on the same plane, but the base of the first is longer than that of the second: the caudal rays are rather long, and the tail is slightly forked. 
Rays. D. 15. 21. $19:$ P. $18:$ V. $6:$ A. 24. 18: C. 25 . Vertebræ 54.

The head slopes suddenly from the crown to the point of the nose; the upper jaw is much longer than the lower one, the nose projecting beyond the opening of the mouth, which is small; the barbel at the chin is small: the eye large, the diameter of the orbit being more than one-fourth of the whole length of the head; the irides are silvery and the pupil large, somewhat angular in form, and blue : the head, cheeks, back, and upper part of the sides are dull greyish white; the lower part of the sides and belly almost white, slightly mottled with grey; the body is covered with small scales; the lateral line strongly marked and black; under the middle of the first dorsal fin, but below the lateral line, there is a black patch, which in many specimens crosses the ridge of the back and unites with the mark on the other side; the dorsal fins and tail are dusky bluish grey; the pectoral, ventral, and anal fins lighter.

Dr. D. H. Storer, in his valuable Report on the Ichthyology of Massachusetts, says that immense shoals of the Haddock are found on that coast in the spring, and continue through the season until autumn.-Page 125.

The vignette represents a Scheveling fish-cart.

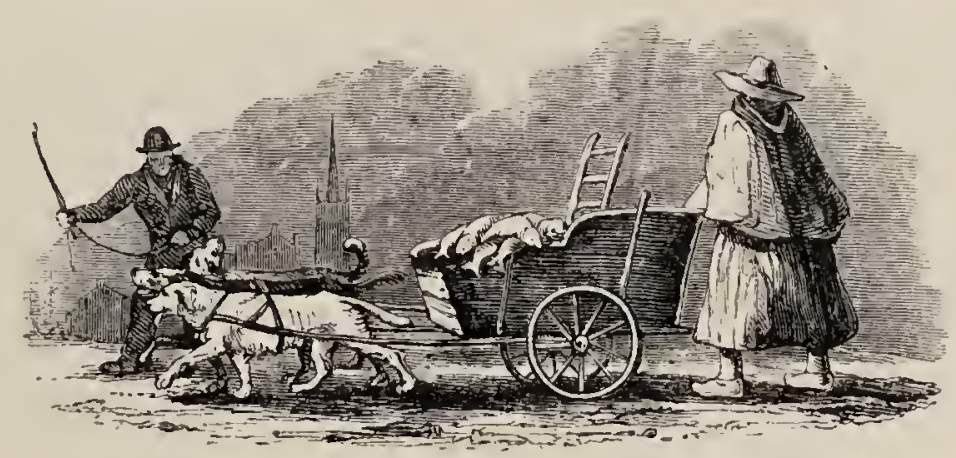




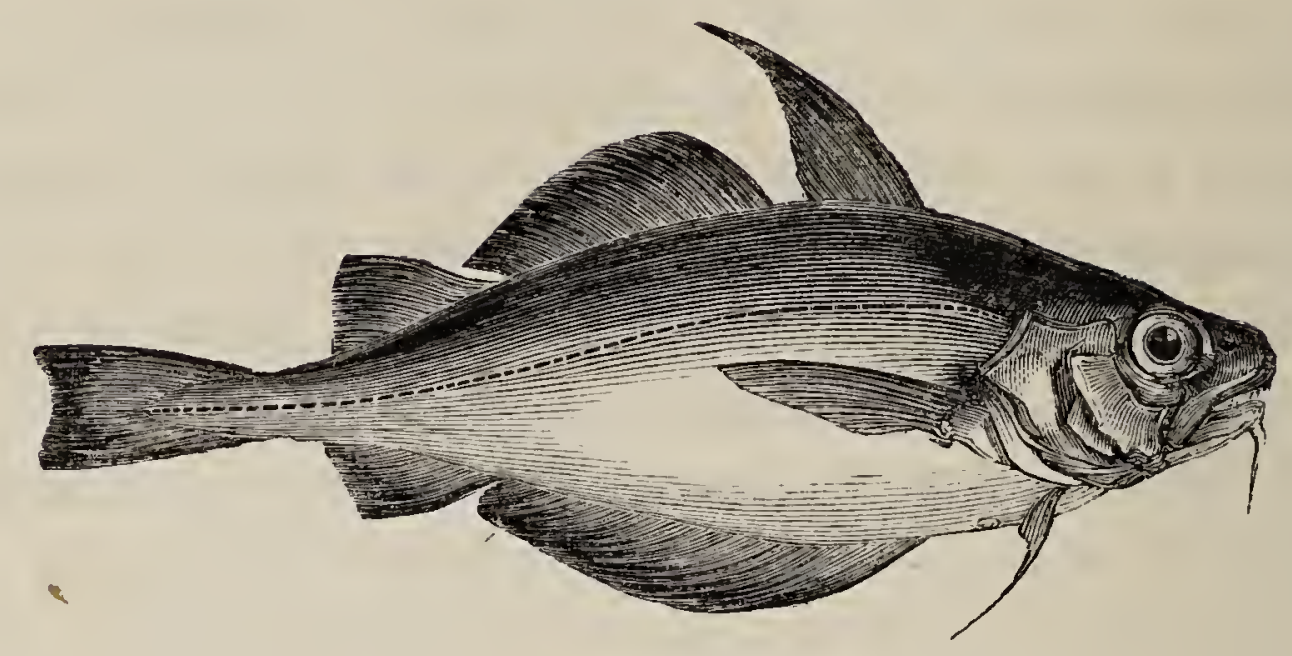

THE BIB, POUT, AND WHITING-POUT.

Smeltie, Zetland.-KLEG, Scarborough.-BLEns and BLInds, Devonshire and Cornwall.-skäGG-Torsk, Sweden.

Morrhua lusca, Bib, Fuem. Brit. An. p. 191, sp. 78.

," barbata, Pout, ,, ,, ,, , sp. 79.

Asellus luscus, Bib and Blinds, Willugribr, p. 169.

,, barbatus, Whiting-Pout, ,, App. 22, L. 4.

Gadus luscus, Linnwus.

,, barbatus, BLoch, pt. v. pl. 166.

", luscus, Bib, Penn. Brit. Zool. vol. iii. p. 247, pl. 34 .

" barbatus, Pout, ,, ,, ,, ,, p. 246.

, luscus, Bib, Donov. Brit. Fish. pl. 19.

, , , Bib or Pout, Jenxws, Brit. Vert. p. 442.

Willughby first described his Asellus luscus, under its Cornish names of Bib and Blinds; and Ray, in his Appendix to Willughby's work, which he edited, admitted from Martin Lister, as another species, the WhitingPout of the London market, not being aware that it was the same fish as the Bib of Cornwall. Ray kept them distinct in his own Synopsis, and was followed by Artedi, Linnæus, and others. Bloch, however, and 
Lacépède received neither into their works; and Pennant, though he gave each fish a place in his British Zoology, was inclined to consider them identical. The excellent figure of the fish given by Ray in Willughby's Ichthyology, the possession of specimens from various localities between Berwick Bay on the north-east, and Devonshire in the south-west, and a comparison of them with drawings by Mr. Couch of the Bib of Cornwall, convince me that the luscus and barbatus of authors are the same fish.

The Bib or Pout, though not abundant, is yet a wellknown species, which is found on many parts of our coast, particularly those that are rocky. Northward it appears to range as far as Greenland; and it is caught on the coasts of Norway and Sweden. It is taken at Zetland and in the Forth, where, as well as in Scotland generally, it is called the Brassy. I have received specimens from Dr. Johnston, taken at Berwick; and it occurs on the coast of Norfolk. It is common about the mouth of the Thames; and on the Dutch as well as the French coast. Along our southern shore as far west as Devonshire, it is very commonly taken in the trawl-nets; but on the rocky coast of Cornwall it is caught by a baited hook. It has been taken on the coast of Carnarvonshire, at Dublin, at Belfast, and Loch Foyle; and I have no doubt may be found all round the coast. "It is brought to Belfast market from the Antrim and Down coasts, under the name of Hen-fish, and in Galway Bay is called Crow-fish."-Thompson.

From a dark spot at the origin of the pectoral fin, in which it resembles the Whiting, one of its nost common names is Whiting-Pout; and from a singular power of inflating a membrane which covers the eyes and other parts about the head, which, when thus distended, have 
the appearance of bladders, it is called Pout, Bib, Blens, and Blinds.* The flesh is excellent; and, like most of the other fishes of this family, it is in the best condition for the table in November and December. Its food is small fish and various crustaceans allied to the shrimps. It is most frequently caught in spring, because it then approaches the shore for the purpose of spawning. The largest specimen I have seen measured in length sixteen inches.

The length of the head is to the whole length of the fish as one to four, while the depth of the body is greater than the length of the head, or compared to the whole length of the fish as one to three and a half; the first dorsal fin commences a little behind the origin of the pectoral fin, and has a base shorter than its longest ray: the rays of the second dorsal in are short, but its base is as long again as that of the first dorsal, and ends nearly on the same plane as the first anal fin ; the third dorsal fin is nearly as short as the first dor'sal, and is opposed throughout to the second anal fin. The ventral fins are considerably in advance of the pectorals, and their first two rays are elongated, and divided at the ends: the anal aperture is under the origin of the pectoral fins, but the cavity containing the intestines extends much farther back; the first anal fin commences nearly opposite the beginning of the first dorsal, and ends under the ending of the second dorsal; its middle rays are the longest, the others declining in length towards each extremity: the tail-fin is long, and the end of its rays nearly square.

Rays. D. 11. 20. $16:$ P. $18:$ V. 6: A. 33. $19:$ C. 21 . Vertebræ 48.

In the caudals of the fishes of this family there are

* Probably derived from Bleb and Blain, two old words meaning a blister or a bubble in the water. 
many short rays which are not counted, being outside the longest ray above and below.

In form the Whiting-Pout is the deepest for its length of the British Gadida: the upper jaw is the longest; the band of teeth consists of several rows, the outer ones being the tallest; on the mandible there is a single row; the barbel at the chin is rather long, and there are various mucous pores about both jaws: the eyes are large, and the orbits are covered with a loose membrane which the fish has the power of distending; the irides are orange-coloured: the dorsal and abdominal profiles exhibit considerable convexity; the body tapers rapidly from behind the second dorsal and first anal fins: the colour of the head, back, upper fins, and upper part of the sides, is a light yellowish brown, with dusky clouds becoming lighter on the belly, and tinged in places with bluish grey; at the base of the pectoral fins there is a black spot, the anterior anal fin and the ventrals are opaque white and a white band edged with black borders the caudal: the scales are small and deciduous: the lateral line is straight posteriorly, and then rises in a curve over the pectoral fin; all the fins, except the ventrals, are dusky brown; but the first anal fin in largesized specimens is edged with fine blue. When newly taken from the water this fish has a golden metallic lustre deepening into a copper tint at certain seasons. The darker clouds which generally assume a striped arrangement disappear from the body very soon after death. 


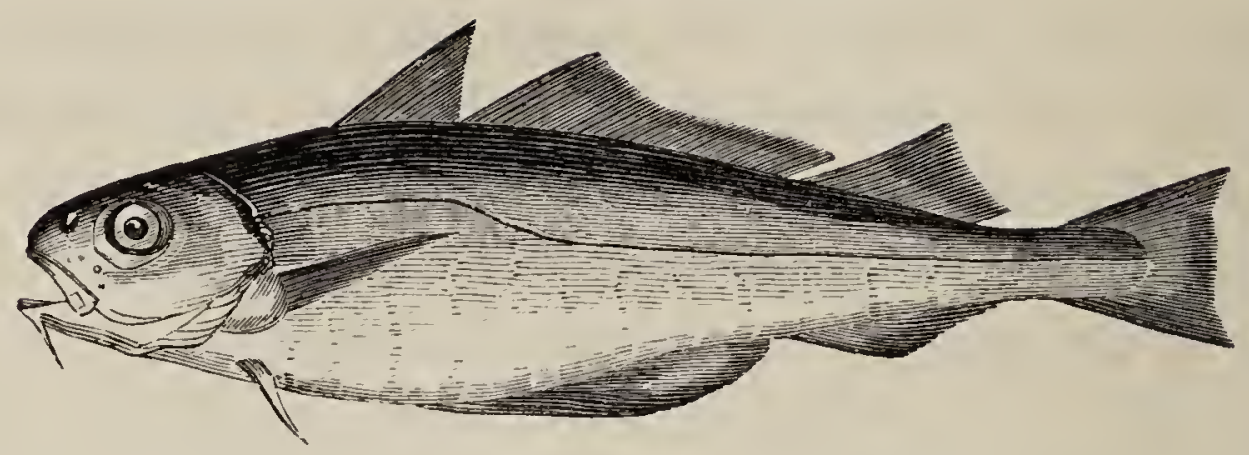

\section{THE POOR, OR POWER COD.}

Bibben-Pout, Cornwall.-GLYsa and GLyskolja, Sweden.

Morrha minuta, Poor, FleM. Brit. An. p. 191, sp. 80.

Gadus minutus, Linneus. Bloch, pt. ii. pl. 67, fig. 1.

, , $\quad$ Power, Penn. Brit. Zool. vol. iii. p. 249, pl. 34.

, , " WillughbY, p. 171.

,, , RAY, Syn. p. 163, fig. 6 .

, , Poor, Jenys, Brit. Vert. pp. 444.

,, , Fries och Ekstrom, Skand. Fisk. pl. 17.

The Poor, or Power Cod, though somewhat similar in general appearance to the Pout last described, and like it in having a depth of body greater than the length of the head, is yet readily to be distinguished from it by several well-marked characters. It is not so deep when of the same length; the first anal fin does not begin so far forward as in the Pout by nearly the whole length of the base of the first dorsal fin; the longest rays of the third dorsal fin and the second anal fin are shorter than the bases of the respective fins, and do not, therefore, produce the same vertically-truncated appearance as in the same relative fins of the Pout; and the barbel at the chin is much shorter. 
The Power, or Poor Cod, the smallest of its genus, so called, it is said, on account of its diminutive size, seldom exceeding six or seven inches in length, and therefore comparatively of little value, was first described as an English fish by Dr. Jago, of Cornwall, and was introduced by Ray at the end of his Synopsis, with a figure that particularly exhibits the specific distinctions afforded by the form and situation of the fins, already adverted to, and by which it may be immediately recognised.

Bloch says that the appearance of this fish in the Baltic is a source of pleasure to the fishermen. It is called the fish-conductor; and excites great hopes of a rich harvest in the capture of the larger species of the genus, the Cod, and others, which follow in the rear, preying relentlessly on their more diminutive generic companions: the fishermen, in their turn, prey upon them.

According to $\mathrm{Mr}$. Couch it frequents the edges of rocks, is caught by the hook, and, though always good for the table, is, on account of its small size, chiefly used for bait. Montagu says it is taken frequently on the Devonshire coast with the hook, and also in the crab-pots. In the nets worked on that coast it is caught along with the Bib, the fishermen selling both as Whiting Pout.

It is included by Mr. Thompson in his catalogue of the Fishes of Ireland, as occurring on various parts of the coast, both in the north and south, at all seasons of the year. It feeds, he says, chiefly on crustaceans. The Norwegian fishermen assert that this fish remains in sculls in certain localities all the year, and is not generally diffused along the coast. Unless the fishermen know the spots they inhabit they seldom take them. Mr. Harris of Gamrie, Banffshire, in a note communicated to the Zoologist (p. 4261), says that it is an abundant fish on that 
coast; and Dr. Baikie records it in his list of Orkney fishes.

Dr. Storer, in his Report, already referred to, and frequently quoted in reference to American fishes, says that this species has been taken once in the harbour of Boston, but had not been previously noticed on the American shores.

The length of the head compared to the whole length of the fish is as one to five; the depth of the body rather more than the length of the head: the first dorsal fin begins behind the origin of the pectorals: the longest ray being as long as the base of the fin: the second dorsal fin begins and ends on the same planes with the first anal fin, and the base of the second dorsal fin is as long again as the base of the first dorsal fin; while the base of the third dorsal fin is rather more than half as long as that of the second; the third dorsal and the second anal fins begin and end on the same planes, and the peculiarity of their forms has been referred to. The vent, or anal aperture, is under the most posterior portion of the first dorsal fin, and the first anal fin begins immediately behind the vent, and under the commencement of the second dorsal fin; the second anal fin has been noticed; the tail is long, with the rays slightly forked. The number of fin-rays :-

D. $12.19 .17:$ P. $14:$ V. $6 \cdot$ A. $25.17:$ C. 18.

The head is short and the nose blunt: the barbel at the chin is neither so long nor so slender as in the Pout; several mucous pores exist about the mouth: the eye is large, its breadth being equal to one-third of the length of the head, and the irides are orange-coloured: the scales of the body are minute and deciduous, and 
the lateral line is but slightly curved, and only where it rises over the pectoral fin: the upper parts of the head and back are brownish yellow, becoming lighter on the cheeks and sides; the belly is dirty white; the pectoral, dorsal, and caudal fins are yellow brown, darker at the edges; the ventral and anal fins dirty yellowish white.

The vignette represents a Folkstone fisherman selling his fish by auction on the beach after landing. This is done, according to the Dutch fashion, by lowering the price demanded for the lot till a bid is made, when the bargain is struck by dropping the shingle, which is held, as represented, between the fore-finger and thumb.

Folkstone Beach.

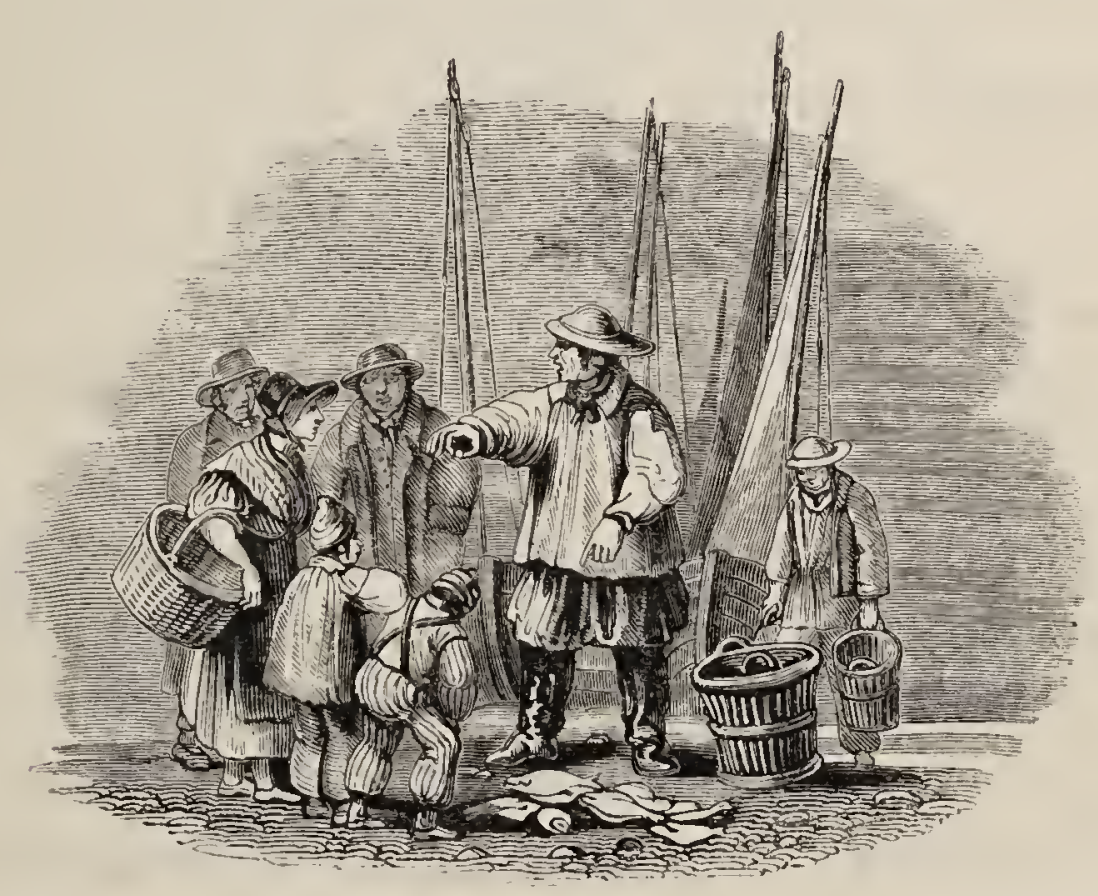




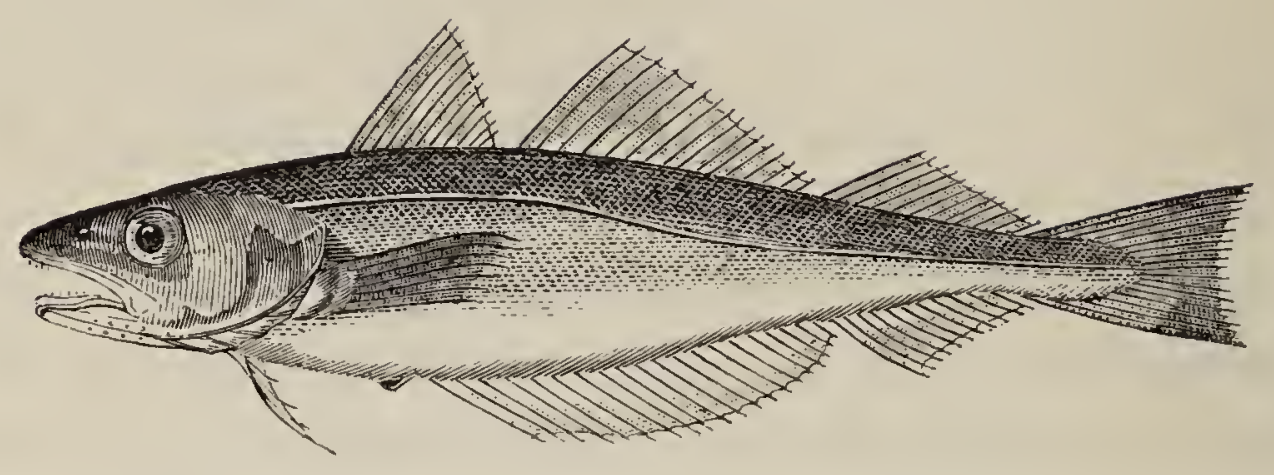

\title{
THE WHITING.
}

\author{
HVITLIN $\dot{G}$, Sweden.
}

Merlangus vulgaris, Cuvier, Règne An. t. ii. p. 332.

, , Whiting, FleM. Brit. An. p. 195, sp. 91.

, , , Willughis, p. 170, L. 5 .

Gadus merlangus, Linnaus. Bloch, pt. ii. pl. 65.

," , Whiting, PENN. Brit. Zool. vol. iii. p. 255.

," , , $\quad$, Donov. Brit. Fish. pl. 36.

," $\quad$ Fries och Eкströм, Skand. Fisk. pl. 18.

Merlangus vulgaris, Jenxes, Brit. Vert. p. 445.

Meriangus. Generic Characters. -The same as those of Morrhua, except that they have no barbel at the chin.

The Whiting is well known for the excellence of its flesh, surpassing in delicacy that of any of the other species of the valuable family of fishes to which it belongs: the pearly whiteness of its flaky muscles, added to its extreme lightness as an article of food, recommend it particularly to invalids who are unable to digest more solid nutriment.

It is caught in great abundance almost all round our coasts, and may be traced from the Orkneys to Cape 
Clear. Whitings of several pounds' weight have been caught as far north as the Dogger Bank; they have been taken also of nearly equal size on the coast of Cornwall; and on the Nymph Bank, along the extended line of the south coast of Ireland. In that country they are found commonly all round the coast. It is a less social fish than others of the family except in spawning time, when it assembles in sculls.

The fishing for Whiting with lines is pursued nearly all the year through; but the fish is most plentiful in the months of January and February, when it comes in large sculls towards the shore for the purpose of depositing its spawn, and is taken in abundance within half a mile, and seldom exceeding three miles, from land. A much larger quantity than is consumed while fresh being frequently taken, a portion is easily preserved either by salting or drying.

The Whiting is a voracious feeder, and seizes indiscriminately any of the mollusca, worms, small crustacea, and young fishes. I remember to have taken several Sprats from the stomach of a Whiting; and Mr. Couch has known four full-grown Pilchards taken from the inside of a Whiting that weighed four pounds. It appears to prefer sandy banks, but shifts its ground frequently in pursuit of the various fry of other fishes, upon which it principally subsists.

? Though occasionally occurring in the London market of three or four pounds' weight, the most usual size is from twelve to sixteen inches in length, and weighing about one pound and a half.

The length of the head compared to that of the body alone is as one to three; the depth of the body not equal to the length of the head, or compared to the whole length as one to six. The first dorsal begins behind the 
origin of the pectorals and before the vent; the second dorsal and first anal fins end on the same line; the third dorsal and second anal fins begin and end on the same planes; the ventral fins are placed very forward: their second ray is elongated: the anal aperture is under the middle of the first dorsal fin; and the first anal fin commences just behind the vent; the tail is elongated, with the end nearly square. The fin-rays are-

\section{13. 19. $18:$ P. $10:$ V. $6:$ A. $31.20:$ C. 30 . Vertebræ 55.}

The body of the Whiting, like the bodies of the Gadide of this division, is longer for its depth than that of the Codfish; the scales are small, oval, and deciduous; the lateral line is dark and straight posteriorly, but rising gradually throughout the anterior half; the head is elongated; the mouth and gape are large: the tongue is white and smooth; the upper jaw is decidedly the longest, and has one row of large and sharp-pointed teeth on the outer edge, and several rows of smaller ones within; the vomer has a few teeth arranged in a semicircular line on the anterior part; the lower jaw shows various mucous orifices along its under surface, and has a single row of sharp teeth along the upper outer edge, which, when the mouth is closed, range within the outer row of teeth on the upper jaw : the eye is in diameter less than one-fourth of the head, and is placed more than its breadth from the end of the nose; the irides are silvery; the pupils blue. The upper parts of the head and the back above the lateral line are pale reddish ash-brown; the sides and belly silvery white; the pectoral, caudal, and dorsal fins are pale brown; the ventral and anal fins almost white; the pectoral fins have each a decided dark patch at the base. 


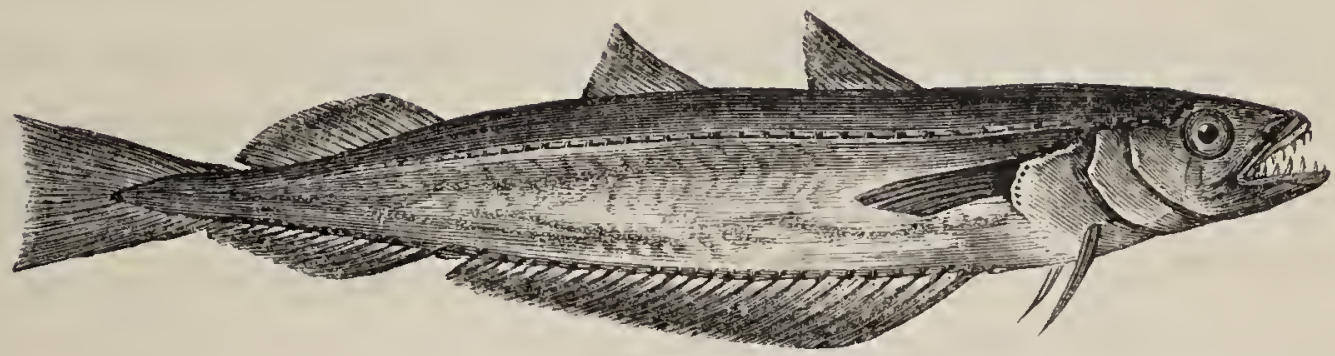

\section{COUCH'S WHITING.}

\section{Merlangus albus.}

Gadus albus, Risso, Ichth. p. 115.

Merlangus poutassou, ,, Hist. vol. iii. p. 227.

In the month of May 1840 I received a communication from Mr. Couch of Polperro, to the following effect:"On the 5th of this month I had the good fortune to procure a new species of the Gadida,-new at least to Britain: it is the species described by M. Risso in his Ichthyology of Nice, page 115, and suspected by him not to be the Whiting of the Northern ocean, from which, indeed, it differs in several decisive particulars."

Mr. R. Q. Couch saw one other specimen taken by a Polperro fisherman, and remarks that it was less dark than the figure in British Fishes.-Zoologist, p. 1824.

M. Risso makes but few observations upon this fish either in his single volume on the Ichthyology of Nice, published in 1810, or in his Natural History of the Productions of the Environs of Nice, published in five volumes in 1826. He says it inhabits the sea of Nice, and is taken at all seasons; that it spawns in the spring, and that its flesh is rather soft. This quality of the flesh 
of the Whiting of the Mediterranean was mentioned to me by Dr. Lush, the superintendent of the Botanic Garden at Bombay, on his recent visit to this country. M. Risso, in his Ichthyology, refers for an illustration of his fish to Bloch's plate 65, which is that of our wellknown and common Whiting; but a glance at the two figures here given will show the distinctions, which $M$. Risso was aware of, as he adds, "this fish appears to me to be a new species: I invite naturalists to compare it with those of the Northern seas."

The fin-rays, as given by M. Risso in the two works already quoted, and by $\mathrm{Mr}$. Couch, are as follows :-

D. 12. 12. 22 : P. 18 : V. $7:$ A. 28. $20:$ C. 38 . Hist.

D. 12. 10. 20 : P. 20 : V. $6:$ A. 34.22 : C. 36 . Ichth.

D. 13. 12. 22 : P. 20 : V. 6: A. 35. 25. Vertebre 53. Couch.

Mr. Couch's description is as follows :-

"Length fifteen inches; the depth in a straight line, two inches and a half: from the base of the first dorsal fin to the vent, along the curve, three inches; from the mouth to the edge of the gill-covers, three inches; from the same to the anterior edge of the eye, one inch; the eye large, the form a perpendicular oval; under jaw the longest, the pre-maxillary bones terminal, the snout receding backward from them, contrary to the form of the Whiting, in which the upper jaw is under a projection; the general form of the body resembles that of a Whiting, but is rather more slender; the back rounded as if the specimen was plump, thus showing its slender form not to be the result of emaciation; teetl in the jaws as in the Whiting; on the roof of the mouth a pair of prominent, sharp, incurved teeth ; lateral line straight, and passing near the back; another line along the middle of the body formed by the meeting of the muscles; the body ending arrow-shaped at the caudal fin; the first 
dorsal fin begins over the posterior third of the pectoral; the second dorsal fin is like the first in form and elevation, both being triangular; between them there is a space about equal to their separate breadth and nearly twice this breadth interposes between the second and the third dorsal fins; the beginning of the third dorsal fin is slightly anterior to that of the second anal fin; caudal fin shaped as in the Whiting, but less wide; the pectoral fin ends opposite the middle of the first dorsal fin; ventral fins small and slender, placed rather high on the side, and much like those of the Whiting Pollack (Merlangus Pollachius); the longest ray measures seven-eighths of an inch; from the point of the under jaw to the vent, four inches and one quarter; from the centre of the vent to the commencement of the first anal fin, one quarter of an inch; first anal fin long, widest in the middle; the second anal longer than the third dorsal, both end close to the caudal fin : colour brown; belly white; a dark spot at the upper margin of the pectoral fin; along the base of the anal fin a broad white band; no such band at their margin. The distinctions between this fish and the Whiting are obvious, in the jaws, fins, lateral line, colour, and vertebræ. The brilliant white along the base of the anal fins remained unaltered, after the brilliancy of all beside had considerably changed. The muscular substance of the fish was more pulpy than that of the Whiting. It was taken with an ordinary bait, at a few miles from land."

The figure given at the head of this subject was carefully reduced from the drawing sent to me by $\mathrm{Mr}$. Couch, who deserves my sincere acknowledgment and thanks for his obliging communication. 


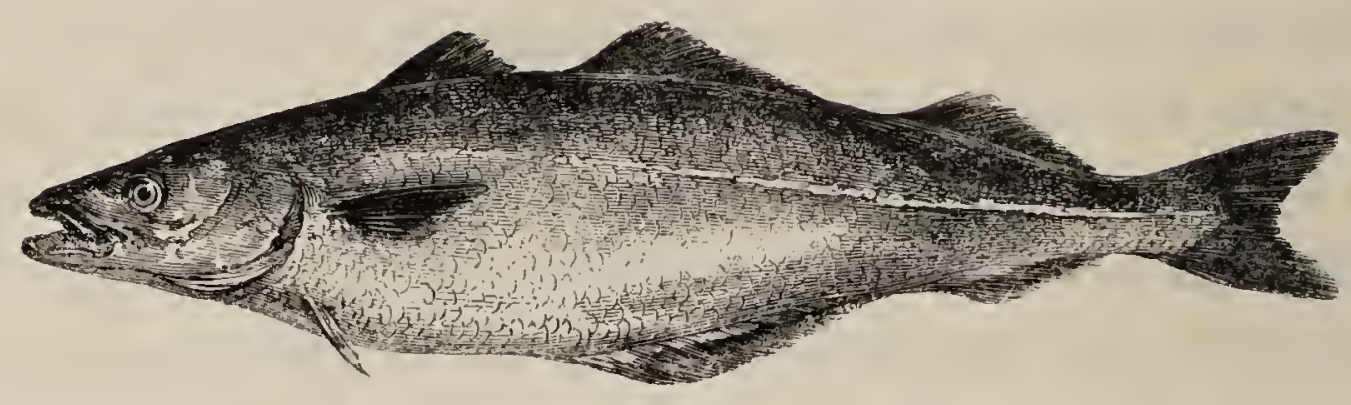

THE COALFISH.

raUner, Cornwall.-GRA-SEY, Sweden.-RotskJEk, Norway.

Merlangus carbonarius, Cuvier, Règne An. t. ii. p. 332.

\begin{tabular}{|c|c|c|c|}
\hline , & ," & Coalfish, & , Flen. Brit. An. p. 195, sp. 93. \\
\hline & , & Colefish, & Willughbi, p. 168, L. 3 . \\
\hline & , & Coalfish, & $\begin{array}{l}\text { Linnaus. Bloch, pt. ii. pl. } 6 \\
\text { Penn. Brit. Zool. vol. iii. p. } 25\end{array}$ \\
\hline & $"$ & seng & Donov. Brit. Fish, pl. 13. \\
\hline erlc & 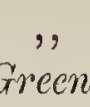 & $"$ & $\begin{array}{l}\text { Jennns, Brit. Vert. p. } 446 . \\
\text { Penn. Brit. Zool. iii. p. } 253\end{array}$ \\
\hline
\end{tabular}

The Coalfish is most decidedly a northern Fish, but, being a hardy species, is not without considerable range to the southward. It was the only fish found by Lord Mulgrave on the shores of Spitzbergen ; and the fry, under four or five inches in length, were canght with the trawlnet on the west coast of Davis's Straits, during the first voyage of Captain Sir Edward Parry. It is found on the coast of the United States. It abounds in all the northern seas and in the Baltic, and may be said to swarm in the Orkneys, where the fry all the months of summer and autumn are the great support of the poor. Dr. Neill, in his tour of the islands of Orkney and Shetland, saw an 
old man, and perhaps one or two boys, seated upon almost every projecting rock, holding in each hand a wand or fishing-rod, and catching young Coalfish as fast as they could bait their hooks. Both young and old come more to the surface than their congeners, and bite eagerly at a white feather.

As an article of food, the Coalfish is more prized when small than when of large size. The flesh of specimens weighing from fifteen to thirty pounds is usually preserved, either salted or dried.

This fish has more provincial names than any other species, some of which only refer to it when of a particular size. Among the Scotch islands, the Coalfish is called Sillock, Piltock, Cooth or Kuth, Harbin, Cudden, Sethe, Sey, and Grey-Lord. In Edinburgh and about the Forth, the young are termed Podleys; at Newcastle the fry are named Coalsey; and, when twelve inches long, Poodlers. Many are caught along shore; and frequently, also, from a boat rowed gently, the angler using a rod in each hand, and trailing a fly from each line.

Mr. Couch says, "They are in the highest condition from October to December, at which season they prowl after prey in large companies, which when met with prove a valuable capture to the fishermen: for though but coarse food, yet being wholesome, substantial, and cheap, they are eagerly purchased by the poor, either fresh or salted. They swim at no great depth, and with great rapidity; but when attracted by bait, will keep near a boat until all are taken; and I have known four men with two boats, two men in each boat, take twenty-four hundred-weight with lines in a very few hours. The season for spawning is early in spring; immediately after which this fish becomes so lank as to be worthless, in which state it continues through the summer." Mr. R. Q. Couch says, "that 
the Coalfish are found assembling in strong currents under shelter of a rock, from whence they rush out to seize food of any kind, living or dead, which the stream is carrying past."-Zoologist, p. 1824.

In the Orkneys, according to $\mathrm{Mr}$. Low, the young appear about May; in the Tyne, about June; and on the Cornish coast in July. The adult fish are called Rauning Pollacks by the Cornish fishermen: rauning being the ancient and even the modern vernacular pronunciation of ravening, used in reference to voracity. Mr. Thompson and Dr. Drummond found the stomachs of Coalfish most frequently filled with small Crustaceans, such as Idotece and Onisci; occasionally also they held one or two shelly mollusks. They are said to swim in shoals after Herrings and to destroy many.

The Coalfish may be traced on the Irish coast from Waterford along the eastern shore to Belfast, under the various names of Black Pollack, Blockin, and Grey-Lord; and it is very abundant on the western and northern coasts of Scotland.

When detained and well fed in a salt-water pond, Coalfish acquire large size. "They were bold and familiar; floating about slowly and majestically, till some food was thrown to them; this they seized voraciously, whether it consisted of shell-fish or ship-biscuit. They would also occasionally approach the margin and take food from the hand."-Jesse's Gleanings.

In Scandinavia the adult fish are dried and sold under the names of Gråsida and Stockfisk.

From the point of the lower jaw to the end of the operculum, the length is to that of the body and tail as one to three and a half; the depth of the body about equal to the length of the head: the first dorsal fin begins behind the origin of the pectoral fin and before the 
line of the vent; the second dorsal and the first anal fins end together nearly on the same plane; the third dorsal and second anal fins are nearly parallel: the fleshy portion of the tail is elongated; the rays forked: the ventral fins are small; and the rays of the pectoral fin extend no farther than the line of the vent. The finrays are-

\section{11. 20. 20: P. 19 : V. 6: A. 24. $19:$ C. 32.}

The head and body are elegantly shaped; the scales small and oblong; the lateral line is silvery white and nearly straight; the upper parts of the head and the back above the lateral line are almost black; but the colour below the line is much lighter, becoming greyish white with golden reflections on the sides and belly; the pectoral, caudal, and dorsal fins, are bluish black; the ventral and anal fins greyish white: the upper jaw is rather the shortest; the lips are tinged with purple red: the mouth is black and the teeth very small; the irides silvery white, and the pupil blue.

\section{Young Coal-Fish or Green Cod.}

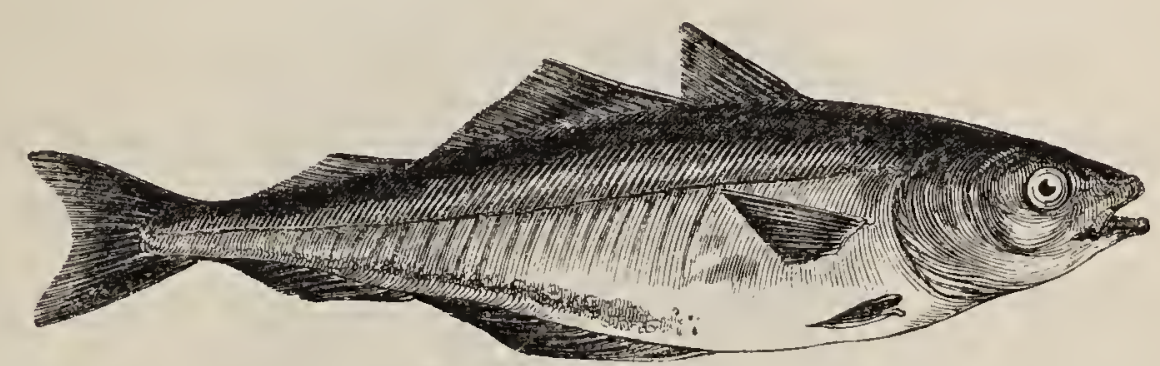

The Green Cod was added to the catalogue of British Fishes as a distinct species by Pennant, but its title to that rank has been often doubted. Mr. Thompson says, "I have often looked for this fish and have obtained examples, agreeing with the brief descriptions of British authors, but they were nothing more than Merlangus car- 
bonarius." - Nat. Hist of Ireland. It was introduced into the former editions of this work on the authority of British ichthyologists who preceded us, and especially of Professors Nillsson and Reinhardt who have devoted so much attention to the Fishes of Scandinavia, but we have never been able to procure a specimen that differed specifically from the common Coalfish. Ekström says, "there is no distinctive difference between Gadus carbonarius and Gadus virens, which are merely the adult and immature fish of one species. The roe and milt of Gadus virens are not developed, as Duhamel long ago remarked."-Skand. Fiskar. 'The weight of authority being against the claim of the Green Cod to rank as a distinct species, the figure merely is reproduced here to keep up the attention of British ichthyologists to the subject.

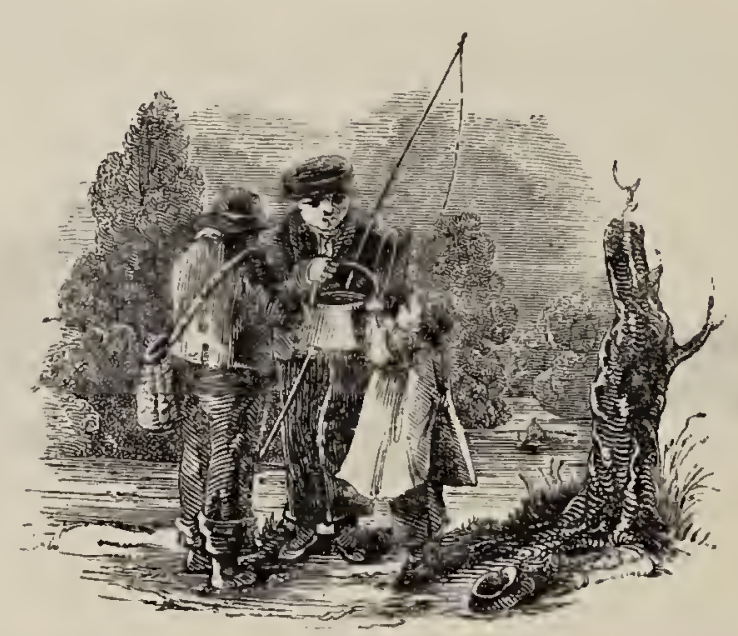




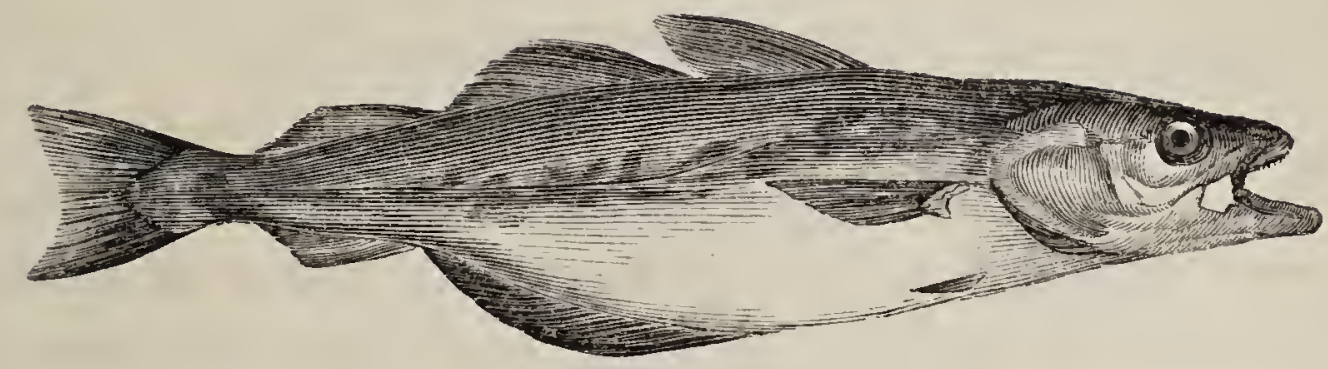

\title{
THE POLLACK.
}

\author{
Whiting POLLACK.-LYTHE, Scotland.- \\ LYR-TORSK, Sweden.
}

\begin{abstract}
Merlangus pollachirus, Cuvier, Règne An. t. ii. p. 333.

\begin{tabular}{|c|c|c|}
\hline ,' &, & Pollack; Flem. Brit. An. p. 195, sp. 92. \\
\hline & , & Whiting Pollack, WiLuughву, p. 167. \\
\hline Gadus & ", & LINN aus. BLOCH, pt. ii. pl. 68. \\
\hline$"$ & , & Pollack, Penn. Brit. Zool. vol. iii. p. 254. \\
\hline Merlangus & , & $\begin{array}{l}\text { Whiting Pollack, Donov. Brit. Fish. pl. } 7 . \\
\text { Pollack, Jenrs, Brit. Vert. p. } 446 .\end{array}$ \\
\hline
\end{tabular}
\end{abstract}

The Pollack is much less abundant on some parts of the coast than the Coalfish; but, like that species, is an inhabitant of the seas all round our shores. Mr. Low, in his "Natural History of the Orkneys," says, "They are frequently caught close in with the shore, almoss among the sea-ware, and in deep holes among the rocks. They seem to be very frolicsome, and I have been several times fishing for them when they would keep a constant plashing in the water. They bite keenly, scarce allowing the hook to be in the water before one or other jumps at it. They are better eating than the Coalfish; but I do not know whether they are ever dried or preserved otherwise, as the quantity caught is scarce worth curing." Hand-line fishing for Pollacks, Mackerel, \&c. is called whiffing 
This fish is named Lythe in Scotland, as already quoted, doubtless from its nimbleness and pliancy which the word signifies. Fine specimens of the Pollack are taken about the rocky coast of Scarborough, where they are called Leets.

The Pollack is caught at Hastings and Weymouth. Colonel Montagu says it is frequently taken in Devonshire, where it is bought by the inexperienced as Whiting. When only twelve or fourteen inches long, the flesh possesses a considerable portion of the pearly appearance and delicacy of that fish.

Mr. Couch says, "The Pollack is at all seasons one of our most common fishes, but it is not gregarious except in pursuit of prey; and it rarely wanders far from its usual haunts, which are along the edges of rocks, where, with the head directed towards the coming tide, it is ready for any prey that approaches. The smaller ones, which occupy such a station covered with oreweed, have their colours very bright, and the belly of a saffron yellow; while on clean ground they are less brilliant. In summer evenings, they are often seen, when eager in pursuit of the Sandlaunce, to spring frequently from their element, and they are often taken by anglers from the rocks and piers. The Pollack spawns in winter near the land; and the young abound near the edge of the tide in rocky ground at the beginning of summer."

In Ireland, the Pollack may be traced as occurring on the coast of the counties of Cork, Waterford, Dublin, Antrim, Londonderry, and Donegal, under the names of Pollack, Laith, and Lythe. Though considered to be superior to the Coalfish as an article of food, both, $\mathrm{Mr}$. Thompson says, are sold at a low price. This gentleman bought one in the Belfast market, which weighed.twenty pounds. It was caught in Lough Isarne. 
The length of the head compared to that of the body is as one to three and a half, and the depth of the body is to the whole length of the fish as one to four and a half: the first dorsal fin begins, as in the Coalfish, behind the origin of the pectoral fin, and before the vent; the second dorsal fin and the first anal fin end on the same line; the third dorsal fin and the second anal fin begin and end very nearly on the same plane; the first ray of each of the dorsal fins is the longest; the ventral fin is very small, and the anal aperture is under the middle of the first dorsal fin; the fleshy portion of the tail is long and slender; the end of the rays concave. The fin-rays in number are-

D. 12. 19. 15: P. $19:$ V. $6:$ A. 24. $16:$ C. 31.

The lower jaw is by much the longest, by which and by the curve of the lateral line the species is readily distinguished from its congeners; the mouth and lips are red, with various mucous orifices about them; the irides are silvery; the sclerotic coat cartilaginous; the upper angle of the operculum is produced; the body elongated; the upper parts of the head and the back above the lateral line are olive brown; the sides dull silvery white mottled with yellow, and in young fish spotted with dull red; the lateral line is dusky, and it is curved over the length of the pectoral fin, then descending and passing in a straight line to the tail fin; the dorsal and caudal fins are brown; the pectoral and anal fins brown-edged and tinged with reddish orange.

In December 1839, my kind friend, Robert Ball, Esq. of Dublin, sent me notice of a curious monstrosity observed in a Pollack caught during the previous spring, consisting in the great elongation of the rays of the first dorsal fin, which had grown to more than three times their usual length.

VOL. I. 


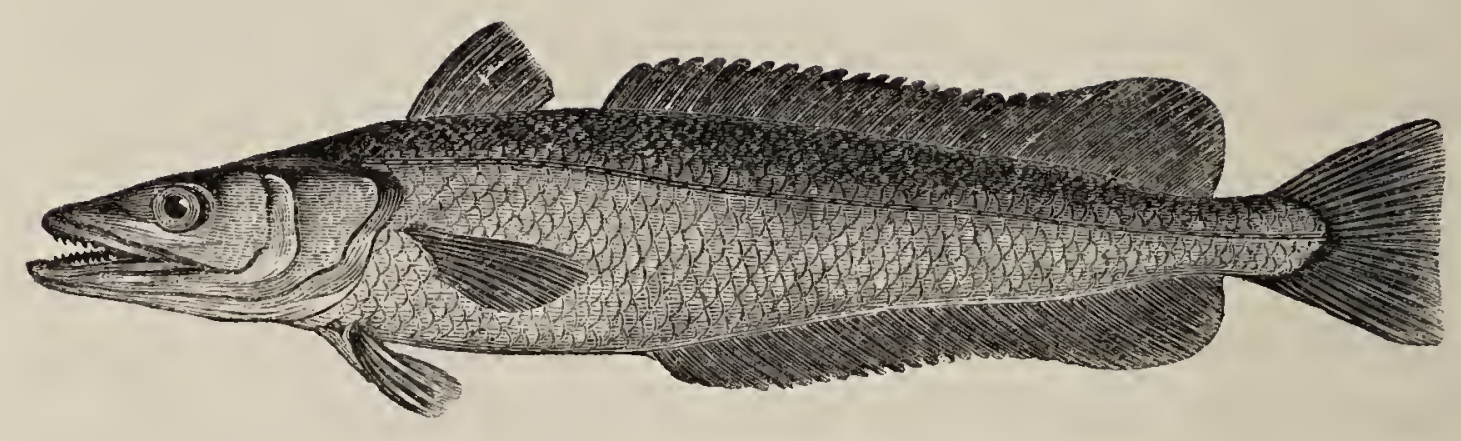

THE HAKE.

cegddu, Wales.-кummer, Sweden.

Merlucius vulgaris, Cuvien, Règne An. t. ii. p. 333.

", , Common Hake, Flem. Brit. An. p. 195, sp. 95.

", The Hake, Willughibr, p. 174.

Gadus Merlucius, Linneus. Bloch, pt. v. pl. 164.

," Hake, Penn. Brit. Zool. vol. iii. p. 257.

", ", Dovov. Brit. Fish. pl. 28.

Merlucius vulgaris, Common Hake, Jenxws, Brit. Vert. p. 447.

", " Kummel, Fries och Ekström, pl. 33.

Mrrudcius. Generic Characters. - The head flattened; the body elongated; two dorsal fins; the first short, the second long; one anal fin, also very long; no barbel at the chin. Teeth larger than in most of the family, and nearly uniserial.

The HaKe is another of the species belonging to this large and valuable family of fishes, which has an extensive range, being found in the seas of the North of Europe, and also in the Mediterranean.

Though frequenting the western coast of Norway, and included by Linnæus in his Fauna Suecica, Dr. Fleming says it is rare in Scotland; and it appears to be most abundant along the southern coast of England. Portsmouth market receives an ample supply, which 
is brought by fishing-boats from the Devonshire coast; and Montagu says there is also an abundance in the market of Plymouth.

According to Mr. Couch, "The Hake is a roving fish on the Cornish coast, without much regularity in its movements. From January to April, which is its season for spawning, it keeps near the bottom, and loses the great voracity by which it is characterized at other times, so that multitudes are caught in trawls, and but few with a line; but, when Pilchards approach the shores, it follows them, in incalculable numbers through the winter. It rarely happens that Pilchards are taken in a sean without many IIakes being enclosed with them; and thus, when the net remains in the water for several days, the captive Hakes have an opportunity of glutting themselves to their heart's desire, which is to such an extent as to render them helpless, and I have seen seventeen Pilchards taken from the stomach of an ordinary-sized Hake. Their digestion, however, is quick, so that they speedily get rid of their load; and fishermen observe that, when hooked, the Hake presently evacuates the contents of the stomach to facilitate its escape; so that when hundreds are taken with a line, in the midst of prey, not one will have anything in its stomach: when near the surface, however, this rejection does not take place until after they are dragged on board."

The Hake may be traced nearly all round the coast of Ireland; and is so abundant in the Bay of Galway, that, according to a recent writer, this bay is named in some ancient maps the Bay of Hakes. On the Nymph Bank off the coast of Waterford, this fish is also so plentiful, that one thousand have been taken by six men with lines in one night. It is a voracious fish, as its systematic name of merlucius (Seapike) implies, and it is a 
coarse fish, not admitted to the tables of the wealthy; but large quantities are annually preserved both by salting and drying, part of which is exported to Spain, and even in its fresh state when properly cooked it is a firm good fish. The mode of cooking it is well understood by the tradespeople of Plymouth, and but for its abundance it might be introduced to tables of a higher order. A primary process in cooking all slimy fishes is to remove the mucus with hot water and a little alkali, otherwise the flavour of the fish is spoiled.

The Hake is very common on the northern shore of the Mediterranean, and considerable traffic is carried on with this fish; they are packed with aromatic plants, and sent to towns removed from the coast. The Hake is described and figured by Rondelet and was known to the older naturalists before him. Sundeval derives the Norwegian name of the Hake, Lysing, from the shining of the fish when alive, and in that country it is called also Kulmund, because of the blackness of its mouth; and of the latter name the Swedish Kummel is, he thinks, a corruption.

A Hake of three feet eight inches long in the shop of a London fishmonger, in May 1835, supplied the means of obtaining the following particulars. The length of the head compared to the length of the body alone is as one to three, and the depth of the body is not so great as the length of the head: the ventral fins are placed in advance of the pectorals, their rays not unequally elongated; the pectoral fins commence under the posterior angle of the operculum, their rays ending even with the end of the first dorsal fin: the first dorsal fin is itself short and triangular in shape; the second dorsal fin commences over the vent, and the anal begins immediately behind that orifice; the second dorsal and the anal terminate 
on the same plane, near the caudal; the posterior rays of both are elongated; the caudal rays are about three inches long, and nearly even. The fin-rays in number are-

\section{D. $10.29:$ P. $11:$ V. $7:$ A. $21:$ C. 19.}

The head is depressed; the inside of the mouth and gill-covers black; lower jaw the longest; teeth slender and sharp, in a single row in each jaw : the irides yellow with a dark outer circle. The lateral line of the body is straight throughout the posterior half, then gradually rises to the upper edge of the operculum; the appearance of the lateral line is that of one white line between two dark ones: the scales are large; and the colour of the body dusky brown above, lighter beneath; the dorsal and caudal fins are dark; the ventral and anal fins pale brown.

I have inserted a new figure of our Hake at the commencement of this subject; the figure used in the first edition, and which now, for comparison, is inserted as a tail-piece, does not sufficiently exhibit the elongation of the rays of the posterior part of the second dorsal and anal fin, the rays being represented as rather adpressed, and appearing shorter than they were intended to be. This has, I fear, led to some misconception, as the following extracts seem to show.

In a communication from the Rev. R. T. Lowe, M.A., printed in the Proceedings of the Zoological Society for the year 1840, page 36, describing certain new species of Madeiran Fishes, and containing additional information relating to those already described, Mr. Lowe observes, "The Madeiran Hake, or Pescada, Merlucius vulgaris of my Synopsis, page 189, proves, upon better acquaintance, distinct from the common British Hake, Cuvier, Yarrell, \&c., Gadus merlucius, Linn. Instead of being 
even, the dorsal and anal fins are each produced at their hinder end into a rounded lobe; the jaws are nearly equal in length; the teeth are large and numerous; the scales small. I do not name it, for I believe it has already been called by Mr. Swainson $M$. sinuatus, and I am doubtful whether it may not also be the $M$. esculentus of Risso, vol. iii. p. 220, though in his synonyms he has confounded it with the true Northern Hake. I believe it to be the fish imperfectly figured long ago by Salviani, p. 73, copied by Willughby, t. L. membr. 2, n. 1, which has usually been referred to also as the Northern Hake."

Mr. Swainson's remarks in his Natural History and Classification of Monocardian Animals, more especially Fishes, vol. i. p. 319, are as follows:- "To the first of these (the Merlucina), named by Rafinesque Merlucius, after the Gadus merlucius of Linnæus, belongs the common Hake, peculiar to the Northern seas, with which the Mediterranean Hake ( $M$. sinuatus, Sw. fig. 73), now

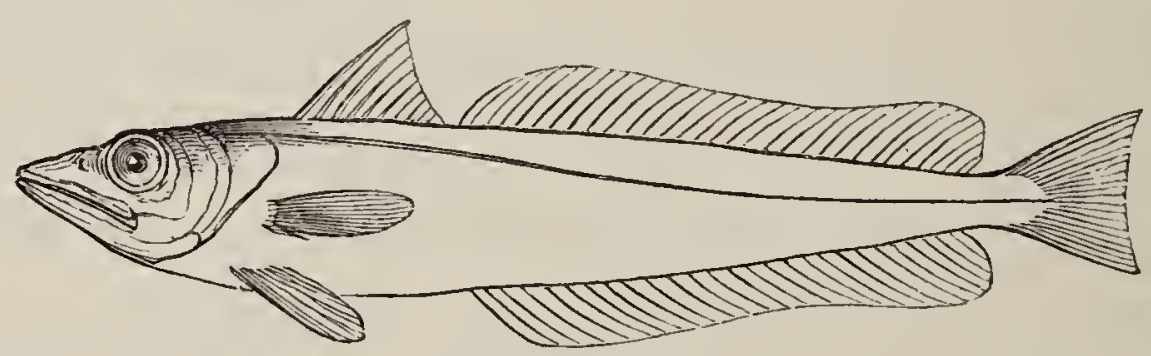

for the first time described, has hitherto been confounded by all writers: we presume this is the species, which, under the belief that it was the common one, Cuvier says is abundant in the Mediterranean."

It is to be regretted that Mr. Swainson has not mentioned the characters upon which he founds his distinction between the Mediterranean and the Northern Hake; 
the name and the figure given, which is here copied, are the only guides. If the specific term sinuatus is intended to refer to the form of the dorsal and anal fins as a distinguishing character, it may be desirable to state that the figures of the common Hake, as given by Duhamel and Bloch, present the same peculiarities, particularly in reference to the elongation of some of the posterior rays of the dorsal and anal fins. Pennant, in describing our British Hake, says of the second dorsal fin, "of which the last rays are the highest." Mr. Couch, who lives on a part of our coast which abounds with Hakes occasionally, sent me word, in answer to my inquiry, that the new figure here employed at the commencement of this subject is a good representation of the general form of our Hake, but that the degree of extension of the fin-rays and the character of the waved lines formed by the margins of the fins vary in different specimens of the fish. Dr. Parnell, in his minute description of the Hake found in the Frith of Forth, says of the second dorsal fin, "the first twenty-two rays of equal length and as long as the sixth ray of the first dorsal, the twenty-third to the twenty-seventh rapidly increasing: the remaining rays gradually diminishing, the last very short." Of the anal fin, Dr. Parnell says, "the first, second, and third rays gradually increasing in length, the following eighteen about equal height; the twenty-seventh considerably the longest, the rest gradually diminishing, the last very short." Lastly, I may add, that the representation of the Northern Hake in the Fishes of Scandinavia by MM. Fries and Ekström exactly accords with the new figure engraved, at the head of this article.

I have no reason to suspect that I made any mistake either in the counting or the printing of the number of the various fin-rays in the specimen I examined; but there 
are considerable differences when compared with the enumeration by Pennant and Dr. Parnell: thus the numbers are, according to several authors-
D. 9.40 :
P. 12: V. $7:$ A. 39. Pennant.
D. 10.39 :
P. 14: V. 7: A. 37: C. 20. Parnell.
D. 10 or 11.37 or $39:$ P. $14:$ V. $7:$ A. 37 or 38 . Sunderall.

The Hake, according to Dr. Mitchell and Dr. Storer, appears to be taken both at New York and at Boston. The fin-rays as given by Drs. Mitchell and Storer :-

D. 12. $38:$ P. $13:$ V. $7:$ A. $41:$ C. 27.

D. $12.38:$ P. $13:$ V. $7:$ A. 39.

Hake, 1st Ed. of Br. Fishes.

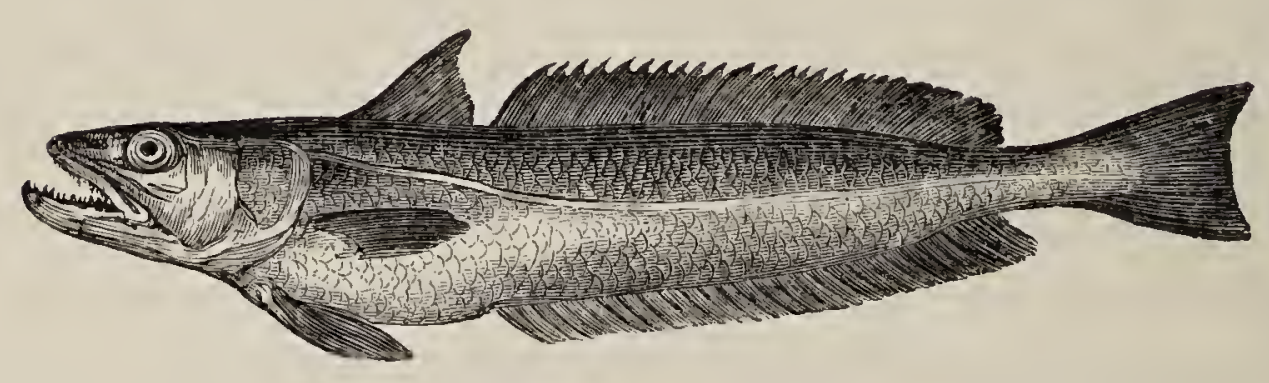




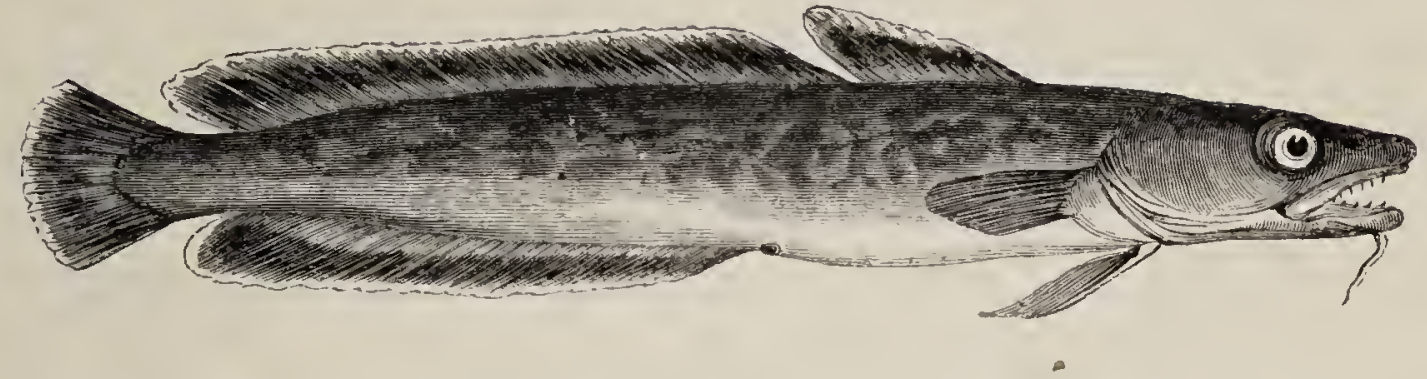

THE LING.

ziLli, Cornwall.-Honos, Wales.

Lota molva, Cuvier, Règne An. t. ii. p. 333.

A sellus longus, Willughby, p. 175, L. 2.

Gadus molva, Linveus. Bloch, pt. ii. pl. 69.

",$\quad$ Ling, Penn. Brit. Zool. vol. iii. p. 262.

,, , , $\quad$ Donov. Brit. Fish. pl. 102.

Molva vulgaris, Common Ling, Fuer. Brit. An. p. 192, sp. 82.

Lota molva, Ling, Jenys, Brit. Vert. p. 448.

Lота. Generic Characters.--In addition to the elongated body, with two dorsal fins and one anal fin, possessed by the species of Merlucius last described, there is one or more barbels on the chin, and the ventrals contain seven rays.

The Ling is a very valuable species, scarcely less so than the Coalfish or the Cod. Large quantities are taken among the Western Islands, in the Orkneys, and on the Yorkshire coast; in Cornwall, and the Scilly Islands; and the species may be traced nearly all round the Irish coast. The fishing for Ling is by hand-lines and long-lines; and besides a portion that is consumed fresh, the fish are split from head to tail, cleaned, salted in brine, washed, and dried: but the demand generally falls short of the quantity cured, and the hardy fishermen 
are but poorly requited. The ports of Spain are the markets supplied; and so valuable an article of commerce was Ling considered formerly, that an act for regulating the price of Ling, Cod, \&c. was passed as early as the reign of Edward the Third.

The air-bladders, popularly called Sounds, are prepared separately, and, with those of the Codfish, are sold pickled. The roes, which are of large size, are also used as food; or when preserved in brine, are sold to be employed to attract fish. Another produce of the Ling is the oil extracted from the liver, which is used by the poor to supply the cottage lamp; and as a medicine, Mr. Couch says, which, by those who have been able to overcome the repugnance arising from its nauseous smell and taste, has been found effectual in severe cases of rheumatism, when taken in small beer in doses of from half an ounce to an ounce and a half. Formerly from fifty to sixty gallons of this oil, and that from the liver of the Codfish, were dispensed in one large establishment for this purpose, and it was found to act best when the perspiration was increased. The exudation from the skin of those to whom it was administered always became strongly tainted with its odour.**

In Zetland, the principal fishing for Ling is from May to August. On the Yorkshire coast the young are called Drizzles: in Cornwall they are caught in January and February, and their favourite haunts are about the margins of the rocky valleys of the ocean. The Ling is exceedingly prolific, and of most voracious appetite, feeding on young fish, not sparing anything that has life, and its prey is swallowed whole, so that no great art is required to catch it. It is tenacious of life, and survives

* Memoirs of the Literary and Philosophical Society of Manchester, vol. iii. ; and Dr. Bardsley's Medical Reports, 8vo. 1807, p. 18. 
great injury. "I once," says Mr. Couch, "saw a Ling. that had swallowed the usual large hook, shaft foremost, of which the point had fixed in the stomach, and as the line drew it, it turned round, entered the opposite side of the stomach, and fastened the organ together in complicated folds; yet having escaped by breaking the line, it survived to swallow another hook and be taken several days after."

The Ling measures from three to four feet; Pennant mentions one which measured seven feet; and Mr. Couch has known examples to weigh seventy pounds.

"Body slender, more elongated than that of the Hake; roundish: head flat: gape large: lower jaw shorter than the upper, with a single barbel at its extremity: teeth in the upper jaw small, and very numerous; those in the lower jaw longer and larger, forming but a single row : lateral line straight: scales small, firmly adhering to the skin: two dorsal fins of equal height; the first short, commencing near the head, not pointed as in the Hake, but with most of the rays even; second long, immediately behind the first, reaching nearly to the caudal; the posterior portion the most elevated: vent in a line with the eighth or ninth ray of the second dorsal fin: anal fin immediately behind it, long, resembling the second dorsal fin, and terminating on the same line with it: caudal rounded at the extremity. The fin-rays are-

$$
\text { D. } 15.65: \text { P. } 15: \text { V. } 6: \text { A. } 97 \text { : C. } 39 .
$$

"The back and sides grey, inclining to olive; sometimes cinereous, without the olivaceous tinge; belly silvery: ventrals white; dorsal and anal edged with white; caudal marked near the end with a transverse black bar; the extreme tip white."-Jenyns, Manual. 


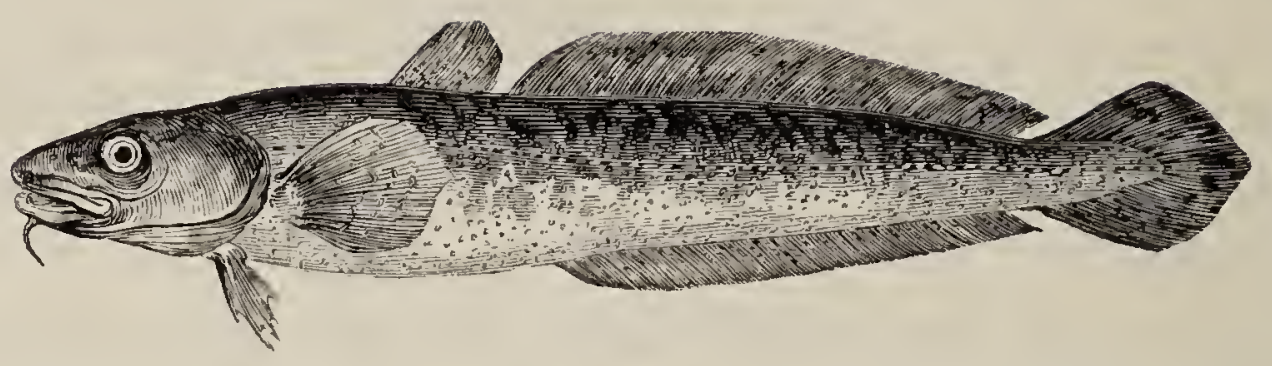

\section{THE BURBOT.}

\section{EELPOUT. BURBOLT.-LLOFEN, Wales.- \\ AaLRUTte, Germany.}

Lota vulgaris, Burbot, Jenrss, Man. Brit. Vert. p. 448, sp. 134.

, $\quad$ " Cuvier, Règne An. t. ii. p. 334.

$, \quad, \quad$ WrLlughby, 125.

Gadus lota, Linneus. Bloch, pt. ii. pl. 70.

,, , Burbot, Pens. Brit. Zool. p. 265.

" " " Dovov. Brit. Fish. pl. 92.

Molva ," ,, Flem. Brit. An. p. 192, sp. 83.

The Burbot is the only British species of this numerous family of fishes that lives permanently in fresh water, and it prefers in this country slow-running rivers; but it is neither so generally known, nor so much esteemed and encouraged, as from the goodness of its flesh it deserves. It is said to be found in various parts of the North of Europe, Siberia, Asia, and India. In this country it is rather local. It occurs in the Cam, and in some of the rivers of Norfolk and Lincolnshire. The Trent produces it, and Nottingham market is occasionally supplied with examples for sale. The Tame is said to contain the Burbot, and so also do several rivers in the counties of Yorkshire and Durham; as the Ouse, the 
Esk, the Skern, near Mainsforth, which afterwards runs into the Tees near Croft Bridge, and the Derwent. It is taken in small numbers in the Yare, the Bure and the Waveney rivers of Norfolk, generally by hooks set for eels.-Rev. R. Lubbock.

The Burbot is not unlike the Eel in some of its habits, concealing itself under stones, waiting and watching for its prey, consisting of aquatic insects and young fish, under arches and near eddies, into which such small and weak animals are likely to be brought by the current of the water. It feeds principally during the night; and, like the Eel, is most frequently caught by trimmers and night-lines.

The Burbot is sometimes called Coney-fish, from its habit of lurking and hiding itself in holes like a rabbit.

It spawns in February or March : is very tenacious of life, and is said to have lived a considerable time in a damp and cold situation, fed on small fishes and raw meat. In this country it has been known to attain the weight of four pounds and a half; but a more common size is about two pounds' weight. Pennant mentions one taken in the Trent which weighed eight pounds. In the Lake of Geneva, into which it is stated the Burbot was introduced from Neufchâtel, it has been taken of seven pounds' weight. The flesh is white, firm, and of good flavour, by some considered superior to that of the Eel; and as the Burbot is in its nature extremely hardy, few difficulties present themselves in the way of their increase in quantity, while the value of the fish would amply repay the trouble or the cost of the experiment. It would probably thrive well and multiply in large lakes.

Length from one to two feet: the head depressed, smooth; jaws equal; chin with one barbel; the gape 
- large, with small teeth above and below; eyes of moderate size; gill-opening large: the length of the head compared to that of the body as one to four: the form of the body cylindrical, compressed posteriorly. The first dorsal fin small and rounded; the second elongated, reaching nearly to the tail fin; both dorsal fins nearly uniform in height: ventral fins placed very forward, narrow, and pointed; the pectoral fins large and rounded; the anal fin begins behind the commencement of the second dorsal fin, but ends very nearly on the same plane with that fin : the tail fin oval, and slightly pointed. The fin-rays in number are-

\section{D. $14.68:$ P. $20:$ V. $6:$ A. $67:$ C. 36.}

The colour of the body is yellowish brown, clouded and spotted with darker brown, and covered with a mucous secretion; the under parts lighter: the lateral line is indistinct and straight; the scales small; the fins partaking of the colour of the part of the body from which they emanate, those of the lower surface being much the lightest. Pyloric cæca twenty-eight in some individuals, in others fewer, grouped in bundles.

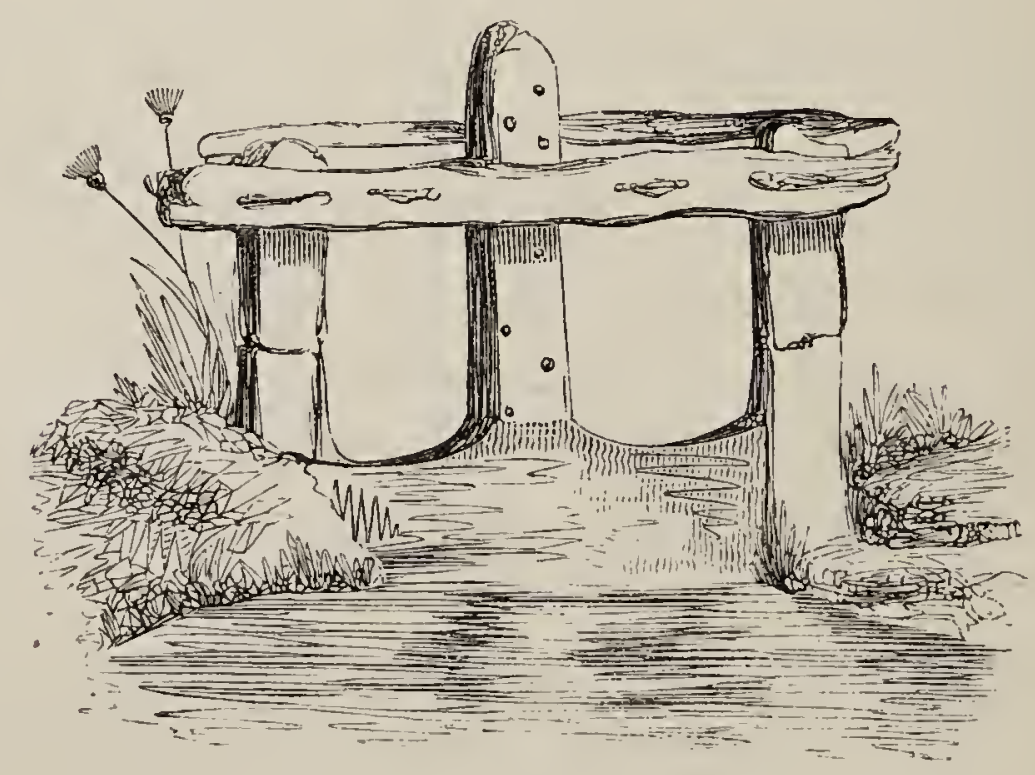




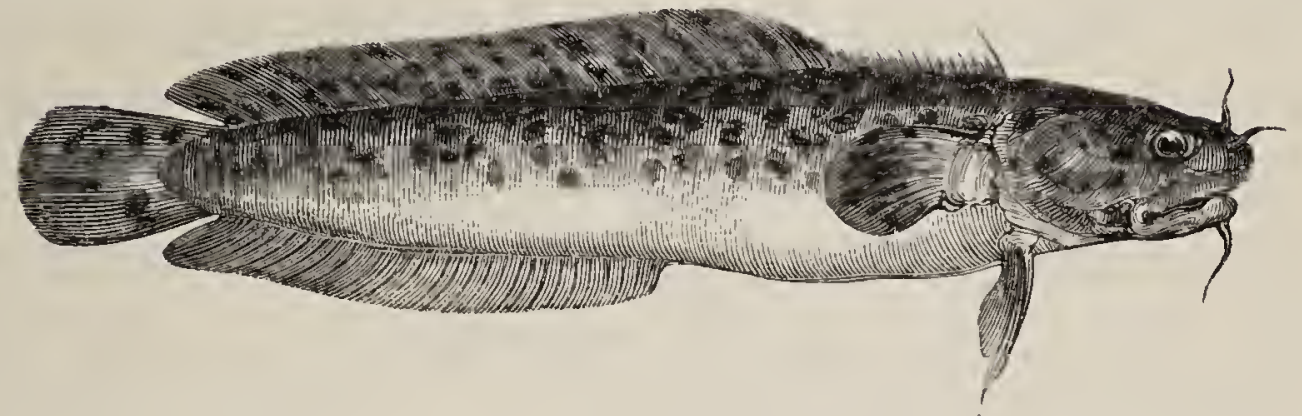

\section{THE THREE-BEARDED ROCKLING.}

\section{SEA LOCHE.-WHistler, West of Cornwall.}

Motella vulgaris, Cuvier, Règne An. t. ii. p. 334.

,, tricirrata, NiLsson, p. 48.

" " $\quad$ Three-Bearded Rockling, Jenyns, Man. Brit. Vert. p. 449.

,, ,, Willughi, p. 121, H. 4, fig. 4.

Mustela marina, Rock-ling, RAY, Syn. p. 164, sp. 9, fig. 9.

Gadus tricirratus, Bцосн, pt. v. pl. 165.

,, mustela, Three-Bearded Cod, Penn. Brit. Zool. vol.iii. p. 267, pl. 36.

, ," Rockling, Donov. Brit. Fish. pl. 2.

", tricirratus, Three-Bearded Gade, Flen. Brit. An. p. 193, sp. 86.

Motelia. Generic Characters.-Body elongated, cylindrical, compressed posteriorly; the first dorsal fin very slightly elevated, delicate in structure, scarcely perceptible; second dorsal and anal fins long, continued nearly to the base of the tail. Nasal and mandibular barbels.

The Three-Bearded Rockling, included by the Rev. Mr. Jago in his Catalogue of the rarer Fishes of Cornwall, and published by Ray, with a figure, at the end of his Synopsis, though not uncommon on the Devonshire and Cornish coasts, as noticed by Colonel Montagu and $\mathrm{Mr}$. Couch, is more rare on our shores generally than the Five-Bearded Rockling, of which by some it has 
been considered only as a variety. It is also rare on the east coast of Scotland. It frequents rocky ground that is well furnished with sea-weed, among which it threads its way with great ease and rapidity. Besides the localities mentioned, it has been taken also at Weymouth, in Belfast Bay, and in the vicinity of Carlisle, probably in the Solway Frith. 'The individual figured by Willughby, whose early representation of this fish is very good, was obtained by him at Chester.

Mr. Thompson says it is generally, though sparingly, distributed on the coast of Ireland. It is said to be very common at Roundstone in Connemara.

Of its habits, Mr. Couch says, "It keeps in shallow water, feeds on aquatic insects, and will take a bait; but it is not commonly used as food, because it smells unpleasantly in the course of a few hours. It is not easy to explain the use of the fringed membrane behind the head and before the dorsal fin; it has nothing in common with the fins; but when the fish is lying perfectly still, and all the fins are at rest, this is often in rapid motion. The barbels on the upper jaw are always extended in front, and probably serve the same purposes as the antennæ in insects."

Bloch says that it spawns in autumn; but other observers consider that it deposits its spawn in winter, like most of, if not all, those of the same family. Two males examined by Mr. Thompson, had the milt highly developed in October.

Pennant, in his account of the Five-Bearded Rockling, says, "The Cornish fishermen are said to whistle, and make use of the words bod, bod, vean, when they are desirous of taking this fish, as if by that they facilitated the capture, in the same manner as the Sicilian fishermen repeat their Mamassu di pajanu, \&c. when they are in 
pursuit of the Swordfish." But this name of Whistlefish was, according to Jago's Catalogue, attached to the Rockling with three barbels only, and even among them was but occasionally applied to the larger specimens. Pennant, it will be observed, speaks of the cause of the application of the name of Whistle-fish on the authority of others; and on inquiry, I find that the custom of whistling when fishing is neither practised nor known to the Cornish fishermen of the present day, and, in fact, that this fish is of too little value to be an object of any solicitude. I believe, indeed, that while preserving the sound of the name, the term has been changed, and a very different word substituted, and that for Whistle-fish we ought to read Weasel-fish. Both the Three and the FiveBearded Rocklings were called mustela from the days of Pliny to those of Rondelet, and thence to the present time. In accordance with this remark, the Swedish vernacular name for the genus Motella, anciently Mustela, is Sjövessla or Sea-weasel.

A specimen fourteen inches long, and beautifully spotted, was presented to the Zoological Society in 1832, but the finest examples of this species I have seen were two given to me in December 1834, by Dr. Thackeray, the Provost of King's College, Cambridge, from the largest of which, measuring seventeen inches in length, the wood-engraving was executed, and the following description taken.

The length of the head compared to the length of the body alone, without the caudal rays, is as one to four; and the depth of the body equals the length of the head: the first dorsal fin is delicate in structure, its first ray being elongated, the rest hair-like: the second dorsal fin commences immediately behind the end of the first, and reaches along the back to the tail, but ends a little 
short of the base of the caudal rays: in the ventral fins the first two rays are elongated, the second the most so, and the two are disunited; the other five rays are nearly equal, united, and short; the pectoral fins are rather large and rounded: the vent is half-way between the point of the chin and the end of the fleshy portion of the tail; the anal fin commences immediately behind the vent, is one-fourth less in length than the second dorsal, and ends on the same plane with it: the tail-fin is moderate in size, and rounded at the end.

The fin-rays in number are-

$$
\text { 2nd D. 55: P. 20: V. } 7: \text { A. } 49: \text { C. } 18 .
$$

The head is depressed; the mouth wide: the jaws nearly equal, but when separated, the lower jaw is the longest, with one barbel at the chin; there is a mixture of small and large teeth in each jaw; the upper jaw has one barbel on each side of the middle, between the lip and the nostril; the inner part of the upper lip is crenate: the irides are golden yellow; the anterior portion of the body of the fish is cylindrical, or slightly depressed; and the tail compressed. The general colour of the body and head is a rich yellow brown, spotted on the top of the head, along the back, the pectoral, dorsal, and caudal fins, with rich chestnut brown; the lower part of the sides, the ventral and anal fins, are pale yellow brown, approaching to white, and without spots.

Young fish of this species are of a uniform brown colour until they have acquired six or seven inches in length; in this condition they are the Mustela alia of Ray. 


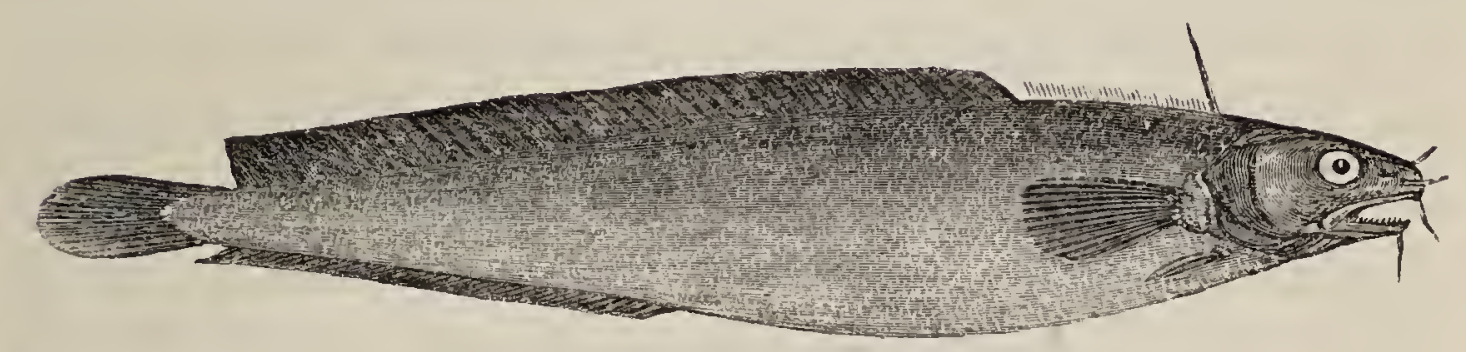

\section{THE FOUR-BEARDED ROCKLING.}

Motella cimbria, The Four-bearded Rockling, Pannelu, Wern. M. vii. pl. 44. Gaclus cimbrius,

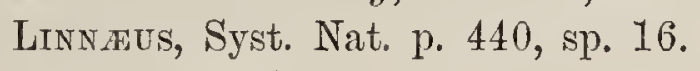

Enchclyopus cimbricus, Schneider, Syst. Ichth. p. 50, sp. 1, tab. 9. Moiclla cimbrica, Nitsson, Prod. Ichth. Scand. p. 48, sp. 2.

Tris species of Motella, first described by Linnæus, is included by Dr. Parnell in his description of the Fishes of the Forth, a specimen, fourteen inches in length, having been brought to him by a Newhaven fisherman, who had caught it a little to the east of Inchkeith on a Haddock line baited with mussels. It is a species perfectly distinct from the Three or the Five-Bearded Rockling, which are so much more common on various parts of the coast, and may at once be distinguished from either by the greater length of the filament, that is in advance of the almost obsolete first dorsal fin. This filament in a fish of nine inches long, measures one inch and seven-eighths; and in another fish of ten inches and a half in length, measures two inches and a quarter, as I 
find from portions of two specimens sent me by $\mathrm{Mr}$. Euing of Glasgow, to whom I am indebted for the opportunity of making known the new species of Smelt. These two specimens of the Four-Bearded Rockling were taken near Rothsay, and in reference to them, Mr. Euing's letters contain the following remarks:- "I have never met with the Three or the Five-Bearded Rockling, but small specimens of that with four cirri are frequently brought in on the long lines from deep water. It is, indeed, by no means a very rare fish with us, and I have seen it at almost every visit to the coast since 1827 , the year in which I first observed it."

I have since received two preserved specimens from Dr. Edward Clarke, who obtained several examples from the Frith of Forth while he was residing in Edinburgh; he is now settled at Hartlepool, and Ichthyology is likely to be greatly assisted by his observation and exertions.

This fish is rare in the Baltic, but is not uncommon on the southern coast of Sweden; it is found also among the islands of the Kattegat, on the west coast of Norway, and in the Atlantic.

Dr. Parnell says, "On dissecting the specimen, I found the stomach filled with shrimps and small crabs. The cæcal appendages were few in number; the roe was large; the ova small and numerous, and apparently in a fit state to be deposited. It is probable that the habits of this fish are similar to those of the other species, but from its rarity they are difficult to determine."

Description by Dr. Parnell, from a specimen fourteen inches in length: "Form closely resembling that of the Five-Bearded Rockling, but the length of the head somewhat greater compared to that of the body. The body elongated, rounded in front, compressed behind, tapering from the vent to the caudal extremity; greatest depth 
less than the length of the head. Head one-sixth of the entire length, caudal fin included, slightly depressed; snout blunt, projecting considerably beyond the under jaw; eye large, of an oval form, placed high up, and about its own length from the point of the nose; operculum rounded, oblique; gill-opening large; gape wide; maxillary extending in a line with the posterior margin of the orbit; teeth sharp and fine, forming two rows in the under jaw, and five rows in the upper; a few are also placed in a cluster on the anterior part of the vomer; barbels four, one a little in front of each nostril, one at the extremity of the upper lip, and one on the chin; tongue fleshy, smooth, and without teeth. Fins:-the first dorsal fin obsolete, scarcely discernible, commencing over the operculum, and terminating a little in front of the second dorsal, composed of a number of short, fine, capillary rays, of which the first is by far the largest; second dorsal taking its origin over the ends of the pectorals, and terminating a little in advance of the caudal; anal fin commencing under the twelfth ray of the second dorsal, and ending under the last ray but three of the same fin, in form similar to the second dorsal, but the rays scarcely more than one-half the length ; the first ray simple, the rest branched; caudal rounded at the extremity, the length of the middle rays equalling the space between the first and twelfth rays of the anal, the lateral rays simple; ventral fins jugular, the second rays the longest, and about two-thirds of the length of the pectorals; the pectoral fins rounded at the extremities, equalling the length of the caudal; the first rays stout and simple, the rest branched. The fin-rays in number are,-

1st D. $50: 2$ nd D. $50:$ P. $16:$ V. $5:$ A. $43:$ C. 20 . Vert. 52.

"Scales small, smooth, and adherent, covering the head, 
body, and membranes of the dorsal, caudal, and anal fins; lateral line formed by a number of oval depressions, placed at intervals from each other, commencing over the operculum, taking a bend under the ninth, tenth, and eleventh rays of the second dorsal fin, from thence running straight to the middle ray of the caudal. Colours:-Back and sides of a greyish brown; belly dirty white; second dorsal fin lighter in colour at the edge; pectorals, caudal, and lower part of the dorsal, dark brown, approaching to black; anal and ventrals dusky."

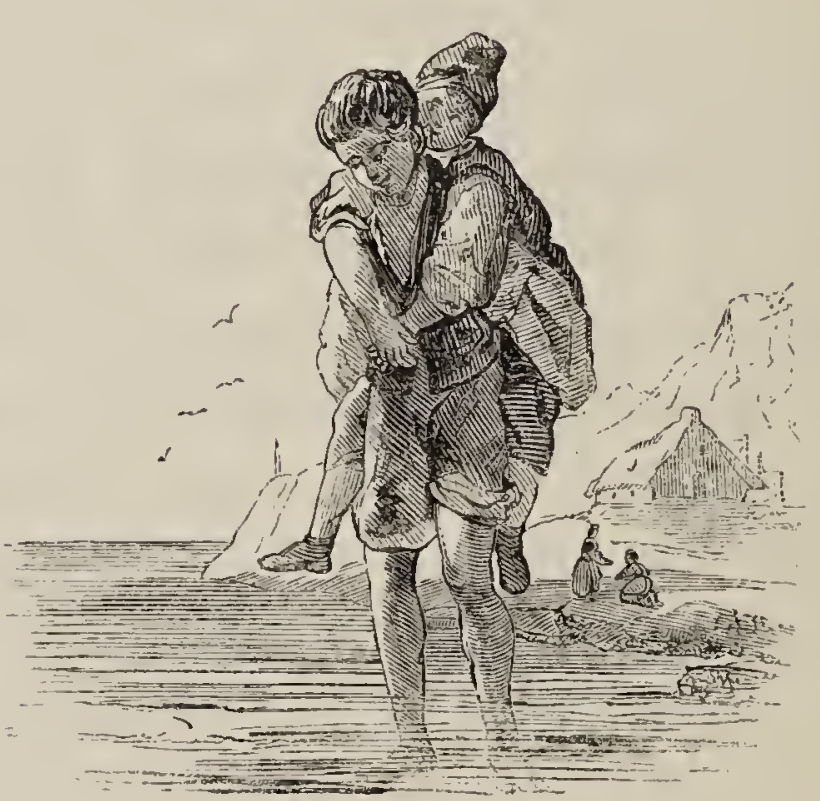




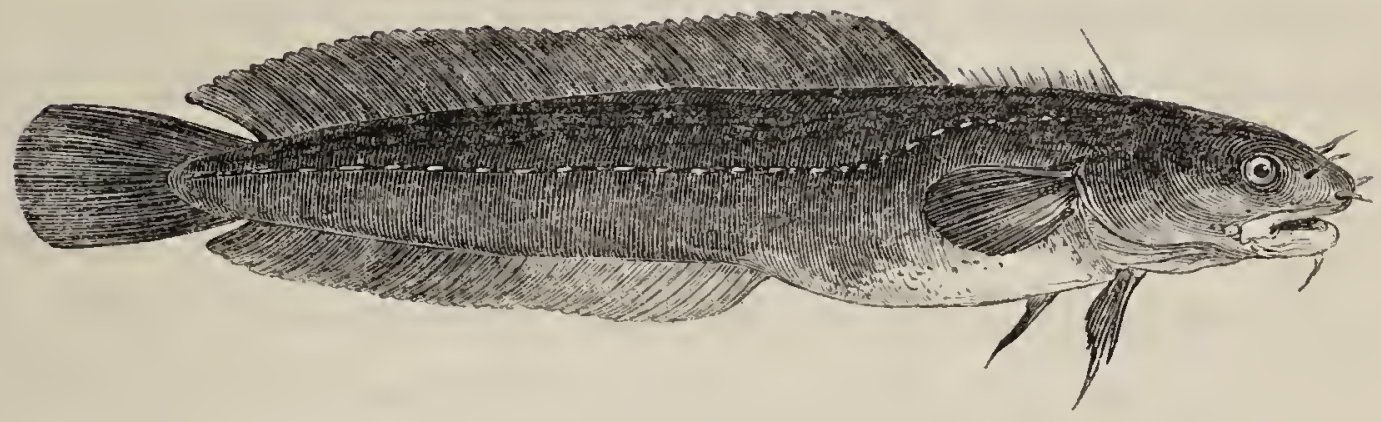

THE FIVE-BEARDED ROCKLING.

Motella quinquecirrata, Cuvien, Règne An. t. ii. p. 334, note.

, mustela, Mustela vulyaris,

Gadus mustela,

"

Fine-Bearded Rockling, JENYws, Brit. Vert. p. 450. Willughis, p. 121.

LinNaUS.

Five-Bearded Cod, Penn. Brit. Zool. vol. iii. pl. 36. Dovov. Brit. Fish. pl. 14.

Gade, Fuenr. Brit. An. pl. 193, sp. 85.

I Have found the Five-Bearded Rockling, when of small size, a very common fish on the Kentish coast in autumn, left by the retiring tide, in small pools among the rocks, and generally lying concealed under the tufts of sea-weed that hang over the edges of the stones into the water: and I have observed it as far to the westward as Portland Island. Colonel Montagu considered it more rare in Devonshire than the species with three barbels at the mouth, just described: Mr. Couch observes it on the Cornish shore: it is plentiful on the flats of the Lincolnshire Wash; and Mr. Low says it is common in Orkney, where it is found under stones among sea-weed, but seldom exceeding nine or ten inches in length. Pennant says it attains the length of eighteen or nineteen 
inches. It spawns in the winter, and feeds principally on small thin-shelled crustacea and young fishes. Mr. Low says, "They are reckoned pretty good eating, but are never got in any quantity; never caught at a hook: the only method of getting them is by shifting the stones at low water, when they are to be found with the Blennies."

Dr. Johnston says it is not uncommon at Berwick, and Dr. Parnell finds it in the Forth: the young are about two inches long in July. Mr. Thompson states that it is much more common round the Irish coast than the three-bearded species.

In its habits it closely resembles the Three-Bearded Rockling, and several naturalists consider them only as varieties of the same species. Professor Nilsson regards them as distinct, and follows Linnæus in considering a fish with four barbels as another distinct species.

The length of the head compared to the length of the body alone, is as one to four; and the depth of the body is less than the length of the head: in shape the body is less cylindrical than that of the Three-Bearded Rockling, and the nose more pointed; the position and elevation of the fins are similar to those of the fishes last described, but the first ray of the first dorsal fin is longer and more conspicuous, and the vent is nearer the head, being less than half the distance from the nose to the end of the fleshy portion of the tail. The fin-rays in number are-

2nd D. 52 : P. $14:$ V. $6:$ A. $40:$ C. 20.

The body compressed; the head depressed ; the mouth rather small, with a band of small teeth in each jaw, and a patch of similar teeth at the anterior part of the roof of the mouth; the under jaw the shortest, with a single 
barbel at the chin; the upper lip plain, without crenature, with two small barbels near the point of the nose, and two others, as long again, about as much before and within the nostrils as the nostrils are before and within the eyes. The eyes are small, and placed near the nose. The colour of the upper part of the head, back, and sides, is an uniform dark brown; the lower part of the sides lighter brown; and the under surface of the lower jaw, the ventral fins, and the belly to the vent, white; the other fins dusky brown: the course of the lateral line is distinctly marked by a series of short, slender white streaks, as shown in the wood-engraving.

I have been favoured by Sir John Richardson with the following description of the appearance of a fine example of this species :-General colour of the body pale bronze, approaching to that of jeweller's gold, with streaks of purer gold colour above the lateral line in the direction of the ribs. The upper parts of the head and the gillcovers yellowish brown, blended on the cheeks with the bronze. The fins are also of a brownish orange or bronze colour, but without the metallic lustre, and their margins are blood red; the red tinge is more general on the pectorals; the irides silvery, the pupils bluish black.

The three species last described have been called mustela by different authors. Linnæus attached this term to the species with five barbels: Cuvier, in the Règne Animal, identifies the Three-Bearded Rockling: with this same word. As the number of barbels appears to be peculiar to each, and constant, a reference to the number in the specific name is, perhaps, the least objectionable. Linnæus, and other authors to the present time, continue, as before stated, to consider the northern species with four barbels as distinct from both, and there is no doubt that they are all three good species. 


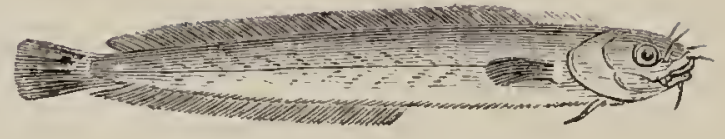

\section{THE MACKEREL MIDGE.}

Motella glanca, Mackerel Midlye, Jenyns, Man. Brit. Vert. p. 451, sp. 137. Ciliate ," ,, , Covch, Zool. Journ. vol. i. p. 132.

," $\quad$, $\quad$, , Mag. Nat. Hist. vol. v. pp. 15, 16,

Mr. Couch's MS. account of this beautiful little fish is as follows:- "It is about one inch and a quarter in length, moderately elongated; head obtuse, compressed; upper jaw the longest, with four straight barbels; the under jaw with one barbel; teeth in both jaws: gill membrane with seven rays; eyes large and bright; a fringed membrane in a depression behind the head; pectoral and ventral fins rather large for the size of the fish; dorsal and anal fins single, and reaching near to the tail; scales deciduous; colour on the back bluish green; belly and fins silvery. This seems to be one of the species spoken of by the older naturalists under the name of apua; and which, from their minute size, and the multitudes in which they sometimes appeared, they judged to be produced by spontaneous generation from the froth of the sea, or the putrefaction of marine substances. The name I have assigned to it is that in use among our fishermen, and is descriptive of its colour and very minute 
size, for it is the smallest fish with which I am acquainted."

"This fish is gregarious and migratory, never making its appearance before May, after which it is abundant from the edge of the shore to every part of the Channel. Its winter station is probably deep in the water; but in summer it keeps near the surface, and seeks the shelter of everything it finds floating; - a circumstance that often leads to its destruction, for it is frequently hauled on board boats among the corks of nets, or with the line, or floating weeds; and in a storm it is often thrown into boats through the breaking of the sea,-a circumstance which shows that at such seasons it must be on the crest of the wave." "It dies instantly on being taken out of the water."

Part of a letter received from Mr. Couch in May 1840 is to the following effect:- "I yesterday had an opportunity of observing the actions of a little company of Mackerel Midges that had been left by the tide in a large pool. Sometimes they gamboled about, keeping the body permanently bent at nearly a right angle, and moving the tail with great rapidity; at other times they kept under the shelter of a piece of sea-weed, or other floating substance, and, passing across it repeatedly, seemed to delight in rubbing their backs against it."

Mr. R. Q. Couch states in the Zoologist for 1847 (p. 1823) that the Midgen or Mackerel Midges are uncertain in their appearance, for though scarce in some seasons, in others they are in countless multitudes. In March and April they are seen dispersed, swimming on the surface of the deep sea; but in May and June they associate in numbers and approach the shores, when multitudes are cast on the beach in boisterous weather. Unlike its congeners, the Midgen is a high swimmer 
and does not seek the shelter of stones. In Thompson's Natural History of Ireland, vol. iv. page 188, there is an extended notice of this curious fish, which appears to be not uncommon on the Irish and Scottish coasts.

This small fish has much the appearance of being the young of a larger species, closely allied in form to the Five-Bearded Rockling, but presents in its economy some of the attributes of a species. Unlike the fish last described, which is very tenacious of life, this little fish, as has been said above, dies instantly on being taken out of the water: it does not appear every summer, as might be expected if it was the young of so common and local a species as the Five-Bearded Rockling; and although present, as it is frequently, during the greater part of the summer, when fry grow most rapidly, no increase is observed in its size.

RGO RETIA SERVO.

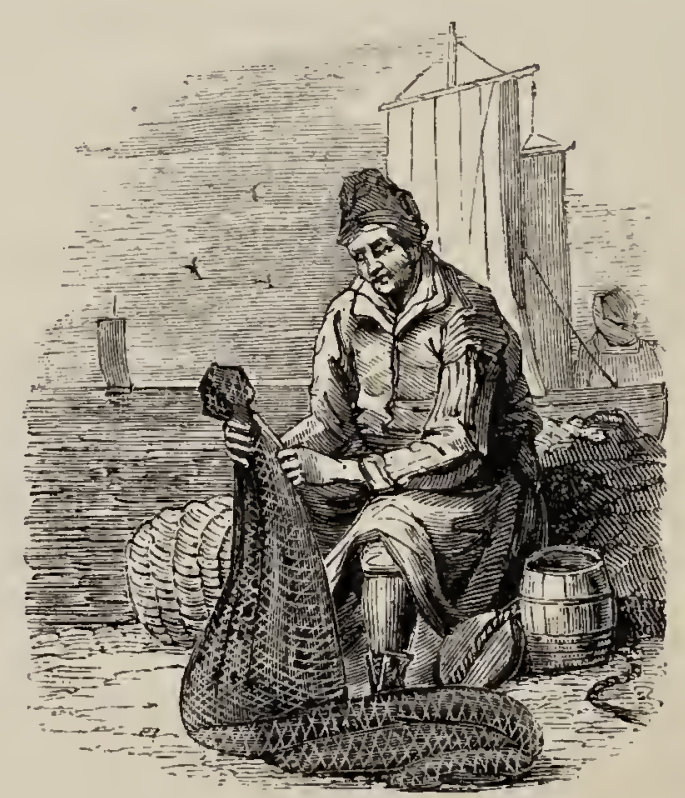




\section{THE SILVERY GADE.}

Motella argenteola, Yarrell.

Gadus argenteolus, Silvery Gade, Montaad, Mem. Wern. Soc. vol. ii. p. 449.

The following is Colonel Montagu's account of this small fish :- "There is a small species of Gadus, which is occasionally found on the western coast, that is nearly allied to the Three-Bearded Cod (Rockling) in most particulars; but the shape of the head and the colour are essentially different. It has very much the appearance of the fry of some larger species, and might have been suspected to be the young of the Ling, had it not been for a little difference in the first dorsal fin and the two cirri which this has before the nostrils. If a fourth cirrus could have been discovered, suspicions would have arisen whether it might not have been the cimbrius of Gmelin. Its essential characters may stand thus :-

"With two dorsal fins, the anterior very obscure, except the first ray, which is much the longest: cirri three, two before the nostrils, and one on the chin: upper jaw longest; back bluish green; sides and belly silvery.

"The head is obtuse; eyes lateral, irides silvery: all the fins are of a pale colour, and the whole fish is of a silvery resplendence, except the back, which is blue, changeable to dark green : the pectoral fin is rounded with sixteen or eighteen rays; ventral, six or seven, the 
middle ray considerably the longest, and placed much before the pectoral: the first dorsal fin commences above the gills, and the rays are very minute and obscure, the first excepted, but more than thirty have been counted; the second dorsal commences close to the other, in a line with the end of the pectoral, and terminates close to the caudal; the rays are innumerable: the anal fin begins immediately behind the vent, and terminates even with the dorsal; the caudal fin is nearly even at the end. Length about two inches.

"I first noticed many of these fishes thrown upon the shore in the south of Devonshire, in the summer of 1808, and have taken two or three since. The fishermen called it Whitebait, but I afterwards found they had mistaken it for the fry of Herring and Pilchard, which indiscriminately go by that name, and are sold together in some places under the name of Herring-Sprat.

"The Three-Bearded Cod (Rockling) is a very common species of the western coast, which I have taken of all sizes, from the most minute to its full growth of sixteen or seventeen inches, and never observed it to vary in colour, except that as it grows large it becomes more rufous and throws out spots, which are never observed till it exceeds six or seven inches, but it is invariably rufous brown in its infant state."

It is worthy of remark, that this little fish, representing in miniature the Three-Bearded Rockling, offers an instance perfectly analogous to the representation in an equally diminutive size of the five-bearded species, by $\mathrm{Mr}$. Couch's recent discovery of the Mackerel Midge. 


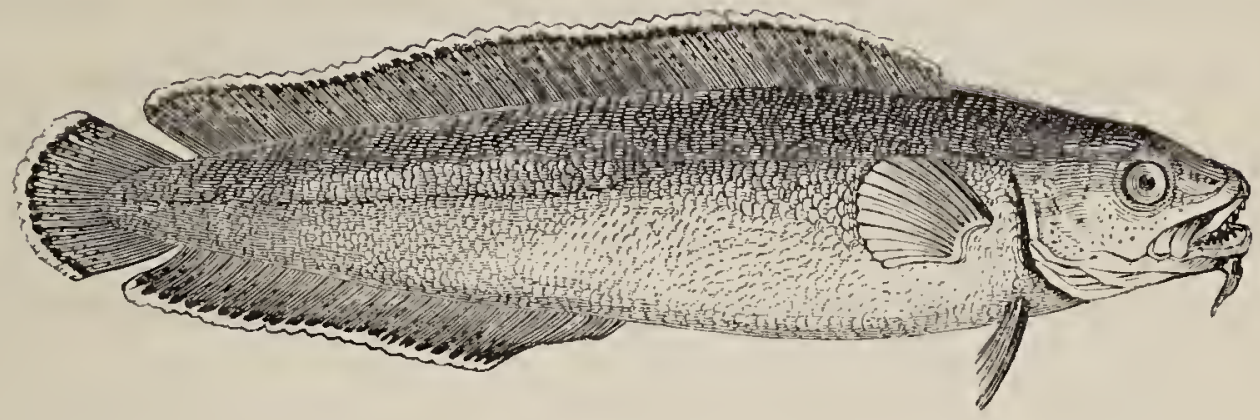

\section{THE TORSK, OR I'USK.}

Brosmius vulgaris, Cuvien, Règne An. t. ii. p. 334.

Brosmus ," Common Tusk, Flex. Brit. An. p. 194, sp. 90.

Gadus brosme, Torsk, Jenves, Brit. Vert. p. 452.

$\begin{array}{cll}\text { Gadus brosme, } & , \quad \text { Penn. Brit. Zool. vol. iii. p. 269, pl. } 37 . \\ ,, \quad, & \text { Scotch Torsk, } & \text { Donov. Brit. Fish. pl. 70. }\end{array}$

", ", Nilsson, Prod. p. 47, sp. 14.

Brosmius. Generic Characters.-Body elongated; a single dorsal fin extending the whole length of the back; one anal fin; one mandibular barbel.

The Torsk, or Tusk, is a northern species, which is only occasionally caught in the Forth, and is then brought to the Edinburgh market. It is found more frequently in the Orkney Islands, and swarms among those of Zetland, where it makes a very considerable article in their fish trade. It is caught with lines and hooks when fishing for Ling and Cod, and is salted and dried in the same manner. When eaten fresh, it is very firm and rather tough; which makes most people prefer it dry. It is one of the best fishes when cured, swells much in boiling, and parts into very thick flakes. I observed three examples of this fish, each about sixteen inches in length, in the London market, during the month of 
January 1831. They were brought from the North in the lobster-boats. The length assigned to this species by M. Nilsson is from eighteen inches to two feet, rarely three feet. Mr. Low says the largest he had heard of was three feet and a half. Mr. Donovan's specimen, which was brought alive to London in the well of a fishing boat, measured twenty-five inches.

But little being known in the South of the habits of this fish, an abridgment of Faber's account of it may be interesting.

"A northern fish, scarcely occurring below $60^{\circ}$ or above $73^{\circ}$; not migrating regularly, and therefore rarely seen by the ichthyologists of the South. Plentiful on the coasts of Norway as far as Finmark, among the Faroë Islands, and on the west and south coasts of Iceland, but rare on the north and east coasts. It must be uncommon in Greenland, as Fabricius only knew it from the report of the natives. It just touches the most northern point of Denmark, at Skagen in Jutland, where it is sometimes taken, but not at all in the south. It approaches the land early in the year in sculls, coming to Iceland in January; remaining there in company with the FiveBearded Rockling, and going away again late in summer. It lives in deep water, and is therefore seldom taken, even where most abundant. It prefers a rocky bottom, on which sea-weeds grow. Nothing is ever found in its stomach; and this has probably given rise to the saying, that it lives on the juice of sea-weeds. In April and May it spawns among the fuci along the coast. Is rarely taken with the Cod hooks, more frequently at the smaller lines, but sometimes it is caught by the Norwegian fishermen among the Holibuts. It must have less power of resisting the violence of the sea than its congeners, as it is thrown up dead in incredible 
numbers after a storm on the coasts of the Faroë Islands and the south coasts of Iceland. Its flesh is hard, but well flavoured. In Iceland it is seldom dried, and is eaten fresh, but Jan Olsen says that the fresh flesh is badly tasted, and that when dried it is best. In Norway it is treated like the Stockfish, but forms no branch of merchandise. The hard roe, according to Pontoppidan, has a good flavour. Its enemies are the larger species of Cod. It is much infested by a worm which forms a nidus in its skin, and produces rounded swellings." - Faber.

It is proper to observe that the Torsk of the Swedes is our Common Cod-fish, as noted on page 524. The Tusk, as the name is pronounced in Orkney and Zetland, is the $L u b b$ of Scandinavia. Low says that it is also called Cat-fish in Orkney, and Pennant mentions that in Zetland it has a second name of Brismak, arising probably from its resemblance to the arm of a balance so termed. The generic epithet Brosmius is merely a Latin form given by Cuvier to the Linnæan specific name Brosme.

Dr. Storer says that a fish which he believes to be the same as our Torsk, is not uncommonly seen in the Boston market in spring, but that in winter it is more rare. It is taken with the hook when fishing for deepwater Cod.

The description of this fish by Mr. Low is here adopted, with slight modification. The measurements of the specimen from which this description was taken were the following:- "The whole length twenty inches and a half: the greatest breadth four and a half, which was taken at the end of the pectoral fin; at the vent four inches; something more than half-way from the vent to the tail, two inches; at the tail, one inch and a quarter: the length of the head four inches; from the point of the nose to the commencement of the dorsal fin, six

VOL. I. 
inches; length of the dorsal fin, thirteen inches; from the point of the lower jaw to the vent, eleven inches; length of the anal fin, eight inches; tail-fin something more than two inches."

"The head small in proportion to the fish, with a single barbel under the chin: the upper jaw very little longer than the lower; in the jaws there are great numbers of very small teeth, and in the roof of the mouth a rough or toothed bone, much in the shape of a horseshoe; a pretty broad furrow runs from the nape to the commencement of the dorsal fin, which extends the whole length of the back to within about an inch of the tail; the caudal is rounded; the anal fin begins at the vent and ends at the caudal, but is not joined to it; the rays of the dorsal and anal fins are numerous, but their softness and the thickness of the investing skin hinder them from being counted with exactness: the edges of the dorsal, anal, and caudal fins, are white; the rest dusky: the pectoral fins are rounded, broad, and of a brown colour; the ventrals small, thick, and fleshy, ending in points; the body to the vent is roundish; the belly from the throat growing suddenly very prominent, continuing so to the vent, where it becomes smaller to the tail-fin; behind the vent the body is pretty much compressed; the colour of the head is dusky; the back and sides yellow, which tint becoming lighter by degrees, is lost in the white of the belly; the lateral line is scarcely discernible, but runs nearer the back than the belly, till towards the middle of the fish, in its passage backwards, it curves a little downwards, and runs straight to the tail."

The fin-rays, according to Mr. Donovan, are-

D. 49 : P. 21 : V. $5:$ A. $37:$ C. 35 . 


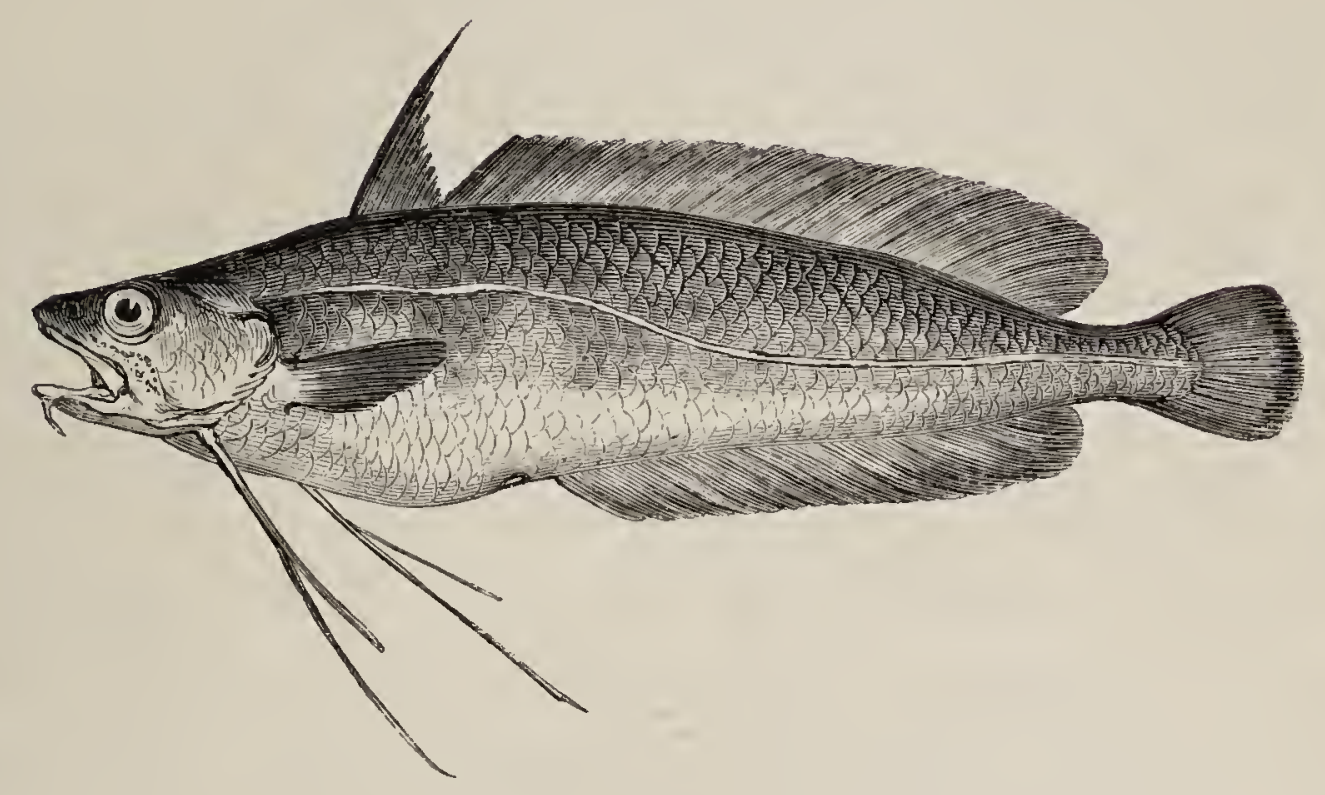

THE GREAT FORKED BEARD.

\title{
FORKED HAKE. HAKE'S DAME, Cornwall.
}

Phycis furcatus, Common Fork Beard, Fuem. Brit. An. p. 193, sp. 84.

\author{
,, ", Le Barbu, $\quad$ Cuvier, Règne An. t. ii. p. 335.
}

Barbus major, Great Forked Beard, RAY, Syn. p. 163, fig. 7 .

Blennius phycis, Forked Hake, Penn. Brit. Zool. vol. iii. p. 259, pl. 35.

Phycis furcatus, Common Fork Beard, Jenyns, Brit. Vert. p. 452.

Phycrs. Generic Characters. - Body elongated; two dorsal fins, the first short, the second long; ventral fins with a single forked ray; one barbel on the chin.

The Great Forked Beard was first discovered on the Cornish coast by Mr. Jago, and inserted by Ray, with a figure, in his Synopsis, as referred to. Pennant's fish was taken on the coast of Flintshire. A specimen appeared in Carlisle market in December 1833, which was caught near Bowness and communicated to me by T. C. Heysham, Esq. : this fish has also occurred at St. Andrews in Scotland, as noticed in the sixth volume of the Memoirs of the Wernerian Natural History Society, page 569. It is obtained occasionally in Cornwall; $\mathrm{Mr}$. 
Dillwyn has published a notice of one, measuring two feet in length, which was cast ashore in Oxwich Bay, and weighed four pounds; and Mr. William Thompson has noticed the occurrence of this fish in Ireland.

The figure here given is taken from a drawing by Mr. Couch, whose MS. contains the following notice of this species:- "The head flat on the top, compresssd at the sides, small in proportion to the body; eyes large; nostrils in a depression before them : mouth wide: under jaw shortest; teeth in both jaws fine; some larger teeth on the palate : a barbel at the lower jaw : body compressed, slender towards the tail, which is small in proportion; belly tumid; lateral line elevated at first, afterwards low; body and head with scales: two dorsal fins, the first elevated and pointed; second dorsal and anal fins long, expanded, bound down towards the tail-fin; the ventral fins composed each of a simple ray, very long, divided or forked, one of the divisions longer than the other; a few spines before the anal fin; tail-fin rounded, all the rays soft. Colour of the sides and back dusky brown; of the gill-covers sometimes greenish; fins, ex- cept the ventrals, dusky purple; belly whitish.

"This fish grows to the length of two feet: in a specimen of this size the longest portion of the ventral ray was eight inches, the shortest five inches and a half.

"Hake's Dame is the name by which alone this fish is known to our fishermen. It is not uncommon in Cornwall; but I have never seen it except in winter, when it seems to come into shallow water to spawn. It takes a bait, and is used as food, but is not much esteemed."

The number of fin-rays are-

. 1st D. $9: 2$ nd D. $58:$ P. $16:$ V. $1:$ A. $51:$ C. 18.

It is desirable to notice the specific characters of this fish, in order to distinguish between it and a Mediterra- 
nean species of the same genus, which, according to Cuvier, is the true Blennius phycis of Linnæus, and different from the British fish. The latter has the first dorsal fin triangular, much higher than the second, its anterior rays produced, and the ventral rays twice as long as the head. The Mediterranean fish, of which I possess a specimen, has the first dorsal fin low and rounded, very similar in character to that of the Burbot, as figured at page 5\%2 of this volume, with the ventral rays much shorter. A description and figure of this fish is given by Willughby, page 205 , pl. N. 12, fig. 3.

At the time of the publication of the first edition of this work, I had not seen a specimen of this fish. Since then I have received a very fine example from T. C. Heysham, Esq., of Carlisle, obtained on the west coast, where it has occurred lately in two or three instances: one was taken on the coast of the Solway Frith, near Whitehaven. $\mathrm{Mr}$. Couch has very kindly sent me two examples of this species, one an adult specimen, the other a young fish only three inches long, which was fished up in the shell of a large pinna, from a depth of fifty fathoms, in July 183\%. Mr. Thompson, in the An. of Nat. Hist. ii. p. 14, gives an extended description of a specimen taken at Carrickfergus, which had 64 rays in the second dorsal, and 54 in the anal. It was a male.

The third ray of the first dorsal was the tallest and measured three inches, the whole fish twenty-five inches long. The second dorsal and anal increased gradually in height and terminated rectangular-wise. The colour of the body was lilac grey, becoming paler towards the belly; the fins also lilac grey edged with black, the ventrals having' white tips. 'The stomach contained two small Whitings and several Crustaceans. 


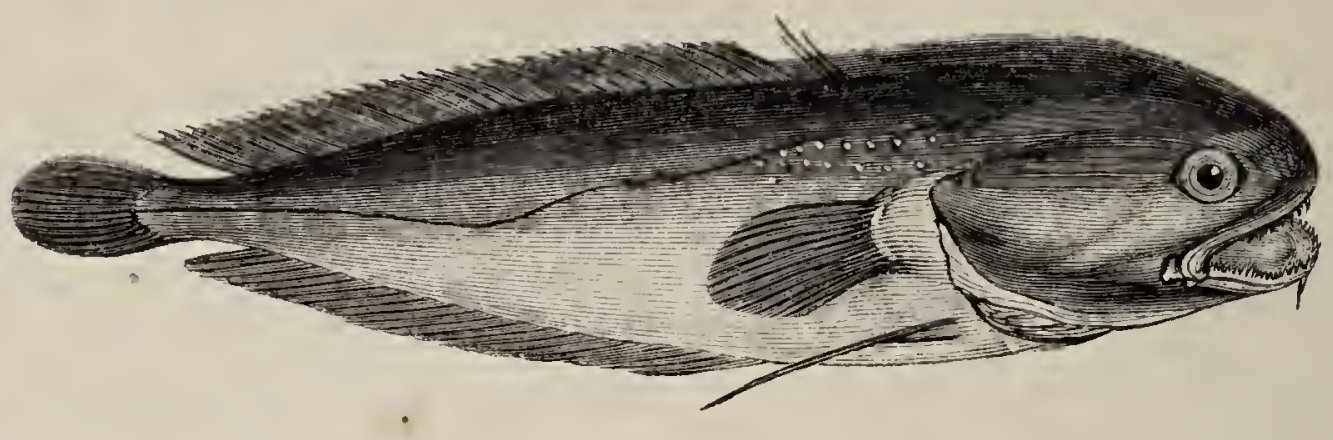

THE TADPOLE HAKE.

TOMMY NODDY, THE LESSER FORKED BEARD, TRIFURCATED HAKE.-PADD-TORSK, Sweden.

Raniceps fuscus, Whine, Cat. Brit. Fish. Brit. Mus.

Blennius fuscus, Sтröм, Söndm. sid. 322.

Gadus raninus, Brünn. Dansk. vid. Selsk. Skr. xii. 291.

Barbus minor, Ray (Jago), Syn. Pisc. 164, f. 8.

" " Covor, Linn. Trans. xiv. p. 75.

Batrachoides trifurcatus, Tadpole Fish, Pens. Brit. Zool. iii. p. 272, pl. 38. Raniceps trifurcatus et Jago, Fuen. Brit. An. p. 194.

" ", Lesser Forked Beard, YARr. Brit. Fish. Ed. 1st and 2nd.

RANICEPS. Generic Characters.-Gadoid, tadpole-like fishes, having a great, broad, depressed head, and a tapering and much compressed body and tail, the latter being very narrow in the brief interval between the three vertical fins. First dorsal very small, followed immediately by the second one, which is long and even-edged, and is opposed to the similar anal; ventrals six-rayed, tapering into a long filament. A barbel under the chin. Teeth on the jaws, front of the vomer, pharyngeals, and tubercular gillrakers, acute. Scales small, tender, sunk in the skin of the whole body, head, and branchiostegous membranes. Branchiostegals seven. No pyloric cæca. Swim-bladder divided.

Dr. George Johnston, in an anniversary address read to the members of the Berwickshire Naturalist's Club in September 1832, says, "Of the Tadpole fish, which is 
one of the rarest of the British species, and previously known only as an inhabitant of the shores of Cornwall, I had the pleasure of exhibiting to you a living specimen, which was captured in Berwick Bay. When alive, and when recently dead, the body appeared everywhere smooth and even; but after having lain three days on a plate and become a little shrivelled, there appeared an obscure row of tubercles, running backwards from the pectoral fins,-and these pea-like tubercles could be more readily distinguished by drawing the finger over the skin. I would call attention to this fact, because the only good distinction between the Raniceps trifurcatus and R. Jago of Dr. Fleming is derived from the presence of these tubercles; in the former, the lateral line is said to be tuberculated above the pectoral fins, in the latter it is said to be smooth: but here we have a specimen which when alive exhibits the character of Jago,-when dead, that of the trifurcatus; and hence I am induced to think that both are the same animal, having the tubercles more or less prominent and obvious according to the leanness or other conditions of the body."

Cuvier, in the Règne Animal, places the raninus of Ström and Müller as distinct from the trifurcatus of Pennant, but Fries in the Skandinaviens Fiskar has more correctly considered them to be merely different appellations of the same species, and the same view was taken in the former editions of British Fishes that were antecedent to the excellent work on Scandinavian fishes, to which we refer for an excellent coloured plate of this species. Dr. Fleming, in keeping separate the fishes of Jago and Pennant, did so in the absence of specimens for comparison.

Mr. Jonathan Couch says that the only example of this fish which he ever saw was taken on rocky ground 
with a hook in the month of April; the remains of an echinus were found in its gut. Other specimens have been taken since then on the Cornish coast, as mentioned by Mr. R. Q. Couch in the Zoologist; and also both on the eastern and western coasts of Scotland, where Dr. Parnell says it feeds on small insects and spawns in April. Mr. Newman in the Zoologist (4673) mentions that the Tadpole Hake is occasionally brought to Billingsgate Market among Sprats, and the same work for 1853 (4097) contains an elaborate description by $\mathrm{Mr}$. Thompson of one taken off Weymouth, on the wreck of the Abergavenny, about five miles from the shore, by a hook baited with a lug-worm (Arenicola piscatorum). This gentleman noticed ten tubercles placed in a row above the pectoral fin, and considered them to be the ends of bones protruding from among the muscles. Dr. Johnston's description was quoted in the former editions of this work; it agrees with that of $\mathrm{Mr}$. Thompson, and in all essential particulars with the following one, of a specimen four inches and a half long, obtained in the river Crouch in Essex, by the Rev. S. W. Waud in May 1858, and obligingly transmitted to us.

A general idea of the form of this fish is, as Dr. Johnston has observed, correctly conveyed by the epithet of Tadpole fish. The head is large, broad and depressed; and when viewed from above, its anterior outline is seen to be the segment of a circle; or if the whole head be included, the half of a very blunt ellipse. Its length is one fourth of that of the whole fish, excluding the short caudal which forms only about a tenth of the entire length; and its breadth at the gill-covers where it is greatest is only a little inferior to its length and exceeds a fifth of the length of the fish including the caudal. Seen in profile the snout appears rounded vertically for a 
brief space, projects beyond the mouth, and then slopes gradually to the dorsal, along whose base the descent is gradual and straight to the caudal; in the same degree the under profile slopes upwards along the base of the anal, in front of which fin the belly is somewhat protuberant, and the under aspect of the head flattish. The three vertical fins approach near to each other, but do not actually meet, and the interposed part of the tail is very narrow. From the pectoral fins the compression of the body increases posteriorly, the tail becoming very thin. The greatest height is behind the shoulder and about equals the breadth there.

The eye is round, is situated in the anterior third of the length of the head, and almost touches the profile. Close before it are the nostrils. The mouth is wholly under the snout, and its orifice has the same semicircular course, its corners passing the eyes. Its upper border, formed entirely of the slender premaxillaries, retreats under an edge of skin or preorbitar lip, and has a narrow proper or premaxillary lip which folds back on the bone. The edge of this lip is black, but the inside of the mouth and all the folds that are concealed by the open jaws are white, including the integument clothing the maxillary. This bone is toothless, and lying behind the slender limb of the premaxillary does not enter into the composition of the orifice of the mouth, and is not visible unless when forcibly brought into view by distending the jaws. The amount of protrusion of which the upper jaw is naturally capable is very inconsiderable. The mandible fitting the premaxillary curve shuts rather within it, and neither of the jaws can be seen when the fish is examined directly from above. A short conical barbel depends from the chin. Both jaws and a transverse plate on the front of the vomer are armed 
with crowded small acute teeth; and on the inside of the mouth and on the tongue numerous small papillæ that look like teeth stand up, but the integument is smooth to the touch. The single specimen which is the object of this description was not sacrificed for internal examination, but Mr. Fries says that the upper pharyngeals consist of two plates, the posterior one being crescentic, and that the lower ones are oval, all of them furnished with teeth; four branchial arches are provided on both their edges with knob-like rakers. The rather loose skin of the head conceals the opercular bones entirely. An ample gill-opening commencing above the root of the pectoral descends below that fin, and then runs forward between the limbs of the jaw to opposite the corner of the mouth. A rather narrow branchiostegous membrane is supported by seven branchiostegals.

With the exception of the lips, the skin of the whole head and body is bedecked with small scales sunk in its thickness. When alive the fish is covered with mucus, which Fries says gives it a smooth and glistening appearance, and the lateral line he says is scarcely perceptible in the living fish. In the specimen now before us we cannot trace it at all, except in the supra scapular region and above the pectoral fin, where two not very regular rows of mucous pores can be made out with aid of a lens. The integument here seems to be inflated as far as under the front of the second dorsal, forming on both sides a tapering elevation which otherwise does not differ from the rest of the skin, and presents no tubercles either to the finger or eye. Posteriorly the lateral line is imperceptible, there being no pores visible to indicate its course ; but from the thinness of the fish, the line of the decussation of the muscles corresponding with the spinal column is very faintly shown. 
The vent is situated at the second fifth of the length, caudal excluded, and immediately behind it is the small efferent orifice of the urinary bladder and genital organs.

The ventrals situated well apart from each other, and close to the gill-opening taper into a fine thread-like point which passes the vent. If handled, the point of the first ray and that of the last four conjoined ones becomes detached from the second, which is by much the longest. Fries represents the ventrals with three separated and curving filamentous points in the living fish. The pectorals are small, and when spread out rounded. In a mesial furrow over the basal third of the pectorals stands the minute subulate first dorsal of three rays; and immediately behind it commences the even second dorsal which extends to the base of the caudal. The anal commencing more posteriorly is otherwise like the second dorsal, and reaches as far. The caudal is obovate, rounded broadly to the extremity, but tapering forwards at its base; this form causes it to appear to be more widely separated from the other two vertical fins than it really is as they approach close to its base. A correct enumeration of the rays would have necessitated the removal of the integument, but the numbers ascertained without injuring the specimen were identical with, or closely approximated to, the following fin-formula, which is copied from the Skandinaviens Fiskar.

Br. 7 : D. 3-65: A. 60 : P. 21 to 23 : V. 6 : C. 35.

From the same work we gather that its food consists of soft marine animals, such as Crustaceans, Mollusks, and Star fishes: that the structure of its intestines is essentially that of the other Gadoids, except that there are no pancreatic cæca, there being only the merest indication of two rudinentary projections: that the swim- 
bladder is divided into two parts, the anterior one being the biggest: and that while alive the fish has an uniform deep brown colour, with an intense and beautiful blue lustre that varies with the incidence of the light. The border of the second dorsal, and of the commencement of the anal, together with the upper edge of the caudal, are white. As soon as the fish dies it becomes pale reddish and loses its blue glance. On account of the dull black colour it assumes on the western rocky coasts of Norway it gets the name of Smed or Smith, and it is frequently named Paddål, the Frog, or in Scotch the Paddock.

The following passage is quoted from Mr. Couch's paper referred to above:-

"Mr. Jago, whose name occurs at the head of a list of fishes at the end of Ray's Synopsis Piscium, was a native of Cornwall, and a minister of the Church of England. When Bishop Trelawney, so well known as one of the six bishops who were committed to the Tower by James the Second, endowed the Chapel of Ease at East Looe, and thereby obtained the consent of the Rector of St. Martin to name the curate, he appointed his friend Mr. Jago to the curacy; and the latter embraced the favourable opportunity thus placed within his reach to make collections for an intended History of Cornish Fishes, which, however, he never perfected. Not having been married, his MS. and drawings at his decease came into the possession of his friend Mr. Dyer, by whom they were delivered to Dr. Borlase, the author of the History of Cornwall."-Jon. Couch, Esq. 


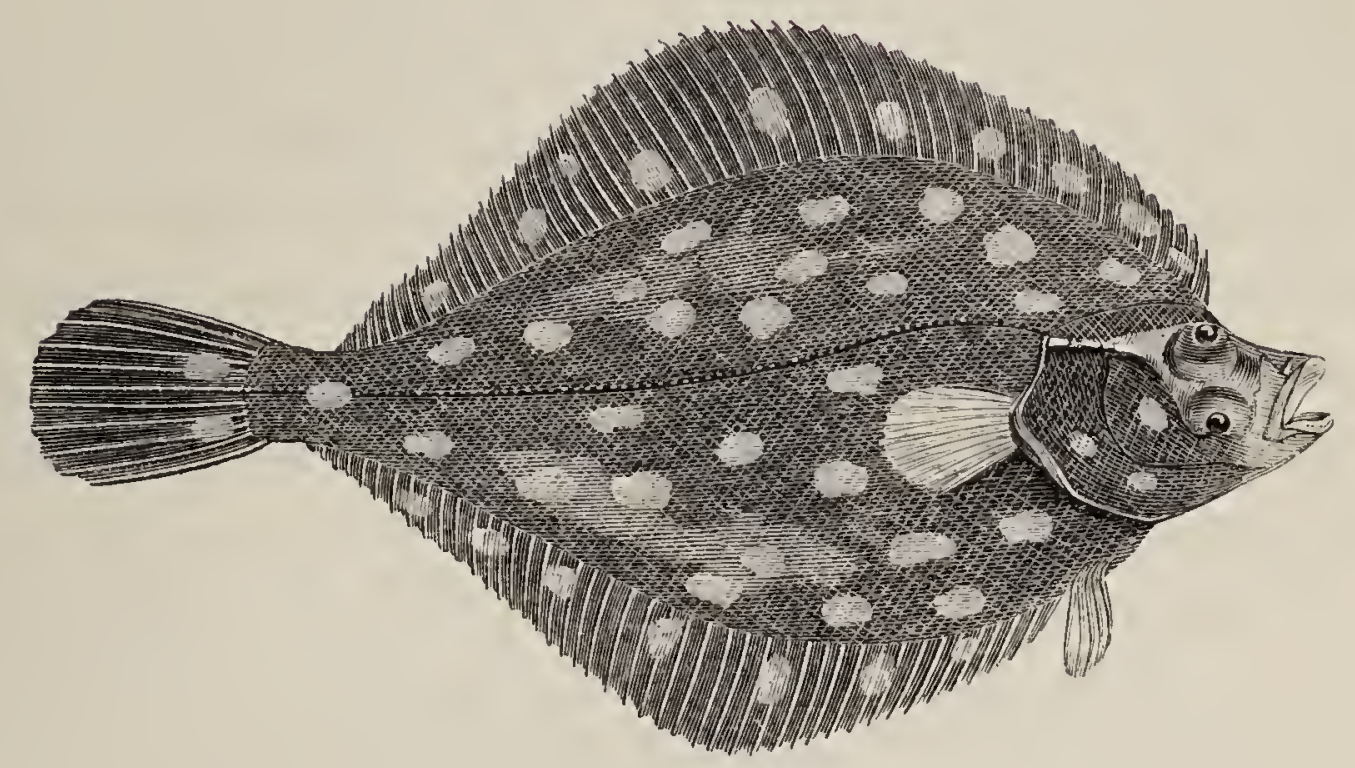

THE PLAICE.

\section{Fluke, Scotland.-sPätTFlundra, Sweden.}

Platessa vulgaris, Plaise, Flem. Brit. An. p. 198, sp. 103.

", $\quad, \quad$ Cuvier, Règne An. t. ii. p. 338.

Pleuronectes platessa, Linamus. Bloch, pt. ii. pl. 42.

$, \quad, \quad$ Plaise, Penn. Brit. Zool. vol. iii. p. 304.
,$\quad$ Donov. Brit. Fish. pl. 6.

Pleuronectide. Family Characters. - Want of symmetry; cranial bones distorted; sides of the extremely compressed body differing in colour; thin edges of the back and belly fringed by the dorsal and anal fins. Right and left jaws unequal. No air-bladder. Branchiostegals six.

Platessa. Generic Characters.--Teeth on the jaws trenchant, uniserial ; on the pharyngeals, usually molars; eyes separated by an elevated ridge, and for the most part on the right side, the inferior eye being farthest forward. Three small pancreatic crca. Scales smooth in some species, ciliated in others; anal spine also present in some, absent in others.

\section{The want of symmetry so unusual in vertebrated} animals is the most striking and distinctive character of the fishes of this family; the twisted head with both eyes

* Having dissimilar parts, i. e. sides of face and body, limbs, \&c. 
on the same side, one higher than the other, not in the same vertical line, and often unequal in size; the mouth cleft awry, and the frequent want of uniformity in those fins that are in pairs, the pectoral and ventral fins of the under side being generally smaller; and the whole of the colour of the fish confined to one side, while the other side remains white,-produce a grotesque appearance: yet a little consideration will prove that these various and seemingly obvious anomalies are perfectly in harmony with that station in nature which an animal possessing such conformation is appointed to fill.

As birds are seen to occupy very different situations, some obtaining their food on the ground, others on trees, and not a few at various degrees of elevation in the air, so are fishes destined to reside in different depths of water: the Flatfishes and the various species of Skate are, by their depressed form of body, admirably adapted to inhabit the lowest position, where they occupy the least space, among their kindred fishes.

Preferring sandy or muddy shores, and unprovided with swimming-bladders, their place is close to the ground, where, hiding their bodies horizontally in the loose soil at the bottom, with the head only slightly elevated, an eye on the under side of the head would be useless; but both eyes placed on the upper surface affords them an extensive range of view in those various directions in which they may either endeavour to find suitable food, or avoid dangerous enemies. Light, one great cause of colour, strikes on the upper surface only; the under surface, like that of most other fishes, remains perfectly colourless. Having little or no means of defence, had their colour been placed only above the lateral line on each side, in whatever position they moved, their piebald appearance would have rendered them conspicuous 
objects to all their enemies. When near the ground, they swim slowly, maintaining their horizontal position; and the smaller pectoral and ventral fins on the under side are advantageous where there is so much less room for their action, than with the larger fins that are above. When suddenly disturbed, they sometimes make a rapid shoot, changing their position from horizontal to vertical: if the observer happens to be opposite the white side, they may be seen to pass with the rapidity and flash of a meteor; but they soon sink down, resuming their previous motionless, horizontal position, and are then distinguished with difficulty, owing to their great similarity in colour to the surface on which they rest.

The peculiar form of the head is owing to the distortion of certain cranial bones, and especially of the midfrontal and presphenoid: but there is no want of symmetry in the spinal column posterior to the scapular arch. The interhæmal and interneural bones are in pairs right and left, but the dermal spines they support are single. The vent is situated very far forward between the ventral fins and the commencement of the anal fin; and the abdominal cavity extends backwards to a considerable distance, the intestine returning by a convolution.

M. Quensel divides the family into two sections, viz.,A. Pleuronectes having complete jaws, not covered with scales; the maxillary dilated and free at its extremity; the mandible with cutaneous folds between its limbs, at the chin. Gill-opening extending above the opercular angle or at least above the pectoral. The lower eye more anterior than the upper one, and the nostrils distant from the jaws, that of the blind side being near the dorsal edge.

B. Solea, in which the jaws are covered with scales, the 
superior one not fully developed, and the scaly mandible not showing the usual folds at the chin. Gill-openings wholly below the pectorals. The inferior eye farther back than the superior one. Nostrils on both sides near the jaws. All the fin-rays divided, no spine in the anal. - Vet. Acad. Handl. 1806.

Most of the Flatfishes are deservedly in great request as articles of food, and as they bear carriage well, and remain in good condition for several days after death, they are consumed in considerable quantities in the interior of our island. The number of species diminishes as the degrees of northern latitude increase. In this country we have sixteen species; at the parallel of Jutland, Denmark, and the islands at the mouth of the Baltic, there are thirteen; on the coast of Norway they are reduced to ten species; at Iceland the number is but five, and at Greenland only three.

The Plaice is described and figured by Rondelet, and was known to the older naturalists long before his time. It inhabits sandy banks and muddy grounds in the sea; and among the Orkney Islands is caught by lines and hooks; but as it is not of large size there, it is not much sought after: it is common, however, in the Edinburgh market, where the small ones are called Fleuks. On the English coast the Plaice is obtained in abundance generally wherever either lines or trawl-nets can be used; and in Ireland, this fish is taken from the county of Cork round Cape Clear, along the whole Atlantic coast.

Plaice, called there as elsewhere in Scotland, Fleuks, abound on the sandy flats of the Solway Firth, and are taken by the fishermen and their families wading in the shoal water with bare feet. When a fish is felt, it is pressed by the foot firmly against the bottom until it can be secured by the hand and transferred to the basket. 
Long practice gives the dexterity which renders this kind of fishing successful.

The Plaice spawns in February or March, and is considered to be in the finest condition for the table at the end of May. Diamond Plaice is a name attached to those which are caught at a particular fishing-station off the Sussex coast, which is called the Diamond ground; they are remarkable for the purity of the brown colour and the brilliancy of the spots.

The Plaice feeds on soft-bodied animals generally, young fish and small crustaceans, and has been known to attain the weight of fifteen pounds; but one of seven or eight pounds' weight is considered to be a Plaice of large size. It is taken sometimes in almost incredible numbers, and so great a glut occurred once in Billingsgate market, that, although crowded with dealers, hundreds of bushels of Plaice remained unsold. Great quantities of the fish, averaging three pounds' weight each, were sold at one penny per dozen, and one salesman, having in vain endeavoured to sell a hundred bushels at the rate of fifty fish for four-pence, left them with $\mathrm{Mr}$. Goldham, the clerk of the market, requesting him to sell them for anything he could get. Unable to dispose of them otherwise, Mr. Goldham, by direction of the Lord Mayor, divided them among the poor.

In some parts of the North of Europe, where from the rocky nature of the soil the sea is remarkably trans. parent, Plaice, and some other Flatfish of large size, are taken by dropping down upon them, from a boat, a doubly-barbed short spear, heavily leaded to carry it with velocity to the bottom, with a line attached to it, by which the fish, when transfixed, is hauled up.

In East Friesland the Plaice has been transferred to fresh-water ponds, wherein it thrives well. Like other 
ground-fish, all the Pleuronectida are very tenacious of life.

The length of the head, compared to the whole length of the head, body, and tail, is as two to nine, and the depth of the solid part of the body, without including the dorsal or anal fins, rather exceeds one-third of the whole length; the form subrhomboidal; the mouth is rather small, and the obtuse teeth contiguous so as to produce an incisorial edge; the upper eye is the largest, and is placed rather more backward than the lower eye ; there is a strong and prominent bony ridge between the orbits, and several tubercles form a curved line from the posterior part of the ridge to the commencement of the lateral line: the preoperculum is situated vertically over the origin of the ventral fin ; and the operculum terminates in an angle upon the base of the pectoral fin; the lateral line is prominent, and commencing at the upper margin of the operculum, is arched over the pectoral firl, then runs straight along the middle of the fleshy portion of the tail, and over the membrane connecting the central caudal rays. The dorsal fin commences over the upper eye; its longest rays are rather behind the middle of its whole length: the anal fin, preceded by a spine, begins under the origin of the pectoral fin; its longest rays are rather before its middle: both dorsal and anal fins end on the same plane, and short of the end of the fleshy portion of the tail, which, as well as the caudal rays, is narrow and elongated; the tail is rounded.

The fin-rays in number are-

$$
\text { D. } 73: \text { P. } 11: \text { V. } 6: \text { A. } 1+55: \text { C. } 16 .
$$

The body is smooth on both sides, the scales small: the colour of the upper or right side being a rich brown, with a row of bright orange-red spots along the dorsal and anal 
fins, and other spots of the same colour dispersed over the body; the under side is entirely white. Young Plaice have frequently a dark spot in the centre of the red ones.

The Plaice, the Flounder, and the Craig-fluke, which are arranged in sequence in this work, agree in having smooth or cycloid scales and a spine in the anal fin.

The Pleuronectida with the eyes and the colour on the right side of the body are distinguished by the term dextral fishes. Plaice with the belly dark or piebald are of occasional occurrence, and generally pass under the names of Black-bellied Flounders.

The vignette represents the bones of the head in the genus Platessa.

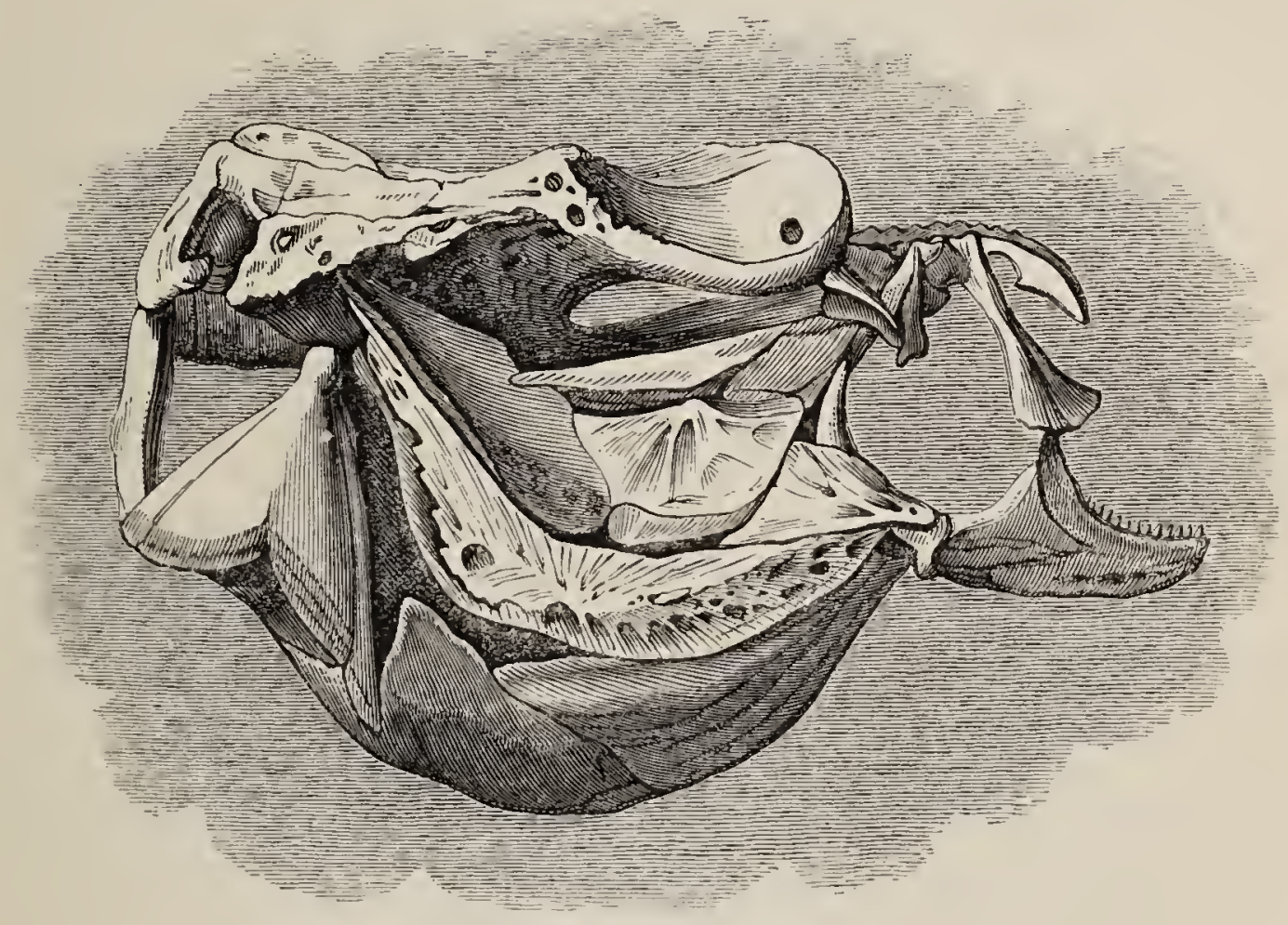


ANACANTHINI.

PLEURONECTIDA. ANISOMERI.

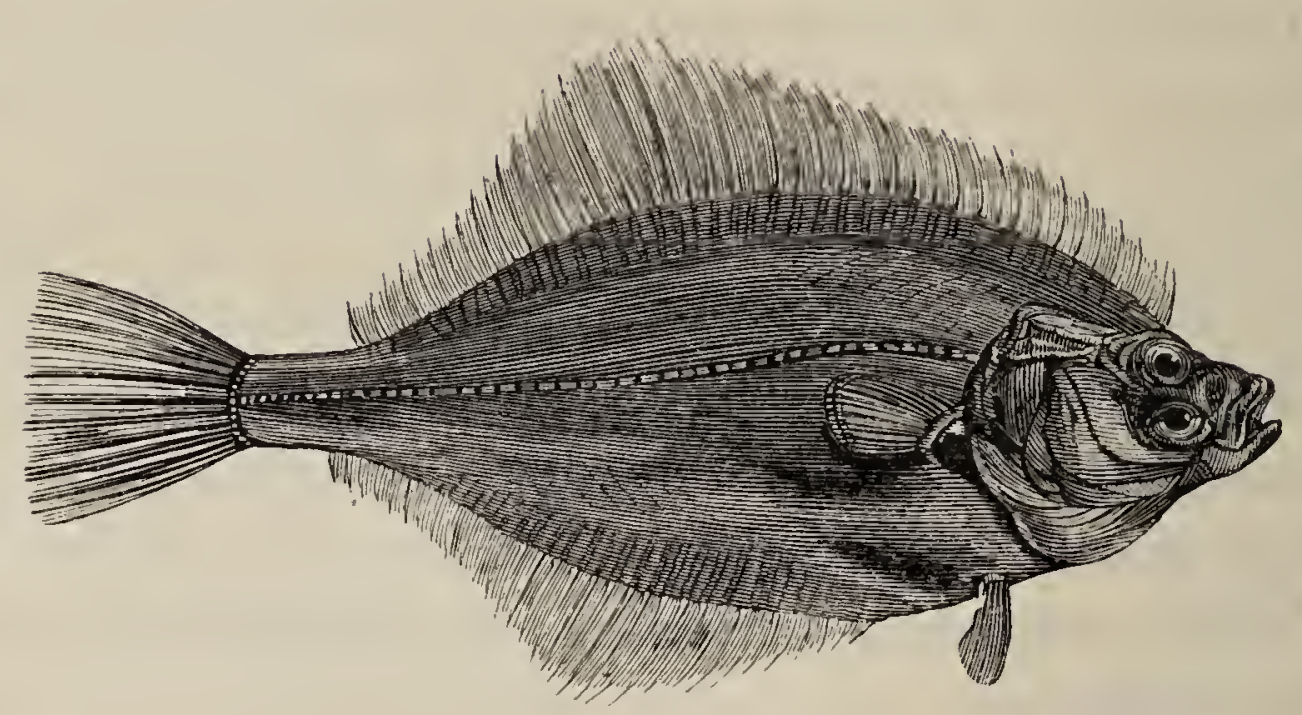

\section{THE FLOUNDER.}

FLOOK, Merret.-MAYOCK FLEUKE, Edinb.-BUTT.SKRUBbFlundra, Sweden.

Platessa flesus, Flounder, FleM. Brit. An. p. 198, sp. 104.

,, ,, Le Flet, Cuvien, Règne An. t. ii. p. 339.

Plcuronectus fluviatilis, Fluke, Wrllugins, p. 97, F. 4.

\begin{tabular}{|c|c|c|c|}
\hline ", & flesus, & & LINNAUS. Bloch, pt. ii. pl. $44 \& 50$. \\
\hline$"$ & "9 & Flounder, & 1. vol. ili. p. 305 . \\
\hline & ," & ", & Donov. Brit. Fish. pl. 94. \\
\hline & , & ," & Jenyss, Brit. Vert. p. 455. \\
\hline
\end{tabular}

The Flounder is one of the most common of the Flatfish, and is found in the sea and near the mouths of large rivers all round our coast, being more particularly abundant where the bottom is soft, whether of sand, clay, or mud. All the bays, creeks, and inlets of Orkney produce it, according to $\mathrm{Mr}$. Low; and it is taken in abundance in different parts of Scotland, where it is called Fluke and Mayock Fleuke,-a term having re- 
ference to the flattened form of the fish. It is common at Berwick and Yarmouth, at which latter place it is called a Butt-a northern term; and those Flounders that are caught in the extensive backwaters behind Yarmouth, where there is a considerable deposit of mud, are in consequence so dark in colour as to be distinguished from the lighter-coloured ones caught on the sands of the sea, by the name of Black Butts. This similarity in colour between certain fishes and the bottom upon which they feed has been already referred to as affording security to the defenceless from the attacks of their enemies, and exhibits a beautiful instance of provision made for the preservation of species. In Sweden, according to Linnæus, this fish is called Flundra, from which our word Flounder is probably derived, and is said to refer to its manner of swimming when close to the ground.

The Flounder lives and thrives whether stationary in the sea, the brackish water, or the fresh water. In the Thames it is taken as high up as Teddington and Sunbury: Mr. Jesse mentions having seen the Flounder pursue Minnows with great eagerness into the shallows where the Mole runs into the Thames at Hampton Court. This species is caught in considerable quantities from Deptford to Richmond by Thames fishermen, who, with the assistance of an apprentice, use a net of a particular sort, called a tuck-net, or tuck-sean. One end of this net is fixed for a short time by an anchor or grapple, and its situation marked by a floating buoy; the boat is then rowed, or rather sculled, by the apprentice in a circle, the fisherman near the stern handing out and clearing the net: when the circle is completed and a space inclosed, the net is hauled in near the startingpoint in a direction across the fixed end. 
Flounders ascend rivers generally. Colonel Montagu says they are found up the Avon within three miles of Bath. They have been successfully transferred to freshwater ponds : being long-lived out of water, the carriage from one place to another is a matter of very little difficulty. Along our southern shore the Flounder is very common; and it occurs on the Irish coast from Cork up the eastern side to Antrim, and thence northward and westward to Donegal.

The Flounder feeds upon aquatic insects, worms, and small fishes, and has been known to acquire the weight of four pounds, but is not usually seen nearly so large. It spawns in February or March, and the young Flounders may be seen alive by the end of April. Varieties of the Flounder occur much more commonly than those of any other species of Flatfish. I have before me, while now writing, specimens without any colour on either side; specimens coloured on both sides; and specimens with both eyes and the whole of the colour on the left side instead of the right. Those without any dark colour on either side are albino varieties, through the transparent skins of which the colour of the bloodvessels and muscles has suggested the trivial names of rosea and carnaria to the authors who considered them species. The Pl. passer, figured by Bloch, pt. ii. pl. 50, is certainly only a reversed Flounder, having the eyes and the colour on the left side;-a variety so common, that it is scarcely possible to examine a peck measure of Flounders without finding one or more reversed specimens. One of the most remarkable specific distinctions of the Flounder, the series of denticulated tubercles placed between the rays of the fins along the dorsal and abdominal lines, is distinctly figured in both Bloch's plates as quoted, pt. ii. plates 44 and 50 . 
The length of the head is to the whole length of the fish as one to four; and the greatest width of the body, without the fins, is to the whole length of the fish as one to three: the mouth is small: the teeth placed in one row in each jaw are small and numerous; the upper eye is situated nearly over the lower one; the lateral line is but very slightly curved over the pectoral fin, and is marked with numerous rough stellated tubercles at its commencement, more of which are arranged in two lines, one above, the other below the lateral line throughout its course: the body is smooth; the scales small; the dorsal and abdominal lines armed with a series of denticulated tubercles, one in each space, between the rays, and alternating with them; the dorsal fin extends from the eye almost to the tail ; the ventral fin is placed a little farther back than in the Plaice, under the margin of the operculum; the anal fin, preceded by a spine directed forwards, also commences farther back; both dorsal and anal fins terminate on the same plane; the fleshy portion of the tail is narrow, its rays elongated, and almost square at the end. The fin-rays in number are-

$$
\text { D. } 55: \text { P. } 11: \text { V. } 6: \text { A. } 1+42: \text { C. } 14 \text {. }
$$

The colour of this species is variable, the shades of brown depending on the nature of the ground from which the fish is taken, but generally mottled with darker brown; the fins light brown, occasionally varied with patches of darker brown, yet generally lighter than the body. Examples sometimes occur with a few indistinct reddish spots on the upper surface; but the roughness of the lateral line in the Flounder, and its smoothness in the Plaice, is a distinguishing character in these two species, however similar they may happen to be in colour or size. 


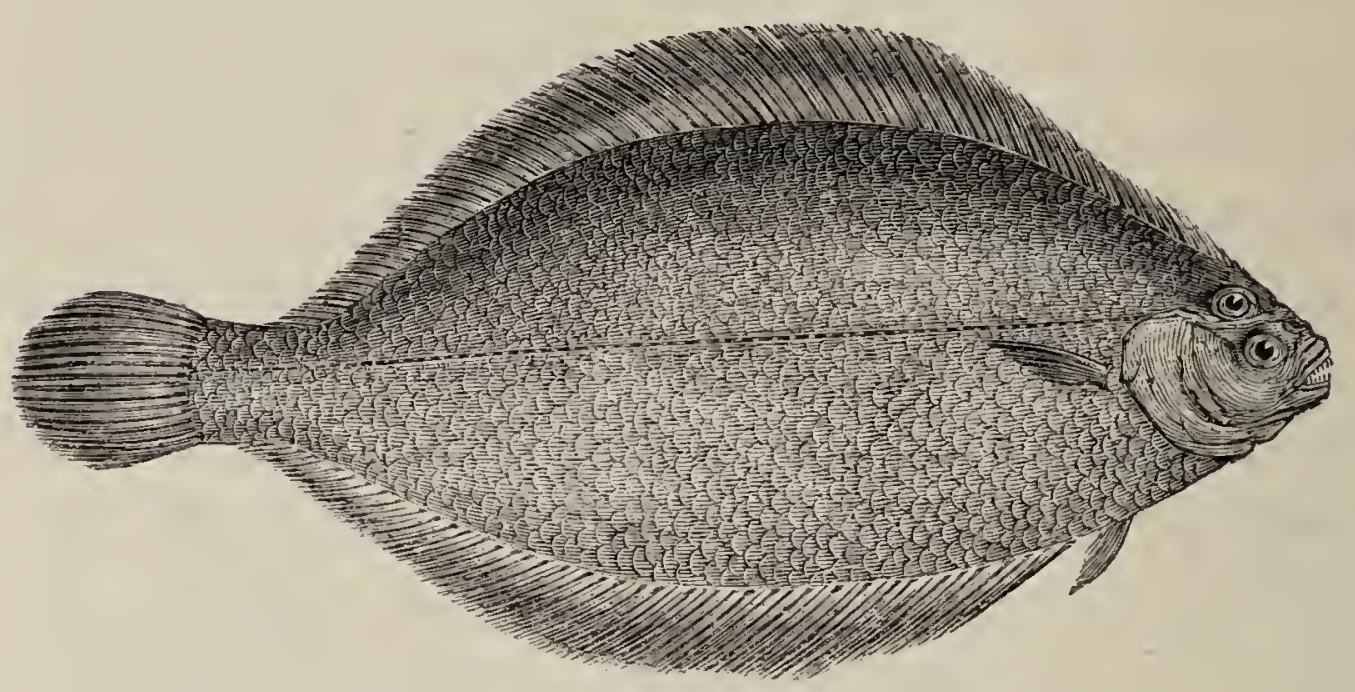

THE POLE, OR CRAIG FLUKE.

SKäRrFuUndra, Sweden.

Platessa cynoglossus, Fries, Act. Holm. 1838.

" Pola, The Pole, Jenxws, Man. Brit. Vert, p. 458, sp. 145.

", " Craig Fluke, Parneli, Ed. Phil. J. July 1835, p. 210.

, cynoglossus, Linn. Syst. Nat. i. p. 456.

, , Gronov. Mus. Ichth. i. p. 14, sp. 39.

, nigromanus, Nilss. Prod. Ichth. Scand. p. 55.

ThIs Platessa, which is rare on our coast, agrees with the preceding two in having obtuse contiguous teeth on the jaws, smooth scales and an anal spine, but it is readily distinguished by its more oval outline and slighter approach to that rhomboidal form which they exhibit when their fins are displayed. In the month of May $1833 \mathrm{I}$ observed a specimen twelve inches long in the shop of Mr. Groves of Bond Street: and on pointing out the differences between this and other Flatfishes by comparison with several species among which it was placed for sale, and mentioning its rarity, $\mathrm{Mr}$. Groves immediately sent it to the Zoological Society for preservation, ob- 
serving that he had not noticed the difference, and did not recollect that he had ever seen that species before. From this specimen the woodcut was executed. In May 1835, Dr. Parnell very kindly sent to me frorn Edinburgh, for examination, a skin of this species nineteen inches in length, with several other preserved skins of fishes taken in the Frith of Forth, where the Craig Fluke, as this fish is there called by the fishermen, is occasionally taken in the months of April, May, and June.

These are the only examples of this fish taken in our seas that I was acquainted with in 1841; but $\mathrm{Mr}$. Thompson had procured six specimens in Belfast market in 1837, and his detailed account of them is reprinted in his Natural History of Ireland published after his death. He states that the Pole is taken on the north-east, east, and south-west coasts of Ireland.

The head is small; its Iength compared to that of the whole fish is as one to six : the greatest breadth of body, dorsal and anal fins excluded, is to the whole length rather more than a third; including the dorsal and anal fins, rather less than a half: the form of the body is an elongated oval, pointed at each end : the mouth is small ; and the lips thin; a single row of teeth exists in each jaw, close set, smooth, incisor-like, with thin and even edges: the eyes are rather large; the upper one ranging vertically behind the line of the lower, with the usual intervening bony ridge; the irides are orange: the pectoral and ventral fins small: the dorsal and anal fins extend very nearly the whole length of the body, and both end on the same plane; the rays about the middle of each are the longest; those at the extreme ends, before and behind, being very short: tail is rather long and is rounded. 
The fin-rays in number in one specimen were-

$$
\text { D. } 109: \text { P. } 11: \text { V. } 7: \text { A. } 1+93: \text { C. } 19 .
$$

Br. 5 : D. 102 to $110:$ P. $10-12:$ V. $6:$ A. 88 to 100 : according to Thompson.

The body is quite smooth; the scales rather large, deciduous, but neither ciliated nor roughened in any way beyond a few radiating striæ; the head is smooth, without tubercles; the lateral line is straight, and extends, as in all the other species of Platessa, to the end of the membrane connecting the caudal rays. The colour of the body is an uniform yellowish brown; the edges of all the fins being darker; when dried for preservation, the colour of the skin of the body becomes clove-brown; that of the fins brocoli-brown.

The vignette below represents the Thames Peter-boat rigged with a fore-sail and main-sail, as used by the fishermen about Greenwich, and from thence along the course of the river downwards.

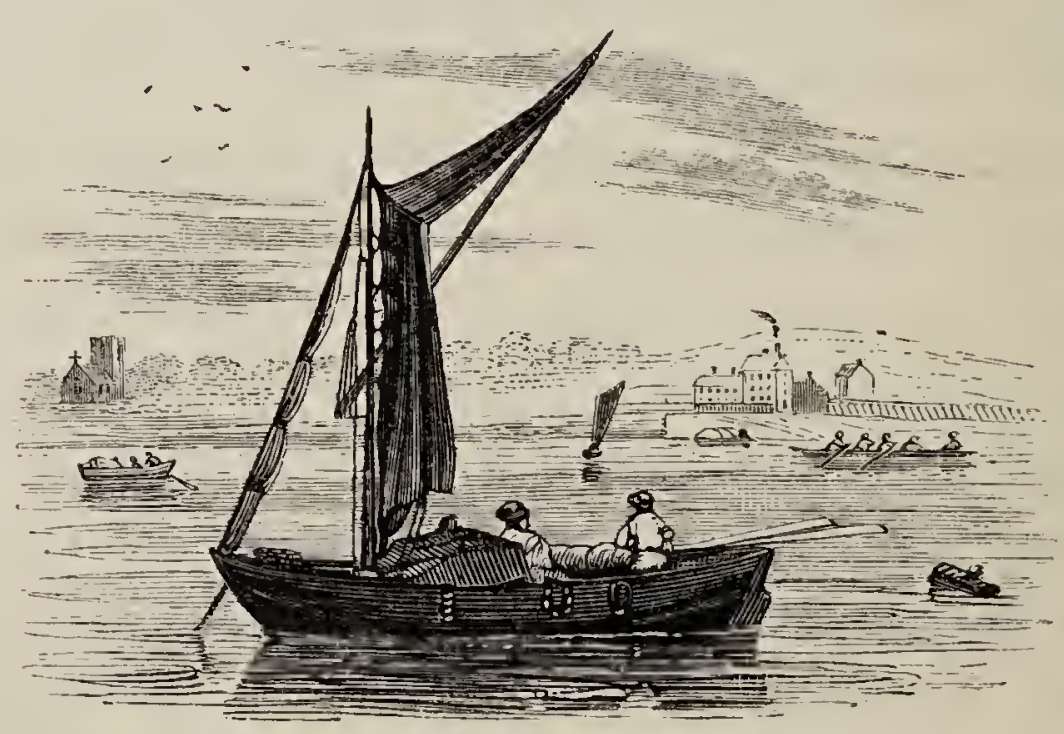




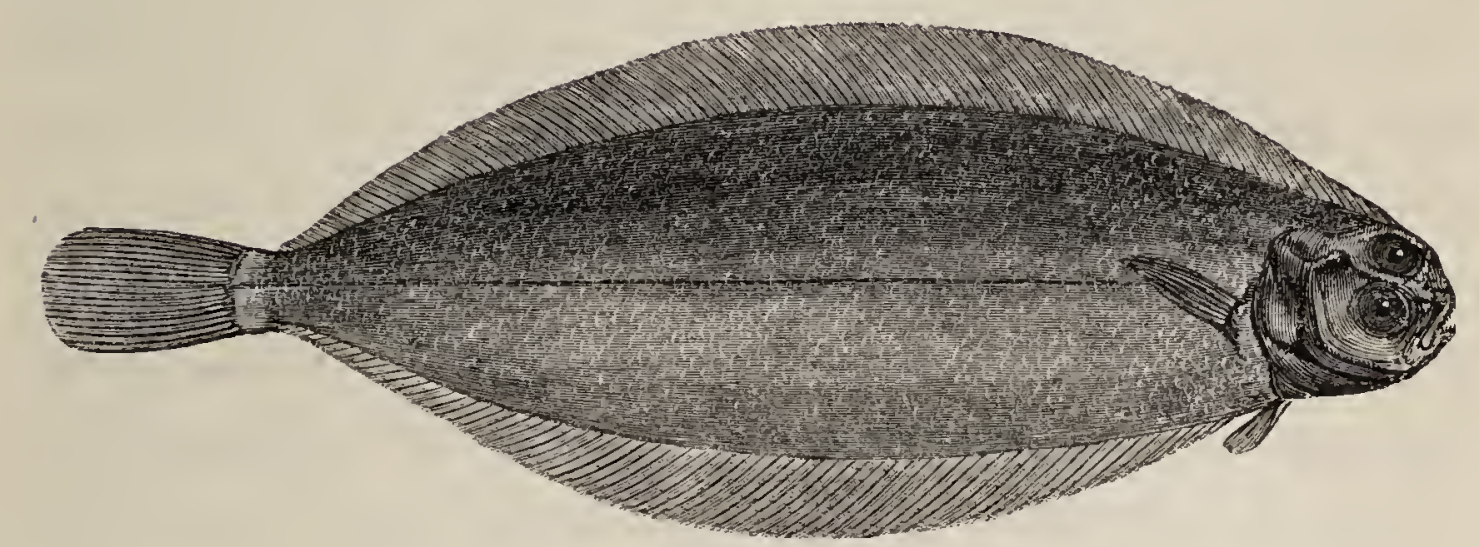

THE LONG FLOUNDER.

Platessa elongata, The Long Flounder, YARreu, Suppl. to Brit. Fishes.

I AM indebted to Mr. Baker, of Bridgewater, for several interesting communications on Birds and Fishes, one of the most valuable of which is, the opportunity afforded me of making known what appeared to that gentleman to be a species of Flounder undescribed as a British Fish, and which, after having made the usual search, I have reason to believe is not only undescribed as a British Fish, but is altogether new to Ichthyology. I have seen only the single specimen sent to me by $\mathrm{Mr}$. Baker, from which a drawing has been made of the natural size, and the reduced representation here given engraved on wood; but I understand from Mr. Baker's son that his father had obtained a second example of the same fish. The specimen now before me was taken at Stoford, in Bridgewater Bay, in the month of December. Little is 
of course known of the habits of so recent and so rare an acquisition.

The whole length of this specimen is seven inches and three-quarters; the length of the head one inch and one quarter, and, compared to the whole length of the fish, is as one to six; the greatest breadth of the body, dorsal and anal fins included, is one inch and three-quarters, and when compared to the whole length of the fish, it is as one to four and a half; the breadth, including the dorsal and, anal fin, is to the whole length as three to eight. The body is very thin, and very much elongated in form; the lateral line passing straight from the tail along the middle of the fish when it approaches the operculum-rises in a slight curve over the base of the pectoral fin. The scales on the body are of medium size, oval, with numerous radiating striæ on the free portion; the fins deep, and the tail long.

The outline of the whole head is rather circular, the mouth oblique from below upwards, and situated below the line of the longitudinal axis of the body; the jaws, nearly equal in length, are each furnished with a single row of small and regular teeth; the eyes are rather large, the upper eye being a little in advance of the lower one; the inter-orbital bony ridge is prominent; the boundary lines of the preoperculum and operculum form two concentric portions of circles. The pectoral fin, arising immediately behind the edge of the operculum, is about half as long as the head; the ventral fin, attached under the edge of the operculum, is about half as long as the pectoral fin. The dorsal fin, commencing with short rays in a line over the eye, reaches its greatest elevation about the middle of the fish, and from thence diminishes gradually to the end, which is on the fleshy portion of the tail, and short of the origin of the caudal 
rays; the anal fin begins close to the ventral fin, immediately behind the post-anal spine; its first and last rays are short, those in the middle of the fin are the longest, and the fin ends on the same plane as the dorsal. The tail-fin is elongated; its length equals that of the head, and it is but slightly rounded at the end; its sides are parallel.

The fin-rays in number are-

$$
\text { D. } 110: \text { P. } 11: \text { V. } 6: \text { A. } 96: \text { C. } 24 .
$$

The colour of this specimen on the upper surface is a uniform pale brown, the membranes of the different fins being rather lighter in colour than the body of the fish; the under surface of the body is very pale wood-brown; the irides yellow.

This specimen has been preserved dry.

The vignette below represents the skeleton of the Common Flounder.

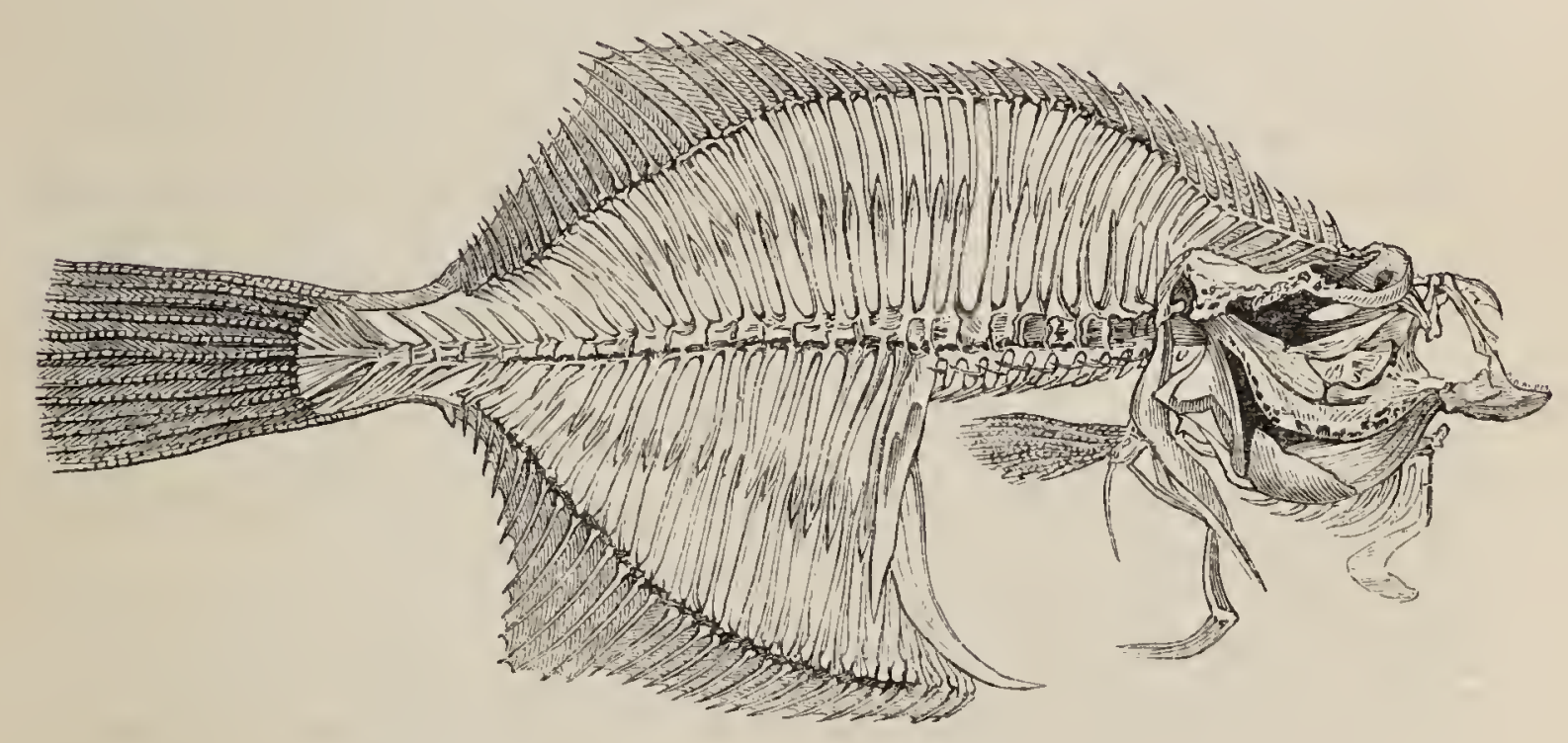


ANACA NTIIINI.

PLEURONECTIDE. ANISOMERI.

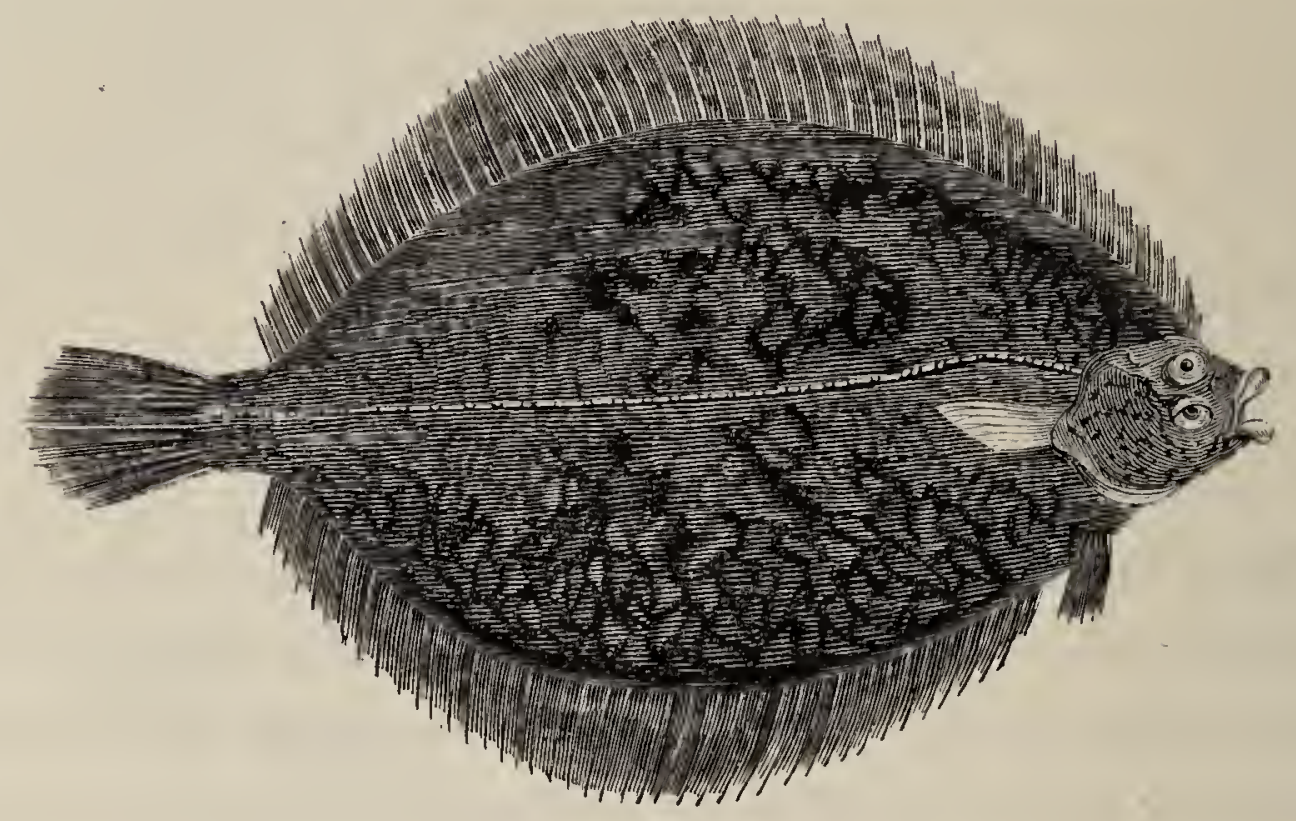

LEMON DAB, SMOOTH DAB.

SMEAR DAB.- SANDFLEUK, Edinburgh.-

town-dab, Hastings.-Mary-sole, Devonshire.MAREFLUNDRA, Sweden.

(Platessa) Rhombus lcevis Cornubicus, JAGo. RAY, Syn. p. 162, f. 1.

La vaie Limandelle, Platessa microcephalus, , microcephala, Pleuronectcs levis,
Duнax. T. des Pêches, t. iii. tab. vi. f. 3.4.

Smcar Dab, FuEMr. Brit. An. p. 198, sp. 106.

Lemon Dab, Jenyns, Man. Brit. Vert. p. 457.

Smear Dab, Penn. Brit. Zool. vol. iii. p. 309, pl.47.

" microcephalus, Small-headed Dab, Donov. Brit. Fish. pl. 42.

,, microstomus, Nilsson, Prod. Ichth. Scand. p. 53.

The Lemon Dab, or Smooth Dab, is not of very frequent occurrence, but it attracts attention on account of the mixture of various shades of reddish brown and yellow colours, which it exhibits. It agrees with the Plaice and Common Flounder in having obtuse, contiguous teeth and smooth scales, but wants the anal spine, which they possess.

In tracing the occurrence of the Smooth Dab round the coast, Dr. Neill of Edinburgh says it is taken off 
Seton Sands and Aberlady Bay. Dr. Richard Parnell, who has devoted great attention to the fishes of the Forth, and to whose kindness I am indebted for the largest example of this species I have yet seen, obtained it, and other specimens, on the Fifeshire coasts during the months of February, March, and April. Mr. Harris mentions one taken at Gamrie of the length of thirteen inches, but says that it is a species of unfrequent occurrence there. It is also enumerated in Dr. Baikie's list of Orkney fishes. I have received specimens also from Dr. Johnston of Berwick. It is not uncommon in the London market; and is taken on the Sussex coast, where it is known by the name of Town-Dab. Colonel Montagu observed it frequently in Devonshire, where it is called Mary-Sole. Mr. Couch says it is rather a rare fish in Cornwall, and does not readily take a bait; but he has known it to be caught in the trawl-nets. Mr. Couch adds, he has no doubt this fish is the Kitt of Jago, figured in Ray's Synopsis, No. 1 ; the fish being reversed on the paper, and appearing with its eyes and colour on the left side, as in the sinistral fishes.

Mr. Thompson says the Smooth Dab is widely distributed on the coasts of Ireland, and it is reported to be very common during summer in Dingle Bay; examples exceeding a foot in length having a very sweet flavour. Saunders' News-Letter, 16 April, 1850.

The flesh of the Smootl Dab is considered equal to that of the Common Dab, and the substance of the body is much thicker. This species spawns in May and June. It feeds on testaceous and crustaceous animals, and is said to feed also on chitons. Duhamel was well acquainted with the Smooth Dab; but considered it a rare fish on the coast of France, and on some parts of it entirely unknown. 
The form of the body is rhomboidal ; small-sized specimens are more elongated: the length of the head is to that of the head and body, without the caudal rays, as one to five and a half; and the depth of the body, including the dorsal or anal fin, only just equals half the whole length of the fish; the mouth is small; the lips tumid; the jaws equal in length; the teeth stand in an even, close, regular row in each jaw, but extend further back on the white under side of the fish than on the upper or eye side; the nostrils are double: the eyes are exactly on the same vertical line; the orbits are separated by a strong, prominent, bony ridge, but without tubercles: the head is small; the pectoral fin is but little more than half the length of the head; the ventral fins are small; the dorsal and anal fins reach near to the tail-fin, but are distinct from it; the caudal is rounded. The fin-rays in number are-

\section{D. $86:$ P. $10:$ V. 5: A. $70:$ C. 16 . Vertebræ 46.}

The general colour of the upper surface of the body is a mixture of pale reddish brown and yellow, with small dark-brown specks; the lips are orange, as is also the posterior edge of the operculum, and the anterior edge of the body immediately behind it; the body is smooth, and is covered with a mucous secretion; the lateral line is but little arched over the pectoral fin; the under parts are white.

Sundevall mentions, as one of the characters of this species, the adhesion of the upper angle of the gillcover to the shoulder. He says that it was first entered on the list of Swedish fishes by Hollberg, under the appellation of Pleuronectes Quenselii, and in 1824 it was introduced into Danish Ichthyology by Bishop Otho Fabricius under the name of Pleuronectes quadridens. 


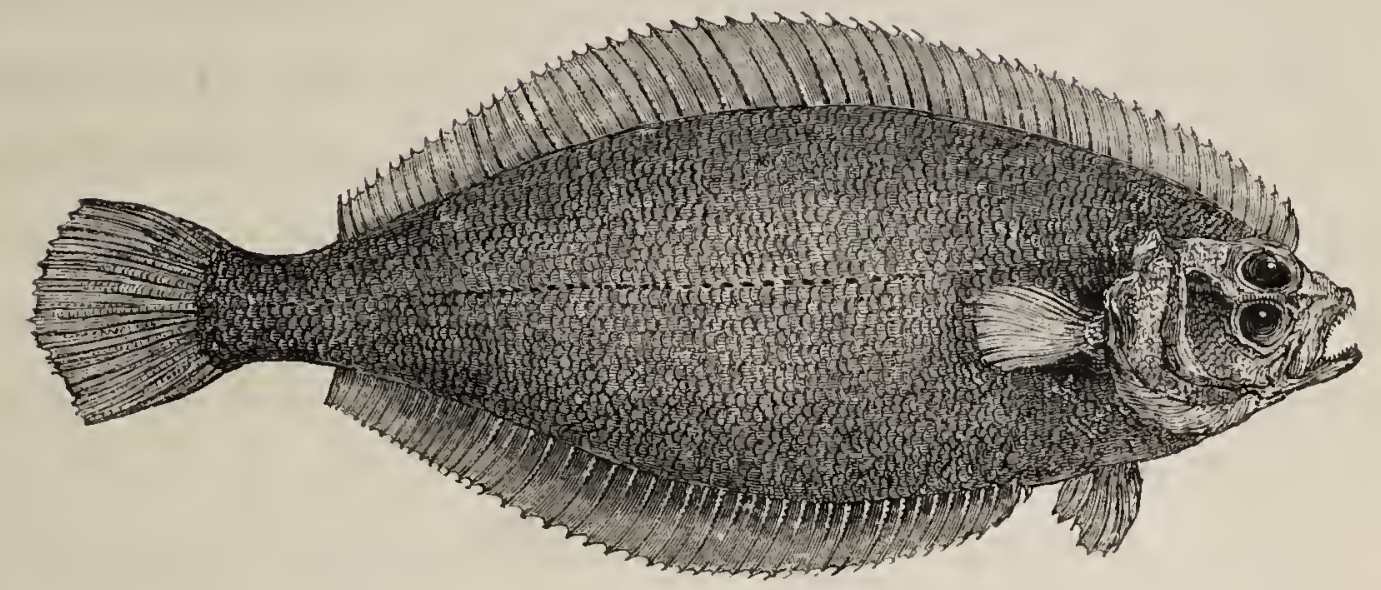

THE LONG ROUGH DAB.

SANDNECKER, SAND FLEUK, AND LONG FLEUK, Edinburgh. -LERFLUNDRA, Sweden.

Platessa limandoïdes, Sandnecker, Jenyns, Man. Brit. Vert. p. 459, sp. 146. Pleuronectes Parneli, Ed. Phil. Journ. 1835, p. 210.

". . . Long Rough Dab, BLOCH, pt. vi. pl. 186.

The Long Rough $\mathrm{D}_{\Lambda \mathrm{B}}$ is a recent addition to the catalogue of British Fishes. The first notice I had of the occurrence of this species on our coast was in the autumn of 1833, from Dr. John Harwood, of St. Leonard's, near Hastings, who had seen a specimen that was taken on the Sussex coast. In the summer of 1834 I received two specimens from Dr. George Johnston of Berwick, which had been taken in that vicinity. In May 1835 I was favoured by Dr. Parnell with the largest specimen I had seen, measuring fifteen inches; who, at the same time, sent me word they were to be had VOL.I. 
frequently in the Frith of Forth in May, June, and July. Soon afterwards I learned by a letter from George $T$. Fox, Esq., of Durham, that a specimen of Pl. limandoïdes of Bloch had been taken some years before on the coast of Sunderland, and was still preserved in the possession of Thomas Wilkinson, Esq., of Bishop Wearmouth. The first recorded notice of this fish as British, that I am aware of, is that by Dr. Parnell, in the Edinburgh New Philosophical Journal, already quoted, where, by an error of the press, the fish is called Pl. limandanus, but this was corrected in the History of the Fishes of the Frith of Forth.

Bloch received his specimen from Hamburgh, and states that this fish is caught by the hook in the vicinity of Heligoland. He says it feeds on young crabs and young lobsters, and that its flesh is white and good.

This species and the Common Dab belong to a section of the genus characterized by their teeth being subacute, and not closely set, the scales ciliated, and the anal fin containing a spinous ray in front. The very slight curve of the lateral line over the pectoral fin distinguishes the Long Fleuk from the Common Dab.

The length of the head compared to the whole length of the fish is as one to five; and the breadth of the body, not including the dorsal or anal fins, is equal to one-third of the whole length; with the dorsal and anal fins it equals half the distance from the point of the nose to the end of the fleshy portion of the tail: the form of the body is an elongated oval, almost equally pointed at both ends; the parts of the mouth are capable of some protrusion; teeth standing in a single row in each jaw, separate, conical, and curving slightly inwards: eyes rather large; the upper one a little before the line of the other; the orbits separated by a bony ridge: pectoral and ventral 
fins small; the former only half the length of the head: dorsal and anal fins extending nearly to the tail; both fins ending on the same plane: the tail slightly rounded.

The cheeks, operculum, and body, are covered with harsh, ciliated scales, rendering the surface exceedingly rough to the touch; and a row of ciliated scales flanks each ray of the dorsal and anal fins; the lateral line is straight, or very slightly inclining upwards as it approaches the operculum; the head and body are of one uniform pale brown colour; the fins lighter; the under surface of the body is rough and white.

The fin-rays in number are-

$$
\text { D. } 76: \text { P. } 10: \text { V. 5: A. } 64 \text { : C. } 16 .
$$

The vignette represents a fishing-boat of Cadiz Bay, olim Tartessos, Carteiavel Gaddir.

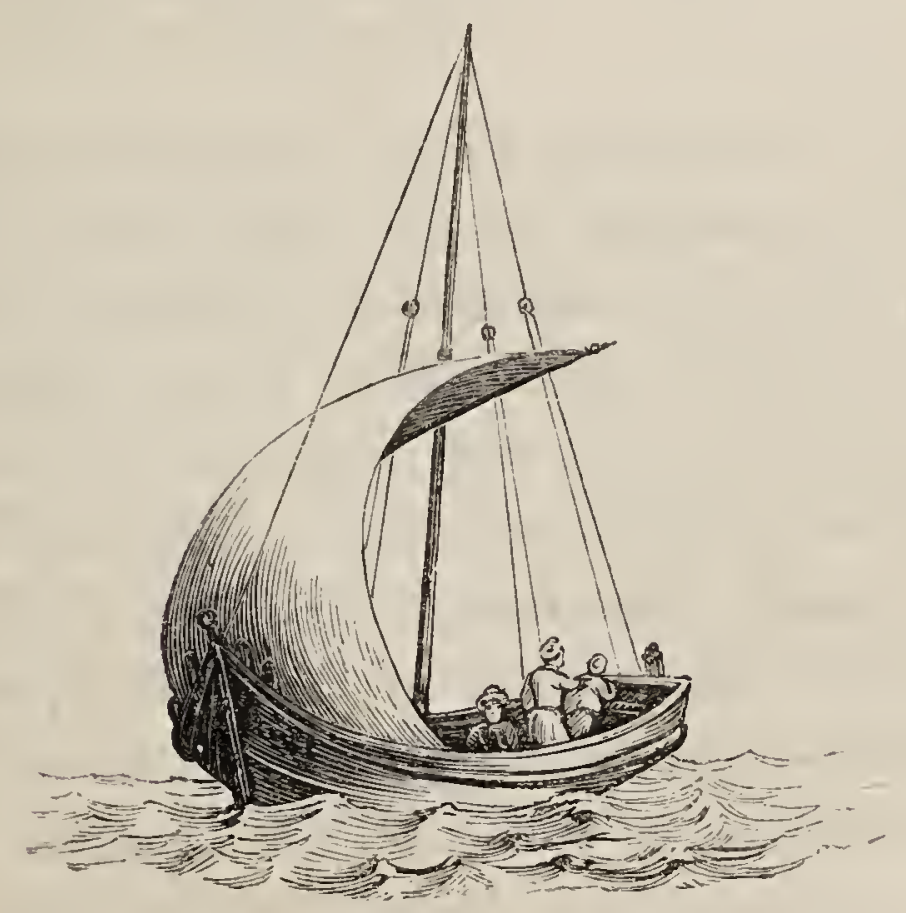


ANACANTHINI.

PLEURONECTIDA. ANISOMERI.

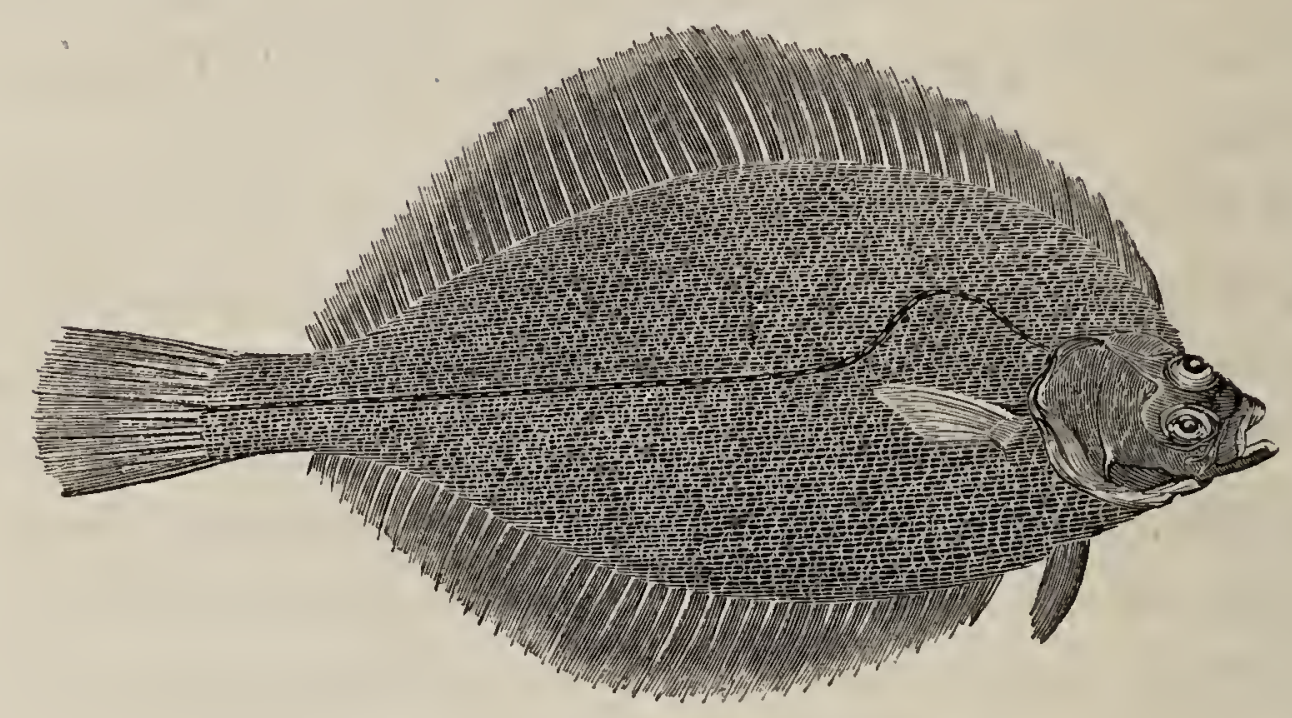

THE COMMON DAB.

SALTIE, AND SALT-WATER FLEUK, Edinburgh.-SANDFLUNDRA, Sweden.

Platessa limanda, Dab, Flem. Brit. An. 198, sp. 105.

" $\quad$ " La Limande, Cuvrer, Règne An. t. ii. pp. 339 \& 340.

Passer asper, Dab, Wrllughby, p. 97, F. 4.

Pleuronectes limanda, Linnaus. Bloch, pt. ii. pl. 46.

$\begin{array}{cccl},, & , & \text { Dab, } & \text { Penn. Brit. Zool. vol. iii. p. } 308 . \\ \text { Platessa } & , & , & \text { Donov. Brit. Fish. pl. } 44 . \\ & , & , & \text { Jenyns, Brit. Vert. p. } 456 .\end{array}$

The $D_{A B}$ is common to all the sandy parts of the coast, and is usually caught along with Plaice and Flounder; but is immediately distinguished from either by its more uniform and lighter brown colour, its more curved lateral line, and the roughness of the scaly surface, from which latter circumstance it has been called in Latin, limanda, from lima, a file. Dr. Neill reports it as common in the market of Edinburgh, where it is called Saltie, or Salt-water Fleuk. I have received it from Berwick, and it is taken at Yarmouth. It is very common in the London market, and Colonel Montagu says it is caught along the Devonshire coast with the seine-net; many are also taken by trawling. It occurs 
in Cornwall, and is recorded as found on several parts of the east coast of Ireland between Waterford and Belfast.

The Dab feeds on small fish, crustacea, and testacea, particularly Pecten obsoletus; and is in best condition for the table in February, March, and April. Its flesh is considered superior to that of the Plaice or Flounder; Cuvier says that it is held in higher estimation in Paris than the Flounder, because it bears carriage better. It spawns in May or June; inhabits deeper water generally than the Flounder; and on some parts of the coast is caught both by sea-lines and hand-lines, the hooks of which are baited with the usual marine sand-worm, or a portion of the body of some of the testaceous mollusca. The size of the Dab is commonly about eight or nine inches in length, and seldom exceeds twelve inches.

The form of the body is like that of the Flounder : the length of the head is to that of the body as one to five; the greatest breadth compared to the whole length being as two to five: the mouth and teeth are small, the latter separated; the eyes rather large, and the orbits divided by a bony ridge, which is not very prominent ; the length of the pectoral fin nearly equals two-thirds the length of the head; the ventral fins are small, and under the origin of the pectoral fin: the dorsal and anal fins extend along the body nearly to the tail, both ending on the same plane; and the longest rays of both are situated behind their centres; the tail-fin is slender, elongated, and slightly rounded. The fin-rays are in number-

$$
\text { D. } 76: \text { P. } 11: \text { V. } 6: \text { A. } 59: \text { C. } 14 .
$$

The form of the body is subrhomboidal; the scales rough, their margins ciliated; the lateral line is arched high over the pectoral fin, thence to the caudal it is straight; the rays of the dorsal and anal fins are scaly; the colour of the fish is of an uniform pale brown, with the under surface white. 
ANACANTHINI.

PLEURONECTIUE. ANISOMERI.

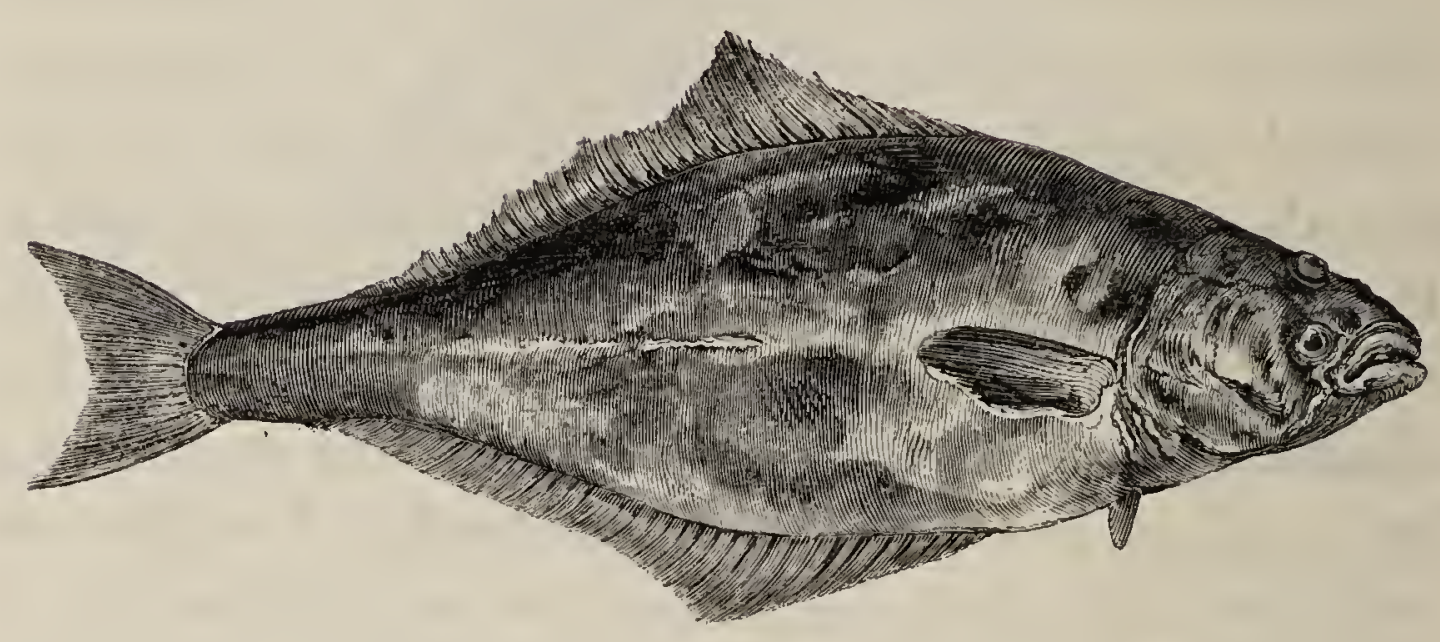

THE HOLIBUT.

Helgar-FISKar, Iceland.-HäLle-FLundra, Sweden.

Hippoglossus vulgaris, Holibut, FLem. Brit. Arı. p. 199, sp. 108.

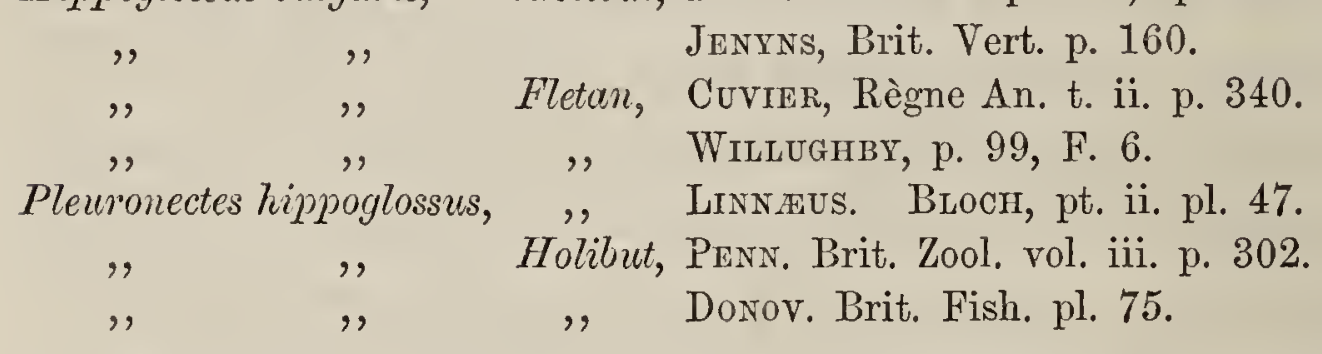

Hippoglossus. Generic Chanacters. - Teeth pluriserial, rather distant, strong, incurved and acute, the largest in front. Space between the eyes broad, depressed. Candal fin composed of thick branching, spreading rays. Body more elongated, and departing less from the common piscine form than others of the family. Anal spine present. Caudal fin crescentic. Urinary oritice behind the anus.

The Holibut is one of the largest species of the Pleuronectida, but its capture is principally confined to the Northern fisheries ; it is noticed by Pennant in his Arctic Zoology, and is well known on the coasts of Norway, Iceland, and Greenland. It is usually caught with lines and hooks. The Greenlanders eat the flesh of this fish both fresh and dried, for which latter purpose 
it is cut into long slips and exposed to the air. Holibut is fished for successfully by the natives of the Orkneys, who ply their lines in the slack water and in the various eddies produced by the different islands, in the race of the tides; these quiet places being more particularly the haunts of this species and of the Flatfish generally. A large quantity of oil is obtained from it.

The Norwegian and Icelandic discoverers of America in the beginning of the eleventh century reported the existence of the Helgar Fiskar, Holyfish or Holibut, in the Bay of Massachusetts.

The Holibut is not found in the Baltic, but it is taken on the west coast of Norway, and, according to Lacépède, in the Iceland seas. It appears by the Appendix of Captain James C. Ross that several were taken off the west coast of Greenland in July 1829, and Dr. Storer mentions that large quantities are brought to Boston market.

In our Northern seas, Holibuts weighing nearly five hundred pounds are said to have been obtained; and examples of large size have occasionally occurred nearer home. In April 1828, a Holibut seven feet six inches in length, three feet six inches in breadth, and weighing three hundred and twenty pounds, was taken off the Isle of Man, and sent to Edinburgh market. It was said to have been the largest specimen ever exhibited there.

Mr. William Thompson mentions that the Holibut is common around the coast of Ireland; and Mr. Couch says it is not uncommon in Cornwall. In London this fish is occasionally seen in the months of March and April, and there, from its large size, is sold in slices at a low price by the pound weight. The flesh, though white and firm, is dry, the muscular fibre coarse, with but 
little flavour : the head and fins are said to be the best parts. Specimens only two feet long are occasionally seen in summer, but in general the examples are much larger.

The Holibut feeds close to the ground, on the smaller species of Flatfish and various crustacea. It spawns in spring; the roe is of a pale red colour, and the ova in the female very numerous. A specimen five feet two inches long, in the shop of a London fishmonger, was the subject of the following description:-

Eyes and colour on the right side, in which respects it differs from the Turbot. The length of the head compared to the whole length of the fish without the caudal rays, is as one to four; and the greatest breadth one-third of the whole length, dorsal, anal, and caudal fin-rays all excluded: the head is small, but the mouth large; teeth standing in two rows in each jaw, small for the size of the fish, conical, pointed, and separated; the irides yellow, the pupils black; the pectoral fin on the coloured or dextral side is one-fourth larger than that on the white or under side; the dorsal fin commences over the eye, and its rays are longest over the widest part of the body; the anal fin is of similar character: both dorsal and anal fins terminate on the same plane, and are distinct from the caudal fin, the posterior margin of which is concave; the ventral fins are small, the white ventral fin of the under side being the smaller of the two: immediately in advance of the anal fin are two apertures; the anterior opening is large, and evidently connected with the intestines; the posterior opening smaller, and apparently forming the outlet of the urinary bladder and sexual organs. The fin-rays in number are-

D. $104:$ P. $16:$ V. $6:$ A. $81:$ C. 16. 
The form of the body is elongated; the surface smooth, covered with small oval-shaped soft scales; the lateral line is arched over the pectoral fin; the colour clouded, and varying from light brown to dusky brown; the under surface is perfectly smooth and white.

The vignette below represents the Argulus foliaceus of Jurine; a species of parasitic animal occasionally found attached to fresh-water fishes. Specimens have been taken from the Pike and the Trout. The figure on the left hand represents the upper surface of a male: under the microscope some of the vessels become visible through the external tunic. The figure on the righthand represents the under surface of a female: its ova are very conspicuous. The small figure between the two is of the natural size.

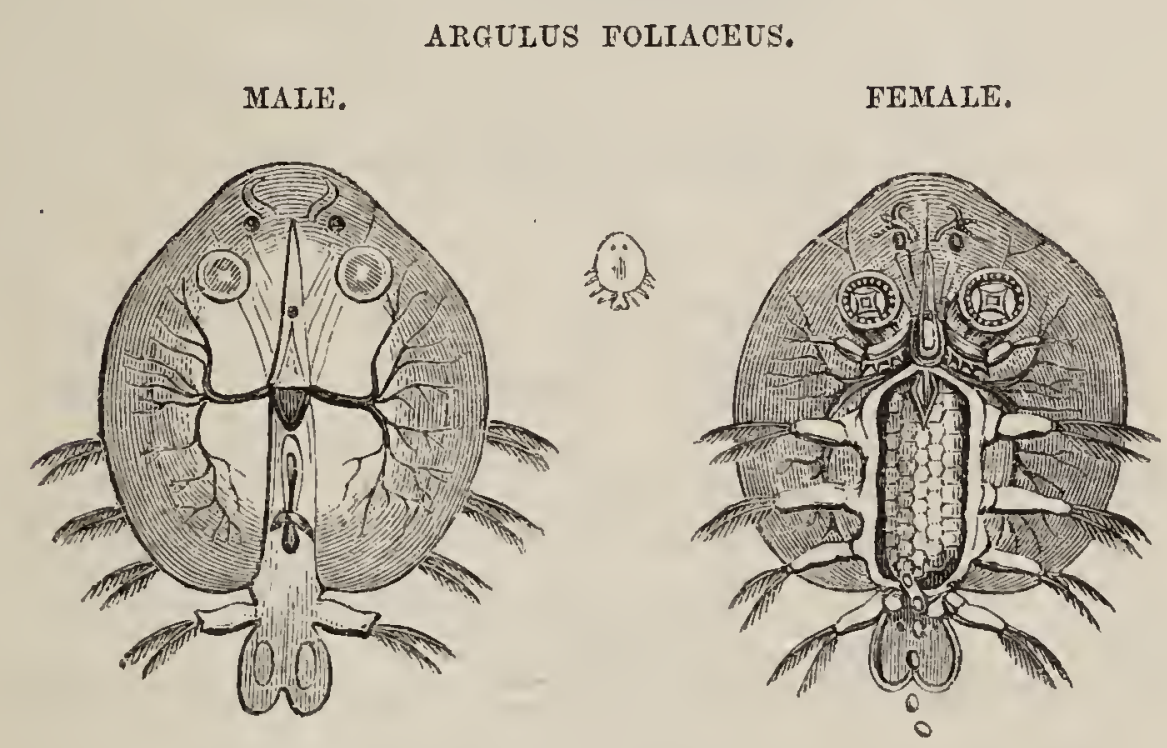


634 ANISOMERI.

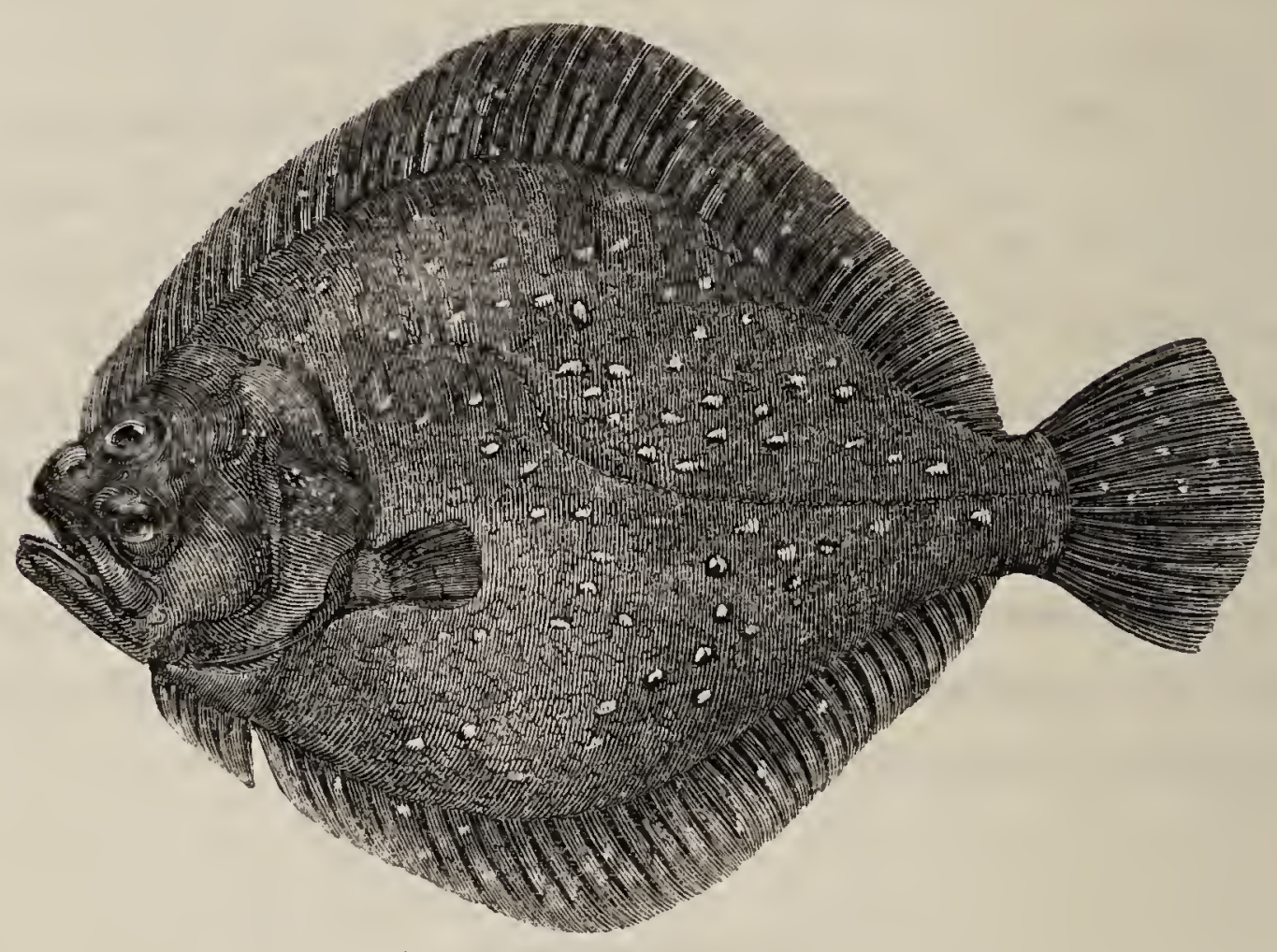

\section{THE TURBOT.}

RAWN FLEUK, AND BANNOCK FLEUK, Scotland.-PIGGHVARF, Sweden.

Psetta maxima, Swatnson, Lard. Cycl. ii. p. 302.

Rhombus maximus, Le Turbol, Covien, Règne An. t. ii. p. 340.

\begin{tabular}{|c|c|c|c|}
\hline & ", & Turbot, & Willughby, p. 94, F. 2. \\
\hline Pleuronectes & , & LINNAUS. & BLOCH, pt. ii. pl. 49. \\
\hline$"$ & "' & T'urbot, & PEnn. Brit. Zool, vol. iii. p. 315, pl. 49. \\
\hline " & , & , & Flem. Brit. An. p. 196, sp. 96. \\
\hline & & $"$ & Jenyns, Brit. Vert. p. 461. \\
\hline
\end{tabular}

Pserma. Generic Characters. - Teeth pluserial acicular, ventrals similar in structure to the vertical fins, the rays distinct at their roots : dorsal commencing before the eyes: no anal spine. Eyes sinistral, fringed, space between them wide and depressed. Scales small, smooth.

'The Turbot, so well known, and so highly and justly esteemed, is considered the best, as it is also one of 
the largest, of our Flatfishes; and like the Salmon, notwithstanding its great excellence, and the immense numbers that are caught in various ways, it is still in great abundance, but not equally so on all parts of the coast.

According to Mr. Low, it is rare in Orkney; but the numbers taken increase on coming southward: and in the market of Edinburgh, according to Dr. Neill, it is commonly denominated Rawn Fleuk, from its being thought best for the table when in rawn, or roe; it is sometimes also called Bannock Fleuk, on account of its circular shape.*

On the coasts of Berwick, Northumberland, Durham, and Yorkshire, a considerable fishery for Turbot is carried on by the fishermen with long lines, the mode of using which was described when speaking of the Common Codfish. A large proportion of the Turbot brought to the English market is taken on or near the various sandbanks between the long line of our eastern shore and the coast of Holland. Mr. James Wilson, the writer of the article "Fisheries," in the recent editions of the Encyclopædia Britannica, says, "The only fishery, perhaps, which neither the Scotch nor the English follow up with the same success as the Dutch, is that of the Turbot; the finest of which are supposed to be taken upon the Flemish banks. The Turbot fishery begins about the end of March, when the Dutch fishermen assemble a few leagues to the south of Scheveling. As the warm weather approaches, the fish gradually advance to the northward, and during the months of April and May they are found in great sculls on the banks called the Broad Forties. Early in June they have proceeded to the banks which surround the small island of Heligoland, off the mouth

* Bonnock, a round flat cake. 
of the Elbe, where the fishery continues to the middle of August, when it terminates for the year. The mode of taking Turbot is as follows:-At the beginning of the season the trawl-net is used; which being drawn along the banks, brings up various kinds of Flatfish, as Soles, Plaice, Thornbacks, and Turbots; but when the warm weather has driven the fish into deeper water, and upon banks of a rougher surface, where trawling is no longer practicable, the fishermen have then recourse to their manyhooked lines. The hooks are baited with the common Smelt, and a small fish resembling an Eel, called the Gorebill. (Belone.) Though very considerable quantities of this fish are now taken on various parts of our own coasts, from the Orkneys to the Land's End, yet a preference is given in the London market to those caught by the Dutch, who are supposed to have drawn not less than $£ 80,000$ a year for the supply of this market alone; and the Danes from $£ 12,000$ to $£ 15,000$ a year for sauce to this luxury of the table, extracted from one million of lobsters, taken on the rocky shores of Norway,-though our own shores are in many parts plentifully supplied with this marine insect, equal in goodness to those of Norway."

About one-fourth of the whole supply of Turbot to the London market is furnished by Dutch fishermen, who pay a duty of $\mathfrak{E} 6$ per boat, each boat bringing from one hundred to one hundred and fifty Turbot. A very considerable quantity is also purchased of the Dutch fishermen at sea on the fishing stations near their own shore by English fishermen, who bring it to our market in their own boats, paying no duty.

Along our southern coast many Turbot are caught by the trawling vessels and long-line fishing at particular seasons on the Varne and on the Ridge,-two extensive banks 
of sand, the first about seven miles, and the second about twelve miles from Dover, towards the French coast. On these banks French fishermen also lay their long lines; and when they do not succeed in selling their 'Turbot at sea, which suits them best, they freight one or more of their own boats with them, and send them into Dover Harbour for sale, paying the usual duty. They are not, however, allowed to sell any fish but Turbot, except under particular circumstances. If in want of provision, or their boat has suffered damage from bad weather, they are then permitted, by certificate from a magistrate, to sell as much fish as will procure them food, or pay the cost of repairs.

Along the Devonshire coast, where trawling on an extensive scale is practised, a portion of the Turbot and Dory is forwarded during the season to Bath and Exeter; the remainder is sent to the London market by land-carriage. It is observed that the Turbot of the northern part of our own coast, and those bought of or brought by the Dutch fishermen, are darker in colour than those from the south-western shores of England.

Mr. Couch says, "The Turbot keeps in sandy ground, and is a great wanderer, usually in companies; and though its proper habitation is close to the bottom, it sometimes mounts aloft, and I have known it upon the surface over a depth of thirty fathoms: I have been informed also of its pursuing to the surface a companion that was drawn up by the line, when both were taken together."

The Turbot, though a voracious fish, is particular as to the quality of its food: the bait used for it should be very fresh; if it happens to be in the least degree tainted, the Turbot will not touch it. The most enticing baits are such small fishes as are either very bright in colour or very tenacious of life; the Atherine, 
and the two common species of the genus Cottus, the SeaScorpion and Father-Lasher, are most frequently used; the first attracts by its shining silvery appearance, and the others by living a long time on the hook, and showing themselves in their struggles to get free. The River Lampern was formerly used in large quantities by the Dutch, and was a great favourite with them as bait for Turbot, on account of the facility with which they could be kept alive while the boats were at sea, and combining bright silvery colour with great power of resisting the usual effect of mutilation. The principal food of the Turbot is small fish, crustaceans, and mollusks. It spawns about August, but rapidly recovers its condition and firmness.

Turbot are recorded as having been taken on the south coast of Ireland; I have seen one that was caught on the coast of Londonderry in the north; and this valuable species occurs also at many intermediate localities.

"The Turbot was known to the Athenians, and has been ever since a worthy object of gastronomical worship." The most common size varies from five to ten pounds' weight; occasionally this fish attains to twenty pounds, and sometimes thirty pounds. Mr. Couch notices in his MS. a record of one taken in the year 1730 at Cawsand, near Plymouth, which weighed seventy pounds and Rondelet states that he had seen a Turbot five cubits in length, four in breadth, and a foot in thickness. The Turbot is considered to have been the Rhombus* of the ancient Romans, of which a specimen of enormous size is said to have been taken in the reign of

\footnotetext{
* The word Rhombus having been appropriated by Lacépède to a group of Scomberoid fishes, was changed by Mr. Swainson for Psetta, by which Aristotle had designated a flat fish of some kind. Had Mr. Swainson adopted the synonymous form of the word Psessa, there would have been less danger of confounding it with Psettus, a Chœtodontoid genus of fishes.
} 
Domitian, who ordained a Senatus Consultum to devise the best mode of bringing it to table.-Juven. Sat. IV.

"No vessel they find fit to hold such a fish, And the senate 's convoked to decree in new dish."

Sir Thomas Browne seems to have been quite aware of the good qualities of Turbot and Brill as compared to Plaice, Flounders, and Dabs; he says-

"Of wry-mouthed fish, give me the left side black;

Except the Sole, which hath the daintiest smack."

Yet a Plaice, scored and fried, is a good fish, and much better than when boiled.

Quin, of epicurean notoriety, is said to have given it as his opinion that the flesh on the dark-coloured side of the Turbot was the best meat; and as examples occasionally occur that are dark-coloured on both sides, some London fishmongers, from experience in their good qualities, recommend such fish as deserving particular attention. Reversed Turbots, as they are called,- - that is, Turbots having the eyes and dark colour on the right side instead of the left,-are also occasionally brought to market; I have seen two or three such; but they have exhibited a slight degree of malformation in the form of a notch or depression on the top of the head. The Pleuronectes cyclops of $\mathrm{Mr}$. Donovan, plate 90, I believe to be an example of the young fry of the Turbot, the head of which is not perfectly formed.

The number of Turbot brought to Billingsgate market within twelve months, up to a recent period, was 87,958 ; and the number of lobsters within the same period, $1,904,000$.

The form of the Turbot, exclusive of the caudal rays, is nearly round : the length of the head compared to the length of the head and body is as one to three; and the depth of the body, including both dorsal and anal 
fins, is equal to the length from the nose to the end of the fleshy portion of the tail: the mouth is large, and the direction of its opening is obliquely upwards : the teeth are small and numerous in both jaws; the eyes are placed one directly over the other; the whole surface of the cheeks, and all the parts of the gill-cover on the upper or coloured side are studded with numerous tubercles; the operculum ends in an angle directed backwards over the base of the pectoral fin; the gill-openings are large ; the pectoral fin small ; the dorsal fin, commencing by short rays immediately over the nostril and anterior to the upper eye, extends very nearly to the end of the fleshy portion of the tail, where the rays are again short, its longest rays being over the middle of the body; the broad ventral fins, placed very far forward, appear like the commencement of the anal fin, and are separated from it by only a narrow space; the anal fin ends by short rays near the tail, and on the same vertical plane as the dorsal; the caudal rays are moderately long, and slightly rounded. The fin-rays in number are-

\section{D. $64:$ P. $12:$ V. $6:$ A. $48:$ C. 15 . Vertebræ 30.}

The whole of the upper or coloured side of the body is studded with hard roundish tubercles, the surface otherwise being covered with small, smooth scales; the prevailing colour consists of varying shades of brown, the fins being a little lighter; the lateral line is arched high over the pectoral fin, and then runs straight to the tail: the under surface of the body is smooth, and generally perfectly white. 


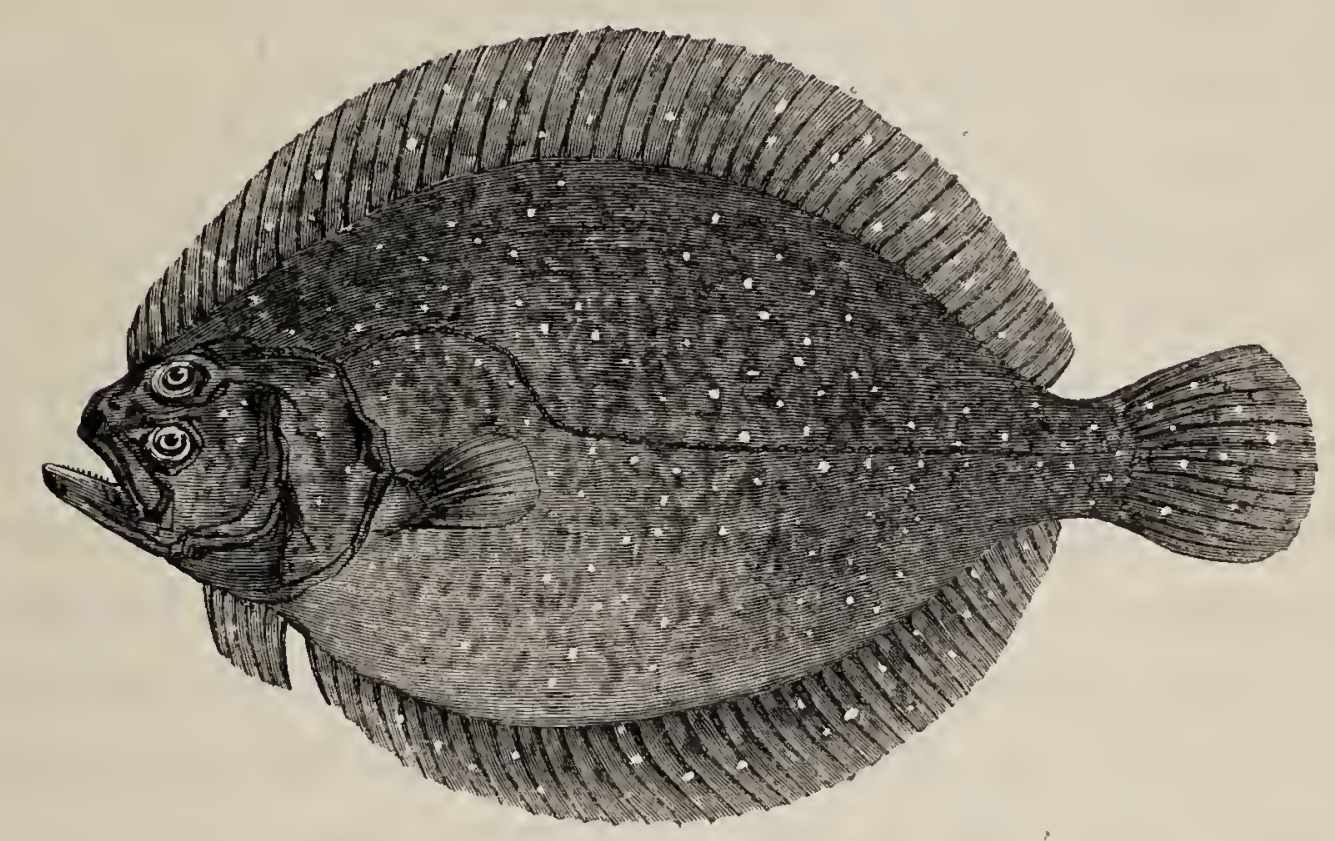

\section{THE BRILL.}

PEARL, KITE，BRETT, BONNET-FLEUK.

Psetta rhombus, " Bonaparte, Pesci Europ. 49*. (White.)

Rhombus vulgaris, La Barbue, Cuvier, Règne An. t. ii. p. 341.

,, non aculeatus, Wildughis, p. 95, tab. F. 1.

Pleuronectes rhombus, Linneus. Bloch, pt. ii. pl. 43.

\begin{tabular}{|c|c|c|}
\hline ", & ', & Pearl, Penn. Brit. Zool. p. 321, pl. 50. \\
\hline , & , & Brill, Donov. Brit. Fish. pl. 97. \\
\hline & , & Flem. Brit. An. p. 196, sp. 9 \\
\hline & ," & Jenyns, Brit. Vert. p. 462. \\
\hline
\end{tabular}

The Brill is a well-known fish, brought in abundance to the London market, and procured from the same localities and by the same modes as the Turbot; but is not held in equal estimation, being considered by some as inferior to the Sole, but very superior to the Plaice.

Dr. Neill says it is found in Aberlady Bay, where it is called Bonnet-Fleuk; it is taken also at Yarmouth, and other places along our eastern coast; and it is abun-

voL. I. 
dant on our southern coast, inhabiting sandy bays as well as deep water, from whence the principal part of the supply for the London market is derived. It is taken also in Ireland. Its food, as well as its season of spawning, are similar to the Turbot, but it does not usually appear so large, seldom exceeding eight pounds in weight. It should be borne in mind, that the Kite of the Devonshire and Cornish coasts is the same as the Brill ; but that the Kit of Jago is the Smooth or Smallheaded Dab, figured and described in this volume at page 622. Another name quoted among those in use for the Brill, namely the Brett, is said to be derived from the Cornish word "brit;" signifying speckled or spotted.

The writer of the supplementary part to the Class Fishes, in Mr. Griffith's edition of Cuvier's Animal Kingdom, says that the enormous fish presented to the Roman Emperor Domitian was a Brill, Rhombus vulgaris of Cuvier, and not the Turbot; but the authority or the reasons for this opinion are not given. Bloch, in his account of the Brill, makes a similar statement.

The length of the head from the point of the lower jaw to the edge of the operculum is, when compared to the length of the body alone without the head or caudal rays, as one to two; the breadth of the body, dorsal and anal fins excluded, equals half the whole length of the fish; the whole breadth, dorsal and anal fins included, is to the whole length as two to three: the form of the body is rhomboidal; its surface perfectly smooth; the position and extent of the fins are very similar to those of the turbot last described; a few of the most anterior rays of the dorsal fin extend beyond the connecting membrane; the tail-fin is rounded.

The fin-rays in number are-

D. $76:$ P. $10:$ V. $6:$ A. $59:$ C. 16 . Vertebræ 35. 
The mouth is large, and deeply cleft, the under jaw being the longest; the teeth numerous, small, pointed, and sharp: the upper eye more posterior than the lower one: the irides yellow: the cheek and operculum smooth, without tubercles; the basal and ascending edges of the preoperculum form nearly a right angle; the lateral line is arched over the pectoral fin, then runs straight to the end of the tail: the scales are nearly round, small, and smooth; the colours of the body are a reddish sandy-brown, varied with darker brown, and sprinkled over with white pearl-like specks, whence, probably, another of the names bestowed on this fish has originated: the under surface is smooth and white. The young are of a pale reddish brown, marked with very dark brown or black spots.

The vignette represents the outline of the anterior part of a Brill with a malformed head. For the fish from which this sketch was taken, I am indebted to the kindness of Mrs. Nelson of Devonport. It was taken in that vicinity in June 1835, and was brought on shore alive. A similar monstrosity of less magnitude is figured in the Zoologist for 1855, p. 4596.

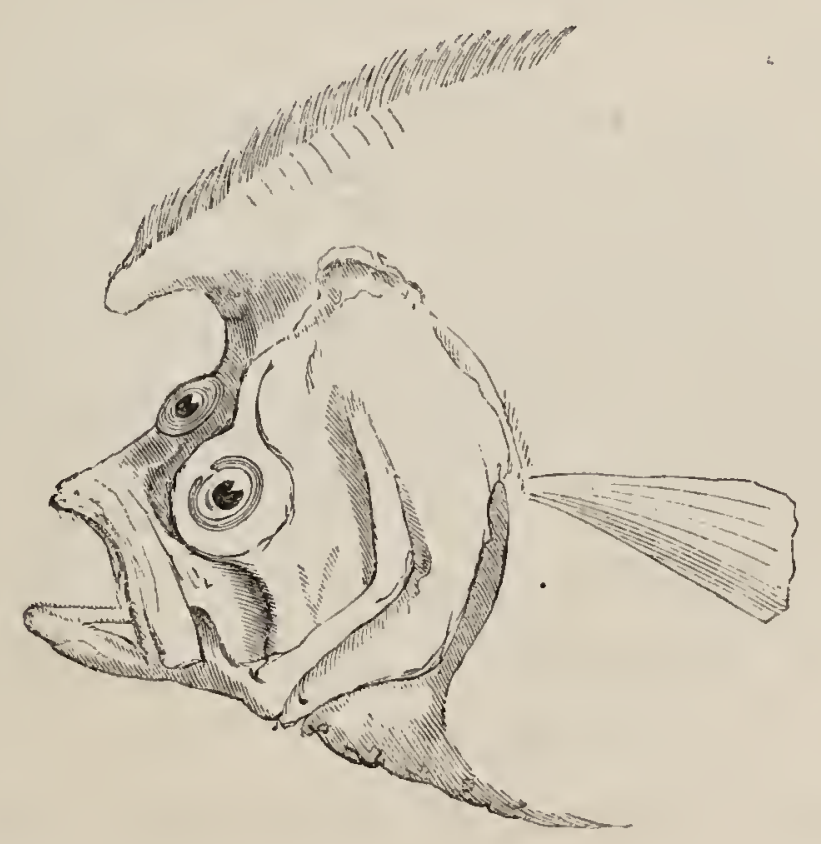




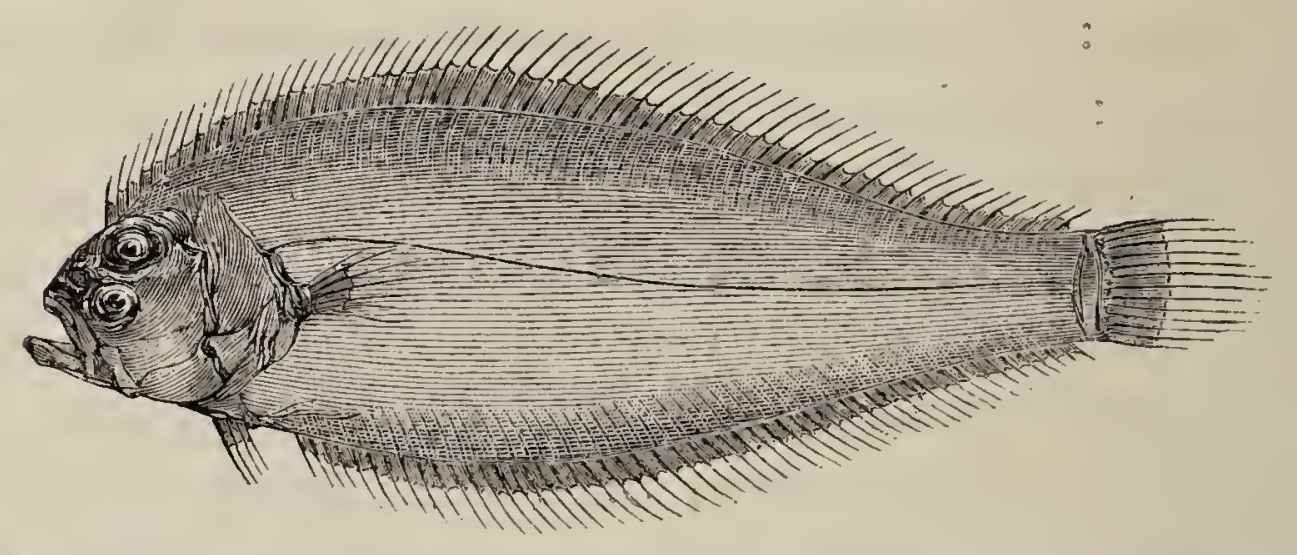

\section{THE SCALDFISH.}

MEGRIM, Cornwall.-SMooth soLE.

Psetta arnoglossa, Scaldfish, YARrelu.

Arnoglossus lavis. $\quad, \quad$ Wrllughby, p. 102, F. 8, fig. 7.

Pleuronectes casurus, ", Penn. Brit. Zool. vol. iii. p. 325, pl. 53.

", arnoglossus, ", Fuen. Brit. An. p. 197, sp. 100.

The Scaldfish, or Megrim, as it is called in Cornwall, was supposed to be exclusively. confined to the southern coast, between Weymouth and the Land's End, but Mr. Thompson mentions an instance of its capture off Galway in 1848, and several specimens have been taken since that date in Dingle Bay in twenty-five fathoms water.

Mr. Couch says, "he has never known it to take a bait, and its diminutive size prevents its being an object of attention to fishermen ; but they say it is much preyed upon by Congers and other large fishes, in the stomachs of which they often find it: it follows from this that it keeps in deep water." It seldom exceeds four or five inches in length; but Mr. Couch has seen one that measured six inches and a half. M. Risso says the females are very prolific.

The length of the head is to that of the body as 
one to three, caudal rays excluded; the depth of the body, without the dorsal or anal fins, equals one-third of the whole length; the dorsal fin commences over the upper eye, and reaches very nearly to the end of the fleshy portion of the tail; the pectoral fin is long and narrow, but the under one is shorter and smaller; the anal fin commences under the pectoral, and ends on the same plane as the dorsal fin; but the rays of all the fins in both the specimens before me, from which the description is taken, extend considerably beyond the connecting membranes of each, as shown in the woodcut.

$$
\text { Rays: D. } 87: \text { P. } 6: \text { V. } 10: \text { A. } 60: \text { C. } 18 .
$$

The mouth is large, with small teeth in both jaws; the lower jaw is the longest when separated: the eyes rather large; the pupils blue, and irides yellow; orbits separated by a bony ridge; upper eye larger and rather behind the lower one: the body is an elongated oval, narrowed towards the tail; the scales are large, round, thin, transparent, and deciduous on the slightest touch, so that the body of the fish generally appears naked. I am indebted to the kindness of $\mathrm{Mr}$. Couch for a Cornish specimen: I also possess one from the Mediterranean, which enables me to say that our fish is the Rhombus nudus of M. Risso. The lateral line after its commencement at the posterior edge of the operculum rises over the pectoral fin rather higher than the representation indicates; then descending gradually, deviates but little from a straight line throughout the remainder of its course to the tail. The colour of both specimens is alike, a uniform pale yellow-brown. 


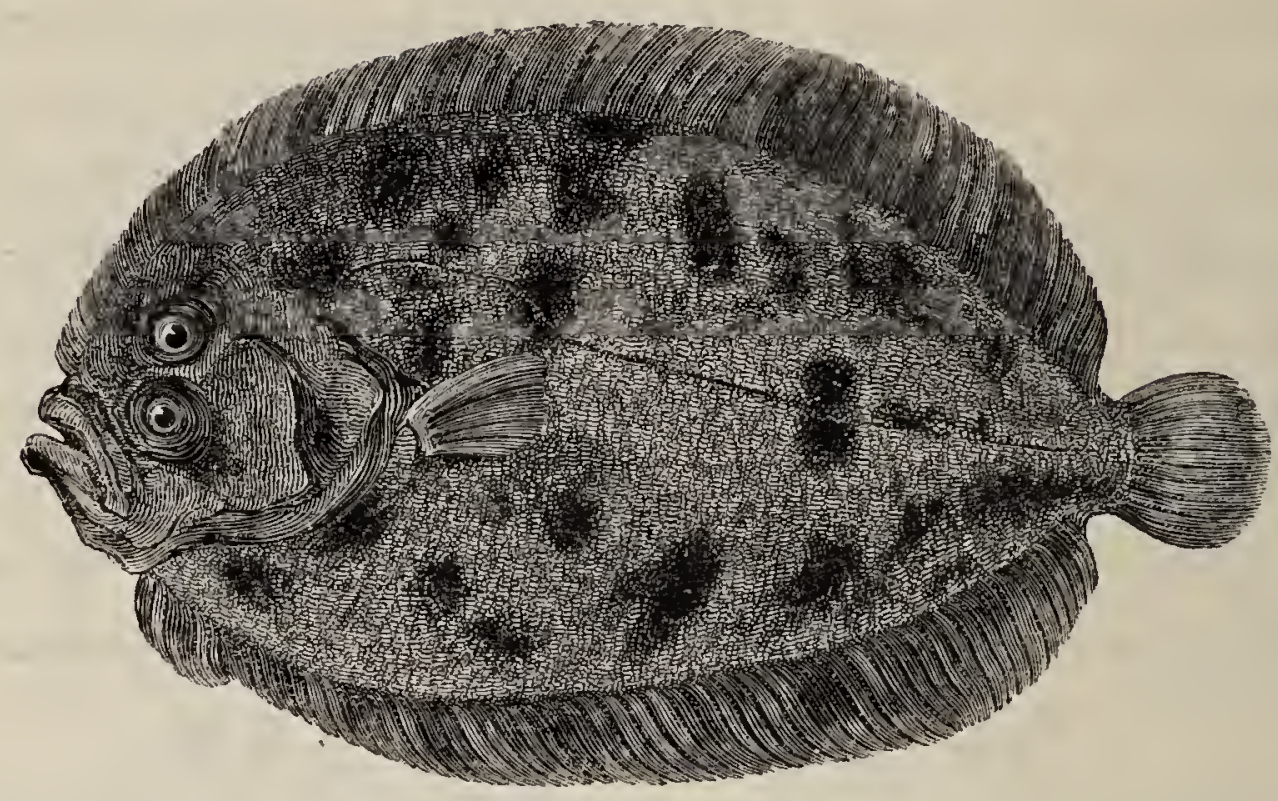

MÜLLER'S TOPKNOT.

\section{ROUGH BRILL, BRowny, Cornwall.}

Zeugoptcrus hirtus,

Rhombus ",

Pleuronectes ,,

$"$

Gotrsche. White, Cat. Br. Mus. p. 103.

Müller's T'ophnot, Yarreld, Br. Fishes, 1st \& 2nd Ed. Mülleer, Zool. Dan. vol. iii. p. 36, pl. 103.

punctatus, Toplnot, Pens. Brit. Zool. vol. iii. p. 322, pl. 51; and edit. 1776, pl. 41, but named by mistake Smear Dab.

Le Gros Plie on Targeur, Dumanel, sect. ix. pl. 5, fig. 4.

Pleuronectcs hirtus, Miiller's Topknot, Jenres, Man. Brit. Vert. p. 463.

ZFugopterus. Generic character's. - Scales ciliated with spines; eyes without the fringe, and the interval between them narrow and elevated. In other respects like $P_{\text {setta. }}$

Several modern authors have confounded the present fish with the species next to be described; and Cuvier,* as well as Professor Nilsson, $\uparrow$ have brought together the Pleuronectes hirtus of Müller, and the Pl. punctatus of Bloch, apparently considering them as the same. Müller doubted whether the punctatus of Bloch was the same

\footnotetext{
* Règne An. t. ii. p. $341 . \quad$ + Prod. Ichth. Scand, p. 59, sp. 11.
} 
as his fish, and notices the points in which they differ. The opportunity of examining some specimens in 1835, confirmed the existence of two distinct species on our shores. Though somewhat similar in the form of the body, the colouring, and the spots, there are still the following well-marked distinguishing specific characters.

The hirtus of Müller, and those included in the synonymes here given, have the coloured side only of the body rough; the under or eyeless side smooth; the eyes and mouth small : the first ray of the dorsal fin not longer than the succeeding rays; the ventral and anal fins united; the dorsal and anal fins also connected to the caudal by a membrane; the caudal short and rounded; the scales of the body when detached higher than wide.

The punctatus of Bloch, and its synonymes given with the next species, have both sides of the body rough; the eyes large and prominent; the mouth larger than in hirtus, and not so oblique; the first ray of the dorsal fin elongated; the ventral and anal fins separated; the caudal rather long; and the scales of the body when detached wider than high.

The hirtus of Müller appears to be the most common species of the two; but neither occur very frequently. Dr. Parnell has obtained hirtus in the Forth, where it is occasionally caught in the crab-cages. I have received a specimen from Dr. George Johnston, which was captured near Berwick Bay; and I am indebted to Professor Henslow of Cambridge for a drawing of one taken in the Medway. Dr. John Harwood, of St. Leonard's, possesses a specimen procured on the Sussex coast; and both Colonel Montagu and $\mathrm{Mr}$. Hanmer obtained specimens in Devonshire.

Mr. Couch considers it to be not an uncommon fish in the West of England, and has furnished me with two 
examples, from one of which the figure was taken. It appears to keep among rocks, where it is not readily distinguished, on account of the similarity of its colour to that of the sea-weed; and it is chiefly taken in the nets which are set for Red Mullet. In winter the boys find small ones, not larger than a half-crown piece, in the pools left by the tide. This species of Flatfish does not probably attain any great size; the largest examples I have seen not exceeding seven or eight inches in length. It is said to feed on mollusks and small star-fishes. Mr. R. Q. Couch says that this species inhabits by preference sandy inlets bordered by shelving rocks, clothed with sea-weed, and that like the common Brill it is very subject to malformations of the anterior end of the dorsal fin, causing it to form an arch over the eyes.Zoologist.

Mr. Baker, of Bridgewater, sent me a specimen, beautifully preserved, that was taken in the Bristol Channel: examples have been caught at several places on the coast of Ireland, and Dr. Baikie, in his list of Orkney fishes, mentions the capture of several specimens in that quarter.

The whole length of the specimen described is five inches and one quarter; the length of the head compared to that of the body, without the caudal rays, is as one to two and a half; and the breadth of the body, not including the dorsal and anal fins, equals half of the whole length : the form of the body, including both these fins, is rhomboid: the dorsal fin commences immediately over the upper lip, the rays lengthening by degrees, and being longest over the posterior third part of the body; the pectoral fin is small: the ventral fins are situated under the middle of the head, and are attached to the commencement of the anal fin by a membrane: this, last- 
named fin commences under the posterior ascending margin of the preoperculum; both dorsal and anal fin end on the same plane, and are connected to the fleshy portion of the tail by a membrane, in such a manner that both fins pass under the base of the caudal on the blind or colourless side: the tail is small and rounded. The fin-rays in number are-
D. 90 : P. $11:$ V. 6 :
A. 70 :
C. 14. Vertebræ 33.

The mouth is small, and almost vertical; the teeth distinct, small, conical, and sharp: the diameter of the eye equals one-fourth of the length of the head; the upper eye is placed nearly half its width behind the line of the lower: the basal and ascending margins of the preoperculum form an obtuse angle; and the cheeks, operculum, and body are covered with rough or spinous scales, which, when detached, are longest in their vertical diameter.

The colour of the body is a reddish brown, mottled and spotted with very dark brown or black; a large conspicuous dark spot is placed behind, and above the ends of the pectoral fin-rays; the lateral line is curved over the pectoral fin, then descends and intersects the lower portion of the large dark spot, and afterwards passes straight to the caudal; the fins are paler brown than the body; all the rays of the dorsal and anal fins are flanked in front by a line or row of denticulated scales; but the under side of the body is smooth and white.

Fries says that this species, and not the next one, is the Pleuronectes hirtus of Abilgaard in the Zoologia Danica, and of Retz in the Fauna Suecica. 


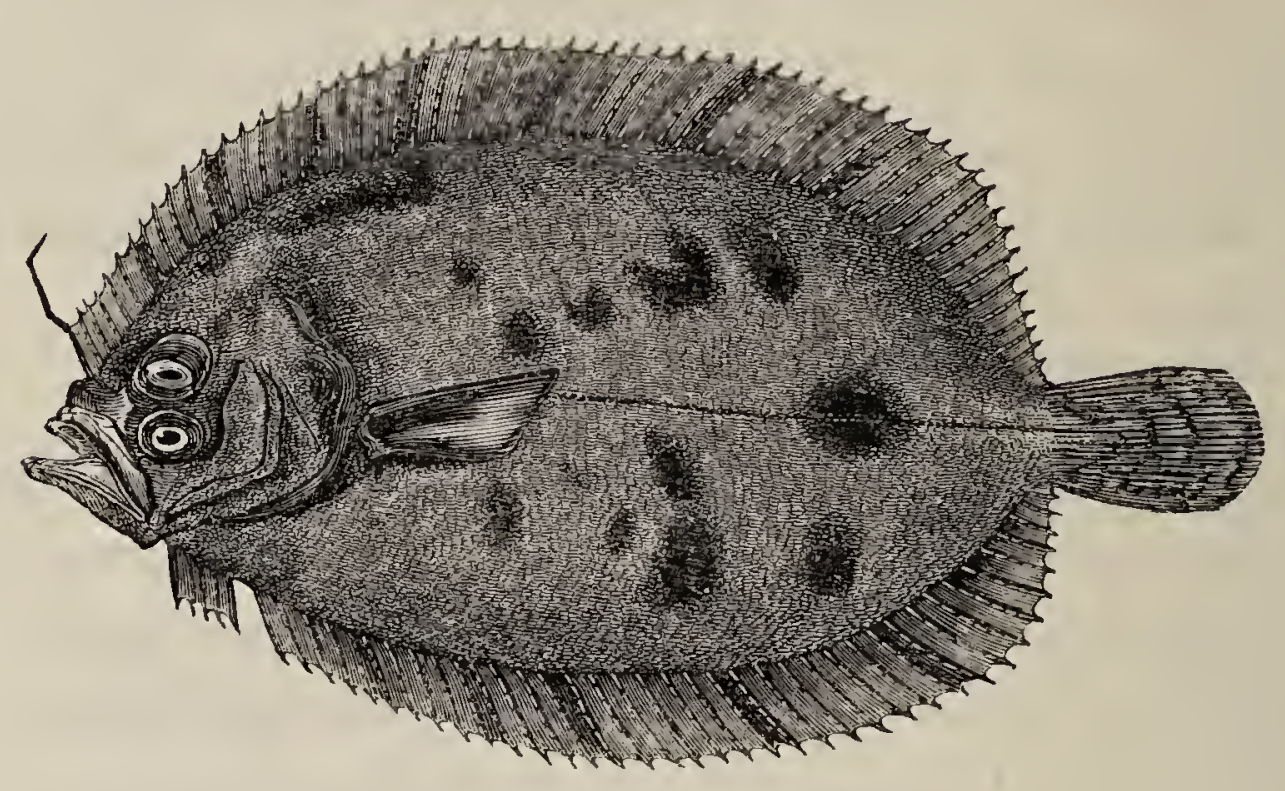

\section{BLOCH'S TOPKNOT.}

Zeugopterus punctatus, Whiтe, Cat. Brit. Mus. p. 104.

Rhombus punctatus, Bloch's Tophinot, YARRELL, 1st and 2nd edit.

Pleuronectes ,, BLOCH, pt. vi. pl. 189.

La petite Limande, DumaMer, sect. ix. pl. 6, fig. 5.

Pleuronectes punctatus, Flex. Wern. Mem. vol. ii. p. 241.

$\begin{array}{llll}, & , & , & \text { Phil. Zool. pl. 3, fig. } 2 . \\ , & , & , & \text { Brit. An. p. 196, sp. } 99 .\end{array}$

Rhombus unimaculatus, Risso, Hist. tom. iii. p. 252, fig. 35.

Pleuronectes punctatus, Bloch's Topknot, Jenyns, Man. Brit. Vert. p. 462.

The Pleuronectes punctatus of Bloch, or, as I have called it, Bloch's Topknot, is much more rare than the Topknot of Müller; but appears, like it, to have an extended range. Professor Nilsson includes but one species in his Fishes of Scandinavia, and brings together the trivial names of the hirtus of Müller and the punctatus of Bloch.

By a paper published in the Swedish language by M. B. F. Fries of Stockholm in 1839, and of which a translation in German is given in M. Wiegmann's Archives for 1840, it appears that the Swedish Ichthyologist, having 
obtained an example of the $P$. punctatus of Bloch, which fish had not been previously recognised as a distinct Scandinavian species, had satisfied himself that the views of Mr. Jenyns and myself were correct as to the distinctive characters existing between the $P$. hirtus of Müller and the $P$. punctatus of Bloch.

Dr. Fleming procured the true punctatus in Zetland, where, according to the testimony of the fishermen, it is not uncommon : and Professor Henslow obtained at Weymouth the specimen from which Mr. Jenyns' description and the figure here inserted were taken. The capture of several examples on the coast of Ireland is recorded by Mr. William Thompson of Belfast, in his Natural History of Ireland (Ed. 1856). A comparison of the figures and descriptions referred to under the present fish with those of the Rhombus unimaculatus of M. Risso, in his Histoire Naturelle, will convince the enquirer that they are intended for the same fish.

Bloch, if he has correctly figured his species, was, I think, mistaken in supposing his fish to be the same as Le Gros Plie ou Targeur of Duhamel; as the separation between the ventral and the anal fins, and the want of connection between the ends of both dorsal and anal fins with the caudal, will demonstrate on comparing the two figures ; but the character and disposition of the spots are something like those of Müller's fish. The figure by Dr. Fleming, in his Philosophy of Zoology, wants only the greater elongation of the first ray of the dorsal fin, perhaps a sexual distinction, to render it identical with the figure here given, and with that of M. Risso.*

* C. J. Sundevall more recently, in his description of the Smihtarf (Skandinaviens Fiskar, pl. 50), assumes that species to be the Pleuronectes cardina of Cuvier, and assigns reasous for the $P l$. punctatus being identical with the hirtus of British ichthyologists, while Bloch's Topknot of British Fishes is, he thinks, an intermediate species. Sundevall's handsome figure 
I avail myself, by permission, of the very full description of this fish given by Mr. Jenyns in his Manual, taken from the specimen in the collection of the Philosophical Society of Cambridge.

" Length five inches and a half. Form roundish oval; the dorsal and ventral lines equally convex: greatest breadth, fins excluded, just half the length : head a little less than one-third of the same: profile notched immediately before the eyes : mouth of moderate size, very protractile; jaws nearly equal; the lower one by a very little the longest, and ascending obliquely at an angle of rather more than forty-five degrees: teeth so fine as to be scarcely visible: eyes large, remarkably full and prominent; their diameter about one-fourth the length of the head; placed on the left side; approximating; the lower one rather more advanced than the upper; between them a projecting ridge; basal and posterior margins of the preopercle meeting at a very obtuse angle, the former rising obliquely to meet the latter; lateral line commencing at the upper part of the opercle, at first very much arched, but afterwards straight : both sides of the body, but more especially the upper one, extremely rough: scales minute; those on the upper side having their free margins set with from four to six denticles; those beneath having the denticles finer and more numerous: dorsal fin commencing immediately in advance of the upper eye, and, extending very nearly to the caudal, at

of the Smaihvarf resembles that of our Müller's Topknot or hirtus in form and markings more than it does Bloch's Topknot. His enumeration of the finrays, made from four specimens, is, D. 78 to 80, A. 58 to 64 , which do not accord well with either of the British species referred to, and are equally remote from those of the Whiff, to which the figure of the Sminkruif hears little resemblance. A close comparison of authentic specimens from Norway, England, and France, would be the best way of clearing up the donbts raised by Mr. Sundevall. We believe that, when submitted to this test, the Smilcvurf will prove to be the livtus of British ichthyologists. 
the same time passing underneath the tail, where the rays become very delicate; greatest elevation of the fin near its retral extremity ; first ray very much produced, nearly three times the length of those which follow; most of the rays divided at their tips; some of the last in the fin branched from the bottom: anal fin commencing in a line with the posterior angle of the preopercle, answering to the dorsal, and terminating in the same manner beneath the tail; greatest elevation corresponding: caudal oblong, the extremity rounded: pectorals inserted behind the posterior lobe of the opercle, a little below the middle; the first ray very short, the next three or four longest, the succeeding ones nearly as long; pectoral on the side of the eyes, rather larger than that on the blind side: ventral fins immediately before the anal, and appearing like a continuation of that fin, but not connected with it, as in the other species: vent situated between the two last pairs of rays : the rays of all the fins covered with rough scales nearly to their tips. The numbers of the fin-rays are-

D. 87 : P. left side 12 : right side 11 ? V. $6:$ A. $68:$ C. 16.

"The colour above brown, or reddish brown, mottled and spotted with black; a large round spot, more conspicuous than the others, in the middle of the side towards the posterior part of the body; fins spotted : under side plain white."

Sundevall describes the Swedish examples as having separate, indeterminate brown spots on the margins of the back and belly, and a larger patch than the others behind the pectoral fin, extending across the curvature of the lateral line; besides others less conspicuous on the body and fins. 


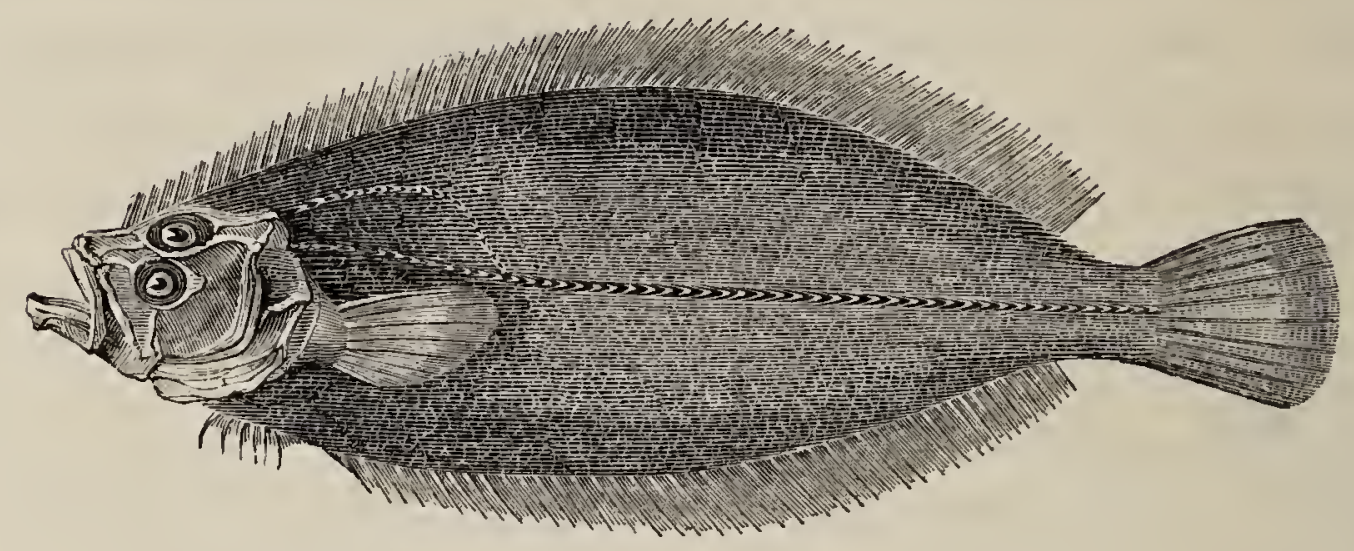

THE WHIFE.

tite CARTER OR LANTERN, Cornwall.

Zeugopterus megastomus, Whiff, $\quad$ YanneLi, 3rd ed.

," ," La Carcline, Cuvier, Règne An. t. ii. p. 341.

Passer Cormuliensis, Whiff, RAY, Syn. p. 163, fig. 2.

Pleuronectes pseudopalus, ,, Penn. Brit. Zool. iii. p. 324, pl. 52.

," megastoma, ", Dorev. Brit. Fish. pl. 51.

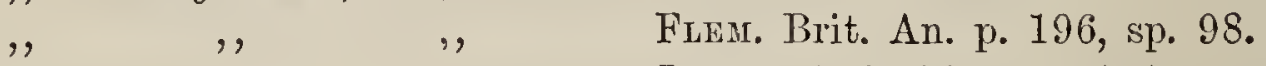

," $\quad$, $\quad$ Jinyns, Brit. Vert. p. 464.

The Whiff appears to have been first described and figured by Ray from Mr. Jago's Catalogue of Cornish Fishes, which is introduced, with short notices and representations, in Ray's Synopsis. This fish seems to occur more frequently in Devonshire and Cornwall than on any other part of our coast, and $\mathrm{Mr}$. Couch says, "The species is well known to the Cornish fishermen, who apply the name of Carter to it. It keeps on sandy ground, at no great distance from land, and takes a bait, so that it is caught as often as any of the salt-water Flatfishes; but it is not highly esteemed for the table, chiefly from being so thin." From this cause it is sometimes called Lanternfish, in reference to its semi-transparency when held up 
between the eye and the light; but from experience I can say that the flesh is excellent when fried, almost as good as that of the Sole.

Mr. Donovan found it in Wales; it is not unfrequent in Ireland. Mr. Jenyns has described it in his valuable Manual of the British Vertebrate Animals, from a specimen obtained by Professor Henslow at Weymouth. Most of the specimens recorded measured from eigliteen to twenty-one inches in length. Mr. Thompson states it to be of occasional occurrence on the east coast of Ireland. It is called "the Sole" in the Belfast market, and "White Sole" at Dublin.

Dr. Johnston says it is rare at Berwick, and Dr. Parnell does not include it among his Fishes of the Forth.

But few particulars are known of this fish. It appears but seldom in the London market: I obtained one in June 1834 which measured seventeen inches in length, from which a representation and the following description are taken.

The length of the head from the point of the upper jaw to the posterior edge of the operculum, compared to the length of the body alone, without the head or caudal rays, is as one to three; and the breadth of the body, dorsal and anal fins excluded, is as to the whole length of the fish rather less than one-third: the dorsal fin commences halfway between the point of the nose and the anterior edge of the upper orbit, and extends to within three-quarters of an inch of the end of the fleshy portion of the tail and the base of the caudal rays: the pectoral fin on the under or white side is considerably smaller in size, and contains two rays less than that on the upper side: the ventral fins are of some longitudinal extent at the base, as in the preceding species of the genus Psetta: the anal fin commences under the origin of the pectoral 
fin, extends along the whole length of the abdominal line, and ends near the tail on the same plane as the dorsal fin; the fleshy portion of the tail is narrow; the caudal rays are three inches long and slightly rounded.

The fin-rays in number are-

D. $89:$ P. 11 : V. $6:$ A. 71 : C. 13. Vertebræ 41.

The mouth is large; and the lower jaw, which is the longest, has a rounded projection under the symphysis; the teeth on both jaws stand in crowded bands, pointed, and sharp; the eyes are large; the upper one being the most so, and placed farther back than the lower one : the orbits are separated by a prominent bony ridge : the lateral line is conspicuous and elevated, and is double over the pectoral fin, one portion being a continuation of the prominent straight line that traverses the body and corresponds to the spinal column, the other taking a high eurve over the pectoral fin; both lines ultimately approaching each other again at the upper angle of the operculum, as shown in the woodcut: the form of the body is an elongated oval; the surface is rough; the scales being rough and rather large; the colour is a uniform yellow-brown; the fins being rather lighter; and the under side smooth and white. A. specimen in the British Museum exhibits faint indications of various spots, as shown in Mr. Donovan's coloured plate, and in the figure by Ray in his Synopsis, but this is not uniformly the case. Mr. R. Q. Couch states that the dorsal surface is mottled in individuals which inhabit rough ground.

Pennant states that the Welsh name of this species is Lleden arw fafrnwth. 


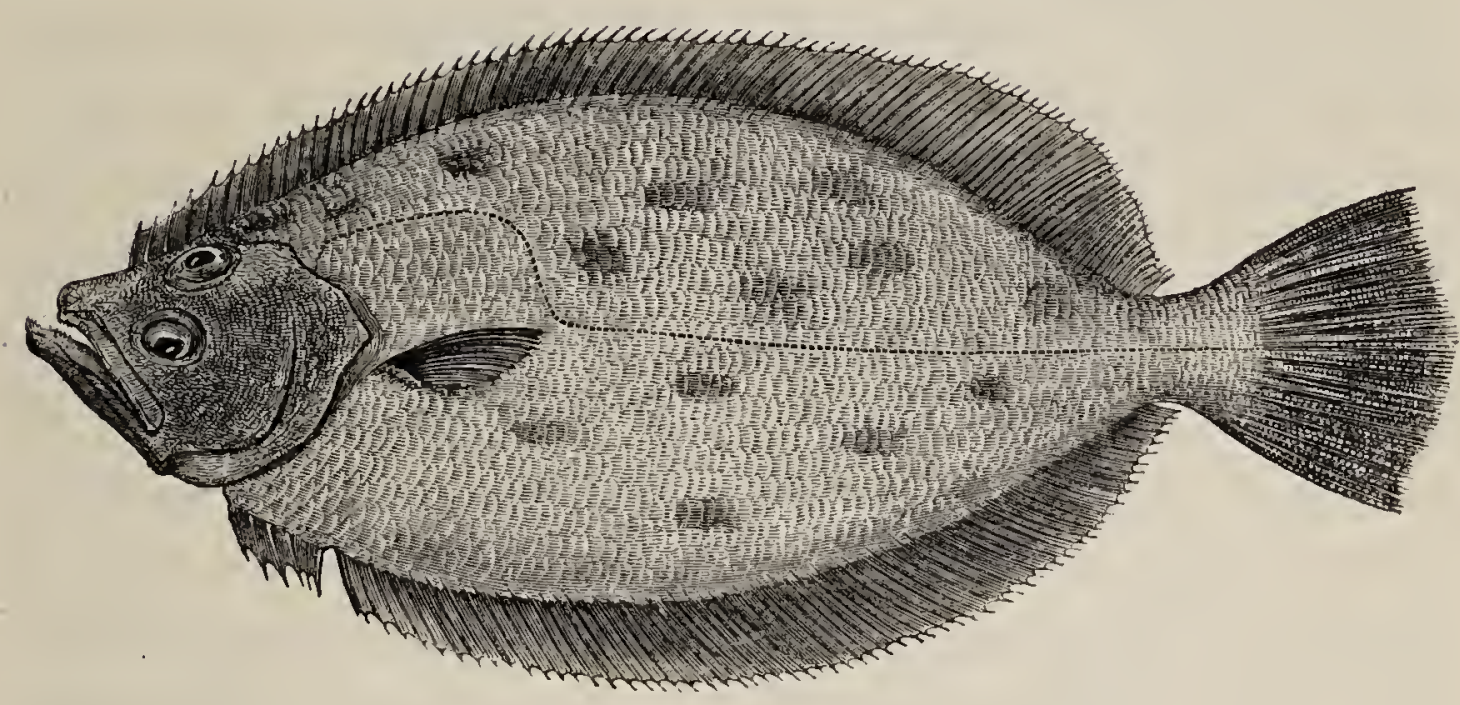

\section{THE SAIL-FLUKE.}

Zeugopterus? velivolans. EDrTor of the Third Ed. of Br. Fishes.

Dr. Barkie, writing from the banks of the Niger, referred to Dr. Alex. Duguid of Kirkwall for information respecting the very curious habits of this fish, and that gentleman, on being applied to, most kindly sent a sketch made by a friend of his, said to be very correct, from which the above wood-cut has been engraved. He also furnished the following particulars of the history of the fish. This Fluke, he says, is highly prized as an article of food, its flesh being firm and white. It does not take a bait, and he only once saw it caught in a net, but it comes ashore, spontaneously, with its tail erected above the water, like a boat under sail, whence its name. This it does generally in calm weather, and on sandy shores, and the country people residing near such places train their dogs to catch it. The following letter was written by Mr. Robert Scarth, of North Ronaldshay, the northernmost island of the Orkney group, where the Sail-fluke is very common:- " It is never caught by hook or by net, and I have in vain set ground lines for it in the South

VOL. I.

$\mathrm{T} \mathrm{T}^{*}$ 
Bay, baited with Lug-worms, Limpets and Sellocks, neither have Flounder or Skate nets, drawn there, inclosed a Sail-fluke. It seldom comes to the shore earlier than October or later than April, though it is often driven by storms on the beach, entangled among sea-weed. The great supply is, however, obtained in the following manner:-In the winter and early spring a pair of Blackheaded Gulls take possession of the Bay, drive away all interlopers, and may be seen at daybreak every morning beating from side to side, on the wing, and never both in one place, except in the act of crossing as they pass. The Sail-fluke skims the ridge of the wave towards the shore with its tail raised over its back, and when the wave recedes is left on the sand, into which it burrows so suddenly and completely, that though I have watched its approach, only once have I succeeded in finding its burrow. The Gull, however, has a surer eye, and casting like a hawk, pounces on the Fluke, from which by one stroke of his bill it extracts the liver. If not disturbed, the Gull no sooner gorges this luscious morsel, than it commences dragging the fish to some outlying rock, where he and his consort may discuss it at leisure. By robbing the Black-backs I have had the house supplied daily with this excellent fish, in weather during which no fishing-boat could put to sea. Close to the beach of South Bay a stone wall has been raised to shelter the crops from the sea-spray. Behind this we posted a smart lad, who kept his eye on the soaring Gulls. The moment one of the birds made its well-known swoop, the boy rushed to the sea-strand, shouting with all his might. He was usually in time to scare the Gull away and secure the Fluke, but in almost every case with the liver torn out. If the Gull by chance succeeded in carrying his prey off to the rock, he and his partner set up a triumphant cack- 
ling, as if deriding the disappointed lad. Seals often pursue these Flukes into the bay, and frequently leave servicable morsels unconsumed. The Sail-fluke exhibits its gambols most frequently before a storm, or when a thaw succeeds a frost. It is the most delicious fish of our seas, but loses its flavour by a day's keeping."-19 Feb. 1849.

Length of a specimen, twenty-one inches. Height, excluding the fins, seven inches and a half, or including them, ten inches. Weight three pounds.

\section{87 : A. $69:$ P. 11 : V. $5:$ C. $19 \frac{2}{2}$.}

The dorsal commences before the upper eye, which is three-quarters of an inch before the lower one. The rough lateral line is much arched over the pectoral fin. Scales large and striated from the centre, roughish on the pale belly, and very small on the fronts of the fin-rays. There is one row of minute sharp teeth on each jaw, and also some teeth on the vomer. Tongue round and conical. Operculum and interoperculum thin and very diaphanous, the bony plates, and the cheeks being as thin as silk paper, so that the smallest type may be read through them. The left or coloured side of the fish is like that of the Common Dab, yellowish-brown, with scattered dark blotches.-Another specimen weighed four pounds, and had ninety-one dorsal rays, with seventy-five anal ones.-(Dr. Duguid.)

The oval of the body is wider vertically than that of the Smähvarf (Pl. 50) of the Scandinaviens Fiskar, but narrower than the ovals of either of our English Top-knots. In the facial profile and forms of the vertical fins there is much similarity between the Smähvarf and the Sail-fluke, but none of the four specimens of the former, noticed by Sundevall, have so many dorsal and anal rays as the Orkney Fluke. In the latter, also, the upper eye is more distinctly behind the lower one, and the mandible pro- 
trudes farther. Sundevall makes no mention of transparent cheeks ; for the present, therefore, they are described as distinct, such a proceeding being less injurious to science than the junction of two species divers in structure and habits under one name. In the absence of a specimen, the Sail-fluke is placed in the genus Zeugopterus interrogatively. A single row of jaw-teeth only is mentioned by Dr. Duguid, but he probably means laterally, where the Smähvarf has only one row, though there is a crowded patch at the symphyses of its jaws.

The existence of the Sail-fluke induces us to recall the conjecture, hazarded at p. 651 , respecting the identity of the Smähvarf and Zeugopterus hirtus.

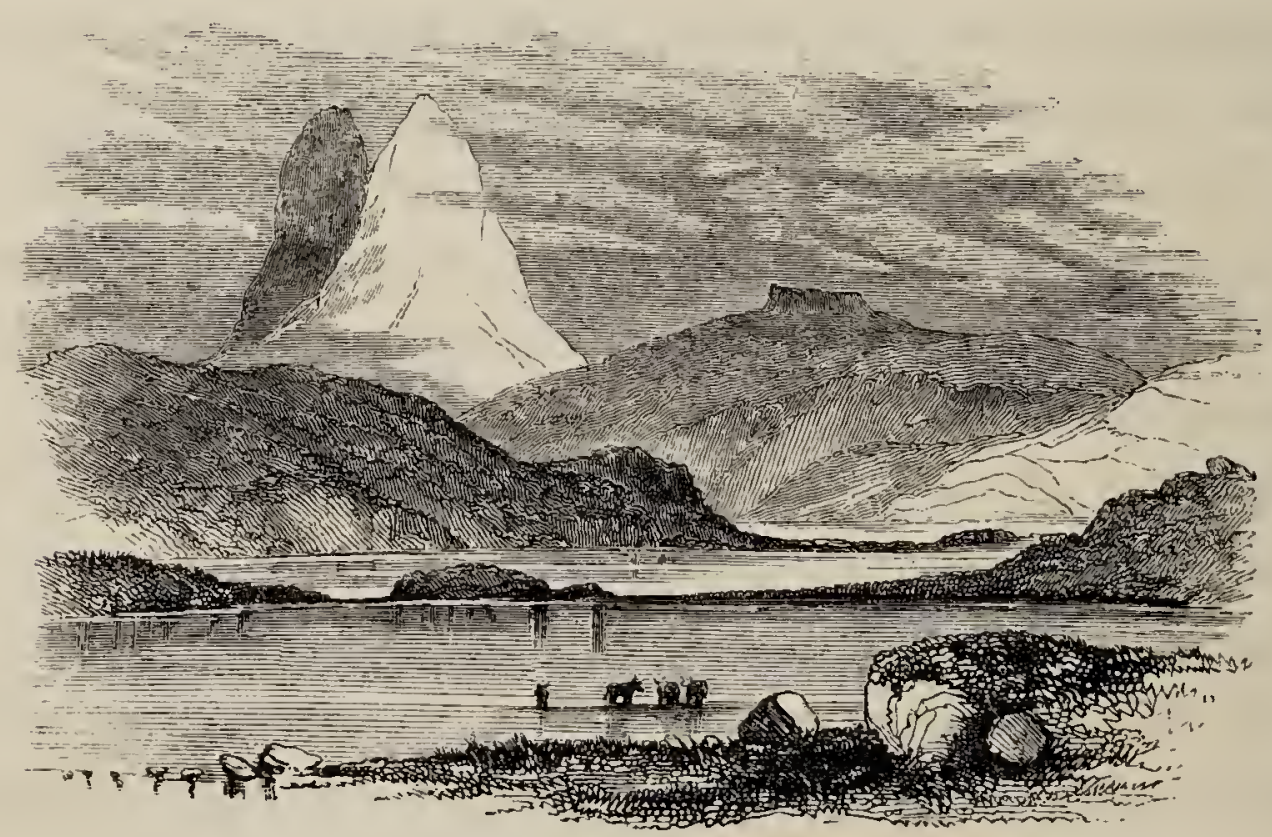




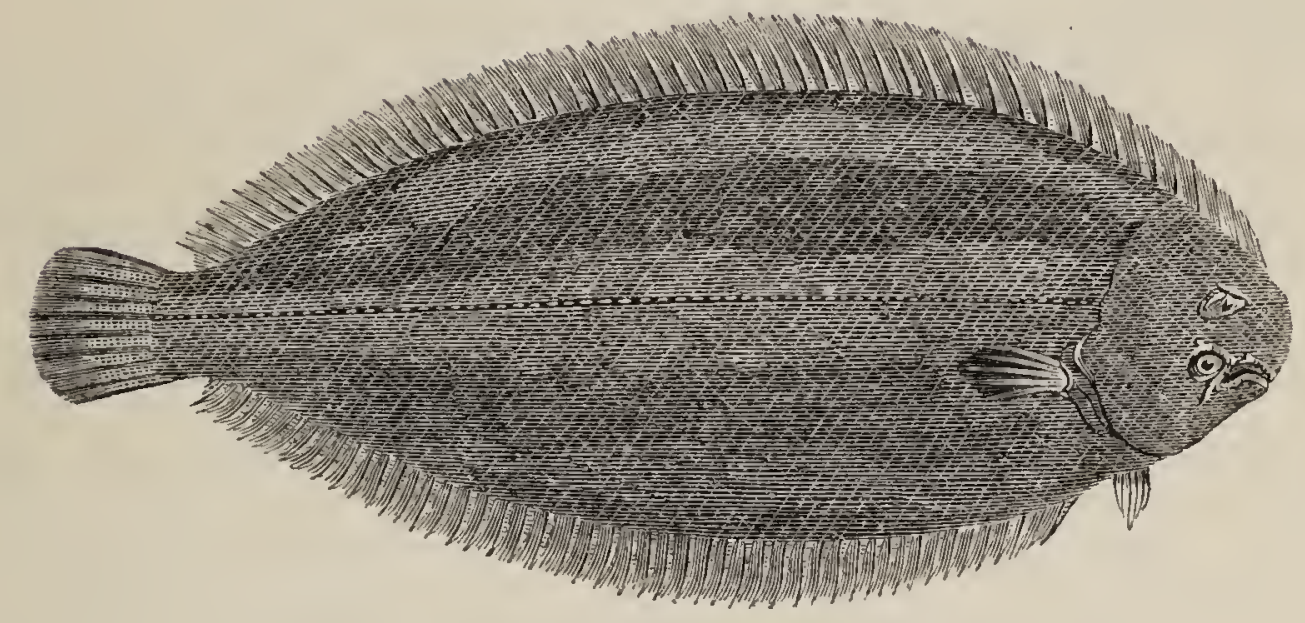

\section{THE SOLE.}

TAFOD YR HYDD, Wales.-TUNGA, Sweden.

Solea vulgaris, La Sole, Cuvien, Règne An. t. ii. p. 342.

,, ,, A Sole, Merremt, Pinax. p. 187.

Buglossus seu Solect, Sole, Willugnibx, p. 100, F. 7.

Pleuronectes Solea, ,, Linnaus. Bloch, pt. ii. pl. 45.

,",$\quad$, Penn. Brit. Zool. vol. iii. p. 311.

" $\quad$, Common Sole, Dovov. Brit. Fish. pl. 62.

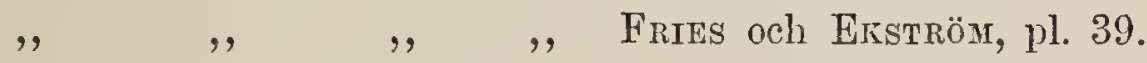

SoLEs. Generic Characters. - Jaws concealed by scaly integument, the upper one incomplete, and the mandible short; chin scaly, without the usual folds between the limbs of the mandible. Gill-openings closed above the pectorals. Upper eye the most forward of the two. Nostrils on both sides, close to the maxilla. Rays of the fins all divided; no spine. Mouth beneath the snout; pectorals present on both sides; candal fin separate from the dorsal and anal.

The common Sole is so universally known as to require only a particular notice of those points in its economy that are the least obvious. It inhabits the sandy shore all round our coast, where it keeps close to the bottom, feeding on the smaller testaceous animals, and the spawn and fry of other fishes. It is taken among the Orkneys, 
and along the north-east coast; but it is of small comparative size: the soles of the south and west are much larger, and considered otherwise superior to those of the north and east.

The Sole is found northward as far as the Baltic and the seas of Scandinavia; and southward along the shores of Spain, Portugal, and the Mediterranean. It was first described by Belon.

Soles-and of these an enormous quantity - are caught almost entirely by trawling; they seldom take any bait. It is usual to send them to market in baskets, within which the Soles of small size, called Slips, are arranged nearest the wicker-work forming the outside of the basket : the larger Soles, being more valuable, are packed in the middle. Eighty-six thousand bushels of Soles have been received within twelve months at Billingsgate market alone.

Soles are found full of roe at the latter end of February. They are then for a few weeks soft and watery; but they soon recover, and throughout a great portion of the year are deservedly in high estimation; the flesh is white, firm, and of excellent flavour; those in deep water are the finest in quality.

The principal trawling-ground in England is along the south coast from Sussex to Devonshire: the Sole has also been taken on the shores of various counties in Ireland, viz. Cork, Waterford, Antrim, Londonderry, and Donegal. On the Devonshire coast the great fishing station is at Brixham in Torbay, where the boats, using large trawling-nets from thirty to thirty-six feet in beam, produce a continual supply. Soles of very large size are occasionally taken. I have a record of one pair taken in Torbay which measured twenty-three inches in length each, and weighed together ten pounds; but for 
the particulars of the largest I have heard of, I am indebted to the kindness of the Rev. W. F. Cornish, of Totness. This specimen, a remarkably fine-grown fish, and very thick, was twenty-six inches long, eleven inches and a half wide, and weighed nine pounds. It was brought to Totness Market on June 21, 1826.

Soles appear to thrive well in fresh water. Dr. M`Culloch, in his papers on "Changing the Residence of certain Fishes from salt water to fresh," * says, he was informed that a Sole had been kept in a fresh-water pond in a garden for many years; and adds, that in $\mathrm{Mr}$. Arnold's pond at Guernsey, which has been before referred to, the Sole becomes twice as thick as a fish of the same length from the sea. A letter from a gentleman residing on the banks of the Arun contains the following statement:- "I succeeded yesterday in seeing the person who caught the Soles about which you inquire, and who has been in the constant habit of trawling for them with a ten-feet beam trawl in this river for the last forty years. The season for taking them is from May till November. They breed in the river (Arun), frequenting it from the mouth five miles upwards, which is nearly to the town of Arundel, and remain in it the whole year, burying themselves in the sand during the cold months. The fisherman has occasionally taken them of large size, two pounds' weight each, but frequently of one pound; and they are thicker in proportion than the Soles usually caught at sea: in other respects precisely the same; and it is evident they breed in great numbers in the river, from the quantity of small ones about two inches long that are constantly brought on shore when drawing the net for Grey Mullet."

* Royal Institution Quarterly Journal, No. xxxiv. July 1824, and No. xxxviii. July 1825. 
Reversed Soles-that is, having the eyes and the brown colour on the left side instead of the right-are not uncommon: and I possess a specimen that is of the usual dark colour, with rough ciliated scales on both sides.

The length of the head is to the wliole length of the entire fish as one to six ; the breadth of the body, dorsal and anal fins excluded, compared to the whole length, being as one to three: the nose is rounded and produced, projecting beyond the mouth: the upper jaw is the longest; and both jaws are furnished with minute teeth on the under or white side of the fish only; the eyes are small; the lower eye placed over the angle of the mouth; the upper eye being more forward; the irides are yellow; the pupils blue; the space between the eyes, the cheek, and operculum, flat, and covered with small, rough, ciliated scales: only about two-thirds of the white or sinistral side of the head is scaly: the pectoral and ventral fins are small; the dorsal fin begins at the point of the nose, the anal fin under the edge of the gill-cover; both extend the whole length of the body, and end on the same plane, near the base of the caudal rays; and both these fins have a series of small, rough, ciliated scales, flanking each ray: the caudal is rather long, and is slightly rounded.

The fin-rays in number are-

\section{D. $84:$ P. $7:$ V. $5:$ A. $67:$ C. 17 . Vertebræ 47.}

The form of the body is a long oval, widest at a short distance behind the head, becoming narrower and rather pointed towards the tail; the colour on the upper side is an almost uniform dark brown; the scales are small, ciliated on the edge, and rough to the touch; the lateral line runs straight from the tail forward to the operculum, then rises and ends on a line with the superior edge of the upper orbit; the pectoral fin is tipped with 
black. On the under side the colour is white: about the nostril and mouth there are numerous soft papillæ.

Dr. Kaup says that the subfamily of Soleina are without exception dextral fishes, with their jaws much contorted towards the left side, and furnished with very fine, many-rowed, card-like teeth. The anal never has a spine before it, nor are the pectorals ever much developed, and they are sometimes rudimentary on the left side, or wholly absent. In the true Achiri they are wanting on both sides.

The vignette below represents a Peter-boat as used by the Thames fishermen between and above the different bridges.

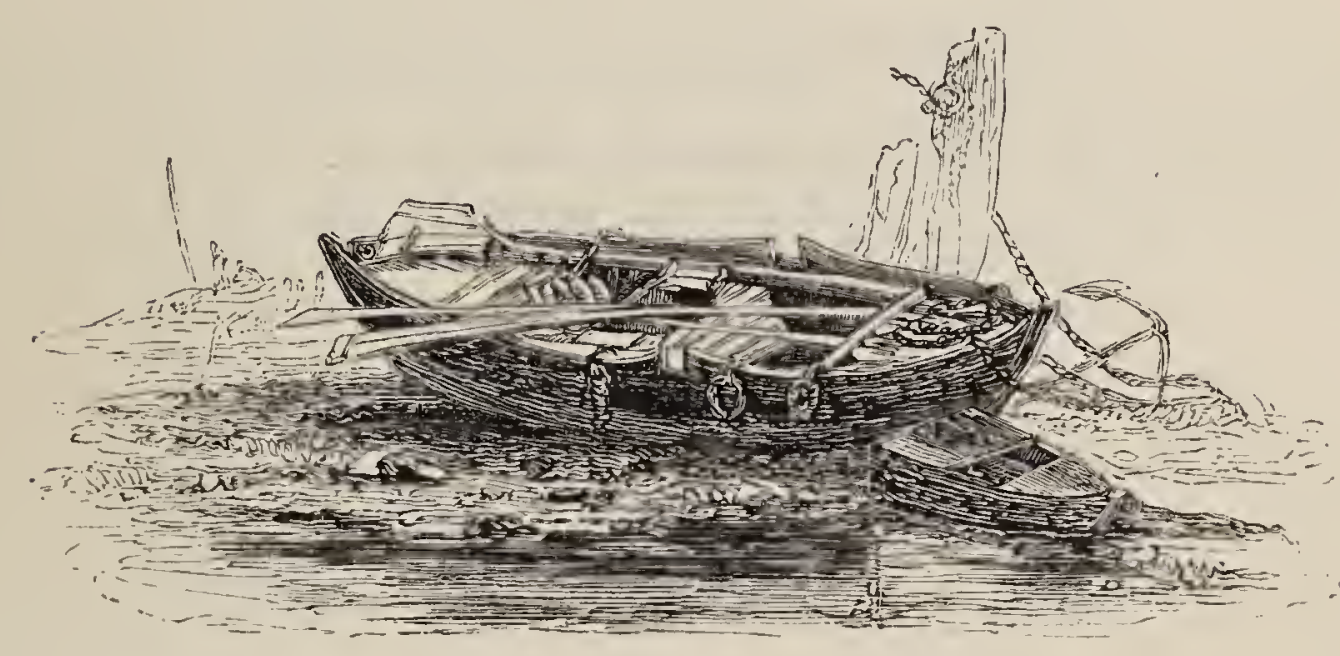




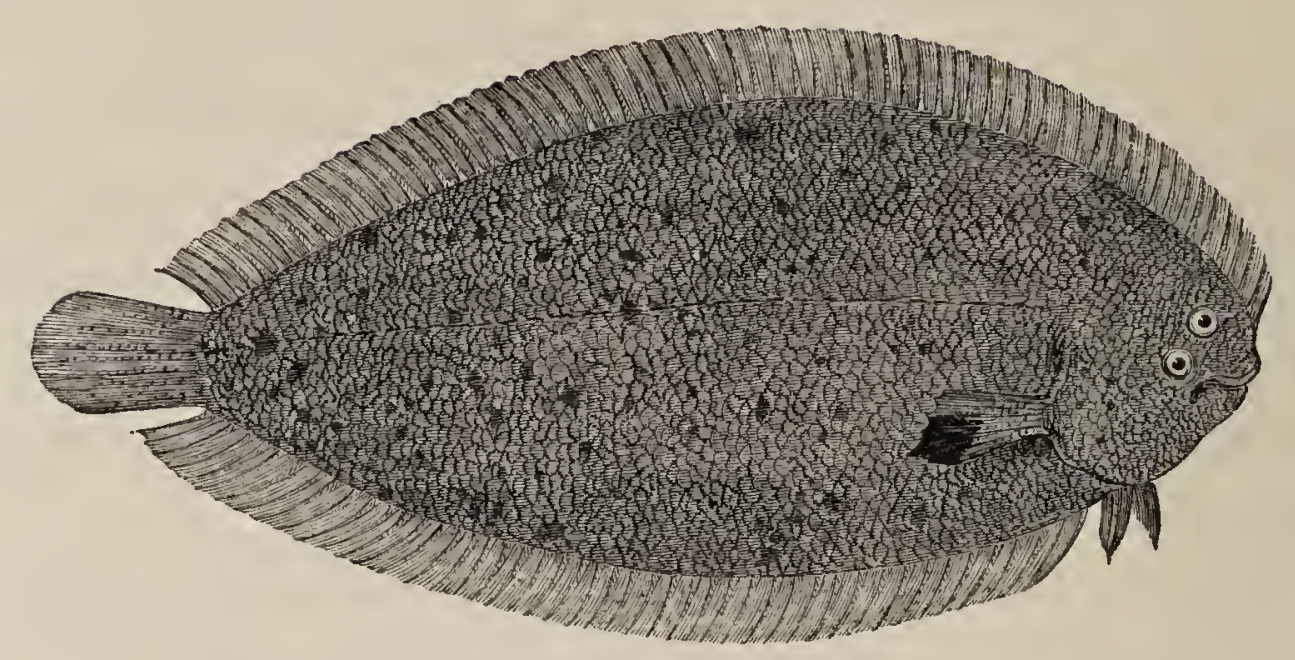

\section{THE LEMON SOLE.}

THE FRENCH SOLE, Sussex coast.

Solea nasuta, Nordn. Kadp, Uebers. der Soleince.

Pleuronectes nasutus, Paldas, Zoogr. vol. iii. 426.

Solea pegusa, Lemon Sole, YARreur, Zool. Journ. vol. iv. p. 467, pl. 16.

," , ", , Janyns, Man. Brit. Vert. p. 467, sp. 155.

During a short visit to Brighton in the last week of. February 1829, I obtained a single example of this species of Sole, which appeared to have been previously unnoticed as occurring on our shores. Since it was described in the Zoological Journal, as above quoted, I have obtained, but at considerable intervals, two or three other specimens of this fish in the London market, and have now deposited examples in the British Museum and the collection of the Zoological Society.

This species is occasionally taken with the common Sole when trawling over a clear bottom of soft sand, about sixteen miles from Brighton in a direction towards the coast of France; from which circumstance this fish is known to some of our fishermen by the name of French 
Sole; others call it by that of Lemon Sole, in reference to its prevailing yellowish colour, and on the Devonshire coast it is called the Sand Sole. This species has since been taken in Belfast Bay, as recorded by $\mathrm{Mr}$. William Thompson.

In shape the Lemon Sole is wider in proportion to its whole length than the common Sole, and it is also somewhat thicker; the head is smaller, being in proportion to the whole length of the fish rather less than as one to seven; the breadth of the body, dorsal and anal fins included, exactly half the whole length: the arrangement of the fins is nearly the same as in the common Sole; but the fin-rays and the number of vertebræ differ.

\section{81 : P. 8 : V. $5:$ A. $69:$ C. 17 . Vertebræ 43.}

The prevailing colour is a mixture of orange and light brown, freckled over with numerous small round spots of dark nutmeg brown, giving a mottled appearance to the whole upper surface. The scales differ in character; the lateral line is straight, but not so prominent or so strongly marked; the tail-fin is narrower than in the common Sole, though containing the same number of rays; the end of the pectoral fin is spotted with black. On the other side the appearance is still more characteristic of the distinction of the species. The under surface of the head is almost smooth, without any of the papillary eminences so numerous and remarkable in the common Sole, and the nostril is pierced in a prominent tubular projection, which is wanting in the other: the under surface is white, with the appearance of the scales more strongly marked than upon the upper.

The Solea pegusa of Kaup, or Monochir pegusa of Risso, is different from the Lemon Sole. 
ANACANTHINI.

PLEURONECTIDA. ANISOMERI.

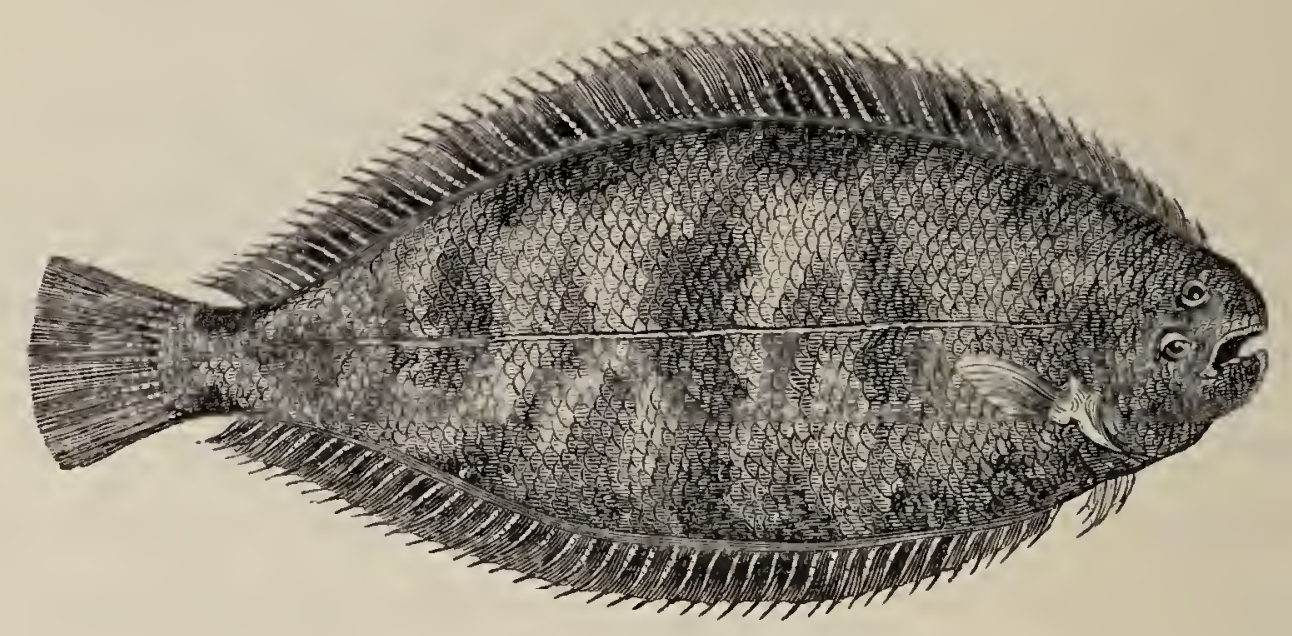

\section{THE VARIEGATED SOLE.}

Solea variegata, Flem. Brit. An. p. 197.

Monochirus rariegatus, Thomeson, Ann. Nat. Hist. vol. ii. p. 404.

Pleuronestes lingula, Redbacked Flounder, Pens. Brit. Zool. vol. iii. pl. 49.

, variegatus, Variegated Sole, Donov. Brit. Fish. pl. 117.

Rhombus mangili, Rrsso. Bonap. Faun. It. vol. iii. 27.

, lacteus, ID.

Monochir microchir, Cuv. Règ. An. vol. iii. p. 343.

The Variegated Sole appears, like the Lemon Sole last described, to be a rare species, and but few specimens are to be found in collections, though it seems to have a wide range. According to Professor Reinhardt, it is found on the shores of Scandinavia. In the Magazine of Natural History, conducted by Mr. Loudon, a notice appears, vol. vi. page 530, that it has been taken at Rothsay. Mr. Donovan obtained one seven inches long in the London market. Colonel Montagu mentions that Dr. Leach bought three in Plymouth market in August 1808, and gave him one of them, measuring nine inches in length, from which his notes of the species 
were recorded in his MS.; and Mr. Couch, who has observed it in Cornwall, very kindly sent me a specimen, from which the woodcut was executed. But little is known of the habits of this species; but it is stated in Pennant that it appears about Plymouth in the spring. It has since been found by Mr. William Thompson in Belfast Bay.

It is immediately distinguished from either of the Soles previously described here, by its variegated colour ; by its scales, which are larger ; by its pectoral fins, which are much smaller, that on the under side being very minute; and by the dorsal and anal fins, as shown in the cut, ending considerably short of the tail-fin.

The whole length of the specimen described was five inches; and the breadth without the fins, one inch and three-eighths; the length of the head compared to that of the body alone being as one to four: the dorsal and anal fins end on the same plane, but do not reach the base of the caudal rays, and both have their numerous rays projecting beyond the edges of the connecting membranes, as shown in the cut; the right pectoral fin is small, and that on the under side consists of two unequal, slender, and short rays only.

The fin-rays in number are-

D. 67 : P. right side 4 : left side 2 : V. $5:$ A. 52 : C. 16.

The body is thicker in proportion than either of the Soles previously described; the scales larger, the divisions strongly marked, the edges ciliated, rough to the touch; the lateral line straight : the colour of the upper side reddish brown, clouded both on the body and fins with darker brown; the under surface white; scales also ciliated and harsh to the touch. 


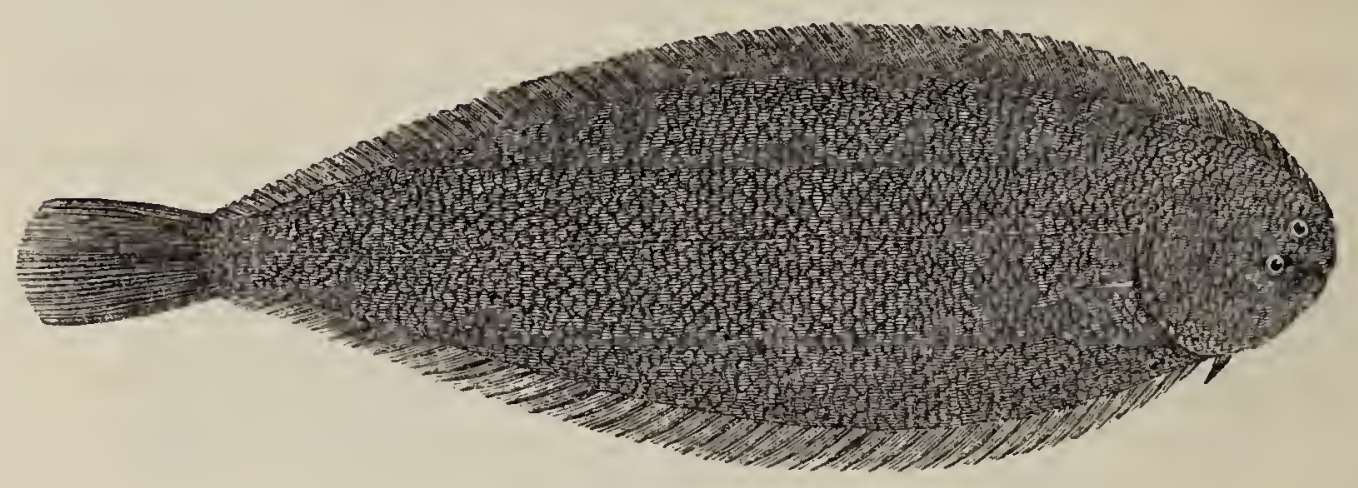

THE SOLENETTE,

OR LITTLE SOLE.

Solea lingula, Rondelet. KaUp, Uebers. der Soleinæ.

Monochirus linguatulus, Cuvier, Règne An. t. ii. p. 343.

Solea parva sive lingula Rondeletii, Willughis, p. 102, F. 8, fig. 1.

Pleuronectes lingula, $\quad$ Linn. Syst. Nat. p. 457, sp. 10.

Solenette,

DuHar, sect. ix. pl. 2, fig. $1 \& 2$.

Solea lingula, Red-backed Sole, Jenyns, Brit. Vert. p. 468.

Monochirus minutus, Parnell, Mag. Zool. and Bot. vol. i. p. 527.

" linguatulus, Thompson, Ann. Nat. Hist. vol. ii. p. 405.

Ar the time of writing the description of the Variegated Sole for the first edition of the British Fishes, vol. ii. p. 262, I had not seen a specimen of the true Solea parva sive lingula of Rondelet, and I find that I then included two distinct species in the synonymes employed to designate the Variegated Sole. The Rev. L. Jenyns, in his Manual of British Vertebrate Animals, appears to have suspected that there was a fourth species of Sole on our coast, since, at the conclusion of the description of his third species, he has observed, "further observation is necessary in order to decide whether, in this instance, I have confounded two nearly-allied species." 
In the published proceedings of the Royal Society of Edinburgh for January 1837, Dr. Parnell has figured and briefly described, under the name of Monochirus minutus, a small species of Sole, obtained by him at Brixham on the Devonshire coast, which appears to be the true Solea parva sive lingula of Rondelet. This small fish is at once distinguished from the Variegated Sole of Donovan, and other English authors, by the tapering of the body towards the tail, and more particularly by the dorsal and caudal fins being united to the base of the tail, which is not the case in the Variegated Sole. This union of the two fins with the tail is shown in the figure given by Rondelet, and again by Willughby, who copied Rondelet's figure.

Dr. Parnell has obtained several examples of this interesting little species, which is not unfrequently taken in the trawl-nets by the fishermen of Brixham, but on account of its diminutive size it is seldom brought on shore. It has evidently been confounded with the Variegated Sole; but, independently of other distinctions, the Variegated Sole has the tail separated from the dorsal and caudal fins by a considerable interval.

The Variegated Sole of Donovan and of Montagu's MS., the Red-backed Flounder of Pennant's Zoology, and the Variegated Sole of Dr. Fleming, are so many specimens of the truly Variegated Sole, and are each of them quite distinct from the true lingula. Duhamel appears to have distinguished and figured both species. Mr. Thompson has obtained both species on the coast of the North of Ireland, and he kindly sent me his specimens for comparative examination. Dr. Parnell has given me two examples of his Monochirus minutus, which, as observed above, I believe to be the true Solea parva sive lingula of Rondelet; and I have also two specimens 
of the true Variegated Sole; one of them, the subject of our figure on p. 664, has a dark cloud of colour extending, as in Donovan's figure, over the back and fins: in a specimen belonging to $\mathrm{Mr}$. Thompson, in one of $\mathrm{my}$ own, and in Montagu's, as described in his MS., the dark clouds are limited to patches on the fins, as in Pennant's figure; but without reference to colour, this species is immediately known by the space which intervenes between the three vertical fins, which Montagu says was equal to half an inch in his specimen, which measured nine inches. The Solea lingula or Monochirus linguatulus of Cuvier has the smaller upper pectoral fin of the two, as observed by Mr. Thompson, who has, in the second volume of the Annals of Natural History, published some interesting details respecting this species and the Solea variegata.

From the number of these small Soles which are taken in the trawl-nets off Brixham throughout the whole year, says Dr. Parnell, and from their never appearing to attain a large size, there can be little doubt but that they have arrived at their full growth. The fishermen, who are perfectly familiar with their appearance, call them Red Soles; and scarcely a trawl-boat leaves Brixham Harbour that does not capture a dozen or more of these fish daily; but, from their diminutive size, they are either thrown overboard, or left to decay at the bottom of the vessels.

Description :-_"Length five inches; the width at the upper third nearly two inches: the colour of the back light reddish brown, the under surface pale white; every sixth or seventh ray of the dorsal and anal fin black. In shape this fish is similar to the common Sole, but it is more wedge-shaped, becoming narrow at the caudal extremity. The head is small, being only one-sixth of the whole length; the mouth is crooked; each jaw is furnished 
with a number of minute teeth, placed close together, and extending but half way round the mouth; the eyes are small; the upper, or left eye, a little in advance. The dorsal fin commences immediately over the upper lip, and runs down the back, to be connected with the caudal rays; the anal fin begins under the posterior margin of the operculum, and continues to the tail. The number of the fin-rays are-

$$
\text { D. } 73: \text { P. } 4: \text { V. } 4: \mathrm{A}: 54: \text { C. } 14 .
$$

The scales are small, with from twelve to fifteen denticles at their free extremity, rendering the whole surface of the fish rough to the touch when the finger is passed along from the tail to the head. The pectoral fin, on the eye-side, is small, with the lower half black, while the fin on the opposite side is very minute, and of a pale white; the lateral line is straight throughout; the tail is rounded at the end and mottled with brown."-Parnell.

The descriptions contained in the preceding pages show that the members of the family of Pleuronectida, in addition to many striking peculiarities of form, offer the anomaly of some genera having smooth, others ciliated scales, and some with a spine in the anal fin, while others want them. The existence of a spinous ray accords ill with the appellation of Anacanthoid bestowed on the order, but the gradations and variations of structure in the animal kingdom cannot be pressed into uniformity with the abrupt definitions used in systematic classification.

We have not seen the Solea Trevelyani of Ireland (Sanders' News-letter, 16th April, 1850). It is dark-bellied, and is described as having a projection on the head like the monstrosity figured on page 643 .

Dr. Baikie, in a letter written from the banks of the Niger to the Editor of this edition of British 
Fishes, mentions an undescribed Sole that is frequently observed in the Sounds of the Orkneys, skimming over the surface of the water with its tail raised at a right angle, like a sail. This nautical Sole is not the object of any fishery, but examples of it are occasionally got by watching the Skua Gulls who feed on it, and when one of these birds has carried its prey to the shore, driving it away before it has time to devour it. Our endeavours to procure a specimen for description have not hitherto succeeded.

A perfectly circular Sole was seen at Scarborough by Mr. Alfred Roberts, Curator of the Museum there, but he unfortunately did not succeed in catching it, for, having mistaken the head for the tail, which were alike, he approached it with his net in the wrong direction, causing it to dart off, to his great disappointment.

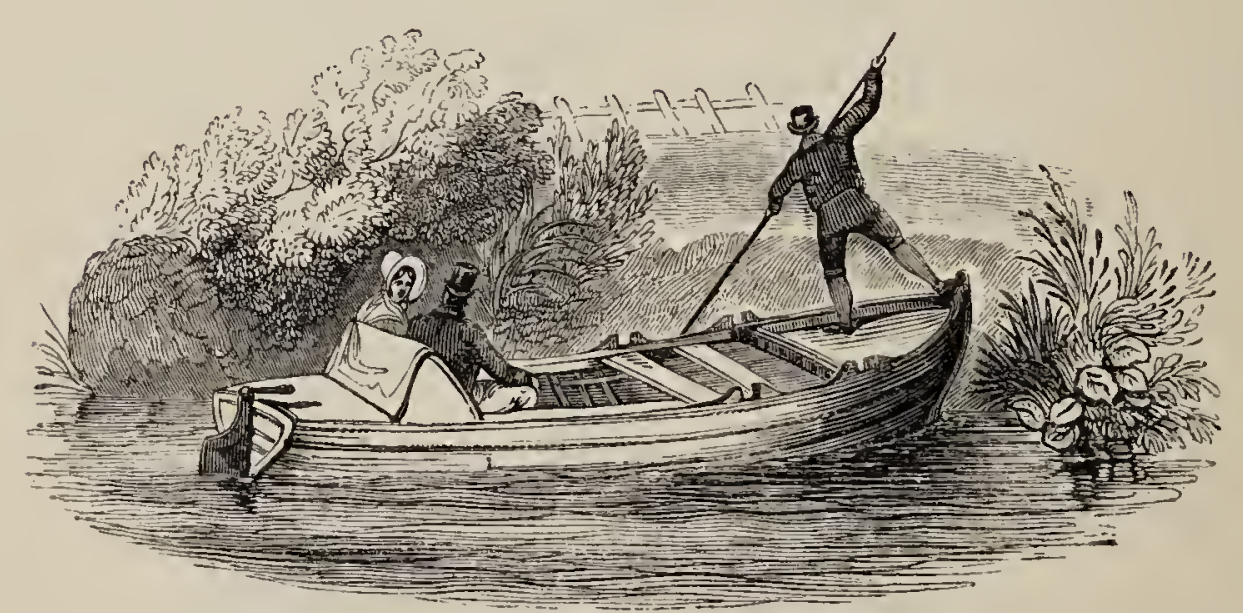




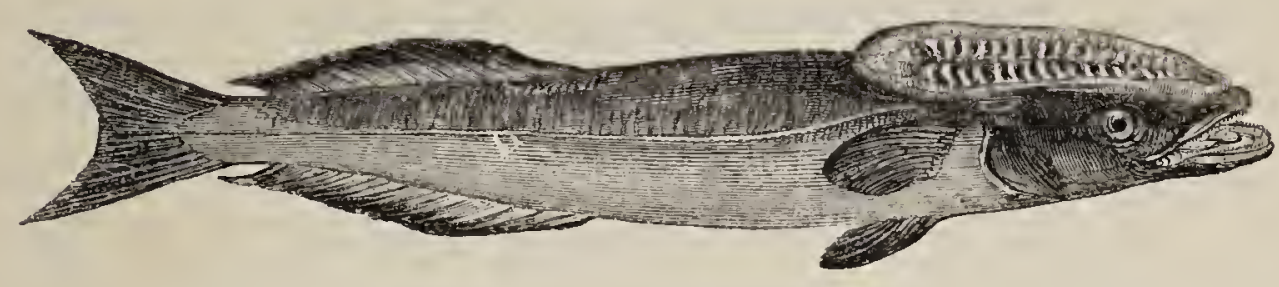

\section{THE COMMON REMORA.}

Echeneis remora, Sucking-fish, Turtor, Brit. Faun. p. 94, sp. 38.

\begin{tabular}{|c|c|c|c|}
\hline "9 & Le Remora, & BLOCH, & pt. v. pl. 172. \\
\hline & & CUVIER, & Règne An. t. ii. p. 347. \\
\hline & Mediterranean & Remora, & Penn. Br. Zool. iii. App. p. 524 \\
\hline & Common & ", & JenYys, Man. Brit. Vert. p. 473 \\
\hline
\end{tabular}

ECHENEID \&. Family Characters. - Head flat, occupied above by a suctorial disk. Body elongated, tapering posteriorly, scaly. Dorsal single, opposite to the anal, no spines in either. Eyes lateral. Mouth terminal, horizontal, small, mandible projecting beyond the premaxillaries. Villiform teeth on the jaws and vomer; tongue rough. Branchiostegals 8. Stomach large, cœcal, intestine short and wide. No air-bladder.

Echeneis. Generic Characters. - Those of the family.

Dr. Turton includes this species of Sucking-fish in his British Fauna, having taken a specimen himself at Swansea, from the back of a Codfish in the summer of 1806, and Dr. Ball of Dublin obtained another on July the 29th, 1848, which had that morning been taken by Mr. N. A. Nicholson from the gills of a shark (Carcharias glaucus $)+\phi$

The generic appellation of the Sucking-fish, Echeneis, is a Greek term compounded of two others, which signify that the fish holds or stays ships in their course,

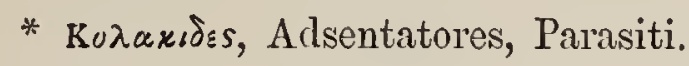

† Thompson, Nat. Hist. vol. iii. p. 222. Edit. 1856. 
and is equivalent to the Latin word Remora. 'The power this little creature was supposed to possess was enormous, and the old naturalists and divines loved to descant on it. 'The mechanism of the organ by which it adheres to other fishes, vessels, or rocks, is figured in the vignette at the end of the article, and fully described in page 674. Its structure and the use to which it is applied, require a flatness of the head, and a straight dorsal line, unusual in fishes, and when the Echeneis is seen in. the water, it has the aspect of a fish swimming belly upwards. Fish of this family abound on the tropical coasts of Africa, and a Shark is seldom taken without several Sucking-fish adhering to it, until it is raised above the water, when they leave it, and attach themselves to the bottom of the ship. Some hundreds sometimes affix themselves to one vessel, and when the washings of the cook's copper's are thrown overboard, they shoot off in a body to pick up the particles of grease that discolour the water. They also consume less savoury matters that drop from a ship, and may be caught with a very small hook buried in a pellet of fat. They are unsightly, and therefore seldom eaten, but not unwholesome, and some seamen are bold enough to eat them. Though natives of warmer latitudes, it is not surprising that they should occasionally come into the precincts of the Channel, sticking on the bottoms of ships or transported by cosmopolite Sharks.

The numbers of the discal laminæ vary with the species, as does also the strength of the spines by which the laminæe are bordered. One species has bony compressed rays in the pectoral fin, terminated by a little crenulated disk. Some authors have supposed the disk on the head to be a first dorsal fin, modified for the special function which it performs. 
The length of the head, from the end of the upper jaw, which is much the shortest, to the end of the operculum, is nearly one-fifth of the whole length of the fish; and the depth of the body is about one-seventh of the whole length: the form of the head is flattened, being very much depressed; the body about the middle is nearly round and posteriorly compressed and tapering; the mouth is wide; the opening nearly horizontal, with two bands of minute teeth in the elongated lower jaw, a single band on the upper jaw, and others on the tongue and vomer, all curving inwards: the eye is placed about half-way between the point of the upper jaw and the rounded end of the operculum; the gill-apertures are very large; the adhesive disk in this species contains seventeen or eighteen transverse laminæ, divided by a longitudinal mesial ridge; the disk commences just behind and above the upper lip, and extends nearly as far back as the ends of the pectoral fin-rays: all the fins are covered with a dense membrane, which imparts to them the consistence of leather; the pectoral fins are rather small and rounded; the ventrals narrow, and very close together, the inner ray of each being attached to the central line of the belly by a membrane; the dorsal and anal fins are both placed behind the midlength of the fish, beginning and ending on the same planes; the end of the caudal rays is crescent-shaped.

The fin-rays in number are-

$$
\text { D. } 21: \text { P. } 22: \text { V. } 4: \text { A. } 20: \text { C. } 20 .
$$

The colour is dusky brown; the under part of the body being rather lighter than the back, and the fins darker in colour than the body.

The disk of the adhesive apparatus in the specimen VOL. I. 
now described has seventeen transverse laminæ, and is one-third of the whole length of the fish, not including the caudal rays; its breadth is one inch and a quarter. The figure on the left side of the vignette represents the outer surface of the anterior half of the disk: its margin is free, flexible, and of considerable breadth, to secure perfect contact with the surface to which it is opposed; the parallel lamino are repiesented as in the condition of slight elevation; the degree of adhesion is in proportion to the power used to raise the inner surface of the disk in a direction perpendicular to the plane of contact. The figure on the right side of the vignette represents the under surface of the posterior half of the disk. The vertical direction of the moveable laminæ is effected by sets of muscles going off obliquely right and left from two elongated bony processes, one on each half of each of these moveable divisions. The contraction of these muscles, acting upon these levers, raises the external edges of the parallel divisions, increasing the area of the vacuum; and it will be observed that the points of the moveable transverse divisions to which the muscles are attached, are nearer the middle line than the outer edge, by which the clrance of interfering with the perfect continuity of the free margin, and thereby destroying the vacuum, is diminished. All the bony laminæ, the outer edges of which are furnished with rows of minute toothlike projections, are moved simultaneously, like the thin vertical divisions of our common wooden window-blinds, by means of the mechanical contrivance in the framework. The longer muscles, placed nearer the outer oval edge, are probably instrumental in preserving the contact of the more flexible margin, and the serrated external edges of the parallel laminæ help to preserve the degree 
of elevation obtained: the adhesive power, as before observed, is in proportion to the area of the vacuum.
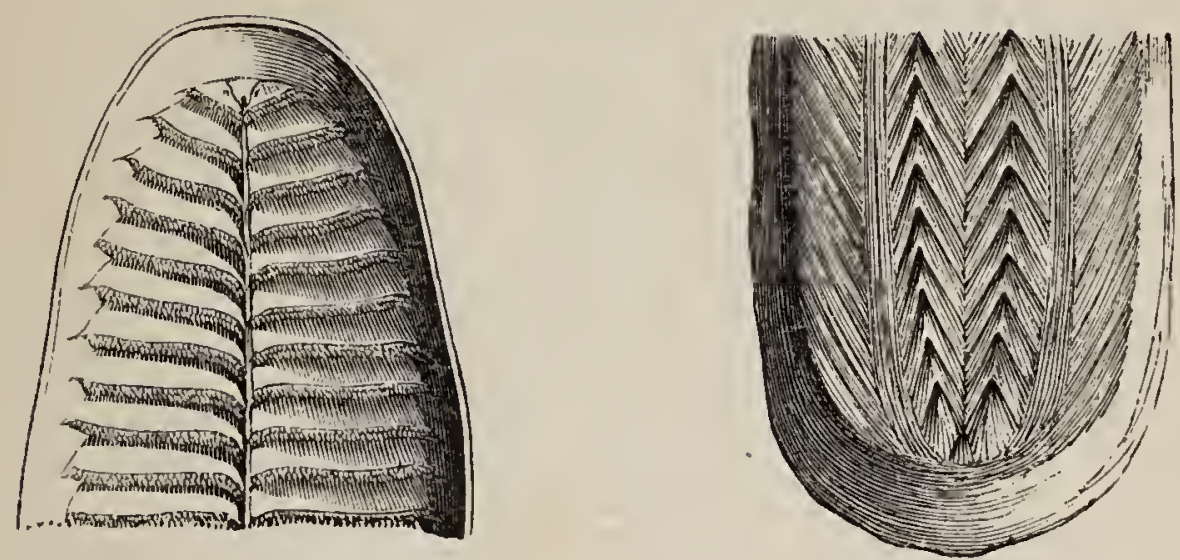

The volume which concludes with this species contains the fishes which in the older arrangements used to be called soft-rayed or Malacopterygian, with the addition of some groups that were formerly placed either among the Acanthopterygian or with the Cartilaginous fishes. The next volume will be devoted to the two last-named orders, and to the Ganoids and Scleroderms.

END OF VOL. 1. 





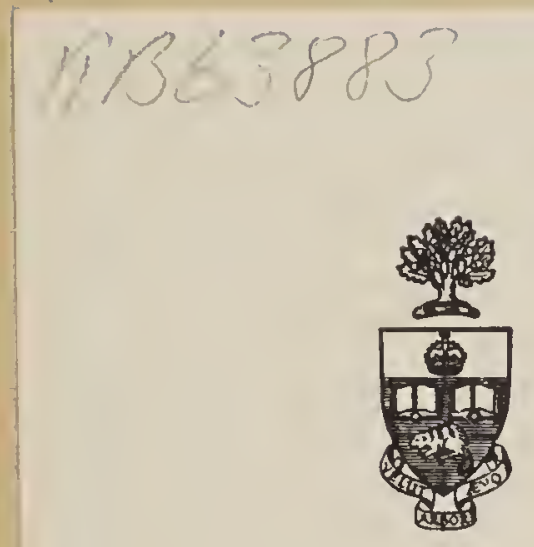

\section{Library}

of the

University of Toronto

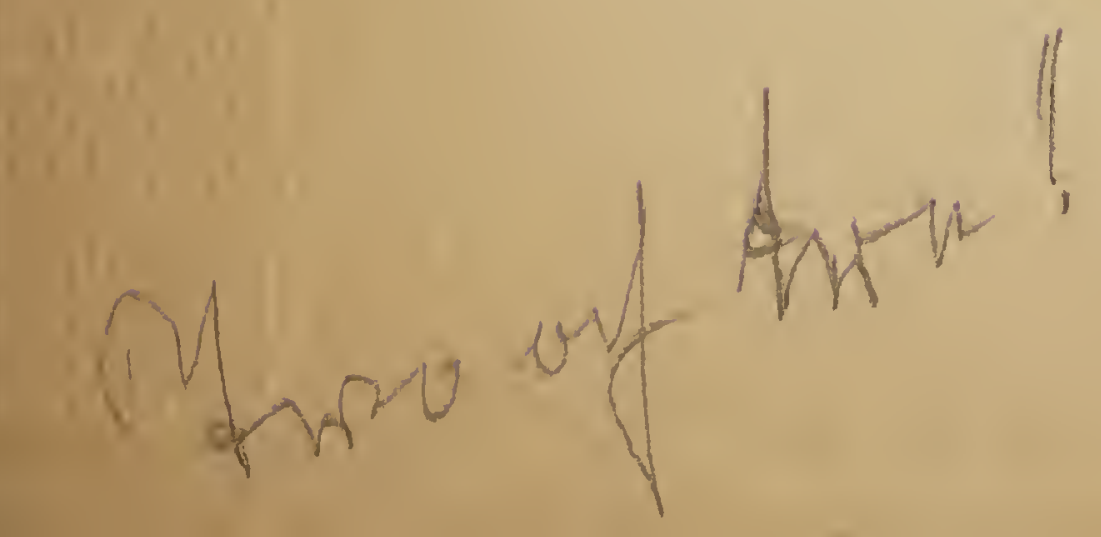




\section{เำเ}

2. 15y 3.

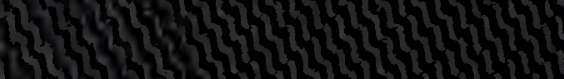

1.

sith

35,

Hysth

Muthxthty

Buththนthนtน

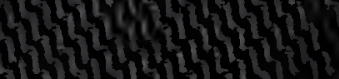

ty 